PNNL-12040

Rev. 0

Pacific Northwest

National Laboratory

Operated by Battelle for the

U.S. Department of Energy.

\section{Regulatory Data Quality Objectives Supporting Tank Waste Remediation System Privatization Project}
K.D. Wiemers
M.E. Lerchen
M. Miller
K. Meier

December 1998

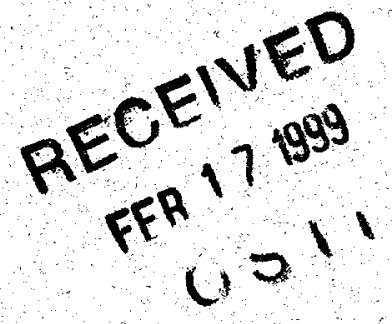

Prepared for the U.S. Department of Energy under Contract DE-ACO6-76RLO 1830 


\title{
DISCLAIMER
}

This report was prepared as an account of work sponsored by an agency of the United States Government. Neither the United States Government nor any agency thereof, nor Battelle Memorial Institute, nor any of their employees, makes any warranty, express or implied, or assumes any legal liability or responsibility for the accuracy, completeness, or usefulness of any information, apparatus, product, or process disclosed, or represents that its use would not infringe privately owned rights. Reference herein to any specific commercial product, process, or service by trade name, trademark, manufacturer, or otherwise does not necessarily constitute or imply its endorsement, recommendation, or favoring by the United States Government or any agency thereof, or Battelle Memorial Institute. The views and opinions of authors expressed herein do not necessarily state or reflect those of the United States Government or any agency thereof.

\author{
PACIFIC NORTHWEST NATIONAL LABORATORY \\ operated by \\ BATTELLE \\ for the \\ UNITED STATES DEPARTMENT OF ENERGY \\ under Contract DE-AC06-76RLO 1830
}

\begin{abstract}
Printed in the United States of America
Available to DOE and DOE contractors from the

Office of Scientific and Technical Information, P.O. Box 62, Oak Ridge, TN 37831;

prices available from (615) $576-8401$.
\end{abstract}

\begin{abstract}
Available to the public from the National Technical Information Service,
U.S. Department of Commerce, 5285 Port Royal Rd., Springfield, VA 22161
\end{abstract}

Note: Each of the attachments to this document can be ordered separately from the sources above. The information you need to order these documents follows.

A Compilation of Regulated Organic Constituents Not Associated with the Hanford Site, Richland, Washington, KD Wiemers, RT Hallen, H Babad, LK Jagoda, K Meier, PNNL-11927, Pacific Northwest National Laboratory, Richland, Washington.

Rationale for Selection of Pesticides, Herbicides, and Related Compounds from the Hanford SSTIDST Waste Considered for Analysis in Support of the Regulatory DQO (Privatization), $\mathrm{KD}$ Wiemers, P Daling, K Meier, PNNL-12039, Pacific Northwest National Laboratory, Richland, Washington.

An Approach for the Analysis of Regulatory Analytes in High Level Radioactive Waste Stored at Hanford, Richland, Washington, KD Wiemers, M Miller, ME Lerchen, PNNL-11942, Pacific Northwest National Laboratory, Richland, Washington.

An Assessment of the Stability and the Potential for In-Situ Synthesis of Regulated Organic Compounds in High Level Radioactive Waste Stored at Hanford, Richland, Washington, $\mathrm{KD}$ Wiemers, H Babad, RT Hallen, ME Lerchen, LP Jackson, PNNL-11943, Pacific Northwest National Laboratory, Richland, Washington. 


\section{DISCLAIMER}

Portions of this document may be illegible in electronic image products. Images are produced from the best available original document. 


\section{Regulatory Data Quality Objectives Supporting Tank Waste Remediation System Privatization Project}

December 1998

KD Wiemers

ME Lerchen

$\mathrm{M}$ Miller

$\mathrm{K}$ Meier

Prepared for

the U.S. Department of Energy

under Contract DE-AC06-76RLO 1830

Pacific Northwest National Laboratory

Richland, Washington 


\section{Acknowledgments}

The authors would like to acknowledge the following staff for their contributions to these documents:

\section{Coauthors of Technical Support Documents}

$\begin{array}{ll}\text { H Babad } & \text { RT Hallen } \\ \text { PM Daling } & \text { LP Jackson }\end{array}$

Lead Technical Support

H Babad, Consultant RT Hallen, PNNL CM Seidel, RFSH

SC Goheen, PNNL LP Jackson, EQM TL Welsh, BWP

\section{Technical Contributions}

SF Bobrowski, PNNL DM Camaioni, PNNL JA Campbell, PNNL PM Daling, PNNL

Administrative Support

DR Baxter, EQM

RL Browne, EQM
RA Esch, RFSH

LK Holton, PNNL

V Hunter, PNNL

JE Hyatt, RFSH
JL Kovach, Consultant MF Marcus, RFSH $\mathrm{CH}$ Mulkey, LMHC
LP Oates, EQM DS Sklarew, PNNL RA Watrous, LMHC

\section{U.S. Department of Energy, Richland Operations Office}

NR Brown, Technical

LA Huffman, Regulatory

NC Welliver, Lead Interface with Washington State Department of Ecology

Washington State Department of Ecology

MN Jaraysi

LE Ruud

$A B$ Stone

JW Yokel 


\section{Contents}

Abbreviations and Acronyms $\ldots \ldots \ldots \ldots \ldots \ldots \ldots \ldots \ldots \ldots \ldots \ldots \ldots \ldots \ldots \ldots \ldots \ldots \ldots$

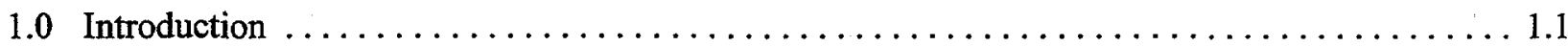

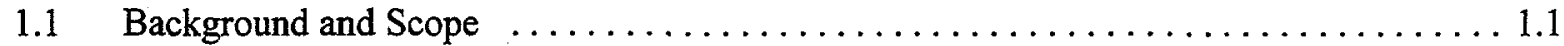

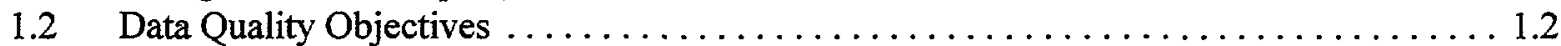

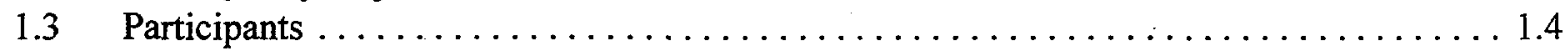

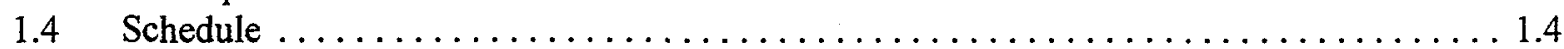

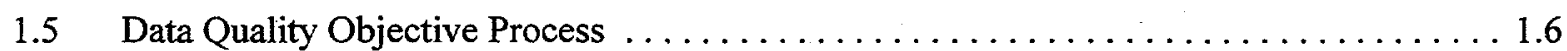

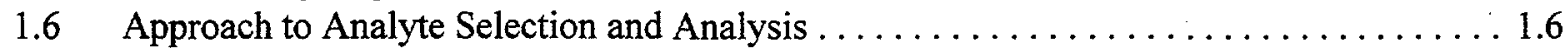

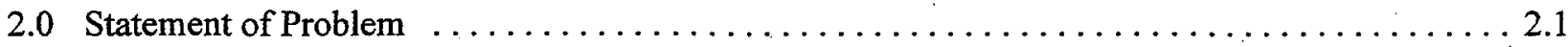

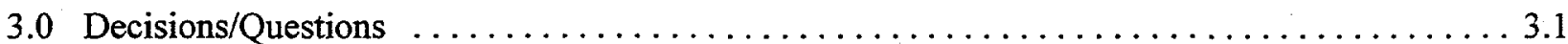

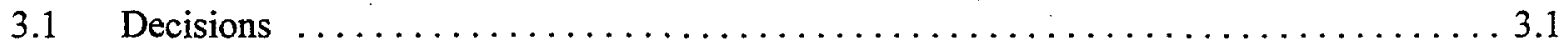

3.2 Data Quality Objective Implementation Logic for Review of Historical Data Adequacy . 3.3

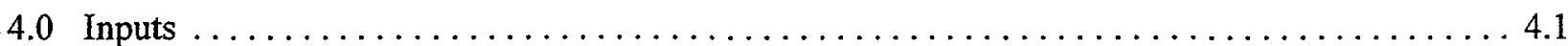

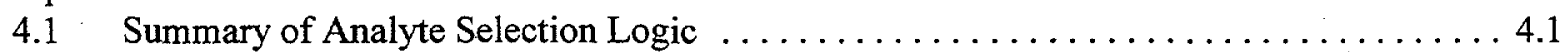

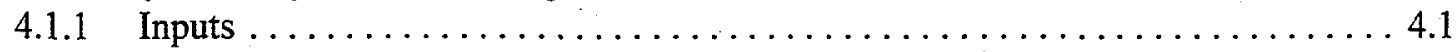

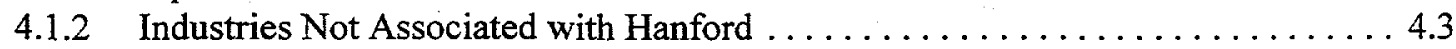

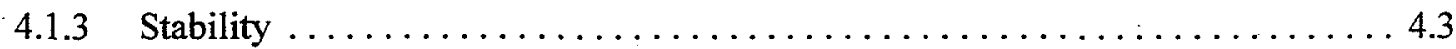

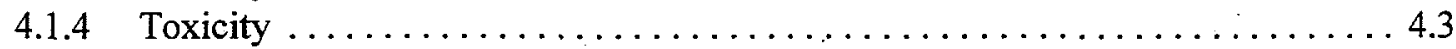

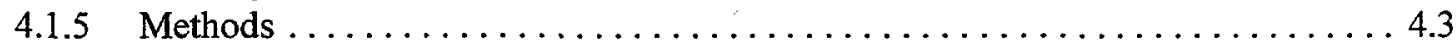

4.2 Regulated Organic Analyte Selection Logic $\ldots \ldots \ldots \ldots \ldots \ldots \ldots \ldots \ldots \ldots \ldots . . \ldots \ldots$

4.3 Organic Compounds Detected in Single-Shell Tank/Double-Shell Tank Waste $\ldots \ldots .4 .5$

4.3.1 Regulatory Data Quality Objective Database Refinement ............. 4.5

4.3.2 Identification of Positive Detects . . . . . . . . . . . . . . . . . 4.12

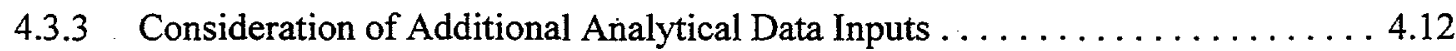

4.3.4 Final List of Detected Organic Single-Shell Tank/Double-Shell Tank

Waste Compounds . . . . . . . . . . . . . . . . . . . . 4.13

4.4 Regulatory Data Quality Objective Analyte Input Lists $\ldots \ldots \ldots \ldots \ldots \ldots \ldots \ldots . \ldots \ldots$

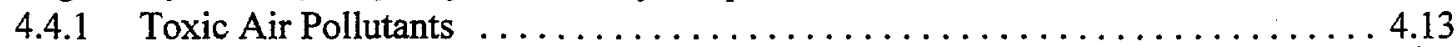

4.4.2 Underlying Hazardous Constituents and Universal Treatment Standards . . . . 4.13

4.4.3 Double-Shell Tank Resource Conservation and Recovery Act of 1976

Part A Permit Application . . . . . . . . . . . . . . . . . . . . . . . . . . . 4.14

4.4.4 Double-Shell Tank Waste Stream Profile Sheets . . . . . . . . . . . . . . . . . . 4.14

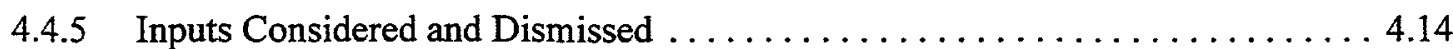

4.4.6 Consolidation of Chemical Abstract Service Number Assignments . . . . . . 4.15

4.4.7 Organic Regulatory Data Quality Objective Input List . . . . . . . . . . . 4.16

4.5 Selection of Regulated Non-Detected Compounds of Higher Toxicity . . . . . . . 4.16

4.5.1 Used in Industrial Applications Not Associated with Hanford . . . . . . . . . . 4.16

4.5.2 Stability in Tank Waste Environment . . . . . . . . . . . . . . . 4.19

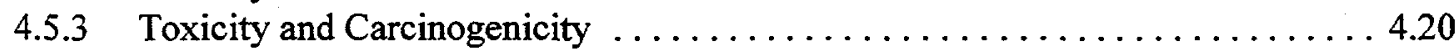


4.6 Selection of Detected Compounds with Higher Toxicity $\ldots \ldots \ldots \ldots \ldots \ldots \ldots \ldots .22$

4.7 Selection of Compounds Detected $\geq 10$ Times and of Lower Toxicity . . . . . . . . 4.22

4.8 Analytical Methods for Compounds of Higher Toxicity . . . . . . . . . . . . 4.23

4.9 Analytical Methods for Compounds of Lower Toxicity . . . . . . . . . . . . 4.24

4.10 Priority Regulated Organic Compounds for Characterization in Support of

Regulatory Data Quality Objective $\ldots \ldots \ldots \ldots \ldots \ldots \ldots \ldots \ldots \ldots \ldots \ldots \ldots \ldots \ldots \ldots \ldots \ldots \ldots \ldots \ldots \ldots .28$

4.11 Non-Organic Compounds and Test Parameters Selection Rationale . . . . . . . . 4.28

4.11.1 Regulated Analytes Not Included in Site Inventory and Retained for Analysis . 4.32

4.11.2 Regulated Analytes Excluded from Consideration for Analysis . . . . . . . . 4.32

4.11.3 Regulated Analytes with Alternatives to Direct Analysis . . . . . . . . . . . . 4.32

4.11.4 Rationale for Test Parameters and Characteristics ................ 4.33

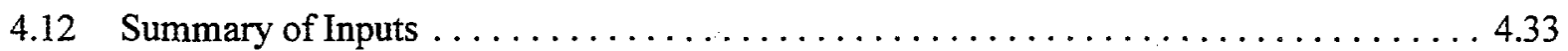

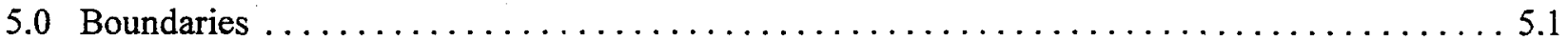

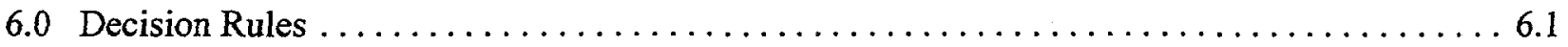

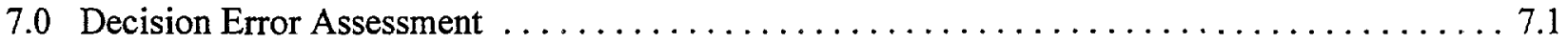

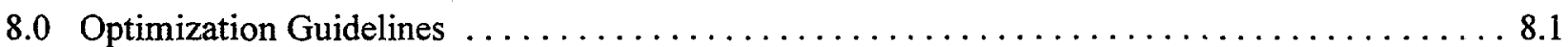

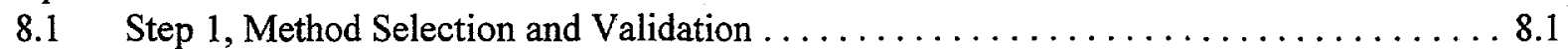

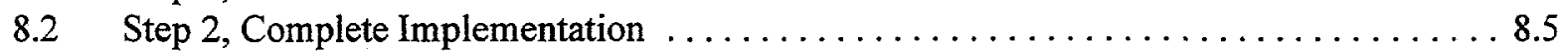

8.3 Sample Collection and Compositing Requirements $\ldots \ldots \ldots \ldots \ldots \ldots \ldots \ldots .6 \ldots$

8.3 .1 Collection Strategies . . . . . . . . . . . . . . . 8.7

8.3.2 Compositing and Liquid/Solid Separation $\ldots \ldots \ldots \ldots \ldots \ldots \ldots \ldots \ldots . \ldots \ldots$

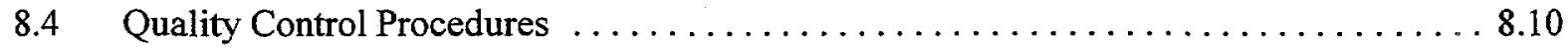

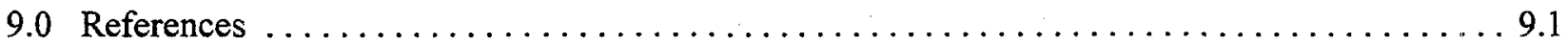

\section{Appendices}

A Appendix VIII Letter/Agreement $\ldots \ldots \ldots \ldots \ldots \ldots \ldots \ldots \ldots \ldots \ldots \ldots \ldots \ldots \ldots \ldots \ldots \ldots \ldots \ldots$

B Analyte Selection Logic Query Outputs $\ldots \ldots \ldots \ldots \ldots \ldots \ldots \ldots \ldots \ldots \ldots \ldots \ldots \ldots \ldots \ldots \ldots$

C Rationale for Selection of Organic Toxic and Carcinogenicity Compounds from the Hanford Single-Shell Tank/Double-Shell Tank Waste Considered for Analysis in Support of the Regulatory Data Quality Objective $\ldots \ldots \ldots \ldots \ldots \ldots \ldots \ldots \ldots \ldots \ldots \ldots \ldots \ldots \ldots \ldots \ldots \ldots \ldots$ 


\section{Attachments}

I A Compilation of Regulated Organic Constituents Not Associated with the Hanford Site, Richland, Washington

II Rationale for Selection of Pesticides, Herbicides and Related Compounds from the Hanford SST/DST Waste Considered for Analysis in Support of the Regulatory DQO (Privatization)

III An Assessment of the Stability and the Potential for In-Situ Synthesis of Regulated Organic Compounds in High Level Radioactive Waste Stored at Hanford, Richland, Washington

IV An Approach for the Analysis of Regulatory Analytes in High Level Radioactive Waste Stored at Hanford, Richland, Washington

\section{Figures}

1.1 A Schematic of the Relationship Between Double-Shell Tank and Single-Shell Tank Waste Source Tanks; High-Level Waste and Low-Activity Waste Feed Staging, Treatment, and Disposal Functions; and the Potential Points for Characterization to Support Regulatory Compliance $\ldots \ldots \ldots \ldots 1.3$

1.2 Conceptual Model for Selection of Analytes To Be Considered for Analysis . . . . . . . . . 1.7

3.1 Regulatory Data Quality Objective Implementation Logic $\ldots \ldots \ldots \ldots \ldots \ldots \ldots \ldots \ldots$

4.0a Simplified Analyte Selection Logic for Organic Regulated Compounds . . . . . . . . . . . 4.2

4.0b Representation of Input List Development for Analyte Selection Logic . . . . . . . . . . 4.2

4.1 Development of Potential Organic Single-Shell Tank/Double-Shell Tank

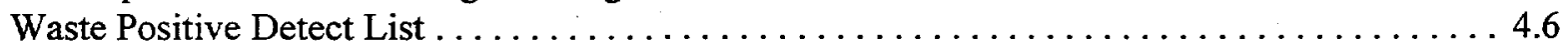

4.2 Regulatory Data Quality Objective Input List and Logic to Segregate Regulated Detected and Non-detected Compounds and Evaluate Detected Compounds for Toxicity

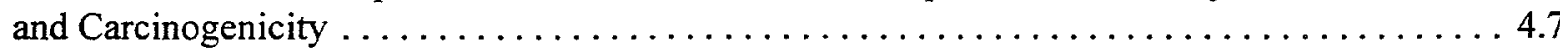

4.3 Logic to Assess Non-detected, Regulated Compounds

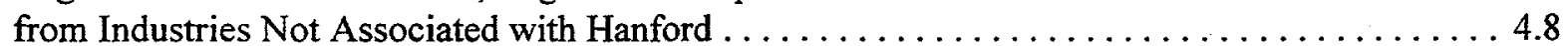

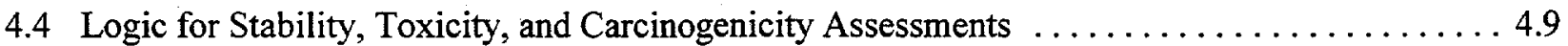

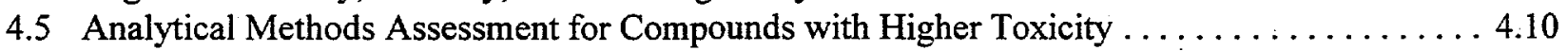

4.6 Analytical Methods Assessment for Compounds with Lower Toxicity and Priority Regulated Compounds for Characterization in Support of the Regulatory Data Quality Objective . . . . 4.11

8.1 Regulatory DQO Implementation Logic Summary Flowsheet $\ldots \ldots \ldots \ldots \ldots \ldots \ldots \ldots$

8.2 Sample Collection and Compositing Strategy for the Regulatory Data Quality Objective . . . . 8.9 


\section{Tables}

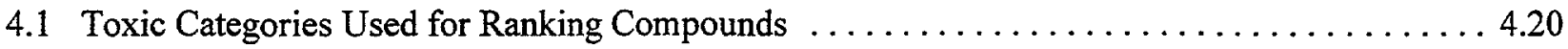

4.2 Prioritization Grouping of Acceptable Source Impact Level Values $\ldots \ldots \ldots \ldots \ldots \ldots \ldots .21$

4.3 Prioritization Grouping of $\log _{(10)}$ Slope Factors $\ldots \ldots \ldots \ldots \ldots \ldots \ldots \ldots \ldots \ldots \ldots \ldots \ldots \ldots \ldots \ldots \ldots \ldots .22$

4.4 Priority Regulated Organic Compounds for Characterization in Support of the Regulatory

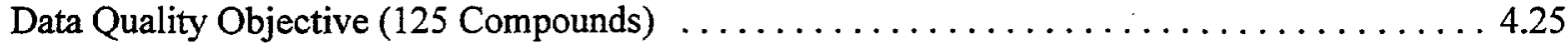

4.5 Summary of Regulated Compounds To Be Considered $\ldots \ldots \ldots \ldots \ldots \ldots \ldots \ldots \ldots \ldots .28$

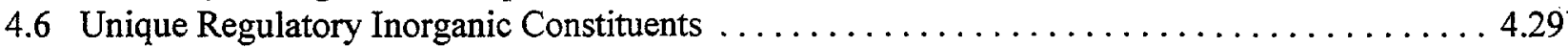

4.7 Inorganic Constituents of Potential Regulatory Concern $\ldots \ldots \ldots \ldots \ldots \ldots \ldots \ldots \ldots \ldots .31$

4.8 Test Parameters and Characteristics for Analysis in Support of the Regulatory Data

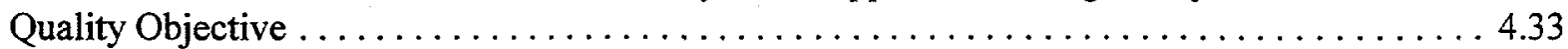

4.9 Comparison of Conceptual Model with Analyte Selection Logic for Organic and

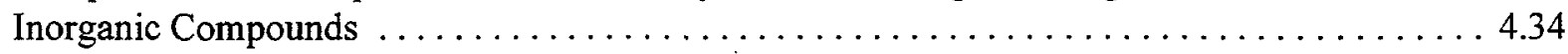

8.1 Selected SW-846 Methods for Implementation of the Regulatory Data Quality Objective . . . . 8.2

8.2 Minimum Sample Collection Requirements for

Regulatory Data Quality Objective Implementation 8.8 


\section{Abbreviations and Acronyms}

\begin{tabular}{|c|c|}
\hline ASIL & acceptable source impact level \\
\hline $\mathrm{BC}$ & below the cut-point \\
\hline CAS\# & chemical abstract service number \\
\hline CFR & Code of Federal Regulations \\
\hline DOE & U.S. Department of Energy \\
\hline DOE-RL & U.S. Department of Energy, Richland Operations Office \\
\hline DQO & data quality objective \\
\hline DST & double-shell tank \\
\hline $\mathrm{ECD}$ & electron capture detector \\
\hline Ecology & Washington State Department of Ecology \\
\hline EPA & U.S. Environmental Protection Agency \\
\hline $\mathrm{EQL}$ & estimate quantitation limit \\
\hline ETF & Effluent Treatment Facility \\
\hline GC/MS & gas chromatography/mass spectrometry \\
\hline HASQARD & Hanford Analytical Services Quality Assurance Requirements Documents \\
\hline HDW & Hanford Defined Waste \\
\hline HEAST & Health Effects Summary Tables \\
\hline HLW & high-level waste \\
\hline HTCE & Historical Tank Content Estimate \\
\hline ICP & inductively coupled plasma \\
\hline ICP/MS & inductively coupled plasma/mass spectrometer \\
\hline IHLW & immobilized high-level waste \\
\hline ILAW & immobilized low-activity waste \\
\hline IRIS & Integrated Risk Information System \\
\hline LAW & low-activity waste \\
\hline LDR & land disposal restriction \\
\hline MDL & minimum detection limit \\
\hline $\mathrm{NPH}$ & normal paraffin hydrocarbon \\
\hline OWVP & Operational Waste Volume Projection \\
\hline PAH & polycyclic aromatic hydrocarbon \\
\hline PCB & polychlorinated biphenyl \\
\hline PNNL & Pacific Northwest National Laboratory \\
\hline QA & quality assurance \\
\hline $\mathrm{OC}$ & quality control \\
\hline RAWP & risk assessment work plan \\
\hline RCRA & Resource Conservation and Recovery Act of 1976 \\
\hline RPD & relative percent difference \\
\hline RSD & relative standard deviation \\
\hline SLRA & screening level risk assessment \\
\hline SST & single-shell tank \\
\hline SVOA & semivolatile organic analysis \\
\hline TAP & toxic air pollutant \\
\hline TBP & tributyl phosphate \\
\hline TCDD & tetrachlorodibenzo-p-dioxin \\
\hline
\end{tabular}




$\begin{array}{ll}\text { TCLP } & \text { toxicity characteristic leaching procedure } \\ \text { TCD } & \text { tank characterization database } \\ \text { TCR } & \text { tank characterization report } \\ \text { THF } & \text { tetrahydrofuran } \\ \text { TIC } & \text { tentatively identified compound } \\ \text { Tri-Party Agreement } & \text { Hanford Federal Facility Agreement and Consent Order } \\ \text { TSCA } & \text { Toxic Substances Control Act } \\ \text { TSD } & \text { Treatment Storage Disposal } \\ \text { TWINS } & \text { Tank Waste Information Network System } \\ \text { TWRS } & \text { Tank Waste Remediation System } \\ \text { TWRSOUP } & \text { TWRS Operational and Utilization Plan } \\ \text { UHC } & \text { underlying hazardous constituents } \\ \text { UTS } & \text { universal treatment standards } \\ \text { VOA } & \text { volatile organic analysis } \\ \text { WAC } & \text { Washington Administrative Code } \\ \text { WDOH } & \text { Washington Department of Health } \\ \text { WIRD } & \text { Waste Information Requirements Document } \\ \text { WSPS } & \text { Waste Stream Profile Sheet }\end{array}$




\subsection{Introduction}

\subsection{Background and Scope}

This document describes the results of the data quality objective (DQO) process undertaken to define the Tank Waste Remediation System (TWRS) Privatization Project data needs for waste generated by the U.S. Department of Energy (DOE) and its predecessors. This waste was generated from historical practices and is currently stored in double-shell tanks (DST) and single-shell tanks (SST) at the Hanford Site. Hereafter, this document is referred to as the Regulatory DQO.

It is anticipated that the information needs identified here and the information needs identified in other TWRS DQOs will be defined in a Waste Information Requirements Document (WIRD) to be submitted annually to the Washington State Department of Ecology (Ecology) in accordance with the Hanford Federal Facility Agreement and Consent Order (Tri-Party Agreement) (Ecology et al. 1994) Milestone M-44-00A et seq. as applicable. The WIRD identifies annual characterization deliverables to support safe storage, retrieval, and disposal of tank waste. The WIRD describes the characterization deliverables to be issued each year based on existing Tri-Party Agreement milestones and specifies the contents of these deliverables. TWRS waste management activities are or will be covered under the DOE-held Hanford Site final status Resource Conservation and Recovery Act of 1976 (RCRA) permit, WA 7890008967, except for the eventual disposal of the immobilized high-level waste (IHLW) at the proposed federal repository.

The primary drivers for characterization under this DQO are the waste characterization requirements pursuant to RCRA regulations and the corresponding state requirements (hereafter collectively referred to as RCRA requirements). Under RCRA, the generator is required to designate the waste and determine the applicability of land disposal restrictions (LDR). ${ }^{1}$ Ecology has determined that DOE, the waste generator, has adequately designated the existing waste. Based on the designation, DOE has determined that LDR are applicable to tank waste. Designation and LDR information on newly accepted waste is gathered through the use of the Waste Stream Profile Sheets (WSPS). Data needs defined in this DQO are intended to support, in part, LDR waste analysis and recordkeeping activities for existing legacy waste. Ecology has also determined that because TWRS waste is legacy waste, point-of-generation data may be found through current characterization, if not already available. This determination does not mean that Ecology considers this waste to be newly generated. Ecology and DOE have agreed that if the compound is not detected in the source tank waste and the compound is not expected to be generated within the treatment facility, then additional analysis for the compound within the treatment facility and the final waste form will not be required.

Ecology and DOE have agreed that additional tank waste characterization data would facilitate permitting and compliance activities for treatment and disposal of the waste. In particular, data needs relating to compliance activities associated with delisting, risk assessment, and permitting for treatment and disposal need to be addressed. Therefore, in addition to the RCRA considerations described above,

140 Code of Federal Regulations (CFR) 261, 40 CFR 268.7; Washington Administrative Code (WAC) 173303-070, WAC 173-303-140. 
Ecology and DOE agreed to evaluate characterization needs to address air emissions and polychlorinated biphenyls (PCB) management.

For air emissions, Ecology and DOE agreed that along with the other regulatory inputs, inclusion of the promulgated lists for Class A and Class B toxic air pollutants (TAP) (WAC 173-460) would be sufficient. Additionally, while PCBs are regulated under RCRA, consideration was also given to the possibility that $\mathrm{PCBs}$ may be present at levels triggering waste management requirements under the Toxic Substances Control Act (TSCA). While there is no historical process knowledge or empirical data for tank waste at or above TSCA-regulated levels, potential impacts to required treatment levels are significant enough that prudence dictates examining tank wastes for PCBs.

Figure 1.1 provides a schematic of the relationship between the source tanks, staged waste, treatment facility, and storage and disposal facilities and identifies potential points for sampling to satisfy characterization needs. The waste feed will be staged in the source tank or an intermediate staging tank before transfer to the treatment facility. Staging may involve a number of preparation steps including decanting of supernate, mixing of solid and liquid phases, chemical adjustments to meet contract specifications, and/or blending of waste from several source tanks. After treatment, the immobilized waste form will be transported to the disposal facility.

The data needs identified through the DQO process described in this document will be applied to the analysis of waste stored in double-shell and single-shell source tanks. Tank waste analysis needs identified under this DQO will ideally be satisfied while the waste is in static storage. All Phase I candidate feed tank wastes are static with respect to future transfers, with the exception of of Tank C-106 waste that is scheduled to be transferred to AY-102 before the end of fiscal year 1999. Priority for analysis requested in this DQO is to be given to Phase I candidate tank waste. Application of this DQO to less homogeneous Phase II tank waste will likely be during mobilization and/or retrieval activities.

Additional analysis to support regulatory compliance will occur in the process of retrieving and staging for treatment and prior to delivery to the treatment facility. If necessary, subsequent $D Q O(s)$ will address additional data needs. It is anticipated that the results from predecessor $\mathrm{DQO}(\mathrm{s})$ will in part drive the data needs of subsequent $\mathrm{DQO}(\mathrm{s})$.

This Regulatory DQO process addresses data needs for non-radioactive waste constituents and characteristics. It is understood that knowledge of the radionuclide content will be needed for permitting the treatment facility. Radionuclide data will be available through other. DQO(s), most notably the LowActivity Waste (LAW) Feed DQO (Wiemers and Miller 1997) and the High-Level Waste (HLW) Feed DQO (Wiemers et al. 1998).

\subsection{Data Quality Objectives}

The objectives of this Regulatory DQO process are to:

- identify the analytes that are needed to address regulatory issues and which are known or potentially present in the tank waste,

- identify analytes to test for through sampling and laboratory analysis, 
Figure 1.1. A Schematic of the Relationship Between Double-Shell Tank and Single-Shell Tank Waste Source Tanks; High-Level Waste and Low-Activity Waste Feed Staging, Treatment, and Disposal Functions; and the Potential Points for Characterization to Support Regulatory Compliance.

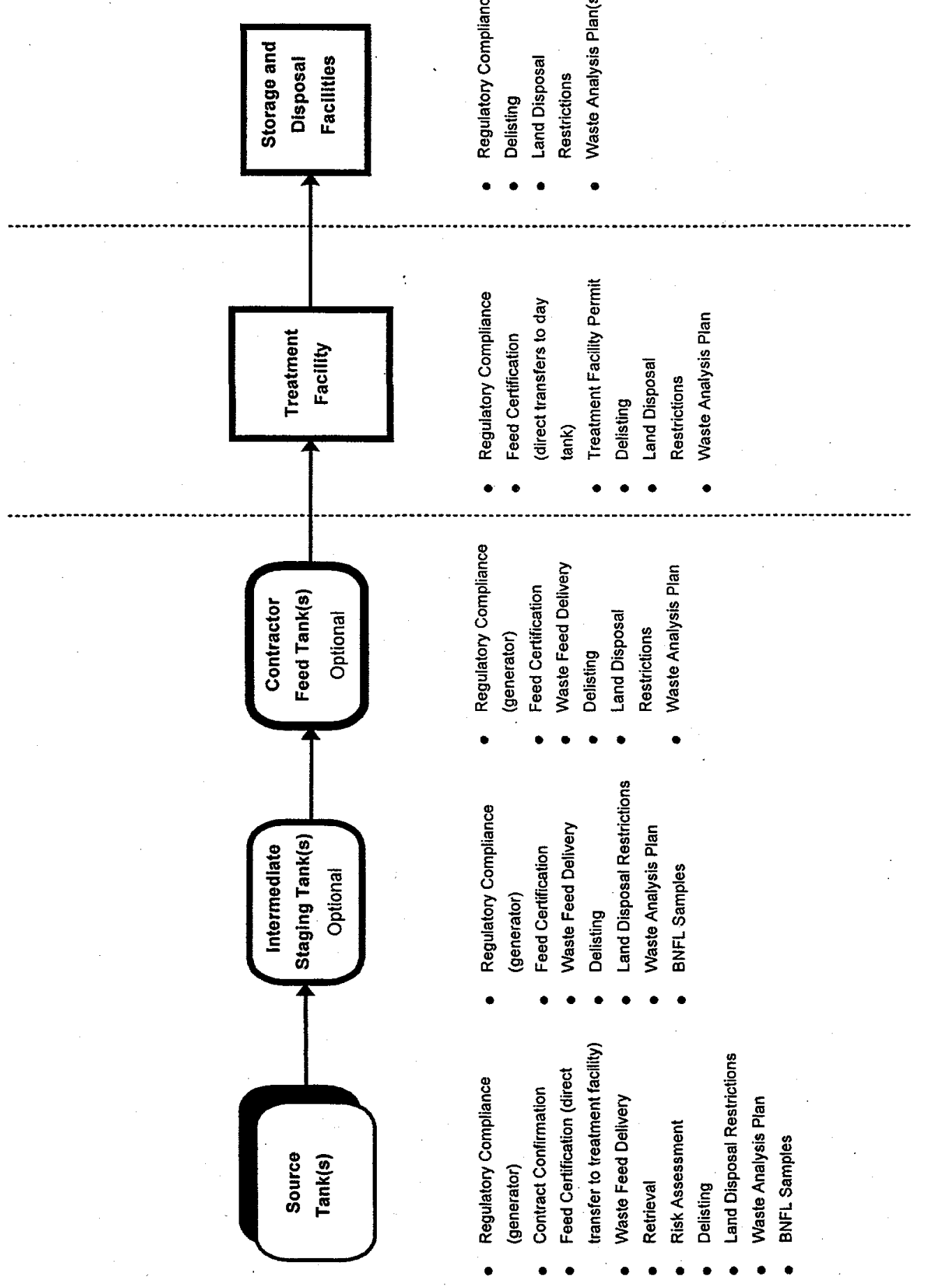


- identify the appropriate analytical methods that provide acceptable detection capability and quality, and

- obtain source tank waste data on the identified analytes using the identified methods and quality expectations.

\subsection{Participants}

The following personnel actively participated in this Regulatory DQO:

- DOE managers, supported by Pacific Northwest National Laboratory (PNNL) technical staff and

- Ecology RCRA managers and supporting chemists and permitting staff.

Attendance, discussion, decisions, agreements, and actions items are documented in meeting minutes which are available in the administrative record.

This DQO process was undertaken during contract negotiations for TWRS Privatization Phase I Part B-1. ${ }^{2}$ Representatives from the TWRS Privatization treatment facility contractor were not present during this DQO process, although Ecology recommended their participation. DOE obtained the contractor input in parallel with the DQO process due to contractual issues and proprietary processes. This input was incorporated similarly to other draft technical input, and does not necessarily have traceability to formal transmittal records.

\subsection{Schedule}

This DQO process identifies data needs to support delisting; LDR compliance, risk assessment, and permitting for treatment and disposal. These compliance driven activities are anticipated to require additional data collection until their completion.

DOE has placed requirements on performing contractors for identification of a detailed approach for delisting the treated HLW (DE-AC06-96RL13308 - Mod. No. A006). An initial draft on a documented approach to delisting is due for DOE review November 1999 with a final for DOE review and approval due April 2000. Data as requested under this DQO will, in part, validate the proposed approach and provide a basis for DOE's decision. The vitrified HLW product must be delisted in order to meet the planned waste acceptance criteria at the proposed national repository for treated high-level waste.

${ }^{2}$ DOE has authorized BNFL to proceed with Part B-1 of the TWRS Privatization Project (August 24, 1998, Contract Number DE-AC06-96RL13308). 
The treatment facility's permitting and associated risk assessment efforts are in progress with initial draft deliverables scheduled for first quarter fiscal year 1999. Key near-term events in the treatment facility's permitting and risk assessment efforts along with anticipated dates are as follows:

- Initial submittal of the treatment facility's draft RCRA Part B dangerous waste permit application (DWPA) and thermal treatment facility risk assessment work plan (RAWP) to Ecology (May 1999)

- Initial screening level risk assessment (SLRA) (August 1999)

- Submittal of final RAWP for Ecology approval (August 1999)

- Begin running risk assessment models in accordance with Ecology approved RAWP (November 1999)

- Submittal of final DWPA to Ecology for inclusion in the Hanford RCRA Permit (WA 7890008967) (May 2000)

- Ecology issues modification to the Hanford RCRA Permit for the draft treatment facility permit conditions (July 2000).

The following activities are important in continuing data needs for permitting of the treatment facility and regulatory compliance in feed delivery to the treatment facility:

- Initiate construction (July 2001)

- Initiate pretreatment hot start (April 2006)

- Initiate HLW hot start (February 2007)

- Initiate HLW treatment services (July 2008)

- Initiate LAW hot start (January 2008)

- Initiate LAW treatment services (April 2009).

The treatment of waste under TWRS Privatization is scheduled to occur in two phases. Priority for this Regulatory DQO is to be given to Phase I candidate tank waste. The selection of feed source tanks must remain flexible to allow for accommodation of other tank farm operations, safety issue resolution, and the treatment facility requirements. DOE contract negotiations may also influence selection of tank waste. A description of the candidate waste feed selection process is updated and published each year in the TWRS Operational and Utilization Plan (TWRSOUP) (Kirkbride et al. 1997). The candidate Phase I tanks are not scheduled to be receivers for future waste transfers from evaporator campaigns and salt well pumping. All Phase I candidate feed tank wastes are static with respect to future transfers; with the exception of Tank C-106 the partial contents of which are scheduled to be transferred to Tank AY-102 before the end of fiscal year 1999. Eleven tank wastes, 9 DSTs and 2 SSTs have been selected as primary feed source candidates for the first treatment phase. These tanks are AN-102, AN-103, AN-104, AN-105, AN-107, AW-101, AZ-101, AZ-102, AY-102, C-106, and C-104. Two additional tank waste feed sources have been assigned for contingency batches, SY-101 and C-102. 


\subsection{Data Quality Objective Process}

The TWRS DQO process is implemented per guidance based on the U.S. Environmental Protection Agency's (EPA's) DQO Process document (EPA 1994a). This Regulatory DQO document will be revised as new information warrants.

\subsection{Approach to Analyte Selection and Analysis}

Analytes considered under the scope of this Regulatory DQO were selected from a large universe of regulated constituents using a technically defensible decision logic. The logic selected compounds plausible to be in the waste and of potential concern relative to the treatment facility risk assessment and permitting activities. It is envisioned that this analyte selection process will be the first in a series of such processes to identify analysis needs in support of characterization for regulatory compliance.

The general approach to analyte selection for this Regulatory DQO process is represented conceptually in Figure 1.2. The conceptual model shows the relationship between groups of analytes to be considered from the beginning of this Regulatory DQO process through disposal of the final waste form. The relative areas of each circle and overlaps between circles are not necessarily scaled to the number of analytes represented. A comparison of the conceptual and implemented analyte selection logic is provided in Table 4.9.

The analyte selection process begins with the starting universe of regulated analytes represented by Circle A. Circle B represents available historical information and data, some of which overlaps with the starting analyte list. Circle $C$ represents the data that will be obtained primarily from the source tanks. Circle $\mathrm{C}$ contains regulated analytes not previously detected or analyzed for in the waste, plausible to be present in the tank waste, and of higher toxicity relative to other regulated analytes. Circle $\mathrm{C}$ also contains regulated analytes previously detected and for which confirmation of their presence and concentration would be helpful in the treatment facility risk assessment planning. Circle D represents the data that are anticipated to be gathered at multiple points downstream from the source tanks. These points include but are not limited to the staged feed, the treatment facility process control points, and treated waste form along with associated secondary wastes. The requested analyte sets at each downstream characterization point are not necessarily the same. The information included in Circle $A$ and not in Circles B, C, and D is composed of regulated analytes thought unlikely to exist in the tank waste either because it is unlikely that such chemicals were used at Hanford or that the constituent is unstable in the waste matrix and unlikely to be synthesized in situ. The characterization requirements at these later points will be defined in subsequent DQOs or other documentation. This DQO scope is limited to analysis of waste in the source tanks as represented in Circle C. 
Figure 1.2. Conceptual Model for Selection of Analytes To Be Considered for Analysis.

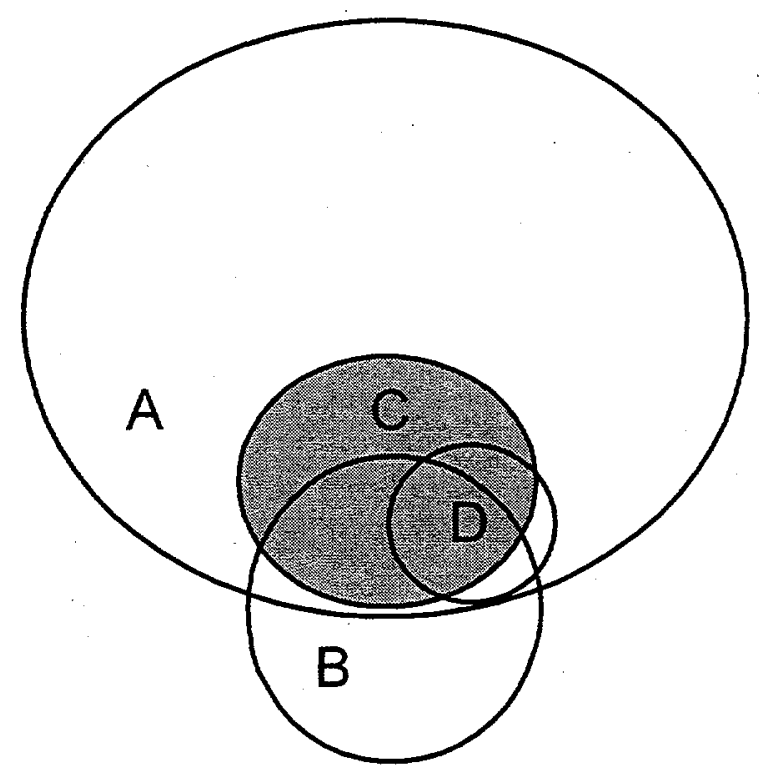

A: Universe of Regulated Analytes to be Considered in this Regulatory DQO

B: Analytes Reported in Historical Data or Identified through Process Knowledge

C: Scope of this Regulatory DQO

Analytes to be Considered for Analysis in Source Tank Waste

D: Analytes to be Considered for Analysis in Staged Feed and other Downstream Processes. 


\subsection{Statement of Problem}

The following problem statement was agreed to by DOE and Ecology during the initial phases of the DQO process:

There is a considerable knowledge base regarding the tank waste. However, it has not been compiled or verified to establish that sufficient information exists to meet RCRA compliance requirements. This information is needed for meeting generator compliance requirements and providing adequate information for the treatment plant risk assessment work plan development.

In particular, it has not been established that existing waste characterization data will meet waste generator characterization requirements as stated under WAC 173-303. The Washington State program includes the entire federal program. Thus, all subsequent citations will reference federal requirements for clarity purposes (40 CFR 268.7, "Land Disposal Restrictions, Waste Analysis and Record Keeping," and 40 CFR 261, "Identification and Listing of Hazardous Waste"). Ecology has determined that all state-only LDR will be met through vitrification. ${ }^{3}$

In agreeing on this problem statement and in subsequent discussions, the following points have been made and are provided here for additional context and clarification:

- RCRA compliance requirements for tank waste characterization are covered under Tri-Party Agreement Milestone M-44-00 et seq. and the Hanford Site RCRA permit (currently interim status for DST and SST System Units).

- Ecology has stated that additional data are required under RCRA regardless of whether tank waste is to be treated.

- Regulatory driven data needs identified in the LAW Feed DQO (Wiemers and Miller 1997, developed for TPA Target Date M-60-14-T01) and the HLW Feed DQO (Wiemers et al. 1998, developed for TPA Target Date M-51-04A-T01) were not entirely accepted by Ecology; this document supplements those DQOs.

- Data gathered through this effort will provide an initial understanding of the tank waste to support meeting the regulatory data needs for the tank waste treatment facility. Additional data needs regarding the tank waste feeds and other concerns are anticipated to be identified as the project is further refined.

- Data requirements for treatment facility operations and immobilized waste forms will be established under the Hanford Site-wide permit (WA 7890008967) through the permit modification process.

${ }^{3}$ This agreement, that all state-only LDR will be met through vitrification, is documented in the DQO meeting minutes. 
- Data requirements for waste feed deliveries between the DST System Unit and the planned waste treatment facility unit will be established under the Hanford Site-wide permit (WA 7890008967) through the permit modification process. 


\subsection{Decisions/Questions}

The correct type, quantity, and quality of data needed are determined by understanding the decisions to which data will be applied. Asking principal study questions and defining the alternative actions resulting from answering the questions are used to generate a decision statement. The result of this Regulatory DQO is a list of analytes, methods, target estimate quantitation limits (EQLs), and quality control (QC) criteria to support the decisions identified in the following text.

The regulations discussed in the decisions include those pertinent to LDRs pursuant to 40 CFR 268.7 and WAC 173-303-140; petitions for exemption or exclusion (delisting) per 40 CFR 260.20, 40 CFR 260.22, and WAC 173-303-910; and obtaining data to support development of a risk assessment work plan as required for permitting the treatment facility. DOE has completed tank waste designation pursuant to WAC 173-303-070 (Double-Shell Tank System Part A, Form 3, September 1996). This DQO did not focus on compliance needs for the liquid effluents as the treatment facility concept requires all liquid effluents to be further managed in existing permitted DOE facilities.

\subsection{Decisions}

Question \#1: Do existing waste characterization data meet requirements for generators under 40 CFR 268.7, "Land Disposal Restrictions, Waste Analysis and Recordkeeping"?

Alternative Actions: . Data meet requirements and allow selection of treatment alternative and disposal per the regulations.

Data do not meet requirements and additional data will be gathered to support treatment and disposal.

Data do not meet requirements and the waste remains in storage.

Decision \#1: $\quad$ Determine whether there are sufficient data to meet $40 \mathrm{CFR}$ 268.7 that allow selection of the treatment alternative and eventual disposal of the waste.

Question \#2: Is there sufficient generator information to support development of a risk assessment for the treatment facility?

Alternative Actions: Sufficient information is available to adequately identify analytes driving risk assessment for the treatment facility.

Available information is insufficient to support the risk assessment and permitting activities for the treatment facility and additional data will be gathered. 
Available information is insufficient to support the risk assessment and permitting activities for the treatment facility. Conservative values for plausible tank constituent concentrations will be assumed. These assumptions may lead to a risk assessment that drives prohibitively small treatment facility throughput rates and inappropriately conservative control technologies. Cost and schedule impacts for design, permitting, construction, and operation of the treatment facility will be incurred.

Decision \#2: $\quad$ Determine whether identification and quantification of analytes driving risk assessment for the treatment facility is sufficient to allow preparation of the treatment facility risk assessment supporting appropriate design, permitting, construction, and operation.

Question \#3: Is there sufficient generator characterization information to support future development and submittal of a delisting petition ${ }^{4}$ in accordance with 40 CFR 260.20, 40 CFR 260.22, and WAC 173-303-910?

Alternative Actions: Sufficient data of appropriate quality are available and allow submittal of the petition.

Available data are of insufficient quality for submittal of the petition and additional data will be gathered.

Available data are of insufficient quality for submittal of the petition and the delisting package may be rejected. There is a risk of IHLW not meeting the repository requirements.

Decision \#3: $\quad$ Determine the amount and quality of generator characterization data needed to support the delisting petition.

${ }^{4}$ Question \#3 pertains to delisting the vitrified product, which is a requirement for the IHLW and an option for immobilized low-activity waste (ILAW). Delisting requires a strategy that shows the regulator and public that the waste does not need to be managed under Subtitle $C$ of RCRA. The Hanford Site Effluent Treatment Facility (ETF) Delisting Petition, which was granted in 1992, is an example (DOE-RL 1993). Data obtained from tank waste characterization and data from the treatment process itself will support the petition for delisting a particular treated waste stream. 


\subsection{Data Quality Objective Implementation Logic for Review of Historical Data Adequacy}

A generic logic for determining whether historical data and inventories for a given tank waste are sufficient to address the decisions is presented in Figure 3.1. Some variation in implementation of the logic may be required due to differences in the HLW feed and LAW feed retrieval and staging scenarios.

Implementation of the logic results in a decision as to what additional information from analysis of waste stored in the source tanks is required to support generator's characterization requirements.

Completeness of the data is judged by comparing the analytes and test parameters measured with the analytes requested in Tables $4.4,4.7$, and 4.8 and the associated acceptance criteria information presented in Section 8.0.

For purposes of discussion, each logic diagram element has been numbered relative to each applicable decision sequence shown. The cited input sources may be replaced with equivalent documentation at a future date. The references apply to the most recent revision at the time this Regulatory DQO was issued. Additional sources may be sought if the referenced documents are not updated. Data collected before May 1989 may be used if they are validated with post-May 1989 data.

Gate 1: Are any major waste transfers planned between the scheduled sampling date and the scheduled date for staging the feed [GATE 1]?

Because transfer of wastes within the tank farm may significantly impact the composition of the source tank waste, highest priority for sampling and characterization will be given to those tank wastes for which no transfer activities are planned up to the scheduled staging date.

Two input sources [1-1] will be used to determine [1-2] the transfer activity for a given tank waste relative to the planned dates and final transfer to the intermediate feed staging tank:

- TWRSOUP (Kirkbride et al. 1997) will provide the scheduled date for staging.

- Operational Waste Volume Projection (OWVP) (Koreski 1997) identifies the planned waste transfers, from which a determination of dates of future transfers may be identified.

If major transfer activities are not planned for the source tank before feed staging, the tank waste is a candidate for sampling and characterization (continue to Gate 2). Conversely, if a significant number of transfers or transfer of a large quantity of waste are planned, ${ }^{5}$ do not sample, but perform sample collection after the transfers [1-3] [continue to Endfunction B].

${ }^{5}$ Major transfer [quantities] and significant number of transfers refer to any transfer which may affect the knowledge of the candidate tank waste composition to the extent that uncertainties in the staged feed composition relative to contract and/or permit limits present an unacceptable risk to meeting requirements. Configuration control of the tank waste contents will be used by DOE and its contractors to manage this risk. The impact of historical and planned transfers on analytical data and waste composition, respectively, will be evaluated on a tank by tank basis under Gates 1 and 2 of the tank waste selection logic. 
Figure 3.1. Regulatory Data Quality Objective Implementation Logic (Page 1 of 3)

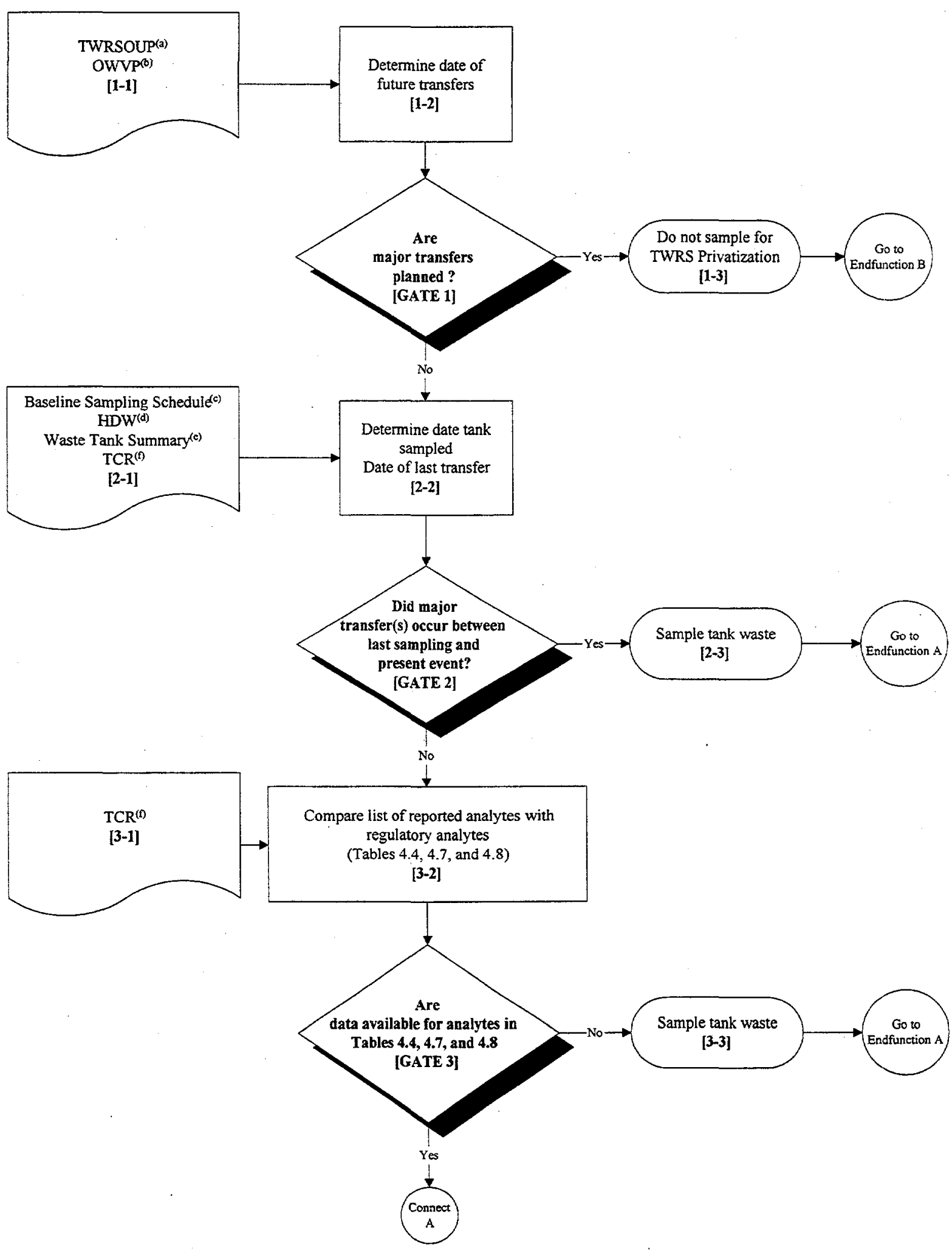


Figure 3.1. Regulatory Data Quality Objective Implementation Logic. (Page 2 of 3)

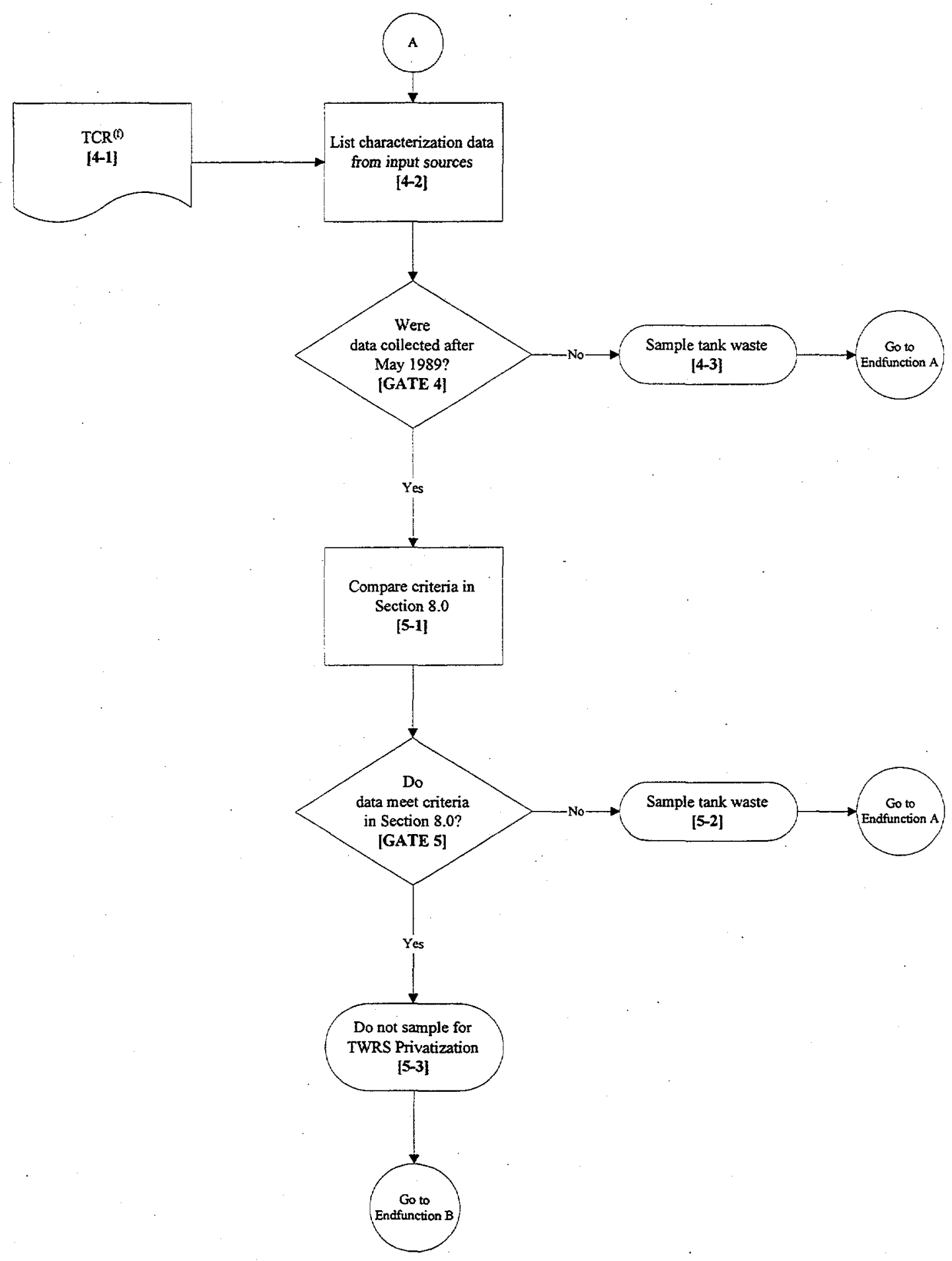


Figure 3.1. Regulatory Data Quality Objective Implementation Logic. (Page 3 of 3)

\section{ENDFUNCTION A}

Collect sample and conduct analyses in compliance with Section 8.0. The analyses are to support completion of the data request. When multi-analyte techniques are employed, consideration is to be given to obtaining replicate data for analytes of concern.

\section{ENDFUNCTION B}

If sample collection and multiple-analyte techniques are required to support other DQOs, all analytes/properties measured via these techniques are to be reported in support of TWRS Privatization.

Notes:

${ }^{(a)}$ Kirkbride et al. (1997).

(b)Koreski (1997).

(c)Stanton, G.A. 1998. Baseline Sampling Schedule. Change 09-0X (internal memorandum). Lockheed Martin Hanford Company, Richland, Washington.

(d)Agnew (1997).

(e) Hanlon (1998).

(1) Individual tank characterization reports. When available, technical reports, TWINS Tank Characterization

Database and vapor database and the standard inventory (Kupfer 1997) may be used as supporting input sources.

DQO = data quality objective.

HDW $\quad=$ Hanford defined waste.

OWVP $=$ Operational Waste Volume Projection.

TCR $=$ tank characterization report.

TWINS $=$ Tank Waste Information Network System.

TWRS $=$ Tank Waste Remediation System.

TWRSOUP $=$ TWRS Operational and Utilization Plan. 


\section{Gate 2: Have any major tank waste transfers occurred between the last sampling event and the current event [GATE 2]?}

The representativeness of existing characterization information relative to the current tank contents will depend, in part, on the number, quantity, and type of waste transfers that have occurred since the last sampling event.

Input sources [2-1] to be used to determine [2-2] the historical transfer activity for a given tank waste relative to the most recent sampling event:

- Baseline Sampling Schedule (Stanton memo) ${ }^{6}$ is updated, as needed, to reflect the most current sampling schedule and will be used to identify previous sampling events and planned future sample dates.

- The Hanford Defined Waste (HDW) document (Agnew 1997, previously known as the Historical Tank Content Estimate [HTCE]), which describes transfers through December 31, 1993.

- Waste Tank Summary reports (e.g., Hanlon 1998) will provide a complementary source of recent waste transfer information.

- Tank characterization reports (TCR) provide tank specific information.

If, since the most recent sampling event, a significant number of transfers or transfer of a large quantity of waste has occurred, or a dissimilar waste type has been transferred to the source tank, then the tank waste is a candidate for sampling and characterization [2-3] (continue to Endfunction A). ${ }^{7}$

If, since the most recent sampling event, significant waste transfers have not been associated with the source tank, further consideration is required to determine whether additional sampling and characterization are required (continue to Gate 3 ).

NOTE: Chemical reactions occurring with time, also known as aging, may also alter the waste composition and properties. Although there is insufficient scientific information to quantitatively predict the extent of change due to aging, a large body of data exists which may be used to define the general abundance and nature of the aging products. Consideration may also be given as to the representativeness of the data relative to the period of time elapsed since the last sampling event.

Gate 3: Are data available for analytes and parameters in Tables 4.4, 4.7, and 4.8 [GATE 3]?

Decision Gate 3 addresses the quantity of data. The quantity is defined by the number of samples to be collected from each tank and whether data is available for all of the analytes listed in Tables 4.4, 4.7,

${ }^{6}$ Stanton, G.A. 1998. Baseline Sampling Schedule. Change 09-0X (internal memorandum). Lockheed Martin Hanford Company, Richland, Washington.

${ }^{7}$ Wastes classified as static may undergo a limited amount of chemical adjustments (i.e., caustic addition) or blending with other static or well-characterized waste streams. Tank waste that undergoes significant blending may need to be reanalyzed. Refer also to Gate 1 criteria relative to waste transfers. 
and 4.8. The existing data are compared to a required number of samples specified in Section 8.0 and the analytes listed in Tables 4.4, 4.7, and 4.8.

The first step requires consolidation of all analytical data and information identified. The tank characterization reports will be used as primary input sources from which the list of reported analytes and physical properties will be derived [3-1]. When available, technical reports, the Tank Waste Information Network System (TWINS) Tank Characterization Database (TCD) and vapor database, and the standard inventory (Kupfer 1997) may be used as supporting input sources.

A list of analytes measured in the tank waste is prepared and compared to the analyte list required for this Regulatory DQO in Tables 4.4, 4.7, and 4.8 [3-2].

If the list of reported analytes is incomplete (when compared with Tables 4.4, 4.7, and 4.8), then the tank waste is to be sampled and characterized [3-3] (continue to Endfunction A). The analyses are to support completion of the data requested in this Regulatory DQO. When multi-analyte techniques are employed, consideration is to be given to obtaining replicate data for previously reported analytes of concern. If the list of reported analytes is complete when compared to Tables $4.4,4.7$, and 4.8 , then further assessment of the characterization information is required (continue to Gates 4 and 5 ).

\section{Gate 4: Were data collected after May 1989 [GATE 4]?}

The historical data for the analytes listed in Tables 4.4, 4.7, and 4.8 will be compiled [4-2] from the input sources [4-1] and dates of collection compared to May 1989. Any data collected after May 1989 will be used and data before May 1989 that is validated with post-May 1989 data will be considered for the quality evaluation step [Gate 5]. If data after May 1989 for given analytes are not available, the tank will be sampled [4-3] (continue to Endfunction A).

\section{Gate 5: Do data meet criteria in Section 8.0 of this document [GATE 5]?}

The historical data are compared with performance criteria described in Section 8.0 [5-1]. If characterization information meets the criteria set forth in this Regulatory DQO process, sampling specifically for Regulatory DQO analytes is not required [5-3]. If the data do not meet the criteria in Section 8.0, then the tank waste will be considered by DOE and Ecology for sampling to support the Regulatory DQO [5-2] (continue to Endfunction A). 


\subsection{Inputs}

\subsection{Summary of Analyte Selection Logic}

This section defines the decision logic constructed and implemented as a part of the Regulatory DQO process for selection and prioritization of regulated analytes to be characterized in source tank waste. The logic provides a technically defensible basis for evaluating the potential presence of the regulated compounds in the tank waste and provides prioritization for analysis based on toxicity and the applicability of analytical methods. Each step in the logic was developed and implemented by a team of scientists and DOE and Ecology representatives. The results were concurred with jointly by DOE and Ecology.

The logic is shown in Figure 4.0a, described briefly here and described in more detail in subsequent sections. The logic involves five primary decision steps.

1. What are the appropriate analytes to consider as inputs to the logic?

2. Are the regulated analytes used in industries not associated with the Hanford Site?

3. Would the regulated analytes be stable in the tank waste environment?

4. Is the compound of higher toxicity relative to other regulated analytes?

5. Is there an analytical method for the analyte and the method adaptable to the waste matrix?

The first step, inputs, results in a set of regulated organic constituents for consideration. Regulated organic analytes previously reported as detected were evaluated separately from the "non-detects." The evaluation included number of detects, relative toxicity and carcinogenicity, and applicable analytical methods. Regulated, non-organic constituents and characteristics were also assessed separately. After filtering for plausible and known regulated organic compounds in steps 2 and 3, compounds that have further data needs which may be met through sampling and analysis were identified.

Process knowledge was used in three areas of the analyte selection logic:

- the historical data from previous tank waste sampling was used in the inputs to identify regulated and not reported, and regulated and detected analytes,

- knowledge of processes used at the Hanford Site was used to identify analytes not associated with the Hanford Site, and

- tank chemistry based on process history, general literature information, and previous analyses of tank waste samples used to assess the stability of compounds in the tank waste environment.

\subsubsection{Inputs}

An input list was created from analytes identified in regulations agreed to be applicable by Ecology and $\mathrm{DOE}$, and in previous waste analyses (see Figure $4.0 \mathrm{~b}$ ). To manage these compounds in a logical fashion, constituents were grouped together into organic constituents and non-organic constituents. Nonorganic constituents were evaluated separately as described in Section 4.11. The organic compounds 
Figure 4.0a. Simplified Analyte Selection Logic for Organic Regulated Compounds.

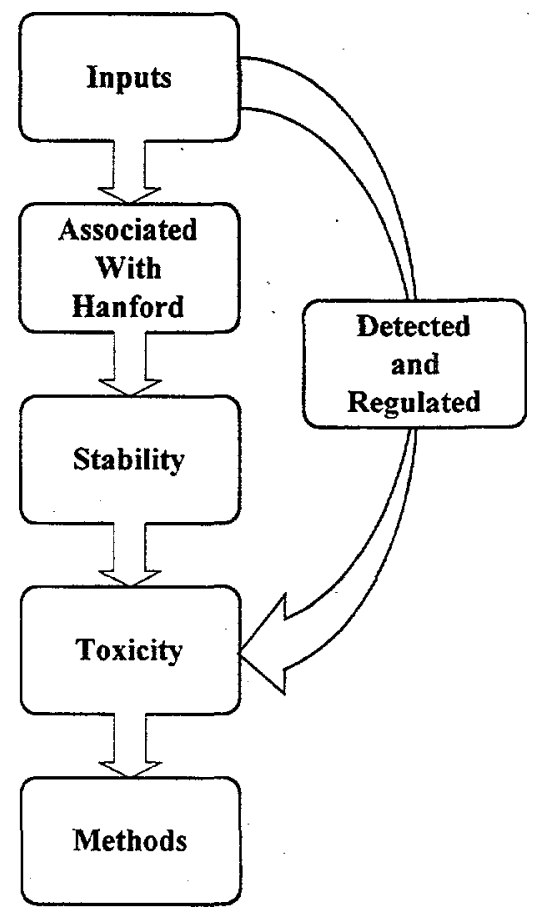

Figure 4.0b. Representation of Input List Development for Analyte Selection Logic.

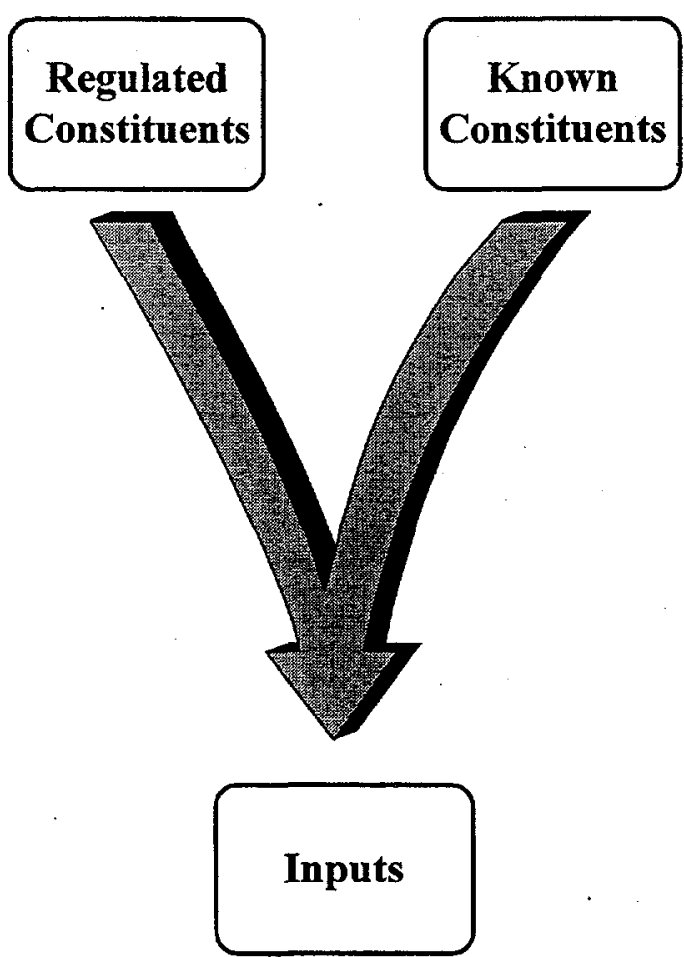


were separated into two groups of interest: (1) regulated and not reported (referred to as non-detected) and (2) regulated and detected. ${ }^{8}$ All subsequent steps in the logic focus on selecting and prioritizing these regulated organic analytes for future characterization based on the following technical decisions. Decision steps described in Sections 4.1.2 to 4.1.4 established the plausibility of the regulated compound's presence in the tank waste.

\subsubsection{Industries Not Associated with Hanford}

The regulated non-detected organic compounds were evaluated to assess potential use at the Hanford Site (Attachment I). This evaluation was based on published information on predominant uses from a number of commercial databases and best professional judgment. Compounds identified as not associated with the Hanford Site were eliminated from the selection of regulated organic compounds. Compounds previously identified in tank waste were not removed in the Industry evaluation.

\subsubsection{Stability}

The remaining regulated non-detected compounds were evaluated for stability in the tank waste environment (Attachment III). Compounds assessed as unlikely to be stable in the tank waste were excluded from further consideration.

\subsubsection{Toxicity}

The regulated organic compounds were also reviewed for their possible toxicity and carcinogenicity (Appendix C). Compounds were ranked by their assigned toxicity and carcinogenicity. A numerical threshold was used to assign "higher" and "lower" toxicity classes. Compounds with assigned values above the threshold remained in the selection process.

\subsubsection{Methods}

The regulated compounds were then reviewed against analytical methods from SW-846 (EPA 1997) and the specific selection criteria provided the final list of analytes for the characterization in support of the Regulatory DQO.

\subsection{Regulated Organic Analyte Selection Logic}

The detailed logic for selection of organic compounds for analysis is shown in Figures 4.1 through 4.6. Each decision is identified with a " $D$ " and each database query is identified with a "Q." A database referred to as the Regulatory $\mathrm{DQO}$ database was compiled to implement this logic. The figures and text reference both decisions and queries as applicable. Outputs from selected database queries are provided

\footnotetext{
${ }^{8}$ Non-regulated detected compounds were not directly applicable to this DQO and were removed from further consideration for sampling and analysis. These compounds were considered in assessing the stability of regulated compounds in the tank waste environment (Attachment III).
} 
in Appendix B. The appendix includes a reference table that links each output data table with a query. The brief explanations below describe the figures and steps in the decision logic process:

Figure 4.1: "Development of Potential Organic Single-Shell Tank/Double-Shell Tank Waste Positive Detect List."

The logic used to prepare a list of positive detects of organic SST/DST waste constituents based on previously reported analytical data.

Figure 4.2: "Regulatory Data Quality Objective Input Lists and Logic to Segregate Regulated Detected and Non-detected Compounds and Evaluate Detected Compounds for Toxicity and Carcinogenicity."

The logic to:

- define Regulatory DQO Input List,

- list compounds that are regulated and have not been reported in TWINS Tank Characterization Database and vapor database, and

- list compounds that are regulated and have been reported in the referenced TWINS databases.

This logic also separates the list of regulated detected compounds into three groups: (1) those of higher toxicity, (2) those of lower toxicity that have been detected at least 10 times, and (3) those of lower or unknown toxicity that have been detected fewer than 10 times.

Figure 4.3: "Logic to Assess Non-detected, Regulated Compounds from Industries Not Associated with Hanford."

The logic to assess whether the non-detected, regulated compounds were likely to be used at Hanford.

Figure 4.4: "Logic for Stability, Toxicity, and Carcinogenicity Assessments."

The logic to evaluate non-detected, regulated compounds for stability in the tank waste environment and for toxicity and carcinogenicity.

Figure 4.5: "Analytical Methods Assessment for Compounds with Higher Toxicity."

The logic to evaluate if compounds with higher toxicity are amenable for analyses by SW846 analytical methods.

Figure 4.6: "Analytical Methods Assessment for Compounds with Lower Toxicity and Priority Regulated Compounds for Characterization in Support of the Regulatory Data Quality Objective." 
The logic to compare analytical methods used to characterize higher toxicity/carcinogenicity compounds versus methods to characterize compounds of lower toxicity/carcinogenicity. The logic concludes with a final list of priority regulated organic compounds for analysis in tank waste.

The discussions in the following sections first address the starting lists for analytes in this Regulatory DQO. Two lists were compiled for examination:

- the list of organic compounds detected in the SST/DST waste (Section 4.3) and

- the regulatory analyte input list (Section 4.4).

After explaining the analyte input list, the following three groups of analytes (based on the logic in Figures 4.1 through 4.6) are presented:

- regulated, non-detected compounds of higher toxicity (Section 4.5),

- regulated, detected compounds of higher toxicity (Section 4.6), and

- regulated compounds, detected $\geq 10$ times and of lower toxicity (Section 4.7 ).

The decision logic concludes with an evaluation of selected analytes versus potential analytical methods. All actions discussed in the following sections are based on agreements between DOE and Ecology unless specifically stated.

\subsection{Organic Compounds Detected in Single-Shell Tank/Double-Shell Tank Waste}

Over 9,000 analytical records were reviewed from the TWINS Tank Characterization Database (SST and DST solids and liquids) and the TWINS SST vapor database (databases obtained on October 25, 1997). The information obtained from the TWINS databases, including the number of detects reported was used to create the Regulatory DQO database. The analytical data presented in the TWINS databases were assumed to be verified against the analytical records. The referenced TWINS databases values were used as presented without any further validation.

\subsubsection{Regulatory Data Quality Objective Database Refinement}

Operations completed to refine the Regulatory DQO database for application to the analyte selection logic include:

Treatment of Tentatively Identified Compounds. Compounds reported as tentatively identified compounds (TICs) are identified by comparison of mass spectra from the sample to libraries of spectra. The identification and quantitation are not confirmed by the running of standards on the instrument used to analyze the sample. Therefore, significant uncertainty is associated in the identity and quantification of TICs. TICs are identified by either a compound name from best match from the library, as a compound class (e.g., aromatic), or are reported as an unknown. 
Figure 4.1. Development of Potential Organic Single-Shell Tank/ Double-Shell Tank Waste Positive Detect List.

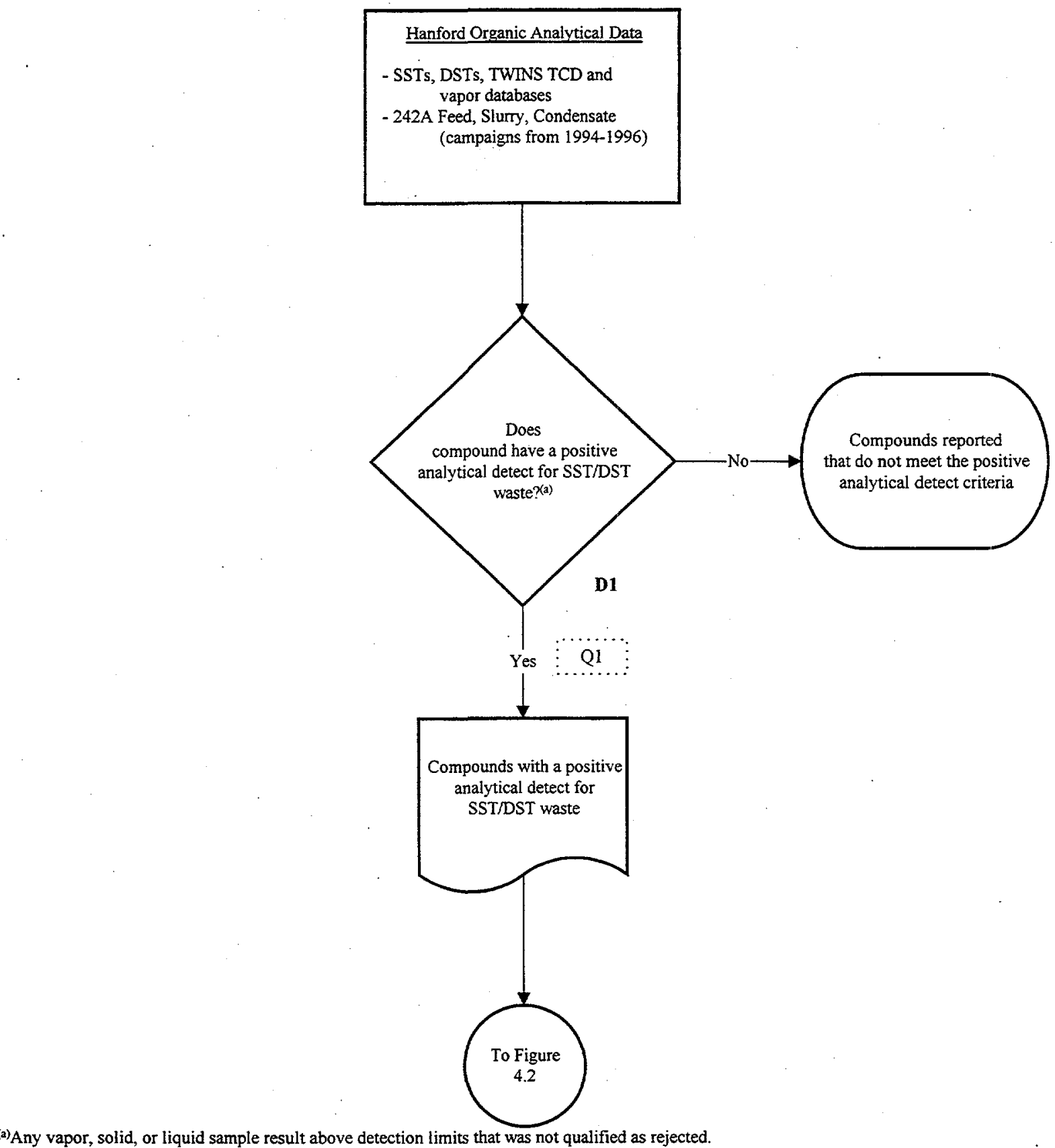

Where duplicate results existed, and one result was detected, a detected was included. Where duplicate results were presented and one result was rejected, the results were considered a positive detect.

DST = double-shell tank

SST $=$ single-shell tank.

TWINS $=$ Tank Waste Information Network System

$\mathrm{TCD}=$ Tank Characterization Database. 
Figure 4.2. Regulatory Data Quality Objective Input List and Logic to Segregate Regulated Detected and Non-detected Compounds and Evaluate Detected Compounds for Toxicity and Carcinogenicity.

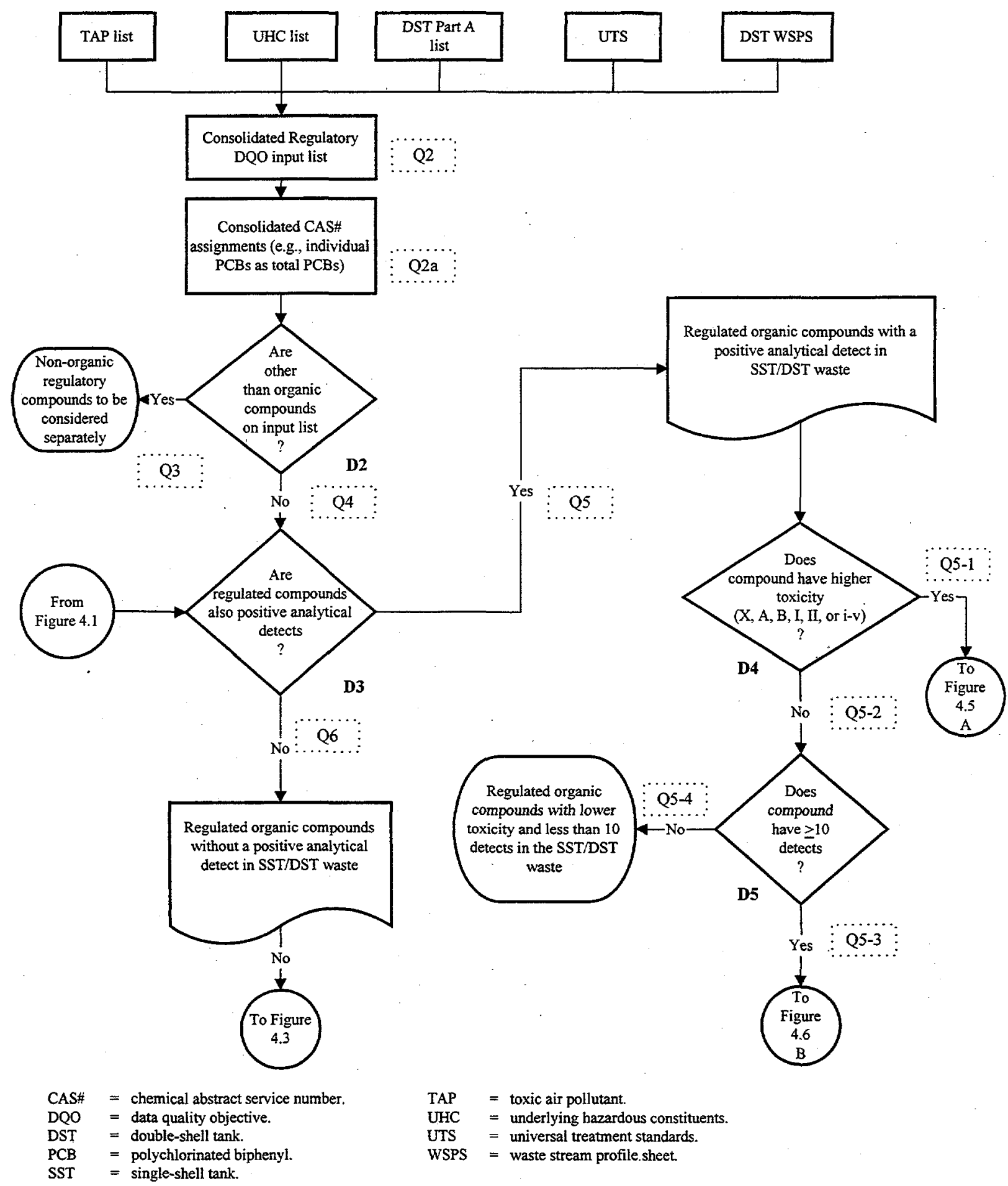


Figure 4.3. Logic to Assess Non-detected, Regulated Compounds from Industries Not Associated with Hanford.

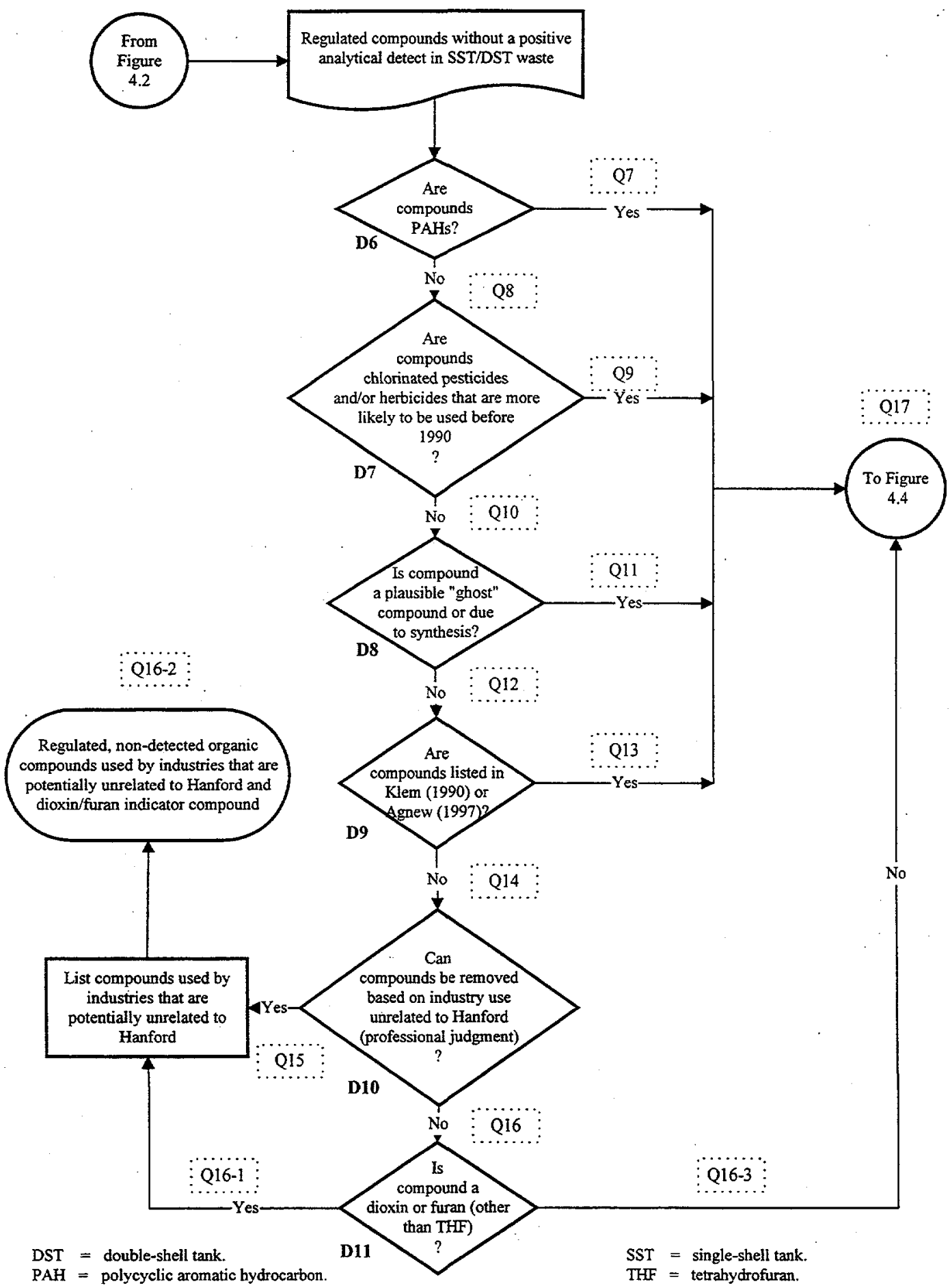


Figure 4.4. Logic for Stability, Toxicity, and Carcinogenicity Assessments.

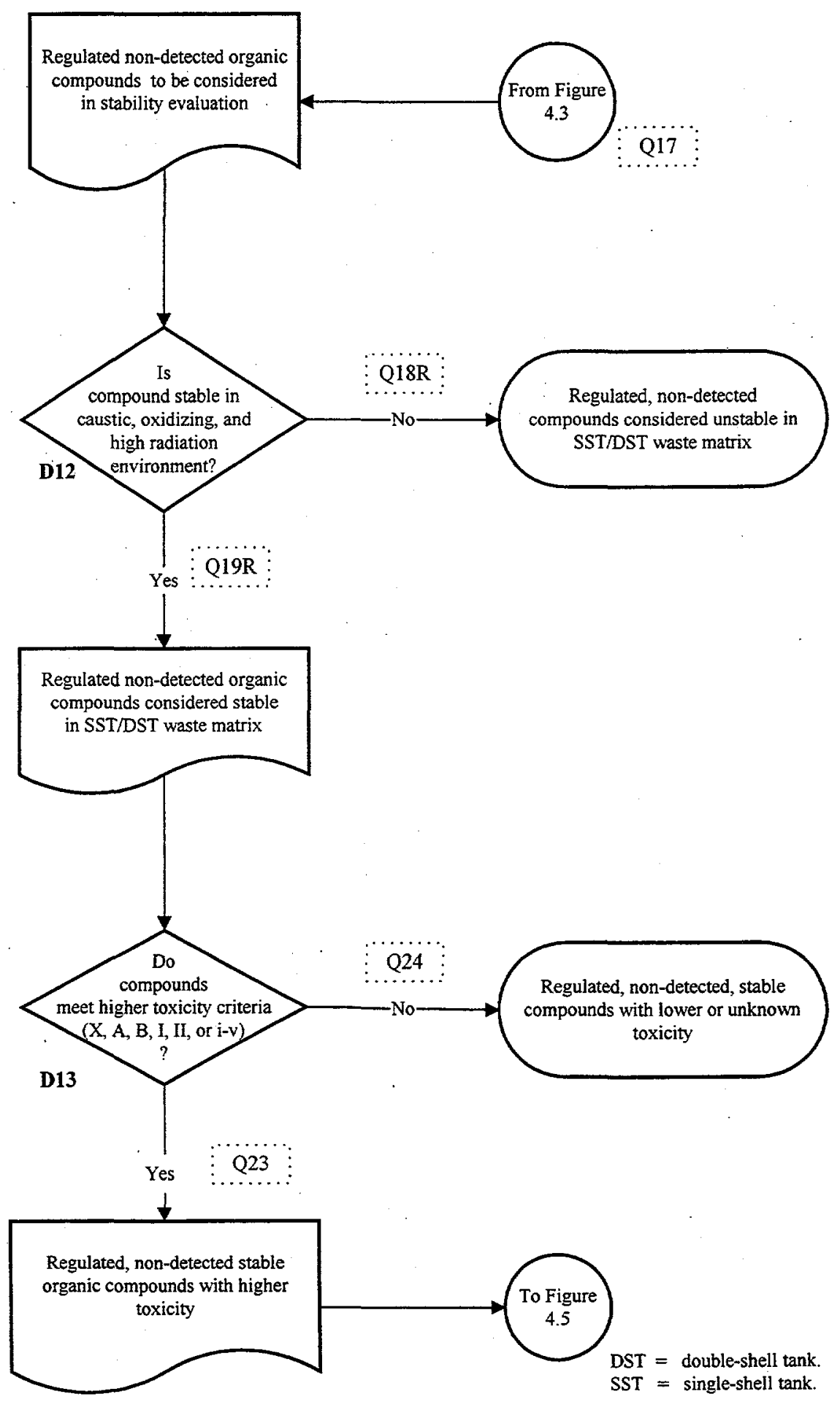


Figure 4.5. Analytical Methods Assessment for Compounds with Higher Toxicity.

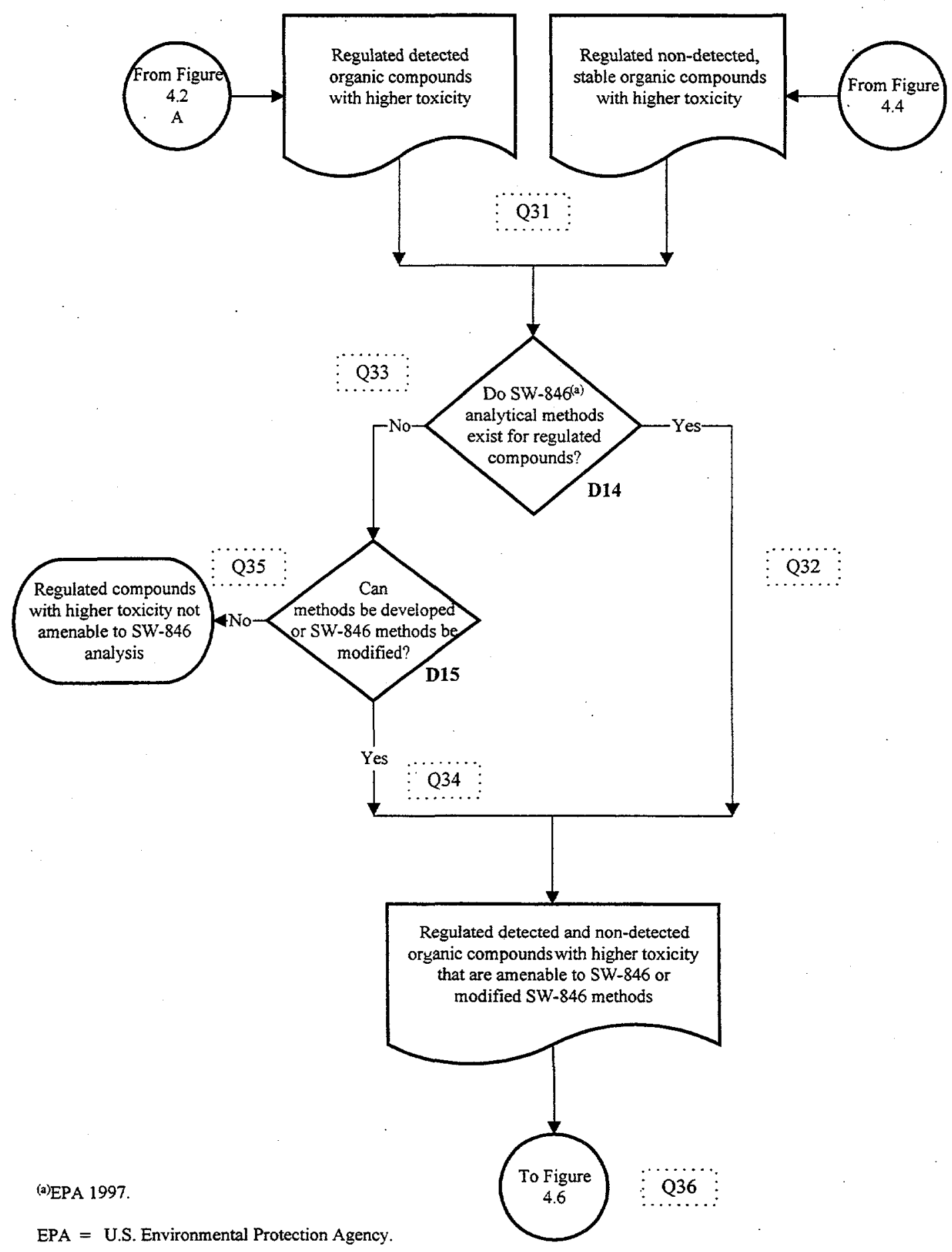


Figure 4.6. Analytical Methods Assessment for Compounds with Lower Toxicity and Priority Regulated Compounds for Characterization in Support of the Regulatory Data Quality Objective.

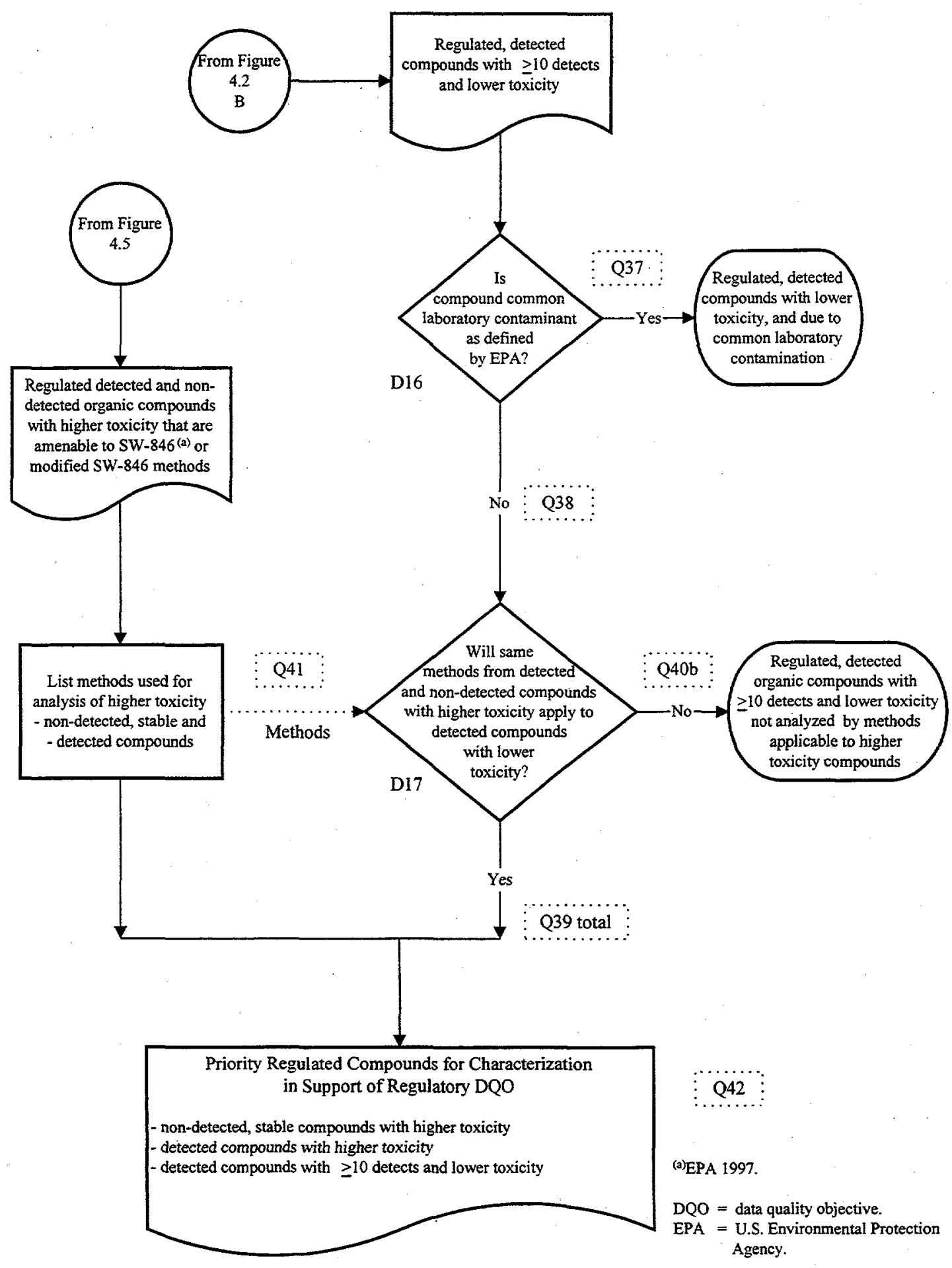


The TIC data in the vapor phase versus the solid/liquid phases were managed differently in the Regulatory DQO database due to the availability of verified data. The TICs identified in the TWINS vapor database represent the majority of reported data for regulated analytes in tank waste. For this reason, the vapor phase TIC data were retained in the Regulatory DQO database for assessment of "number of detects." The TICs reported in the TWINS Tank Characterization Database included a large number of analytical artifacts specifically excluded by EPA. The Tank Characterization Database TICs were flagged as TICs in the Regulatory DQO database and were not counted as detects.

Removal of Non-organics, Quality Control Reagents, and Artifacts. The original TWINS data were filtered to exclude inorganic analytes and test parameters, analytical quality control reagents (i.e., analytical method surrogates and internal standards), and analytical artifacts (i.e., siloxanes from gas chromatography column degradation). Non-organic analytes and test parameters are considered separately in Section 4.11 .

Consolidation of Chemical Abstract Service Numbers. Cross-references were performed in the TWNS Tank Characterization Database and vapor database on chemical names, and a list of synonyms consisting of over 7,500 entries was reviewed. One specific, commonly used chemical name was assigned to each chemical abstract service number (CAS\#). The final list of unique compounds considered in this DQO was consolidated to 1,227 . The CAS\# is used as the key field for comparison of compounds across the database and with other databases. For example, methylene chloride and dichloromethane were consolidated as dichloromethane with CAS\# 75-09-2. Compounds that were listed as mixtures specifying more than one compound were not included in the assessment. For example, xylene (CAS\# 1330-20-7) was removed since the individual isomers (para, meta, and ortho) were included as individual compounds.

Oregon Graduate Institute Data. The Oregon Graduate Institute data were flagged in the TWINS vapor database stating that either no approved quality assurance (QA) documentation existed, or that a significant QA deficiency was associated with the reported results. All Oregon Graduate Institute analytes retained in the Regulatory DQO database were confirmed by analyses from other laboratory(ies).

\subsubsection{Identification of Positive Detects}

The remaining data were reviewed for determination of "positive detect" status. A positive response is defined as one or more detects that are not qualified as a reject or reported at or below the analytical detection limit. Duplicate samples with one reported detect were counted as a positive detect.

\subsubsection{Consideration of Additional Analytical Data Inputs}

The compounds with positive responses from the analyses of 242A Evaporator process condensate, slurry, and feed from 1994 (campaign \#1) to 1996 (campaign \#2) were also included in the SST/DST waste compound list (WHC 1994a, 1994b, 1994c; WHC 1995a, 1995b; WHC1996a, 1996b).

Organic species were measured in liquid phase waste samples as part of the organic safety program (Campbell et al. 1996a, 1996b). The list of regulated compounds considered in this Regulatory DQO does not include these organic species with the exception of tributyl phosphate (TBP), formate, and oxalate. These three compounds were also positive detects as reported in TWINS Tank Characterization 
Database and/or vapor database and are included in the Regulatory DQO Input List. Therefore, the compounds measured by Campbell were not added to the inventory of detected compounds.

\subsubsection{Final List of Detected Organic Single-Shell Tank/ Double-Shell Tank Waste Compounds}

The compiled list of organic SST/DST waste compounds assigned as "detects" is presented in Appendix B, Table B-1 (Figure 4.1, Q1, 1,227 compounds). The detected analytes were compared with the Regulatory DQO Input List (Section 4.5).

\subsection{Regulatory Data Quality Objective Analyte Input Lists}

The Regulatory DQO analyte input lists include the:

- Toxic Air Pollutant (TAP) lists Classes A (WAC 173-460-150) and B (WAC 173-460-160),

- Underlying Hazardous Constituents (UHC) list (40 CFR 268.2(i)),

- Universal Treatment Standards (UTS) list (40 CFR 268.48),

- Double Shell Tank RCRA Part A permit application, except waste code F039 (DOE-RL 1996a), and

- Double Shell Tank Waste Stream Profile Sheet constituents.

The following sections discuss each of the inputs considered for inclusion. Appendix B provides the lists and shows the compounds common and unique to the various lists. The combined Regulatory DQO analyte input list contains 850 compounds (Figure 4.2, Q2).

\subsubsection{Toxic Air Pollutants}

The TAP lists include carcinogenic and noncarcinogenic toxic compounds. The compounds in the TAP lists were promulgated by the Washington State Department of Health (WDOH) for regulation of air pollutants. Class A pollutants are known and probable carcinogens listed in WAC 173-460-150. The Class B pollutants are toxic compounds listed in WAC 173-460-160 and are substances that are not simple asphyxiant or nuisance particulates. The Class B compounds would be considered in evaluating the risk of airborne material potentially exiting. a newly permitted facility. The Class $\mathrm{A}$ and $B$ compounds are used by the State of Washington in regulating offgas emission control systems. Ecology and DOE agreed that information regarding the TAP Classes A and B compounds may be useful in the risk assessment to support the treatment facility's permitting process.

\subsubsection{Underlying Hazardous Constituents and Universal Treatment Standards}

The RCRA LDR regulations require the generator to determine the Underlying Hazardous Constituents (UHC) pursuant to 40 CFR 268.7 through testing or knowledge of the waste. In addition, 
LDR regulations have required treatment standards, the Universal Treatment Standards (UTS) at 40 CFR 268.48 for individual waste constituents. The UTS list is a consolidated listing containing all UTS and UHC constituents. ${ }^{9}$ During the DQO process, consideration was given to both UTS and UHC constituents to ensure that evaluation of these compounds was addressed.

\subsubsection{Double-Shell Tank Resource Conservation and Recovery Act of 1976 Part A Permit Application}

The DST RCRA Part A permit application (DOE-RL 1996a) lists the waste codes applicable to DST waste based on previous waste designation. For specific waste codes, specific treatment criteria apply. The DST waste codes include all the SST waste codes and include metals, organic compounds, and select characteristics such as ignitability. The F039 waste codes are included in the DST RCRA permit and apply to waste resulting from landfill leachate. To date, no landfill leachate has been added to the tanks; therefore, F039 compounds were not included in the Regulatory DQO database. Should landfill leachate be added to tanks, the waste will be characterized before it is added to the tanks. The waste is required to be treated using particular technologies and/or standards under RCRA based on the applicable waste codes. Future demonstration that particular treatment standards have been met will in many cases be dependent on waste feed characterization data.

\subsubsection{Double-Shell Tank Waste Stream Profile Sheets}

The DST WSPS describe newly generated waste that is to be stored in the DST system. Since 1996, a profile is required to be provided by the generator and approved by TWRS before acceptance of the waste into the DST system in accordance with the DST Waste Acceptance Criteria. The DST WSPS have included organics, metals, select radionuclides (total alpha, plutonium-239/240, and uranium-235) and other waste properties such as $\mathrm{pH}$ and specific gravity (hereafter referred to as "test parameters") (WHC 1996c). Radionuclides are not specifically addressed in this Regulatory DQO. Test parameters are addressed in Section 4.11.

Flammable gas prevention is evaluated as part of the DST waste acceptance criteria. The criteria for evaluating flammable gas waste transfer issues is in the Compatibility DQO (Mulkey and Miller 1997). The Flammable Gas DQO (Bauer 1997) addresses the steady state flammable gas condition of a tank. Presently the Flammable Gas DQO includes analysis of compounds which may have an effect on flammability. The analytes in the Flammable Gas DQO are evaluated for inclusion into the Compatibility DQO analyte list when the DQO is revised. The Compatibility DQO is used as a rationale for safety analytes to be included in the DST Waste Acceptance Plan. Ecology requested and DOE agreed to include the Flammable Gas DQO analytes in the Regulatory DQO analyte input list.

\footnotetext{
${ }^{9}$ As defined at 40 CFR 268.2(i), "Underlying hazardous constituent means any constituent listed in $\$ 268.48$, Table UTS-Universal Treatment Standards, except fluoride, vanadium, and zinc, which can reasonably be expected to be present at the point of generation of the hazardous waste, at a concentration above the constituent-specific UTS treatment standards."
} 


\subsubsection{Inputs Considered and Dismissed}

Two inputs were considered and dismissed from inclusion in the regulatory analyte input list, Appendix VIII of 40 CFR Part 261 and the ETF Delisting Petition (DOE-RL 1993).

Appendix VIII. The Appendix VIII list of compounds applies to delisting (40 CFR Part 261). The Appendix VIII list of compounds was considered and dismissed as a potential input for this Regulatory DQO. The decision not to include the Appendix VIII list was based on a letter from T. Cusack to J.C. Armbruster dated August 27, 1996, and an agreement between DOE and Ecology as to the meaning of the letter (Appendix A).

Effluent Treatment Facility. Ecology reviewed the ETF Delisting Petition (DOE-RL 1993) to determine whether additional compounds should be added to the regulatory list based on ETF data needs. The ETF has its own permit and the effluent has undergone delisting. The ETF generates a specific treatment plan for each waste feed. The plan is provided to the regulators for approval before processing waste. This is done to ensure that the permit is met. Ecology and the DOE agreed that since a plan will be generated by ETF for treatment of new waste feed, and since the ETF Delisting Petition dealt with many of the same compounds in the regulatory lists that are part of this DQO, no additional analytes should be added to the source tank characterization based on ETF data needs.

\subsubsection{Consolidation of Chemical Abstract Service Number Assignments}

Isomers and congeners ${ }^{10}$ were evaluated for potential consolidation of CAS\#s. Polychlorinated biphenyls (PCBs), dioxins and furans, and cresols were consolidated as follows. This consolidation of CAS\# assignments resulted in 845 compounds following Figure 4.2, Q2a.

Polychlorinated Biphenyls. Since the individual PCBs are similar in their chemical behavior, toxicity, and carcinogenicity, the various Aroclors (e.g., PCB-1242, PCB-1248, PCB-1254, PCB-1260) were combined as "total PCBs" (CAS\# 1336-36-3).

Dioxin and Furans. During the analyte selection logic steps of queries Q1, Q2, Q3, and Q4, any compounds listed from the group of dioxins and furans were compared to the list of detected compounds from the TWINS Tank Characterization Database and vapor database. To ensure matching of information throughout the remaining database operations, all listed dioxins and furans except tetrahydrofuran (THF) were grouped together and 2,3,7,8-tetrachlorodibenzo-p-dioxin (TCDD) (CAS\# 1746-01-6) was used as a representative indicator compound for the dioxins/furan group in the Regulatory DQO database. TCDD was selected as the indicator for the dioxin/furan group because it has the highest toxicity ranking within this group. THF was excluded from this grouping of dioxins and furans since it was a known process chemical at Hanford. THF was tracked through the analyte selection logic separate from TCDD.

Cresols. In the case of the cresols (meta, ortho, and para), the individual isomers have different chemical behavior and; therefore, were not combined and remained as individual isomers. "Total

\footnotetext{
${ }^{10} \mathrm{~A}$ congener is a compound within the same chemical class (e.g., furans or dioxins).
} 
cresols" had a TAP toxicity ranking assigned of III, but the individual isomers had no rankings (refer to Appendix C). Therefore, the TAP toxicity ranking from the "total cresols" was assigned to the three individual isomers.

\subsubsection{Organic Regulatory Data Quality Objective Input List}

Since this analyte selection logic applies to organics only, all other compounds, such as inorganics and organometallics, and test parameters were excluded. These excluded compounds and parameters are considered in a separate logic described in Section 4.11 (Figure 4.2, Q3, 222 compounds). The final organic Regulatory DQO analyte input list consists of 623 compounds (Figure 4.2, Q4).

\subsection{Selection of Regulated Non-Detected Compounds of Higher Toxicity}

The next step in the analyte selection process was to separate the regulatory analytes into two groups: analytes that were detected in the SST/DST waste and analytes that were not previously reported (Figure 4.2, D3). The detected compounds from Figure 4.1, Q1 were compared with the regulatory compounds (Figure $4.2, \mathrm{Q} 4$ ) in D3. The regulated analytes were separated into 477 compounds that have not been reported as previously detected (Figure 4.2, Q6) and 146 compounds meeting the detected criteria (Section 4.2.1.2) (Figure 4.2, Q5). The detected, regulated compounds were next evaluated for relative toxicity (Section 4.6). The non-detected regulated compounds were evaluated for potential exclusions and/or uses in industrial applications not associated with Hanford (Section 4.5.1), stability in tank waste environment (Section 4.5.2), and relative toxicity/carcinogenicity (Section 4.5.3).

\subsubsection{Used in Industrial Applications Not Associated with Hanford}

The input lists selected for this Regulatory DQO originated from non-nuclear industries and therefore include a large number of compounds not associated with the operations at the Hanford Site. Industry uses for each non-detected or reported regulated compound were identified and used in the evaluation of industry applications not associated with the Hanford Site (Attachment $I$ ). This evaluation of compounds involved several steps: identification of "special interest" compounds, examination of published site inventories, and assignment of predominant industry uses.

Identification of "Special Interest" Compounds. As a part of the evaluation of compounds not associated with Hanford, several compounds of known or suspected association with Hanford were identified (Figure 4.3). These compounds were retained for further consideration. The compounds included polycyclic aromatic hydrocarbons (PAHs), pesticides and herbicides, ghost compounds (compounds with a plausible, but undocumented, path to Hanford tank inventories), and those which may be present in the tank waste as a result of in-situ synthesis.

Polycyclic Aromatic Hydrocarbons (PAHs). Since it has been established that at one point in time, the waste tanks were lined with tar (a material that mainly consists of PAHs), PAHs were not eliminated on the basis of industry use and were retained for further consideration (Figure 4.3, Q7, 14 compounds).

Pesticides and Herbicides. DOE and Ecology agreed that chlorinated pesticides and herbicides were likely to have been used during early Hanford Site operations. Therefore, the chlorinated pesticides 
and herbicides were not eliminated for industry uses (Figure 4.3, Q9, 39 compounds). The detailed discussion of the technical rationale for selection of pesticide and herbicide compounds in support of the Regulatory DQO is included in Attachment II.

Ghosts. Regulated compounds that are suspected to have been used at the Hanford Site, however, not documented in existing inventories were evaluated as "ghosts." For example, PCBs used in electrical equipment and residuals may have entered into the tanks (Figure 4.3, Q11, 1 compound).

Synthesis. Synthesis of compounds during waste storage in the tanks was evaluated and is discussed fully in Attachment III. The potential for synthesis focuses primarily on the materials known to be placed in the tank such as the solvents and complexants. The aging products were considered, particularly the material generated by cleavage and oxidation of normal paraffin hydrocarbons (NPHs). The possibility of generating halogen or nitrogen substituted aromatics from materials detected and known to be stable to tank conditions was evaluated. Generation of halo substituted carbon compounds or nitro aliphatic compounds was also considered.

The criteria used to identify stable and unstable chemicals was based on the reactivity of functional groups. This same criteria was applied to any regulated compound potentially synthesized "in-situ," i.e., in the tank waste matrix. However, if synthesized compounds with high-vapor pressures were formed continuously, in even low concentrations, these compounds might be identified in the dome vapor space in the tank. This leads one to believe that most of these compounds could only be present at less than steady-state concentrations as they are removed/isolated from the reactive environment, such as being swept out of the tank waste into the dome space or as a less likely alternative, adhere to the tank solids.

While considering the synthetic pathways, examples were noted to explain the detection of regulated compounds that were not otherwise added to the tanks (i.e., nitriles). No equally credible synthetic pathways could be proposed to add regulated compounds not previously detected (Figure 4.3, D8).

Inventory. A comparison was performed (Figure 4.3, Q13, 7 compounds) of the regulated compounds to two existing Hanford inventories (Klem 1990; Agnew 1997) to ensure that compounds from the existing Hanford inventory would not be removed during the Hanford industry association assessment.

Industries Not Associated with Hanford. The remaining regulatory compounds from D9 (Figure 4.3, Q14, 416 compounds) were reviewed by the technical staff of PNNL, Ecology, and independent consultants for specific compounds typically used in industries or applications not associated with Hanford activities (Figure 4.3, Q15, 207 compounds). The Effluent Treatment Facility (ETF) Delisting Petition (DOE-RL 1993) was used as the basis for establishing a list of industry categories that are not associated with Hanford activities. The categories are as follows:

- pesticides,

- military,

- dyestuff,

- pharmaceutical,

- solvent,

- consumer,

- group/mixture, and

- polymer. 
A discussion of each category is presented with examples of compounds present. Material Safety Data Sheets, the Merck Index, and other technical databases were consulted to evaluate the potential uses of each compound. The detailed list of compounds in each category is presented in Attachment I.

Pesticides. Compounds included in this category and referred to in this logic as pesticides, include pesticides, miticides, insecticides, fungicides, rodenticides, and herbicides. Attachment II provides a detailed discussion of the method to identify the pesticides that were excluded and included in the logic. Examples of compounds potentially not used at Hanford are TEPP, (synonyms nifost; vapotone; tetron; killax; moropal; tetraethyl pyrophosphate; ethyl pyrophosphate; tetraethyl ester diphosphonic acid), CAS\# 107-49-3; and naled, (synonyms: bromochlorphos, dimethyl-1,2-dibromo-2,2-dichlorethyl; dibrom; phosphoric acid 1,2-dibromo-2,2-dichloroethyl dimethyl ester; 1,2-dibromo-2,2-dichloroethyl dimethyl phosphate; alvora) CAS\# 300-76-5.

Military. This category includes compounds such as explosives and chemical war agents. Examples of compounds include nitrogen mustard N-oxide (CAS\# 126-85-2) and nitroglycerin (CAS\# 55-63-0).

Dyestuff. This category includes compounds used in the fabrication of dyes or actual dyes used in all types of materials, food, textiles, etc. Examples of these compounds include xylidine (CAS\# 1300-73-8) and o-Anisidine (CAS\# 90-04-0).

Pharmaceuticals. This category includes chemicals used in making pharmaceuticals. An example of a compound used in pharmaceuticals is safrole (CAS\# 94-59-7).

Solvent. This category includes solvents that were not used in Hanford processes. An example is epichlorohydrin (CAS\# 106-89-8). It is a solvent for natural and synthetic resins, gums, cellulose esters and ethers, paints, varnishes, nail enamels and lacquers, and cements for celluloid. It is used in surface-active agents, pharmaceuticals, insecticides, agricultural chemicals, textile chemicals, coatings, adhesives, plasticizers, glycidyl esters, ethymyl-ethylenic alcohol, and fatty acid derivatives.

Consumer. This category includes chemicals used in consumer products. An example is isosafrole (CAS\# 120-58-1) used to manufacture Heliotropin; to modify oriental perfumes; to strengthen soap perfumes; in small quantities together with methyl salicylate in root beer and sarsaparilla flavors.

Group/Mixtures. This category includes mixtures such as turpentine and asphalt.

Polymers. This category includes chemicals used to make polymers such as neoprene and rubbers. 4,4'-methylenebisbenzenamine dihydrochloride (CAS\# 13552-44-8) is used as a closed-system intermediate in the production of 4,4'-methylenediphenyl diisocyanate, which is used in rigid urethane foams for insulation material, in semiflexible polyurethane foams for automobile safety cushioning, and in the manufacture of elastomers such as spandex fibers. It is also used as a curing agent for epoxy resins (as cross-linking agent), in the manufacture of 4,4'-methylenebis (cyclohexaneamine), in the formation of a polyamide imide or a polyester imide (which is used as a wire coating), in the preparation of azo dyes, as a reagent for the determination of tungsten and sulfates, as a corrosion inhibitor for iron under acidic conditions, as a curative for neoprene rubber, in a heat-sensitive hair-setting cream, and in the formulation of polyurethanes for encapsulating instruments for measuring water flow. 
Dioxins and Furans. If the compound was a dioxin or furan (other than tetrahydrofuran [THF]), it was also removed (Figure 4.3, Q16-1, 1 compound). Dioxins/furans are toxic by-products of incomplete combustion of halogenated materials. Since the treatment facility will need to manage the generation and associated risk of having these compounds as a result of the thermal treatment process, no further evaluation for dioxins and furans was performed. Tetrahydrofuran was a known process chemical at Hanford and was therefore retained for further consideration.

Analytes Removed for Industry Uses. Non-detected, regulated compounds that were used in industries unrelated to Hanford were removed from further consideration in the Regulatory DQO analyte selection logic (Figure 4.3, Q16-2, 208 compounds). The regulated compounds remaining after D11 (Figure 4.3, Q16-3, 208 compounds) were combined with the analytes excluded above in D6, D7, D8, and D9 (Figure 4.3, Q17, 269 compounds) and are carried forward to the stability in tank waste environment evaluation (Figure 4.4).

\subsubsection{Stability in Tank Waste Environment}

The compounds from Figure 4.3, Q17 (269 compounds) were regulated constituents expected or likely present in the DST/SST waste and were next reviewed for stability in the highly alkaline ( $\mathrm{pH}>9.0$ ), nitrate/nitrite rich (oxidizing), and radioactive waste tank environments. Each compound was evaluated separately by a team of organic chemists familiar with tank waste conditions. DOE and Ecology concurrence was reached for each compound assignment. A detailed discussion of stability of chemical compounds in the SST/DST waste is included in Attachment III.

Compounds that could potentially survive for significant periods in the tanks ( $>1$ year) were considered as stable. Possible reactions in the alkaline, highly concentrated oxidizing (nitrate/nitrite), radioactive, and elevated temperature matrix include:

- addition (condensation and radical coupling),

- elimination (dehydrohalogenation),

- hydrolysis,

- oxidation,

- radical reductive dehalogenation, and

- substitution (nucleophilic displacement by hydroxide ion).

In addition, possible degradation (aging) of solvents and complexants and radiolytic reactions were considered. The compounds were screened on a compound-by-compound basis and the susceptibility of the functional group to the previous list of reactions was evaluated. In the absence of literature references, professional judgment was used to assess the compound's reactivity. In-situ synthesis is closely linked with the evaluation of waste stability and is discussed in Attachment III. From the reviewed compounds, 179 regulated compounds were considered unstable in the tank waste (Figure 4.4, Q18R).

Stability of Salts. The tank wastes range in alkalinity from a pH of greater than 9 for some SSTs (Wodrich et al. 1992) to those exceeding $\mathrm{pH} 12$ due to the sodium hydroxides. The carboxylic acids and phenols have a wide range of acid dissociation constant ( $\mathrm{pKa}$ ) values but most values are less than 10 , so acids and phenols will exist in the salt form in the tanks waste material. However, for the stability evaluation if either the acid or its salt form were deemed stable, both forms were treated as stable. That is, for this Regulatory DQO, the simple acid-base reaction of an acidic compound was not considered to 
constitute instability if no other reactive functional group is present. The relative environmental risk associated with the dissociated versus the undissociated species is dependent on the treatment process and environmental conditions. No compounds were removed from further consideration based on reversible dissociation reactivity.

Other Factors Considered. The boiling point and solubility of organic compounds in the tank waste were considered as evaluation criteria for inclusion/exclusion of analytes for potential analyses.

However, the solubility information available for organic compounds is based on solubility in aqueous neutral solutions and the tank waste is aqueous, alkaline $(\mathrm{pH}>9)$, and with high salt concentration. Therefore, no rational criteria could be established for solubility of organics in the present tank matrix. Based on similar logic, a criterion (or a cut-point) for the boiling point for organic compounds could not be established. It is acknowledged that constituents with a low boiling point may be removed during the mixing and transfer of waste feed before the waste is sent to the treatment facility.

\subsubsection{Toxicity and Carcinogenicity}

Ninety non-detected compounds were considered stable (Figure 4.4, Q19R) and were evaluated for toxicity and carcinogenicity. The detailed technical rationale on the selection criteria for toxic and carcinogenic compounds is included in Appendix C. The toxicity and carcinogenicity rankings were based on information obtained through the UHCs, Class B Toxic Air Pollutants, and slope factors.

Underlying Hazardous Constituents (UHC) Toxicity Ranking Criteria. For the UHCs, each compound's toxicity ranking was determined by Rust Federal Services of Hanford, Inc. in accordance with the method provided under the "Dangerous Waste Regulations" at WAC 173-303-100(5)(b), book designation procedure. This method ranks compounds into toxic categories of $\mathrm{X}, \mathrm{A}, \mathrm{B}, \mathrm{C}$, and $\mathrm{D}$ as shown in Table 4.1. The compounds assigned higher toxicity are those with rankings of $\mathrm{X}, \mathrm{A}$, or $\mathrm{B}$.

Table 4.1. Toxic Categories Used for Ranking Compounds.

\begin{tabular}{|c|c|c|c|c|}
\hline $\begin{array}{l}\text { Toxic Ranking } \\
\text { Category* }\end{array}$ & $\begin{array}{l}\text { Fish } \\
\mathrm{LC}_{50}(\mathrm{ng} \mathrm{g})\end{array}$ & $\begin{array}{l}\text { Oral (Rat) } \\
\text { LD }(\text { og }(\text { kg) }\end{array}$ & $\begin{array}{l}\text { Inhalation (Rat) } \\
\text { LC so }(\mathrm{mg} L)\end{array}$ & $\begin{array}{l}\text { Dermal (Rabbit) } \\
\text { LB } \text { L }_{50} \text { (mg/kg) }\end{array}$ \\
\hline $\mathrm{X}$ & $<0.01$ & $<0.5$ & $<0.02$ & $<2$ \\
\hline A & $0.01 \leq 0.1$ & $0.5 \leq 5$ & $0.02 \leq 0.2$ & $2 \leq 20$ \\
\hline B & $0.1 \leq 1$ & $5 \leq 50$ & $0.2 \leq 2$ & $20 \leq 200$ \\
\hline $\mathrm{C}$ & $1 \leq 10$ & $50 \leq 500$ & $2 \leq 20$ & $200 \leq 2,000$ \\
\hline $\mathrm{D}$ & $10-100$ & $500-5,000$ & $20-200$ & $2,000-20,000$ \\
\hline
\end{tabular}

*Toxicity decreases from $\mathrm{X}$ to $\mathrm{D}$.

Class A and Class B Toxic Air Pollutant Toxicity Ranking Criteria. The measure of toxicity used for Class B TAPs is based on their assigned acceptable source impact levels (ASIL) as promulgated under WAC 173-460. The ASIL is given in micrograms per cubic meter for a continuous 24-hr period. The smaller the ASIL value, the more toxic the compound. 
The process used for this assessment was to sort all TAPs Class B compounds by their ASIL, from highly toxic to less toxic compounds. The compounds were then broken into groups as shown in Table 4.2.

Table 4.2: Prioritization Grouping of Acceptable Source Impact Level Values.

\begin{tabular}{|l|c|}
\hline 1.10 & Toxic Ranking \\
\hline$<1 \mu \mathrm{g} / \mathrm{m}^{3}-24 \mathrm{hr}$ & Categoryt \\
\hline $1 \mu \mathrm{g} / \mathrm{m}^{3}$ to $10 \mu \mathrm{g} / \mathrm{m}^{3}-24 \mathrm{hr}$ & I \\
\hline$>10 \mu \mathrm{g} / \mathrm{m}^{3}$ to $100 \mu \mathrm{g} / \mathrm{m}^{3}-24 \mathrm{hr}$ & II \\
\hline$>100 \mu \mathrm{g} / \mathrm{m}^{3}$ to $1,000 \mu \mathrm{g} / \mathrm{m}^{3}-24 \mathrm{hr}$ & III \\
\hline$>1,000 \mu \mathrm{g} / \mathrm{m}^{3}-24 \mathrm{hr}$ & IV \\
\hline
\end{tabular}

*Toxicity decreases from I to $\mathrm{V}$.

ASIL = acceptable source impact level.

Based on comparison of compounds regulated as both an UHC and Class B TAP, compounds with rankings of I and II were considered higher toxicity (see Table 4.1). "Total cresols" had a TAP toxicity ranking assigned of III, but the individual isomers had no rankings. Therefore, the TAP toxicity ranking from the "total cresols" was assigned to the three individual isomers.

No specific ranking, other than carcinogenicity was conducted for the Class A TAP constituents.

Carcinogenicity - Slope Factors for Inhalation. Slope factors for regulated compounds screened for toxicity and carcinogenicity were obtained from the EPA Integrated Risk Information System (IRIS) and the Health Effects Summary Tables (HEAST) databases. The carcinogenicity rankings were assigned by using the greater of the available slope factors from IRIS and HEAST, taking the logarithm and sorting the results into the groups as shown in Table 4.3. The cutoff point was set at slope factor $=1$. Compounds below slope factor $=1$ are designated as below the cut-point (BC). Compounds with slope factors of I-v are considered of higher toxicity.

The weight of evidence is an EPA classification system for characterizing the extent to which the available data indicate than an agent is a human carcinogenicity. The evidence is based on published information and professional judgment. EPA has examined the compounds in the IRIS and HEAST databases and indicated the weight-of-evidence classification. The weight of evidence of the compounds was reviewed. Because the cut-point for inclusion of compounds was set conservatively low, the weight of evidence was not a discriminating parameter for the evaluation of toxicity/carcinogenicity.

The compounds without a toxicity or carcinogenicity ranking in the IRIS or HEAST databases were removed from further consideration in the Regulatory DQO. The IRIS and HEAST databases are commonly used by EPA during a risk assessment for toxicity data. Compounds with no readily available ranking must be individually researched and data obtained through literature search. Ecology and DOE agreed that this level of effort is not customary or necessary. Therefore, these compounds without a toxicity or carcinogenicity ranking were removed from further consideration in the Regulatory DQO. 
Table 4.3. Prioritization Grouping of $\log _{(10)}$ Slope Factors.

\begin{tabular}{|c|c|c|}
\hline $\begin{array}{l}\text { Carcinogenicity } \\
\text { Ranking } \\
\text { Category }\end{array}$ & Log, 10 Slope Factor & Range of Slope Factors \\
\hline $\mathrm{i}$ & $\therefore>3.5$ & $>3,162$ \\
\hline ii & 3.5 to $>3.0$ & 3,162 to $>1,000$ \\
\hline iii & 3.0 to $>2.0$ & 1,000 to $>100$ \\
\hline iv & 2.0 to $>1.0$ & 100 to $>10$ \\
\hline $\mathbf{v}$ & 1.0 to 0 & 10 to 1 \\
\hline $\mathrm{BC}$ & $<0$ & $<1$ \\
\hline
\end{tabular}

${ }^{*}$ Carcinogenicity decreases from $i$ to $\mathrm{V}$.

Analyte Selection Based on Toxicity and Carcinogenicity. Of the 90 input compounds from the stability assessment (D13), 25 were assigned higher toxicity (rankings of X, A, B, I, II, i, ii, iii, iv, or v) (Figure 4.4, Q23). The regulated, non-detected compounds with lower or unknown toxicity and carcinogenicity ranking(s) were removed from further consideration at D13 (Figure 4.4, Q24, 65 compounds). Higher toxicity and/or carcinogenicity, regulated, stable, and non-detected compounds were next evaluated for potentially applicable analytical methods (Section 4.8; Figure 4.5).

\subsection{Selection of Detected Compounds with Higher Toxicity}

Previous discussion has focused on the non-detected compounds. This section and Section 4.7 describe the logic path specific to the detected regulated compounds. The detected compounds from Figure 4.1, Q1, were compared with the regulatory compounds from Figure 4.2, Q4, at D3. This decision separated the regulated compounds into 477 non-detected compounds (Section 4.5) and 146 detected compounds (Figure 4.2, Q5).

The 146 detected regulated organic compounds were screened for toxicity and carcinogenicity. The basis for the toxicity and carcinogenicity rankings is discussed in Appendix C. Of these 146 compounds, 19 were assigned higher toxicity based on a ranking of $\mathrm{X}, \mathrm{A}, \mathrm{B}, \mathrm{I}, \mathrm{II}, \mathrm{i}$, ii, iii, iv, or v (Figure 4.2, Q5-1). The compounds of higher toxicity and/or carcinogenicity continue to Figure 4.5 for analytical method assessment (Section 4.8). The regulated detected compounds with lower toxicity and carcinogenicity were considered separately with respect to first the number of detects (Section 4.7) and then applicable analytical methods (Section 4.9).

\subsection{Selection of Compounds Detected $\geq 10$ Times and of Lower Toxicity}

After the toxicity and carcinogenicity screening of the 146 detected regulated analytes (Figure 4.2 , Q5-2), the remaining 127 lower toxicity and/or carcinogenicity compounds were reviewed for the number of detections reported in the TWINS Tank Characterization Database and vapor database (Figure 4.2,D5). There were 42 compounds that were reported as positive detects (Section 4.2.1.2) in the referenced TWINS databases with less than 10 detects (Figure 4.2, Q5-4). The number "10" was selected as it appeared to be a natural breakpoint in the number of detects reported in these TWINS 
databases. In general, there were either a very low number (e.g., 1 to 6) of detects for a particular compound or many (e.g., more than a hundred); therefore, 10 detections provided a conservative break point in the number of detections.

Detected compounds with lower toxicity were considered, because large concentrations of a compound with lower toxicity could have an impact on the risk associated with treatment of the waste. A majority of lower toxicity compounds were detected in the vapor phase and are reported as TICs. This leads to a large uncertainty in the value of the data (refer to Section 4.3.1). Further analyses of the lower toxicity detected compounds are requested with the implication that should such analyses show that these compounds are not present, further consideration of the compounds being derived from the source tank waste would not be required. The compounds with 10 or more positive detections and of lower toxicity and carcinogenicity ranking continue on to Figure 4.6 for the analytical method assessment (Figure 4.2, Q5-3, 85 compounds).

\subsection{Analytical Methods for Compounds of Higher Toxicity}

The technical details for this section can be found in Attachment IV. The SW-846 was used as a basis for identifying analytical methods applicable to the regulated compounds (1) detected and with higher toxicity and/or carcinogenicity ranking(s) and (2) non-detected, considered stable in the tank waste matrix and ranked higher in toxicity and/or carcinogenicity. Because this data will be used in future compliance activities under WAC 173-303, sampling and analysis methods should conform to the requirements of WAC 173-303-110, "Sampling and Testing Methods."

In Figure 4.5, Q31, the regulated non-detected, stable compounds with higher toxicity (from Figure 4.4, Q23, 25 compounds) and the regulated detected compounds with higher toxicity (from Figure 4.2, Q5-1, 19 compounds) were combined (44 compounds). Analytes listed in SW-846 methods were compared to the combined list of compounds (Figure 4.5,D14). From this comparison, 28 compounds can be analyzed by SW-846 methods. However, many analytes from the UHC and the TAPs lists do not have SW-846 methods. The analytes that are not part of SW-846 were further examined (Figure 4.5, D15). If the analyte was of a similar chemical functional group applicable to an existing method, the SW-846 method was listed as a method that might be amended to accommodate regulated compounds of interest.

For 16 compounds, existing analytical methods from SW-846 could be modified (e.g., by adding the appropriate calibration standards) for analysis (Figure 4.5, Q34). Methods were selected based on those providing the most reliable identification (gas chromatography/mass spectrometry [GC/MS]) and methods allowing the greatest number of analytes per method. This allows cost-effective identification and quantitation of the analytes. Methods identified as "suggested" may be adaptable to compounds with no published methods. New calibration standards may be required.

From D14 and D15, all 44 regulated compounds of higher toxicity and/or carcinogenicity can be associated with an analytical method from SW-846 (Figure 4.5, Q32 and Q34). 
It is uncertain whether the SW-846 organic methods will effectively quantify tank waste constituents. The waste sample matrix is much more complex than the groundwater or other effluent streams in agriculture or industrial settings, for which SW-846 methods were developed. These issues are addressed further in Section 8.0.

The methods selected for regulated compounds with higher toxicity and/or carcinogenicity were next used as a basis for identifying which detected, lower toxicity and/or carcinogenicity compounds would be considered for analysis (Figure 4.6, Q41).

\subsection{Analytical Methods for Compounds of Lower Toxicity}

The regulated detected compounds that were detected 10 times or more were evaluated to determine if detections might be due to common laboratory contamination during the analysis process. The criteria for this evaluation were taken from the USEPA Contract Laboratory Program National Functional Guidelines for Organic Data Review (EPA 1994b). The guidelines state that acetone, 2-butanone, methylene chloride, and the common phthalates are considered laboratory contaminants. At this point it is not possible to evaluate if the reported concentration in TWINS Tank Characterization Database and vapor database was due to actual concentrations present in the analysis samples or due to laboratory contamination during the analysis process. It is very likely that the reported detections of these compounds were due to contamination. During this analyte evaluation, acetone, 2-butanone, and methylenechloride were identified in both vapor and liquid phase. These compounds are very likely to react with sodium hydroxide in the tank waste environment, degrading to other compounds. However, inadequate quality control data were available from the liquid phase to discern whether these analytes were present or were laboratory contaminants. Therefore, these three compounds remain on the analyte list in Table 4.4. These compounds were not eliminated as possible laboratory contaminants. In D16 two compounds [bis(2-ethylhexyl)-phthalate; diethyl-phthalate] were removed due to possible lab contamination (Figure 4.6, Q37).

The remaining 83 compounds were compared to the list of analytical methods obtained in Figure 4.6, Q41, from the regulated compounds with higher toxicity. From this comparison, 81 of the detected compounds may be analyzed by the same analytical methods that were used for the analyses of the regulated compounds with higher toxicity (Figure 4.6, Q39 total). Two compounds (Figure 4.6, Q40b), n-valeraldehyde and acetaldehyde, need to be analyzed by analytical methods not required for the higher toxicity compounds. These compounds were not considered for analysis at this time. Many of the detected, lower toxicity compounds will require additional standards and method validation to ensure the method will work for the analytes in question. The proposed steps for methods validation are discussed in Section 8.0. 


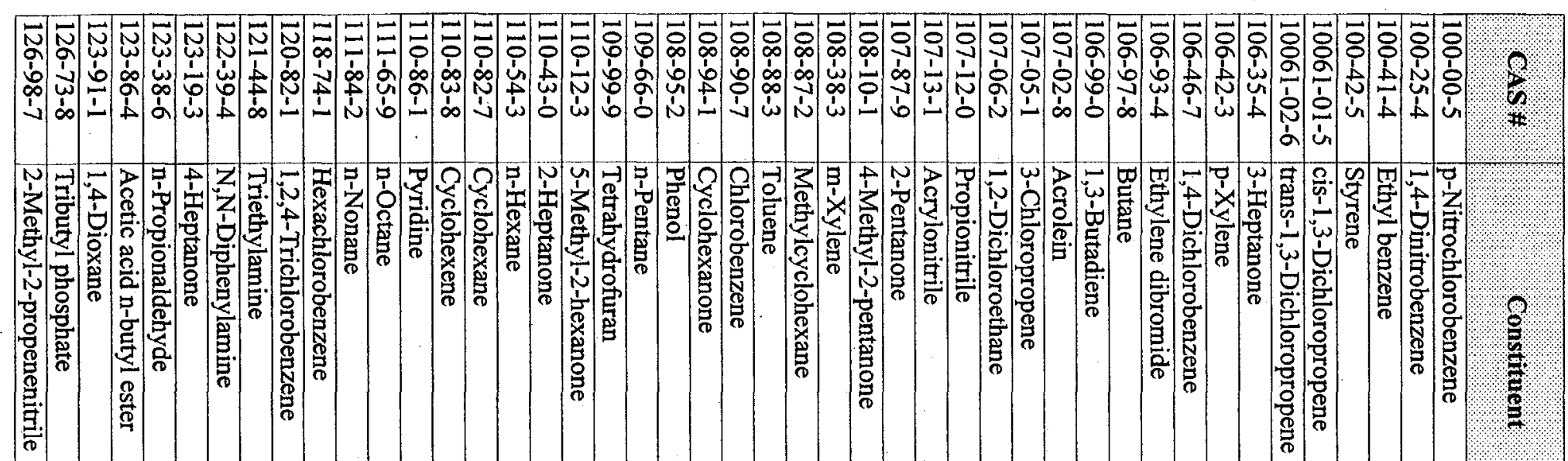

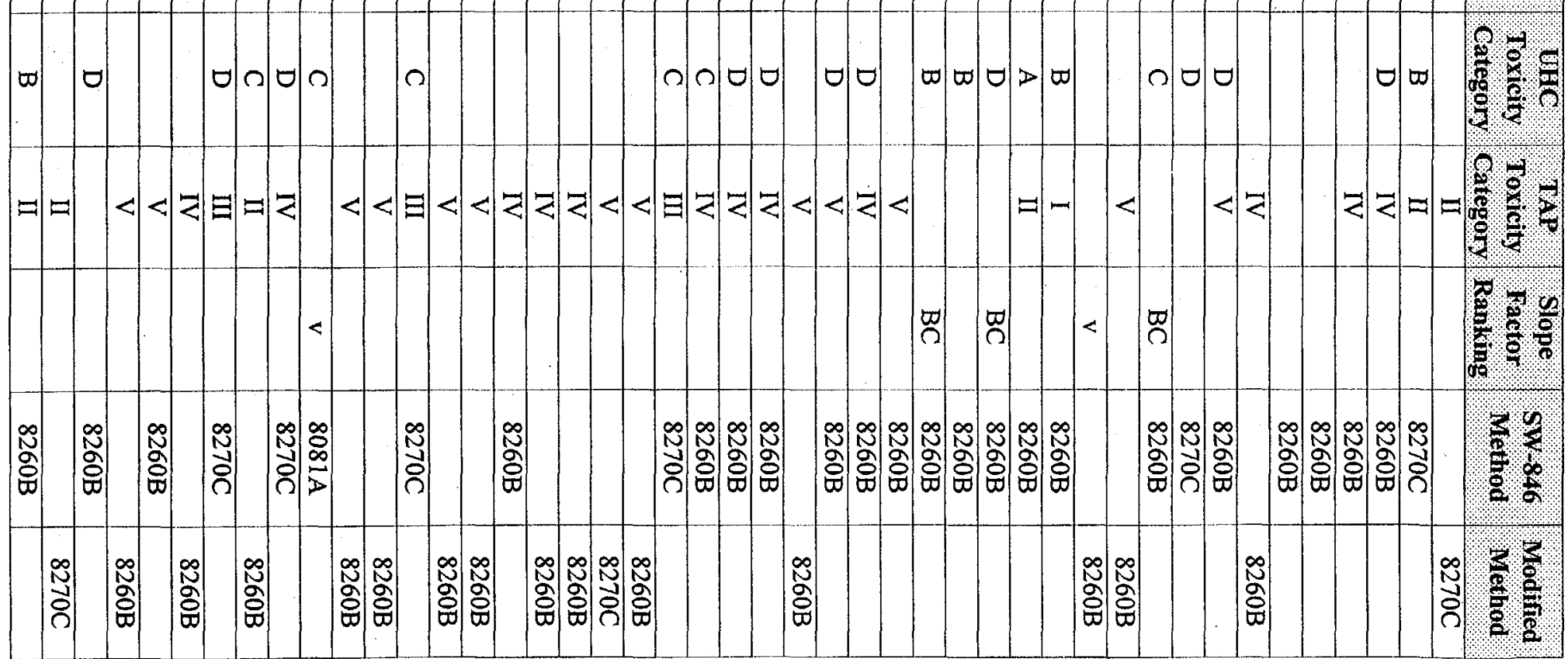


Table 4.4. Priority Regulated Organic Compounds for Characterization in Support of the Regulatory Data Quality Objective (125 Compounds). (Page 2 of 3 )

\begin{tabular}{|c|c|c|c|c|c|c|}
\hline CAS\# & Constituent & $\begin{array}{l}\text { UHC } \\
\text { Toxicity } \\
\text { Category }\end{array}$ & $\begin{array}{l}\text { TAP } \\
\text { Toxicity } \\
\text { Category }\end{array}$ & $\begin{array}{l}\text { Slope } \\
\text { Factor } \\
\text { Ranking }\end{array}$ & SW-846. & $\begin{array}{l}\text { Modified } \\
\text { Method }\end{array}$ \\
\hline $127-18-4$ & $1,1,2,2$-Tetrachloroethene & $\mathrm{D}$ & & $\mathrm{BC}$ & $8260 \mathrm{~B}$ & \\
\hline $128-37-0$ & 2,6-Bis(tert-butyl)-4-methylphenol & & III & & & $8270 \mathrm{C}$ \\
\hline $1321-64-8$ & Pentachloronaphthalene & & II & & & $8270 \mathrm{C}$ \\
\hline $1335-87-1$ & Hexachloronaphthalene & & I & & & $8270 \mathrm{C}$ \\
\hline $1335-88-2$ & Tetrachloronaphthalene & & II & & & $8270 \mathrm{C}$ \\
\hline $1336-36-3$ & Polychlorinated biphenyls (PCBs) & B & & $\mathrm{BC}$ & 8082 & \\
\hline $141-78-6$ & Acetic acid ethyl ester & D & V & & $8260 \mathrm{~B}$ & \\
\hline $142-82-5$ & n-Heptane & & $\mathrm{V}$ & & & $8260 \mathrm{~B}$ \\
\hline $144-62-7$ & Oxalic acid & & II & & & (9056) \\
\hline $2234-13-1$ & Octachloronaphthalene & & I & & $8081 \mathrm{~A}$ & \\
\hline $287-92-3$ & Cyclopentane & & $\mathrm{V}$ & & & $8270 \mathrm{C}$ \\
\hline $309-00-2$ & Aldrin & A & & iv & $8081 \mathrm{~A}$ & \\
\hline $319-84-6$ & alpha-BHC & $\mathrm{C}$ & & $\mathrm{v}$ & $8081 \mathrm{~A}$ & \\
\hline $319-85-7$ & beta-BHC & & & $\mathrm{v}$ & $8081 \mathrm{~A}$ & \\
\hline $3825-26-1$ & Ammonium perfluorooctanoate & & I & & & 8330 \\
\hline $4170-30-3$ & 2-Butenaldehyde (2-Butenal) & & III & & $8260 \mathrm{~B}$ & \\
\hline $465-73-6$ & Isodrin & B & & & $8081 \mathrm{~A}$ & \\
\hline $50-32-8$ & Benzo(a)pyrene & & & $\mathrm{v}$ & $8270 \mathrm{C}$ & \\
\hline $53-70-3$ & Dibenz $[\mathrm{a}, \mathrm{h}]$ anthracene & & & $\mathrm{v}$ & $8270 \mathrm{C}$ & \\
\hline $541-73-1$ & 1,3-Dichlorobenzene & & & & $8270 \mathrm{C}$ & \\
\hline $56-23-5$ & Carbon tetrachloride & $\mathrm{D}$ & & $\mathrm{BC}$ & $8260 \mathrm{~B}$ & \\
\hline $563-80-4$ & 3-Methyl-2-butanone & & $\mathrm{V}$ & & & $8260 \mathrm{~B}$ \\
\hline $57-14-7$ & 1,1-Dimethylhydrazine & & II & v & & $8270 \mathrm{C}$ \\
\hline $58-89-9$ & gamma-BHC (Lindane) & B & & & $8081 \mathrm{~A}$ & \\
\hline $591-78-6$ & 2-Hexanone & & III & & $8260 \mathrm{~B}$ & \\
\hline $60-34-4$ & Methylhydrazine & & II & & & $8270 \mathrm{C}$ \\
\hline $60-57-1$ & Dieldrin & $\mathrm{X}$ & & iv & $8081 \mathrm{~A}$ & \\
\hline $62-75-9$ & N-Nitroso-N,N-dimethylamine & $\bar{B}$ & & iv & $8270 \mathrm{C}$ & \\
\hline $624-83-9$ & Methyl isocyanate & & $\mathrm{I}$ & & & 8330 \\
\hline $627-13-4$ & Nitric acid, propyl ester & & IV & & & $8270 \mathrm{C}$ \\
\hline $64-17-5$ & Ethyl alcohol & & $\mathrm{V}$ & & $8260 \mathrm{~B}$ & \\
\hline $64-18-6$ & Formic acid & & III & & & $(9056)$ \\
\hline 64-19-7 & Acetic acid & & III & & & $(9056)$ \\
\hline $67-56-1$ & Methyl alcohol (Methanol) & $\overline{\mathrm{D}}$ & IV & & $8260 \mathrm{~B}$ & \\
\hline $67-63-0$ & $\begin{array}{l}\text { 2-Propyl alcohol (Isopropanol; } \\
\text { Propan-2-01) }\end{array}$ & & $\mathrm{V}$ & & $8260 \mathrm{~B}$ & \\
\hline $67-64-1$ & 2-Propanone (Acetone) & & $\mathrm{V}$ & & $8260 \mathrm{~B}$ & \\
\hline $67-66-3$ & Chloroform & D & & $\mathrm{BC}$ & $8260 \mathrm{~B}$ & \\
\hline $684-16-2$ & Hexafluoroacetone & & II & & & $8260 \mathrm{~B}$ \\
\hline $71-23-8$ & n-Propyl alcohol (1-propanol) & & $\mathrm{V}$ & & $8260 \mathrm{~B}$ & \\
\hline $71-36-3$ & n-Butyl alcohol & $\mathrm{D}$ & IV & & $8260 \mathrm{~B}$ & \\
\hline $71-43-2$ & Benzene & $\mathrm{D}$ & & $\mathrm{BC}$ & $8260 \mathrm{~B}$ & \\
\hline $71-55-6$ & 1,1,1-Trichloroethane & $\mathrm{D}$ & $\mathrm{V}$ & & $8260 \mathrm{~B}$ & \\
\hline $72-20-8$ & Endrin & A & $\bar{I}$ & & $8081 \mathrm{~A}$ & \\
\hline $74-83-9$ & Bromomethane & $\mathrm{C}$ & II & & $8260 \mathrm{~B}$ & \\
\hline
\end{tabular}


Table 4.4. Priority Regulated Organic Compounds for Characterization in Support of the Regulatory Data Quality Objective (125 Compounds). (Page 3 of 3 )

\begin{tabular}{|c|c|c|c|c|c|c|}
\hline CAS\# & Constituent & $\begin{array}{l}\text { UHC } \\
\text { Toxicity } \\
\text { Category }\end{array}$ & $\begin{array}{l}\text { TAP } \\
\text { Toxicity } \\
\text { Category }\end{array}$ & $\begin{array}{l}\text { Slope } \\
\text { Factor } \\
\text { Ranking }\end{array}$ & SWethod & Modified \\
\hline $74-87-3$ & Chloromethane & $\mathrm{C}$ & IV & $\mathrm{BC}$ & $8260 \mathrm{~B}$ & \\
\hline $75-00-3$ & Chloroethane & $\mathrm{D}$ & $\mathrm{V}$ & & $8260 \mathrm{~B}$ & \\
\hline $75-01-4$ & 1-Chloroethene & $\bar{D}$ & & $\mathrm{BC}$ & $8260 \mathrm{~B}$ & \\
\hline $75-05-8$ & Acetonitrile & $\mathrm{C}$ & IV & & $8260 \mathrm{~B}$ & \\
\hline $75-09-2$ & $\begin{array}{l}\text { Dichloromethane (Methylene } \\
\text { Chloride) }\end{array}$ & $\mathrm{D}$ & & $\mathrm{BC}$ & $8260 \mathrm{~B}$ & \\
\hline $75-15-0$ & Carbon disulfide & $\mathrm{D}$ & III & & $8260 \mathrm{~B}$ & \\
\hline $75-21-8$ & Oxirane & B & & $\mathrm{BC}$ & $8260 \mathrm{~B}$ & \\
\hline $75-34-3$ & 1,1-Dichloroethane & D & V & & $8260 \mathrm{~B}$ & \\
\hline $75-35-4$ & 1,1-Dichloroethene & $\mathrm{C}$ & III & $\mathrm{BC}$ & $8260 \mathrm{~B}$ & \\
\hline $75-43-4$ & Dichlorofluoromethane & & IV & & & $8260 \mathrm{~B}$ \\
\hline $75-45-6$ & Chlorodifluoromethane & & $\mathrm{V}$ & & & $8260 \mathrm{~B}$ \\
\hline $75-65-0$ & 2-Methyl-2-propanol & & IV & & $8260 \mathrm{~B}$ & \\
\hline $75-69-4$ & Trichlorofluoromethane & & $\mathrm{V}$ & & $8260 \mathrm{~B}$ & \\
\hline $75-71-8$ & Dichlorodifluoromethane & & $\mathrm{V}$ & & $8260 \mathrm{~B}$ & \\
\hline $76-13-1$ & $\begin{array}{l}\text { 1,2,2-Trichloro-1,1,2- } \\
\text { trifluoroethane }\end{array}$ & & $\mathrm{V}$ & & $8260 B$ & \\
\hline $76-14-2$ & $\begin{array}{l}\text { 1,2-Dichloro-1,1,2,2- } \\
\text { tetrafluoroethane }\end{array}$ & & V & & $8260 \mathrm{~B}$ & \\
\hline $76-44-8$ & Heptachlor & B & & $\mathrm{v}$ & 8081A & \\
\hline $78-87-5$ & 1,2-Dichloropropane & $\mathrm{D}$ & & & $8260 \mathrm{~B}$ & \\
\hline $78-92-2$ & 1-Methylpropyl alcohol(2-butanol) & & IV & & & $8260 \mathrm{~B}$ \\
\hline $78-93-3$ & 2-Butanone & D & IV & & $8260 \mathrm{~B}$ & \\
\hline $79-00-5$ & 1,1,2-Trichloroethane & $\mathrm{D}$ & IV & $\mathrm{BC}$ & $8260 \mathrm{~B}$ & \\
\hline $79-01-6$ & 1,1,2-Trichloroethylene & & & $\mathrm{BC}$ & $8260 \mathrm{~B}$ & \\
\hline $79-10-7$ & 2-Propenoic acid & & I & & & $8270 \mathrm{C}$ \\
\hline $79-34-5$ & 1,1,2,2-Tetrachloroethane & D & III & $\mathrm{BC}$ & $8260 \mathrm{~B}$ & \\
\hline $8001-35-2$ & Toxaphene & $\mathrm{C}$ & & $\mathrm{v}$ & $8081 \mathrm{~A}$ & \\
\hline $82-68-8$ & Pentachloronitrobenzene (PCNB) & $\mathrm{B}$ & II & & $8270 \mathrm{C}$ & \\
\hline $87-68-3$ & Hexachlorobutadiene & B & $\mathrm{I}$ & $\mathrm{BC}$ & $8270 \mathrm{C}$ & \\
\hline $87-86-5$ & Pentachlorophenol & B & & & & $8270 \mathrm{C}$ \\
\hline 88-85-7 & $\begin{array}{l}\text { 2-sec-Butyl-4,6-dinitrophenol } \\
\text { (Dinoseb) }\end{array}$ & B & & & $8151 \mathrm{~A}$ & \\
\hline $88-89-1$ & Picric acid & & I & & & 8330 \\
\hline $92-52-4$ & 1,1'-Biphenyl & & II & & & $8270 \mathrm{C}$ \\
\hline $95-47-6$ & o-Xylene & D & $\mathrm{V}$ & & $8260 \mathrm{~B}$ & \\
\hline $95-50-1$ & 1,2-Dichlorobenzene & D & IV & & $8270 \mathrm{C}$ & \\
\hline $96-22-0$ & 3-Pentanone & & $\mathrm{V}$ & & & $8260 \mathrm{~B}$ \\
\hline $98-86-2$ & Acetophenone & $\mathrm{D}$ & $\mathrm{V}$ & & $8270 \mathrm{C}$ & \\
\hline $98-95-3$ & Nitrobenzene & $\mathrm{D}$ & II & & $8270 \mathrm{C}$ & \\
\hline $\begin{array}{l}\text { CAS\# }= \\
\text { TAP }= \\
\text { UHC }=\end{array}$ & $\begin{array}{l}\text { toxic air pollutants. } \\
\text { underlying hazardous constituents. }\end{array}$ & & & & & \\
\hline
\end{tabular}




\subsection{Priority Regulated Organic Compounds for Characterization in Support of Regulatory Data Quality Objective}

The priority regulated organic compounds for characterization in source tank waste consist of three groups:

1. non-detected, stable in tank waste, higher toxicity (25 compounds);

2. detected, higher toxicity ( 19 compounds); and

3. detected, lower toxicity, common method with higher toxicity ( 81 compounds).

The priority compound list, 125 compounds, proposed SW-846 method, and associated toxicity ranking are given in Table 4.4.

\subsection{Non-Organic Compounds and Test Parameters Selection Rationale}

There were 222 regulated parameters and non-organic constituents identified in the Regulatory DQO Input List and considered separately from the regulated organic analytes (Figure 4.2, D2). The distribution between inorganic and organometallic constituents, radionuclides, chemical groups and mixtures, and chemical properties is shown in Table 4.5.

Table 4.5. Summary of Regulated Compounds To Be Considered.

\begin{tabular}{|l|c|}
\hline \multicolumn{1}{|c|}{ ConstituentParameter } & Number \\
\hline Regulated inorganic constituents & 165 \\
\hline Regulated organometallic constituents & 10 \\
\hline Regulated radionuclides & 3 \\
\hline Regulated chemical groups and mixtures & 35 \\
\hline Regulated chemical properties & 10 \\
\hline Total constituents/parameters to be considered in separate logic & 222 \\
\hline
\end{tabular}

A final list of inorganic constituents to be analyzed was obtained by:

- listing all inorganic compounds and metals in the starting regulatory lists,

- identifying the metals/ions associated with the compound,

- consolidating the list of metals/ions (Table 4.6),

- comparing the resulting regulated list to the Hanford Site inventories (Klem 1990; Agnew 1997),

- considering analytical methods applicability to HLW samples, and

- assessing alternative sources of information.

The final list of inorganic constituents and the recommended SW-846 method are provided in Table 4.7. The rationale for deriving the final list for analysis is addressed in terms of analytes retained and analytes excluded for analysis, and those for which alternatives to direct analysis are provided. The specific analytes and justifications for these actions are provided in the following sections. 
Table 4.6. Unique Regulatory Inorganic Constituents. (Page 1 of 2)

\begin{tabular}{|c|c|c|c|c|c|c|c|}
\hline $\mathrm{CAs} \#$. & 100 & Constituent & $\begin{array}{l}\text { rotround in } \\
\text { mantord }\end{array}$ & $\begin{array}{l}\text { Not in } \\
\text { (OOD } 19 \\
(1996 \mathrm{~b})\end{array}$ & 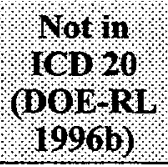 & $\begin{array}{l}\text { SW 846 } \\
\text { Method : } \\
\text { (EPA 1997). }\end{array}$ & $\begin{array}{l}\text { Modified } \\
\text { Method }\end{array}$ \\
\hline $7429-90-5$ & $\mathrm{Al}$ & Aluminum & & & & $6010 \mathrm{~B}$ & \\
\hline $7664-41-7$ & NH4/NH3 & $\begin{array}{l}\text { Ammonial } \\
\text { Ammonium }\end{array}$ & & & & & 350.3 \\
\hline $7440-36-0$ & $\mathrm{Sb}$ & Antimony & & & & $6010 \mathrm{~B}$ & \\
\hline $7440-38-2$ & As & Arsenic & & & & $6010 \mathrm{~B}$ & \\
\hline $7440-39-3$ & $\mathrm{Ba}$ & Barium & & & & $6010 \mathrm{~B}$ & 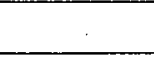 \\
\hline $7440-41-7$ & $\mathrm{Be}$ & Beryllium & & & & $6010 \mathrm{~B}$ & \\
\hline $7440-69-9$ & $\mathrm{Bi}$ & Bismuth & & $X$ & & 6020 & \\
\hline $7440-42-8$ & $\mathrm{~B}$ & Boron & & $\mathrm{X}$ & & $6010 \mathrm{~B}$ & \\
\hline 24959-67-9 & $\mathrm{Br}$ & Bromide & & $\mathrm{X}$ & $X$ & 9056 & \\
\hline $7440-43-9$ & $\mathrm{Cd}$ & Cadmium & & & & $6010 \mathrm{~B}$ & \\
\hline $7440-70-2$ & $\mathrm{Ca}$ & Calcium & & & & $6010 \mathrm{~B}$ & \\
\hline $1333-86-4$ & $\mathrm{C}$ & Carbon & & $X$ & $\mathrm{X}$ & 9060 & \\
\hline $3812-32-6$ & $\mathrm{CO} 3$ & Carbonate ${ }^{(\mathrm{a})(\mathrm{b})}$ & & $\mathrm{X}$ & & & 130 \\
\hline $7440-46-2$ & $\mathrm{Cs}$ & Cesium & & $\mathrm{X}$ & & 6020 & \\
\hline $16887-00-6$ & $\mathrm{Cl}$ & Chloride & & & & 9056 & \\
\hline $18540-29-9$ & $\mathrm{Cr}$ & Chromium & & & & $6010 \mathrm{~B}^{(\mathrm{c})}$ & \\
\hline $7440-48-4$ & $\mathrm{Co}$ & Cobalt & & & & $6010 \mathrm{~B}$ & \\
\hline $7440-50-8$ & $\mathrm{Cu}$ & Copper & & & & $6010 \mathrm{~B}$ & \\
\hline $57-12-5$ & $\mathrm{CN}$ & Cyanide & & $X$ & & $9010 \mathrm{~B}$ & \\
\hline $16984-48-8$ & $F$ & Fluoride & & & & 9056 & \\
\hline $7440-56-4$ & $\mathrm{Ge}$ & Germanium & $\mathrm{X}$ & $\mathrm{X}$ & $X$ & 6020 & \\
\hline $7440-58-6$ & $\mathrm{Hf}$ & Hafnium & $\mathrm{X}$ & $\mathrm{X}$ & $X$ & 6020 & \\
\hline $14280-30-9$ & $\mathrm{OH}$ & Hydroxide & & $\mathrm{X}$ & $X$ & & 310.1 \\
\hline $7440-74-6$ & In & Indium & $\mathrm{X}$ & $\mathrm{X}$ & $\mathrm{X}$ & 6020 & \\
\hline $7553-56-2$ & $\mathrm{I}$ & Iodine & & $\mathrm{X}$ & $X$ & & 345.1 \\
\hline $7439-89-6$ & $\mathrm{Fe}$ & Iron & & & & $6010 \mathrm{~B}$ & \\
\hline $7439-92-1$ & $\mathrm{~Pb}$ & Lead & & & & $6010 \mathrm{~B}$ & \\
\hline $7439-93-2$ & $\mathrm{Li}$ & Lithium & & $\mathrm{X}$ & & $6010 \mathrm{~B}$ & \\
\hline $7439-95-4$ & $\mathrm{Mg}$ & Magnesium & & & & $6010 \mathrm{~B}$ & \\
\hline $7439-96-5$ & $\mathrm{Mn}$ & Manganese & & $\mathrm{X}$ & & $6010 \mathrm{~B}$ & \\
\hline $7439-97-6$ & $\mathrm{Hg}$ & Mercury & & & & $7470 \mathrm{~A} / 7471 \mathrm{~A}$ & \\
\hline $7439-98-7$ & Mo & Molybdenum & & & & $6010 \mathrm{~B}$ & \\
\hline $7440-02-0$ & $\mathrm{Ni}$ & Nickel & & & & $6010 \mathrm{~B}$ & \\
\hline $7697-37-2$ & NO3 & Nitrate & & & & 9056 & \\
\hline $14797-65-0$ & $\mathrm{NO} 2$ & Nitrite & & & & 9056 & \\
\hline
\end{tabular}


Table 4.6. Unique Regulatory Inorganic Constituents. (Page 2 of 2)

\begin{tabular}{|c|c|c|c|c|c|c|c|}
\hline CAs I & Ion & Constiruent & $\begin{array}{l}\text { Not Found in } \\
\text { Hanford }\end{array}$ & 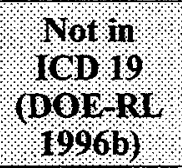 & 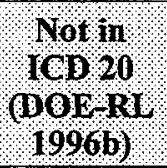 & $\begin{array}{l}\text { SW } 846 \\
\text { Method } \\
\text { (EPA } 1997)\end{array}$ & Modified \\
\hline $7727-37-9$ & $\mathrm{~N}$ & Nitrogen & & (d) & (d) & & $350.1 / 350.3$ \\
\hline $7440-04-2$ & Os & Osmium & $\mathrm{X}$ & $X$ & $X$ & 7550 & \\
\hline $14265-44-2$ & PO4 & Phosphate & & & $\mathrm{X}$ & 9056 & \\
\hline $7723-14-0$ & $\mathrm{P}$ & Phosphorus & & & & $6010 \mathrm{~B}$ & \\
\hline $7440-06-4$ & $\mathrm{Pt}$ & Platinum & & & $\mathrm{X}$ & $255.1 / 255.2$ & \\
\hline $7440-09-7$ & $\mathrm{~K}$ & Potassium & & & & $6010 \mathrm{~B}$ & \\
\hline $7440-16-6$ & $\mathrm{Rh}$ & Rhodium & (e) & $X$ & & 6020 & \\
\hline $7782-49-2$ & $\mathrm{Se}$ & Selenium & & . & & $6010 \mathrm{~B}$ & \\
\hline $7440-21-3$ & $\mathrm{Si}$ & Silicon & & $\mathrm{X}$ & & & $6010 \mathrm{~B}$ \\
\hline $7440-22-4$ & $\mathrm{Ag}$ & Silver & & & & $6010 \mathrm{~B}$ & \\
\hline $7440-23-5$ & $\mathrm{Na}$ & Sodium & & & & $6010 \mathrm{~B}$ & \\
\hline $14808-79-8$ & $\mathrm{SO} 4$ & Sulfate & & & $X$ & 9056 & \\
\hline $18496-25-8$ & $S$ & Sulfides & & $X$ & & 9031 & \\
\hline $14265-45-3$ & $\mathrm{SO} 3$ & Sulfite & & $\mathrm{X}$ & $\mathrm{X}$ & & 377.1 \\
\hline $7440-25-7$ & $\mathrm{Ta}$ & Tantalum & & $X$ & & 6020 & \\
\hline $13494-80-9$ & $\mathrm{Te}$ & Tellurium & $\mathrm{X}$ & $X$ & & 6020 & \\
\hline $7440-28-0$ & $\mathrm{Tl}$ & Thallium & $\mathrm{X}$ & $\mathrm{X}$ & & $6010 \mathrm{~B}$ & \\
\hline $7440-31-5$ & Sn & Tin & & & $\mathrm{X}$ & 7870 & \\
\hline $7440-32-6$ & $\mathrm{Ti}$ & Titanium & & & & & $6010 \mathrm{~B}$ \\
\hline $7440-33-7$ & W & Tungsten & & $X$ & & & $6010 \mathrm{~B}$ \\
\hline $7440-61-1$ & $\mathrm{U}$ & Uranium & (e) & & & & $6010 \mathrm{~B}$ \\
\hline $7440-62-2$ & $\mathrm{~V}$ & Vanadium & & & & $6010 \mathrm{~B}$ & \\
\hline $7440-65-5$ & $Y$ & Yttrium & & & & & $6010 \mathrm{~B}$ \\
\hline $7440-66-6$ & $\mathrm{Zn}$ & Zinc & & & & $6010 \mathrm{~B}$ & \\
\hline $7440-67-7$ & $\mathrm{Zr}$ & Zirconium & & & & & $6010 \mathrm{~B}$ \\
\hline
\end{tabular}

Notes: ${ }^{(a)}$ Carbonate originates from the DST WSPS and is not required for risk assessment.

(b) TIC analysis requested in LAW Feed DQO (Wiemers and Miller 1997).

(c) Total $\mathrm{Cr}$ analysis requested. Refer to Section 4.11.3.

(d) Nitrogen is measured as ammonia, ammonium, or nitrate as requested in the LAW and HLW Feed DQOS

(Wiemers and Miller 1997; Wiemers et al. 1998).

(e) Analytes that have been measured in tank waste and are not in the Hanford Inventory documents

(Klem 1990; Agnew 1997).

CAS\# = chemical abstract service number. $\quad$ ICD $=$ Interface Control Document.

$\mathrm{DQO}=$ data quality objective. $\quad \mathrm{LAW}=$ low-activity waste.

DST $=$ double-shell tank. $\quad$ TIC $=$ total inorganic carbon.

$\mathrm{EPA}=$ U.S. Environmental Protection Agency. WSPS $\quad$ waste stream profile sheet.

HLW = high-level waste. 
Table 4.7. Inorganic Constituents of Potential Regulatory Concern.

\begin{tabular}{|c|c|c|}
\hline CASH & Cation & Constituent \\
\hline $7440-22-4$ & $\mathrm{Ag}$ & Silver \\
\hline $7429-90-5$ & $\mathrm{Al}$ & Aluminum \\
\hline $7440-38-2$ & As & Arsenic \\
\hline $7440-42-8$ & B & Boron \\
\hline $7440-39-3$ & $\mathrm{Ba}$ & Barium \\
\hline $7440-41-7$ & $\mathrm{Be}$ & Beryllium \\
\hline $7440-69-9$ & $\overline{B i}$ & Bismuth \\
\hline $7440-70-2$ & $\mathrm{Ca}$ & Calcium \\
\hline $7440-43-9$ & $\mathrm{Cd}$ & Cadmium \\
\hline $7440-48-4$ & $\mathrm{Co}$ & Cobalt \\
\hline $18540-29-9$ & $\mathrm{Cr}$ & Chromium \\
\hline (2) & I) & (6) \\
\hline $7440-50-8$ & $\mathrm{Cu}$ & Copper \\
\hline $7439-89-6$ & $\overline{\mathrm{Fe}}$ & Iron \\
\hline $7439-97-6$ & $\mathrm{Hg}$ & Mercury \\
\hline $7440-09-7$ & $\mathrm{~K}$ & Potassium \\
\hline $7439-93-2$ & $\overline{\mathrm{Li}}$ & Lithium \\
\hline $7439-95-4$ & $\mathrm{Mg}$ & Magnesium \\
\hline $7439-96-5$ & $\mathrm{Mn}$ & Manganese \\
\hline $7439-98-7$ & Mo & Molybdenum \\
\hline $7440-23-5$ & $\mathrm{Na}$ & Sodium \\
\hline $7440-02-0$ & $\mathrm{Ni}$ & Nickel \\
\hline $7723-14-0$ & $\bar{P}$ & Phosphorus \\
\hline $7439-92-1$ & $\overline{\mathrm{Pb}}$ & Lead \\
\hline 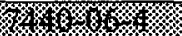 & 9 & 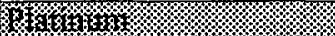 \\
\hline $7440-16-6$ & $\mathrm{Rh}$ & Rhodium \\
\hline $63705-05-5$ & $\mathbf{S}$ & Total Sulfur \\
\hline $7440-36-0$ & $\mathrm{Sb}$ & Antimony \\
\hline $7782-49-2$ & Se & Selenium \\
\hline $7440-21-3$ & Si & Silicon \\
\hline $7440-31-5$ & Sn & Tin \\
\hline $7440-25-7$ & Ta & Tantalum \\
\hline $7440-28-0$ & Tl & Thallium \\
\hline $7440-61-1$ & $\overline{\mathrm{U}}$ & Uranium \\
\hline $7440-62-2$ & $\bar{V}$ & Vanadium \\
\hline $7440-33-7$ & W & Tungsten \\
\hline $7440-65-5$ & $\bar{Y}$ & Yttrium \\
\hline $7440-66-6$ & $\mathrm{Zn}$ & Zinc \\
\hline $7440-67-7$ & $\mathrm{Zr}$ & Zirconium \\
\hline $7664-41-7$ & NH4/NH3 & Ammonia/Ammonium \\
\hline
\end{tabular}

\begin{tabular}{|c|c|c|}
\hline CASH & Anion & Constituent \\
\hline $24959-67-9$ & $\mathrm{Br}$ & Bromide \\
\hline $16887-00-6$ & Cl & Chloride \\
\hline $57-12-5$ & $\mathrm{CN}$ & Cyanide \\
\hline $16984-48-8$ & $\mathrm{~F}$ & Fluoride \\
\hline $7553-56-2$ & I & Iodine \\
\hline $14797-65-0$ & $\mathrm{NO} 2$ & Nitrite \\
\hline $7697-37-2$ & $\mathrm{NO3}$ & Nitrate \\
\hline $14280-30-9$ & $\mathrm{OH}$ & Hydroxide \\
\hline $14265-44-2$ & $\widehat{\mathrm{PO} 4}$ & Phosphate \\
\hline$y_{4} 6$ & 2 & S.M \\
\hline 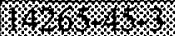 & 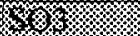 & 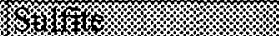 \\
\hline $14808-79-8$ & $\mathrm{SO} 4$ & Sulfate \\
\hline
\end{tabular}

Shaded cells are not requested at this time as the constituent requires a unique analysis and alternative methods for estimating concentration are provided for consideration.

CAS\# = chemical abstract service number . 


\subsubsection{Regulated Analytes Not Included in Site Inventory and Retained for Analysis}

Uranium. Uranium is not in the referenced Hanford inventory (Klem 1990; Agnew 1997) but given the type of reactor fuel used, it is included for analysis.

Rhodium. Rhodium has been detected in HLW and is included for analysis (Esch 1997a).

Thallium. Thallium is not listed in the inventory but is of significant concern for toxicity, is more frequently used in the industry than metals dismissed from further consideration in this DQO (refer to Section 4.11.2.), is of concern for RCRA, and therefore, is included for analysis.

\subsubsection{Regulated Analytes Excluded from Consideration for Analysis}

Regulated Analytes not Included in Site Inventory, Seldom Used in Industry and not Retained for Analysis. The following analytes listed on the regulatory list, were not listed in the Klem (1990) and Agnew (1997) inventories, are seldom used in nuclear industry, and are not proposed for analyses: germanium, hafnium, osmium, indium, and tellurium.

Carbon. Inorganic carbon is included on regulatory starting lists (TAPs) as graphite, dust, or main group carbon compounds (e.g., $\mathrm{COS}, \mathrm{COF}_{2}, \mathrm{CBr}_{4}$ ). The graphite and dust were determined to be nuisance compounds in bulk quantities (e.g., particulate concerns). The main group carbon compounds are unlikely to be stable in the tank waste matrix. Inorganic carbon will not be requested for analysis.

\subsubsection{Regulated Analytes with Alternatives to Direct Analysis}

Platinum. Platinum is a regulated metal and is not included for analysis as it requires a unique and difficult analysis method. Platinum was analyzed for in tank C-106 waste and a result of $3.07 \mathrm{E}+1$ (30.7) $\mu \mathrm{g} / \mathrm{g}$ dried solids was reported (Esch 1997a). Platinum is not requested as part of the Regulatory DQO.

Sulfite and Sulfides. Sulfite is difficult to measure in tank waste samples due to matrix interference with the spectrophotometric method used for sulfite analysis. Measurements of sulfate and sulfur in tank waste suggests that total sulfur analysis would bound the sulfur-ion concentrations (Esch 1997b, 1997c). Therefore, total sulfur will be analyzed instead of sulfite and sulfide.

Total Cesium. Total cesium is difficult to measure. It can be measured using gamma spectroscopy and inductively coupled plasma mass spectrometry (ICP/MS) summing the cesium-137, cesium-135, and cesium-134 isotope concentrations. In most cases, tank waste analysis for privatization will include cesium-137. Total cesium may be estimated using the ratio of cesium total to cesium-137 of 3:1 (Esch 1997a). Total cesium will not be requested as part of the Regulatory DQO.

Total Chromium Versus Hexavalent Chromium. For this Regulatory DQO, total chromium will be measured by ICP. Chromium will not be speciated, it is left to the data user to manage for chromium appropriately. Often there is guidance or other requirements regarding chromium valence states. For example, the latest guidance from EPA regarding chromium speciation for hazardous waste combustion facilities states, "... unless site-sampling or process-specific information is provided, the worst-case 
assumption--that 100 percent of the facility chromium emissions are in the hexavalent form--should be used." (EPA, July 1998)

Radionuclides. For the purpose of this Regulatory $\mathrm{DQO}$, it is assumed that the radionuclide analyses requested in the LAW Feed DQO (Wiemers and Miller 1997) and HLW Feed DQO (Wiemers et al. 1998) will be sufficient to meet permitting needs.

\subsubsection{Rationale for Test Parameters and Characteristics}

Figure 4.2, Q3, Appendix B, Table B.3 list the non-organic regulatory compounds and parameters to be considered. After evaluation of the inorganic, metals, and organometallic compounds, several parameters remain. Table 4.8 lists the parameter and the reason for inclusion in this Regulatory DQO.

Table 4.8. Test Parameters and Characteristics for Analysis

in Support of the Regulatory Data Quality Objective.

\begin{tabular}{|l|l|}
\hline \multicolumn{1}{|c|}{ Test Parameter/Characteristics } & \multicolumn{1}{c|}{ Reason for lnclusion } \\
\hline Ignitability & Waste characteristic included in DST Part A List ${ }^{(\mathrm{a})}$ \\
\hline Corrosivity $(\mathrm{pH})$ & Waste characteristic included in DST Part A List ${ }^{(\mathrm{a})}$ \\
\hline Separable organics & Contract requirement $t^{(\mathrm{b})}$ \\
\hline Specific gravity & Required for concentration calculation \\
\hline Percent solids & Contract requirement $t^{(\mathrm{b})}$ \\
\hline Percent moisture & Contract requirement ${ }^{(\mathrm{b})}$ \\
\hline
\end{tabular}

$\begin{array}{lll}\text { DST }=\text { double-shell tank. } & \text { (a) DOE-RL 1996a } & \text { (b) DOE-RL 1996b }\end{array}$

\subsection{Summary of Inputs}

The conceptual approach to the analyte selection process is discussed in Section 1.6. In order to relate the approach to the logic, a comparison of the information in Figure 1.2 versus the decision logic is presented in Table 4.9 .

The logic allowed prioritization of the analytes for analyses. Tables $4.4,4.7$, and 4.8 list the analytes, parameters, and characteristics of potential regulatory concern including:

- non-detected regulated organic compounds of higher toxicity,

- detected regulated organic compounds of higher toxicity,

- regulated organic compounds, detected $\geq 10$ times and of lower toxicity,

- inorganics, and

- parameters and characteristics.

The sample collection strategy, final method selection and validation, and QC criteria are defined in Section 8.0. 
Table 4.9. Comparison of Conceptual Model with Analyte Selection Logic for Organic and Inorganic Compounds.

\begin{tabular}{|c|c|c|}
\hline Information from Motel & Information from Logic (Figures 4 /2 & Tables \\
\hline $\begin{array}{l}\text { Circle A (starting list of } \\
\text { analytes) }\end{array}$ & $\begin{array}{l}\text { Consists of the following starting analyte } \\
\text { lists: TAP, UHC, DST Part A, UTS and } \\
\text { DST WSPS (Figure 4.2) }\end{array}$ & Appendix B, Table B.2 \\
\hline $\begin{array}{l}\text { Circle B historical data, } \\
\text { inventories, process } \\
\text { knowledge. }\end{array}$ & $\begin{array}{l}\text { The set of compounds, which includes } \\
\text { analytes that are regulated organic } \\
\text { compounds with a positive analytical } \\
\text { detect in SSTDST waste. }\end{array}$ & Table B.5. \\
\hline $\begin{array}{l}\text { Circle C (regulated analytes } \\
\text { plausible to be considered } \\
\text { for analysis in Hanford tank } \\
\text { waste) }\end{array}$ & $\begin{array}{l}\text { Analytes selected for analysis } \\
\text { (Figure } 4.6 \text { ). } \\
\text { Scope of this DQO }\end{array}$ & Tables $4.4,4.7$, and 4.8 . \\
\hline $\begin{array}{l}\text { Circle A minus C (starting } \\
\text { list of analytes not applicable } \\
\text { to Regulatory DQO) }\end{array}$ & $\begin{array}{l}\text { The set of compounds that are on the } \\
\text { input list that are not considered for } \\
\text { additional analyses. These analytes are: } \\
\text { - non-detected compounds used by } \\
\text { industries not associated with } \\
\text { Hanford (Figure } 4.3 \text { ), } \\
\text { non-detected and unstable in the } \\
\text { tank waste environment } \\
\text { (Figure } 4.4 \text { ), } \\
\text { non-detected, stable in tank waste } \\
\text { environment, and of lower } \\
\text { toxicity/carcinogenicity } \\
\text { (Figure } 4.4 \text { ), } \\
\text { detected < 10 times and of lower } \\
\text { toxicity/carcinogenicity } \\
\text { (Figure } 4.2 \text { ), and } \\
\text { detected, common laboratory } \\
\text { contaminants (Figure 4.6). }\end{array}$ & $\begin{array}{l}\text { Germanium, hafnium, osmium, } \\
\text { indium, tellurium, carbon, nitrogen. } \\
\text { Appendix B, Table B.18. } \\
\text { Appendix B, Table B.21. } \\
\text { Appendix B, Table B. } 23 \text {. }\end{array}$ \\
\hline $\begin{array}{l}\text { Circle B minus C (regulated } \\
\text { analytes, applicable to } \\
\text { Hanford tank waste and not } \\
\text { considered for measurement } \\
\text { in source tanks) }\end{array}$ & $\begin{array}{l}\text { Compounds with } \geq 10 \text { detects, lower } \\
\text { toxicity/carcinogenicity, common } \\
\text { laboratory contaminants and/or not } \\
\text { analyzed by methods applicable to higher } \\
\text { toxicity compounds (Figures } 4.5 \\
\text { and } 4.6 \text { ). }\end{array}$ & Appendix B, Tables B.30 and B.32. \\
\hline $\begin{array}{l}\text { Circle D (staged feed, and } \\
\text { other downstream processes) }\end{array}$ & \multicolumn{2}{|c|}{$\begin{array}{l}\text { Compounds that may be identified as requiring further analysis in the staged } \\
\text { feed and other downstream processes. For example, these compounds may be } \\
\text { indicator compounds of significant risk drivers based on preliminary risk } \\
\text { screening performed by the treatment contractor. The identification of these } \\
\text { compounds is outside the scope of this DQO. The identity of these compounds } \\
\text { is unknown at this time. }\end{array}$} \\
\hline
\end{tabular}

DQO $=$ data quality objective.

UHC = underlying hazardous constituents.

DST = double-shell tank.

SST = single-shell tank.

$\mathrm{TAP}=$ toxic air pollutant.

UTS $=$ universal treatment standards.

WSPS $=$ waste stream profile sheet. 


\subsection{Boundaries}

Boundaries include identification of specific tank wastes to which the DQO applies and any strata within the tank waste. The waste in the boundary of this Regulatory DQO is the material in the source tanks (see Figure 1.1). This Regulatory DQO applies in effect to all DSTs and SSTs and will be applied in a number of steps thus allowing assessment and refinement based on newly gathered data. Currently, two steps are defined. The first step addresses selection and validation of methods and the Holding Time and Storage Conditions study. Step 2 includes consideration of all DSTs and SSTs that are not part of Step 1. DOE and Ecology have agreed to analyze some archived and recently collected Phase I candidate LAW and HLW samples. Analysis of archive samples initiates Step 2, Complete Implementation. Analysis of archive samples is to be initiated concurrently with the Holding Time and Storage Conditions study.

The strata within a tank waste must also be considered in identifying sampling boundaries. The boundaries within an unmixed tank will be modeled as though the waste was composed of strata, including consideration of floating crust, supernate, saturated supernate or slurry, and solids (sludge). The initial strata assignments will be based on historical records, such as core sample analyses and fill history. The evaluation by substrata is needed for defining the sampling and compositing strategy. Composites are to be prepared representing supernate and solids fractions.

This Regulatory DQO process does not establish additional characterization requirements that may apply in the future to the staged waste feed. Further, this Regulatory DQO does not establish requirements of the treatment contractor to confirm the composition of the waste received by the generator, or any other characterization needs related to the treatment, storage, and disposal activities. It is anticipated by Ecology and DOE that the data gathered through implementation of this Regulatory DQO will support the establishment of characterization requirements for these future activities. 


\subsection{Decision Rules}

Decision rules define the actions required as a result of exceeding or not exceeding an action level. For this DQO, the decision rules and action levels apply to the ability of DOE, as the generator, to meet the need for characterization of their waste currently stored in the source tanks. Because the treatment facility risk assessment planning information was not available during this DQO process and no action levels are provided in other applicable regulations, Ecology and DOE agreed that the EQLs associated with the applicable SW-846 methods will be used as target action limits for method acceptability until additional inputs to action levels are available. In addition to EQLs, QC requirements for the selected analyses are specified in Section 8.0.

The analysis of a tank waste currently stored in the source tank will be considered complete if the target EQLs and QC requirements are satisfied for the analytes specified in this Regulatory DQO. When a constituent is analyzed for and not found above the EQL, in an agreed-upon number of samples with agreed-upon analytical methods and detection limits, this constituent is considered to be not present from the feed source in all downstream locations. The number of samples and the analytical methods and detection limits to be used to make this determination will be the subject of negotiations between DOE and Ecology once initial studies are completed.

DOE and Ecology have agreed to revisit the analyte list, sample and analysis methods' requirements, and the list of source tanks to be analyzed throughout the implementation of this Regulatory DQO. The first re-evaluation will occur during the Step 1 , methods selection and validation, as described in Section 8.0. 


\subsection{Decision Error Assessment}

The purpose of this step in the DQO process is to assess the consequences of making an incorrect decision as a result of an error, to estimate the allowable error rate, and to use this information to calculate the number of samples (EPA 1994a). The parameters listed below are considered in the error assessment and used to calculate the number of samples.

- level of false positives, Type I error with probability $\alpha$,

- level of false negatives, Type II error with probability $\beta$,

- action level, and

- variance (standard deviation or relative standard deviation [RSD]).

Normally, the result of the decision error assessment is a recommendation as to the number of samples and the sampling design. Typically, the Type I and II errors, action levels, and variance are known or estimated and the number of samples calculated based on these parameters.

The action levels other than defaulting to EQLs were unknown at the time of preparation of this Regulatory DQO. The following explains why there are no action limits related to each of the decisions presented in Section 3.0.

Decision \#1 is related to characterizing the waste to meet RCRA generator requirements for LDRs and has no action levels applicable to the source tank waste. Decision \#2 is the development of the risk assessment work plan. The risk assessment work plan is incomplete at this time. Target action levels will ultimately be derived from the potential risk screening levels and will be available after completion of the risk assessment work plan or preliminary risk screening. Decision \#3 is related to delisting. Delisting requires meeting treatment concentration limits for select analytes. However, these treatment limits are applied to the final waste form (e.g., IHLW or ILAW) not to the source tanks. Since the boundary of the Regulatory DQO is the source tanks, the limits for delisting are not applicable.

The variance is normally calculated from historical data. This was done for the metals and radionuclides in Section 6.0 of the LAW Feed DQO (Wiemers and Miller 1997) and HLW Feed DQO (Wiemers et al. 1998) using the envelope limits from the contract between DOE and the treatment contractor as the action limits. Most of the organic data are from the vapor concentrations measured in the headspace of the tank. Much of this data is based on tentative identification and has a high uncertainty. Therefore, the team agreed that there are insufficient organic data of the appropriate quality to calculate a variance.

Variance for inorganics was calculated and compared to the contract envelope limits in the LAW Feed DQO (Wiemers and Miller 1997) and HLW Feed DQO (Wiemers et al. 1998), but these envelope limits are not directly related to the Regulatory DQO. Since no action levels are available for either organics or inorganics for the Regulatory $\mathrm{DQO}$, and there is a lack of appropriate information for a variance calculation for organics, no statistical design is presented for the Regulatory DQO. The number of samples is based on the information that pertains to inorganics in Sections 6.0 and 7.0 of the LAW Feed DQO and HLW Feed DQOs. 
Without action limits, a discussion of the consequence of taking an incorrect action is not appropriate. It is envisioned that the decision error will be calculated once the risk assessment work plan information and/or additional data are available.

There are several questions of concern in regard to uncertainty and the number of samples.

1. When will enough data be generated to assess whether sufficient samples have been collected from a given tank?

2. Are sufficient subsamples being collected from each composite?

3. When will a sufficient number of tanks be sampled?

In order to assess Question \#1, one must have an action level other than the EQL and variance estimates based on two or more samples from a given tank. Samples will be composited for each of two risers for the HLW feed candidate tanks. Samples will be collected and composited from one riser for the LAW feed candidate tanks. For this project, composite samples for both the solid and liquid fractions will be prepared. A composite represents an average of the tank waste composition. One cannot estimate from a composite sample whether a sufficient number of samples are collected from each level in the tank. Previous data presented in the LAW Feed DQO (Wiemers and Miller 1997) support collection of material from five levels. When data are obtained from Step 1 and more risk limits are available, an evaluation as to the acceptability of the error can be made for the number of samples from the HLW.

In order to address Question \#2, an action level other than the EQL is needed and the variance estimates from Step 1 sampling is needed. One caution is given, if one chooses to use the error evaluation for Step 1 to predict errors in sampling and analysis of Step 2, one is assuming that the waste types are similar.

The following approach may be used to estimate whether a sufficient number of tanks have been sampled to achieve a given decision $(\alpha, \beta)$ (Question \#3).

- Tanks should be grouped by similar waste constituents.

- Data from two or more tanks in each "group," collected by similar sampling and analytical methods should be available.

- Action limits other than the EQL are needed.

Once this information is available, tank to tank variance within and between groupings of tanks will be available and the number of tanks to sample in each group may be estimated.

A discussion of the number of samples based on the LAW Feed DQO (Wiemers and Miller 1997) and HLW Feed DQO (Wiemers et al. 1998) is presented in Section 8.0. 


\subsection{Optimization Guidelines}

The optimization guidelines for this Regulatory DQO are addressed in two steps. Step 1, "Method Selection and Validation," provides guidance for validation of methods required for analysis under RCRA using EPA protocols. Step 1 is described in Section 8.1. Step 2, "Complete Implementation," provides guidelines for implementing this Regulatory DQO to characterize source tank waste. Step 2 is described in Section 8.2. During both Step 1 and Step 2, the respective guidelines are to be reviewed as new information is obtained. New information includes that from analyses of source tanks and from the treatment facility permitting activities. The review will ensure that the characterization efforts have been optimized to meet the end-user needs. Sample collection and compositing requirements and quality control criteria applicable to both Step 1 and Step 2 are described in Sections 8.3 and 8.4, respectively.

\subsection{Step 1, Method Selection and Validation}

The objective of Step 1 is to validate the methods required for implementation of this Regulatory DQO on tank waste. Table 8.1 lists the SW-846 methods that were derived from the DQO process. The lists of priority regulated compounds are provided in Tables 4.4 and 4.7. The methods will be validated per EPA protocol in accordance with SW-846 and WAC 173-303-110. The method validation will consist of three activities: (1) verify the ability of the performing laboratory(ies) to meet the SW-846 minimum detection limit (MDL) for the required method(s), (2) establish the estimated quantitation limits (EQL) and quality control (QC) using liquid and sludge tank waste samples, and (3) conduct the Holding Time and Storage Conditions study. The results from these activities will be reported to DOE and Ecology as requested under this Regulatory DQO. These agencies will then jointly decide how to proceed in Step 2.

To select methods, the requirements in the regulations must be considered. The primary regulations for consideration are those pertaining to the LDR and delisting requirements in the context of generator information to be provided to a waste treatment facility. The LDR regulations are found at 40 CFR 268 and WAC 173-303-140. Also important in LDR compliance are regulations relating to petitions for exemptions or exclusions (e.g., delisting, 40 CFR 260.20 and 260.22, WAC 173-303-072 and -910) and petitions for variance (40 CFR 268.6, WAC 173-303-910). Furthermore, SW-846 methods are acceptable for regulatory characterization needs under WAC 173-303-110.

The LDR regulations require use of SW-846 for toxicity characteristic leaching procedure (TCLP). In addition, if a petition for LDR exemption is ever submitted as part of the final LDR determination (WAC 173-303-910(6)(a)), SW-846 methods are required. If any petition is submitted, per WAC 173303-910, SW-846 methods must be used. If SW-846 methods cannot be used, the petitioner must explain why the methods cannot be used. This regulatory logic is in agreement with the information presented in the Selection of Analytical Methods for Mixed Waste Analysis at the Hanford Site (DOE-RL 1994).

Both state and Federal regulations apply for delisting. The delisting regulations require the use of SW-846 methods or submittal of a petition to use alternate methods for delisting a treated waste. These regulations will apply to the IHLW and are considered by DOE as an option for the ILAW. 
Table 8.1. Selected SW-846 Methods for Implementation of the Regulatory Data Quality Objective.

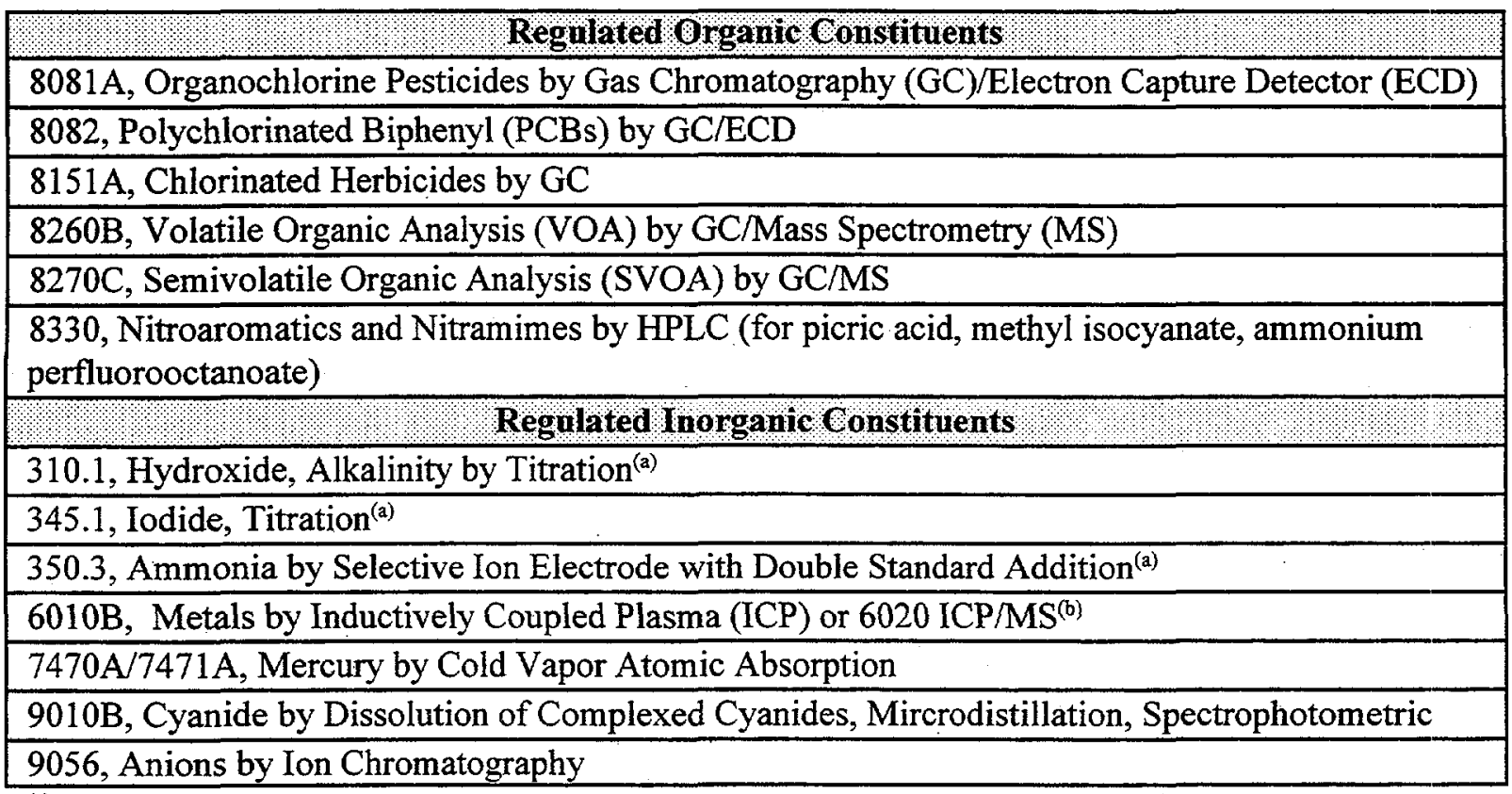

${ }^{(a)}$ EPA methods for Chemical Analysis of Water and Wastes (EPA 1995).

(b) For this Regulatory Data Quality Objective, total $\mathrm{Cr}$ will be measured by ICP. Assumptions regarding the oxidation state of $\mathrm{Cr}$ in the waste are the responsibility of the data user. (Refer to Section 4.11.3.)

Note: Test parameters identified in Table 4.8 are to be measured for all tank waste selected for analysis under this DQO, unless adequate data is available.

Regulations for permitting miscellaneous units (WAC 173-303-680) should also be considered as these are applicable to the thermal treatment facility permitting. Under the provisions of these regulations, consideration must be given during permitting to risk assessment requirements under WAC 173-303-807. Permits for miscellaneous units are to contain such terms and provisions as necessary to protect human health and the environment, including, but not limited to, as appropriate, design, construction, and operating requirements; detection and monitoring requirements; and requirements for responses to releases of dangerous waste or dangerous constituents from the unit. Specifically, the waste analysis must have included an analysis of this waste feed sufficient to provide all information required by WAC 173-303-807 or 173-303-806 (3) and (4). Generally, data collected per SW-846 protocol is desirable in supporting such permitting activities.

Characterization in this document applies to waste in the source tank, before staging for transfer to the treatment facility. Knowledge regarding the analytes of concern from the source tank waste will minimize risk to the DOE and facilitate compliance with delisting and LDR requirements. The waste feed staging/transfer schedule imposes significant constraints on analytical turnaround times. In addition, discovery in the staged feed of constituents not within the treatment facility permit presents a significant risk to the DOE of idle facility costs (estimated at $\$ 3 \mathrm{M} /$ day). Final verification of organic and metal constituents that are regulated as UHC/UTS and delisting analytes will be very difficult in the 
solidified waste form. After treatment, data on the untreated waste that indicates specific analytes are or are not present could be used with process knowledge to demonstrate that treatment standards are met. Because SW-846 methods are required for delisting and for TCLP testing under LDR, the preferred methods for analysis of source tank waste are from SW-846. If SW-846 methods are used during characterization of the source tank waste, these data will be available for use in the delisting petition and for evaluating whether LDR is met.

If methods other than SW-846 are selected, a petition for acceptance of the proposed method will need to be developed for delisting. To avoid petitions, SW-846 methods are the first methods of choice. In addition, it is highly desirable to provide sufficient information to exclude analytes not detected in the waste, and to ensure comparability with analysis of the final waste form. If SW-846 methods do not meet validation criteria presented in this Regulatory DQO, methods other than SW-846 will be considered but must be acceptable to regulators as stipulated under WAC 173-303-110.

The EPA methods have not been validated for Hanford's high-level radioactive tank waste. It is recognized that due to the radioactivity and complex sample matrix for tank waste it is likely that the SW-846 methods will need to be modified or alternative methods selected as stipulated under WAC 173303-110. The WAC 173-303-910 indicates that if alternate methods are required, one must explain or show with data why the SW-846 methods are not acceptable. Specific method limitations may include sample size, holding times, storage requirements, and matrix interference.

An approach agreed to by the Ecology and DOE to provide a technical basis for modification of an existing SW-846 method or selection of the alternative methods consistent with the SW-846 is described in detail in Attachment IV. The following outlines the Step 1 implementation strategy requested under this Regulatory DQO. A logic flowsheet for Step 1 is provided in Figure 8.1.

1. Performing laboratory(ies) prepare a detailed test plan for MDL, EQL, and QC measurements. The plan will be reviewed and approved by DOE and Ecology.

2. Performing laboratory(ies) demonstrates the ability to achieve the MDL for the required $\mathrm{SW}-846$ methods in accordance with Hanford Analytical Services Quality Assurance Requirements Documents (HASQARD) (DOE 1997). The MDLs are to be met for both liquid and solids standards.

3. If MDLs are met, the performing laboratory(ies) demonstrates the ability to achieve target EQLs and $\mathrm{QC}$ in both a liquid and a solid (sludge) tank waste matrix. The waste samples are to be supernate from a Phase I candidate LAW feed tank waste with a high concentration of organic constituents relative to other tank waste and solid (sludge) phase from a Phase I candidate HLW feed tank waste. Target EQLs and QC for solids is to be in the range given for low-concentration soil and high-concentration soil and sludges, or equivalent. Target EQLs and QC for liquid waste matrices have not been agreed to by Ecology and DOE and will be addressed during review/approval of the test plan. For single analytes with no EQLs listed in a specific SW-846 method, no special target EQL is required provided the analytes with EQL criteria for that method meet the target EQL criteria for that method as specified in SW-846. 
Figure 8.1. Regulatory DQO Implementation Logic Summary Flowsheet

Step 1, Method Selection and Validation (a)

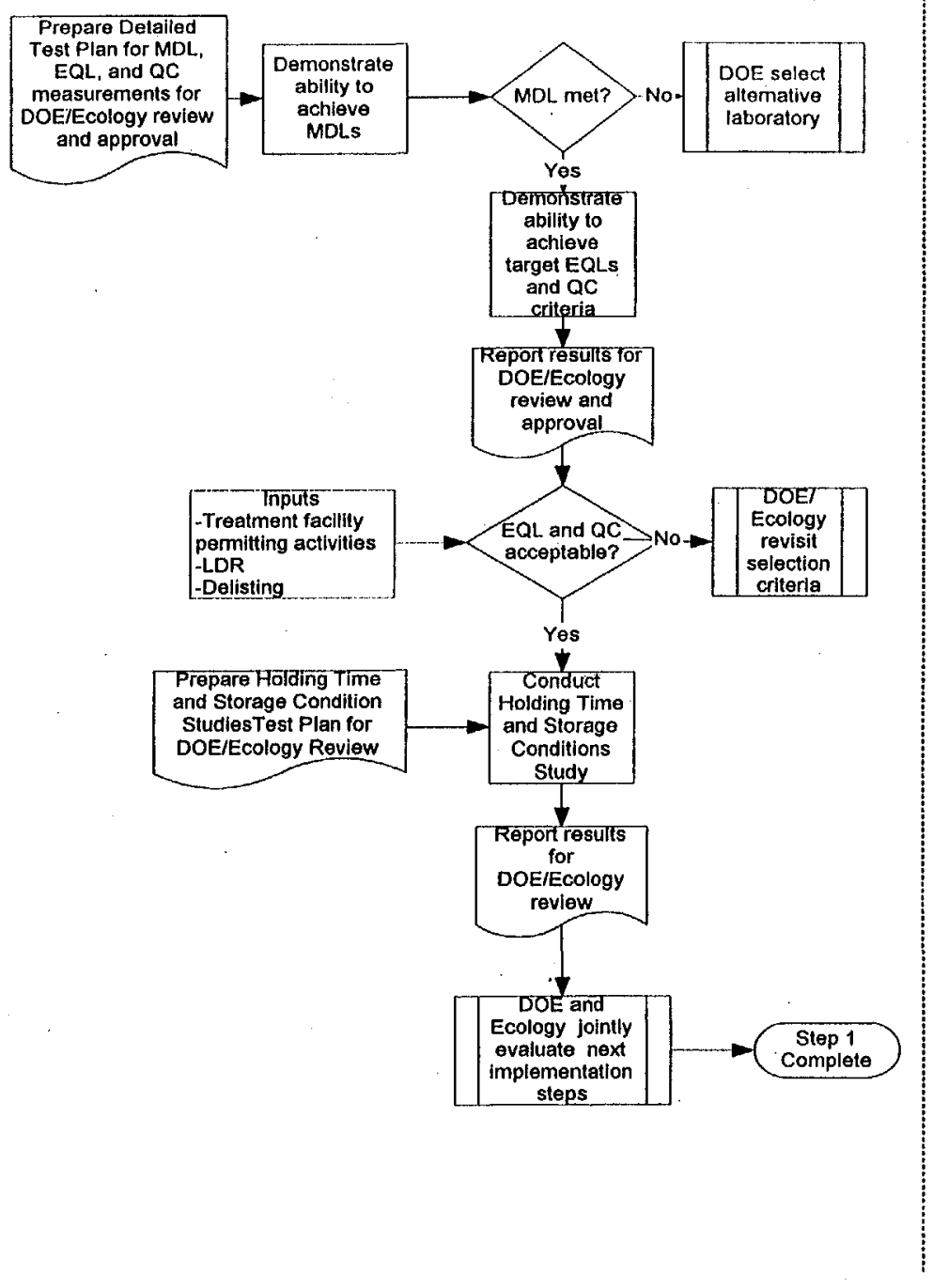

Step 2, Complete Implementation

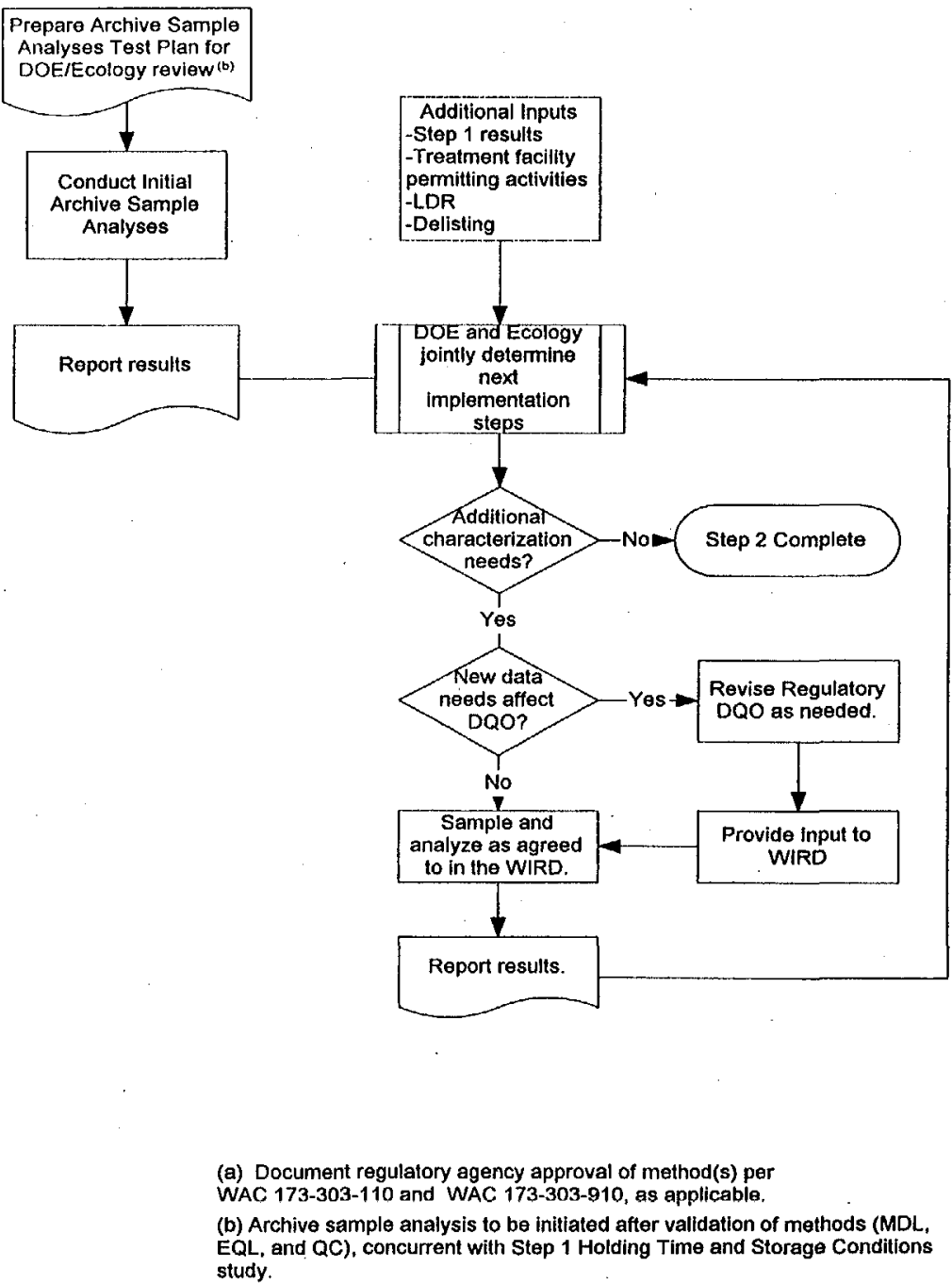


4. Performing laboratory(ies) reports results including information as detailed under WAC 173-303910, Petitions, and the HASQARD (DOE 1997, Volume 4, Section 5). Changes (substitutions, deviations) relative to the standard SW-846 procedure and the reason for the changes are to be documented and included in the report.

5. DOE and Ecology review results with performing laboratory(ies).

6. If MDL, EQL, and QC results, performing laboratory(ies) prepare a detailed test plan for Holding Time and Storage Conditions study. The study is to be conducted based on the method described by Maskarinec and Bayne (1996). DOE and Ecology will review and approve the test plan.

7. Performing laboratory(ies) conduct Holding Time and Storage Conditions study on both a liquid and a solid (sludge) tank waste matrix. The waste samples are to be supernate from a Phase I candidate LAW feed tank waste with a high concentration of organic constituents relative to other tank waste and solid (sludge) phase from a Phase I candidate HLW feed tank waste. The waste samples are to be from the same source tank as used for the EQL and QC demonstration (Step 3), unless otherwise agreed to by DOE and Ecology.

8. Performing laboratory(ies) prepare technical report summarizing the Holding Time and Storage Condition study results. DOE and Ecology review report.

9. DOE and Ecology jointly determine whether changes are warranted in Step 2 implementation based on Step 1 results. Note that consistent with DOE and Ecology agreement, Step 2 implementation on archive samples will be concurrent with the Step 1 Holding Time and Storage Condition study.

Step 1 will result in selection and validation of the analytical methods requested in this DQO for the performing laboratory(ies) per EPA protocol, and analysis of a minimum of two Phase I candidate tank wastes. The Step 1 approach incorporates a number of checkpoints for the purpose of review by DOE and Ecology. DOE and Ecology will use the results from Step 1 in refining the selected methods, analytes, and additional tank waste to characterize in Step 2. As available, data needs identified during the treatment facility permitting process and LDR/Delisting will be used as input to the refinement process.

\subsection{Step 2, Complete Implementation}

The objective of Step 2 is to provide the remaining characterization data needed to support the key drivers identified in the problem statement of this DQO. The general steps envisioned in the Step 2 approach are identified in Figure 8.1. DOE and Ecology agreed to begin analysis of some archive samples concurrent with the Step 1 Holding Time and Storage Condition study. Analysis of archive samples will initiate Step 2 activities.

The list of analytes, methods, and tank waste selected for analysis will be reviewed as new information is available. The new information may consist of characterization data, input from the treatment facility permitting process LDR/Delisting information needs and DOE's Privatization Phase II strategy and developments. If additional characterization needs are identified, the Regulatory DQO will 
be updated as needed and these needs will be prioritized and scheduled through the WIRD. Samples will be initially collected from the Phase I candidate feed source tanks (Kirkbride 1997).

The following outlines the initial Step 2 activities requested under this Regulatory DQO:

1. Performing laboratory(ies) prepare a detailed test plan for analysis of some archive samples. DOE and Ecology review the test plan. The archive samples are to be from Phase I tank waste. The time between sample collection and planned sample analysis is to be one year or less. Analysis of archive samples will be for SVOAs, metals, PCBs, and/or pesticides, depending on the archive sample volume and archive storage conditions. Analyses with RCRA holding times of less than 30 days (VOAs, mercury, ammonia, iodide, cyanide, sulfide, hydroxide, and anions) will not be attempted for archive samples. Analysis of all constituents (VOAs, etc.) will be considered after review of the holding time and storage condition data, and future data needs.

2. Performing Laboratory(ies) complete analysis of archive samples using methods selected and validated (MDL, EQL, and QC) in Step 1. These analyses are to begin before completion of the holding time study.

3. Performing laboratory(ies) report data through pathways agreed to by DOE and Ecology and defined in the test plan. If SW-846 requirements are met, the reported data will be flagged as such in site reports and databases.

4. DOE and Ecology review results collected to date and current status of data needs. DOE and Ecology jointly determine whether changes are warranted in Step 2 implementation.

5. Prioritization and scheduling of characterization needs are documented through the WIRD. If data needs are met, the DQO is closed out.

Implementation of Step 2 will result in the remaining characterization data needed to support the key drivers identified in the problem statement of this Regulatory DQO.

\subsection{Sample Collection and Compositing Requirements}

These guidelines apply to both Step 1 and Step 2. Interim review(s) of newly obtained data and identified permitting needs will be used to re-evaluate the sample collection and compositing requirements during this Regulatory DQO implementation process. 


\subsubsection{Collection Strategies}

The sampling strategy is to be tailored to the individual source tank waste. ${ }^{11}$ In general, tank wastes consist of one or more of the following major strata types: saltcake, crust, supernate, slurry, sludge, and hard pan. The saltcake, crust, and slurry are composed primarily of salts that upon dilution will dissolve. The sludge contains interstitial liquid and insoluble salts and minerals. A hard pan strata may reside at the bottom of a source tank and consist primarily of insoluble materials. The degree to which stratification exists within a tank is dependent on the fill history, waste storage conditions, the waste types and tank farm activities such as mixing and retrieval operations. The primary source of feed for the LAW treatment facility will consist of the soluble waste fractions: crust, supernate, slurry, and/or saltcake. The primary source of feed for the IHLW product will be sludge/insoluble solids.

Sample collection for this Regulatory DQO will be driven to obtain representative samples of the various soluble and insoluble strata, with the exception of the hard pan. ${ }^{12}$ Representative fractions from each strata type will be used to prepare solid and liquid composites. Minimum requirements for sampling as a function of potential tank waste stratification profiles and in-tank mixing are presented in Table 8.2. The table should be examined with Figure 8.2 which schematically represents sample collection, compositing and analysis strategies. For candidate $\mathrm{HLW}$ feed source tanks sampling from two risers maximally separated is requested. Sampling from two risers is requested as knowledge of waste homogeneity in unmixed tank waste with relatively large fractions of insoluble solids is limited. Sampling from two risers will also help to define the homogeneity of post mixed waste, a currently unknown parameter for the HLW feed source tanks. Sampling from one riser is recommended for LAW feed sources based on previous work by Welsh (1991a, 1991b, 1993, and 1997) which suggests these water soluble wastes can be expected to be relatively homogenous across the width of the tank.

Selection of a tank waste sample collection strategy will require an understanding of the tank waste stratification. Modifications to these strategies may be required to address specific waste types. Examples of the Privatization Phase I feed source tanks are provided in Table 8.2 for each set of requirements based on the current state of knowledge with respect to the waste stratification and the waste management plans for these tank wastes. A large majority of the Phase II feed sources are expected to originate from the SSTs. Analysis of Phase II feed source tanks for this Regulatory DQO is expected to occur predominately during retrieval, after which the waste will be more homogenous.

\footnotetext{
${ }^{11}$ The sample collection strategy for this Regulatory DQO is not directly dependent on the planned retrieval and staging operations. The extent of additional analysis required for the staged waste feed will, in part, depend on the extent of the retrieval and staging operations. In-tank pretreatment, retrieval, and staging scenarios may include in-line or in-tank dilution, decant of the tank waste supernate, mixing before retrieval, blending with other waste(s), chemical adjustments such as caustic addition, transfers to an intermediate staging tank(s) or feed to the treatment facility directly from the source tank, and retrieval of a range of batch sizes. The analysis of the staged feed is not within the scope of this Regulatory DQO.

${ }^{12}$ The hard pan strata is being managed as part of Privatization Phase II. Sampling and retrieval technologies for hard pan materials are currently being developed.
} 
Table 8.2. Minimum Sample Collection Requirements for Regulatory Data Quality Objective Implementation.

\begin{tabular}{|c|c|c|c|c|c|c|c|c|c|}
\hline \multirow{2}{*}{$\begin{array}{l}\text { Reference } \\
\text { Number }\end{array}$} & \multirow{2}{*}{$\begin{array}{c}\text { Sample Collection } \\
\text { Type }\end{array}$} & \multirow[b]{2}{*}{ Feed Source } & \multirow[b]{2}{*}{ Mixing Status } & \multirow[b]{2}{*}{ Riser } & \multicolumn{4}{|c|}{ Minimum Number of Vertical Levels ${ }^{(2)}$} & \multirow{2}{*}{$\begin{array}{l}\text { Phasel } \\
\text { Example }\end{array}$} \\
\hline & & & & & Crust & Supernate & Slurry & Slidge & \\
\hline I & Grab & HLW/LAW & After & 2 & NA & \multicolumn{3}{|c|}{5 or every $2 \mathrm{ft}$} & $\mathrm{AZ}-101$ \\
\hline II & Grab or Core & HLW/LAW & Before & 2 & NA & 3 or every $2 \mathrm{ft}$ & NA & 3 or every $2 \mathrm{ft}$ & $\begin{array}{l}\mathrm{AZ}-101 \\
\mathrm{AZ}-102\end{array}$ \\
\hline III & Grab & HLW & After & 2 & NA & \multicolumn{3}{|c|}{5 or every $2 \mathrm{ft}$} & $\begin{array}{c}\text { C-106/ } \\
\text { AY-102 }\end{array}$ \\
\hline IV & Grab or Core & HLW & Before & 2 & NA & 3 or every $2 \mathrm{ft}$ & NA & 3 or every $2 \mathrm{ft}$ & $\begin{array}{l}C-102 \\
C-104 \\
C-106\end{array}$ \\
\hline V & Grab or Core & LAW & Before & 1 & NA & \multicolumn{3}{|c|}{5 including 3 supernate and 1 sludge } & $\begin{array}{l}\text { AN-102 } \\
\text { AN-107 }\end{array}$ \\
\hline VI & Core & LAW & Before & 1 & 1 & \multicolumn{3}{|c|}{4 including 1 sludge } & $\begin{array}{l}\text { AN-103 } \\
\text { AN-104 } \\
\text { AN-105 }\end{array}$ \\
\hline VII & Grab & LAW & Before & 1 & NA & \multirow{2}{*}{\multicolumn{3}{|c|}{$\begin{array}{l}5 \text { including } 3 \text { supernate and } 1 \text { sludge } \\
5 \text { including minimum of } 2 \text { convective } \\
\text { layer and } 2 \text { non-convective layer }\end{array}$}} & AW-101 \\
\hline VIII & Grab or Core & LAW & Before & 1 & $\mathrm{NA}$ & & & & $\begin{array}{l}S Y-101 \\
S Y-103\end{array}$ \\
\hline
\end{tabular}

(a) Minimum sample collection requirements are specified in terms of the minimum number of levels to be sampled or maximum vertical depth separation, whichever represents the optimum number of samples relative to representation of the predicted tank waste strata.

(b) Either C-106/AY-102 or C-104 may be used for solid matrices method validation and holding time studies. Either AN-102, AN-107, AW-101, SY-101 or SY-103 may be used for the liquid matrices method validation and holding time studies. The availability of archive samples for initiation of Step 2 has not yet been determined.

HLW $=$ high-level waste.

LAW $=$ low-activity waste.

$\mathrm{NA}=$ not applicable 


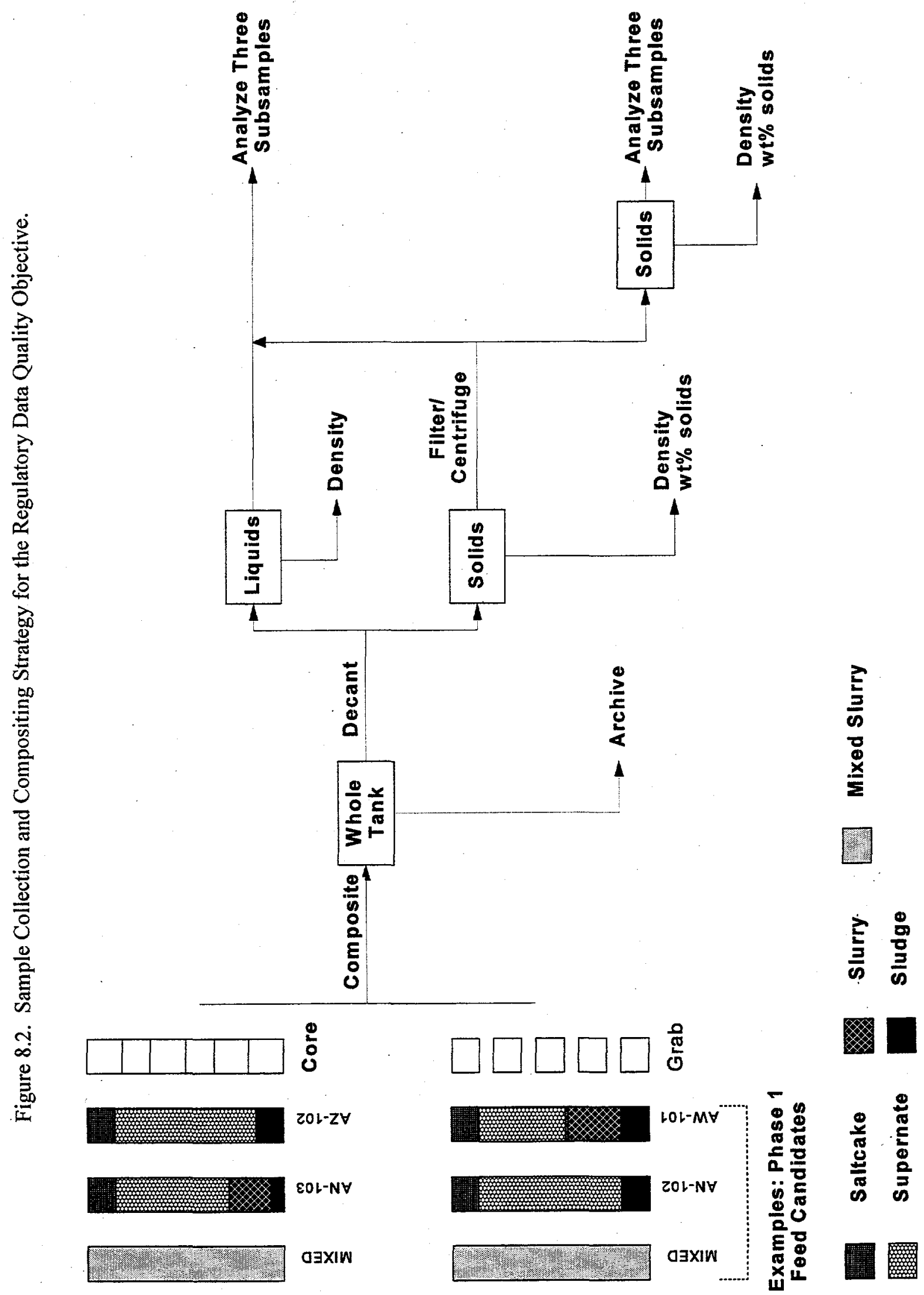




\subsubsection{Compositing and Liquid/Solid Separation}

The compositing and analysis strategy is shown schematically in Figure 8.2. A whole tank composite from each riser sampled is to be prepared based on a representative weight fraction of each strata. The liquid composite consists of liquid decanted from the whole tank composite and liquid removed during the filtration/centrifuging step. ${ }^{13}$ A second solids/liquid separation step is requested as a part of the solids composite analysis to reduce the error associated with obtaining representative aliquots of moderate or greater concentrated slurries. The solids composite will consist of the solids remaining after decanting and filtering or centrifuging.

A material balance using the weight of the waste sample materials is to be maintained for each step throughout the compositing activities. The density of the liquid composite and solid composite, and the weight percent $(\mathrm{wt} \%)$ dried solids of the solids composite before and after the filtration/centrifugation step are to be measured. A sample of the whole tank composite is to be archived.

\subsection{Quality Control Procedures}

These guidelines apply to both Step 1 and Step 2. Interim review(s) of newly obtained data and identified permitting needs will be used to re-evaluate the quality control requirements during this Regulatory DQO implementation process.

Precision and accuracy are to be determined as specified in SW-846 and companion sections of HASQARD. Attachment IV provides additional clarification of the quality control requirements.

Matrix spikes and surrogates as defined in SW-846 will be used to assess bias (also known as accuracy). The matrix spike compound recovery listed in the appropriate SW-846 methods will be used as the initial advisory limits for bias. Spike recoveries for organics vary by analyte and by method. Spike recoveries for metals and anions are 75 to 125 percent for most methods. For analytes without a SW-846 spike recovery criteria, 75 to 125 percent will be used.

Duplicates and matrix spike duplicates are used to assess precision. The relative percent difference (RPD) between two sample duplicates is used or the RSD is used if three or more samples from the same location are evaluated. The precision for organic methods varies depending on the analyte and method and is specified in each method. For inorganic methods, the RPD is typically specified as \pm 20 percent. For analytes without a SW-846 RPD criteria \pm 20 percent RPD will be used. For those methods that do not have specified RSD or tables such as those presented in $8270 \mathrm{C}$, Table $7, \pm 20$ percent RSD will be used.

The matrix spikes and duplicates must be taken through sample preparation and analysis, as appropriate. For example, no preparation is needed for the titration for hydroxide, but sample preparation is appropriate for organic SVOAs.

\footnotetext{
${ }^{13}$ Record the method used for solid/liquid separation. During centrifuge and separation steps, additional liquid may be required for sample transfer, etc. This liquid should come from the original sample liquid. If the original tank waste liquid cannot be used for the separation process, the composition of any alternative rinse solution(s) used is to be reported.
} 


\subsection{References}

40 CFR 260.20. "Hazardous Waste Management System: General." U.S. Code of Federal Regulations, as amended.

40 CFR 260.22. "Hazardous Waste Management System: Petitions to amend Part 261 to exclude a waste produced at a particular facility." U.S. Code of Federal Regulations, as amended.

40 CFR 261. "Identification and Listing of Hazardous Waste." U.S. Code of Federal Regulations, as amended.

40 CFR 268.7. "Land Disposal Restrictions, Waste Analysis and Record Keeping." U.S. Code of Federal Regulations, as amended.

40 CFR 268.48. "Land Disposal Restrictions." U.S. Code of Federal Regulations, as amended.

Agnew SM. 1997. Hanford Tank Chemical and Radionuclide Inventories: HDW Model. LA-UR-96-3860, Rev. 4. Los Alamos National Laboratory, Los Alamos, New Mexico.

Bauer RE. 1997. Data Quality Objective to Support Resolution of the Flammable Gas Safety Issue. HNF-SD-WM-DQO-004, Rev 3. Duke Engineering Services Hanford, Richland, Washington.

Campbell JA, KL Wahl, SA Clauss, KE Grant, V Hoopes, GM Mong, J Rau, and R Steele. 1996a. Organic Tanks Safety Program: Advanced Organic Analysis FY 1996 Progress Report. PNNL-11309. Pacific Northwest National Laboratory, Richland, Washington.

Campbell JA, SA Clauss, KE Grant, V Hoopes, GM Mong, J Rau, R Steele, and KL Wahl. $1996 \mathrm{~b}$. Flammable Gas Safety Program: Actual Waste Analysis FY 1996 Progress Report. PNNL-1 1307. Pacific Northwest National Laboratory, Richland, Washington.

DOE-RL. 1997. Hanford Analytical Services Quality Assurance Requirements Documents.

DOE/RL-96-89. U.S. Department of Energy, Richland Operations Office, Richland, Washington.

DOE-RL. 1993. 200 Area Effluent Treatment Facility Delisting Petition. DOE/RL-92-72, Rev. 1. U.S. Department of Energy, Richland Operations Office, Richland, Washington.

DOE-RL. 1994. Selection of Analytical Methods for Mixed Waste Analysis at the Hanford Site. DOE/RL-94-97, Rev. 0. U.S. Department of Energy, Richland Operations Office, Richland, Washington.

DOE-RL. 1996a. Single-Shell Tank System. Rev. 4; and Double-Shell Tank System. DOE/RL-88-21, Rev. 8. U.S. Department of Energy, Richland Operations Office, Richland, Washington.

DOE-RL. 1996b. U.S. Department of Energy Contract DE-AC-06-R113308. Rev. 2. Dated July 15, 1998. U.S. Department of Energy, Richland Operations Office, Richland, Washington. 
Ecology, EPA, and DOE. 1994. Hanford Federal Facility Agreement and Consent Order. (Tri-Party Agreement), 2 vols., as amended. Washington State Department of Ecology, U.S. Environmental Protection Agency, and U.S. Department of Energy, Olympia, Washington.

EPA. 1994a. Guidance for the Data Quality Objectives Process. EPA QA/G-4. U.S. Environmental Protection Agency, Washington, D.C.

EPA. 1994b. USEPA Contract Laboratory Program National Functional Guidelines for Organic Data Review. EPA 540/R-94/012. Office of Emergency and Remedial Response. U.S. Environmental Protection Agency, Washington, D.C.

EPA. 1995. Chemical Analysis of Water and Wastes. EPA-600/4-79-020. U.S. Environmental Protection Agency, Washington, D.C.

EPA. 1997. Test Methods for Evaluation Solid Waste Physical/Chemical Methods. SW-846, 3rd Edition, as amended by Updates I (July, 1992), IIA (August, 1993), IIB (January, 1995), and III. U.S. Environmental Protection Agency, Washington, D.C.

Esch RA. 1997a. Tank Waste Remediation System (TWRS) Privatization Contractor Samples Waste Envelope D Material 241-C-106, Final Analytical Report. HNF-SD-WM-DP-225, Rev. 1. Rust Federal Services of Hanford Inc., Richland, Washington.

Esch RA. 1997b. Tank Waste Remediation System (TWRS) Privatization Contractor Samples for Low Activity Waste Envelope B, Tank 241-AN-105, Final Analytical Report. HNF-SD-WM-SP-218, Rev. 1. Rust Federal Services of Hanford Inc., Richland, Washington.

Esch RA. 1997c. Tank Waste Remediation System (TWRS) Privatization Contractor Samples for Low Activity Waste Envelope A, Tank 241-AW-101, Final Analytical Report. HNF-SD-WM-SP-204, Rev. 1. Rust Federal Service of Hanford Inc., Richland, Washington.

Hanlon BM. 1998. Waste Tank Summary Report for Month Ending September 1997, WHC-EP0182-97. Westinghouse Hanford Company, Richland, Washington.

Kirkbride RA et al. 1997. Tank Waste Remediation System Operation and Utilization Plan. HNF-SD-WM-SP-012, Rev. 0, Vol. I and II. Numatec Hanford Corporation, Richland, Washington.

Klem MJ. 1990. Inventory of Chemicals Used at Hanford Site Production Plants and Support Operations (1944-1980). WHC-EP-0172, Rev. 1. Westinghouse Hanford Company, Richland, Washington.

Koreski GM. 1997. Operational Waste Volume Projection. WHC-SD-ER-029, latest revision. Lockheed Martin Hanford Company, Richland, Washington.

Kupfer MJ. 1997. Inventories of Chemicals and Radionuclides in Hanford Site Tank Wastes. HNF-SD-WM-TI-740. Lockheed Martin Hanford Company, Richland, Washington. 
Maskarinec MP and CK Bayne. 1996. Principles of Environmental Sampling. Chapter 16. "Developmental of Stability Data for Organic Compounds in Environmental Samples." Oak Ridge National Laboratory, Oak Ridge, Tennessee.

Mulkey CH and M Miller. 1997. Data Quality Objectives for Tank Farms Waste Compatibility Program. HNF-SD-WM-DQO-001, Rev 2. Lockheed Martin Hanford Company, Richland, Washingon.

Resource Conservation and Recovery Act of 1976. 42 USC 6901 et seq.

WAC 173-303. "Dangerous Waste Regulations." Washington Administrative Code, as amended.

WAC 173-460. "Controls for New Sources of Toxic Air Pollutants." Washington Administrative Code, as amended.

Welsh TL. 1991a. Tank 241-AP-106 Characterization Results. WHC-SD-CP-TP-065, Rev. 0. Westinghouse Hanford Company, Richland, Washington.

Welsh TL. 1991b. Tank 241-AP-101 Characterization Results. WHC-SD-WM-TRP-055, Rev. 0.

Westinghouse Hanford Company, Richland, Washington.

Welsh TL. 1993. Tank 241-AP-102 Characterization and Grout Product Test Results. WHC-SD-WMTRP-168, Rev. 1. Westinghouse Hanford Company, Richland, Washington.

Welsh TL. 1997. Waste Envelope "A" Comparison, Tank 241-ANN-105. HNF-SD-WM-TI-813, Rev. 0, Draft. Lockheed Martin Hanford Company, Richland, Washington.

WHC. 1994a. 242-A Campaign 94-1 Post Run Document. WHC-SD-WM-PE-053, Rev. 0. Westinghouse Hanford Company, Richland, Washington.

WHC. 1994b. Process Control Plan for 242-A Evaporator Campaign 94-2. WHC-SD-WM-PCP-009, Rev. 0. Westinghouse Hanford Company, Richland, Washington.

WHC. 1994c. 242-A Campaign 94-2 Post Run Document. WHC-SD-WM-PE-054, Rev. 0. Westinghouse Hanford Company, Richland, Washington.

WHC. 1995a. Process Control Plan for 242-A Evaporator Campaign 95-1. WHC-SD-WM-PCP-010, Rev. 0. Westinghouse Hanford Company, Richland, Washington.

WHC. 1995b. 242-A Campaign 95-1 Post Run Document. WHC-SD-WM-PE-055, Rev. 0. Westinghouse Hanford Company, Richland, Washington.

WHC. 1996a. Process Control Plan for 242-A Evaporator Campaign 96-1. WHC-SD-WM-PCP-011, Rev. 0. Westinghouse Hanford Company, Richland, Washington.

WHC. 1996b. 242-A Campaign 96-1 Post Run Document. WHC-SD-WM-PE-056, Rev. 0. Westinghouse Hanford Company, Richland, Washington. 
WHC. 1996c. Double-Shell Tank System Waste Analysis Plan. WHC-SD-WM-EV-053, Rev. 4. Westinghouse Hanford Company, Richland, Washington.

Wiemers KD and M Miller. 1997. Low-Activity Waste Feed Data Quality Objectives. WIT-98-010. Pacific Northwest National Laboratory, Richland, Washington.

Wodrich DD, GS Barney, GL Borsheim, DL Becker, WC Carlos, MJ Klem, RE Van der Cook, JL Ryan. 1992. Summary of Single-Shell Waste Tank Stability. WHC-EP-0347. Westinghouse Hanford Company, Richland, Washington. 
Appendix A

Appendix VIII Letter/Agreement

A.1 



\section{$89905 \cdot 960827$}

\section{DEPARTIEAT OF ECOLOCY}

Augues 27, 1996

TO:

J.C. Armbruster, SWRO

FROR:

Thorras Cusack, HirIR/NWT

SURJECT:

Dangerous Waste Constituent Ilst

Thank you for your question. You would I1ke to know the use of the dangerous waste constituent list found at WAC 17.3-303-9905 in using or interpreting the DW Regulations. You vould also Ilke to know were in the Di Regs this list is referenced. As you nozed, most of the Items In that list are also IIsted as $P$ or U listed dangerous wastes. However, there. is a reason and purpose for this 11st.

The first place the lise can be used is in Section -016(1)(b). Here the list is used In determining if a material which in not a solld or dangezous waste per designation, should be a dangerous weste for the purposes outlined in Secrion $-016(1)(b)$.

You will find the list referenced in. Suction $-016(6)(C)(1)(B)$. The list is used as a criteria in evelusting solld wastes and in raking the determination if the waste should be cọnsidered iniherently waste-like when recycled.

"Dangerous waste constituents" are defined in Section -040 .

The darigerous waste constituent list is referenced In Section -072(4). Here It is used as orie factor for determining if a listed waste should be exempt from the DW Regulations. InIs is considered delisting under the federal RCRA program. So be careful, Ecology cannot dellst a federal RCRA waste.

Finally, you will find the .11st referenced in Section $-646(1)$ (c) for corrective action purposes.

I hope this helps. If you find any other place where this Iise is used or referenced, please let me know. Thanks. 


\section{Appendix 8 Letter}

DOE and Ecology agree that the intent of the letter from Thomas Cusack; to J.C. Ambruster is to state that the Appendix VIII list does not apply to the characterization required in the Regulatory DQO. (Letter is attached.)

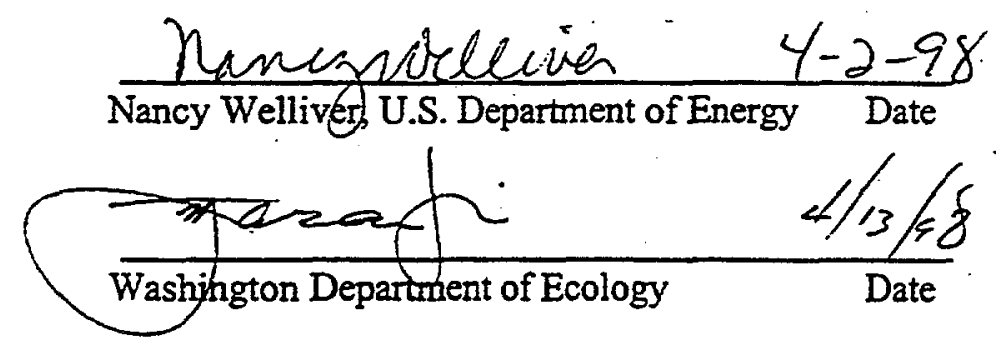




\section{Appendix B}

Tables of Analytes 


\section{Contents}

\begin{tabular}{|c|c|c|c|c|}
\hline Reference & Reference & Table & Titte & Page \\
\hline 4.1 & $\mathrm{Q} 1$ & B. 1 & $\begin{array}{l}\text { Compounds with a Positive Analytical Detect for Single- } \\
\text { Shell Tank/Double-Shell Tank Waste (1,227 Compounds) }\end{array}$ & B.5 \\
\hline 4.2 & Q2 & B.2 & $\begin{array}{l}\text { Consolidated List of Compounds Used as Input } \\
\text { for Regulatory Data Quality Objective List } \\
\text { ( } 850 \text { Compounds) }\end{array}$ & B.31 \\
\hline 4.2 & Q3 & $\overline{B .3}$ & $\begin{array}{l}\text { Regulated Organic Mixtures, Non-organic Regulated } \\
\text { Compounds, and Waste Properties to be Considered } \\
\text { Separately ( } 222 \text { Compounds) }\end{array}$ & $\overline{\mathrm{B} .51}$ \\
\hline 4.2 & $\mathrm{Q} 4$ & $\overline{B .4}$ & $\begin{array}{l}\text { Organic Analyte Regulatory Data Quality Objective Input } \\
\text { List (623 Compounds) }\end{array}$ & B.56 \\
\hline 4.2 & $\mathrm{Q5}$ & B.5 & $\begin{array}{l}\text { Regulated Organic Compounds with a Positive Analytical } \\
\text { Detect in the Single-Shell Tank/Double-Shell Tank Waste } \\
\text { (146 Compounds) }\end{array}$ & B.71 \\
\hline 4.2 & Q5-1 & B.6 & $\begin{array}{l}\text { Regulated Detected Organic Compounds with Higher } \\
\text { Toxicity ( } 19 \text { Compounds) }\end{array}$ & B.75 \\
\hline 4.2 & $\overline{\mathrm{Q} 5-2}$ & B.7 & $\begin{array}{l}\text { Regulated Detected Organic Compounds with Lower } \\
\text { Toxicity ( } 127 \text { Compounds) }\end{array}$ & B.76 \\
\hline 4.2 & Q5-4 & B.8 & $\begin{array}{l}\text { Regulated Organic Compounds with Lower Toxicity and } \\
\text { Less than } 10 \text { Detects in the Single-Shell Tank/Double-Shell } \\
\text { Tank Waste, not Included for Further Analytical } \\
\text { Considerations ( } 42 \text { Compounds) }\end{array}$ & B.79 \\
\hline 4.2 & $\overline{Q 5-3}$ & B.9 & $\begin{array}{l}\text { Regulated Organic Compounds with Lower Toxicity and } \\
\geq 10 \text { Detects ( } 85 \text { Compounds) }\end{array}$ & B.81 \\
\hline 4.2 & Q6 & B.10 & $\begin{array}{l}\text { Regulated Organic Compounds without a Positive } \\
\text { Analytical Detect in Single-Shell Tank/Double-Shell Tank } \\
\text { Waste ( } 477 \text { Compounds) }\end{array}$ & B.83 \\
\hline 4.3 & $\mathrm{Q7}$ & B.11 & $\begin{array}{l}\text { Regulated Non-detected Organic Compounds that are } \\
\text { Classified as Polycyclic Aromatic Hydrocarbons } \\
\text { (14 Compounds) }\end{array}$ & B.94 \\
\hline 4.3 & Q9 & B.12 & $\begin{array}{l}\text { Regulated Non-detected Organic Compounds Classified as } \\
\text { Chlorinated Pesticides and Herbicides That Were Likely to } \\
\text { be Used During Early Hanford Site Operations ( } 39 \\
\text { Compounds). }\end{array}$ & B.95 \\
\hline 4.3 & Q11 & B.13 & $\begin{array}{l}\text { Regulated Non-detected Organic Compound, Plausibly a } \\
\text { "Ghost" Compound (1 Compound) }\end{array}$ & B.96 \\
\hline 4.3 & Q13 & B.14 & $\begin{array}{l}\text { Regulated Non-detected Organic Compounds Listed in } \\
\text { Either Klem (1990) or Agnew (1997) ( } 7 \text { Compounds) }\end{array}$ & B.97 \\
\hline 4.3 & Q14 & B.15 & $\begin{array}{l}\text { Regulated Non-detected Organic Compounds for } \\
\text { Evaluation of Industry Uses Unrelated to Hanford } \\
\text { Activities ( } 416 \text { Compounds) }\end{array}$ & B.98 \\
\hline 4.3 & $\overline{Q 15}$ & B.16 & $\begin{array}{l}\text { Regulated Non-detected Compounds Removed Based on } \\
\text { Industry Uses Unrelated to Hanford ( } 207 \text { Compounds) }\end{array}$ & B.107 \\
\hline 4.3 & Q16-1 & B.17 & $\begin{array}{l}\text { Regulated Non-detected Organic Compound Selected as } \\
\text { Indicator Compound for Analytes, Classified as a Dioxin } \\
\text { or Furan (1 Compound) }\end{array}$ & B.114 \\
\hline 4.3 & Q16-2 & B.18 & $\begin{array}{l}\text { Regulated Non-detected Organic Compounds, Used by } \\
\text { Industries that are Potentially Unrelated to Hanford, and } \\
\text { Dioxin/Furan Indicator Compound ( } 208 \text { Compounds) }\end{array}$ & B.115 \\
\hline
\end{tabular}




\begin{tabular}{|c|c|c|c|c|}
\hline Reference & Reference & Table & Title & Page \\
\hline 4.3 & Q16-3 & B.19 & $\begin{array}{l}\text { Regulated Non-detected Organic Compounds Likely Used } \\
\text { at Hanford ( } 208 \text { Compounds) }\end{array}$ & B.122 \\
\hline 4.3 & Q17 & $\overline{\mathrm{B} .20}$ & $\begin{array}{l}\text { Regulated Non-detected Organic Compounds to be } \\
\text { Considered for Stability Evaluation ( } 269 \text { Compounds) }\end{array}$ & B.127 \\
\hline 4.4 & Q18R & B.21 & $\begin{array}{l}\text { Regulated Non-detected Organic Compounds Considered } \\
\text { Unstable in Single-Shell Tank/Double-Shell Tank Waste } \\
\text { Matrix (179 Compounds) }\end{array}$ & B. 133 \\
\hline 4.4 & Q19R & B.22 & $\begin{array}{l}\text { Regulated Non-detected Organic Compounds Considered } \\
\text { Stable in Single-Shell Tank/Double-Shell Tank Waste } \\
\text { Matrix (90 Compounds) }\end{array}$ & B. 137 \\
\hline 4.4 & Q24 & B.23 & $\begin{array}{l}\text { Regulated Non-detected Stable Organic Compounds with } \\
\text { Lower or Unknown Toxicity and Carcinogenicity ( } 65 \\
\text { Compounds) }\end{array}$ & B.139 \\
\hline 4.4 & Q23 & B.24 & $\begin{array}{l}\text { Regulated Non-detected Stable Organic Compounds with } \\
\text { Higher Toxicity and/or Carcinogenicity ( } 25 \text { Compounds) }\end{array}$ & $\overline{B .141}$ \\
\hline 4.5 & Q31 & B.25 & $\begin{array}{l}\text { Regulated Detected Organic Compounds with Higher } \\
\text { Toxicity and Non-detected Stable Organic Compounds } \\
\text { with Higher Toxicity ( } 44 \text { Compounds) }\end{array}$ & B. 142 \\
\hline 4.5 & Q32 & B. 26 & $\begin{array}{l}\text { Regulated Organic Compounds with Higher Toxicity } \\
\text { Potentially Analyzed by Existing SW-846 Methods (EPA } \\
\text { 1997) ( } 28 \text { Compounds) }\end{array}$ & B. 143 \\
\hline 4.5 & Q33 & B. 27 & $\begin{array}{l}\text { Regulated Organic Compounds with Higher Toxicity with } \\
\text { No Existing SW-846 Methods ( } 16 \text { Compounds) }\end{array}$ & $\overline{B .144}$ \\
\hline 4.5 & $\overline{\text { Q34 }}$ & B.28 & $\begin{array}{l}\text { Regulated Organic Compounds with Higher Toxicity } \\
\text { Potentially Analyzed by Modified SW-846 Methods (EPA } \\
\text { 1997) (16 Compounds) }\end{array}$ & B. 145 \\
\hline 4.5 & Q36 & B.29 & $\begin{array}{l}\text { Regulated Detected and Non-detected Organic Compounds } \\
\text { with Higher Toxicity that are Amenable to SW-846 or } \\
\text { Modified SW-846 Methods (EPA 1997) (44 Compounds) }\end{array}$ & B. 146 \\
\hline 4.6 & Q37 & B.30 & $\begin{array}{l}\text { Regulated Detected Organic Compounds with Lower } \\
\text { Toxicity that are Common Laboratory Contaminants ( } 2 \\
\text { Compounds) }\end{array}$ & $\overline{\text { B. } 148}$ \\
\hline 4.6 & $\overline{Q 38}$ & B.31 & $\begin{array}{l}\text { Regulated Detected Organic Compounds with } \geq 10 \text { Detects } \\
\text { and Lower Toxicity and Associated Methods to be } \\
\text { Compared to the Analytical Methods Chosen for the } \\
\text { Regulated Organic Compounds with Higher Toxicity ( } 83 \\
\text { Compounds) }\end{array}$ & B.149 \\
\hline 4.6 & $\bar{Q} 40 \mathrm{~b}$ & B.32 & $\begin{array}{l}\text { Regulated Detected Organic Compounds with } \geq 10 \text { Detects } \\
\text { and Lower Toxicity Not Analyzed by Methods Applicable } \\
\text { to Higher Toxicity Organic Compounds ( } 2 \text { Compounds) }\end{array}$ & $\overline{B .151}$ \\
\hline 4.6 & Q41 & B.33 & $\begin{array}{l}\text { Analytical Methods Used for Analysis of Higher Toxicity } \\
\text { Organic Compounds }\end{array}$ & $\overline{B .152}$ \\
\hline 4.6 & Q39 Total & B.34 & $\begin{array}{l}\text { Regulated, Detected Organic Compounds with } \geq 10 \text { Detects } \\
\text { and Lower Toxicity that are Amenable to the Same } \\
\text { Analytical Methods as the Non-detected, Stable Organic } \\
\text { Compounds of Higher Toxicity ( } 82 \text { Compounds) }\end{array}$ & $\overline{B .153}$ \\
\hline
\end{tabular}

References 
Table B.1. Compounds with a Positive Analytical Detect for Single-Shell Tank/ Double-Shell Tank Waste (1,227 Compounds). (Page 1 of 26)

\begin{tabular}{|c|c|c|c|}
\hline CAst & Constituent: & Trins solidit & TWINS Yapar \\
\hline $100-00-5$ & p-Nitrochlorobenzene & & 3 \\
\hline $100-41-4$ & Ethyl benzene & & 423 \\
\hline $100-42-5$ & Styrene & 3 & 195 \\
\hline $100-47-0$ & Benzonitrile & & 5 \\
\hline $100-51-6$ & Benzyl alcohol & & 19 \\
\hline $100-52-7$ & Benzaldehyde & & 9 \\
\hline $100-71-0$ & 2-Ethylpyridine & & 3 \\
\hline $100-73-2$ & 3,4-Dihydro-2H-pyran-2-carboxaldehyde & & 3 \\
\hline $100-97-0$ & Hexamethylenetetramine & & 18 \\
\hline $1002-16-0$ & Amyl nitrate & & 28 \\
\hline $1002-17-1$ & 2,9-Dimethyldecane & & 3 \\
\hline $1002-43-3$ & 3-Methylundecane & & 46 \\
\hline $1002-68-2$ & trans-3-Undecene & & 1 \\
\hline $1002-84-2$ & n-Pentadecanoic acid & & 30 \\
\hline $10061-01-5$ & cis-1,3-Dichloropropene & & 27 \\
\hline $10061-02-6$ & trans-1,3-Dichloropropene & 1 & 28 \\
\hline $1008-80-6$ & Naphthalene, decahydro-2,3-dimethyl- & & 15 \\
\hline $101-84-8$ & Diphenyl ether & & 6 \\
\hline $101300-62-3$ & $\begin{array}{l}\text { Silane, (4,5-dimethyl-1,4-cyclohexadiene-1,2- } \\
\text { diyl)bis[trimethyl- }\end{array}$ & & 1 \\
\hline $10203-30-2$ & 3-Dodecanol & & 1 \\
\hline $10264-17-2$ & N-Hexylbutyramide & & 1 \\
\hline $103-23-1$ & Bis(2-ethylhexyl) adipate & & 1 \\
\hline $103-65-1$ & Propylbenzene & & 7 \\
\hline $10374-14-8$ & 2-Ethylcyclobutanone & & 1 \\
\hline $10374-74-0$ & 7-Tetradecene & & 7 \\
\hline $104-50-7$ & 4-Hydroxyoctanoic acid lactone & & 6 \\
\hline $104-61-0$ & 4-Hydroxynonanoic acid lactone & & 3 \\
\hline $104-76-7$ & 2-Ethyl-1-hexanol & & 103 \\
\hline $104-90-5$ & 2-Methyl-5-ethylpyridine & & 2 \\
\hline $10486-19-8$ & Tridecanal & & 1 \\
\hline $105-21-5$ & 4-Hydroxyheptanoic acid lactone & & 14 \\
\hline $105-42-0$ & 4-Methyl-2-hexanone & & 6 \\
\hline $106-35-4$ & 3-Heptanone & 7 & 158 \\
\hline $106-42-3$ & p-Xylene & & 35 \\
\hline $106-46-7$ & 1,4-Dichlorobenzene & & 120 \\
\hline $106-65-0$ & Butanedioic acid, dimethyl ester & 4 & 0 \\
\hline $106-68-3$ & 3-Octanone & & 10 \\
\hline $106-72-9$ & 2,6-Dimethyl-5-heptenal & & 3 \\
\hline $106-88-7$ & 1,2-Epoxybutane & & 1 \\
\hline $106-93-4$ & Ethylene dibromide & & 45 \\
\hline $106-97-8$ & Butane & & 535 \\
\hline $106-98-9$ & 1-Butene & & 91 \\
\hline $106-99-0$ & 1,3-Butadiene & & 46 \\
\hline $1066-40-6$ & \begin{tabular}{|l|} 
Trimethylsilanol \\
\end{tabular} & 32 & 9 \\
\hline $1069-53-0$ & 2,3,5-Trimethylhexane & & 85 \\
\hline $107-01-7$ & 2-Butene & & 14 \\
\hline $107-02-8$ & Acrolein & & 22 \\
\hline
\end{tabular}


Table B.1. Compounds with a Positive Analytical Detect for Single-Shell Tank/ Double-Shell Tank Waste (1,227 Compounds). (Page 2 of 26)

\begin{tabular}{|c|c|c|c|}
\hline CASH & Constituent & TWurs solid/ & TWONS Vapor \\
\hline $107-05-1$ & 3-Chloropropene & & 4 \\
\hline $107-06-2$ & 1,2-Dichloroethane & 1 & 15 \\
\hline $107-12-0$ & Propionitrile & & 593 \\
\hline $107-13-1$ & Acrylonitrile & & 1 \\
\hline $107-16-4$ & 2-Hydroxyacetonitrile & & 1 \\
\hline $107-18-6$ & 2-Propen-1-ol & & 5 \\
\hline $107-31-3$ & Formic acid, methyl ester & & 1 \\
\hline 107-39-1 & 2,4,4-Trimethyl-1-pentene & & 3 \\
\hline $107-46-0$ & Hexamethyldisiloxane & 29 & 0 \\
\hline $107-75-5$ & 3,7-Dimethyl-7-hydroxyoctanal & & 1 \\
\hline $107-83-5$ & Pentane, 2-methyl- & & 111 \\
\hline $107-87-9$ & 2-Pentanone & & 211 \\
\hline $107-92-6$ & Butanoic acid & & 4 \\
\hline $1072-05-5$ & 2,6-Dimethylheptane & & 27 \\
\hline $1073-11-6$ & 4-Methyl-4-vinylbutyrolactone & & 1 \\
\hline $1074-17-5$ & 1-Methyl-2-propylbenzene & & 1 \\
\hline $108-03-2$ & 1-Nitropropane & & 3 \\
\hline $108-05-4$ & Acetic acid vinyl ester & & 1 \\
\hline 108-08-7 & 2,4-Dimethylpentane & & 4 \\
\hline $108-10-1$ & 4-Methyl-2-pentanone & 1 & 374 \\
\hline $108-20-3$ & Bis(isopropyl) ether & & 1 \\
\hline $108-29-2$ & 4-Hydroxypentanoic acid lactone & & 8 \\
\hline $108-30-5$ & Succinic acid anhydride & & 2 \\
\hline $108-38-3$ & m-Xylene & & 24 \\
\hline $108-39-4$ & m-Cresol & & 7 \\
\hline $108-47-4$ & 2,4-Dimethylpyridine & & 2 \\
\hline $108-48-5$ & 2,6-Dimethylpyridine & & 1 \\
\hline $108-67-8$ & 1,3,5-Trimethylbenzene & & 202 \\
\hline $108-87-2$ & Methylcyclohexane & & 132 \\
\hline $108-88-3$ & Toluene & 52 & 738 \\
\hline $108-89-4$ & 4-Methylpyridine & & 8 \\
\hline $108-90-7$ & Chlorobenzene & & 66 \\
\hline $108-93-0$ & Cyclohexanol & & 1 \\
\hline $108-94-1$ & Cyclohexanone & & 192 \\
\hline $108-95-2$ & Phenol & & 19 \\
\hline $108-99-6$ & 3-Methylpyridine & & 8 \\
\hline $1083-56-3$ & 1,4-Diphenylbutane & & 2 \\
\hline $109-06-8$ & 2-Methylpyridine & & 1 \\
\hline $109-08-0$ & 2-Methylpyrazine & & 18 \\
\hline $109-21-7$ & Butanoic acid, butyl ester & & 21 \\
\hline $109-66-0$ & n-Pentane & & 446 \\
\hline $109-67-1$ & 1-Pentene & & 45 \\
\hline $109-68-2$ & 2-Pentene & & 4 \\
\hline $109-69-3$ & n-Chlorobutane & & 7 \\
\hline $109-74-0$ & n-Butyronitrile & & 464 \\
\hline $109-75-1$ & 3-Butenenitrile & & 3 \\
\hline $109-93-3$ & Divinyl ether & & 1 \\
\hline $109-97-7$ & Pyrrole & & 1 \\
\hline
\end{tabular}


Table B.1. Compounds with a Positive Analytical Detect for Single-Shell Tank/ Double-Shell Tank Waste (1,227 Compounds). (Page 3 of 26)

\begin{tabular}{|c|c|c|c|}
\hline \&AS & Constituent & $\begin{array}{l}\text { TYINS Solids } \\
\text { Liquid Hits }\end{array}$ & TWINS Vapor \\
\hline $109-99-9$ & Tetrahydrofuran & 1 & 562 \\
\hline $110-00-9$ & Furan & & 15 \\
\hline $110-12-3$ & 5-Methyl-2-hexanone & & 12 \\
\hline $110-13-4$ & 2,5-Hexanedione & & $\mathrm{I}$ \\
\hline $110-27-0$ & Tetradecanoic acid, 1-methylethyl ester & & 13 \\
\hline $110-36-1$ & Tetradecanoic acid, butyl ester & & 8 \\
\hline $110-43-0$ & 2-Heptanone & & 209 \\
\hline $110-54-3$ & n-Hexane & & 623 \\
\hline $110-59-8$ & Pentanenitrile & & 433 \\
\hline $110-60-1$ & 1,4-Butanediamine & & 2 \\
\hline $110-62-3$ & n-Valeraldehyde & & 54 \\
\hline $110-71-4$ & 1,2-Dimethoxyethane & & 1 \\
\hline $110-82-7$ & Cyclohexane & & 256 \\
\hline $110-83-8$ & Cyclohexene & 19 & 2 \\
\hline $110-86-1$ & Pyridine & & 279 \\
\hline $110-93-0$ & 6-Methyl-5-hepten-2-one & & 1 \\
\hline $111-06-8$ & Hexadecanoic acid, butyl ester & & 1 \\
\hline $111-13-7$ & 2-Octanone & & 177 \\
\hline $111-27-3$ & n-Hexanol & & 31 \\
\hline $111-65-9$ & n-Octane & & 492 \\
\hline $111-66-0$ & 1-Octene & & 15 \\
\hline $111-70-6$ & n-Heptanol & & 38 \\
\hline $111-71-7$ & n-Heptaldehyde & & 70 \\
\hline $111-76-2$ & 2-Butoxyethanol & 6 & 7 \\
\hline $111-84-2$ & n-Nonane & 22 & 528 \\
\hline $111-87-5$ & n-Octyl alcohol & & 26 \\
\hline $111-90-0$ & Ethanol, 2-(2-ethoxyethoxy)- & 4 & 0 \\
\hline $1112-39-6$ & Dimethoxydimethylsilane & & 5 \\
\hline $1115-11-3$ & 2-Methyl-2-butenal & & 8 \\
\hline 1116-90-1 & 4-Methyl-1,4-hexadiene & & 1 \\
\hline $1117-59-5$ & Pentanoic acid, hexyl ester & & 3 \\
\hline $1118-58-7$ & 1,3-Dimethyl-1,3-butadiene & & 10 \\
\hline $112-12-9$ & 2-Undecanone & & 7 \\
\hline $112-30-1$ & n-Decanol & & 1 \\
\hline $112-31-2$ & n-Decaldehyde & 4 & 36 \\
\hline $112-40-3$ & n-Dodecane & 177 & 576 \\
\hline $112-41-4$ & 1-Dodecene & & 7 \\
\hline $112-42-5$ & Undecanol & & 1 \\
\hline $112-44-7$ & Undecanaldehyde & & 4 \\
\hline $112-53-8$ & Dodecanol & & 3 \\
\hline $112-54-9$ & Dodecanaldehyde & & 5 \\
\hline $112-72-1$ & n-Tetradecanol & & 2 \\
\hline $112-80-1$ & cis-9-Octadecenoic acid & & 6 \\
\hline $112-88-9$ & 1-Octadecene & & 1 \\
\hline $112-92-5$ & n-Octadecanol & & 5 \\
\hline $112-95-8$ & n-Eicosane & & 9 \\
\hline $1120-06-5$ & 2-Decanol & & 3 \\
\hline $1120-21-4$ & n-Undecane & 128 & 614 \\
\hline
\end{tabular}


Table B.1. Compounds with a Positive Analytical Detect for Single-Shell Tank' Double-Shell Tank Waste (1,227 Compounds). (Page 4 of 26)

\begin{tabular}{|c|c|c|c|}
\hline CASH & Constituent & 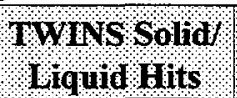 & TWMS Vapor \\
\hline $1120-36-1$ & 1-Tetradecene & & 10 \\
\hline $1120-64-5$ & 4,5-Dihydro-2-methyloxazole & & 14 \\
\hline $1121-05-7$ & 2,3-Dimethyl-2-cyclopentenone & & 1 \\
\hline $1121-07-9$ & $\mathrm{~N}$-Methyl-2,5-pyrrolidinedione & & 5 . \\
\hline $1121-33-1$ & 2,4-Dimethylcyclopentanone & & 1 \\
\hline $115-07-1$ & Propene & & 102 \\
\hline $115-10-6$ & Dimethyl ether & & 23 \\
\hline $115-11-7$ & 2-Methylpropene & & 209 \\
\hline $117-81-7$ & Bis(2-ethylhexyl) phthalate & 33 & 1 \\
\hline $117-84-0$ & Di-n-octylphthalate & 2 & \\
\hline $1184-60-7$ & 2-Fluoropropene & & 5 \\
\hline $1191-95-3$ & Cyclobutanone & & 4 \\
\hline $1191-96-4$ & Ethylcyclopropane & & 15 \\
\hline $1191-99-7$ & 2,3-Dihydrofuran & & 11 \\
\hline $1192-18-3$ & cis-1,2-Dimethylcyclopentane & & 2 \\
\hline $1192-33-2$ & 3,3-Dimethylcyclobutanone & & 1 \\
\hline $1192-51-4$ & 3-Methyl-2,4-furandione & & 3. \\
\hline $1196-92-5$ & Phenol, 4-(aminomethyl)-2-methoxy- & & 1 \\
\hline $120-40-1$ & $\mathrm{~N}, \mathrm{~N}$-Bis(2-Hydroxyethyl)dodecanamide & 1 & 0 \\
\hline $120-82-1$ & $1,2,4$-Trichlorobenzene & 1 & 51 \\
\hline $122-39-4$ & $\mathrm{~N}, \mathrm{~N}$-Diphenylamine & & 22 \\
\hline $123-05-7$ & 2-Ethylhexaldehyde & & 8 \\
\hline $123-15-9$ & 2-Methylpentanal & & 5 \\
\hline $123-19-3$ & 4-Heptanone & & $\overline{44}$ \\
\hline $123-25-1$ & Succinic acid, diethyl ester & & 1 \\
\hline $123-32-0$ & 2,5-Dimethylpyrazine & & 2 \\
\hline $123-38-6$ & n-Propionaldehyde & & 56 \\
\hline $123-51-3$ & 3-Methyl-1-butanol & & 4 \\
\hline $123-72-8$ & n-Butyl aldehyde & & 330 \\
\hline $123-73-9$ & trans-2-Buten-1-al & & 2 \\
\hline $123-75-1$ & Pyrrolidine & & 1 \\
\hline $123-79-5$ & Hexanedioic acid, dioctyl ester & 8 & 5 \\
\hline $123-86-4$ & Acetic acid n-butyl ester & & 25 \\
\hline $123-91-1$ & 1,4-Dioxan & & 19 \\
\hline $123-95-5$ & Octadecanoic acid, butyl ester & & 3 \\
\hline $123-96-6$ & 2-Octanol & & 9 \\
\hline 124-11-8 & 1-Nonene & & 2 \\
\hline $124-12-9$ & n-Octanonitrile & & 53 \\
\hline 124-13-0 & n-Octaldehyde & 1 & 63 \\
\hline $124-18-5$ & n-Decane & 73 & 583 \\
\hline $124-19-6$ & Nonaldehyde & 1 & 69 \\
\hline $126-73-8$ & Tributyl phosphate & 40 & 73 \\
\hline $126-98-7$ & 2-Methyl-2-propenenitrile & & 1 \\
\hline $127-18-4$ & 1,1,2,2-Tetrachloroethene & 2 & 415 \\
\hline $127-19-5$ & N,N-Dimethylacetamide & & 2 \\
\hline $128-37-0$ & 2,6-Bis(tert-butyl)-4-methylphenol & 2 & 13 \\
\hline $129-00-0$ & Pyrene & 6 & \\
\hline $13029-08-8$ & $2,2^{\prime}$-Dichlorobiphenyl & & 4 \\
\hline
\end{tabular}


Table B.1. Compounds with a Positive Analytical Detect for Single-Shell Tank/ Double-Shell Tank Waste (1,227 Compounds). (Page 5 of 26)

\begin{tabular}{|c|c|c|c|}
\hline QASH & Constituent & $\begin{array}{l}\text { TWus Solid/ } \\
\text { Giquid Hits }\end{array}$ & TWINS Vapor \\
\hline $13040-03-4$ & (+)-cis-Verbenol & & 1 \\
\hline $13049-35-9$ & $2,2^{\prime}$-Diethylbiphenyl & & 6 \\
\hline $13151-06-9$ & 7-Methyl-1-octene & & 2 \\
\hline $13151-34-3$ & 3-Methyldecane & & 23 \\
\hline $13151-35-4$ & 5-Methyldecane & & 15 \\
\hline $13151-74-1$ & Decane, 3-cyclohexyl- & & 9 \\
\hline $13151-75-2$ & Decane, 4-cyclohexyl- & & 1 \\
\hline $13151-99-0$ & cis-1,4-Dimethylcyclooctane & & 4 \\
\hline $13286-73-2$ & Tridecane, 3-ethyl- & & 6 \\
\hline $13287-21-3$ & 6-Methyltridecane & & 38 \\
\hline $13287-23-5$ & 8-Methylheptadecane & & 1 \\
\hline $13287-24-6$ & 9-Methylnonadecane & & 3 \\
\hline $1330-20-7$ & Xylene & 30 & 5 \\
\hline $1331-43-7$ & Diethylcyclohexane & & 1 \\
\hline $13360-61-7$ & 1-Pentadecene & & 4 \\
\hline $13475-75-7$ & Pentadecane, 8-hexyl- & & 2 \\
\hline $13475-78-0$ & 5-Ethyl-2-methylheptane & & 3 \\
\hline $13475-82-6$ & $2,2,4,6,6$-Pentamethylheptane & & 8 \\
\hline $135-98-8$ & 2-Phenylbutane & & 3 \\
\hline $136-77-6$ & 4-Hexyl-1,3-dihydroxybenzene & & 2 \\
\hline $13603-07-1$ & Piperidine, 3-methyl-1-nitroso- & 4 & 0 \\
\hline $137-32-6$ & 2-Methylbutyl alcohol & & 5 \\
\hline $138-86-3$ & 4-Isopropenyl-1-methylcyclohexene & & 4 \\
\hline $13828-31-4$ & Cyclohexene, 1-methyl-3-(1-methylethyl)- & & 1 \\
\hline $13861-97-7$ & $2(3 \mathrm{H})$-Furanone, dihydro-4,4-dimethyl- & & 1 \\
\hline $13925-00-3$ & 2-Ethylpyrazine & & 9 \\
\hline $140-79-4$ & Piperazine, 1,4-dinitroso- & 4 & 0 \\
\hline $141-62-8$ & Decamethyltetrasiloxane & & 2 \\
\hline $141-78-6$ & Acetic acid ethyl ester & & 10 \\
\hline $141-79-7$ & 4-Methyl-3-penten-2-one & & 9 \\
\hline $14129-48-7$ & 4-Octen-3-one & & 3 \\
\hline $142-30-3$ & 2,5-Dimethyl-2,5-dihydroxy-3-hexyne & & 3 \\
\hline $142-62-1$ & n-Hexanoic acid & & 2 \\
\hline $142-78-9$ & Dodecanamide, N-(2-hydroxyethyl)- & & 1 \\
\hline $142-82-5$ & n-Heptane & & 626 \\
\hline $142-91-6$ & Crodamol IPP & & 67 \\
\hline $142-96-1$ & Di-n-butyl ether & & 15 \\
\hline $14255-23-3$ & 2,4-Dimethyl-2-hexene & & 1 \\
\hline $143-07-7$ & n-Dodecanoic acid & & 18 \\
\hline $143-08-8$ & n-Nonyl alcohol & & 19 \\
\hline $143-28-2$ & 9-cis-Octadecenol & & 1 \\
\hline $144-62-7$ & Oxalic acid & 1969 & 0 \\
\hline $14476-37-0$ & 4-Undecanone & & 1 \\
\hline $1453-24-3$ & 1-Ethylcyclohexene & & 1 \\
\hline $1453-58-3$ & 3-Methylpyrazole & & 8 \\
\hline $1454-84-8$ & Nonadecyl alcohol & & 1 \\
\hline $1454-85-9$ & n-Heptadecyl alcohol & & 1 \\
\hline 1462-84-6 & 2,3,6-Trimethylpyridine & & 2 \\
\hline
\end{tabular}


Table B.1. Compounds with a Positive Analytical Detect for Single-Shell Tank/

Double-Shell Tank Waste (1,227 Compounds). (Page 6 of 26)

\begin{tabular}{|c|c|c|c|}
\hline $\mathrm{CHS}$ & Constituent & $\begin{array}{l}\text { TWINS Solid/ } \\
\text { Liquid Hits }\end{array}$ & $\begin{array}{l}\text { TWINS Vapor } \\
\text { Hits }\end{array}$ \\
\hline $1467-79-4$ & Cyanamide, dimethyl- & & 3 \\
\hline $14676-29-0$ & 2-Methyl-3-ethylheptane & & 19 \\
\hline $14686-13-6$ & trans-2-Heptene & & 8 \\
\hline $14686-14-7$ & trans-3-Heptene & & 6 \\
\hline $1472-09-9$ & n-Octylcyclopropane & & 7 \\
\hline $14720-74-2$ & 2,2,4-Trimethylheptane & & 3 \\
\hline $1482-15-1$ & 1-Pentyn-3-ol, 3,4-dimethyl- & & $T$ \\
\hline $14850-23-8$ & trans-4-Octene & & 4 \\
\hline $14898-79-4$ & (R)-2-Butanol & & 1 \\
\hline $149-57-5$ & 2-Butylbutanoic acid & 3 & 1 \\
\hline $14905-56-7$ & 2,6,10-Trimethyltetradecane & & 12 \\
\hline $14919-01-8$ & trans-3-Octene & & 4 \\
\hline $1506-02-1$ & $\begin{array}{l}\text { Ethanone, 1-(5,6,7,8-tetrahydro-3,5,5,6,8,8-hexamethyl-2- } \\
\text { naphthalenyl)- }\end{array}$ & & 1 \\
\hline $151-18-8$ & 3-Aminopropionitrile & & 3 \\
\hline $15232-85-6$ & 1-Pentylcyclohexene & & 7 \\
\hline $1526-17-6$ & 2-Fluoro-6-nitrophenol & 4 & 0 \\
\hline $1534-26-5$ & 3-Tridecanone & & 74 \\
\hline $1534-27-6$ & 3-Dodecanone & & 42 \\
\hline $156-59-2$ & 1,2-cis-Dichloroethene & & 34 \\
\hline $1560-88-9$ & 2-Methyloctadecane & & 3 \\
\hline $1560-92-5$ & 2-Methylhexadecane & & 5 \\
\hline $1560-93-6$ & 2-Methylpentadecane & & 13 \\
\hline $1560-96-9$ & 2-Methyltridecane & & 70 \\
\hline $1560-97-0$ & 2-Methyldodecane & & 8 \\
\hline $1565-80-6$ & (S)-2-Methyl-1-butanol & & 1 \\
\hline $1565-81-7$ & 3-Decanol & & 3 \\
\hline $1568-20-3$ & 1H-Pyrazole, 4,5-dihydro-5-methyl- & & 3 \\
\hline $15726-15-5$ & 3-Methyl-4-heptanone & & 3 \\
\hline $1574-41-0$ & cis-1,3-Pentadiene & & 3 \\
\hline $15869-80-4$ & 3-Ethylheptane & & 3 \\
\hline $15869-89-3$ & 2,5-Dimethyloctane & & 4 \\
\hline $15869-92-8$ & 3,4-Dimethyloctane & & 3 \\
\hline $15869-93-9$ & 3,5-Dimethyloctane & & 5 \\
\hline $15877-57-3$ & 3-Methylpentanal & & 6 \\
\hline $15890-40-1$ & cis-1,2-trans-3-Trimethylcyclopentane & & 3 \\
\hline $15892-23-6$ & DL-Butan-2-ol & & 1 \\
\hline $15918-07-7$ & 5-Methyl-4-nonene & & 1 \\
\hline $15932-80-6$ & 2-Isopropylidene-5-methylcyclohexanone & & 3 \\
\hline $1604-34-8$ & 6,10-Dimethyl-2-undecanone & & 1 \\
\hline $16106-59-5$ & 4,5-Dimethyl-1-hexene & & 3 \\
\hline $1615-70-9$ & 1-Cyano-1,3-butadiene & & 1 \\
\hline $1618-22-0$ & 2,6-Dimethyldecalin & & 21 \\
\hline $1620-14-0$ & Diethylaminoacetone & 2 & 0 \\
\hline $1630-94-0$ & 1,1-Dimethylcyclopropane & & 12 \\
\hline $1632-70-8$ & 5-Methylundecane & & 43 \\
\hline $16339-12-1$ & N-Nitrosomethoxymethylamine & & 1 \\
\hline $1638-16-0$ & 2-Propanol, 1,1-[(1-methyl-1,2-ethanediyl)bis(oxy)]bis-(9CI) & 2 & 0 \\
\hline
\end{tabular}


Table B.1. Compounds with a Positive Analytical Detect for Single-Shell Tank/ Double-Shell Tank Waste (1,227 Compounds). (Page 7 of 26)

\begin{tabular}{|c|c|c|c|}
\hline Cas\# & Constituent: & Twins solidy & TWNS \\
\hline $1640-89-7$ & Ethylcyclopentane & & $\frac{3}{6}$ \\
\hline $16519-68-9$ & 2,6-Diethylcyclohexanone & & I \\
\hline $1653-30-1$ & 2-Undecanol & & 1 \\
\hline $1653-31-2$ & 2-Tridecanol & & 1 \\
\hline $16536-57-5$ & Cis-2-Bromocyclohexanol & 1 & $\overline{0}$ \\
\hline $16538-93-5$ & Cyclooctane, butyl- & & 1 \\
\hline $16580-24-8$ & 1-Isopropyl-3-methylcyclohexane & & 3 \\
\hline $16605-91-7$ & 2,3-Dichloro-1,1-biphenyl & & 3 \\
\hline $16606-02-3$ & $2,4^{\prime}, 5$-Trichlorobiphenyl & & 3 \\
\hline 16624-06-9 & Cyclooctanemethanol, .alpha.,.alpha.-dimethyl- & & 3 \\
\hline $16745-94-1$ & 3,4-Dimethyl-1-hexene & & 9 \\
\hline $16746-85-3$ & 4-Ethyl-1-hexene & & 2 \\
\hline $16747-25-4$ & 2,2,3-Trimethylhexane & & 1 \\
\hline $16747-28-7$ & $2,3,3$-Trimethylhexane & & 3 \\
\hline $16778-26-0$ & 1,4,4-Trimethylcyclohexan-2-oneacetic acid enol lactone & & 19 \\
\hline $16778-70-4$ & 1-Ethyl-1,2,4-triazole & & 3 \\
\hline $1678-91-7$ & Ethylcyclohexane & & 17 \\
\hline $1678-92-8$ & n-Propylcyclohexane & & 9 \\
\hline $1678-93-9$ & n-Butylcyclohexane & & 14 \\
\hline $1678-97-3$ & 1,2,3-Trimethylcyclohexane & & 4 \\
\hline $1678-98-4$ & Isobutylcyclohexane & & 3 \\
\hline $1679-08-9$ & 2,2-Dimethylpropanethiol & & 3 \\
\hline $1703-52-2$ & 2-Ethyl-5-methylfuran & & 2 \\
\hline 1708-29-8 & 2,5-Dihydrofuran & & 9 \\
\hline $1712-64-7$ & 2-Propyl nitrate & & 9 \\
\hline $1713-33-3$ & 1-Methylcyclohexene epoxide & & 2 \\
\hline $1717-00-6$ & 1,1-Dichloro-1-fluoroethane & & 33 \\
\hline $17301-22-3$ & 2,5-Dimethylundecane & & 1 \\
\hline $17301-23-4$ & 2,6-Dimethylundecane & & 90 \\
\hline $17301-24-5$ & 2,7-Dimethylundecane & & 3 \\
\hline $17301-25-6$ & 2,8-Dimethylundecane & & 4 \\
\hline $17301-26-7$ & Undecane, 2,9-dimethyl- & . & 5 \\
\hline $17301-27-8$ & 2,10-Dimethylundecane & & 42 \\
\hline $17301-28-9$ & 3,6-Dimethylundecane & & 4 \\
\hline $17301-29-0$ & 3,7-Dimethylundecane & & 25 \\
\hline $17301-30-3$ & 3,8-Dimethylundecane & & 10 \\
\hline $17301-31-4$ & 3,9-Dimethylundecane & & 4 \\
\hline $17301-32-5$ & 4,7-Dimethylundecane & & 36 \\
\hline $17301-33-6$ & 4,8-Dimethylundecane & & 12 \\
\hline $17301-94-9$ & 4-Methylnonane & & 27 \\
\hline $17302-23-7$ & 4,5-Dimethylnonane & & 7 \\
\hline $17302-28-2$ & 2,6-Dimethylnonane & & 44 \\
\hline $17302-32-8$ & 3,7-Dimethylnonane & & 12 \\
\hline $17302-33-9$ & 6-Methylundecane & & 33 \\
\hline $17312-50-4$ & 2,5-Dimethyldecane & & 9 \\
\hline $17312-53-7$ & 3,6-Dimethyldecane & & 24 \\
\hline $17312-55-9$ & 3,8-Dimethyldecane & & 13 \\
\hline $17312-57-1$ & 3-Methyldodecane & & 11 \\
\hline
\end{tabular}


Table B.1. Compounds with a Positive Analytical Detect for Single-Shell Tank/ Double-Shell Tank Waste (1,227 Compounds). (Page 8 of 26)

\begin{tabular}{|c|c|c|c|}
\hline CAs\# & Constituent & 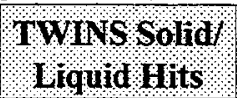 & TWINS Yapor \\
\hline $17312-58-2$ & 3-Ethylundecane & & 2 \\
\hline $17312-60-6$ & 6-Ethylundecane & & 1 \\
\hline $17312-62-8$ & 5-Propyldecane & & 4 \\
\hline $17312-63-9$ & 5-Butylnonane & & 7 \\
\hline $17312-64-0$ & 2,2-Dimethylundecane & & 1 \\
\hline $17312-68-4$ & 4,4-Dimethylundecane & & 6 \\
\hline $17312-73-1$ & 5,5-Dimethylundecane & & 3 \\
\hline $17312-74-2$ & 5-Ethyl-5-methyldecane & & 2 \\
\hline $17312-76-4$ & 6,6-Dimethylundecane & & 1 \\
\hline $17312-77-5$ & 2,3-Dimethylundecane & & 7 \\
\hline $17312-78-6$ & 3,4-Dimethylundecane & & 27 \\
\hline $17312-80-0$ & 2,4-Dimethylundecane & & 22 \\
\hline $17312-81-1$ & 3,5-Dimethylundecane & & 1 \\
\hline $17312-82-2$ & 4,6-Dimethylundecane & & 7 \\
\hline $17312-83-3$ & 5,7-Dimethylundecane & & 6 \\
\hline $17351-34-7$ & 14-Pentadecenoic acid & & 3 \\
\hline $17429-02-6$ & 4-Hydroxy-4-methylcyclohexanone & & 1 \\
\hline $17453-93-9$ & 5-Methyldodecane & & 6 \\
\hline $17453-94-0$ & 5-Ethylundecane & & 13 \\
\hline $1750-51-2$ & Naphthalene, decahydro-1,6-dimethyl- & & 12 \\
\hline $1757-42-2$ & 3-Methylcyclopentanone & & 4 \\
\hline $1759-58-6$ & trans-1,3-Dimethylcyclopentane & & 1 \\
\hline $17622-46-7$ & 2-Cyclohexen-1-one, 4-ethyl-3,4-dimethyl- & & 4 \\
\hline $1779-19-7$ & 1,3,6-Trioxacyclooctane & & 3 \\
\hline $17851-53-5$ & Butyl isobutyl phthalate & & 2 \\
\hline $1795-15-9$ & n-Octylcyclohexane & & 17 \\
\hline $1795-16-0$ & n-Decylcyclohexane & & 3 \\
\hline $1795-21-7$ & n-Decylcyclopentane & & 1 \\
\hline $1795-27-3$ & cis,cis-1,3,5-Trimethylcyclohexane & & 1 \\
\hline $1795-48-8$ & Isopropyl isocyanate & & 1 \\
\hline $1825-61-2$ & Methoxytrimethylsilane & 32 & 0 \\
\hline 18294-04-7 & Oxalic acid, bis(trimethylsilyl) ester & & 8 \\
\hline $18344-37-1$ & $2,6,10,14$-Tetramethylheptadecane & & 1 \\
\hline $1838-59-1$ & Formic acid, 2-propenyl ester & & $\overline{1}$ \\
\hline $1839-63-0$ & 1,3,5-Trimethylcyclohexane & & 8 \\
\hline $1840-42-2$ & Fluorotrinitromethane & & 3 \\
\hline $18433-98-2$ & 2,5-Dimethyl-3-isopentylpyrazine & & 1 \\
\hline $18435-22-8$ & 3-Methyltetradecane & & 13 \\
\hline $18435-45-5$ & 1-Nonadecene & & 1 \\
\hline $18521-07-8$ & 3-Octen-2-ol, 2-methyl-, (Z)- & & 3 \\
\hline $18669-52-8$ & 2,3-Dimethyl-1,4-hexadiene & & 1 \\
\hline $18829-55-5$ & trans-2-Heptenal & & 4 \\
\hline $18829-56-6$ & trans-2-Nonenal & & 3 \\
\hline $1886-75-5$ & Di-tert-Butyl sulfone & & 9 \\
\hline $1888-57-9$ & 2,5-Dimethyl-3-hexanone & & 3 \\
\hline $1921-70-6$ & $2,6,10,14$-Tetramethylpentadecane & & 16 \\
\hline $19269-28-4$ & 3-Methylhexanal & & 3 \\
\hline $1932-92-9$ & Propionic acid, 2-propynyl ester & & 1 \\
\hline
\end{tabular}


Table B.1. Compounds with a Positive Analytical Detect for Single-Shell Tank Double-Shell Tank Waste (1,227 Compounds). (Page 9 of 26)

\begin{tabular}{|c|c|c|c|}
\hline CAS\# & Constituent & $\begin{array}{l}\text { TWINS Solid! } \\
\text { I iquid Gits }\end{array}$ & $\begin{array}{l}\text { TWNS Vapor } \\
\text { Hits }\end{array}$ \\
\hline $19341-98-1$ & trans-1,2-Diethylcyclobutane & & 2 \\
\hline $1937-62-8$ & trans-9-Octadecenoic acid, methyl ester & & 2 \\
\hline 19398-37-9 & 3-Decene & & 4 \\
\hline $19549-80-5$ & 4,6-Dimethyl-2-heptanone & & 1 \\
\hline $19549-87-2$ & 2,4-Dimethyl-1-heptene & & 48 \\
\hline $19550-03-9$ & 2,3-Dimethyl-2-hexanol & & 1 \\
\hline $19550-73-3$ & trans-3,4-Dimethylcyclopentanone & & 1 \\
\hline $1975-78-6$ & n-Decanonitrile & & 3 \\
\hline $19780-10-0$ & 5-Dodecanone & & 17 \\
\hline $19780-59-7$ & 3-Ethyl-2-methyl-2-heptanol & & 2 \\
\hline $19780-63-3$ & 3-Ethyl-2-methyl-2-pentanol & & 1 \\
\hline 19781-07-8 & 2,7-Octanediol, 2,7-dimethyl & & 2 \\
\hline $19781-27-2$ & 6-Ethyl-3-octanol & & 2 \\
\hline $20063-97-2$ & trans-2-Decene & & 2 \\
\hline $20184-91-2$ & 4-Nonyne & & 1 \\
\hline $20192-66-9$ & 1,2-Cyclohexanediol, cyclic carbonate, trans- & & 3 \\
\hline $20193-21-9$ & 1-Butanamine, N-propyl- & 4 & 0 \\
\hline $20278-85-7$ & 2,3,5-Trimethylheptane & & 1 \\
\hline $2030-84-4$ & 4-Dodecene & & 3 \\
\hline 20324-33-8 & 2-Propanol,1-[2-(2-methoxy-1-methylethoxy)-1- & 4 & 0 \\
\hline 2040-07-5 & $2,4,5$-Trimethylacetophenone & & 2 \\
\hline $2049-95-8$ & 2-Methyl-2-phenylbutane & & 2 \\
\hline $2050-67-1$ & 3,3'-Dichlorobiphenyl & & 2 \\
\hline $2050-68-2$ & 4,4'-Dichlorobiphenyl & & 3 \\
\hline $2050-78-4$ & n-Decyl nitrate & & 2 \\
\hline $2051-30-1$ & 2,6-Dimethyloctane & & 18 \\
\hline $2051-49-2$ & n-Hexanoic acid anhydride & & 1 \\
\hline $2051-60-7$ & 2-Chlorobiphenyl & & 7 \\
\hline $2051-61-8$ & 3-Chlorobiphenyl & & 5 \\
\hline $2051-62-9$ & 4-Chlorobiphenyl & & 3 \\
\hline $206-44-0$ & Fluoranthene & 1 & \\
\hline $20633-11-8$ & n-Hexyl nitrate & & 29 \\
\hline $20633-12-9$ & n-Heptyl nitrate & & 6 \\
\hline $20633-13-0$ & n-Nonyl nitrate & & 3 \\
\hline 20691-89-8 & N-Methyl-4-hydroxymethylpiperidine & & 1 \\
\hline $20698-91-3$ & D-(-)-Mandelic acid methyl ester & & 1 \\
\hline $20743-95-7$ & p-Butoxymethoxybenzene & & 1 \\
\hline $20754-04-5$ & 3-Methyl-4-octanone & & 2 \\
\hline $2090-38-2$ & $1,2,4,5$-Tetramethylcyclohexane & & 1 \\
\hline $2091-29-4$ & 9-Hexadecenoic acid & & 30 \\
\hline $20959-33-5$ & 7-Methylheptadecane & & 1 \\
\hline $21078-65-9$ & 2-Ethyl-1-decanol & & 3 \\
\hline $21164-95-4$ & 7,9-Dimethylhexadecane & & 7 \\
\hline $2132-84-5$ & 2-Phenylheptane & & 2 \\
\hline $21328-57-4$ & 1,5-Dimethylcyclooctane & & 4 \\
\hline $2136-70-1$ & Ethylene glycol monotetradecyl ether & & 1 \\
\hline 21964-48-7 & 1,12-Tridecadiene & & 1 \\
\hline
\end{tabular}


Table B.1. Compounds with a Positive Analytical Detect for Single-Shell Tank Double-Shell Tank Waste (1,227 Compounds). (Page 10 of 26)

\begin{tabular}{|c|c|c|c|}
\hline \&ASH & Constifuent: & $\begin{array}{l}\text { TwINS Solid: } \\
\text { Liquid Hits. }\end{array}$ & $\begin{array}{l}\text { TWINS Yapor } \\
\text { Hits }\end{array}$ \\
\hline $22026-12-6$ & 6-Tridecanone & & 20 \\
\hline $22058-71-5$ & Methylamine, N-(1-methylhexylidene)- & & 1 \\
\hline $2213-23-2$ & 2,4-Dimethylheptane & & 96 \\
\hline $2216-30-0$ & 2,5-Dimethylheptane & & 5 \\
\hline $2216-33-3$ & 3-Methyloctane & 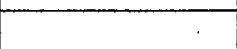 & 10 \\
\hline $2216-34-4$ & 4-Methyloctane & & 15 \\
\hline $2216-87-7$ & 3-Undecanone & & 10 \\
\hline $2223-52-1$ & 1,1,4,4-Tetramethylcyclohexane & & 3 \\
\hline $22319-25-1$ & 4-Methyl-3-hepten-2-one & & 3 \\
\hline $22319-29-5$ & 5-Ethyl-2,4-dimethyl-4-hepten-3-one & & 2 \\
\hline $2243-27-8$ & Nonanonitrile & & 50 \\
\hline $22431-09-0$ & Methanamine, N-(1-methylbutylidene)- & & 6 \\
\hline $2244-07-7$ & n-Undecanonitrile & & 2 \\
\hline $2345-27-9$ & 2-Tetradecanone & & 16 \\
\hline $23462-75-1$ & Tetrahydropyran-3-one & & 2 \\
\hline $2371-19-9$ & 3-Methyl-2-heptanone & & 10 \\
\hline $2384-85-2$ & 3-Decyne & & 6 \\
\hline $2402-06-4$ & trans-1,2-Dimethylcyclopropane & & 2 \\
\hline $2408-37-9$ & 1,1,3-Trimethyl-2-cyclohexanone & & 4 \\
\hline $2415-72-7$ & n-Propylcyclopropane & & 17 \\
\hline $24251-86-3$ & 5,8-Diethyldodecane & & 5 \\
\hline $2432-55-5$ & Butanethioic acid, S-decyl ester & & 6 \\
\hline $2437-56-1$ & 1-Tridecene & & 11 \\
\hline $24405-16-1$ & trans-4-Methyl-5-hydroxyhexanoic acid lactone & & 8 \\
\hline $2452-99-5$ & 1,2-Dimethylcyclopentane & & 56 \\
\hline $2456-28-2$ & n-Decyl ether & & 6 \\
\hline $2490-48-4$ & 2-Methylhexadecan-1-ol & & 2 \\
\hline $24949-38-0$ & 6-Tridecene & & 7 \\
\hline $24949-42-6$ & 7-Methyl-6-tridecene & & 15 \\
\hline $25013-16-5$ & tert-Butyl-4-methoxyphenol & & 1 \\
\hline $2508-29-4$ & 5-Amino-1-pentanol & & 5 \\
\hline $2511-91-3$ & Pentylcyclopropane & & 3 \\
\hline $25117-24-2$ & 4-Methyltetradecane & & 11 \\
\hline $25117-31-1$ & 5-Methyltridecane & & 9 \\
\hline $25117-32-2$ & 5-Methyltetradecane & & 1 \\
\hline $2532-58-3$ & cis-1,3-Dimethylcyclopentane & & 4 \\
\hline $2548-87-0$ & trans-2-Octenal & & 3 \\
\hline $2549-67-9$ & 2-Ethylaziridine & & 11 \\
\hline $2562-37-0$ & 1-Nitrocyclohexene & 2 & 0 \\
\hline $2610-95-9$ & 5-Methyl-5-hydroxyhexanoic acid lactone & & 3 \\
\hline $2613-66-3$ & 1-Methyl-cis-3-ethylcyclopentane & & 2 \\
\hline $26215-90-7$ & 4-Tridecanone & & 3 \\
\hline $26248-42-0$ & Tridecanol & & 1 \\
\hline $2639-63-6$ & Butyric acid, hexyl ester & & 1 \\
\hline $26465-81-6$ & 3,3-Dimethylindanone & & 1 \\
\hline $26496-20-8$ & 4-Tetradecanone & & 3 \\
\hline $26537-19-9$ & p-tert-Butylbenzoic acid methyl ester & & 2 \\
\hline $26730-12-1$ & 4-Methyltridecane & & 40 \\
\hline
\end{tabular}


Table B.1. Compounds with a Positive Analytical Detect for Single-Shell Tank/ Double-Shell Tank Waste (1,227 Compounds). (Page 11 of 26)

\begin{tabular}{|c|c|c|c|}
\hline CAS\# & Constituent & $\begin{array}{l}\text { TWins solid: } \\
\text { Liquid Hits }\end{array}$ & TWNS Vapor \\
\hline $26730-14-3$ & 7-Methyltridecane & & 45 \\
\hline $2719-61-1$ & 2-Phenyldodecane & & 1 \\
\hline $2719-62-2$ & 6-Phenyldodecane & & 4 \\
\hline $2719-63-3$ & 5-Phenyldodecane & & 2 \\
\hline $2719-64-4$ & 4-Phenyldodecane & & 2 \\
\hline $27392-16-1$ & Cyclohexanecarboxylic acid, 2-tert-butyl-, trans- & & 1 \\
\hline $27675-36-1$ & cis-1-Nitropropene & & 3 \\
\hline $27750-45-4$ & $\begin{array}{l}\text { Benzenepropanoic acid, .alpha.-[(trimethylsilyl)oxy]-, } \\
\text { trimethylsilyl ester }\end{array}$ & & 1 \\
\hline $279-23-2$ & Bicyclo[2.2.1]heptane & & 5 \\
\hline $280-65-9$ & Bicyclo[3.3.1]nonane & & 3 \\
\hline 2801-84-5 & 2,4-Dimethyldecane & & 4 \\
\hline $28019-94-5$ & 4,5-Dimethyl-2-pyrazoline & & 2 \\
\hline $2815-57-8$ & 1,2,3-Trimethylcyclopentane & & 4 \\
\hline $2815-58-9$ & 1,2,4-Trimethylcyclopentane & & 6 \\
\hline $28290-01-9$ & 2,3,3-Trimethylcyclobutanone & & 4 \\
\hline $28292-42-4$ & 3-Aminoheptane & 4 & 0 \\
\hline $2847-72-5$ & 4-Methyldecane & & 48 \\
\hline $28473-21-4$ & Nonanol & & 4 \\
\hline $286-08-8:$ & Bicyclo[4.1.0]heptane & & 1 \\
\hline $2865-82-9$ & 4-Methyl-4-hydroxyhexanoic acid lactone & & 3 \\
\hline $287-23-0$ & Cyclobutane & & 7 \\
\hline $287-92-3$ & Cyclopentane & & 16 \\
\hline $288-16-4$ & Isothiazole & & 2 \\
\hline $288-88-0$ & 1H-1,2,4-Triazole & & 1 \\
\hline $2882-96-4$ & 3-Methylpentadecane & & 1 \\
\hline $2883-05-8$ & 2-cyclohexyloctane & & 3 \\
\hline $289-95-2$ & Pyrimidine & & 6 \\
\hline $28981-49-9$ & Ethylcyclododecane & & 1 \\
\hline $290-37-9$ & Pyrazine & & 92 \\
\hline $29006-00-6$ & 6-Methoxyhexan-2-one & & 2 \\
\hline $29052-10-6$ & Butyric acid, ester with p-hydroxybenzonitrile & & 1 \\
\hline 29053-04-1 & 1-Isobutyl-3-methylcyclopentane & & 16 \\
\hline $2922-51-2$ & 2-Heptadecanone & & 2 \\
\hline 29354-98-1 & Hexadecanol & & 1 \\
\hline 29366-35-6 & 11-Methyl-4-dodecanone & & 1 \\
\hline $294-62-2$ & Cyclododecane & & 16 \\
\hline $295-17-0$ & Cyclotetradecane & & 8 \\
\hline $295-65-8$ & Cyclohexadecane & - & 5 \\
\hline $2958-76-1$ & 2-Methyldecalin & & 42 \\
\hline $29799-19-7$ & Cyclohexane, 1-(1,5-dimethylhexyl)-4-methyl- & & 3 \\
\hline $2980-69-0$ & 4-Methylundecane & & 48 \\
\hline $29887-79-4$ & trans-1,3-Dimethoxycycloheptane & & 3 \\
\hline $300-57-2$ & 3-Phenylpropene & & 3 \\
\hline $30135-88-7$ & Bromofluorobenzene & 4 & 0 \\
\hline $3054-63-5$ & 4,9-Dipropyldodecane & & 3 \\
\hline $3054-92-0$ & 2,3,4-Trimethyl-3-pentanol & & 2 \\
\hline $30692-16-1$ & 5-Tridecanone & & 9 \\
\hline
\end{tabular}


Table B.1. Compounds with a Positive Analytical Detect for Single-Shell Tank/ Double-Shell Tank Waste (1,227 Compounds). (Page 12 of 26)

\begin{tabular}{|c|c|c|c|}
\hline Sos & Constituent & $\begin{array}{l}\text { TWYiNS solidr } \\
\text { Liquid Hits }\end{array}$ & TWOKS Vapor \\
\hline $3073-66-3$ & 1,1,3-Trimethylcyclohexane & & 30 \\
\hline $3074-71-3$ & 2,3-Dimethylheptane & & 15 \\
\hline $31053-55-1$ & 2-Methoxy-5-methylthiophene & & 3 \\
\hline $31081-17-1$ & 2-Methyl-5-propylnonane & & $\mathrm{I}$ \\
\hline $31081-18-2$ & 3-Methyl-5-propylnonane & & 8 \\
\hline $311-89-7$ & Tri(perfluorobutyl)amine & & 1 \\
\hline $31295-56-4$ & 2,6,11-Trimethyldodecane & & 19 \\
\hline $31681-26-2$ & alpha-Propyl-2-furanacetaldehyde & & 2 \\
\hline $3178-29-8$ & 4-Propylheptane & & 2 \\
\hline $32064-72-5$ & 2-Nonen-4-one & & 3 \\
\hline $3221-61-2$ & 2-Methyloctane & & 4 \\
\hline $32281-85-9$ & 2-Isopropyl-1,3-dimethylcyclopentane & & 10 \\
\hline $32669-86-6$ & Cyclohexane, cyclopropyl- & & 8 \\
\hline $3290-53-7$ & 2-Methyl-3-phenylpropene & & 1 \\
\hline $33083-83-9$ & 5-Undecanone & & 9 \\
\hline $33342-89-1$ & 1-Propanone, 1-[4-[(trimethylsilyl)oxy]phenyl]- & & 1 \\
\hline $334-48-5$ & Decanoic acid & & 3 \\
\hline $33933-82-3$ & 5,9-Dimethyl-2-decanone & & 1 \\
\hline $34303-81-6$ & cis-3-Hexadecene & & 3 \\
\hline $34314-82-4$ & Furan, 3-(1,1-dimethylethyl)-2,3-dihydro- & & 4 \\
\hline $34379-54-9$ & Furan, 2,3-dihydro-4-(1-methylpropyl)-, (S)- & & 1 \\
\hline $3438-46-8$ & 4-Methyl-1,3-diazine & & 3 \\
\hline $3452-09-3$ & 1-Nonyne & & 4 \\
\hline $3457-90-7$ & 1,3-Propanediol, dinitrate & & 1 \\
\hline $3457-91-8$ & 1,4-Butanediol, dinitrate & & 6 \\
\hline $3457-92-9$ & 1,5-Pentanediol, dinitrate & & 7 \\
\hline $34883-39-1$ & 2,5-Dichlorobiphenyl & & 3 \\
\hline $3522-94-9$ & 2,2,5-Trimethylhexane & & 2 \\
\hline $3524-73-0$ & 5-Methyl-1-hexene & & 7 \\
\hline $35468-97-4$ & 1-Acetoxyhept-1-ene & & 3 \\
\hline $35507-09-6$ & cis-7-Hexadecene & & 10 \\
\hline $35996-97-5$ & Pentadecanoic acid, butyl ester & & 1 \\
\hline $3604-14-6$ & 1,2-Dimethyldecalin & & 3 \\
\hline $3622-84-2$ & Benzenesulfonamide, N-butyl- & & 123 \\
\hline $3638-35-5$ & 1-Isopropylcyclopropane & & 10 \\
\hline $36542-63-9$ & Dichlorohexane & 2 & 0 \\
\hline $3664-60-6$ & 7-Octen-2-one & & 4 \\
\hline $36653-82-4$ & n-Hexadecanol & & 30 \\
\hline $37050-03-6$ & 3,4-Nonadiene & & 3 \\
\hline $37148-64-4$ & $\begin{array}{l}\text { Benzeneacetic acid, .alpha.,4-bis[(trimethylsilyl)oxy]-, } \\
\text { trimethylsilyl ester }\end{array}$ & & 4 \\
\hline $3760-54-1$ & N-Formylpyrrolidine & & 2 \\
\hline $3760-63-2$ & $\mathrm{~N}, \mathrm{~N}$-Dimethyl-3-benzoylpropylamine & & 1 \\
\hline $3761-94-2$ & 1-Methylcycloheptanol & & 3 \\
\hline $3769-23-1$ & 4-Methyl-1-hexene & & 1 \\
\hline $3777-69-3$ & 2-Pentylfuran & & 3 \\
\hline $3777-71-7$ & 2-Heptylfuran & & 2 \\
\hline $3788-32-7$ & Isobutylcyclopentane & & 3 \\
\hline
\end{tabular}


Table B.1. Compounds with a Positive Analytical Detect for Single-Shell Tank/ Double-Shell Tank Waste (1,227 Compounds). (Page 13 of 26)

\begin{tabular}{|c|c|c|c|}
\hline cast & Constituent & $\begin{array}{l}\text { TWins Solid/ } \\
\text { Liquid Hits }\end{array}$ & TWINS Vapor \\
\hline $3789-85-3$ & Benzoic acid, 2-[(trimethylsilyl)oxy] - , trimethylsilyl ester & & 61 \\
\hline $3796-70-1$ & trans-6,10-Dimethyl-5,9-undecadien-2-one & & 1 \\
\hline $38165-93-4$ & $\begin{array}{l}\text { Propanedioic acid, [(trimethylsilyl)oxy]-, bis(trimethylsilyl) } \\
\text { ester }\end{array}$ & & 1 \\
\hline $38447-22-2$ & Hexanedioic acid, bis(1-methylpropyl) ester & & 1 \\
\hline $3879-26-3$ & cis-6,10-Dimethyl-5,9-undecadien-2-one & & 7 \\
\hline $38851-70-6$ & Cyclopropane, 1-butyl-2-methyl-, trans- & & 1 \\
\hline $3891-98-3$ & $2,6,10$-Trimethyldodecane & & 49 \\
\hline $3892-00-0$ & $2,6,10$-Trimethylpentadecane & & 12 \\
\hline $3913-02-8$ & 2-Butyloctanol & & 7 \\
\hline $3913-81-3$ & trans-2-Decenal & & 2 \\
\hline 39168-02-0 & Furan, tetrahydro-2,4-dimethyl-, trans- & & 3 \\
\hline $3944-36-3$ & 1-Isopropoxy-2-propanol & & 1 \\
\hline $39515-51-0$ & 3-Phenoxybenzaldehyde & & 2 \\
\hline $39899-08-6$ & 3-Methyl-3-hepten-2-one & & 1 \\
\hline $403-19-0$ & 2-Fluoro-4-nitrophenol & 6 & 0 \\
\hline $4032-86-4$ & 3,3-Dimethylheptane & & 1 \\
\hline $4032-93-3$ & 2,3,6-Trimethylheptane & & 6 \\
\hline $4050-45-7$ & trans-2-Hexene & & 4 \\
\hline $40702-26-9$ & 1,3,4-Trimethyl-3-cyclohexene-1-carboxaldehyde & & 3 \\
\hline $4088-60-2$ & cis-2-Butenol & & 4 \\
\hline $41239-48-9$ & 2,5-Diethyltetrahydrofuran & & 3 \\
\hline $41446-60-0$ & cis-7-Tetradecene & & 3 \\
\hline $41446-61-1$ & cis-6-Tetradecene & & 4 \\
\hline $41446-66-6$ & trans-5-Tetradecene & & 4 \\
\hline $41446-67-7$ & cis-3-Tetradecene & & 1 \\
\hline $41446-68-8$ & trans-3-Tetradecene & & 6 \\
\hline $41464-49-7$ & $2,3,3^{*}, 5^{\circ}$-Tetrachlorobiphenyl & & 6 \\
\hline $4170-30-3$ & 2-Butenaldehyde & & 37 \\
\hline $41744-75-6$ & 16-Methyl-1-heptadecanol & & 1 \\
\hline $4176-04-9$ & $\begin{array}{l}\text { Bicyclo[4.1.0]heptan-3-one, 4,7,7-trimethyl-, [1R- } \\
\text { (1.alpha.,4.alpha.,6.alpha.)]- }\end{array}$ & & 1 \\
\hline $4179-38-8$ & 2-Octylfuran & & 4 \\
\hline $41977-32-6$ & Cyclopropane, 1,2-dibutyl- & & 3 \\
\hline $41977-33-7$ & Cyclopropane, 1-pentyl-2-propyl- & & 2 \\
\hline $41977-34-8$ & Cyclopropane, 1-butyl-1-methyl-2-propyl- & & 4 \\
\hline $41977-43-9$ & Cyclopropane, 1,1,2-trimethyl-3-(2-methylpropyl)- & & 4 \\
\hline $41977-48-4$ & Bicyclo[4.1.0]heptane, 3-methyl-7-pentyl- & & 3 \\
\hline $420-56-4$ & Fluorotrimethylsilane & & 1 \\
\hline $421-50-1$ & 1,1,1-Trifluoro-2-propanone & & 1 \\
\hline $4229-91-8$ & 2-Propylfuran & & 4 \\
\hline $4254-15-3$ & (S)-1,2-Propanediol & & 3 \\
\hline $42565-49-1$ & 2,2,6,6-Tetramethyl-10-undecen-4-one & & 3 \\
\hline 42604-04-6 & Cycloheptane, methoxy- & & 1 \\
\hline $4272-06-4$ & 4-Undecanol & & 3 \\
\hline $42786-06-1$ & 4H-1,2,4-Triazol-3-amine, 4-ethyl- & & 2 \\
\hline $4291-79-6$ & 1-Methyl-2-propylcyclohexane & & 6 \\
\hline $4291-80-9$ & 1-Methyl-3-propylcyclohexane & & 8 \\
\hline
\end{tabular}


Table B.1. Compounds with a Positive Analytical Detect for Single-Shell Tank/ Double-Shell Tank Waste (1,227 Compounds). (Page 14 of 26)

\begin{tabular}{|c|c|c|c|}
\hline SAS\# & Constituent: & $\begin{array}{l}\text { TWins Solidy } \\
\text { Liquid Hits }\end{array}$ & TWINS Vapor \\
\hline $4292-75-5$ & n-Hexylcyclohexane & & 35 \\
\hline $4292-92-6$ & Pentylcyclohexane & & 53 \\
\hline $4312-99-6$ & Pentyl vinyl ketone & & 2 \\
\hline $4316-65-8$ & 3,5,5-Trimethyl-1-hexene & & 1 \\
\hline $4337-65-9$ & Hexanedioic acid, mono(2-ethylhexyl) ester & & 1 \\
\hline $4342-25-0$ & 3,6-Dioxa-2,4,5,7-tetrasilaoctane, $2,2,4,4,5,5,7,7$-octamethyl- & & 3 \\
\hline $4390-04-9$ & $2,2,4,4,6,8,8$-Heptamethylnonane & & 3 \\
\hline $4457-62-9$ & 2,5-Dipropyltetrahydrofuran & & 3 \\
\hline $4485-09-0$ & 4-Nonanone & & 2 \\
\hline $4485-13-6$ & 4-Propyl-3-heptene & & 1 \\
\hline $4516-69-2$ & 1,1,3-Trimethylcyclopentane & & 5 \\
\hline $4536-87-2$ & 3-Phenylundecane & & 1 \\
\hline $4536-88-3$ & 2-Phenylundecane & & 4 \\
\hline $4537-15-9$ & 5-Phenylundecane & & 3 \\
\hline $4551-51-3$ & cis-Hexahydroindan & & 3 \\
\hline $4573-09-5$ & 2,2,5-Trimethylcyclopentanone & & 2 \\
\hline $460-13-9$ & 1-Fluoropropane & & 1 \\
\hline $463-82-1$ & 2,2-Dimethylpropane & & 13 \\
\hline $4631-98-5$ & Cyclohexanol, 4-(1,1,3,3-tetramethylbutyl)- & & 4 \\
\hline $470-65-5$ & Cyclohexanol, 4-methyl-1-(1-methylethyl)- & & 3 \\
\hline $4737-43-3$ & (1-Methylbutyl)cyclopentane & & 5 \\
\hline $4786-20-3$ & 2-Butenenitrile & & 4 \\
\hline $4799-62-6$ & 5-Methoxy-1-pentanol & & 1 \\
\hline $4806-61-5$ & Ethylcyclobutane & & 1 \\
\hline $4810-09-7$ & 3-Methyl-1-heptene & & 2 \\
\hline $4826-62-4$ & 2-Dodecenal & & 1 \\
\hline $4850-28-6$ & cis,trans-1,2,4-Trimethylcyclopentane & & 9 \\
\hline $486-25-9$ & Fluorenone & & 1 \\
\hline $4866-55-1$ & Cyclopropane, 1,2-dimethyl-3-methylene-, cis- & & 4 \\
\hline $489-20-3$ & Cyclopentane, 1-isopropyl-2,3-dimethyl- & & 6 \\
\hline $4911-70-0$ & 2,3-Dimethyl-2-pentanol & & 6 \\
\hline $4923-77-7$ & cis-1-Ethyl-2-methylcyclohexane & & 4 \\
\hline $4926-78-7$ & cis-1-Ethyl-4-methylcyclohexane & & 14 \\
\hline $493-02-7$ & trans-Decalin & 5 & 49 \\
\hline $4941-53-1$ & 5-Undecene & & 34 \\
\hline $49622-16-4$ & 2,5-Dimethyl-2-undecene & & 1 \\
\hline $50-00-0$ & Formaldehyde & & 3 \\
\hline $502-56-7$ & 5-Nonanone & & 6 \\
\hline $502-69-2$ & 6,10,14-Trimethyl-2-pentadecanone & & 3 \\
\hline $5026-76-6$ & 6-Methyl-1-heptene & & 2 \\
\hline $504-60-9$ & 1,3-Pentadiene & & 4 \\
\hline $5049-61-6$ & Aminopyrazine & 4 & 0 \\
\hline $505-57-7$ & 2-Hexenal & & 2 \\
\hline $50639-02-6$ & 2-Methyl-5-undecanone & & 26 \\
\hline $50746-53-7$ & trans-1-Allyl-2-methylcyclopentane & & 1 \\
\hline $50876-31-8$ & Cyclohexane, $1,1,3,5$-tetramethyl-, trans- & & 2 \\
\hline $50876-32-9$ & Cyclohexane, $1,1,3,5$-tetramethyl-, cis- & & 5 \\
\hline $50915-91-8$ & 1-Butyl-2-ethylcyclopropene & & 4 \\
\hline
\end{tabular}


Table B.1. Compounds with a Positive Analytical Detect for Single-Shell Tank Double-Shell Tank Waste (1,227 Compounds). (Page 15 of 26)

\begin{tabular}{|c|c|c|c|}
\hline CAst & Constituent & $\begin{array}{l}\text { TWINS Solid' } \\
\text { Liquid Hits }\end{array}$ & $\begin{array}{c}\text { TWINS Vapor } \\
\text { Hits }\end{array}$ \\
\hline $50991-08-7$ & 1,1'-Bicyclohexyl, 2-methyl-, cis- & & 3 \\
\hline $50991-09-8$ & 1,1'-Bicyclohexyl, 2-methyl-, trans- & & 1 \\
\hline $5115-98-0$ & 3-Piperidinecarboxamide, N-methyl- & & 3 \\
\hline $512-85-6$ & 2,3-Dioxabicyclo[2.2.2]oct-5-ene, 1-methyl-4-(1-methylethyl)- & & 1 \\
\hline $51284-29-8$ & Cyclohexane, (1,2-dimethylpropyl)- & & 1 \\
\hline $513-35-9$ & 2-Methyl-2-butene & & 3 \\
\hline $513-81-5$ & 2,3-Dimethyl-1,3-butadiene & & 4 \\
\hline $51411-24-6$ & 6,10-Dodecadien-1-ol, 3,7,11-trimethyl- & & 1 \\
\hline $5145-01-7$ & 2(3H)-Furanone, dihydro-3,5-dimethyl- & & 3 \\
\hline $51595-87-0$ & 2-Heptanone, 6-(2-furanyl)-6-methyl- & & 2 \\
\hline $5166-53-0$ & 5-Methyl-3-hexen-2-one & & 3 \\
\hline $5171-86-8$ & 3,3,4,4-Tetraethyl hexane & & 1 \\
\hline $51953-17-4$ & 4(3H)-Pyrimidinone & & 3 \\
\hline $5204-80-8$ & 2-Ethyl-4-pentenal & & 1 \\
\hline $5205-34-5$ & 5-Decanol & & 3 \\
\hline $52588-78-0$ & 3,4-Undecadiene-2,10-dione, 6,6-dimethyl- & & 1 \\
\hline $526-73-8$ & 1,2,3-Trimethylbenzene & & 2 \\
\hline $52663-58-8$ & $2,3,4^{2}, 6-$ Tetrachlorobiphenyl & & 4 \\
\hline $527-84-4$ & 1-Isopropyl-2-methylbenzene & & 1 \\
\hline $52896-87-4$ & 4-Isopropylheptane & & 2 \\
\hline $52896-90-9$ & 3-Ethyl-5-methylheptane & & 3 \\
\hline $53229-39-3$ & Oxirane, (1-methylbutyl)- & 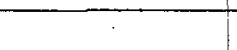 & 3 \\
\hline $53366-38-4$ & (2-Methylbutyl)cyclopentane & & 4 \\
\hline $53398-83-7$ & Butanoic acid, trans-2-hexenyl ester & & 4 \\
\hline $534-22-5$ & 2-Methylfuran & & 2 \\
\hline $535-77-3$ & 1-Isopropyl-3-methylbenzene & & $\overline{2}$ \\
\hline $53535-33-4$ & Heptanol & & 3 \\
\hline $5364-83-0$ & 1-Cyclohexyl-1-propene & & 2 \\
\hline $538-68-1$ & n-Pentylbenzene & & 2 \\
\hline $53833-32-2$ & 2-n-Propyl-4,5-dimethyloxazole & & 8 \\
\hline $53907-60-1$ & cis-1,1,3,4-Tetramethylcyclopentane & & 1 \\
\hline $53907-75-8$ & 2-Methyl-2-pentyloxirane & & 1 \\
\hline $540-97-6$ & Dodecamethylcyclohexasiloxane & 1 & 0 \\
\hline $54004-41-0$ & 4-Methyl-2-propylpentanol & & 1 \\
\hline $541-01-5$ & Heptasiloxane, hexadecamethyl- & & 3 \\
\hline $541-02-6$ & Decamethlycyclopentasiloxane & 1 & 0 \\
\hline $541-05-9$ & Cyclotrisiloxane, hexamethyl- & & 182 \\
\hline $541-35-5$ & n-Butylamide & 4 & 7 \\
\hline $541-73-1$ & 1,3-Dichlorobenzene & & 57 \\
\hline $542-44-9$ & Hexadecanoic acid, 2,3-dihydroxypropyl ester & & 2 \\
\hline $542-55-2$ & Formic acid, 2-methylpropyl ester & & 2 \\
\hline $54244-79-0$ & 5-Methyl-1-decene & & 3 \\
\hline $543-29-3$ & Isobutyl nitrate & & 1 \\
\hline $543-49-7$ & 2-Heptanol & & 6 \\
\hline $543-87-3$ & 3-Methylbutyl nitrate & & 8 \\
\hline $544-16-1$ & n-Butyl nitrite & & 10 \\
\hline $544-63-8$ & n-Tetradecanoic acid & & 60 \\
\hline $544-76-3$ & n-Hexadecane & 2 & 77 \\
\hline
\end{tabular}


Table B.1. Compounds with a Positive Analytical Detect for Single-Shell Tank/ Double-Shell Tank Waste (1,227 Compounds). (Page 16 of 26)

\begin{tabular}{|c|c|c|c|}
\hline CASH & Constituent & TWins Solid/ & TWuS Wapor \\
\hline $54411-00-6$ & Cyclohexane, 1-methyl-4-(1-methylbutyl)- & & 11 \\
\hline $54411-01-7$ & 1-Methyl-2-pentylcyclohexane & & 8 \\
\hline $54411-02-8$ & Cyclohexane, 1-methyl-3-pentyl- & & 6 \\
\hline $5454-28-4$ & Heptanoic acid, butyl ester & & 3 \\
\hline $54549-80-3$ & Cyclopentane, 2-ethyl-1,1-dimethyl- & & 1 \\
\hline $5458-16-2$ & Pentane, 2-cyclopropyl- & & 1 \\
\hline $54658-01-4$ & 3-Methoxyhexane & & 7 \\
\hline $54676-39-0$ & Cyclohexane, 2-butyl-1,1,3-trimethyl- & & 49 \\
\hline $54774-28-6$ & 2-Furanmethanol, tetrahydro-5-methyl-, trans- & & 1 \\
\hline 54823-94-8 & Cyclohexane, 1-(cyclohexylmethyl)-2-methyl-, trans- & & 3 \\
\hline $54823-98-2$ & Cyclohexane, 1-(cyclohexylmethyl)-4-methyl-, trans- & & 4 \\
\hline 54824-04-3 & Cyclohexane, 1-(cyclohexylmethyl)-2-methyl-, cis- & & 1 \\
\hline $54832-83-6$ & 1H-Indene, octahydro-2,2,4,4,7,7-hexamethyl-, trans- & & 3 \\
\hline $54833-48-6$ & $2,6,10,15$-Tetramethylheptadecane & & 1 \\
\hline $54845-26-0$ & 3-Heptene, $2,2,3,5,5,6,6$-heptamethyl- & & 4 \\
\hline $54845-28-2$ & trans-2-hexenyl ester-2-hexenoic acid & & 1 \\
\hline $54934-90-6$ & Cyclohexane, $1,1^{\prime}-(1-$-methylethylidene $)$ bis- & & 3 \\
\hline $54934-93-9$ & Cyclohexane, 1-(cyclohexylmethyl)-2-ethyl-, cis- & & 7 \\
\hline 54934-95-1 & Cyclohexane, 1-(cyclohexylmethyl)-4-ethyl-, cis- & & 3 \\
\hline $54965-05-8$ & Cyclohexane, 1,1,3-trimethyl-2-(3-methylpentyl)- & & 15 \\
\hline $5500-21-0$ & Cyclopropylnitrile & & 4 \\
\hline $55030-62-1$ & 4,8-Dimethyltridecane & & 25 \\
\hline $55045-07-3$ & 2-Methyl-8-propyldodecane & & 22 \\
\hline $55045-08-4$ & 2-Methyl-6-propyldodecane & & 13 \\
\hline $55045-11-9$ & 5-Propyltridecane & & 13 \\
\hline $55045-12-0$ & 4,11-Dimethyltetradecane & & 8 \\
\hline $55045-13-1$ & 6,9-Dimethyltetradecane & & 1 \\
\hline $55045-14-2$ & 4-Ethyltetradecane & & 1 \\
\hline $55170-92-8$ & 2-Undecene, 4,5-dimethyl-, $\left[\mathrm{R}^{*}, \mathrm{R}^{*}\right.$-(E)]- & & 1 \\
\hline $55282-34-3$ & 2,4,6-Trimethyl-1-n-octadecylcyclohexane & & 3 \\
\hline $55334-40-2$ & $\begin{array}{l}\text { Benzeneacetic acid, alpha.,4-bis[(trimethylsilyl)oxy]-, methyl } \\
\text { ester }\end{array}$ & & 4 \\
\hline $55373-86-9$ & 7-Hexyldocosane & & 1 \\
\hline $55429-85-1$ & $\begin{array}{l}\text { Benzeneethanamine, } \mathrm{N}-[(\text { pentafluorophenyl)methylene]- } \\
\text { beta.,4-bis[(trimethylsilyl)oxy]- }\end{array}$ & & 1 \\
\hline 55494-10-5 & 2-Hexenedioic acid, bis(trimethylsilyl) ester, (E)- & & 1 \\
\hline $556-67-2$ & Octamethylcyclotetrasiloxane & & 199 \\
\hline $55702-46-0$ & 2,3,4-Trichlorobiphenyl & & 3 \\
\hline $55702-61-9$ & 4,4,5-Trimethyl-2-hexene & & 3 \\
\hline $558-37-2$ & 3,3-Dimethyl-1-butene. & & 2 \\
\hline $55937-92-3$ & Bicyclo[4.1.0]heptane, 2-methyl-7-pentyl- & & 1 \\
\hline $55956-20-2$ & 2-Oxazolidinone, 3-allyl-5-methyl- & & 10 \\
\hline $56-23-5$ & Carbon tetrachloride & & 181 \\
\hline $560-21-4$ & 2,3,3-Trimethylpentane & & 4 \\
\hline $56052-85-8$ & 2-Pentene, 5-(pentyloxy)-, (E)- & & 2 \\
\hline $56052-94-9$ & cis-3,4-Epoxyheptane & & 3 \\
\hline $562-49-2$ & 3,3-Dimethylpentane & & 7 \\
\hline $56292-65-0$ & 2,5-Dimethyldodecane & & 24 \\
\hline
\end{tabular}


Table B.1. Compounds with a Positive Analytical Detect for Single-Shell Tank Double-Shell Tank Waste (1,227 Compounds). (Page 17 of 26)

\begin{tabular}{|c|c|c|c|}
\hline CAst & Constituent & $\begin{array}{l}\text { TWINS Solid/ } \\
\text { Liquid Hits }\end{array}$ & $\begin{array}{l}\text { TWINS Yapor } \\
\text { Hits }\end{array}$ \\
\hline $56292-66-1$ & 2,5-Dimethyltridecane & & 2 \\
\hline $56292-69-4$ & 2,5-Dimethyltetradecane & & 2 \\
\hline $563-45-1$ & 3-Methyl-1-butene & & 11 \\
\hline $563-46-2$ & 2-Methyl-1-butene & & 6 \\
\hline $563-78-0$ & 2,3-Dimethyl-1-butene & & 4 \\
\hline $563-79-1$ & 2,3-Dimethyl-2-butene & & 4 \\
\hline $563-80-4$ & 3-Methyl-2-butanone & & 34 \\
\hline $565-59-3$ & 2,3-Dimethylpentane & & 64 \\
\hline $565-61-7$ & 3-Methyl-2-pentanone & & 11 \\
\hline $565-67-3$ & 2-Methyl-3-pentanol & & 3 \\
\hline $565-69-5$ & 2-Methyl-3-pentanone & & 9 \\
\hline $565-80-0$ & 2,4-Dimethyl-3-pentanone & & 2 \\
\hline $56554-96-2$ & 2-Octadecenal & & 2 \\
\hline $56728-10-0$ & 3,4,5-Trimethyl-1-hexene & & 3 \\
\hline $5675-51-4$ & 1,12-Dodecanediol & & 1 \\
\hline $56851-45-7$ & 4-Methyl-2-dodecene & & 2 \\
\hline $57-10-3$ & n-Hexadecanoic acid & 3 & 67 \\
\hline $57-11-4$ & n-Octadecanoic acid & & 1 \\
\hline $57-14-7$ & 1,1-Dimethylhydrazine & & 6 \\
\hline $57-55-6$ & 1,2-Propanediol & & 23 \\
\hline $5715-25-3$ & 4,5-Dimethylcyclohexen-2-one & & 3 \\
\hline $5746-58-7$ & Tetradecanoic acid, 12-methyl-, (S)- & & 6 \\
\hline $575-37-1$ & 1,7-Dimethylnaphthalene & & 2 \\
\hline $5756-43-4$ & Ethyl n-hexyl ether & & 1 \\
\hline $57706-88-4$ & 3-Octanol, 3,7-dimethyl-, (.+-.)- & & 2 \\
\hline $578-54-1$ & 2-Ethylaniline & & 3 \\
\hline $57905-86-9$ & 1,1,2,3,3-Pentamethylcyclobutane & & 1 \\
\hline $581-40-8$ & 2,3-Dimethylnaphthalene & & .1 \\
\hline $583-57-3$ & 1,2-Dimethylcyclohexane & & 3 \\
\hline $583-58-4$ & 3,4-Dimethylpyridine & & 1 \\
\hline $584-94-1$ & 2,3-Dimethylhexane & & 10 \\
\hline $585-74-0$ & 3 -Methylacetophenone & & 2 \\
\hline $5857-36-3$ & 2,2,4-Trimethyl-3-pentanone & & 6 \\
\hline $589-34-4$ & 3-Methylhexane & & 84 \\
\hline $589-38-8$ & 3-Hexanone & & 49 \\
\hline $589-43-5$ & 2,4-Dimethylhexane & & 68 \\
\hline $589-53-7$ & 4-Methylheptane & & 5 \\
\hline $589-63-9$ & 4-Octanone & & 17 \\
\hline $589-81-1$ & 3-Methylheptane & & 52 \\
\hline $589-82-2$ & 3-Heptanol & & 47 \\
\hline $589-90-2$ & 1,4-Dimethylcyclohexane & & 54 \\
\hline $589-93-5$ & 2,5-Dimethylpyridine & & 3 \\
\hline $59-50-7$ & 4-Chloro-3-methylphenol & 1 & \\
\hline $59-89-2$ & N-Nitrosomorpholine & 3 & 1 \\
\hline $590-01-2$ & Propionic acid, butyl ester & & 4 \\
\hline $590-18-1$ & cis-2-Butene & & 2 \\
\hline $590-36-3$ & 1,1-Dimethylbutanol & & 17 \\
\hline $590-50-1$ & 4,4-Dimethyl-2-pentanone & & 38 \\
\hline
\end{tabular}


Table B.1. Compounds with a Positive Analytical Detect for Single-Shell Tank/ Double-Shell Tank Waste (1,227 Compounds). (Page 18 of 26)

\begin{tabular}{|c|c|c|c|}
\hline CAst & Constituent & $\begin{array}{l}\text { Twons solid/ } \\
\text { Liquid Hits: }\end{array}$ & TWNS Vapor \\
\hline $590-66-9$ & 1,1-Dimethylcyclohexane & & $\frac{2}{2}$ \\
\hline $590-86-3$ & 3-Methylbutanal & & 4 \\
\hline $591-24-2$ & 3-Methylcyclohexanone & & 3 \\
\hline $591-76-4$ & 2-Methylhexane & & 61 \\
\hline $591-78-6$ & 2-Hexanone & 11 & 248 \\
\hline $591-87-7$ & Acetic acid, 2-propenyl ester & & 1 \\
\hline 591-95-7 & 1,2-Pentadiene & & 4 \\
\hline $5910-87-2$ & trans,trans-2,4-Nonadienal & & 3 \\
\hline $5910-89-4$ & 2,3-Dimethylpyrazine & & 4 \\
\hline $5911-04-6$ & 3-Methylnonane & & 3 \\
\hline $592-13-2$ & 2,5-Dimethylhexane & & 13 \\
\hline $592-27-8$ & 2-Methylheptane & & 19 \\
\hline $592-41-6$ & 1-n-Hexene & & 49 \\
\hline $592-42-7$ & 1,5-Hexadiene & & 4 \\
\hline $592-45-0$ & 1,4-Hexadiene & & 12 \\
\hline $592-76-7$ & 1-n-Heptene & & 31 \\
\hline $592-77-8$ & 2-Heptene & & 13 \\
\hline $592-78-9$ & 3-Heptene & & 3 \\
\hline $592-84-7$ & Formic acid, butyl ester & & 5 \\
\hline $592-98-3$ & 3-Octene & & 1 \\
\hline $593-08-8$ & 2-Tridecanone & & 31 \\
\hline $593-45-3$ & n-Octadecane & & 10 \\
\hline $594-11-6$ & Methylcyclopropane & & 2 \\
\hline $594-70-7$ & 2-Methyl-2-nitropropane & & 54 \\
\hline $594-82-1$ & $2,2,3,3-$ Tetramethylbutane & & 7 \\
\hline $59681-06-0$ & $\begin{array}{l}2,6,10,14,18,22 \text {-Tetracosahexaene, } 2,6,10,19,23 \text {-pentamethyl-, } \\
\text { (all-E)- }\end{array}$ & & 1 \\
\hline 598-32-3 & 2-Hydroxy-3-butene & & 22 \\
\hline $598-58-3$ & Methyl nitrate & & 26 \\
\hline $598-61-8$ & 1-Methylcyclobutane & & 2 \\
\hline $5989-27-5$ & (R)-4-Isopropenyl-1-methyl-1-cyclohexene & & 1 \\
\hline $599-70-2$ & Ethyl phenyl sulfone & & 4 \\
\hline $59983-39-0$ & (S)-1-Amino-2-(methoxymethyl)pyrrolidine & & 1 \\
\hline $60-00-4$ & Ethylene diamine tetraacetic acid (EDTA) & 13 & \\
\hline $60-34-4$ & Methylhydrazine & & 3 \\
\hline $60-35-5$ & Acetamide & & 3 \\
\hline $600-14-6$ & 2,3-Pentanedione & & 1 \\
\hline $600-24-8$ & 2-Nitrobutane & & 2 \\
\hline $6031-02-3$ & 2-Phenylhexane & & 1 \\
\hline $6032-29-7$ & 1-Methylbutanol & & 10 \\
\hline $6044-71-9$ & 6-Methyldodecane & & 9 \\
\hline $6064-27-3$ & 6-Dodecanone & & 27 \\
\hline $60643-93-8$ & 3-Hexene, 2,3,4,5-tetramethyl-, (Z)- & & 5 \\
\hline $6069-98-3$ & 1-Methyl-cis-4-isopropylcyclohexane & & 10 \\
\hline $608-25-3$ & 2,6-Dihydroxytoluene & & 2 \\
\hline $608-33-3$ & 2,6-Dibromophenol & 2 & 0 \\
\hline $609-26-7$ & 2-Methyl-3-ethylpentane & & 4 \\
\hline $6094-02-6$ & 2-Methyl-1-hexene & & 1 \\
\hline
\end{tabular}


Table B.1. Compounds with a Positive Analytical Detect for Single-Shell Tank/ Double-Shell Tank Waste (1,227 Compounds). (Page 19 of 26)

\begin{tabular}{|c|c|c|c|}
\hline s.s\# & Constituent & $\begin{array}{l}\text { TWINS Solid/ } \\
\text { Liquid Hits }\end{array}$ & TWINS Vapor \\
\hline $611-14-3$ & 2-Ethyltoluene & & 172 \\
\hline $61141-57-9$ & Cyclohexene, 1-ethyl-6-ethylidene- & & 2 \\
\hline $61141-72-8$ & 4,6-Dimethyldodecane & 2 & 24 \\
\hline $61141-79-5$ & Cyclohexane, 1,2-diethyl-1-methyl- & & 9 \\
\hline $61141-80-8$ & Cyclohexane, 1,2-diethyl-3-methyl- & & 12 \\
\hline $61142-20-9$ & Cyclohexane, (4-methylpentyl)- & & 13 \\
\hline $61142-23-2$ & Cyclohexane, (2,2-dimethylcyclopentyl)- & & 10 \\
\hline $61142-24-3$ & $\begin{array}{l}\text { Cyclohexane, 1,2,4,5-tetraethyl-, } \\
\text { (1.alpha.,2.alpha.,4.alpha.,5.alpha.)- }\end{array}$ & & 2 \\
\hline $61142-37-8$ & Cyclohexane, (1,2-dimethylbutyl)- & & 2 \\
\hline $61142-38-9$ & Cyclohexane, (3-methylpentyl)- & & 1 \\
\hline $61142-40-3$ & 4-Undecene, 4-methyl- & & 6 \\
\hline $61142-41-4$ & Cyclooctane, ethenyl- & & 3 \\
\hline $61142-47-0$ & 2-Pentene, 2-methoxy- & & 2 \\
\hline $61142-66-3$ & Cyclopentene, 5-hexyl-3,3-dimethyl- & & 3 \\
\hline $61142-68-5$ & Cyclopentane, 1-hexyl-3-methyl- & & 11 \\
\hline $61142-70-9$ & Cyclohexane, 2,4-diethyl-1-methyl- & & 11 \\
\hline $6117-97-1$ & 4-Methyldodecane & & 47 \\
\hline $613-93-4$ & N-Methylbenzamide & & 1 \\
\hline $6137-06-0$ & 4-Methyl-2-heptanone & & 6 \\
\hline $6137-12-8$ & 4-Ethyl-3-hexanone & & 1 \\
\hline $6137-26-4$ & 4-Dodecanone & & 3 \\
\hline $614-99-3$ & 2-Furancarboxylic acid, ethyl ester & $\overline{4}$ & 0 \\
\hline $616-45-5$ & 2-Pyrrolidinone & 4 & 2 \\
\hline $617-29-8$ & 2-Methyl-3-hexanol & & 3 \\
\hline $617-78-7$ & 3-Ethylpentane & & 1 \\
\hline $617-94-7$ & 2-Phenyl-2-propanol & & $\overline{22}$ \\
\hline $6175-49-1$ & 2-Dodecanone & & 6 \\
\hline $61886-62-2$ & 3-Hexadecyne & & 3 \\
\hline $62-75-9$ & N-Nitroso-N,N-dimethylamine & & 62 \\
\hline $620-14-4$ & 3-Ethyltoluene & & 1 \\
\hline $62016-14-2$ & Octane, 2,5,6-trimethyl- & & 4 \\
\hline $62016-18-6$ & Octane, 5-ethyl-2-methyl- & & 3 \\
\hline $62016-19-7$ & Octane, 6-ethyl-2-methyl- & & 13 \\
\hline $62016-30-2$ & Octane, 2,3,3-trimethyl- & & 2 \\
\hline $62016-34-6$ & Octane, 2,3,7-trimethyl- & & 10 \\
\hline $62016-37-9$ & $2,4,6$-Trimethyloctane & & 24 \\
\hline $621-64-7$ & N-Nitroso-di-n-propylamine & 1 & \\
\hline $62108-21-8$ & 6-Ethyl-2-methyldecane & & 1 \\
\hline $62108-25-2$ & Decane, 2,6,7-trimethyl- & & 14 \\
\hline $62108-26-3$ & 2,6,8-Trimethyldecane & & 3 \\
\hline $62108-27-4$ & Decane, $2,4,6$-trimethyl- & & 6 \\
\hline $62108-31-0$ & Heptane, 4-ethyl-2,2,6,6-tetramethyl- & & 3 \\
\hline $62183-55-5$ & Octane, 3-ethyl-2,7-dimethyl- & & 1 \\
\hline $62185-53-9$ & Nonane, 5-(2-methylpropyl)- & & 5 \\
\hline $62199-50-2$ & Cyclopentane, 1-butyl-2-propyl- & & 1 \\
\hline $62199-51-3$ & Cyclopentane, 1-pentyl-2-propyl- & & 9 \\
\hline $622-96-8$ & 4-Ethyltoluene & & 4 \\
\hline
\end{tabular}


Table B.1. Compounds with a Positive Analytical Detect for Single-Shell Tank/ Double-Shell Tank Waste (1,227 Compounds). (Page 20 of 26)

\begin{tabular}{|c|c|c|c|}
\hline CASH & Constituent & $\begin{array}{l}\text { TWINS solid } \\
\text { Liquid Hits }\end{array}$ & TWiNS Vapor \\
\hline $62237-96-1$ & Decane, 2,2,5-trimethyl- & & 24 \\
\hline $62237-97-2$ & Decane, $2,2,6$-trimethyl- & & 3 \\
\hline $62238-01-1$ & 2,2,8-Trimethyldecane & & 1 \\
\hline $62238-08-8$ & Cyclopropane, 1-ethyl-2-pentyl- & & 3 \\
\hline $62238-11-3$ & $2,3,5$-Trimethyldecane & & 3 \\
\hline $62238-12-4$ & Decane, 2,3,6-trimethyl- & & 16 \\
\hline $62238-13-5$ & Decane, 2,3,7-trimethyl- & & 9 \\
\hline $62238-14-6$ & Decane, 2,3,8-trimethyl- & & 6 \\
\hline $62238-33-9$ & Cyclohexane, 1-ethyl-2-propyl- & & 6 \\
\hline $623-37-0$ & 3-Hexanol & & 3 \\
\hline $623-56-3$ & 2-Methyl-4-hexanone & & 2 \\
\hline $623-87-0$ & 1,3-Glyceryl dinitrate & & 1 \\
\hline $62338-08-3$ & 3-Hexene, 3-ethyl-2,5-dimethyl- & & 5 \\
\hline $62338-09-4$ & 2,2,3-Trimethyldecane & & 3 \\
\hline $62338-45-8$ & Bicyclo[2.2.2]octane, 1,2,3,6-tetramethy]- & & 1 \\
\hline $62338-47-0$ & 4-Decene, 3-methyl-, (E)- & & 3 \\
\hline $6236-88-0$ & trans-1-Ethyl-4-methylcyclohexane & & 8 \\
\hline $624-16-8$ & 4-Decanone & & 6 \\
\hline $624-42-0$ & 6-Methyl-3-heptanone & & 7 \\
\hline $624-43-1$ & Glyceryl 1-nitrate & & 1 \\
\hline $624-64-6$ & trans-2-Butene & & 2 \\
\hline $624-83-9$ & Methyl isocyanate & & 1 \\
\hline $624-91-9$ & Nitrous acid, methyl ester & & 47 \\
\hline $624-95-3$ & 3,3-Dimethylbutanol & & 3 \\
\hline $625-25-2$ & 2-Methyl-2-heptanol & & 4 \\
\hline $625-58-1$ & Nitric acid, ethyl ester & & 89 \\
\hline $625-65-0$ & 2,4-Dimethyl-2-pentene & & 6 \\
\hline $625-74-1$ & 2-Methyl-1-nitropropane & & 1 \\
\hline $625-84-3$ & 2,5-Dimethylpyrrole & & 1 \\
\hline $625-86-5$ & 2,5-Dimethylfuran & & 1 \\
\hline $626-97-1$ & Pentanamide & 4 & 0 \\
\hline $627-05-4$ & 1-Nitrobutane & & 12 \\
\hline $627-13-4$ & Nitric acid, propyl ester & & 72 \\
\hline $627-20-3$ & cis-2-Pentene & & 13 \\
\hline $627-27-0$ & 3-Butene-1-ol & & 2 \\
\hline $627-59-8$ & 5-Methyl-2-hexanol & & 3 \\
\hline $628-28-4$ & Methyl butyl ether & & 3 \\
\hline $628-44-4$ & 2-Methyl-2-octanol & & 3 \\
\hline $628-61-5$ & 2-Chlorooctane & & 1 \\
\hline $628-73-9$ & n-Hexanenitrile & & 438 \\
\hline $628-80-8$ & Methyl pentyl ether & & 4 \\
\hline $6281-96-5$ & N-Isobutylformamide & & 1 \\
\hline $629-08-3$ & n-Heptanenitrile & & 142 \\
\hline $629-23-2$ & 3-Tetradecanone & & 8 \\
\hline $629-50-5$ & n-Tridecane & 106 & 654 \\
\hline $629-54-9$ & n-Hexadecanamide & & 1 \\
\hline $629-59-4$ & n-Tetradecane & 155 & 538 \\
\hline 629-60-7 & Tridecanenitrile & & 1 \\
\hline
\end{tabular}


Table B.1. Compounds with a Positive Analytical Detect for Single-Shell Tank/ Double-Shell Tank Waste (1,227 Compounds). (Page 21 of 26)

\begin{tabular}{|c|c|c|c|}
\hline SAst & Constituent & $\begin{array}{l}\text { TWINS Solid/ } \\
\text { Liquid Hits }\end{array}$ & TWINS Vapor \\
\hline $629-62-9$ & n-Pentadecane & 120 & 146 \\
\hline $629-70-9$ & Hexadecyl acetate & & 4 \\
\hline $629-73-2$ & I-n-Hexadecene & & 10 \\
\hline $629-76-5$ & n-Pentadecanol & & 1 \\
\hline $629-78-7$ & n-Heptadecane & 2 & 65 \\
\hline $629-80-1$ & Hexadecanaldehyde & & 1 \\
\hline $629-89-0$ & 1-Octadecyne & & 3 \\
\hline $629-92-5$ & n-Nonadecane & & 3 \\
\hline $629-94-7$ & n-Heneicosane & & 1 \\
\hline $6295-06-3$ & Glyoxylic acid, butyl ester & & 2 \\
\hline $630-01-3$ & n-Hexacosane & & 1 \\
\hline $630-18-2$ & 2,2-Dimethylpropanenitrile & & 8 \\
\hline $630-19-3$ & 2,2-Dimethylpropionaldehyde & & 10 \\
\hline $6304-50-3$ & $2,2,4,9,11,11$-hexamethyl-Dodecane & & 1 \\
\hline $6305-52-8$ & 2-butyldecahydro-Naphthalene & & 3 \\
\hline $637-50-3$ & 1-Phenylpropene & & 3 \\
\hline $637-64-9$ & Tetrahydrofurfuryl acetate & & 3 \\
\hline $637-88-7$ & 1,4-Cyclohexanedione & & 3 \\
\hline $637-92-3$ & Ethyl tert-butyl ether & & 1 \\
\hline $638-04-0$ & cis-1,3-Dimethylcyclohexane & & 9 \\
\hline $638-36-8$ & $2,6,10,14$-Tetramethylhexadecane & & 13 \\
\hline $63830-68-2$ & 4-Nonene, 2,3,3-trimethyl-, (Z)- & & 7 \\
\hline $64-17-5$ & Ethyl alcohol & & 552 \\
\hline $64-18-6$ & Formic acid & 360 & 0 \\
\hline $64-19-7$ & Acetic acid & & 56 \\
\hline $6418-41-3$ & 3-Methyltridecane & & 24 \\
\hline $6418-43-5$ & 3-Methylhexadecane & & 2 \\
\hline $6418-44-6$ & 3-Methylheptadecane & & 4 \\
\hline $643-58-3$ & 2-Methylbiphenyl & & 4 \\
\hline $6434-78-2$ & trans-2-Nonene & & 2 \\
\hline $645-56-7$ & 4-Propylphenol & & 1 \\
\hline $645-62-5$ & 2-Ethyl-2-hexenal & & 3 \\
\hline $646-04-8$ & trans-2-Pentene & & 1 \\
\hline $66-25-1$ & Hexanaldehyde & & 88 \\
\hline $66552-62-3$ & 1,5-Dimethyldecalin & & 9 \\
\hline $66553-50-2$ & Cyclopentane, 1-methyl-2-(4-methylpentyl)-, trans- & & 1 \\
\hline $666-14-8$ & Glycolate & 9 & $\overline{0}$ \\
\hline $66826-95-7$ & Cyclohexane, 1-(cyclohexylmethyl)-4-methyl- & & 3 \\
\hline $67-56-1$ & Methyl alcohol & & 594 \\
\hline $67-63-0$ & 2-Propyl alcohol & & 191 \\
\hline $67-64-1$ & 2-Propanone (Acetone) & 62 & 831 \\
\hline $67-66-3$ & Chloroform & 1 & 118 \\
\hline $67-72-1$ & Hexachloroethane & & \\
\hline $6711-26-8$ & 2-isopropenyl-2,5-dimethyl-Cyclohexanone & & 1 \\
\hline $6728-26-3$ & trans-2-Hexenal & & 5 \\
\hline $6728-31-0$ & cis-4-Heptenal & & 5 \\
\hline $674-76-0$ & trans-4-Methyl-2-pentene & & 4 \\
\hline $6765-39-5$ & 1-Heptadecene & & 1 \\
\hline
\end{tabular}


Table B.1. Compounds with a Positive Analytical Detect for Single-Shell Tank/ Double-Shell Tank Waste (1,227 Compounds). (Page 22 of 26)

\begin{tabular}{|c|c|c|c|}
\hline QSSH & Constituent & $\begin{array}{l}\text { TWus Solidy } \\
\text { Liquid Hits }\end{array}$ & rWNS \\
\hline $67730-63-6$ & 4,6-Decadiene, 3,8-dimethyl-, [S-[R*, $\left.\left.\mathrm{R}^{*}-(\mathrm{E}, \mathrm{E})\right]\right]-$ & & $\frac{7}{7}$ \\
\hline $6783-92-2$ & 1,1,2,3-tetramethyl-Cyclohexane & & 29 \\
\hline $6789-80-6$ & cis-3-Hexenal & & 3 \\
\hline $6836-38-0$ & 6-Dodecanol & & 5 \\
\hline $68443-63-0$ & Hexanoic acid, 2-ethyl-, butyl ester & & 2 \\
\hline $6876-23-9$ & trans-1,2-Dimethylcyclohexane & & 18 \\
\hline $6898-74-4$ & N-Ethylidenebutanamine & & 4 \\
\hline $691-37-2$ & 4-Methyl-1-pentene & & 24 \\
\hline $693-54-9$ & 2-Decanone & & 16 \\
\hline $693-62-9$ & trans-4-Undecene & & 1 \\
\hline $693-98-1$ & 2-Methyl-1H-imidazole & & 3 \\
\hline 694-05-3 & 1,2,3,6-Tetrahydropyridine & & 4 \\
\hline 694-87-1 & Bicyclo[4.2.0]octa-1,3,5-triene & & 1 \\
\hline 695-06-7 & 4-Hydroxyhexanoic acid lactone & & 20 \\
\hline 696-29-7 & (1-Methylethyl)cyclohexane & & 1 \\
\hline $69687-91-8$ & 2-Hexenoic acid, 4-methylphenyl ester & & 3 \\
\hline $6975-98-0$ & 2-Methyldecane & & 37 \\
\hline $69770-96-3$ & Cyclopentanone, 2-methyl-4-(2-methylpropyl)- & & 1 \\
\hline $7012-37-5$ & $2,4,4^{4}$-Trichlorobiphenyl & & 3 \\
\hline $7045-71-8$ & 2-Methylundecane & & 51 \\
\hline $7058-01-7$ & (1-methylpropyl)-Cyclohexane & & 14 \\
\hline 706-14-9 & 4-Hydroxydecanoic acid lactone & & 2 \\
\hline $7094-26-0$ & 1,1,2-Trimethylcyclohexane & & 4 \\
\hline $71-23-8$ & n-Propyl alcohol & & 606 \\
\hline $71-36-3$ & n-Butyl alcohol & 23 & 775 \\
\hline $71-41-0$ & n-Pentyl alcohol & & 30 \\
\hline $71-43-2$ & Benzene & 12 & 638 \\
\hline $71-50-1$ & Acetate & 329 & 0 \\
\hline $71-55-6$ & 1,1,1-Trichloroethane & 22 & 221. \\
\hline $710-04-3$ & 5-Hydroxyundecanoic acid lactone & & 1 \\
\hline $7112-02-9$ & Octanamide, N-(2-hydroxyethyl)- & & 4 \\
\hline $7116-86-1$ & 5,5-Dimethyl-1-hexene & & 4 \\
\hline $7154-80-5$ & 3,3,5-Trimethylheptane & & 6 \\
\hline $717-21-5$ & 2-Propen-1-one, 3-(2-furanyl)-1-phenyl- & & 1 \\
\hline $719-22-2$ & 2,6-Di-tert-butyl-1,4-benzoquinone & & 15 \\
\hline $72014-90-5 \mathrm{M}$ & 1,4-Pentadiene, 2,3,4-trimethyl- and others & & 1 \\
\hline $7206-14-6$ & trans-3-Dodecene & & 9 \\
\hline $7206-15-7$ & trans-4-Dodecene & & 6 \\
\hline $7206-17-9$ & trans-6-Dodecene & & 4 \\
\hline $7206-28-2$ & cis-5-Dodecene & & 3 \\
\hline $7225-64-1$ & Heptadecane, 9-octyl- & & 1 \\
\hline $7239-23-8$ & cis-3-Dodecene & & 2 \\
\hline $7250-80-8$ & $\mathrm{~N}$-Hexylbenzenesulfonamide & & 3 \\
\hline 72993-32-9 & 1-butyl-2-ethyl-Cyclopentane & & 5 \\
\hline $7367-38-6$ & 5-Butyl-4-nonene & & 11 \\
\hline $7385-78-6$ & 3,4-Dimethyl-1-pentene & & 5 \\
\hline $74-82-8$ & Methane & & 93 \\
\hline 74-83-9 & Bromomethane & & 22 \\
\hline
\end{tabular}


Table B.1. Compounds with a Positive Analytical Detect for Single-Shell Tank' Double-Shell Tank Waste (1,227 Compounds). (Page 23 of 26)

\begin{tabular}{|c|c|c|c|}
\hline SASH & Constituent & TWus Solidy & TWINS Yapor \\
\hline $74-84-0$ & Ethane & & 1 \\
\hline $74-87-3$ & Chloromethane & 4 & 194 \\
\hline 74-98-6 & n-Propane & & 230 \\
\hline 74-99-7 & Methylacetylene & & 9 \\
\hline $7433-56-9$ & trans-5-Decene & & 5 \\
\hline $74367-34-3$ & $\begin{array}{l}\text { Propanoic acid, 2-methyl-, 3-hydroxy-2,4,4-trimethylpentyl } \\
\text { ester }\end{array}$ & & 5 \\
\hline $74381-40-1$ & $\begin{array}{l}\text { Propanoic acid, 2-methyl-, 1-(1,1-dimethylethyl)-2-methyl- } \\
\text { 1,3-propanediyl ester }\end{array}$ & & 18 \\
\hline $74421-09-3$ & Cyclopentane, 1,1,3-trimethyl-3-(2-methyl-2-propenyl)- & & 4 \\
\hline $74630-08-3$ & 3-ethyl-1-Octene & & 23 \\
\hline $74630-30-1$ & 4-methyl-(Cis)-2-Decene & & 2 \\
\hline $74630-39-0$ & 4-methyl-1-Undecene & & 10 \\
\hline $74630-40-3$ & 8-methyl-1-Undecene & & 2 \\
\hline $74630-42-5$ & 7-methyl-1-Undecene & & 6 \\
\hline $74630-44-7$ & 8-methyl-(Cis)-2-Undecene & & 5 \\
\hline $74630-48-1$ & 2-methyl-(Cis)-3-Undecene & & 4 \\
\hline $74630-61-8$ & 6-methyl-(trans)-2-Undecene & & 1 \\
\hline $74630-62-9$ & 7-methyl-(Cis)-5-Undecene & & 1 \\
\hline $74630-66-3$ & 7-methyl-(trans)-5-Undecene & & 1 \\
\hline $74630-69-6$ & 5-methyl-(Cis)-4-Undecene & & 1 \\
\hline $74645-98-0$ & $2,7,10$-Trimethyldodecane & & 14 \\
\hline $74646-36-9$ & 1-Dodecyn-4-ol & & 3 \\
\hline $74646-37-0$ & 1-Tridecyn-4-ol & & 3 \\
\hline $74663-66-4$ & 1,5-diethyl-2,3-dimethyl-Cyclohexane & & 4 \\
\hline $74663-86-8$ & 1-ethyl-2-heptyl-Cyclopropane & & 4 \\
\hline $74663-91-5$ & 1-heptyl-2-methyl-Cyclopropane & & 4 \\
\hline $74685-30-6$ & trans-5-Eicosene & & 1 \\
\hline $74752-97-9$ & 3-ethyl-2-methyl-(Cis)-1,3-Hexadiene, & & 1 \\
\hline $74793-02-5$ & $2,2^{\circ}$-Bioxepane & & 16 \\
\hline $74810-41-6$ & Cyclohexane, (2-ethyl-1-methylbutylidene)- & & 2 \\
\hline $74810-42-7$ & Cyclohexane, (2-ethyl-1-methyl-1-butenyl)- & & 3 \\
\hline $75-00-3$ & Chloroethane & & 82 \\
\hline $75-01-4$ & 1-Chloroethene & & 26 \\
\hline $75-02-5$ & 1-Fluoroethene & & 5 \\
\hline $75-05-8$ & Acetonitrile & & 713 \\
\hline $75-07-0$ & Acetaldehyde & & 103 \\
\hline $75-09-2$ & Dichloromethane (Methylene Chloride) & 15 & 567 \\
\hline $75-12-7$ & Formamide & & 1 \\
\hline $75-15-0$ & Carbon disulfide & & 16 \\
\hline $75-19-4$ & Cyclopropane & & 105 \\
\hline $75-21-8$ & Oxirane & & 1 \\
\hline $75-28-5$ & 2-Methylpropane & & 49 \\
\hline $75-34-3$ & 1,1-Dichloroethane & & 29 \\
\hline $75-35-4$ & 1,1-Dichloroethene & & 113 \\
\hline $75-43-4$ & Dichlorofluoromethane & & 20 \\
\hline $75-45-6$ & Chlorodifluoromethane & & 12 \\
\hline $75-50-3$ & Trimethylamine & & 1 \\
\hline
\end{tabular}


Table B.1. Compounds with a Positive Analytical Detect for Single-Shell Tank/ Double-Shell Tank Waste (1,227 Compounds). (Page 24 of 26)

\begin{tabular}{|c|c|c|c|}
\hline 84s\# & Constituent & $\begin{array}{l}\text { TWMS Solid! } \\
\text { Liquid Hits }\end{array}$ & $\begin{array}{l}\text { TWINS Vapor } \\
\text { Hits }\end{array}$ \\
\hline $75-52-5$ & Nitromethane & & 8 \\
\hline $75-55-8$ & 2-Methylaziridine & & 5 \\
\hline $75-65-0$ & 2-Methyl-2-propanol & & 144 \\
\hline $75-68-3$ & 1,1-Difluoro-1-chloroethane & & 87 \\
\hline $75-69-4$ & Trichlorofluoromethane & & 790 \\
\hline $75-71-8$ & Dichlorodifluoromethane & & 252 \\
\hline $75-77-4$ & Trimethylchlorosilane & & 11 \\
\hline $75-83-2$ & 2,2-Dimethylbutane & & 15 \\
\hline $75-84-3$ & 2,2-Dimethyl-1-propanol & & 9 \\
\hline $75-85-4$ & 2-Methyl-2-butanol & & 8 \\
\hline $75-97-8$ & 3,3-Dimethyl-2-butanone & & $\overline{42}$ \\
\hline $75-98-9$ & 2,2-Dimethylpropionic acid & & 23 \\
\hline $75011-90-4$ & 1H-Pyrazole, 4,5-dihydro-5-propyl- & & 1 \\
\hline $75163-97-2$ & 2,6-dimethyl-Octadecane & & 2 \\
\hline $75268-01-8$ & 1H-Azepin-1-amine, N-ethylidenehexahydro- & & 4 \\
\hline $753-89-9$ & 1-Chloro-2,2-dimethylpropane & & 1 \\
\hline $758-86-1$ & 2,3-Dimethyl-1,4-pentadiene & & 1 \\
\hline $76-09-5$ & 2,3-Dimethyl-2,3-butanediol & & 1 \\
\hline $76-13-1$ & 1,2,2-Trichlorotrifluoroethane & & 255 \\
\hline $76-14-2$ & 1,2-Dichloro-1,1,2,2-tetrafluoroethane & & 31 \\
\hline $762-62-9$ & 4,4-Dimethyl-1-pentene & & 6 \\
\hline $763-29-1$ & 2-Methyl-1-pentene & & 19 \\
\hline $763-93-9$ & 3-Hexen-2-one & & 1 \\
\hline $764-96-5$ & cis-5-Undecene & & 3 \\
\hline $764-97-6$ & trans-5-Undecene & & 2 \\
\hline $7642-09-3$ & cis-3-Hexene & & 4 \\
\hline $766-15-4$ & 4,4-Dimethyl-1,3-dioxane & & 1 \\
\hline $7667-60-9$ & trans, cis-1,2,4-Trimethylcyclohexane & & 3 \\
\hline $7688-21-3$ & cis-2-Hexene & & 8 \\
\hline $7726-08-1$ & N-(2-Hydroxyethyl)decanamide & & 2 \\
\hline $774-40-3$ & Benzeneacetic acid, .alpha.-hydroxy-, ethyl ester & & 1 \\
\hline $777-22-0$ & (2-Octyl)benzene & & 1 \\
\hline $78-46-6$ & Dibutyl butanephosphonate & & 41 \\
\hline $78-76-2$ & 2-Bromobutane & & 2 \\
\hline$\overline{78-78-4}$ & 2-Methylbutane & & 29 \\
\hline $78-79-5$ & 2-Methyl-1,3-butadiene & & 8 \\
\hline $78-82-0$ & 2-Cyanopropane & & 1 \\
\hline $78-83-1$ & 2-Methylpropyl alcohol & & 7 \\
\hline $78-84-2$ & 2-Methylpropionaldehyde & & 4 \\
\hline $78-85-3$ & 2-Methyl-2-propenal & & 5 \\
\hline $78-87-5$ & 1,2-Dichloropropane & & 13 \\
\hline $78-92-2$ & 1-Methylpropyl alcohol & & 66 \\
\hline $78-93-3$ & 2-Butanone & 27 & 642 \\
\hline $78-94-4$ & 3-Buten-2-one & & 70 \\
\hline $79-00-5$ & 1,1,2-Trichloroethane & & 111 \\
\hline $79-01-6$ & 1,1,2-Trichloroethylene & 1 & 113 \\
\hline $79-09-4$ & Propanoic acid & & 5 \\
\hline $79-10-7$ & 2-Propenoic acid & & 1 \\
\hline
\end{tabular}


Table B.1. Compounds with a Positive Analytical Detect for Single-Shell Tank/ Double-Shell Tank Waste (1,227 Compounds). (Page 25 of 26)

\begin{tabular}{|c|c|c|c|}
\hline C.st & Constituent & 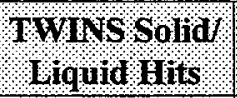 & TWINS Vapor \\
\hline $79-16-3$ & N-Methylacetamide & & 1 \\
\hline $79-20-9$ & Methyl acetate & & 4 \\
\hline $79-29-8$ & 2,3-Dimethylbutane & & 1 \\
\hline $79-34-5$ & 1,1,2,2-Tetrachloroethane & & 51 \\
\hline $80-39-7$ & N-Ethyl-4-methylbenzenesulfonamide & & 1 \\
\hline 814-78-8 & 3-Methylene-2-butanone & & 4 \\
\hline $819-97-6$ & Butanoic acid; 1-methylpropyl ester & & 1 \\
\hline $81983-71-3$ & 1,1-dimethyl-2-propyl-Cyclohexane & & 18 \\
\hline $820-29-1$ & 5-Decanone & & 5 \\
\hline $821-41-0$ & 5-Hexene-1-ol & & 3 \\
\hline $821-55-6$ & 2-Nonanone & & 55 \\
\hline $821-74-9$ & 4,5-Nonadiene & & 1 \\
\hline $821-95-4$ & 1-Undecene & & 9 \\
\hline $821-96-5$ & cis-2-Undecene & & 3 \\
\hline $822-50-4$ & trans-1,2-Dimethylcyclopentane & & 7 \\
\hline $83-32-9$ & Acenaphthene & 1 & \\
\hline $83321-16-8$ & 3-Cyclopenten-1-one, 2,3,4-trimethyl- & & 1 \\
\hline $84-64-0$ & Butyl cyclohexyl phthalate & & 2 \\
\hline $84-66-2$ & Diethyl phthalate & & 24 \\
\hline $84-74-2$ & Di-n-butylphthalate & 2 & 2 \\
\hline $85-68-7$ & Butylbenzylphthalate & 3 & \\
\hline $85-69-8$ & Butyl 2-ethylhexyl phthalate & & 1 \\
\hline $86-73-7$ & Fluorene & & 1 \\
\hline $865-40-7$ & Nitrosomethane & & 3 \\
\hline $87-68-3$ & Hexachlorobutadiene & & 42 \\
\hline $871-71-6$ & N-Butylformamide & & 3 \\
\hline $871-83-0$ & 2-Methylnonane & & 4 \\
\hline $872-05-9$ & 1-Decene & & 12 \\
\hline $872-56-0$ & Isopropylcyclobutane & & 4 \\
\hline $873-94-9$ & 3,3,5-Trimethylcyclohexanone & & 5 \\
\hline $88-06-2$ & 2,4,6-Trichlorophenol & 1 & \\
\hline $88-75-5$ & 2-Nitrophenol & 1 & \\
\hline $883-93-2$ & 2-Phenylbenzothiazole & & 5 \\
\hline $89-82-7$ & Cyclohexanone, 5-methyl-2-(1-methylethylidene)-, (R)- & & 1 \\
\hline $90-12-0$ & 1-Methylnaphthalene & & 1 \\
\hline $91-17-8$ & Decahydronaphthalene & & 3 \\
\hline $91-20-3$ & Naphthalene & 2 & 4 \\
\hline $91-57-6$ & 2-Methylnaphthalene & & 3 \\
\hline $92-51-3$ & 1,1'-Bicyclohexyl & & 1 \\
\hline $92-52-4$ & 1,1`-Biphenyl & & 7 \\
\hline $922-65-6$ & 1,4-Pentadien-3-ol & & 1 \\
\hline $924-46-9$ & 1-Propanamine, N-methyl-N-nitroso- & 2 & 0 \\
\hline $925-78-0$ & 3-Nonanone & & 1 \\
\hline $926-42-1$ & 1-Propanol, 2,2-dimethyl-, nitrate & & 16 \\
\hline $926-82-9$ & 3,5-Dimethylheptane & & 1 \\
\hline $928-45-0$ & Butyl nitrate & & 77 \\
\hline 928-68-7 & 6-Methyl-2-heptanone & & 91 \\
\hline $93-55-0$ & 1-Phenyl-1-propanone & & 3 \\
\hline
\end{tabular}


Table B.1. Compounds with a Positive Analytical Detect for Single-Shell Tank/ Double-Shell Tank Waste (1,227 Compounds). (Page 26 of 26)

\begin{tabular}{|c|c|c|c|}
\hline CASH & Constituent & $\begin{array}{l}\text { Tyins Solid } \\
\text { Liquid Hits }\end{array}$ & TWINS Yapor \\
\hline $930-18-7$ & cis-1,2-Dimethylcyclopropane & & 2 \\
\hline $930-22-3$ & 1,2-Epoxy-3-butene & & 8 \\
\hline $930-36-9$ & 1-Methylpyrazole & & 1 \\
\hline $930-57-4$ & Butylcyclopropane & & 12 \\
\hline $948-65-2$ & 2-Phenylindole & & 1 \\
\hline $95-16-9$ & Benzothiazole & & 9 \\
\hline $95-47-6$ & o-Xylene & & 411 \\
\hline 95-48-7 & o-Cresol & & 2 \\
\hline $95-50-1$ & 1,2-Dichlorobenzene & & 27 \\
\hline $95-57-8$ & 2-Chlorophenol & 1 & \\
\hline $95-63-6$ & 1,2,4-Trimethylbenzene & & 270 \\
\hline $95-95-4$ & 2,4,5-Trichlorophenol & 1 & \\
\hline $96-14-0$ & 3-Methylpentane & & 90 \\
\hline $96-17-3$ & 2-Methylbutyraldehyde & & 7 \\
\hline $96-22-0$ & 3-Pentanone & & 10 \\
\hline $96-37-7$ & Methylcyclopentane & & 45 \\
\hline $96-41-3$ & Cyclopentanol & & 12 \\
\hline $96-48-0$ & 4-Hydroxybutyric acid lactone & & 18 \\
\hline $96-69-5$ & Bis(3-tert-butyl-4-hydroxy-6-methyl-phenyl) sulfide & 1 & \\
\hline $97-87-0$ & Propanoic acid, 2-methyl-, butyl ester & & 2 \\
\hline M97-95-0 & 2-Ethyl-1-butanol & & 18 \\
\hline $97-99-4$ & Tetrahydrofurfuryl alcohol & & 2 \\
\hline $98-06-6$ & t-Butylbenzene & & 4 \\
\hline $98-54-4$ & 4-tert-Butylphenol & & 3 \\
\hline $98-82-8$ & (1-Methylethyl)benzene & & 2 \\
\hline $98-83-9$ & Methylstyrene & & 3 \\
\hline $98-86-2$ & Acetophenone & & 43 \\
\hline 98-95-3 & Nitrobenzene & & 5 \\
\hline $99-08-1$ & 3-Methylnitrobenzene & & 3 \\
\hline $99-28-5$ & 2,6-Dibromo-4-nitrophenol & 2 & 0 \\
\hline 99-82-1 & 1-Isopropyl-4-methylcyclohexane & & 3 \\
\hline $99-99-0$ & 4-Nitrotoluene & & 3 \\
\hline 993-07-7 & Trimethylsilane & & 3 \\
\hline $998-35-6$ & 5-Propylnonane & & 1 \\
\hline CITRATE & Citrate & 16 & 0 \\
\hline ETOX & Extractable total organic halides & 91 & 0 \\
\hline HEDTA & TrisodiumHydroxyethylethylenediaminetriacetate (HEDTA) & 13 & \\
\hline NA13 & Subsurface total organic carbon & & \\
\hline NA14 & Surface total organic carbon & & \\
\hline NA29 & Total organic carbon (TOC) & 2833 & \\
\hline
\end{tabular}

CAS\# $=$ chemical abstract service number.

TWINS = Tank Waste Information Network System. Solid/liquid hits were recorded from the Tank

Characterization Database. Vapor hits were recorded from the vapor database. 
Table B.2. Consolidated List of Compounds Used as Input for Regulatory Data Quality Objective List ( 850 Compounds). (Page 1 of 20)

\begin{tabular}{|c|c|c|c|c|c|c|c|c|}
\hline CAst & Constituent & $\begin{array}{l}\text { Class A } \\
\text { TAPS }\end{array}$ & $\begin{array}{l}\text { Class B } \\
\text { TAPs }\end{array}$ & UHC & Part & UPS & $\begin{array}{l}\text { DST } \\
\text { WSPS }\end{array}$ & Flampable \\
\hline $100-01-6$ & 4-Nitroaniline & & $\mathrm{X}$ & $\mathrm{X}$ & & $\mathrm{X}$ & & \\
\hline $100-02-7$ & 4-Nitrophenol & & $\mathrm{X}$ & $\mathrm{X}$ & & $\mathrm{X}$ & & \\
\hline $100-21-0$ & Phthalic acid & & & $\mathrm{X}$ & & & & \\
\hline $100-25-4$ & 1,4-Dinitrobenzene & & & $\mathrm{X}$ & & $\mathrm{X}$ & & \\
\hline $100-37-8$ & Diethylaminoethanol & & $\bar{X}$ & & & & & \\
\hline $100-41-4$ & Ethyl benzene & & & $\mathrm{X}$ & $\mathrm{X}$ & $\mathrm{X}$ & & \\
\hline $100-42-5$ & Styrene & & $\mathrm{X}$ & & & & & \\
\hline $100-44-7$ & Benzyl chloride & & $\mathrm{X}$ & & & & & \\
\hline $100-61-8$ & N-Methylbenzenamine & & $\mathrm{X}$ & & & & & \\
\hline $100-63-0$ & Phenylhydrazine & & $\mathrm{X}$ & & & & & \\
\hline $100-74-3$ & N-Ethylmorpholine & & $\mathrm{X}$ & & & & & \\
\hline $100-75-4$ & N-Nitrosopiperidine & & & $\mathrm{X}$ & & $\mathrm{X}$ & & \\
\hline $10025-67-9$ & Sulfur monochloride & & $\bar{X}$ & & & & & \\
\hline $10025-87-3$ & Phosphorus oxychloride & & $\mathrm{X}$ & & & & & \\
\hline $10026-13-8$ & Phosphorus pentachloride & & $\mathrm{X}$ & & & & & \\
\hline $10035-10-6$ & Hydrogen bromide & & $\bar{X}$ & & & & & \\
\hline $10049-04-4$ & Chlorine dioxide & & $\mathrm{X}$ & & & & & \\
\hline $10061-01-5$ & cis-1,3-Dichloropropene & & & $\mathrm{X}$ & & $\mathrm{X}$ & & \\
\hline $10061-02-6$ & trans-1,3-Dichloropropene & & & $\mathrm{X}$ & & $\bar{X}$ & & \\
\hline $101-14-4$ & 4,4'-Methylenebis(2-chloroaniline) & $\mathrm{X}$ & & $\mathrm{X}$ & & $\mathrm{X}$ & & \\
\hline $101-27-9$ & Barban & & & & & $\mathrm{X}$ & & \\
\hline $101-55-3$ & 4-Bromophenylphenyl ether & & & $\mathrm{X}$ & & $\mathrm{X}$ & & \\
\hline $101-68-8$ & Methylene bis(phenyl isocyanate) & & $\mathrm{X}$ & & & & & \\
\hline $101-77-9$ & 4,4-Methylene dianiline & $\mathrm{X}$ & & & & & & \\
\hline $101-80-4$ & 4,4'-Diaminodiphenyl ether & $\bar{X}$ & & & & & & \\
\hline $101-84-8$ & Diphenyl ether & & $\mathrm{X}$ & & & & & \\
\hline $101-90-6$ & Diglycidyl resorcinol ether & $\mathrm{X}$ & & $\mathrm{X}$ & & & & \\
\hline $10102-43-9$ & Nitric oxide & & $\mathrm{X}$ & & & & & \\
\hline $102-54-5$ & Dicyclopentadienyl iron & & $\mathrm{X}$ & & & & & \\
\hline $102-81-8$ & 2-N-Dibutylaminoethanol & & $\bar{X}$ & & & & & \\
\hline $10210-68-1$ & Cobalt carbonyl as Co & & $\mathrm{X}$ & & & & & \\
\hline $1024-57-3$ & Heptachlor Epoxide & & & $\mathrm{X}$ & & $\mathrm{X}$ & & \\
\hline $1024-57-\mathrm{D}$ & Heptachlor epoxide isomers & & & $\bar{X}$ & & & & \\
\hline $10294-33-4$ & Boron tribromide & & $\mathrm{X}$ & & & & & \\
\hline $1031-07-8$ & Endosulfan Sulfate & & & $\overline{\mathrm{X}}$ & & $\mathrm{X}$ & & \\
\hline $105-46-4$ & sec-Butyl acetate & & $\mathrm{X}$ & & & & & \\
\hline $105-60-2$ & Caprolactam, vapor & & $\mathrm{X}$ & & & & & \\
\hline $105-60-2 a$ & Caprolactam, dust & & $\mathrm{X}$ & & & & & \\
\hline $105-67-9$ & 2,4-Dimethylphenol & & & $\mathrm{X}$ & & $\mathrm{X}$ & & \\
\hline $10595-95-6$ & $\mathrm{~N}$-Nitrosomethylethylamine & $\mathrm{X}$ & & $\mathrm{X}$ & & $\bar{X}$ & & \\
\hline $106-35-4$ & 3-Heptanone & & $\mathrm{X}$ & & & & & \\
\hline $106-42-3$ & p-Xylene & & & $\mathrm{X}$ & $\mathrm{X}$ & $\mathrm{X}$ & & \\
\hline $106-44-5$ & 4-Methylphenol & & & $\mathrm{X}$ & $\bar{X}$ & $\mathrm{X}$ & & \\
\hline $106-46-7$ & 1,4-Dichlorobenzene & $\mathrm{X}$ & & $\mathrm{X}$ & & $\mathrm{X}$ & & \\
\hline $106-47-8$ & 4-Chloroaniline & & & $\bar{X}$ & & $\mathrm{X}$ & & \\
\hline $106-49-0$ & $\mathrm{p}$-Toluidine & & $\mathrm{X}$ & & & & & \\
\hline $106-50-3$ & p-Phenylenediamine & & $\mathrm{X}$ & $\mathrm{X}$ & & & & \\
\hline
\end{tabular}


Table B.2. Consolidated List of Compounds Used as Input for Regulatory Data Quality Objective List ( 850 Compounds). (Page 2 of 20)

\begin{tabular}{|c|c|c|c|c|c|c|c|c|}
\hline CASH & Constituent & $\begin{array}{l}\text { Class A } \\
\text { TAPs }\end{array}$ & $\begin{array}{l}\text { Class B } \\
\text { TAPs }\end{array}$ & UHC & $\begin{array}{l}\text { Part A } \\
\text { DSTI } \\
\text { SST }\end{array}$ & UTS & WST & $\begin{array}{l}\text { Flampable } \\
\text { Gases }\end{array}$ \\
\hline $106-51-4$ & p-Benzoquinone & & $\mathrm{X}$ & & & & & \\
\hline $106-87-6$ & Vinyl cyclohexene dioxide & & $\mathrm{X}$ & & & & & \\
\hline $106-88-7$ & 1,2-Epoxybutane & & $\bar{X}$ & & & & & \\
\hline $106-89-8$ & Epichlorohydrin & $\mathrm{X}$ & & & & & & \\
\hline $106-92-3$ & Allyl glycidyl ether & & $\mathrm{X}$ & & & & & \\
\hline $106-93-4$ & Ethylene dibromide & $\bar{X}$ & & $\mathrm{X}$ & & $\mathrm{X}$ & & \\
\hline $106-97-8$ & Butane & & $\mathrm{X}$ & & & & & \\
\hline $106-99-0$ & 1,3-Butadiene & $\mathrm{X}$ & & & & & & \\
\hline $10605-21-7$ & Carbendazim & & & & & $\bar{X}$ & & \\
\hline $107-02-8$ & Acrolein & & $\bar{X}$ & $\mathrm{X}$ & & $\mathrm{X}$ & & \\
\hline $107-05-1$ & 3-Chloropropene & & $\bar{X}$ & $\mathrm{X}$ & & $\mathrm{X}$ & & \\
\hline $107-06-2$ & 1,2-Dichloroethane & $\bar{X}$ & & $\mathrm{X}$ & $\bar{X}$ & $X$ & & \\
\hline $107-07-3$ & Ethylene chlorohydrin & & $\mathrm{X}$ & & & & & \\
\hline $107-12-0$ & Propionitrile & & & $\mathrm{X}$ & & $\mathrm{X}$ & & \\
\hline $107-13-1$ & Acrylonitrile & $\bar{X}$ & & $\bar{X}$ & & $\bar{X}$ & & \\
\hline $107-15-3$ & Ethylene diamine & & $\bar{X}$ & & & & & \\
\hline $107-18-6$ & 2-Propen-1-ol & & $\mathrm{X}$ & & & & & \\
\hline $107-19-7$ & Propargyl alcohol & & $\bar{X}$ & & & & & \\
\hline $107-20-0$ & Chloroacetaldehyde & & $\mathrm{X}$ & & & & & \\
\hline $107-21-1$ & Ethylene glycol & & $\mathrm{X}$ & & & & & \\
\hline $107-30-2$ & Chloromethyl methyl ether & $\bar{X}$ & & & & & & \\
\hline $107-31-3$ & Formic acid, methyl ester & & $\overline{\mathrm{X}}$ & & & & & \\
\hline $107-41-5$ & Hexylene glycol & & $\bar{X}$ & & & & & \\
\hline $107-49-3$ & Tetraethyl pyrophosphate & & $\mathrm{X}$ & & & & & \\
\hline $107-66-4$ & Dibutylphosphate & & $\mathrm{X}$ & & & & & \\
\hline $107-87-9$ & 2-Pentanone & & $\bar{X}$ & & & & & \\
\hline $107-98-2$ & Propylene glycol monomethyl ether & & $\mathrm{X}$ & & & & & \\
\hline $108-03-2$ & 1-Nitropropane & & $\bar{X}$ & & & & - & \\
\hline $108-05-4$ & Acetic acid vinyl ester & & $\bar{X}$ & & & & & \\
\hline $108-10-1$ & 4-Methyl-2-pentanone & & $\mathrm{X}$ & $\mathrm{X}$ & $\mathrm{X}$ & $\mathrm{X}$ & & \\
\hline $108-11-2$ & Methyl isobutyl carbinol & & $\mathrm{X}$ & & & & & \\
\hline $108-18-9$ & Diisopropylamine & & $\overline{\mathrm{X}}$ & & & & & \\
\hline $108-20-3$ & Bis(isopropyl) ether & & $\bar{X}$ & & & & & \\
\hline $108-21-4$ & Isopropyl acetate & & $\overline{\mathrm{X}}$ & & & & & \\
\hline $108-24-7$ & Acetic anhydride & & $\overline{\mathrm{X}}$ & & & & & \\
\hline $108-31-6$ & Maleic anhydride (2,5-Furandione) & & $\mathrm{X}$ & & & & & \\
\hline $108-38-3$ & $\mathrm{~m}$-Xylene & & & $\bar{X}$ & $\overline{\mathrm{X}}$ & $\mathrm{X}$ & & \\
\hline $108-39-4$ & $\mathrm{~m}$-Cresol & & $\mathrm{X}$ & $\mathrm{X}$ & & $\mathrm{X}$ & & \\
\hline $108-43-0$ & Chlorophenols & $\mathrm{X}$ & & & & & & \\
\hline $108-44-1$ & m-Toluidine & & $\mathrm{X}$ & & & & & \\
\hline $108-46-3$ & Resorcinol (1,3-Benzenediol) & & $\mathrm{X}$ & & & & & \\
\hline $108-60-1$ & Bis(2-Chloroisopropyl) ether & & & $\overline{\mathrm{X}}$ & & $\bar{X}$ & & \\
\hline $108-83-8$ & Diisobutyl ketone & & $\overline{\mathrm{X}}$ & & & & & \\
\hline $108-84-9$ & sec-Hexyl acetate & & $\bar{X}$ & & & & & \\
\hline $108-87-2$ & Methylcyclohexane & & $\mathrm{X}$ & & & & & \\
\hline $108-88-3$ & Toluene & & $\mathrm{X}$ & $\mathrm{X}$ & $\mathrm{X}$ & $\mathrm{X}$ & & \\
\hline $108-90-7$ & Chlorobenzene & & $\mathrm{X}$ & $\bar{X}$ & $\mathrm{X}$ & $\mathrm{X}$ & & \\
\hline
\end{tabular}


Table B.2. Consolidated List of Compounds Used as Input for Regulatory Data Quality Objective List ( 850 Compounds). (Page 3 of 20)

\begin{tabular}{|c|c|c|c|c|c|c|c|c|}
\hline CAst & Constituent & $\begin{array}{l}\text { Class } \\
\text { Tiars }\end{array}$ & Class B & UHC. & $\begin{array}{l}\text { Part } \\
\text { DSTl } \\
\text { SST }\end{array}$ & UTS & WST & Tlampable \\
\hline $108-91-8$ & Cyclohexylamine & & $\mathrm{X}$ & & & & & \\
\hline $108-93-0$ & Cyclohexanol & & $\mathrm{X}$ & & & & & \\
\hline $108-94-1$ & Cyclohexanone & & $\bar{X}$ & $\bar{X}$ & $\bar{X}$ & $\bar{X}$ & & \\
\hline $108-95-2$ & Phenol & & $\mathrm{X}$ & $\mathrm{X}$ & & $\bar{X}$ & & \\
\hline $108-98-5$ & Thiophenol & & $\mathrm{X}$ & & & & & \\
\hline $109-59-1$ & Isopropoxyethanol & & $\bar{X}$ & & & & & \\
\hline $109-60-4$ & n-Propyl acetate & & $\mathrm{X}$ & & & & & \\
\hline $109-66-0$ & n-Pentane & & $\bar{X}$ & & & & & \\
\hline $109-73-9$ & n-Butylamine & & $\bar{X}$ & & & & & \\
\hline $109-79-5$ & n-Butyl mercaptan & & $\mathrm{X}$ & & & & & \\
\hline $109-86-4$ & 2-Methoxyethanol & & $\mathrm{X}$ & & & & & \\
\hline $109-87-5$ & Methylal & & $\mathrm{X}$ & & & & & \\
\hline 109-89-7 & Diethylamine & & $\bar{X}$ & & & & & \\
\hline 109-94-4 & Ethyl formate & & $\mathrm{X}$ & & & & & \\
\hline $109-99-9$ & Tetrahydrofuran & & $\mathrm{X}$ & & & & & \\
\hline $110-12-3$ & 5-Methyl-2-hexanone & & $\mathrm{X}$ & & & & & \\
\hline $110-19-0$ & Isobutyl acetate & & $\mathrm{X}$ & & & & & \\
\hline $110-43-0$ & 2-Heptanone & & $\mathrm{X}$ & & & & & \\
\hline $110-49-6$ & 2-Methoxyethyl acetate & & $\mathrm{X}$ & & & & & \\
\hline $110-54-3$ & n-Hexane & & $\mathrm{X}$ & & & & & \\
\hline $110-54-3 \mathrm{D}$ & Hexane, other isomers & & $\mathrm{X}$ & & & & & \\
\hline $110-62-3$ & $\mathrm{n}$-Valeraldehyde & & $\mathrm{X}$ & & & & & \\
\hline $110-75-8$ & 2-Chloroethyl vinyl ether & & & $\mathrm{X}$ & & $\bar{X}$ & & \\
\hline $110-80-5$ & 2-Ethoxyethanol & & $\mathrm{X}$ & & $\mathrm{X}$ & & & \\
\hline $110-82-7$ & Cyclohexane & & $\mathrm{X}$ & & & & & \\
\hline $110-83-8$ & Cyclohexene & & $\mathrm{X}$ & & & & & \\
\hline $110-86-1$ & Pyridine & & $\bar{X}$ & $\mathrm{X}$ & $\mathrm{X}$ & $\mathrm{X}$ & & \\
\hline $110-91-8$ & Morpholine & & $\mathrm{X}$ & & & & & \\
\hline $111-15-9$ & 2-Ethoxyethyl acetate & & $\mathrm{X}$ & & & & & \\
\hline $111-30-8$ & Glutaraldehyde & & $\mathrm{X}$ & & & & & \\
\hline $111-40-0$ & Diethylene triamine & & $\bar{X}$ & & & & & \\
\hline $111-42-2$ & Diethanolamine & & $\mathrm{X}$ & & & & & \\
\hline $111-44-4$ & Bis(2-chloroethyl) ether & $\mathrm{X}$ & & $\mathrm{X}$ & & $\mathrm{X}$ & & \\
\hline $111-46-6 \mathrm{D}$ & Glycol ethers & & $\mathrm{X}$ & & & & & \\
\hline $111-65-9$ & n-Octane & & $\mathrm{X}$ & & & & & \\
\hline $111-76-2$ & 2-Butoxyethanol & & $\mathrm{X}$ & & & & & \\
\hline $111-84-2$ & n-Nonane & & $\mathrm{X}$ & & & & & \\
\hline $111-91-1$ & Bis(2-Chloroethoxy)methane & & & $\mathrm{X}$ & & $\mathrm{X}$ & & \\
\hline $1114-71-2$ & Pebulate & & & $\mathrm{X}$ & & $\mathrm{X}$ & & \\
\hline $11141-16-5$ & PCB-1232 & & & $\mathrm{X}$ & & & & \\
\hline $1120-71-4$ & 1,3-Propane sultone & $\mathrm{X}$ & & & & & & \\
\hline $1129-41-5$ & Metolcarb (3-methylcholanthrene) & & & & & $\mathrm{X}$ & & \\
\hline $1134-23-2$ & Cycloate & & & $\mathrm{X}$ & & & & \\
\hline 114-26-1 & Propoxur & & $\mathrm{X}$ & $\mathrm{X}$ & & $\mathrm{X}$ & & \\
\hline $115-29-7$ & Endosulfan & & $\mathrm{X}$ & & & & & \\
\hline $115-86-6$ & Triphenyl phosphate & & $\mathrm{X}$ & & & & & \\
\hline $115-90-2$ & Fensulfothion & & $\mathrm{X}$ & & & & & \\
\hline
\end{tabular}


Table B.2. Consolidated List of Compounds Used as Input for Regulatory Data Quality Objective List ( 850 Compounds). (Page 4 of 20)

\begin{tabular}{|c|c|c|c|c|c|c|c|c|}
\hline CAS\# & Constituent & Class A & Class B & UHC & $\begin{array}{l}\text { Part } \\
\text { DSTI } \\
\text { SST }\end{array}$ & UTS & $\begin{array}{l}\text { DST } \\
\text { WSPS }\end{array}$ & Flamiable \\
\hline $117-79-3$ & 2-Aminoanthraquinone & $\mathrm{X}$ & & & & & & \\
\hline $117-81-7$ & Bis(2-ethylhexyl) phthalate & $\mathrm{X}$ & & $\mathrm{X}$ & & $\mathrm{X}$ & & \\
\hline $117-84-0$ & Di-n-octylphthalate & & & $\bar{X}$ & & $\mathrm{X}$ & & \\
\hline $118-52-5$ & $\begin{array}{l}\text { 1,3-Dichloro-5,5-Dimethyl } \\
\text { hydantoin }\end{array}$ & & $\mathrm{X}$ & & & & & \\
\hline $118-74-1$ & Hexachlorobenzene & $\mathrm{X}$ & & $\mathrm{X}$ & & $\mathrm{X}$ & & \\
\hline $118-96-7$ & 2,4,6-Trinitrotoluene & & $\mathrm{X}$ & & & & & \\
\hline $1189-85-1$ & tert-Butyl chromate, as $\mathrm{CrO} 3$ & & $\mathrm{X}$ & & & & & \\
\hline $119-38-0$ & Isolan & & & & & $\mathrm{X}$ & & \\
\hline $119-90-4$ & 3,3'-Dimethoxybenzidine & $\mathrm{X}$ & & & & & & \\
\hline $119-93-7$ & 3,3'-Dimethylbenzidine. & $\mathrm{X}$ & & & & & & \\
\hline $120-12-7$ & Anthracene & & & $\mathrm{X}$ & & $\mathrm{X}$ & & \\
\hline $120-58-1$ & Isosafrole & & & $\mathrm{X}$ & & $\mathrm{X}$ & & \\
\hline $120-80-9$ & Catechol & & $\mathrm{X}$ & & & & & \\
\hline $120-82-1$ & 1,2,4-Trichlorobenzene & & $\mathrm{X}$ & $\mathrm{X}$ & & $\mathrm{X}$ & & \\
\hline $120-83-2$ & 2,4-Dichlorophenol & & & $\bar{X}$ & & $\mathrm{X}$ & & \\
\hline $12079-65-1$ & $\begin{array}{l}\text { Manganese cyclopentadienyl } \\
\text { tricarbonyl }\end{array}$ & & $\mathrm{X}$ & & & & & \\
\hline $121-14-2$ & 2,4-Dinitrotoluene & & $\mathrm{X}$ & $\mathrm{X}$ & $\mathrm{X}$ & $\mathrm{X}$ & & \\
\hline $121-44-8$ & Triethylamine & & $\bar{X}$ & $\mathrm{X}$ & & $\bar{X}$ & & \\
\hline $121-45-9$ & Trimethyl phosphite & & $\mathrm{X}$ & & & & & \\
\hline $121-69-7$ & Dimethylaniline & & $\mathrm{X}$ & & & & & \\
\hline $121-75-5$ & Malathion & & $\mathrm{X}$ & & & & & \\
\hline $121-82-4$ & Cyclonite & & $\mathrm{X}$ & & & & & \\
\hline $12108-13-3$ & $\begin{array}{l}\text { Methylcyclopentadienylmanganese } \\
\text { tricarbonyl }\end{array}$ & & $\mathrm{X}$ & & & & & \\
\hline $12125-02-9$ & Ammonium chloride (fume) & & $\mathrm{X}$ & & & & & \\
\hline $122-39-4$ & N,N-Diphenylamine & & $\mathrm{X}$ & $\mathrm{X}$ & & $\mathrm{X}$ & & \\
\hline $122-42-9$ & Propham & & & & & $\mathrm{X}$ & & \\
\hline $122-60-1$ & Phenyl glycidyl ether & & $\mathrm{X}$ & & & & & \\
\hline $122-66-7$ & 1,2-Diphenylhydrazine & $\mathrm{X}$ & & $\mathrm{X}$ & & $\bar{X}$ & & \\
\hline $123-19-3$ & 4-Heptanone & & $\mathrm{X}$ & & & & & \\
\hline $123-31-9$ & Hydroquinone & & $\mathrm{X}$ & $\mathrm{X}$ & & & & \\
\hline $123-38-6$ & n-Propionaldehyde & & $\bar{X}$ & & & & & \\
\hline $123-42-2$ & Diacetone alcohol & & $\mathrm{X}$ & & & & & \\
\hline $123-51-3$ & 3-Methyl-1-butanol & & $\mathrm{X}$ & & & & & \\
\hline $123-86-4$ & Acetic acid n-butyl ester & & $\mathrm{X}$ & & & & & \\
\hline $123-91-1$ & 1,4-Dioxan & $\mathrm{X}$ & & $\mathrm{X}$ & & $\mathrm{X}$ & & \\
\hline $123-92-2$ & Isoamyl acetate & & $\mathrm{X}$ & & & & & \\
\hline $124-40-3$ & Dimethylamine & & $\mathrm{X}$ & & & & & \\
\hline $124-48-1$ & Dibromochloromethane & & & $\mathrm{X}$ & & $\mathrm{X}$ & & \\
\hline $126-72-7$ & Tris(2,3-dibromopropyl) phosphate & & & $\mathrm{X}$ & & $\mathrm{X}$ & & \\
\hline $126-73-8$ & Tributyl phosphate & & $\mathrm{X}$ & & & & & \\
\hline $126-85-2$ & Nitrogen mustard N-oxide & $\mathrm{X}$ & & & & & & \\
\hline $126-98-7$ & 2-Methyl-2-propenenitrile & & $\mathrm{x}$ & $\mathrm{X}$ & & $\mathrm{X}$ & & \\
\hline $126-99-8$ & Chloroprene & $\mathrm{X}$ & & $\mathrm{X}$ & & $\mathrm{X}$ & & \\
\hline $12604-58-9$ & Ferrovanadium dust & & $\mathrm{X}$ & & & & & \\
\hline
\end{tabular}


Table B.2. Consolidated List of Compounds Used as Input for Regulatory Data Quality Objective List ( 850 Compounds). (Page 5 of 20)

\begin{tabular}{|c|c|c|c|c|c|c|c|c|}
\hline CAS\# & Constituent & Class $\mathrm{A}$ & Class B & UHC & $\begin{array}{l}\text { Part A } \\
\text { DSTI } \\
\text { SST }\end{array}$ & UTS & $\begin{array}{l}\text { DST } \\
\text { WSPS }\end{array}$ & Flammable \\
\hline $12672-29-6$ & PCB-1248 & & & $\mathrm{X}$ & & & & \\
\hline $127-18-4$ & 1,1,2,2-Tetrachloroethene & $\mathrm{X}$ & & $\mathrm{X}$ & $\mathrm{X}$ & $\mathrm{X}$ & & \\
\hline $127-19-5$ & N,N-Dimethylacetamide & & $\mathrm{X}$ & & & & & \\
\hline $128-37-0$ & 2,6-Bis(tert-butyl)-4-methylphenol & & $\mathrm{X}$ & & & & & \\
\hline $129-00-0$ & Pyrene & & & $\mathrm{X}$ & & $\mathrm{X}$ & & \\
\hline $129-15-7$ & 2-Methyl-1-nitroanthraquinone. & $\mathrm{X}$ & & & & & & \\
\hline $1300-73-8$ & Xylidine & & $\mathrm{X}$ & & & & & \\
\hline $1303-86-2$ & Boron oxide & & $\mathrm{X}$ & & & & & \\
\hline $1303-96-4 \mathrm{Ca}$ & Borates, anhydrous & & $\mathrm{X}$ & & & & & \\
\hline $1303-96-4 \mathrm{Cb}$ & Borates, pentahydrate & 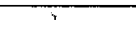 & $\bar{X}$ & & & & & \\
\hline $1303-96-4 \mathrm{Cc}$ & Borates, decahydrate. & & $\mathrm{X}$ & & & & & \\
\hline $1304-82-1$ & Bismuth telluride & & $X$ & & & & & \\
\hline $1305-62-0$ & Calcium hydroxide & & $\mathrm{X}$ & & & & & \\
\hline $1305-78-8$ & Calcium oxide & & $\mathrm{X}$ & & & & & \\
\hline $1309-37-1$ & Iron oxide fume, $\mathrm{Fe} 2 \mathrm{O} 3$ as $\mathrm{Fe}$ & & $\bar{X}$ & & & & & \\
\hline $1309-48-4$ & Magnesium oxide fume & & $\mathrm{X}$ & & & & & \\
\hline $1309-64-4$ & Antimony trioxide, as $\mathrm{Sb}$ & & $\mathrm{X}$ & & & & & \\
\hline $131-11-3$ & Dimethyl phthalate & 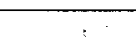 & $\mathrm{X}$ & $\mathrm{X}$ & & $\mathrm{X}$ & & \\
\hline $1310-58-3$ & Potassium hydroxide & & $\mathrm{X}$ & & & & & \\
\hline $1310-73-2$ & Sodium hydroxide & & $\mathrm{X}$ & & & & $\mathrm{X}$ & \\
\hline $13121-70-5$ & Cyhexatin & & $\mathrm{X}$ & & & & & \\
\hline $1314-13-2$ & Zinc oxide, fume & & $\mathrm{X}$ & & & & & \\
\hline $1314-20-1$ & Thorium dioxide & $\mathrm{X}$ & & & & & & \\
\hline $1314-62-1$ & Vanadium pentoxide & & $\mathrm{X}$ & & $\bar{X}$ & & & \\
\hline $1314-80-3$ & Phosphorus pentasulfide & & $\bar{X}$ & & & & & \\
\hline $1319-77-3$ & Cresol polymers & & & & $\mathrm{X}$ & & & \\
\hline $1319-77-3 a$ & Cresols, syn Cresylic acid & & $\mathrm{X}$ & & & & & \\
\hline $132-64-9$ & Dibenzofuran & $\bar{X}$ & & & & & & \\
\hline $1321-64-8$ & Pentachloronaphthalene & & $\mathrm{X}$ & & & & & \\
\hline $1321-65-9$ & Trichloronaphthalene & & $\mathrm{X}$ & & & & & \\
\hline $1321-74-0$ & Divinyl benzene & & $\mathrm{X}$ & & & & & \\
\hline $133-06-2$ & Captan & & $\mathrm{X}$ & & & & & \\
\hline $133-90-4$ & Chloramben & & $\mathrm{X}$ & & & & & \\
\hline $1330-20-7$ & Xylene & & & $\bar{X}$ & $\mathrm{X}$ & $\overline{\mathrm{X}}$ & & \\
\hline $1332-21-4$ & Asbestos (fiberous) & $\bar{X}$ & & & & & & \\
\hline $1333-86-4$ & Carbon black & & $\mathrm{X}$ & & & & & \\
\hline $1335-87-1$ & Hexachloronaphthalene & & $\bar{X}$ & & & & & \\
\hline $1335-88-2$ & Tetrachloronaphthalene & & $\mathrm{X}$ & & & & & \\
\hline $1336-36-3$ & Polychlorinated biphenyls (PCBs) & $\mathrm{X}$ & & $\mathrm{X}$ & & $\mathrm{X}$ & $\mathrm{X}$ & \\
\hline $1338-23-4$ & Methyl ethyl ketone peroxide & & $\mathrm{X}$ & & & & & \\
\hline $134-32-7$ & alpha-Naphthylamine & $\mathrm{X}$ & & $\mathrm{X}$ & & & & \\
\hline $13463-40-6$ & Iron pentacarbonyl, as $\mathrm{Fe}$ & & $\mathrm{X}$ & & & & & \\
\hline $13494-80-9 \mathrm{C}$ & Tellurium \& compounds as $\mathrm{Te}$ & & $\mathrm{X}$ & & & & & \\
\hline $135-20-6$ & Cupferron & $\mathrm{X}$ & & & & & & \\
\hline $135-88-6$ & N-Phenyl-2-napthylamine & & & $\mathrm{X}$ & & & & \\
\hline $13530-65-9$ & Zinc chromates & & $\mathrm{X}$ & & & & & \\
\hline
\end{tabular}


Table B.2. Consolidated List of Compounds Used as Input for Regulatory Data Quality Objective List (850 Compounds). (Page 6 of 20)

\begin{tabular}{|c|c|c|c|c|c|c|c|c|}
\hline CAst & Constituent & $\begin{array}{l}\text { Class A } \\
\text { TAPs }\end{array}$ & $\begin{array}{l}\text { Class B } \\
\text { TAPs }\end{array}$ & UHC & $\begin{array}{l}\text { Parta } \\
\text { osty } \\
\text { sst }\end{array}$ & UTS & WST: & $\begin{array}{l}\text { Tlammable } \\
\text { Gases }\end{array}$ \\
\hline $13552-44-8$ & $\begin{array}{l}\text { 4,4-Methylenedianiline } \\
\text { dihydrochloride }\end{array}$ & $\mathrm{X}$ & & & & & & \\
\hline $136-78-7$ & Sesone & & $\mathrm{X}$ & & & & & \\
\hline $137-05-3$ & Methyl-2-cyanoacrylate & & $\mathrm{X}$ & & & & & \\
\hline $137-26-8$ & Thiram & & $\mathrm{X}$ & & & & & \\
\hline $137-30-4$ & Ziram & & & $\mathrm{X}$ & & $\mathrm{X}$ & & \\
\hline $138-22-7$ & n-Butyl lactate & & $\mathrm{X}$ & & & & & \\
\hline $13838-16-9$ & Enflurane & & $\mathrm{X}$ & & & & & \\
\hline $139-65-1$ & 4,4'-Thiodianiline & $\mathrm{X}$ & & $\mathrm{X}$ & & & & \\
\hline $139-91-3$ & $\begin{array}{l}\text { 5-(Morpholinomethyl)-3-amino-2- } \\
\text { oxazolidinone (furaltudone) }\end{array}$ & $\mathrm{X}$ & & & & & & \\
\hline $1395-21-7$ & Subtilisins & & $\mathrm{X}$ & & & & & \\
\hline $140-57-8$ & Aramite & & & $\mathrm{X}$ & & $\mathrm{X}$ & & \\
\hline $140-88-5$ & Ethylacrylate & & $\mathrm{X}$ & & & & & \\
\hline $141-32-2$ & Butylacrylate & & $\mathrm{X}$ & & & & & \\
\hline $141-43-5$ & Ethanolamine & & $\bar{X}$ & & & & & \\
\hline $141-66-2$ & Dicrotophos & & $\mathrm{X}$ & & & & & \\
\hline $141-78-6$ & Acetic acid ethyl ester & & $\mathrm{X}$ & $\mathrm{X}$ & $\mathrm{X}$ & $\mathrm{X}$ & & \\
\hline $141-79-7$ & 4-Methyl-3-penten-2-one & & $\mathrm{X}$ & & & & & \\
\hline $142-64-3$ & Piperazine dihydrochloride & & $\mathrm{X}$ & & & & & \\
\hline $142-82-5$ & n-Heptane & & $\mathrm{X}$ & & & & & \\
\hline $14265-44-2$ & Phosphate & & & & & & & $\mathrm{X}$ \\
\hline $14280-30-9$ & Hydroxide & & & & & & $\mathrm{X}$ & \\
\hline $143-50-0$ & Kepone & & & $\mathrm{X}$ & & $\bar{X}$ & & \\
\hline $144-62-7$ & Oxalic acid & & $\mathrm{X}$ & & & & & \\
\hline $14484-64-1$ & Ferbam & & $\mathrm{X}$ & & & & & \\
\hline $1477-55-0$ & $\mathrm{~m}$-Xylene-a,a'-diamine & & $\mathrm{X}$ & & & & & \\
\hline $14797-65-0$ & Nitrite & & & & & & $\bar{X}$ & $\mathrm{X}$ \\
\hline $148-01-6$ & Dinitolamide & & $\mathrm{X}$ & & & & & \\
\hline $14808-79-8$ & Sulfate & & & & & & & $\mathrm{X}$ \\
\hline $14977-61-8$ & Chromylchloride & & $\mathrm{X}$ & & & & & \\
\hline $150-76-5$ & 4-Methoxyphenol & & $\bar{X}$ & & & & & \\
\hline $151-56-4$ & Ethyleneimine & & $\mathrm{X}$ & & & & & \\
\hline $151-67-7$ & Halothane & & $\mathrm{X}$ & & & & & \\
\hline $156-60-5$ & 1,2-trans-Dichloroethene & & & $\mathrm{X}$ & $\bar{X}$ & $\mathrm{X}$ & & \\
\hline $156-62-7$ & Calcium cyanamide & & $\mathrm{X}$ & & & & & \\
\hline $1563-38-8$ & Carbofuran phenol & & & & & $\mathrm{X}$ & & \\
\hline $1563-66-2$ & Carbofuran & & $\overline{\mathrm{X}}$ & $\mathrm{X}$ & & $\bar{X}$ & & \\
\hline $1582-09-8$ & Trifluralin & & $\mathrm{X}$ & & & & & \\
\hline $1615-80-1$ & $\mathrm{~N}, \mathrm{~N}^{\prime}$-Diethylhydrazine & $\mathrm{X}$ & & & & & & \\
\hline $16219-75-3$ & Ethylidene norbornene & & $\mathrm{X}$ & & & & & \\
\hline $1634-04-4$ & Methyl tert-butyl ether & & $\mathrm{X}$ & & & & & \\
\hline $1646-88-4$ & Aldicarb sulfone & & & $\mathrm{X}$ & & $\mathrm{X}$ & & \\
\hline $16752-77-5$ & Methomyl & & $\mathrm{X}$ & $\mathrm{X}$ & & $\mathrm{X}$ & & \\
\hline $16842-03-8$ & Cobalt hydrocarbonyl & & $\mathrm{X}$ & & & & & \\
\hline $16887-00-6$ & Chloride & & & & & & $\bar{X}$ & $\mathrm{X}$ \\
\hline 1694-09-3 & Benzyl violet $4 \mathrm{~b}$ & $\mathrm{X}$ & & & & & & \\
\hline
\end{tabular}


Table B.2. Consolidated List of Compounds Used as Input for Regulatory Data Quality Objective List ( 850 Compounds). (Page 7 of 20)

\begin{tabular}{|c|c|c|c|c|c|c|c|c|}
\hline CAS\# & Constituent & $\begin{array}{l}\text { Class } \\
\text { TAPS }\end{array}$ & Class B & UHe & $\begin{array}{l}\text { Part } \\
\text { DSTI } \\
\text { SST }\end{array}$ & USS & $\begin{array}{l}\text { DST } \\
\text { WSPS }\end{array}$ & Tlaminable \\
\hline $16984-48-8$ & Fluoride & & $\mathrm{X}$ & $\mathrm{X}$ & & $\mathrm{X}$ & & $\mathrm{X}$ \\
\hline $1746-01-6$ & TCDD (Dioxin/Furan Indicator) & $\mathrm{X}$ & & $\bar{X}$ & & & & \\
\hline $17702-41-9$ & Decaborane & & $\bar{X}$ & & & & & \\
\hline $17702-57-7$ & Formparanate & & & & & $\bar{X}$ & & \\
\hline $17804-35-2$ & Benomyl & & $\mathrm{X}$ & $\bar{X}$ & & $\bar{X}$ & & \\
\hline $1836-75-5$ & Nitrofen & $\mathrm{X}$ & & & & & & \\
\hline $1888-71-7$ & Hexachloropropylene & & & $\mathrm{X}$ & & $\bar{X}$ & & \\
\hline $189-55-9$ & Dibenzo[a,i]pyrene & $\mathrm{X}$ & & & & & & \\
\hline $189-64-0$ & Dibenzo[a,h]pyrene & $\mathrm{X}$ & & & & & & \\
\hline $191-24-2$ & $\operatorname{Benzo}(g, h, i)$ perylene & & & $\bar{X}$ & & $\overline{\mathrm{X}}$ & & v \\
\hline $191-30-0$ & Dibenzo(a,l)pyrene & $\mathrm{X}$ & & & & & & \\
\hline $1912-24-9$ & Atrazine & & $\mathrm{X}$ & & & & & \\
\hline $1918-02-1$ & Picloram & & $\mathrm{X}$ & & & & & \\
\hline $192-65-4$ & Dibenzo[a,e]pyrene & $\mathrm{X}$ & & $\mathrm{X}$ & & $\mathrm{X}$ & & \\
\hline $19287-45-7$ & Diborane & & $\bar{X}$ & & & & & \\
\hline $1929-77-7$ & Vernolate & & & $\bar{X}$ & & $\overline{\mathrm{X}}$ & & \\
\hline $1929-82-4$ & Nitrapyrin & & $\mathrm{X}$ & & & & & \\
\hline $193-39-5$ & Indeno(1,2,3-cd)pyrene & $\mathrm{X}$ & & $\bar{X}$ & & $\mathrm{X}$ & & \\
\hline $19624-22-7$ & Pentaborane & & $\bar{X}$ & & & & & \\
\hline $2008-41-5$ & Butylate & & & $\mathrm{X}$ & & $\mathrm{X}$ & & \\
\hline $2032-65-7$ & Methiocarb & & & $\mathrm{X}$ & & $\mathrm{X}$ & & \\
\hline $2039-87-4$ & o-Chlorostyrene & & $\mathrm{X}$ & & & & & \\
\hline $205-82-3$ & Benzo[j]fluoranthene & $\mathrm{X}$ & & & & & & \\
\hline $205-99-2$ & Benzo(b)fluoranthene & $\mathrm{X}$ & & $\mathrm{X}$ & & $\mathrm{X}$ & & \\
\hline $206-44-0$ & Fluoranthene & & & $\bar{X}$ & & $\mathrm{X}$ & & \\
\hline $207-08-9$ & Benzo(k)fluoranthene & $\mathrm{X}$ & & $\bar{X}$ & & $\bar{X}$ & & \\
\hline $208-96-8$ & Acenaphthylene & & & $\mathrm{X}$ & & $\mathrm{X}$ & & \\
\hline $20816-12-0$ & Osmium tetroxide & & $\mathrm{X}$ & & & & & \\
\hline $2104-64-5$ & EPN & & $\mathrm{X}$ & & & & & \\
\hline $21087-64-9$ & Metribuzin & & $\mathrm{X}$ & & & & & \\
\hline $21351-79-1$ & Cesium hydroxide & & $\mathrm{X}$ & & & & & \\
\hline $2179-59-1$ & Allyl propyl disulfide & & $\mathrm{X}$ & & & & & \\
\hline $218-01-9$ & Chrysene & & & $\mathrm{X}$ & & $\mathrm{X}$ & & \\
\hline $2212-67-1$ & Molinate & & & $\mathrm{X}$ & & $\mathrm{X}$ & & \\
\hline $22224-92-6$ & Fenamiphos & & $\mathrm{X}$ & & & & & \\
\hline $2234-13-1$ & Octachloronaphthalene & & $\bar{X}$ & & & & & \\
\hline $2238-07-5$ & Diglycidyl ether & & $\mathrm{X}$ & & & & & \\
\hline $224-42-0$ & Dibenz $[\mathrm{a}, \mathrm{j}]$ acridine & $\mathrm{X}$ & & & & & & \\
\hline $226-36-8$ & Dibenz $[\mathrm{a}, \mathrm{h}]$ acridine & $\mathrm{X}$ & & & & & & \\
\hline $22781-23-3$ & Bendiocarb & & & $\mathrm{X}$ & & $\mathrm{X}$ & & \\
\hline $22961-82-6$ & Bendiocarb phenol & & & & & $\mathrm{X}$ & & \\
\hline $2303-17-5$ & Triallate & & & & & $\mathrm{X}$ & & \\
\hline $23135-22-0$ & Oxamy & & & $\mathrm{X}$ & & $\mathrm{X}$ & & \\
\hline $23422-53-9$ & Formetanate hydrochloride & & & & & $\mathrm{X}$ & & \\
\hline $23564-05-8$ & Thiophanate-methyl & & & & & $\mathrm{X}$ & & \\
\hline $2385-85-5$ & Mirex & $\mathrm{X}$ & & & & & & \\
\hline $23950-58-5$ & Pronamide & & & $\mathrm{X}$ & & $\bar{X}$ & & \\
\hline
\end{tabular}


Table B.2. Consolidated List of Compounds Used as Input for Regulatory Data Quality Objective List (850 Compounds). (Page 8 of 20)

\begin{tabular}{|c|c|c|c|c|c|c|c|c|}
\hline CAs\# & Constituent: & Glass A & $\begin{array}{l}\text { Glass B } \\
\text { TAPs }\end{array}$ & UHC. & $\begin{array}{l}\text { Part A. } \\
\text { DSTI }\end{array}$ & UIS & WST & Flampable \\
\hline $2425-06-1$ & Captafol & & $\mathrm{X}$ & & & & & \\
\hline $2426-08-6$ & n-Butyl glycidyl ether & & $\mathrm{X}$ & & & & & \\
\hline $2465-27-2$ & Auramine (technical grade) & $\bar{X}$ & & & & & & \\
\hline $25013-15-4$ & Vinyl toluene & & $\mathrm{X}$ & & & & & \\
\hline $2551-13-7$ & Trimethyl benzene & & $\mathrm{X}$ & & & & & \\
\hline $2551-62-4$ & Sulfur hexafluoride & & $\bar{X}$ & & & & & \\
\hline $25639-42-3$ & Methylcyclohexanol & & $\mathrm{X}$ & & & & & \\
\hline $26140-60-3$ & Terphenyls & & $\bar{X}$ & & & & & \\
\hline $2631-37-0$ & Promecarb & & & & & $\mathrm{X}$ & & \\
\hline $26419-73-8$ & Tirpate & & & & & $\mathrm{X}$ & & \\
\hline $2646-17-5$ & Oil orange SS & $\mathrm{X}$ & & & & & & \\
\hline $26628-22-8$ & Sodium azide & & $\mathrm{X}$ & & & & & \\
\hline $26952-21-6$ & Iso-ocytl alcohol & & $\overline{\mathrm{X}}$ & & & & & \\
\hline $2698-41-1$ & o-Chlorobenylidene malonitrile & & $\mathrm{X}$ & & & & & \\
\hline $2699-79-8$ & Sulfuryl fluoride & & $\bar{X}$ & & & & & \\
\hline $27154-33-2$ & Trichlorofluoroethane & & & & $\mathrm{X}$ & & & \\
\hline $28434-86-8$ & $\begin{array}{l}3,3^{\prime} \text {-Dichloro-4,4'-diaminodiphenyl } \\
\text { ether }\end{array}$ & $\mathrm{X}$ & & & & & & \\
\hline $287-92-3$ & Cyclopentane & & $\mathrm{X}$ & & & & & \\
\hline $29191-52-4$ & Anisidine (o-,p- isomers) & & $\mathrm{X}$ & & & & & \\
\hline $2921-88-2$ & Chlorpyrifos & & $\bar{X}$ & & & & & \\
\hline $2971-90-6$ & Clopidol & & $\bar{X}$ & & & & & \\
\hline $298-00-0$ & Methyl parathion & & $\mathrm{X}$ & $\bar{X}$ & & $\mathrm{X}$ & & \\
\hline $298-02-2$ & Phorate & & $\mathrm{X}$ & $\overline{\mathrm{X}}$ & & $\overline{\mathrm{X}}$ & & \\
\hline $298-04-4$ & Disulfoton & & $\mathrm{X}$ & $\bar{X}$ & & $\mathrm{X}$ & & \\
\hline $299-84-3$ & Ronnel & & $\mathrm{X}$ & & & & & \\
\hline $299-86-5$ & Crufomate & & $\mathrm{X}$ & & & & & \\
\hline $300-76-5$ & Naled & & $\bar{X}$ & & & & & \\
\hline $301-04-2$ & Lead acetate & $\mathrm{X}$ & & & & & & \\
\hline $302-01-2$ & Hydrazine & $\mathrm{X}$ & & & & & & \\
\hline $302-70-5$ & $\begin{array}{l}\text { Nitrogen mustard N-oxide } \\
\text { hydrochloride }\end{array}$ & $\mathrm{X}$ & & & & & & \\
\hline $30402-14-3 \mathrm{D}$ & Tetrachlorodibenzofurans & & & $\mathrm{X}$ & & & & \\
\hline $30402-15-4 D$ & Pentachlorodibenzofurans & & & $\mathrm{X}$ & & & & \\
\hline $30558-43-1$ & A2213 & & & & & $\bar{X}$ & & \\
\hline $3068-88-0$ & B-Butyrolactone & $\bar{X}$ & & & & & & \\
\hline $309-00-2$ & Aldrin & $\mathrm{X}$ & & $\mathrm{X}$ & & $\mathrm{X}$ & & \\
\hline $314-40-9$ & Bromacil & & $\bar{X}$ & & & & & \\
\hline $315-18-4$ & Mexacarbate & & & $\mathrm{X}$ & & $\bar{X}$ & & \\
\hline $319-84-6$ & alpha-BHC & $\mathrm{X}$ & & $\mathrm{X}$ & & $\mathrm{X}$ & & \\
\hline $319-85-7$ & beta-BHC & $\mathrm{X}$ & & $\mathrm{X}$ & & $\mathrm{X}$ & & \\
\hline $319-86-8$ & delta-BHC & & & $\mathrm{X}$ & & $\mathrm{X}$ & & \\
\hline $330-54-1$ & Diuron & & $\mathrm{X}$ & & & & & \\
\hline $33213-65-9$ & Endosulfan II & & & $\mathrm{X}$ & & $\mathrm{X}$ & & \\
\hline $333-41-5$ & Diazinon & & $\mathrm{X}$ & & & & & \\
\hline $3333-52-6$ & Tetramethyl succinonitrile & & $\mathrm{X}$ & & & & & \\
\hline $334-88-3$ & Diazomethane & & $\mathrm{X}$ & & & & & \\
\hline
\end{tabular}


Table B.2. Consolidated List of Compounds Used as Input for Regulatory Data Quality Objective List ( 850 Compounds). (Page 9 of 20)

\begin{tabular}{|c|c|c|c|c|c|c|c|c|}
\hline CAst & Constituent & $\begin{array}{l}\text { Class: } \\
\text { TIAPs }\end{array}$ & $\begin{array}{l}\text { Class } 18 \\
\text { TAPs }\end{array}$ & UHC & $\begin{array}{l}\text { Part A } \\
\text { DSTl }\end{array}$ & UIS & $\begin{array}{l}\text { DST } \\
\text { WSPS }\end{array}$ & Tlammable \\
\hline $3383-96-8$ & Temephos & & $\mathrm{X}$ & & & & & \\
\hline $3424-82-6$ & o, $\mathrm{p}^{\prime}-\mathrm{DDE}\left(2,4^{\prime}-\mathrm{DDE}\right)$ & & & $\mathrm{X}$ & & $\bar{X}$ & & \\
\hline $34465-46-8 \mathrm{D}$ & Hexachlorodibenzo-p-dioxins & & & $\mathrm{X}$ & & & & \\
\hline $34590-94-8$ & Dipropylene glycol methyl ether & & $\bar{X}$ & & & & & \\
\hline $353-50-4$ & Carbon oxyfluoride & & $\mathrm{X}$ & & & & & \\
\hline $35400-43-2$ & Sulprofos & & $\mathrm{X}$ & & & & & \\
\hline $3547-04-4$ & $\begin{array}{l}\mathrm{DDE}\left(\mathrm{p}, \mathrm{p}^{\prime}-\right. \\
\text { Dichlorodiphenyldichloroethylene) }\end{array}$ & $\mathrm{X}$ & & & & & & \\
\hline $36088-22-9 \mathrm{D}$ & Pentachlorodibenzo-p-dioxins & & & $\mathrm{X}$ & & & & \\
\hline $3687-31-8$ & Lead arsenate, as $\mathrm{Pb} 3(\mathrm{~A} 2 \mathrm{O} 4) 2$ & & $\mathrm{X}$ & & & & & \\
\hline $3689-24-5$ & $\begin{array}{l}\text { Tetraethyldithiopyrophosphate } \\
\text { (TEDP) }\end{array}$ & & $\mathrm{X}$ & & & & & \\
\hline $3697-24-3$ & 5-Methylchrysene & $\mathrm{X}$ & & & & & & \\
\hline $3761-53-3$ & Ponceau MX & $\mathrm{X}$ & & & & & & \\
\hline $3812-32-6$ & Carbonate & & & & & & & $\mathrm{X}$ \\
\hline $3825-26-1$ & Ammonium perfluorooctanoate & & $\mathrm{X}$ & & & & & \\
\hline $4016-14-2$ & Isopropyl glycidyl ether (IGE) & & $\mathrm{X}$ & & & & & \\
\hline $4098-71-9$ & Isophorone diisocyanate & & $\bar{X}$ & & & & & \\
\hline $4170-30-3$ & 2-Butenaldehyde & & $\mathrm{X}$ & & & & & \\
\hline $41903-57-5 D$ & Tetrachlorodi-benzo-p-dioxins & & & $\mathrm{X}$ & & & & \\
\hline $420-04-2$ & Cyanamide & & $\overline{\mathrm{X}}$ & & & & & \\
\hline $460-19-5$ & Cyanogen & & $\mathrm{X}$ & & & & & \\
\hline $463-51-4$ & Ketene & & $\mathrm{X}$ & & & & & \\
\hline $463-58-1$ & Carbon oxide sulfide (COS) & & $\bar{X}$ & & & & & \\
\hline $465-73-6$ & Isodrin & & & $\mathrm{X}$ & & $\mathrm{X}$ & & \\
\hline $4685-14-7$ & Paraquat & & $\mathrm{X}$ & & & & & \\
\hline $479-45-8$ & Tetryl & & $\mathrm{X}$ & & & & & \\
\hline $50-00-0$ & Formaldehyde & $\bar{X}$ & & & & & & \\
\hline $50-29-3$ & 4,4-DDT & $\mathrm{X}$ & & $\mathrm{X}$ & & $\mathrm{X}$ & & \\
\hline $50-32-8$ & Benzo(a)pyrene & $\mathrm{X}$ & & $\bar{X}$ & & $\mathrm{X}$ & & \\
\hline $504-29-0$ & 2-Aminopyridine & & $\mathrm{X}$ & $\mathrm{X}$ & & & & \\
\hline $506-77-4$ & Cyanogen chloride & & $\bar{X}$ & & & & & \\
\hline $509-14-8$ & Tetranitromethane & & $\bar{X}$ & & & & & \\
\hline $51-28-5$ & 2,4-Dinitrophenol & & $\mathrm{X}$ & $\bar{X}$ & & $\mathrm{X}$ & & \\
\hline $51-79-6$ & Ethyl carbamate (urethane) & & $\bar{x}$ & & & & & \\
\hline $510-15-6$ & Chlorobenzilate & $\mathrm{X}$ & & $\mathrm{X}$ & & $\mathrm{X}$ & & \\
\hline $5124-30-1$ & $\begin{array}{l}\text { Methylene-bis-(4-cyclo- } \\
\text { hexylisocyanate) }\end{array}$ & & $\mathrm{X}$ & & & & & \\
\hline $52-85-7$ & Famphur & & & $\mathrm{X}$ & & $\mathrm{X}$ & & \\
\hline $528-29-0$ & Dinitrobenzene, all isomers & & $\mathrm{X}$ & $\mathrm{X}$ & & & & \\
\hline $52888-80-9$ & Prosulfocarb & & & & & $\mathrm{X}$ & & \\
\hline $53-19-0$ & o,p'-DDD (2,4'-DDD) & & & $\mathrm{X}$ & & $\mathrm{X}$ & & \\
\hline $53-70-3$ & Dibenz[a,h]anthracene & $\mathrm{X}$ & & $\mathrm{X}$ & & $\mathrm{X}$ & & \\
\hline $53-96-3$ & 2-Acetylaminofluorene & $\mathrm{X}$ & . & $\mathrm{X}$ & & $\mathrm{X}$ & & \\
\hline $531-82-8$ & $\begin{array}{l}\text { N-(4-(5-Nitro-2-furyl)-2- } \\
\text { thiazolyl)acetamide }\end{array}$ & $\overline{\mathrm{X}}$ & & & & & & \\
\hline $532-27-4$ & a-Chloroacetophenone & & $\mathrm{X}$ & & & & & \\
\hline
\end{tabular}


Table B.2. Consolidated List of Compounds Used as Input for Regulatory Data Quality Objective List (850 Compounds). (Page 10 of 20)

\begin{tabular}{|c|c|c|c|c|c|c|c|c|}
\hline ess & Constituent & $\begin{array}{l}\text { Class } \mathrm{A} \\
\text { TAPs }\end{array}$ & Class B & UHC & $\begin{array}{l}\text { Part } \\
\text { DSTI } \\
\text { SST }\end{array}$ & UTS & WST & flammable \\
\hline $534-52-1$ & 4,6-Dinitro-o-cresol & & $\mathrm{X}$ & $\mathrm{X}$ & & $\mathrm{X}$ & & \\
\hline $54-11-5$ & Nicotine & & $\mathrm{X}$ & $\mathrm{X}$ & & & & \\
\hline $540-59-0$ & 1,2-Dichloroethylene & & $\mathrm{X}$ & & & & & \\
\hline $540-73-8$ & 1,2-Dimethylhydrazine & $\mathrm{X}$ & & & & & & . \\
\hline $540-84-1$ & 2,2,4-Trimethylpentane & & $\mathrm{X}$ & & & & & \\
\hline $540-88-5$ & tert-Butyl acetate & & $\mathrm{X}$ & & & & & \\
\hline $541-73-1$ & 1,3-Dichlorobenzene & & & $\mathrm{X}$ & & $\bar{X}$ & & \\
\hline $541-85-5$ & Ethyl amyl ketone. & & $\mathrm{X}$ & & & & & \\
\hline $542-75-6$ & 1,3-Dichloropropene & & $\bar{X}$ & & & & & \\
\hline $542-88-1$ & Dichloromethyl ether & $\mathrm{X}$ & & & & & & . \\
\hline $542-92-7$ & Cyclopentadiene & & $\mathrm{X}$ & & & & & \\
\hline $55-18-5$ & N-Nitrosodiethylamine & $\mathrm{X}$ & & $\mathrm{X}$ & & $\mathrm{X}$ & & \\
\hline $55-38-9$ & Fenthion & & $\mathrm{X}$ & & & & & \\
\hline $55-63-0$ & Nitroglycerin & & $\mathrm{X}$ & & & & & \\
\hline $552-30-7$ & Trimellitic anhydride & & $\mathrm{X}$ & & & & & \\
\hline $55285-14-8$ & Carbosulfan & & & & & $\mathrm{X}$ & & \\
\hline $55406-53-6$ & $\begin{array}{l}\text { 3-Iodo-2-propynyl n- } \\
\text { butylcarbamate }\end{array}$ & & & $\mathrm{X}$ & & & & \\
\hline $555-84-9$ & $\begin{array}{l}\text { 1-(5-Nitrofurfurylidene)amino)-2- } \\
\text { imidazolidinone }\end{array}$ & $\mathrm{X}$ & & & & & & \\
\hline $556-52-5$ & Glycidol & & $\mathrm{X}$ & & & & & \\
\hline 55684-94-1D & Hexachlorodibenzofurans & & & $\mathrm{X}$ & & & & \\
\hline $55720-99-5$ & Chlorinated diphenyl oxide & & $\bar{X}$ & & & & & \\
\hline $55738-54-0$ & $\begin{array}{l}\text { trans- } \\
\text { 2((Dimethylamino)methylimino)-5- } \\
\text { (2-(5-nitro-2-furyl) vinyl-1,3,4- } \\
\text { oxadiazole }\end{array}$ & $\bar{X}$ & & & & & & \\
\hline $558-13-4$ & Carbon tetrabromide & & $\mathrm{X}$ & & & & & \\
\hline $56-23-5$ & Carbon tetrachloride & $\mathrm{X}$ & & $\mathrm{X}$ & $\mathrm{X}$ & $\mathrm{X}$ & & \\
\hline $56-38-2$ & Parathion & & $\mathrm{X}$ & $\mathrm{X}$ & & $\bar{X}$ & & \\
\hline $56-49-5$ & 3-Methylcholanthrene & & & $\mathrm{X}$ & & $\bar{X}$ & & \\
\hline $56-55-3$ & Benzo(a)anthracene & $\bar{X}$ & & $\mathrm{X}$ & & $\mathrm{X}$ & & \\
\hline $563-12-2$ & Ethion & & $\mathrm{X}$ & & & & & \\
\hline $563-80-4$ & 3-Methyl-2-butanone & & $\mathrm{X}$ & & & & & \\
\hline $57-12-5$ & Cyanide & & $\mathrm{X}$ & $\mathrm{X}$ & & $\mathrm{X}$ & & \\
\hline $57-12-5 a$ & Cyanide (amenable) & & & $\mathrm{X}$ & & $\mathrm{X}$ & & \\
\hline $57-14-7$ & 1,1-Dimethylhydrazine & & $\mathrm{X}$ & & & & & \\
\hline $57-24-9$ & Strychnine & & $\mathrm{X}$ & & & & & \\
\hline $57-47-6$ & Physostigmine & & & & & $\mathrm{X}$ & & \\
\hline $57-57-8$ & B-Propiolactone & & $\mathrm{X}$ & & & & & \\
\hline $57-64-7$ & Physostigmine salicylate & & & & & $\bar{X}$ & & \\
\hline $57-74-9$ & Chlordane & $\mathrm{X}$ & & $\mathrm{X}$ & & $\mathrm{X}$ & & \\
\hline 57-74-D & $\begin{array}{l}\text { Chlordane (alpha and gamma } \\
\text { isomers) }\end{array}$ & & & $\mathrm{X}$ & & & & \\
\hline $5714-22-7$ & Sulfur pentafluoride & & $\mathrm{X}$ & & & & & \\
\hline $58-89-9$ & gamma-BHC (Lindane) & $\mathrm{X}$ & & $\mathrm{X}$ & & $\mathrm{X}$ & & \\
\hline $58-90-2$ & 2,3,4,6-Tetrachlorophenol & & & $\mathrm{X}$ & & $\mathrm{X}$ & & \\
\hline
\end{tabular}


Table B.2. Consolidated List of Compounds Used as Input for Regulatory Data Quality Objective List (850 Compounds). (Page 11 of 20)

\begin{tabular}{|c|c|c|c|c|c|c|c|c|}
\hline CAsH & Constituent & Class A & Glass B & GHC & $\begin{array}{l}\text { Part A } \\
\text { DSTl } \\
\text { SST }\end{array}$ & UIS & WSPS & Flaminable \\
\hline $583-60-8$ & o-Methylcyclohexanone & & $\mathrm{X}$ & & & & & \\
\hline $584-84-9$ & 2,4-Toluene diisocyanate & $\mathrm{X}$ & & & & & & \\
\hline $59-50-7$ & 4-Chloro-3-methylphenol & & & $\bar{X}$ & & $\mathrm{X}$ & & \\
\hline $59-87-0$ & Nitrofurazone & $\mathrm{X}$ & & & & & & \\
\hline $59-89-2$ & N-Nitrosomorpholine & $\bar{X}$ & & $\bar{X}$ & & $\bar{X}$ & & \\
\hline $591-78-6$ & 2-Hexanone & & $\mathrm{X}$ & & & & & \\
\hline $592-62-1$ & Methyl azoxymethyl acetate & $\bar{X}$ & & & & & & \\
\hline $593-60-2$ & Vinyl bromide & & $\bar{X}$ & & & & & \\
\hline $59355-75-8$ & $\begin{array}{l}\text { Methyl acetylene-propadiene } \\
\text { mixture (MAPP) }\end{array}$ & & $\mathrm{X}$ & & & & & \\
\hline $594-42-3$ & Perchloromethyl mercaptan & & $\mathrm{X}$ & & & & & \\
\hline $594-72-9$ & 1,1-Dichloro-1-nitroethane & & $\mathrm{X}$ & & & & & \\
\hline 5952-26-1 & Diethylene glycol, dicarbamate & & & & & $\mathrm{X}$ & & \\
\hline $59669-26-0$ & Thiodicarb & & & & & $\mathrm{X}$ & & \\
\hline $60-11-7$ & p-Dimethylaminoazobenzene & & $\mathrm{X}$ & $\mathrm{X}$ & & $\mathrm{X}$ & & \\
\hline $60-29-7$ & Ethyl ether & & $\mathrm{X}$ & $\mathrm{X}$ & $\mathrm{X}$ & $\mathrm{X}$ & & \\
\hline $60-34-4$ & Methylhydrazine & & $\mathrm{X}$ & & & & & \\
\hline $60-35-5$ & Acetamide & & $\mathrm{X}$ & & & & & \\
\hline $60-57-1$ & Dieldrin & $\bar{X}$ & & $\mathrm{X}$ & & $\mathrm{X}$ & & \\
\hline $600-25-9$ & 1-Chloro-1-nitropropane & & $\mathrm{X}$ & & & & & \\
\hline $602-87-9$ & 5-Nitroacenaphthene & $\mathrm{X}$ & & & & & & \\
\hline $603-34-9$ & Triphenyl amine & & $\mathrm{X}$ & & & & & \\
\hline $606-20-2$ & 2,6-Dinitrotoluene & & & $\mathrm{X}$ & & $\bar{X}$ & & \\
\hline $608-93-5$ & Pentachlorobenzene & & & $\mathrm{X}$ & & $\mathrm{X}$ & & \\
\hline $61-82-5$ & Amitrole & $\mathrm{X}$ & & & & & & \\
\hline $613-35-4$ & N,N-Diacetylbenzidine & $\overline{\mathrm{X}}$ & & & & & & \\
\hline $615-53-2$ & N-Nitroso-N-methylurethane & $\mathrm{X}$ & & & & & & \\
\hline $62-44-2$ & Phenacetin & & & $\mathrm{X}$ & & $\mathrm{X}$ & & \\
\hline $62-53-3$ & Aniline & $\mathrm{X}$ & $\mathrm{X}$ & $\mathrm{X}$ & & $\mathrm{X}$ & & \\
\hline $62-73-7$ & Dichlorvas & & $\bar{X}$ & & & & & \\
\hline 62-74-8 & $\begin{array}{l}\text { Fluoroacetic acid, sodium salt } \\
\text { (Fratol) }\end{array}$ & & $\mathrm{X}$ & & & & & \\
\hline $62-75-9$ & $\mathrm{~N}$-Nitroso-N,N-dimethylamine & $\mathrm{X}$ & & $\mathrm{X}$ & & $\mathrm{X}$ & & \\
\hline $621-64-7$ & N-Nitroso-di-n-propylamine & $\mathrm{X}$ & & $\mathrm{X}$ & & $\mathrm{X}$ & & \\
\hline $624-83-9$ & Methyl isocyanate & & $\bar{X}$ & & & & & \\
\hline $626-17-5$ & m-Phthalodinitrile & & $\mathrm{X}$ & & & & & \\
\hline $626-38-0$ & sec-Amyl acetate & & $\mathrm{X}$ & & & & & \\
\hline $627-13-4$ & Nitric acid, propyl ester & & $\mathrm{X}$ & & & & & \\
\hline $628-63-7$ & n-Amyl acetate & & $\mathrm{X}$ & & & & & \\
\hline $628-96-6$ & Ethylene glycol dinitrate & & $\mathrm{X}$ & & & & & \\
\hline $63-25-2$ & Carbaryl & & $\mathrm{X}$ & $\bar{X}$ & & $\mathrm{X}$ & & \\
\hline $63-92-3$ & Phenoxybenzamine hydrochloride & $\mathrm{X}$ & & & & & & \\
\hline $630-20-6$ & 1,1,1,2-Tetrachloroethane & & & $\mathrm{X}$ & $\mathrm{X}$ & $\mathrm{X}$ & & \\
\hline $636-21-5$ & o-Toluidine hydrochloride & $\mathrm{X}$ & & & & & & \\
\hline $638-21-1$ & Phenylphosphine & & $\mathrm{X}$ & & & & & \\
\hline $64-00-6$ & m-Cumenyl methylcarbamate & & & & & $\mathrm{X}$ & & \\
\hline $64-17-5$ & Ethyl alcohol & & $\mathrm{X}$ & & & & & \\
\hline
\end{tabular}


Table B.2. Consolidated List of Compounds Used as Input for Regulatory

Data Quality Objective List ( 850 Compounds). (Page 12 of 20)

\begin{tabular}{|c|c|c|c|c|c|c|c|c|}
\hline CASt? & Constituent & Class A & Class B & UHC: & Part A & UTS & WST: & Flammable \\
\hline $64-18-6$ & Formic acid & & $\mathrm{X}$ & & & & & \\
\hline 64-19-7 & Acetic acid & & $\mathrm{X}$ & & . & & & \\
\hline $64-67-5$ & Diethyl sulfate & & $\mathrm{X}$ & & & & & \\
\hline $64091-91-4$ & $\begin{array}{l}\text { 4-(Methylnitrosamino)-1-(3- } \\
\text { pyridyl)-1-butanone }\end{array}$ & $\mathrm{X}$ & & & & & & \\
\hline $6423-43-4$ & Propylene glycol dinitrate & & $\mathrm{X}$ & & & & & \\
\hline 644-64-4 & Dimetilan & & & & & $\mathrm{X}$ & & \\
\hline $66-27-3$ & Methyl methanesulfonate & & & $\mathrm{X}$ & & $\mathrm{X}$ & & \\
\hline $67-45-8$ & Furazolidone & $\overline{\mathrm{X}}$ & & & & & & \\
\hline $67-56-1$ & Methyl alcohol & & $\mathrm{X}$ & $\mathrm{X}$ & $\mathrm{X}$ & $\mathrm{X}$ & & \\
\hline $67-63-0$ & 2-Propyl alcohol & & $\mathrm{X}$ & & & & & \\
\hline $67-64-1$ & 2-Propanone (Acetone) & & $\mathrm{X}$ & $\bar{X}$ & $\mathrm{X}$ & $\mathrm{X}$ & & \\
\hline $67-66-3$ & Chloroform & $\mathrm{X}$ & & $\mathrm{X}$ & $X$ & $\mathrm{X}$ & & \\
\hline $67-72-1$ & Hexachloroethane & & $\mathrm{X}$ & $\mathrm{X}$ & $\bar{X}$ & $\mathrm{X}$ & & \\
\hline $68-11-1$ & Thioglycolic acid & & $\mathrm{X}$ & & & & & \\
\hline $68-12-2$ & Dimethylformamide & & $\mathrm{X}$ & & & & & \\
\hline $680-31-9$ & Hexamethylphosphoramide & $\mathrm{X}$ & & & & & & \\
\hline $681-84-5$ & Methyl silicate & & $\mathrm{X}$ & & & & & \\
\hline $684-16-2$ & Hexafluoroacetone & & $\bar{X}$ & & & & & \\
\hline $684-93-5$ & N-Nitroso-N-methylurea & & $\mathrm{X}$ & & & & & \\
\hline $68476-85-7$ & Liquified petroleum gas & & $\mathrm{X}$ & & & & & \\
\hline $6923-22-4$ & Monocrotophos & & $\bar{X}$ & & & & & \\
\hline $696-28-6$ & Dichlorophenylarsine & $\mathrm{X}$ & & & & & & \\
\hline $71-23-8$ & n-Propyl alcohol & & $\mathrm{X}$ & & & & & \\
\hline $71-36-3$ & n-Butyl alcohol & & $\mathrm{X}$ & $\mathrm{X}$ & $\mathrm{X}$ & $\mathrm{X}$ & & \\
\hline $71-43-2$ & Benzene & $\mathrm{X}$ & & $\bar{X}$ & $\mathrm{X}$ & $\bar{X}$ & & \\
\hline $71-55-6$ & 1,1,1-Trichloroethane & & $\mathrm{X}$ & $\mathrm{X}$ & $\bar{X}$ & $\mathrm{X}$ & & \\
\hline $72-20-8$ & Endrin & & $\mathrm{X}$ & $\mathrm{X}$ & & $\mathrm{X}$ & & \\
\hline $72-43-5$ & Methoxychlor & & $\bar{X}$ & $\mathrm{X}$ & & $\mathrm{X}$ & & \\
\hline $72-54-8$ & 4,4-DDD & & & $\bar{X}$ & & $\mathrm{X}$ & & \\
\hline $72-55-9$ & 4,4-DDE & & & $\mathrm{X}$ & & $\bar{X}$ & & \\
\hline $74-83-9$ & Bromomethane & & $\mathrm{X}$ & $\mathrm{X}$ & & $\bar{X}$ & & \\
\hline $74-87-3$ & Chloromethane & & $\mathrm{X}$ & $\mathrm{X}$ & & $\mathrm{X}$ & & \\
\hline $74-88-4$ & Iodomethane & & $\mathrm{X}$ & $\mathrm{X}$ & & $\mathrm{X}$ & & \\
\hline $74-89-5$ & Methylamine & & $\mathrm{X}$ & & & & & \\
\hline $74-90-8$ & Hydrogen cyanide & & $\mathrm{X}$ & & & & & \\
\hline $74-93-1$ & Thiomethanol & & $\mathrm{X}$ & & & & & \\
\hline $74-95-3$ & Dibromomethane & & & $\mathrm{X}$ & & $\bar{X}$ & & \\
\hline $74-96-4$ & Ethyl bromide & & $\mathrm{X}$ & & & & & \\
\hline $74-97-5$ & Bromochloromethane & & $\mathrm{X}$ & & & & & \\
\hline $74-99-7$ & Methylacetylene & & $\bar{X}$ & & & & & \\
\hline $7421-93-4$ & Endrin aldehyde & & & $\mathrm{X}$ & & $\mathrm{X}$ & & \\
\hline $7429-90-5$ & Aluminum & & $\mathrm{X}$ & & & & $\mathrm{X}$ & $\mathrm{X}$ \\
\hline $7429-90-5 \mathrm{Ca}$ & Aluminum, $\mathrm{Al}$ alkyls & & $\mathrm{X}$ & & & & & \\
\hline $7429-90-5 \mathrm{Cb}$ & Aluminum, as AL pyro powders & & $\mathrm{X}$ & & & & & \\
\hline $7429-90-5 \mathrm{Cc}$ & Aluminum, as Al soluble salts & & $\mathrm{X}$ & & & & & \\
\hline $7429-90-5 \mathrm{Ce}$ & Aluminum, as Al welding fumes & & $\mathrm{X}$ & & & & & \\
\hline
\end{tabular}


Table B.2. Consolidated List of Compounds Used as Input for Regulatory Data Quality Objective List ( 850 Compounds). (Page 13 of 20)

\begin{tabular}{|c|c|c|c|c|c|c|c|c|}
\hline $\mathrm{CASH}$ & Constituent & $\begin{array}{l}\text { Class A } \\
\text { Tips }\end{array}$ & $\begin{array}{l}\text { Class } \mathrm{B} \\
\text { TAPs }\end{array}$ & UHC & $\begin{array}{l}\text { Part A } \\
\text { osTl }\end{array}$ & UTS & DST: & Flamuable \\
\hline $7439-89-6$ & Iron & & & & & & $\mathrm{X}$ & $\mathrm{X}$ \\
\hline $7439-89-6 \mathrm{D}$ & Iron salts, soluble as $\mathrm{Fe}$ & & $\mathrm{X}$ & & & & & \\
\hline $7439-92-1$ & Lead & & & $\mathrm{X}$ & & $\bar{X}$ & & \\
\hline $7439-92-1 \mathrm{D}$ & Lead compounds & $\mathrm{X}$ & & & & & & \\
\hline $7439-96-5$ & Manganese & & & & & & $\mathrm{X}$ & \\
\hline 7439-96-5Ca & Manganese dust \& compounds & & $\bar{X}$ & & & & & \\
\hline $7439-96-5 \mathrm{Cb}$ & Manganese fume & & $\mathrm{X}$ & & & & & \\
\hline $7439-97-6$ & Mercury & & & $\mathrm{X}$ & $\bar{X}$ & $\bar{X}$ & & \\
\hline $7439-97-6 \mathrm{Ca}$ & Mercury, Aryl \& inorganic cmpd & & $\overline{\mathrm{X}}$ & & & & & \\
\hline $7439-97-6 \mathrm{Cb}$ & Mercury, as Hg Alkyl compounds & & $\mathrm{X}$ & & & & & \\
\hline $7439-97-6 \mathrm{Cc}$ & Mercury, vapors except alkyl & & $\mathrm{X}$ & & & & & \\
\hline 7439-98-7Ca & Molybdenum, insoluble cpds & & $\bar{X}$ & & & & & . \\
\hline $7439-98-7 \mathrm{Cb}$ & Molybdenum, as Mo soluble cpds & & $\bar{X}$ & & & & & \\
\hline $7440-02-0$ & Nickel & & & $\bar{X}$ & & $\mathrm{X}$ & $\mathrm{X}$ & $\bar{X}$ \\
\hline $7440-02-0 \mathrm{C}$ & Nickel compounds & $\mathrm{X}$ & & & & & & \\
\hline $7440-06-4$ & Platinum, metal & & $\mathrm{X}$ & & & & & 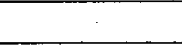 \\
\hline $7440-06-4 C$ & Platinum, soluble salts as $\mathrm{Pt}$ & & $\bar{X}$ & & & & & \\
\hline $7440-09-7$ & Potassium & & & & & & & $\mathrm{X}$ \\
\hline $7440-16-6$ & Rhodium Metal & & $\mathrm{X}$ & & & & & \\
\hline $7440-16-6 \mathrm{Ca}$ & Rhodium, insoluble compounds & & $\mathrm{X}$ & & & & & \\
\hline $7440-16-6 \mathrm{Cb}$ & Rhodium, soluble compounds & & $\mathrm{X}$ & & & & & \\
\hline $7440-21-3$ & Silicon & & & & & & & $\mathrm{X}$ \\
\hline $7440-22-4$ & Silver & & $\mathrm{X}$ & $\mathrm{X}$ & $\bar{X}$ & $\mathrm{X}$ & & \\
\hline $7440-22-4 \mathrm{Da}$ & Silver, soluble compounds as $\mathrm{Ag}$ & & $\mathrm{X}$ & & & & & \\
\hline $7440-23-5$ & Sodium & & & & & & $\mathrm{X}$ & $\mathrm{X}$ \\
\hline $7440-25-7 C$ & Tantalum, metal \& oxide dusts & & $\mathrm{X}$ & & & & & \\
\hline $7440-28-0$ & Thallium & & & $\mathrm{X}$ & & $\mathrm{X}$ & & \\
\hline $7440-28-0 \mathrm{C}$ & Thallium, soluble compounds, $\mathrm{Tl}$ & & $\mathrm{X}$ & & & & & \\
\hline $7440-31-5$ & $\begin{array}{l}\text { Tin, oxide \& inorganic except } \\
\text { SnH4 }\end{array}$ & & $\bar{X}$ & & & & & \\
\hline $7440-31-5 a$ & Tin, metal & & $\mathrm{X}$ & & & & & \\
\hline $7440-31-5 C$ & Tin, organic compounds, as Sn & & $\mathrm{X}$ & & & & & \\
\hline $7440-33-7 \mathrm{Ca}$ & Tungsten, insoluble compounds & & $\mathrm{X}$ & & & & & \\
\hline $7440-33-7 \mathrm{Cb}$ & Tungsten, soluble compounds & & $\bar{X}$ & & & & & \\
\hline $7440-36-0$ & Antimony & & & $\mathrm{X}$ & & $\mathrm{X}$ & & \\
\hline $7440-36-0 \mathrm{C}$ & Antimony \& compounds as $\mathrm{Sb}$ & & $\mathrm{X}$ & & & & & \\
\hline $7440-38-2$ & Arsenic & & & $\mathrm{X}$ & $\mathrm{X}$ & $\mathrm{X}$ & & . \\
\hline $7440-38-2 C$ & $\begin{array}{l}\text { Arsenic and inorganic arsenic } \\
\text { compounds }\end{array}$ & $\bar{X}$ & & & & & & \\
\hline $7440-39-3$ & Barium & & & $\mathrm{X}$ & $\bar{X}$ & $\mathrm{X}$ & & $\mathrm{X}$ \\
\hline $7440-39-3 \mathrm{Da}$ & Barium, soluble compounds $\mathrm{Ba}$ & & $\mathrm{X}$ & & & & & \\
\hline $7440-41-7$ & Beryllium & & & $\mathrm{X}$ & & $\mathrm{X}$ & & \\
\hline $7440-41-7 a$ & Beryllium powder & $\mathrm{X}$ & & & & & & \\
\hline $7440-42-8$ & Boron & & & & & & & $\mathrm{X}$ \\
\hline $7440-43-9$ & Cadmium & $\bar{X}$ & & $\bar{X}$ & $\bar{X}$ & $\bar{X}$ & & \\
\hline $7440-47-3$ & Chromium & & $\mathrm{X}$ & $\mathrm{X}$ & & $\mathrm{X}$ & $\mathrm{X}$ & $\mathrm{X}$ \\
\hline
\end{tabular}


Table B.2. Consolidated List of Compounds Used as Input for Regulatory

Data Quality Objective List ( 850 Compounds). (Page 14 of 20)

\begin{tabular}{|c|c|c|c|c|c|c|c|c|}
\hline CAst & Constituent & Class A & Class B & UHC: & $\begin{array}{l}\text { Part A } \\
\text { DSTI }\end{array}$ & UIS & WST & Tlaminable \\
\hline $7440-47-3 \mathrm{Da}$ & $\begin{array}{l}\text { Chromium, hexavalent metal and } \\
\text { compounds }\end{array}$ & $\mathrm{X}$ & & & & & & \\
\hline $7440-47-3 \mathrm{Db}$ & Chromium (II) compounds, as $\mathrm{Cr}$ & & $\mathrm{X}$ & & & & & \\
\hline $7440-47-3 D c$ & Chromium (III) compounds, $\mathrm{Cr}$ & & $\mathrm{X}$ & & & & & \\
\hline $7440-48-4 a$ & Cobalt as Co metal dust and fume & & $\mathrm{X}$ & & & & & \\
\hline $7440-50-8$ & Copper & & $\mathrm{X}$ & & & & & \\
\hline $7440-50-8 C$ & Copper, Dusts and mists, as $\mathrm{Cu}$ & & $\mathrm{X}$ & & & & & \\
\hline $7440-58-6$ & Hafnium & & $\mathrm{X}$ & & & & & \\
\hline $7440-61-1 C$ & Uranium, insoluble \& soluble & & $\mathrm{X}$ & & & & & \\
\hline $7440-62-2$ & Vanadium & & & $\mathrm{X}$ & & $\mathrm{X}$ & & \\
\hline $7440-65-5 \mathrm{C}$ & Yttrium, metal and compounds as Y & & $\mathrm{X}$ & & & & & \\
\hline $7440-66-6$ & Zinc & & & $\mathrm{X}$ & & $\mathrm{X}$ & & $\mathrm{X}$ \\
\hline $7440-67-7$ & Zirconium & & & & & & $\mathrm{X}$ & $\mathrm{X}$ \\
\hline $7440-67-7 \mathrm{C}$ & Zirconium compounds, as $\mathrm{Zr}$ & & $\mathrm{X}$ & & & & & \\
\hline $7440-69-9$ & Bismuth & & & & & & & $\mathrm{X}$ \\
\hline $7440-70-2$ & Calcium & & & & & & & $\mathrm{X}$ \\
\hline $7440-74-6 \mathrm{C}$ & Indium, \& compounds as In & & $\mathrm{X}$ & & & & & \\
\hline $7446-27-7$ & Lead phosphate & $\mathrm{X}$ & & & & & & \\
\hline $75-00-3$ & Chloroethane & & $X$ & $\mathrm{X}$ & & $\mathrm{X}$ & & \\
\hline $75-01-4$ & 1-Chloroethene & $\mathrm{X}$ & & $\mathrm{X}$ & & $\mathrm{X}$ & & \\
\hline $75-04-7$ & Ethylamine & & $\mathrm{X}$ & & & & & \\
\hline $75-05-8$ & Acetonitrile & & $\mathrm{X}$ & $\mathrm{X}$ & & $\mathrm{X}$ & & \\
\hline $75-07-0$ & Acetaldehyde & $\mathrm{X}$ & & & & & & \\
\hline $75-08-1$ & Ethyl mercaptan & & $\mathrm{X}$ & & & & & \\
\hline $75-09-2$ & $\begin{array}{l}\text { Dichloromethane (Methylene } \\
\text { Chloride) }\end{array}$ & $\mathrm{X}$ & & $\mathrm{X}$ & $\mathrm{X}$ & $\bar{X}$ & & \\
\hline $75-12-7$ & Formamide & & $\mathrm{X}$ & & & & & \\
\hline $75-15-0$ & Carbon disulfide & & $\mathrm{X}$ & $\mathrm{X}$ & $\mathrm{X}$ & $\mathrm{X}$ & & \\
\hline $75-21-8$ & Oxirane & $\mathrm{X}$ & & $\mathrm{X}$ & & $\bar{X}$ & & \\
\hline $75-25-2$ & Tribromomethane & $\mathrm{X}$ & & $\mathrm{X}$ & & $\mathrm{X}$ & & \\
\hline $75-27-4$ & Bromodichloromethane & & & $\mathrm{X}$ & & $\mathrm{X}$ & & \\
\hline $75-31-0$ & Isopropylamine & & $\mathrm{X}$ & & & & & \\
\hline $75-34-3$ & 1,1-Dichloroethane & & $\bar{X}$ & $\mathrm{X}$ & & $\bar{X}$ & & \\
\hline $75-35-4$ & 1,1-Dichloroethene & & $\mathrm{X}$ & $\mathrm{X}$ & & $\mathrm{X}$ & & \\
\hline $75-43-4$ & Dichlorofluoromethane & & $\mathrm{X}$ & & & & & \\
\hline $75-44-5$ & Phosgene & & $\mathrm{X}$ & & & & & \\
\hline $75-45-6$ & Chlorodifluoromethane & & $\mathrm{X}$ & & & & & \\
\hline $75-47-8$ & Iodoform & & $\mathrm{X}$ & & & & & \\
\hline $75-50-3$ & Trimethylamine & & $\mathrm{X}$ & & & & & \\
\hline $75-52-5$ & Nitromethane & & $\mathrm{X}$ & $\mathrm{X}$ & & & & \\
\hline $75-55-8$ & 2-Methylaziridine & & $\mathrm{X}$ & & & & & \\
\hline $75-56-9$ & Propylene oxide & $\mathrm{X}$ & & & & & & \\
\hline $75-61-6$ & Difluorodibromomethane & & $\mathrm{X}$ & & & & & \\
\hline $75-63-8$ & Trifluorobromomethane & & $\mathrm{X}$ & & & & & \\
\hline $75-65-0$ & 2-Methyl-2-propanol & & $\mathrm{X}$ & & & & & \\
\hline $75-69-4$ & Trichlorofluoromethane & & $\bar{X}$ & $\mathrm{X}$ & & $\mathrm{X}$ & & \\
\hline $75-71-8$ & Dichlorodifluoromethane & & $\mathrm{X}$ & $\mathrm{X}$ & & $\mathrm{X}$ & & \\
\hline
\end{tabular}


Table B.2. Consolidated List of Compounds Used as Input for Regulatory Data Quality Objective List ( 850 Compounds). (Page 15 of 20)

\begin{tabular}{|c|c|c|c|c|c|c|c|c|}
\hline CAS\# & Constituent & Gassal & $\begin{array}{l}\text { Class B } \\
\text { TAPs }\end{array}$ & UHe & Part & UIS & WST & Tlaminable \\
\hline $75-74-1$ & Tetramethyl lead, as $\mathrm{Pb}$ & & $\bar{X}$ & & & & & \\
\hline $75-99-0$ & 2,2-Dichloropropionic acid & & $\mathrm{X}$ & & & & & \\
\hline $7550-45-0$ & Titanium tetrachloride & & $\mathrm{X}$ & & & & & \\
\hline $7553-56-2$ & Iodine & & $\bar{X}$ & & & & & \\
\hline $7572-29-4$ & Dichloroacetylene & & $\mathrm{X}$ & & & & & \\
\hline $7580-67-8$ & Lithium hydride & & $\mathrm{X}$ & & & & & \\
\hline $759-73-9$ & N-Nitroso-N-ethylurea & $\mathrm{X}$ & & & & & & \\
\hline $759-94-4$ & EPTC & & & $\bar{X}$ & & $\mathrm{X}$ & & \\
\hline $76-01-7$ & Pentachloroethane & & & $\mathrm{X}$ & & $\mathrm{X}$ & & \\
\hline $76-03-9$ & Trichloroacetic acid & & $\mathrm{X}$ & & & & & \\
\hline $76-06-2$ & Chloropicrin & & $\mathrm{X}$ & & & & & \\
\hline $76-11-9$ & $\begin{array}{l}\text { 1,1,1,2-Tetrachloro-2,2- } \\
\text { difluoroethane }\end{array}$ & & $\mathrm{X}$ & & & & & \\
\hline $76-12-0$ & $\begin{array}{l}\text { 1,1,2,2-Tetrachloro-1,2- } \\
\text { difluoroethane }\end{array}$ & & $\mathrm{X}$ & & & & & \\
\hline $76-13-1$ & 1,2,2-Trichlorotrifluoroethane & & $\mathrm{X}$ & $\mathrm{X}$ & $\mathrm{X}$ & $\bar{X}$ & & \\
\hline $76-14-2$ & $\begin{array}{l}\text { 1,2-Dichloro-1,1,2,2- } \\
\text { tetrafluoroethane }\end{array}$ & & $\mathrm{X}$ & & & & & \\
\hline $76-15-3$ & Chloropentafluoroethane & & $\mathrm{X}$ & & & & & \\
\hline $76-22-2$ & Camphor, synthetic & & $\bar{X}$ & & & & & \\
\hline $76-44-8$ & Heptachlor & $\mathrm{X}$ & & $\mathrm{X}$ & & $\bar{X}$ & & \\
\hline $7616-94-6$ & Perchloryl fluoride & & $\mathrm{X}$ & & & & & \\
\hline $7631-90-5$ & Sodium bisulfite & & $\mathrm{X}$ & & & & & \\
\hline $764-41-0$ & 1,4-Dichloro-2-butene & $\bar{X}$ & & & & & & \\
\hline $7646-85-7$ & Zinc chloride fume & & $\mathrm{X}$ & & & & & \\
\hline $7647-01-0$ & Hydrogen chloride & & $\mathrm{X}$ & & & & & \\
\hline $765-34-4$ & Glycidylaldehyde & $\mathrm{X}$ & & & & & & \\
\hline $7664-38-2$ & Phosphoric acid & & $\overline{\mathrm{X}}$ & & & & & \\
\hline $7664-39-3$ & Hydrogen fluoride & & $\bar{X}$ & & & & & \\
\hline $7664-41-7$ & Ammonia & & $\bar{X}$ & & & & $\mathrm{X}$ & \\
\hline $7664-93-9$ & Sulfuric acid & & $\bar{X}$ & & & & & \\
\hline $76737-07-2$ & Boron trifluoride & & $\bar{X}$ & & & & & \\
\hline $768-52-5$ & $\mathrm{~N}$-Isopropylaniline & & $\mathrm{X}$ & & & & & \\
\hline $7681-57-4$ & Sodium metabisulfite & & $\bar{X}$ & & & & & \\
\hline $7697-37-2$ & Nitric acid/Nitrate & & $\bar{X}$ & & & & $\mathrm{X}$ & $\mathrm{X}$ \\
\hline $77-47-4$ & Hexachlorocyclopentadiene & & $\mathrm{X}$ & $\bar{X}$ & & $\mathrm{X}$ & & \\
\hline $77-73-6$ & Dicyclopentadiene & & $\mathrm{X}$ & & & & & \\
\hline $77-78-1$ & Dimethyl sulfate & $\bar{X}$ & & & & & & \\
\hline $7719-09-7$ & Thionyl chloride & & $\mathrm{X}$ & & & & & \\
\hline $7719-12-2$ & Phosphorus trichloride & & $\mathrm{X}$ & & & & & \\
\hline $7722-84-1$ & Hydrogen peroxide & & $\bar{X}$ & & & & & \\
\hline $7722-88-5$ & Tetrasodium pyrophosphate & & $\mathrm{X}$ & & & & a. & \\
\hline $7723-14-0$ & Phosphorus & & $\mathrm{X}$ & & & & & \\
\hline $7726-95-6$ & Bromine & & $\mathrm{X}$ & & & & & \\
\hline $7758-97-6$ & Lead chromate, as $\mathrm{Cr}$ & & $\bar{X}$ & & & & & \\
\hline $7773-06-0$ & Ammonium sulfamate & & $\mathrm{X}$ & & & & & \\
\hline $7782-41-4$ & Fluorine & & $\mathrm{X}$ & & & & & \\
\hline
\end{tabular}


Table B.2. Consolidated List of Compounds Used as Input for Regulatory Data Quality Objective List (850 Compounds). (Page 16 of 20)

\begin{tabular}{|c|c|c|c|c|c|c|c|c|}
\hline $\mathrm{CASH}$ & Constituent & $\begin{array}{l}\text { Class A } \\
\text { TAPs: }\end{array}$ & $\begin{array}{l}\text { Class B } \\
\text { TAPs }\end{array}$ & UHe & $\begin{array}{l}\text { part } \\
\text { ost? } \\
\text { Sst }\end{array}$ & USS & $\begin{array}{l}\text { DST } \\
\text { WSPS }\end{array}$ & Tlampable \\
\hline $7782-49-2$ & Selenium & & & $\mathrm{X}$ & $\mathrm{X}$ & $\mathrm{X}$ & & \\
\hline $7782-49-2 C$ & Selenium compounds, as Se & & $\mathrm{X}$ & & & & & \\
\hline $7782-50-5$ & Chlorine & & $\mathrm{X}$ & & & & & \\
\hline $7782-65-2$ & Germanium tetrahydride & & $\mathrm{X}$ & & & & & \\
\hline $7783-06-4$ & Hydrogen sulfide & & $\mathrm{X}$ & & & & & \\
\hline $7783-07-5$ & Hydrogen selenide, as Se & & $\bar{X}$ & & & & & \\
\hline $7783-41-7$ & Oxygen difluoride & & $\mathrm{X}$ & & & & & \\
\hline $7783-54-2$ & Nitrogen trifluoride & & $\mathrm{X}$ & & & & & \\
\hline $7783-60-0$ & Sulfur tetrafluoride & & $\bar{X}$ & & & & & \\
\hline $7783-79-1$ & Selenium hexafluoride, as $\mathrm{Se}$ & & $\mathrm{X}$ & & & & & \\
\hline $7783-80-4$ & Tellurium hexafluoride, as Te & & $\mathrm{X}$ & & & & & \\
\hline $7784-42-1$ & Arsine & & $\mathrm{X}$ & & & & & \\
\hline $7786-34-7$ & Mevinphos & & $\mathrm{X}$ & & & & & \\
\hline $7789-30-2$ & Bromine pentafluoride & & $\mathrm{X}$ & & & & & \\
\hline $7790-91-2$ & Chlorine trifluoride & & $\mathrm{X}$ & & & & & \\
\hline $78-00-2$ & Tetraethyl lead & & $\mathrm{X}$ & & & & & \\
\hline $78-10-4$ & Ethyl silicate & & $\mathrm{X}$ & & & & & \\
\hline $78-30-8$ & Triorthocresyl phosphate & & $\mathrm{X}$ & & & & & \\
\hline $78-34-2$ & Dioxathion & & $\mathrm{X}$ & & & & & \\
\hline $78-59-1$ & Isophorone & & $\mathrm{X}$ & & & & & \\
\hline $78-83-1$ & 2-Methylpropyl alcohol & & $\mathrm{X}$ & $\mathrm{X}$ & $\mathrm{X}$ & $\mathrm{X}$ & & \\
\hline $78-87-5$ & 1,2-Dichloropropane & $\mathrm{X}$ & & $\bar{X}$ & & $\mathrm{X}$ & & \\
\hline $78-92-2$ & 1-Methylpropyl alcohol & & $\mathrm{X}$ & & & & & \\
\hline $78-93-3$ & 2-Butanone & & $\mathrm{X}$ & $\mathrm{X}$ & $\mathrm{X}$ & $\mathrm{X}$ & & \\
\hline $7803-51-2$ & Phosphine & & $\bar{X}$ & & & & & \\
\hline $7803-52-3$ & Stibine & & $\mathrm{X}$ & & & & & \\
\hline $7803-62-5$ & Silicon tetrahydride & & $\mathrm{X}$ & . & & & & \\
\hline $789-02-6$ & $o, p^{\prime}-\mathrm{DDT}\left(2,4^{\prime}-\mathrm{DDT}\right)$ & & & $\mathrm{X}$ & & $\mathrm{X}$ & & \\
\hline $79-00-5$ & 1,1,2-Trichloroethane & & $\mathrm{X}$ & $\mathrm{X}$ & $\mathrm{X}$ & $\mathrm{X}$ & & \\
\hline $79-01-6$ & 1,1,2-Trichloroethylene & $\mathrm{X}$ & & $\mathrm{X}$ & $\mathrm{X}$ & $\mathrm{X}$ & & \\
\hline $79-04-9$ & Chloroacetyl chloride & & $\mathrm{X}$ & & & & & \\
\hline $79-06-1$ & Acrylamide & $\mathrm{X}$ & & $\mathrm{X}$ & & $\bar{X}$ & & \\
\hline $79-09-4$ & Propanoic acid & & $\mathrm{X}$ & & & & & \\
\hline $79-10-7$ & 2-Propenoic acid & & $\mathrm{X}$ & & & & & \\
\hline $79-11-8$ & Chloroacetic acid & & $\mathrm{X}$ & & & & & \\
\hline $79-20-9$ & Methyl acetate & & $\mathrm{X}$ & & & & & \\
\hline $79-24-3$ & Nitroethane & & $\mathrm{X}$ & & & & & \\
\hline $79-27-6$ & Acetylene tetrabromide & & $\bar{X}$ & & & & & \\
\hline $79-34-5$ & 1,1,2,2-Tetrachloroethane & & $\mathrm{X}$ & $\mathrm{X}$ & & $\mathrm{X}$ & & \\
\hline $79-41-4$ & Methacrylic acid & & $\mathrm{X}$ & & & & & \\
\hline $79-44-7$ & Dimethylcarbamoyl chloride & & $\bar{X}$ & & & & & \\
\hline $79-46-9$ & 2-Nitropropane & $\mathrm{X}$ & & & & & & \\
\hline $794-93-4$ & $\begin{array}{l}\text { Panfuran S } \\
\text { (dihydroxymethylfuratrizine) }\end{array}$ & $\bar{X}$ & & & & & & \\
\hline $80-62-6$ & Methyl methacrylate & & $\mathrm{X}$ & $\mathrm{X}$ & & $\mathrm{X}$ & & \\
\hline $8001-35-2$ & Toxaphene & $\mathrm{X}$ & & $\mathrm{X}$ & & $\mathrm{X}$ & & \\
\hline 8001-58-9 & Creosote & $\mathrm{X}$ & & & & & & \\
\hline
\end{tabular}


Table B.2. Consolidated List of Compounds Used as Input for Regulatory Data Quality Objective List ( 850 Compounds). (Page 17 of 20)

\begin{tabular}{|c|c|c|c|c|c|c|c|c|}
\hline $\mathrm{QAs} \|$ & Constituent & $\begin{array}{l}\text { Class A } \\
\text { TAPs }\end{array}$ & Class B & UHC & $\begin{array}{l}\text { Part } \\
\text { DSTI } \\
\text { SST }\end{array}$ & UTS & WST: & Trammable \\
\hline $8002-74-2$ & Parafin wax fume & & $\mathrm{X}$ & & & & & \\
\hline $8003-34-7$ & Pyrethrum & & $\mathrm{X}$ & & & & & \\
\hline $8006-64-2$ & Turpentine & & $\bar{X}$ & & & & & \\
\hline $8012-95-1$ & Oil mist, mineral & & $\mathrm{X}$ & & & & & \\
\hline $8022-00-2$ & Methyl demeton & & $\overline{\mathrm{X}}$ & & & & & \\
\hline $8030-30-6$ & Rubber solvent (Naphtha) & & $\mathrm{X}$ & & & & & \\
\hline $8032-32-4$ & VM \& P Naphtha & & $\mathrm{X}$ & & & & & \\
\hline $8052-42-4$ & Asphalt (petroleum) fumes & & $\mathrm{X}$ & & & & & \\
\hline $8065-48-3$ & Demeton & & $\mathrm{X}$ & & & & & \\
\hline $81-81-2$ & Warfarin $(>0.3 \%)$ & & $\mathrm{X}$ & & & & & \\
\hline $81-81-2 a$ & Warfarin $(<0.3 \%)$ & & $\bar{X}$ & & & & & \\
\hline $82-68-8$ & Pentachloronitrobenzene (PCNB) & & $\mathrm{X}$ & $\mathrm{X}$ & & $\mathrm{X}$ & & \\
\hline $822-06-0$ & Hexamethylene diisocyanate & & $\mathrm{X}$ & & & & & \\
\hline $83-26-1$ & Pindone & & $\mathrm{X}$ & & & & & \\
\hline $83-32-9$ & Acenaphthene & & & $\mathrm{X}$ & & $\mathrm{X}$ & & \\
\hline $83-79-4$ & Rotenone & & $\mathrm{X}$ & & & & & \\
\hline $838-88-0$ & 4,4'-Methylenebis(2-methylaniline) & $\mathrm{X}$ & & & & & & \\
\hline $84-66-2$ & Diethyl phthalate & & $\mathrm{X}$ & $\mathrm{X}$ & & $\mathrm{X}$ & & \\
\hline $84-74-2$ & Di-n-butylphthalate & & $\mathrm{X}$ & $\mathrm{X}$ & & $\mathrm{X}$ & & \\
\hline $8496-25-8$ & Sulfide & & & $\bar{X}$ & & $\bar{X}$ & & \\
\hline $85-00-7$ & Diquat & & $\mathrm{X}$ & & & & & \\
\hline $85-01-8$ & Phenanthrene & & & $\mathrm{X}$ & & $\mathrm{X}$ & & \\
\hline $85-44-9$ & Phthalic anhydride & & $\mathrm{X}$ & $\bar{X}$ & & $\mathrm{X}$ & & \\
\hline $85-68-7$ & Butylbenzylphthalate & & & $\mathrm{X}$ & & $\bar{X}$ & & \\
\hline $86-30-6$ & N-Nitrosodiphenylamine & $\mathrm{X}$ & & $\mathrm{X}$ & & $\mathrm{X}$ & & \\
\hline $86-50-0$ & Azinphos-methyl & & $\bar{X}$ & & & & & \\
\hline $86-73-7$ & Fluorene & & & $\mathrm{X}$ & & $\mathrm{X}$ & & \\
\hline $86-88-4$ & alpha-Naphthylthiourea & & $\mathrm{X}$ & & & & & \\
\hline $87-65-0$ & 2,6-Dichlorophenol & & & $\mathrm{X}$ & & $\mathrm{X}$ & & \\
\hline $87-68-3$ & Hexachlorobutadiene & & $\mathrm{X}$ & $\mathrm{X}$ & $\mathrm{X}$ & $\bar{X}$ & & \\
\hline $87-86-5$ & Pentachlorophenol & $\mathrm{X}$ & & $\mathrm{X}$ & & $\mathrm{X}$ & & \\
\hline $88-06-2$ & 2,4,6-Trichlorophenol & $\mathrm{X}$ & & $\mathrm{X}$ & & $\mathrm{X}$ & & \\
\hline $88-72-2$ & Nitrotoluene & & $\mathrm{X}$ & & & & & \\
\hline $88-74-4$ & 2-Nitroaniline & & & $\mathrm{X}$ & & $\mathrm{X}$ & & \\
\hline $88-75-5$ & 2-Nitrophenol & & & $\mathrm{X}$ & & $\mathrm{X}$ & & \\
\hline $88-85-7$ & $\begin{array}{l}\text { 2-sec-Butyl-4,6-dinitrophenol; syn } \\
\text { Dinoseb }\end{array}$ & & & $\mathrm{X}$ & & $\mathrm{X}$ & & \\
\hline $88-89-1$ & Picric acid & & $\mathrm{X}$ & & & & & \\
\hline $89-72-5$ & o-sec-Butylphenol & & $\mathrm{X}$ & & & & & \\
\hline $90-04-0$ & o-Anisidine & $\mathrm{X}$ & & & & & & \\
\hline $91-20-3$ & Naphthalene & & $\mathrm{X}$ & $\bar{X}$ & & $\mathrm{X}$ & & \\
\hline $91-22-5$ & Quinoline & & $\mathrm{X}$ & & & & & \\
\hline $91-58-7$ & 2-Chloronaphthalene & & & $\overline{\mathrm{X}}$ & & $\mathrm{X}$ & & \\
\hline $91-59-8$ & 2-Napthylamine & & & $\mathrm{X}$ & & $\mathrm{X}$ & & \\
\hline $91-80-5$ & Methapyrilene & & & $\mathrm{X}$ & & $\mathrm{X}$ & & \\
\hline $91-94-1$ & 3,3-Dichlorobenzidine & $\mathrm{X}$ & & & & & & \\
\hline $92-52-4$ & 1,1`-Biphenyl & & $\mathrm{X}$ & & & & & \\
\hline
\end{tabular}


Table B.2. Consolidated List of Compounds Used as Input for Regulatory Data Quality Objective List (850 Compounds). (Page 18 of 20)

\begin{tabular}{|c|c|c|c|c|c|c|c|c|}
\hline CLS\# & Constituent & $\begin{array}{l}\text { Glass:A } \\
\text { TAPs }\end{array}$ & Glass B & UHC & $\begin{array}{l}\text { Part A } \\
\text { osT } \\
\text { SST }\end{array}$ & UTS & WST & $\begin{array}{l}\text { Tlammable } \\
\text { Gases }\end{array}$ \\
\hline $92-67-1$ & 4-Aminobiphenyl & $\mathrm{X}$ & & $\mathrm{X}$ & & $\mathrm{X}$ & & \\
\hline $92-84-2$ & Phenothiazine & & $\mathrm{X}$ & & & & & \\
\hline $92-87-5$ & Benzidine & $\mathrm{X}$ & & & & & & \\
\hline $92-93-3$ & 4-Nitrobiphenyl & & $\mathrm{X}$ & & & & & \\
\hline $924-16-3$ & N-Nitrosodi-n-butylamine & $\mathrm{X}$ & & $\bar{X}$ & & $\mathrm{X}$ & & \\
\hline $93-72-1$ & Silvex $(2,4,5-\mathrm{TP})$ & & & $\bar{X}$ & & $\bar{X}$ & & \\
\hline $93-76-5$ & $2,4,5-\mathrm{T}$ & & $\mathrm{X}$ & $\mathrm{X}$ & & $\mathrm{X}$ & & \\
\hline $930-55-2$ & N-Nitrosopyrrolidine & & & $\mathrm{X}$ & & $\mathrm{X}$ & & \\
\hline $94-36-0$ & Benzoyl Peroxide & & $\bar{X}$ & & & & & \\
\hline $94-59-7$ & Safrole & & & $\bar{X}$ & & $\mathrm{X}$ & & \\
\hline $94-75-7$ & $2,4-\mathrm{D}$ & $\mathrm{X}$ & & $\mathrm{X}$ & & $\mathrm{X}$ & & \\
\hline $944-22-9$ & Fonofos & & $\mathrm{X}$ & 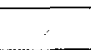 & & & & \\
\hline $95-13-6$ & Indene & & $\mathrm{X}$ & & & & & \\
\hline $95-47-6$ & o-Xylene & & & $\bar{X}$ & $\mathrm{X}$ & $\mathrm{X}$ & & \\
\hline $95-48-7$ & o-Cresol & & $\mathrm{X}$ & $\mathrm{X}$ & $\mathrm{X}$ & $\mathrm{X}$ & & \\
\hline $95-49-8$ & o-Chlorotoluene & & $\bar{X}$ & & & & & \\
\hline $95-50-1$ & 1,2-Dichlorobenzene & & $\mathrm{X}$ & $\mathrm{X}$ & $\mathrm{X}$ & $\mathrm{X}$ & & \\
\hline $95-53-4$ & o-Toluidine (2-methylaniline) & $\mathrm{X}$ & & & & & & \\
\hline $95-54-5$ & 1,2-Phenylenediamine & & & & & $\mathrm{X}$ & & \\
\hline $95-57-8$ & 2-Chlorophenol & & & $\mathrm{X}$ & & $\mathrm{X}$ & & \\
\hline $95-80-7$ & Toluene-2,4-diamine & $\mathrm{X}$ & & & & & & \\
\hline $95-94-3$ & 1,2,4,5-Tetrachlorobenzene & & & $\bar{X}$ & & $\mathrm{X}$ & & \\
\hline $95-95-4$ & 2,4,5-Trichlorophenol & & $\bar{X}$ & $\bar{X}$ & $\mathrm{X}$ & $\bar{X}$ & & \\
\hline $959-98-8$ & Endosulfan I & & & $\mathrm{X}$ & & $\bar{X}$ & & \\
\hline $96-09-3$ & Styrene oxide & & $\mathrm{X}$ & & & & & \\
\hline $96-12-8$ & 1,2-Dibromo-3-chloropropane & & $\bar{X}$ & $\bar{X}$ & & $\mathrm{X}$ & & \\
\hline $96-18-4$ & $1,2,3$-Trichloropropane & & $\mathrm{X}$ & $\bar{X}$ & & $\bar{X}$ & & \\
\hline $96-22-0$ & 3-Pentanone & & $\mathrm{X}$ & & & & & \\
\hline $96-33-3$ & Methyl acrylate & & $\mathrm{X}$ & & & & & \\
\hline $96-45-7$ & Ethylenethiourea & $\mathrm{X}$ & & & & & & \\
\hline $96-69-5$ & $\begin{array}{l}\text { Bis(3-tert-butyl-4-hydroxy-6- } \\
\text { methyl-phenyl) sulfide }\end{array}$ & & $\mathrm{X}$ & & & & & \\
\hline $97-56-3$ & o-Aminoazotoluene & $\mathrm{X}$ & & & & & & \\
\hline $97-63-2$ & Ethyl methacrylate & & & $\mathrm{X}$ & & $\mathrm{X}$ & & \\
\hline $97-77-8$ & Disulfiram & & $\mathrm{X}$ & & & & & \\
\hline $98-00-1$ & Furfuryl alcohol & & $\mathrm{X}$ & & & & & \\
\hline 98-01-1 & Furfural & & $\mathrm{X}$ & & & & & \\
\hline 98-07-7 & Benzotrichloride & & $\mathrm{X}$ & & & & & \\
\hline $98-51-1$ & p-tert-Butyltoluene & & $\mathrm{X}$ & & & & & \\
\hline $98-82-2$ & Cumene & & $\mathrm{X}$ & & & & & \\
\hline $98-83-9$ & Methylstyrene & & $\mathrm{X}$ & & & & & \\
\hline $98-86-2$ & Acetophenone & & $\mathrm{X}$ & $\mathrm{X}$ & & $\mathrm{X}$ & & \\
\hline $98-87-3$ & Benzal chloride & & & $\mathrm{X}$ & & $\mathrm{X}$ & & \\
\hline $98-95-3$ & Nitrobenzene & & $\mathrm{X}$ & $\mathrm{X}$ & $\mathrm{X}$ & $\mathrm{X}$ & & \\
\hline $99-55-8$ & 5-Nitro-o-toluidine & & & $\mathrm{X}$ & & $\mathrm{X}$ & & \\
\hline $999-61-1$ & 2-Hydroxypropyl acrylate & & $\mathrm{X}$ & & & & & \\
\hline
\end{tabular}


Table B.2. Consolidated List of Compounds Used as Input for Regulatory Data Quality Objective List (850 Compounds). (Page 19 of 20)

\begin{tabular}{|c|c|c|c|c|c|c|c|c|}
\hline CAs\# & Constituent & Class & Glass B & UHC & Parta & USS & WST: & Flammable \\
\hline HxCDD & $\begin{array}{l}\text { HxCDDs (All Hexachlorodibenzo- } \\
\text { p-dioxins) }\end{array}$ & & & & & $\mathrm{X}$ & & . \\
\hline $\mathrm{HxCDF}$ & $\begin{array}{l}\text { HxCDFs (All } \\
\text { Hexachlorodibenzofurans) }\end{array}$ & & & & . & $\mathrm{X}$ & & \\
\hline I127 & $\mathrm{Pu}-239 / 240$ & & & & & & $\mathrm{X}$ & \\
\hline $\mathrm{I} 175$ & $\mathrm{U}-235$ & & & & & & $\mathrm{X}$ & \\
\hline$\overline{\mathrm{I} 176}$ & U-gross & & & & & & $\mathrm{X}$ & \\
\hline I4 & $\begin{array}{l}\text { Aluminum smelter polyaromatic } \\
\text { hydrocarbon emissions }\end{array}$ & $\mathrm{X}$ & & & & & & \\
\hline 151 & Cotton dust, raw & & $\bar{X}$ & & & & & \\
\hline NA1 & Chlorinated fluorocarbons, N.O.S. & & & & $\mathrm{X}$ & & & \\
\hline NA115 & Viscosity & & & & & & $\bar{X}$ & \\
\hline NA117 & Ignitability (Flash Point) & & & & & & $\mathrm{X}$ & \\
\hline NA118 & Color & & & & & & $\mathrm{X}$ & \\
\hline NA12 & Organics, separable & & & & & & $\mathrm{X}$ & \\
\hline NA2 & Specific gravity (SPG) & & & & & & $\mathrm{X}$ & \\
\hline NA20 & Welding fumes & & $\mathrm{X}$ & & & & & \\
\hline NA21 & Polyaromatic hydrocarbons (PAH) & $\bar{X}$ & & & & & & \\
\hline NA22 & Fine mineral fibers & & $\mathrm{X}$ & & & & & \\
\hline NA23 & Fibrous glass dust & & $\mathrm{X}$ & & & & & \\
\hline NA24 & Dioxins and furans & $\mathrm{X}$ & & & & & & \\
\hline NA25 & Coke oven emissions & $\mathrm{X}$ & & & & & & \\
\hline NA28 & $\%$ solids & & & & & & $\mathrm{X}$ & \\
\hline NA29 & Total organic carbon (TOC) & & & & & & $\mathrm{X}$ & \\
\hline NA3 & $\%$ moisture & & & & & & $\mathrm{X}$ & \\
\hline NA30 & Total suspended solids & & & & & & $\mathrm{X}$ & \\
\hline NA31 & $\begin{array}{l}\text { DW, WP02, persistent DW } \\
\text { halogenated hydrocarbons }\end{array}$ & & & & $\bar{X}$ & & & \\
\hline NA32 & $\begin{array}{l}\text { EHW, WP01, persistent DW } \\
\text { halogenated hydrocarbons }\end{array}$ & & & & $\bar{X}$ & & & \\
\hline NA33 & DW, WT02, toxic dangerous waste & & & & $\mathrm{X}$ & & & \\
\hline NA34 & $\begin{array}{l}\text { EHW, WT01, toxic dangerous } \\
\text { waste }\end{array}$ & & & & $\mathrm{X}$ & & & \\
\hline NA38 & Total Alpha (AT) & & & & & & $\mathrm{X}$ & \\
\hline NA6 & $\mathrm{pH}$ & & & & & & $\mathrm{X}$ & $\mathrm{X}$ \\
\hline NA7 & Energetics & & & & & & $\mathrm{X}$ & \\
\hline PeCDD & $\begin{array}{l}\text { PeCDDs (All Pentachlorodibenzo- } \\
\text { p-dioxins) }\end{array}$ & & & & & $\mathrm{X}$ & & \\
\hline PeCDF & $\begin{array}{l}\text { PeCDFs (All } \\
\text { Pentachlorodibenzofurans) }\end{array}$ & & & & & $\mathrm{X}$ & & \\
\hline TCDD & $\begin{array}{l}\text { TCDDs (All Tetrachlorodibenzo-p- } \\
\text { dioxins) }\end{array}$ & & & & & $\mathrm{X}$ & & \\
\hline TCDF & $\begin{array}{l}\text { TCDFs (All } \\
\text { Tetrachlorodibenzofurans) }\end{array}$ & & & & & $\mathrm{X}$ & & \\
\hline
\end{tabular}


Table B.2. Consolidated List of Compounds Used as Input for Regulatory Data Quality Objective List ( 850 Compounds). (Page 20 of 20)

\begin{tabular}{|c|c|c|c|c|c|c|c|c|c|}
\hline \multicolumn{2}{|c|}{ QASH } & Constituent: & $\begin{array}{l}\text { Class A } \\
\text { TAPs? }\end{array}$ & $\begin{array}{l}\text { Class B } \\
\text { TAPS }\end{array}$ & UHC: & Part & UIS & \multirow[t]{2}{*}{$\begin{array}{l}\text { DST } \\
\text { WSPS }\end{array}$} & Glammable \\
\hline UN6 & & Isopropyl oils & $\mathrm{X}$ & & & & & & \\
\hline UN8 & & Nitrofurans & $\overline{\mathrm{X}}$ & & & & & & \\
\hline CAS\# & $=$ & chemical abstract service number. & & & & & & & \\
\hline DST & $=$ & double-shell tank. & & & & & & & \\
\hline SST & $=$ & single-shell tank. & & & & & & & \\
\hline TAP & $=$ & toxic air pollutant. & & & & & & & \\
\hline UHC & $=$ & underlying hazardous constituents. & & & & & & & \\
\hline UTS & $=$ & universal treatment standards. & & & & & & & \\
\hline WSPS & $=$ & Waste Stream Profile Sheet. & & & & & & & \\
\hline
\end{tabular}


Table B.3. Regulated Organic Mixtures, Non-organic Regulated Compounds, and Waste Properties to be Considered Separately (222 Compounds). (Page 1 of 5)

\begin{tabular}{|l|l|}
\hline \multicolumn{1}{|c|}{ CASH } & \multicolumn{1}{|c|}{ Constituent .1.} \\
\hline $10025-67-9$ & Sulfur monochloride \\
\hline $10025-87-3$ & Phosphorus oxychloride \\
\hline $10026-13-8$ & Phosphorus pentachloride \\
\hline $10035-10-6$ & Hydrogen bromide \\
\hline $10049-04-4$ & Chlorine dioxide \\
\hline $10102-43-9$ & Nitric oxide \\
\hline $10210-68-1$ & Cobalt carbonyl as Co \\
\hline $1024-57-D$ & Heptachlor epoxide isomers \\
\hline $102-54-5$ & Dicyclopentadienyl iron \\
\hline $10294-33-4$ & Boron tribromide \\
\hline $110-54-3 D$ & Hexane, other isomers \\
\hline $111-46-6 D$ & Glycol ethers \\
\hline $1189-85-1$ & tert-Butyl chromate, as CrO3 \\
\hline $12079-65-1$ & Manganese cyclopentadienyl tricarbonyl \\
\hline $12108-13-3$ & Methylcyclopentadienylmanganese tricarbonyl \\
\hline $12125-02-9$ & Ammonium chloride (fume) \\
\hline $12604-58-9$ & Ferrovanadium dust \\
\hline $1303-86-2$ & Boron oxide \\
\hline $1303-96-4$ Ca & Borates, anhydrous \\
\hline $1303-96-4$ Cb & Borates, pentahydrate \\
\hline $1303-96-4 C c$ & Borates, decahydrate \\
\hline $1304-82-1$ & Bismuth telluride \\
\hline $1305-62-0$ & Calcium hydroxide \\
\hline $1305-78-8$ & Calcium oxide \\
\hline $1309-37-1$ & Iron oxide fume, Fe2O3 as Fe \\
\hline $1309-48-4$ & Magnesium oxide fume \\
\hline $1309-64-4$ & Antimony trioxide, as Sb \\
\hline $1310-58-3$ & Potassium hydroxide \\
\hline $1310-73-2$ & Sodium hydroxide \\
\hline $1314-13-2$ & Zinc oxide, fume \\
\hline $1314-20-1$ & Thorium dioxide \\
\hline $1314-62-1$ & Vanadium pentoxide \\
\hline $1314-80-3$ & Phosphorus pentasulfide \\
\hline $1319-77-3$ & Cresol polymers \\
\hline $1332-21-4$ & Asbestos (fiberous) \\
\hline $1333-86-4$ & Carbon black \\
\hline $13463-40-6$ & Iron pentacarbonyl, as Fe \\
\hline $13494-80-9$ C & Tellurium \& compounds as Te \\
\hline $13530-65-9$ & Zinc chromates \\
\hline $14265-44-2$ & Phosphate \\
\hline $14280-30-9$ & Hydroxide \\
\hline $14797-65-0$ & Nitrite \\
\hline $14808-79-8$ & Sulfate \\
\hline $14977-61-8$ & Chromylchloride \\
\hline $16842-62-7$ & Calcium cyanamide \\
\hline $16887-00-6$ & Cobalt hydrocarbonyl \\
\hline
\end{tabular}


Table B.3. Regulated Organic Mixtures, Non-organic Regulated Compounds, and Waste Properties to be Considered Separately (222 Compounds). (Page 2 of 5)

\begin{tabular}{|l|l|}
\hline \multicolumn{1}{|c|}{ CASH } & \multicolumn{1}{|c|}{ Constituent } \\
\hline $16984-48-8$ & Fluoride \\
\hline $17702-41-9$ & Decaborane \\
\hline $19287-45-7$ & Diborane \\
\hline $19624-22-7$ & Pentaborane \\
\hline $20816-12-0$ & Osmium tetroxide \\
\hline $21351-79-1$ & Cesium hydroxide \\
\hline $2551-62-4$ & Sulfur hexafluoride \\
\hline $26628-22-8$ & Sodium azide \\
\hline $2699-79-8$ & Sulfuryl fluoride \\
\hline $301-04-2$ & Lead acetate \\
\hline $30402-14-3 \mathrm{D}$ & Tetrachlorodibenzofurans \\
\hline $30402-15-4 \mathrm{D}$ & Pentachlorodibenzofurans \\
\hline $34465-46-8 \mathrm{D}$ & Hexachlorodibenzo-p-dioxins \\
\hline $353-50-4$ & Carbon oxyfluoride \\
\hline $36088-22-9 \mathrm{D}$ & Pentachlorodibenzo-p-dioxins \\
\hline $3687-31-8$ & Lead arsenate, as Pb3 (A2O4)2 \\
\hline $3812-32-6$ & Carbonate \\
\hline $41903-57-5 \mathrm{D}$ & Tetrachlorodi-benzo-p-dioxins \\
\hline $460-19-5$ & Cyanogen \\
\hline $463-58-1$ & Carbon oxide sulfide (COS) \\
\hline $506-77-4$ & Cyanogen chloride \\
\hline $55684-94-1 \mathrm{D}$ & Hexachlorodibenzofurans \\
\hline $558-13-4$ & Carbon tetrabromide \\
\hline $57-12-5$ & Cyanide \\
\hline $57-12-5 \mathrm{a}$ & Cyanide (amenable) \\
\hline $5714-22-7$ & Sulfur pentafluoride \\
\hline $57-74-\mathrm{D}$ & Chlordane (alpha and gamma isomers) \\
\hline $7429-90-5$ & Aluminum \\
\hline $7429-90-5 \mathrm{Ca}$ & Aluminum, Al alkyls \\
\hline $7429-90-5 \mathrm{Cb}$ & Aluminum, as AL pyro powders \\
\hline $7429-90-5 \mathrm{Cc}$ & Aluminum, as Al soluble salts \\
\hline $7429-90-5 \mathrm{Ce}$ & Aluminum, as Al welding fumes \\
\hline $7439-89-6$ & Iron \\
\hline $7439-89-6 \mathrm{D}$ & Iron salts, soluble as Fe \\
\hline $7439-92-1$ & Lead \\
\hline $7439-92-1 \mathrm{D}$ & Lead compounds \\
\hline $7439-96-5$ & Manganese \\
\hline $7439-96-5 \mathrm{Ca}$ & Manganese dust \& compounds \\
\hline $7439-96-5 \mathrm{Cb}$ & Manganese fume \\
\hline $7439-97-6$ & Mercury \\
\hline $7439-97-6 \mathrm{Ca}$ & Mercury, Aryl \& inorganic cmpd \\
\hline $7439-97-6 \mathrm{Cb}$ & Mercury, as Hg Alkyl compounds \\
\hline $7439-97-6 \mathrm{Cc}$ & Mercury, vapors except alkyl \\
\hline $7439-98-7 \mathrm{Ca}$ & Molybdenum, insoluble cpds \\
\hline $7440-98-7 \mathrm{Cb}$ & Molybdenum, as Mo soluble cpds \\
\hline & Nickel \\
\hline
\end{tabular}


Table B.3. Regulated Organic Mixtures, Non-organic Regulated Compounds, and Waste Properties to be Considered Separately (222 Compounds). (Page 3 of 5)

\begin{tabular}{|l|l|}
\hline \multicolumn{1}{|c|}{ CASH } & . \\
\hline $7440-06-4$ & Platinum, metal \\
\hline $7440-06-4 \mathrm{C}$ & Platinum, soluble salts as $\mathrm{Pt}$ \\
\hline $7440-09-7$ & Potassium \\
\hline $7440-16-6$ & Rhodium Metal \\
\hline $7440-16-6 \mathrm{Ca}$ & Rhodium, insoluble compounds \\
\hline $7440-16-6 \mathrm{Cb}$ & Rhodium, soluble compounds \\
\hline $7440-21-3$ & Silicon \\
\hline $7440-22-4$ & Silver \\
\hline $7440-22-4 \mathrm{Da}$ & Silver, soluble compounds as $\mathrm{Ag}$ \\
\hline $7440-23-5$ & Sodium \\
\hline $7440-25-7 \mathrm{C}$ & Tantalum, metal \& oxide dusts \\
\hline $7440-28-0$ & Thallium \\
\hline $7440-28-0 \mathrm{C}$ & Thallium, soluble compounds, $\mathrm{Tl}$ \\
\hline $7440-31-5$ & Tin, oxide \& inorganic except SnH4 \\
\hline $7440-31-5 \mathrm{a}$ & Tin, metal \\
\hline $7440-31-5 \mathrm{C}$ & Tin, organic compounds, as $\mathrm{Sn}$ \\
\hline $7440-33-7 \mathrm{Ca}$ & Tungsten, insoluble compounds \\
\hline $7440-33-7 \mathrm{Cb}$ & Tungsten, soluble compounds \\
\hline $7440-36-0$ & Antimony \\
\hline $7440-36-0 \mathrm{C}$ & Antimony \& compounds as $\mathrm{Sb}$ \\
\hline $7440-38-2$ & Arsenic \\
\hline $7440-38-2 \mathrm{C}$ & Arsenic and inorganic arsenic compounds \\
\hline $7440-39-3$ & Barium \\
\hline $7440-39-3 \mathrm{Da}$ & Barium, soluble compounds Ba \\
\hline $7440-41-7$ & Beryllium \\
\hline $7440-41-7 \mathrm{a}$ & Beryllium powder \\
\hline $7440-42-8$ & Boron \\
\hline $7440-43-9$ & Cadmium \\
\hline $7440-47-3$ & Chromium \\
\hline $7440-47-3 \mathrm{Da}$ & Chromium, hexavalent metal and compounds \\
\hline $7440-47-3 \mathrm{Db}$ & Chromium (II) compounds, as Cr \\
\hline $7440-47-3 \mathrm{Dc}$ & Chromium (III) compounds, $\mathrm{Cr}$ \\
\hline $7440-48-4 \mathrm{a}$ & Cobalt as Co metal dust and fume \\
\hline $7440-50-8$ & Copper \\
\hline $7440-50-8 \mathrm{C}$ & Copper, Dusts and mists, as Cu \\
\hline $7440-58-6$ & Hafnium \\
\hline $7440-61-1 \mathrm{C}$ & Uranium, insoluble \& soluble \\
\hline $7440-62-2$ & Vanadium \\
\hline $7440-65-5 \mathrm{C}$ & Yttrium, metal and compounds as Y \\
\hline $7440-66-6$ & Zinc \\
\hline $7440-67-7$ & Zirconium \\
\hline $7440-67-7 \mathrm{C}$ & Zirconium compounds, as $\mathrm{Zr}$ \\
\hline $7440-69-9$ & Bismuth \\
\hline $7440-70-2$ & Calcium \\
\hline $7440-74-6 \mathrm{C}$ & Indium, \& compounds as In \\
\hline $74-90-8$ & Head phosphate \\
\hline
\end{tabular}


Table B.3. Regulated Organic Mixtures, Non-organic Regulated Compounds, and Waste Properties to be Considered Separately (222 Compounds). (Page 4 of 5)

\begin{tabular}{|l|l|}
\hline \multicolumn{1}{|c|}{ CASH } & \multicolumn{1}{c|}{ Constituent } \\
\hline $75-44-5$ & Phosgene \\
\hline $7550-45-0$ & Titanium tetrachloride \\
\hline $7553-56-2$ & Iodine \\
\hline $75-74-1$ & Tetramethyl lead, as Pb \\
\hline $7580-67-8$ & Lithium hydride \\
\hline $7616-94-6$ & Perchloryl fluoride \\
\hline $7631-90-5$ & Sodium bisulfite \\
\hline $7646-85-7$ & Zinc chloride fume \\
\hline $7647-01-0$ & Hydrogen chloride \\
\hline $7664-38-2$ & Phosphoric acid \\
\hline $7664-39-3$ & Hydrogen fluoride \\
\hline $7664-41-7$ & Ammonia \\
\hline $7664-93-9$ & Sulfuric acid \\
\hline $76737-07-2$ & Boron trifluoride \\
\hline $7681-57-4$ & Sodium metabisulfite \\
\hline $7697-37-2$ & Nitric acid/Nitrate \\
\hline $7719-09-7$ & Thionyl chloride \\
\hline $7719-12-2$ & Phosphorus trichloride \\
\hline $7722-84-1$ & Hydrogen peroxide \\
\hline $7722-88-5$ & Tetrasodium pyrophosphate \\
\hline $7723-14-0$ & Phosphorus \\
\hline $7726-95-6$ & Bromine \\
\hline $7758-97-6$ & Lead chromate, as Cr \\
\hline $7773-06-0$ & Ammonium sulfamate \\
\hline $7782-49-2$ & Selenium \\
\hline $7782-49-2$ C & Selenium compounds, as Se \\
\hline $7782-50-5$ & Chlorine \\
\hline $7782-65-2$ & Germanium tetrahydride \\
\hline $7783-06-4$ & Hydrogen sulfide \\
\hline $7783-07-5$ & Hydrogen selenide, as Se \\
\hline $7783-41-7$ & Oxygen difluoride \\
\hline $7783-54-2$ & Nitrogen trifluoride \\
\hline $7783-60-0$ & Sulfur tetrafluoride \\
\hline $7783-79-1$ & Selenium hexafluoride, as Se \\
\hline $7783-80-4$ & Tellurium hexafluoride, as Te \\
\hline $7784-42-1$ & Arsine \\
\hline $7789-30-2$ & Bromine pentafluoride \\
\hline $7790-91-2$ & Chlorine trifluoride \\
\hline $78-00-2$ & Tetraethyl lead \\
\hline $7803-52-3$ & Stibine \\
\hline $7803-62-5$ & Silicon tetrahydride \\
\hline $8002-74-2$ & Parafin wax fume \\
\hline $8012-95-1$ & Oil mist, mineral \\
\hline $8030-30-6$ & Rubber solvent (Naphtha) \\
\hline $8032-32-4$ & VM \& P Naphtha \\
\hline HxCDD & Hulfide \\
\hline
\end{tabular}


Table B.3. Regulated Organic Mixtures, Non-organic Regulated Compounds, and Waste Properties to be Considered Separately (222 Compounds). (Page 5 of 5)

\begin{tabular}{|l|l|}
\hline \multicolumn{1}{|c|}{ CASH } & \multicolumn{1}{c|}{ Constituent } \\
\hline HxCDF & HxCDFs (All Hexachlorodibenzofurans) \\
\hline 1127 & Pu-239/240 \\
\hline I175 & U-235 \\
\hline I176 & U-gross \\
\hline I4 & Aluminum smelter polyaromatic hydrocarbon emissions \\
\hline I51 & Cotton dust, raw \\
\hline NA1 & Chlorinated fluorocarbons, N.O.S. \\
\hline NA115 & Viscosity \\
\hline NA117 & Ignitability (Flash Point) \\
\hline NA118 & Color \\
\hline NA12 & Organics, separable \\
\hline NA2 & Specific gravity (SPG) \\
\hline NA20 & Welding fumes \\
\hline NA21 & Polyaromatic hydrocarbons (PAH) \\
\hline NA22 & Fine mineral fibers \\
\hline NA23 & Fibrous glass dust \\
\hline NA24 & Dioxins and furans \\
\hline NA25 & Coke oven emissions \\
\hline NA28 & $\%$ solids \\
\hline NA3 & $\%$ moisture \\
\hline NA30 & Total suspended solids \\
\hline NA31 & DW, WP02, persistent DW halogenated hydrocarbons \\
\hline NA32 & EHW, WP01, persistent DW halogenated hydrocarbons \\
\hline NA33 & DW, WT02, toxic dangerous waste \\
\hline NA34 & EHW, WT01, toxic dangerous waste \\
\hline NA38 & Total Alpha (AT) \\
\hline NA6 & pH \\
\hline NA7 & Energetics \\
\hline PeCDD & PeCDDs (All Pentachlorodibenzo-p-dioxins) \\
\hline PeCDF & PeCDFs (All Pentachlorodibenzofurans) \\
\hline TCDD & TCDDs (All Tetrachlorodibenzo-p-dioxins) \\
\hline TCDF & TCDFs (All Tetrachlorodibenzofurans) \\
\hline UN6 & Isopropyl oils \\
\hline UN8 & Nitrofurans \\
\hline
\end{tabular}

CAS\# = chemical abstract service number. 
Table B.4. Organic Analyte Regulatory Data Quality Objective Input List (623 Compounds). (Page 1 of 15)

\begin{tabular}{|c|c|c|c|c|c|c|c|c|}
\hline QAS\# & Constituent & $\begin{array}{l}\text { Class } \mathrm{A} \\
\text { TAPs. }\end{array}$ & Glass B & UHC & $\begin{array}{l}\text { Part A } \\
\text { DST/SST }\end{array}$ & USS & WST & $\begin{array}{l}\text { Flammable } \\
\text { Gases }\end{array}$ \\
\hline $100-00-5$ & p-Nitrochlorobenzene & & $\mathrm{X}$ & & & & & \\
\hline $100-01-6$ & 4-Nitroaniline & & $\bar{X}$ & $\mathrm{X}$ & & $\mathrm{X}$ & & \\
\hline $100-02-7$ & 4-Nitrophenol & & $\mathrm{X}$ & $\mathrm{X}$ & & $\mathrm{X}$ & & \\
\hline $100-21-0$ & Phthalic acid & & & $\mathrm{X}$ & & & & \\
\hline $100-25-4$ & 1,4-Dinitrobenzene & & & $\bar{X}$ & & $\mathrm{X}$ & & \\
\hline $100-37-8$ & Diethylaminoethanol & & $\mathrm{X}$ & & & & & \\
\hline $100-41-4$ & Ethyl benzene & & & $\mathrm{X}$ & $\mathrm{X}$ & $\bar{X}$ & & \\
\hline $100-42-5$ & Styrene & & $\mathrm{X}$ & & & & & \\
\hline $100-44-7$ & Benzyl chloride & & $\mathrm{X}$ & & & & & \\
\hline $100-61-8$ & N-Methylbenzenamine & & $\bar{X}$ & & & & & \\
\hline $100-63-0$ & Phenylhydrazine & & $\mathrm{X}$ & & & & & \\
\hline $100-74-3$ & N-Ethylmorpholine & & $\mathrm{X}$ & & & & & \\
\hline $100-75-4$ & N-Nitrosopiperidine & & & $\mathrm{X}$ & & $\mathrm{X}$ & & \\
\hline $10061-01-5$ & cis-1,3-Dichloropropene & & & $\mathrm{X}$ & & $\mathrm{X}$ & & \\
\hline $10061-02-6$ & trans-1,3-Dichloropropene & & & $\bar{X}$ & & $\bar{X}$ & & \\
\hline $101-14-4$ & $\begin{array}{l}4,4^{\prime}-\text { Methylenebis }(2- \\
\text { chloroaniline) }\end{array}$ & $\mathrm{X}$ & & $\mathrm{X}$ & & $\mathrm{X}$ & & \\
\hline $101-27-9$ & Barban & & & & & $\mathrm{X}$ & & \\
\hline $101-55-3$ & 4-Bromophenylphenyl ether & & & $\mathrm{X}$ & & $\mathrm{X}$ & & \\
\hline $101-68-8$ & $\begin{array}{l}\text { Methylene bis(phenyl } \\
\text { isocyanate) }\end{array}$ & & $\mathrm{X}$ & & & & & \\
\hline $101-77-9$ & 4,4-Methylene dianiline & $\mathrm{X}$ & & & & & & \\
\hline $101-80-4$ & 4,4'-Diaminodiphenyl ether & $\mathrm{X}$ & & & & & & \\
\hline $101-84-8$ & Diphenyl ether & & $\mathrm{X}$ & & & & & \\
\hline $101-90-6$ & Diglycidyl resorcinol ether & $\mathrm{X}$ & & $\mathrm{X}$ & & & & \\
\hline $102-81-8$ & 2-N-Dibutylaminoethanol & & $\mathrm{X}$ & & & & & \\
\hline $1024-57-3$ & Heptachlor Epoxide & & & $\mathrm{X}$ & & $\bar{X}$ & & \\
\hline $1031-07-8$ & Endosulfan Sulfate & & & $\mathrm{X}$ & & $\bar{X}$ & & \\
\hline $105-46-4$ & sec-Butyl acetate & & $\mathrm{X}$ & & & & & \\
\hline $105-60-2$ & Caprolactam, vapor & & $\mathrm{X}$ & & & & & \\
\hline $105-60-2 a$ & Caprolactam, dust & & $\mathrm{X}$ & & & & & \\
\hline $105-67-9$ & 2,4-Dimethylphenol & & & $\mathrm{X}$ & & $\mathrm{X}$ & & \\
\hline $10595-95-6$ & N-Nitrosomethylethylamine & $\mathrm{X}$ & & $\mathrm{X}$ & & $\mathrm{X}$ & & \\
\hline $106-35-4$ & 3-Heptanone & & $\mathrm{X}$ & & & & & \\
\hline $106-42-3$ & p-Xylene & & & $\bar{X}$ & $\mathrm{X}$ & $\bar{X}$ & & \\
\hline $106-44-5$ & 4-Methylphenol & & & $\mathrm{X}$ & $\mathrm{X}$ & $\mathrm{X}$ & & \\
\hline $106-46-7$ & 1,4-Dichlorobenzene & $\mathrm{X}$ & & $\mathrm{X}$ & & $\mathrm{X}$ & & \\
\hline $106-47-8$ & 4-Chloroaniline & & & $\bar{X}$ & & $\bar{X}$ & & \\
\hline $106-49-0$ & p-Toluidine & & $\bar{X}$ & & & & & \\
\hline $106-50-3$ & p-Phenylenediamine & & $\mathrm{X}$ & $\mathrm{X}$ & & & & \\
\hline $106-51-4$ & p-Benzoquinone & & $\mathrm{X}$ & & & & & \\
\hline $106-87-6$ & Vinyl cyclohexene dioxide & & $\mathrm{X}$ & & & & & \\
\hline $106-88-7$ & 1,2-Epoxybutane & & $\mathrm{X}$ & & & & & \\
\hline $106-89-8$ & Epichlorohydrin & $\mathrm{X}$ & & & & & & \\
\hline $106-92-3$ & Allyl glycidyl ether & & $\mathrm{X}$ & & & & & \\
\hline $106-93-4$ & Ethylene dibromide & $\mathrm{X}$ & & $\mathrm{X}$ & & $\mathrm{X}$ & & \\
\hline $106-97-8$ & Butane & & $\mathrm{X}$ & & & & & \\
\hline $106-99-0$ & 1,3-Butadiene & $\mathrm{X}$ & & & & & & \\
\hline
\end{tabular}


Table B.4. Organic Analyte Regulatory Data Quality Objective Input List (623 Compounds). (Page 2 of 15 )

\begin{tabular}{|c|c|c|c|c|c|c|c|c|}
\hline CAsH & Constituent & Class A & $\begin{array}{l}\text { Class B } \\
\text { TAPs }\end{array}$ & UHe & Partit & U1s. & $\begin{array}{l}\text { DST: } \\
\text { WSPS }\end{array}$ & Flammable \\
\hline $10605-21-7$ & Carbendazim & & & & & $\mathrm{X}$ & & \\
\hline $107-02-8$ & Acrolein & & $\mathrm{X}$ & $\mathrm{X}$ & & $\bar{X}$ & & \\
\hline $107-05-1$ & 3-Chloropropene & & $\bar{X}$ & $\bar{X}$ & & $\bar{X}$ & & \\
\hline $107-06-2$ & 1,2-Dichloroethane & $\mathrm{X}$ & & $\overline{\mathrm{X}}$ & $\bar{X}$ & $\bar{X}$ & & \\
\hline $107-07-3$ & Ethylene chlorohydrin & & $\bar{X}$ & & & & & \\
\hline $107-12-0$ & Propionitrile & & & $\bar{X}$ & & $\mathrm{X}$ & & \\
\hline $107-13-1$ & Acrylonitrile & $\mathrm{X}$ & & $\mathrm{X}$ & & $\mathrm{X}$ & & \\
\hline $107-15-3$ & Ethylene diamine & & $\mathrm{X}$ & & & & & \\
\hline $107-18-6$ & 2-Propen-1-ol & & $\bar{X}$ & & & & & \\
\hline $107-19-7$ & Propargyl alcohol & & $\mathrm{X}$ & & & & & \\
\hline $107-20-0$ & Chloroacetaldehyde & & $\mathrm{X}$ & & & & & \\
\hline $107-21-1$ & Ethylene glycol & & $\bar{X}$ & & & & & \\
\hline $107-30-2$ & Chloromethyl methyl ether & $\mathrm{X}$ & & & & & & \\
\hline $107-31-3$ & Formic acid, methyl ester & & $\mathrm{X}$ & & & & & \\
\hline $107-41-5$ & Hexylene glycol & & $\bar{X}$ & & & & & \\
\hline $107-49-3$ & Tetraethyl pyrophosphate & & $\bar{X}$ & & & & & \\
\hline $107-66-4$ & Dibutylphosphate & & $\mathrm{X}$ & & & & & \\
\hline $107-87-9$ & 2-Pentanone & & $\bar{X}$ & & & & & \\
\hline $107-98-2$ & $\begin{array}{l}\text { Propylene glycol } \\
\text { monomethyl ether }\end{array}$ & & $\mathrm{X}$ & & & & & \\
\hline $108-03-2$ & 1-Nitropropane & & $\bar{X}$ & & & & & \\
\hline $108-05-4$ & Acetic acid vinyl ester & & $\bar{X}$ & & & & & \\
\hline $108-10-1$ & 4-Methyl-2-pentanone & & $\mathrm{X}$ & $\mathrm{X}$ & $\mathrm{X}$ & $\mathrm{X}$ & & \\
\hline $108-11-2$ & Methyl isobutyl carbinol & & $\mathrm{X}$ & & & & & \\
\hline $108-18-9$ & Diisopropylamine & & $\mathrm{X}$ & & & & & \\
\hline $108-20-3$ & Bis(isopropyl) ether & & $\mathrm{X}$ & & & & & \\
\hline $108-21-4$ & Isopropyl acetate & & $\mathrm{X}$ & & & & & \\
\hline $108-24-7$ & Acetic anhydride & & $\bar{X}$ & & & & & \\
\hline $108-31-6$ & $\begin{array}{l}\text { Maleic anhydride (2,5- } \\
\text { Furandione) }\end{array}$ & & $\mathrm{X}$ & & & & & \\
\hline $108-38-3$ & m-Xylene & & & $\bar{X}$ & $\bar{X}$ & $\overline{\mathrm{X}}$ & & \\
\hline $108-39-4$ & m-Cresol & & $\mathrm{X}$ & $\mathrm{X}$ & & $\mathrm{X}$ & & \\
\hline $108-43-0$ & Chlorophenols & $\mathrm{X}$ & & & & & & \\
\hline $108-44-1$ & m-Toluidine & & $\mathrm{X}$ & & & & & \\
\hline $108-46-3$ & Resorcinol (1,3-Benzenediol) & & $\mathrm{X}$ & & & & & \\
\hline $108-60-1$ & Bis(2-Chloroisopropyl) ether & & & $\bar{X}$ & & $\mathrm{X}$ & & \\
\hline $108-83-8$ & Diisobutyl ketone & & $\mathrm{X}$ & & & & & \\
\hline $108-84-9$ & sec-Hexyl acetate & & $\mathrm{X}$ & & & & & \\
\hline $108-87-2$ & Methylcyclohexane & & $\mathrm{X}$ & & & & & \\
\hline $108-88-3$ & Toluene & & $\bar{X}$ & $\mathrm{X}$ & $\overline{\mathrm{X}}$ & $\mathrm{X}$ & & \\
\hline $108-90-7$ & Chlorobenzene & & $\overline{\mathrm{X}}$ & $\mathrm{X}$ & $\mathrm{X}$ & $\mathrm{X}$ & & \\
\hline $108-91-8$ & Cyclohexylamine & & $\mathrm{X}$ & & & & & \\
\hline $108-93-0$ & Cyclohexanol & & $\mathrm{X}$ & & & & & \\
\hline $108-94-1$ & Cyclohexanone & & $\mathrm{X}$ & $\mathrm{X}$ & $\mathrm{X}$ & $\mathrm{X}$ & & \\
\hline $108-95-2$ & Phenol & & $\mathrm{X}$ & $\mathrm{X}$ & & $\mathrm{X}$ & & \\
\hline $108-98-5$ & Thiophenol & & $\mathrm{X}$ & & & & & \\
\hline $109-59-1$ & Isopropoxyethanol & & $\bar{X}$ & & & & & \\
\hline $109-60-4$ & n-Propyl acetate & & $\bar{X}$ & & & & & \\
\hline
\end{tabular}


Table B.4. Organic Analyte Regulatory Data Quality Objective Input List (623 Compounds). (Page 3 of 15)

\begin{tabular}{|c|c|c|c|c|c|c|c|c|}
\hline / बast & Constituent & $\begin{array}{l}\text { Class a } \\
\text { Taps }\end{array}$ & Class B & UHe & $\begin{array}{l}\text { Part A } \\
\text { DSTSST }\end{array}$ & UIS & WST & $\begin{array}{l}\text { Flammable } \\
\text { Gases }\end{array}$ \\
\hline $109-66-0$ & n-Pentane & & $\mathrm{X}$ & & & & & \\
\hline $109-73-9$ & n-Butylamine & & $\mathrm{X}$ & & & & & \\
\hline $109-79-5$ & n-Butyl mercaptan & & $\mathrm{X}$ & & & & & \\
\hline $109-86-4$ & 2-Methoxyethanol & & $\mathrm{X}$ & & & & & \\
\hline $109-87-5$ & Methylal & & $\mathrm{X}$ & & & & & \\
\hline $109-89-7$ & Diethylamine & & $\mathrm{X}$ & & & & & \\
\hline $109-94-4$ & Ethyl formate & & $\mathrm{X}$ & & & & & \\
\hline $109-99-9$ & Tetrahydrofuran & & $\mathrm{X}$ & & & & & \\
\hline $110-12-3$ & 5-Methyl-2-hexanone & & $\mathrm{X}$ & & & & & \\
\hline $110-19-0$ & Isobutyl acetate & & $\mathrm{X}$ & & & & & \\
\hline $110-43-0$ & 2-Heptanone & & $\mathrm{X}$ & & & & & \\
\hline $110-49-6$ & 2-Methoxyethyl acetate & & $\mathrm{X}$ & & & & & \\
\hline $110-54-3$ & n-Hexane & & $\mathrm{X}$ & & & & & \\
\hline $110-62-3$ & n-Valeraldehyde & & $\mathrm{X}$ & & & & & \\
\hline $110-75-8$ & 2-Chloroethyl vinyl ether & & & $\mathrm{X}$ & & $\mathrm{X}$ & & \\
\hline $110-80-5$ & 2-Ethoxyethanol & & $\mathrm{X}$ & & $\mathrm{X}$ & & & \\
\hline $110-82-7$ & Cyclohexane & & $\bar{X}$ & & & & & \\
\hline $110-83-8$ & Cyclohexene & & $\mathrm{X}$ & & & & & \\
\hline $110-86-1$ & Pyridine & & $\mathrm{X}$ & $\mathrm{X}$ & $\mathrm{X}$ & $\mathrm{X}$ & & \\
\hline $110-91-8$ & Morpholine & & $\mathrm{X}$ & & & & & \\
\hline $111-15-9$ & 2-Ethoxyethyl acetate & & $\bar{X}$ & & & & & \\
\hline $111-30-8$ & Glutaraldehyde & & $\mathrm{X}$ & & & & & \\
\hline $111-40-0$ & Diethylene triamine & & $\mathrm{X}$ & & & & & \\
\hline $111-42-2$ & Diethanolamine & & $\bar{X}$ & & & & & \\
\hline $111-44-4$ & Bis(2-chloroethyl) ether & $\mathrm{X}$ & & $\mathrm{X}$ & & $\mathrm{X}$ & & \\
\hline $111-65-9$ & n-Octane & & $\mathrm{X}$ & & & & & \\
\hline $111-76-2$ & 2-Butoxyethanol & & $\mathrm{X}$ & & & & & \\
\hline $111-84-2$ & n-Nonane & & $\mathrm{X}$ & & & & & \\
\hline $111-91-1$ & Bis(2-Chloroethoxy)methane & & & $\mathrm{X}$ & & $\bar{X}$ & & \\
\hline $1114-71-2$ & Pebulate & & & $\mathrm{X}$ & & $\mathrm{X}$ & & \\
\hline $1120-71-4$ & 1,3-Propane sultone & $\mathrm{X}$ & & & & & & \\
\hline $1129-41-5$ & $\begin{array}{l}\text { Metolcarb (3- } \\
\text { methylcholanthrene) }\end{array}$ & & & & & $\mathrm{x}$ & & \\
\hline $1134-23-2$ & Cycloate & & & $\mathrm{X}$ & & & & \\
\hline $114-26-1$ & Propoxur & & $\overline{\mathrm{X}}$ & $\bar{X}$ & & $\mathrm{X}$ & & \\
\hline $115-29-7$ & Endosulfan & & $\mathrm{X}$ & & & & & \\
\hline $115-86-6$ & Triphenyl phosphate & & $\mathrm{X}$ & & & & & \\
\hline $115-90-2$ & Fensulfothion & & $\mathrm{X}$ & & & & & \\
\hline $117-79-3$ & 2-Aminoanthraquinone & $\mathrm{X}$ & & & & & & \\
\hline $117-81-7$ & Bis(2-ethylhexyl) phthalate & $\mathrm{X}$ & & $\mathrm{X}$ & & $\mathrm{X}$ & & \\
\hline $117-84-0$ & Di-n-octylphthalate & & & $\mathrm{X}$ & & $\mathrm{X}$ & & \\
\hline $118-52-5$ & $\begin{array}{l}\text { 1,3-Dichloro-5,5-Dimethyl } \\
\text { hydantoin }\end{array}$ & & $X$ & & & & & \\
\hline $118-74-1$ & Hexachlorobenzene & $\mathrm{X}$ & & $\mathrm{X}$ & & $\mathrm{X}$ & & \\
\hline $118-96-7$ & 2,4,6-Trinitrotoluene & & $\mathrm{X}$ & & & & & \\
\hline $119-38-0$ & Isolan & & & & & $\mathrm{X}$ & & \\
\hline $119-90-4$ & 3,3'-Dimethoxybenzidine & $\mathrm{X}$ & & & & & & \\
\hline 119-93-7 & 3,3'-Dimethylbenzidine. & $\mathrm{X}$ & & & & & & \\
\hline
\end{tabular}


Table B.4. Organic Analyte Regulatory Data Quality Objective Input List (623 Compounds). (Page 4 of 15)

\begin{tabular}{|c|c|c|c|c|c|c|c|c|}
\hline CAst & Constituent & Glass A & Mass B & UHC & Part A & UIS & WST: & Tlammable \\
\hline $120-12-7$ & Anthracene & & & $\mathrm{X}$ & & $\mathrm{X}$ & & \\
\hline $120-58-1$ & Isosafrole & & & $\mathrm{X}$ & & $\mathrm{X}$ & & \\
\hline $120-80-9$ & Catechol & & $\mathrm{X}$ & & & & & \\
\hline $120-82-1$ & 1,2,4-Trichlorobenzene & & $\mathrm{X}$ & $\mathrm{X}$ & & $\mathrm{X}$ & & \\
\hline $120-83-2$ & 2,4-Dichlorophenol & & & $\mathrm{X}$ & & $\mathrm{X}$ & & \\
\hline $121-14-2$ & 2,4-Dinitrotoluene & & $\mathrm{X}$ & $\mathrm{X}$ & $\mathrm{X}$ & $\mathrm{X}$ & & \\
\hline $121-44-8$ & Triethylamine & & $\bar{X}$ & $\overline{\mathrm{X}}$ & & $\bar{X}$ & & \\
\hline $121-45-9$ & Trimethyl phosphite & & $\mathrm{X}$ & & & & & \\
\hline $121-69-7$ & Dimethylaniline & & $\bar{X}$ & & & & & \\
\hline $121-75-5$ & Malathion & & $\bar{X}$ & & & & & \\
\hline $121-82-4$ & Cyclonite & & $\mathrm{X}$ & & & & & \\
\hline $122-39-4$ & N,N-Diphenylamine & & $\mathrm{X}$ & $\mathrm{X}$ & & $\bar{X}$ & & \\
\hline $122-42-9$ & Propham & & & & & $\bar{X}$ & & \\
\hline $122-60-1$ & Phenyl glycidyl ether & & $\mathrm{X}$ & & & & & \\
\hline $122-66-7$ & 1,2-Diphenylhydrazine & $\mathrm{X}$ & & $\bar{X}$ & & $\mathrm{X}$ & & \\
\hline $123-19-3$ & 4-Heptanone & & $\mathrm{X}$ & & & & & \\
\hline $123-31-9$ & Hydroquinone & & $\mathrm{X}$ & $\mathrm{X}$ & & & & \\
\hline $123-38-6$ & n-Propionaldehyde & & $\mathrm{X}$ & & & & & \\
\hline $123-42-2$ & Diacetone alcohol & & $\mathrm{X}$ & & & & & \\
\hline $123-51-3$ & 3-Methyl-1-butanol & & $\mathrm{X}$ & & & & & \\
\hline $123-86-4$ & Acetic acid n-butyl ester & & $\mathrm{X}$ & & & & & \\
\hline $123-91-1$ & 1,4-Dioxan & $\mathrm{X}$ & & $\mathrm{X}$ & & $\mathrm{X}$ & & \\
\hline $123-92-2$ & Isoamyl acetate & & $\mathrm{X}$ & & & & & \\
\hline $124-40-3$ & Dimethylamine & & $\mathrm{X}$ & & & & & \\
\hline $124-48-1$ & Dibromochloromethane & & & $\mathrm{X}$ & & $\bar{X}$ & & \\
\hline $126-72-7$ & $\begin{array}{l}\text { Tris(2,3-dibromopropyl) } \\
\text { phosphate }\end{array}$ & & & $\mathrm{X}$ & & $\mathrm{X}$ & & \\
\hline $126-73-8$ & Tributyl phosphate & & $\bar{X}$ & & & & & \\
\hline $126-85-2$ & Nitrogen mustard N-oxide & $\overline{\mathrm{X}}$ & & & & & & \\
\hline $126-98-7$ & 2-Methyl-2-propenenitrile & & $\mathrm{X}$ & $\bar{X}$ & & $\mathrm{X}$ & & \\
\hline $126-99-8$ & Chloroprene & $\mathrm{X}$ & & $\mathrm{X}$ & & $\mathrm{X}$ & & \\
\hline $127-18-4$ & $1,1,2,2$-Tetrachloroethene & $\mathrm{X}$ & & $\bar{X}$ & $\bar{X}$ & $\bar{X}$ & & \\
\hline $127-19-5$ & N,N-Dimethylacetamide & & $\mathrm{X}$ & & & & & \\
\hline $128-37-0$ & $\begin{array}{l}\text { 2,6-Bis(tert-butyl)-4- } \\
\text { methylphenol }\end{array}$ & & $\mathrm{X}$ & & & & & \\
\hline $129-00-0$ & Pyrene & & & $\mathrm{X}$ & & $\mathrm{X}$ & & \\
\hline $129-15-7$ & $\begin{array}{l}\text { 2-Methyl-1- } \\
\text { nitroanthraquinone }\end{array}$ & $\mathrm{X}$ & & & & & & \\
\hline $1300-73-8$ & Xylidine & & $\mathrm{X}$ & & & & & \\
\hline $131-11-3$ & Dimethyl phthalate & & $\mathrm{X}$ & $\mathrm{X}$ & & $\mathrm{X}$ & & \\
\hline $13121-70-5$ & Cyhexatin & & $\bar{X}$ & & & & & \\
\hline $132-64-9$ & Dibenzofuran & $\mathrm{X}$ & & & & & & \\
\hline $1321-64-8$ & Pentachloronaphthalene & & $\mathrm{X}$ & & & & & \\
\hline $1321-65-9$ & Trichloronaphthalene & & $\bar{X}$ & & & & & \\
\hline $1321-74-0$ & Divinyl benzene & & $\mathrm{X}$ & & & & & \\
\hline $133-06-2$ & Captan & & $\bar{X}$ & & & & & \\
\hline $133-90-4$ & Chloramben & & $\bar{X}$ & & & & & \\
\hline $1335-87-1$ & Hexachloronaphthalene & & $\bar{X}$ & & & & & \\
\hline
\end{tabular}


Table B.4. Organic Analyte Regulatory Data Quality Objective Input List (623 Compounds). (Page 5 of 15)

\begin{tabular}{|c|c|c|c|c|c|c|c|c|}
\hline$\triangle A S \#$ & Constituent & Glass $\mathrm{TAP}$ & Class B & UHC & Dart A & UTS & $\begin{array}{l}\text { DST } \\
\text { WSPS }\end{array}$ & Fammable \\
\hline $1335-88-2$ & Tetrachloronaphthalene & & $\mathrm{X}$ & & & & & \\
\hline $1336-36-3$ & $\begin{array}{l}\text { Polychlorinated biphenyls } \\
\text { (PCBs) }\end{array}$ & $\mathrm{X}$ & & $\mathrm{X}$ & & $\mathrm{X}$ & $\mathrm{X}$ & \\
\hline $1338-23-4$ & Methyl ethyl ketone peroxide & & $\mathrm{X}$ & & & & & \\
\hline $134-32-7$ & alpha-Naphthylamine & $\bar{X}$ & & $\mathrm{X}$ & & & & \\
\hline $135-20-6$ & Cupferron & $\mathrm{X}$ & & & & & & \\
\hline $135-88-6$ & N-Phenyl-2-napthylamine & & & $\mathrm{X}$ & & & & \\
\hline $13552-44-8$ & $\begin{array}{l}\text { 4,4-Methylenedianiline } \\
\text { dihydrochloride }\end{array}$ & $\mathrm{X}$ & & & & & & \\
\hline $136-78-7$ & Sesone & & $\mathrm{X}$ & & & & & \\
\hline $137-05-3$ & Methyl-2-cyanoacrylate & & $\mathrm{X}$ & & & & & \\
\hline $137-26-8$ & Thiram & & $\mathrm{X}$ & & & & & \\
\hline $137-30-4$ & Ziram & & & $\mathrm{X}$ & & $\mathrm{X}$ & & \\
\hline $138-22-7$ & n-Butyl lactate & & $\bar{X}$ & & & & & \\
\hline $13838-16-9$ & Enflurane & & $\mathrm{X}$ & & & & & \\
\hline $139-65-1$ & 4,4'-Thiodianiline & $\mathrm{X}$ & & $\mathrm{X}$ & & & & \\
\hline $139-91-3$ & $\begin{array}{l}\text { 5-(Morpholinomethyl)-3- } \\
\text { amino-2-oxazolidinone } \\
\text { (furaltudone) }\end{array}$ & $\mathrm{X}$ & & & & & & \\
\hline $1395-21-7$ & Subtilisins. & & $\mathrm{X}$ & & & & & \\
\hline $140-57-8$ & Aramite & & & $\mathrm{X}$ & & $\mathrm{X}$ & & \\
\hline $140-88-5$ & Ethylacrylate & & $\mathrm{X}$ & & & & & \\
\hline $141-32-2$ & Butylacrylate & & $\mathrm{X}$ & & & & & \\
\hline $141-43-5$ & Ethanolamine & & $\bar{X}$ & & & & & \\
\hline $141-66-2$ & Dicrotophos & & $\mathrm{X}$ & & & & & \\
\hline $141-78-6$ & Acetic acid ethyl ester & & $\bar{X}$ & $\bar{X}$ & $\mathrm{X}$ & $\mathrm{X}$ & & \\
\hline $141-79-7$ & 4-Methyl-3-penten-2-one & & $\mathrm{X}$ & & & & & \\
\hline $142-64-3$ & Piperazine dihydrochloride & & $\overline{\mathrm{X}}$ & & & & & \\
\hline $142-82-5$ & n-Heptane & & $\mathrm{X}$ & & & & & \\
\hline $143-50-0$ & Kepone & & & $\mathrm{X}$ & & $\mathrm{X}$ & & \\
\hline $144-62-7$ & Oxalic acid & & $\mathrm{X}$ & & & & & \\
\hline 14484-64-1 & Ferbam & & $\bar{X}$ & & & & & \\
\hline $1477-55-0$ & $\mathrm{~m}$-Xylene-a, $\mathrm{a}^{\prime}$-diamine & & $\mathrm{X}$ & & & & & \\
\hline $148-01-6$ & Dinitolamide & & $\mathrm{X}$ & & & & & \\
\hline $150-76-5$ & 4-Methoxyphenol & & $\mathrm{X}$ & & & & & \\
\hline $151-56-4$ & Ethyleneimine & & $\mathrm{X}$ & & & & & \\
\hline $151-67-7$ & Halothane & & $\mathrm{X}$ & & & & & \\
\hline $156-60-5$ & 1,2-trans-Dichloroethene & & & $\bar{X}$ & $\mathrm{X}$ & $\bar{X}$ & & \\
\hline $1563-38-8$ & Carbofuran phenol & & & & & $\mathrm{X}$ & & \\
\hline $1563-66-2$ & Carbofuran & & $\mathrm{X}$ & $\mathrm{X}$ & & $\mathrm{X}$ & & \\
\hline $1582-09-8$ & Trifluralin & & $\bar{X}$ & & & & & \\
\hline $1615-80-1$ & N,N'-Diethylhydrazine & $\mathrm{X}$ & & & & & & \\
\hline $16219-75-3$ & Ethylidene norbornene & & $\mathrm{X}$ & & & & & \\
\hline $1634-04-4$ & Methyl tert-butyl ether & & $\mathrm{X}$ & & & & & \\
\hline $1646-88-4$ & Aldicarb sulfone & & & $\mathrm{X}$ & & $\mathrm{X}$ & & \\
\hline $16752-77-5$ & Methomyl & & $\mathrm{X}$ & $\mathrm{X}$ & & $\mathrm{X}$ & & \\
\hline 1694-09-3 & Benzyl violet $4 b$ & $\mathrm{X}$ & & & & & & \\
\hline
\end{tabular}


Table B.4. Organic Analyte Regulatory Data Quality Objective Input List (623 Compounds). (Page 6 of 15)

\begin{tabular}{|c|c|c|c|c|c|c|c|c|}
\hline CAS\# & Constituent & $\begin{array}{l}\text { Class } \mathrm{A} \\
\text { TAPs }\end{array}$ & Class B & Unc & Partat & UTS & WST & Glammable \\
\hline $1746-01-6$ & $\begin{array}{l}\text { TCDD (Dioxin/Furan } \\
\text { Indicator) }\end{array}$ & $X$ & & $\mathrm{X}$ & & & & \\
\hline $17702-57-7$ & Formparanate & & & & & $\mathrm{X}$ & & \\
\hline $17804-35-2$ & Benomyl & & $\mathrm{X}$ & $\mathrm{X}$ & & $\mathrm{X}$ & & \\
\hline $1836-75-5$ & Nitrofen & $\mathrm{X}$ & & & & & & \\
\hline $1888-71-7$ & Hexachloropropylene & & & $\mathrm{X}$ & & $\mathrm{X}$ & & \\
\hline $189-55-9$ & Dibenzo[a,i]pyrene & $\mathrm{X}$ & & & & & & \\
\hline $189-64-0$ & Dibenzo[a,h]pyrene & $\mathrm{X}$ & & & & & & \\
\hline $191-24-2$ & Benzo(ghi)perylene & & & $\mathrm{X}$ & & $\mathrm{X}$ & & \\
\hline $191-30-0$ & Dibenzo(a,1)pyrene & $\mathrm{X}$ & & & & & & \\
\hline $1912-24-9$ & Atrazine & & $\mathrm{X}$ & & & & & \\
\hline 1918-02-1 & Picloram & & $\mathrm{X}$ & & & & & \\
\hline $192-65-4$ & Dibenzo[a,e]pyrene & $\mathrm{X}$ & & $\mathrm{X}$ & & $\mathrm{X}$ & & \\
\hline $1929-77-7$ & Vernolate & & & $\mathrm{X}$ & & $\mathrm{X}$ & & \\
\hline $1929-82-4$ & Nitrapyrin & & $\mathrm{X}$ & & & & & \\
\hline $193-39-5$ & Indeno(1,2,3-cd)pyrene & $\mathrm{X}$ & & $\mathrm{X}$ & & $\bar{X}$ & & \\
\hline $2008-41-5$ & Butylate & & & $\bar{X}$ & & $\mathrm{X}$ & & \\
\hline $2032-65-7$ & Methiocarb & & & $\mathrm{X}$ & & $\mathrm{X}$ & & \\
\hline $2039-87-4$ & o-Chlorostyrene & & $\mathrm{X}$ & & & & & \\
\hline $205-82-3$ & Benzo[j]fluoranthene & $\mathrm{X}$ & & & & & & \\
\hline $205-99-2$ & Benzo(b)fluoranthene & $\mathrm{X}$ & & $\mathrm{X}$ & & $\mathrm{X}$ & & \\
\hline $206-44-0$ & Fluoranthene & & & $\bar{X}$ & & $\mathrm{X}$ & & \\
\hline $207-08-9$ & Benzo(k)fluoranthene & $\mathrm{X}$ & & $\mathrm{X}$ & & $\mathrm{X}$ & & \\
\hline $208-96-8$ & Acenaphthylene & & & $\mathrm{X}$ & & $\mathrm{X}$ & & \\
\hline $2104-64-5$ & EPN & & $\mathrm{X}$ & & & & & \\
\hline $21087-64-9$ & Metribuzin & & $\bar{X}$ & & & & & \\
\hline $2179-59-1$ & Allyl propyl disulfide & & $\mathrm{X}$ & & & & & \\
\hline $218-01-9$ & Chrysene & & & $\mathrm{X}$ & & $\mathrm{X}$ & & \\
\hline $2212-67-1$ & Molinate & & & $\mathrm{X}$ & & $\mathrm{X}$ & & \\
\hline $22224-92-6$ & Fenamiphos & & $\mathrm{X}$ & & & & & \\
\hline $2234-13-1$ & Octachloronaphthalene & & $\mathrm{X}$ & & & & & \\
\hline $2238-07-5$ & Diglycidyl ether & & $\mathrm{X}$ & & & & & \\
\hline $224-42-0$ & Dibenz $[a, j]$ acridine & $\bar{X}$ & & & & & & \\
\hline $226-36-8$ & Dibenz $[\mathrm{a}, \mathrm{h}]$ acridine & $\mathrm{X}$ & & & & & & \\
\hline $22781-23-3$ & Bendiocarb & & & $\mathrm{X}$ & & $\mathrm{X}$ & & \\
\hline $22961-82-6$ & Bendiocarb phenol & & & & & $\mathrm{X}$ & & \\
\hline $2303-17-5$ & Triallate & & & & & $\mathrm{X}$ & & \\
\hline $23135-22-0$ & Oxamy & & & $\mathrm{X}$ & & $\bar{X}$ & & \\
\hline $23422-53-9$ & Formetanate hydrochloride & & & & & $\bar{X}$ & & \\
\hline $23564-05-8$ & Thiophanate-methyl & & & & & $\bar{X}$ & & \\
\hline $2385-85-5$ & Mirex & $\mathrm{X}$ & & & & & & \\
\hline 23950-58-5 & Pronamide & & & $\mathrm{X}$ & & $\mathrm{X}$ & & \\
\hline $2425-06-1$ & Captafol & & $\mathrm{X}$ & & & & & \\
\hline $2426-08-6$ & n-Butyl glycidyl ether & & $\mathrm{X}$ & & & & & \\
\hline $2465-27-2$ & Auramine (technical grade) & $\mathrm{X}$ & & & & & & \\
\hline $25013-15-4$ & Vinyl toluene & & $\bar{X}$ & & & & & \\
\hline $2551-13-7$ & Trimethyl benzene & & $\mathrm{X}$ & & & & & \\
\hline $25639-42-3$ & Methylcyclohexanol & & $\mathrm{X}$ & & & & & \\
\hline
\end{tabular}


Table B.4. Organic Analyte Regulatory Data Quality Objective Input List (623 Compounds). (Page 7 of 15)

\begin{tabular}{|c|c|c|c|c|c|c|c|c|}
\hline CASH & Constituent & Cass a & Tlass B & UHe & Part A & UTS & WSTS & Fiammable \\
\hline $26140-60-3$ & Terphenyls & & $\mathrm{X}$ & & & & & \\
\hline $2631-37-0$ & Promecarb & & & & & $\mathrm{X}$ & & \\
\hline $26419-73-8$ & Tirpate & & & & & $\bar{X}$ & & \\
\hline $2646-17-5$ & Oil orange SS & $\mathrm{X}$ & & & & & & \\
\hline $26952-21-6$ & Iso-ocytl alcohol & & $\bar{X}$ & & & & & \\
\hline $2698-41-1$ & $\begin{array}{l}\text { o-Chlorobenylidene } \\
\text { malonitrile }\end{array}$ & & $\mathrm{X}$ & & & & & \\
\hline 27154-33-2 & Trichlorofluoroethane & & & & $\mathrm{X}$ & & & \\
\hline $28434-86-8$ & \begin{tabular}{|l|} 
3,3'-Dichloro-4,4'- \\
diaminodiphenyl ether
\end{tabular} & $\mathrm{X}$ & & & & & & \\
\hline $287-92-3$ & Cyclopentane & & $\mathrm{X}$ & & & & & \\
\hline $29191-52-4$ & Anisidine (o-, p- isomers) & & $\mathrm{X}$ & & & & & \\
\hline $2921-88-2$ & Chlorpyrifos & & $\mathrm{X}$ & & & & & \\
\hline $2971-90-6$ & Clopidol & & $\mathrm{X}$ & & & & & \\
\hline $298-00-0$ & Methyl parathion & & $\bar{X}$ & $\mathrm{X}$ & & $\bar{X}$ & & \\
\hline $298-02-2$ & Phorate & & $\mathrm{X}$ & $\overline{\mathrm{X}}$ & & $\mathrm{X}$ & & \\
\hline $298-04-4$ & Disulfoton & & $\mathrm{X}$ & $\mathrm{X}$ & & $\mathrm{X}$ & & \\
\hline $299-84-3$ & Ronnel & & $\mathrm{X}$ & & & & & \\
\hline $299-86-5$ & Crufomate & & $\bar{X}$ & & & & & \\
\hline $300-76-5$ & Naled & & $\mathrm{X}$ & & & & & \\
\hline $302-01-2$ & Hydrazine & $\mathrm{X}$ & & & & & & \\
\hline $302-70-5$ & $\begin{array}{l}\text { Nitrogen mustard N-oxide } \\
\text { hydrochloride }\end{array}$ & $\mathrm{X}$ & & & & & & \\
\hline $30558-43-1$ & A2213 & & & & & $\bar{X}$ & & \\
\hline $3068-88-0$ & B-Butyrolactone & $\mathrm{X}$ & & & & & & \\
\hline $309-00-2$ & Aldrin & $\mathrm{X}$ & & $\mathrm{X}$ & & $\mathrm{X}$ & & \\
\hline $314-40-9$ & Bromacil & & $\mathrm{X}$ & & & & & \\
\hline $315-18-4$ & Mexacarbate & & & $\mathrm{X}$ & & $\overline{\mathrm{X}}$ & & \\
\hline $319-84-6$ & alpha-BHC & $\mathrm{X}$ & & $\bar{X}$ & & $\bar{X}$ & & \\
\hline $319-85-7$ & beta-BHC & $\mathrm{X}$ & & $\mathrm{X}$ & & $\mathrm{X}$ & & \\
\hline $319-86-8$ & delta-BHC & & & $\mathrm{X}$ & & $\bar{X}$ & & \\
\hline $330-54-1$ & Diuron & & $\mathrm{X}$ & & & & & \\
\hline $33213-65-9$ & Endosulfan II & & & $\mathrm{X}$ & & $\mathrm{X}$ & & \\
\hline $333-41-5$ & Diazinon & & $\mathrm{X}$ & & & & & \\
\hline $3333-52-6$ & Tetramethyl succinonitrile & & $\mathrm{X}$ & & & & & \\
\hline $334-88-3$ & Diazomethane & & $\overline{\mathrm{X}}$ & & & & & \\
\hline $3383-96-8$ & Temephos & & $\mathrm{X}$ & & & & & \\
\hline $3424-82-6$ & $0, p^{\prime}-\mathrm{DDE}\left(2,4^{\prime}-\mathrm{DDE}\right)$ & & & $\mathrm{X}$ & & $\mathrm{X}$ & & \\
\hline $34590-94-8$ & $\begin{array}{l}\text { Dipropylene glycol methyl } \\
\text { ether }\end{array}$ & & $\mathrm{X}$ & & & & & \\
\hline $35400-43-2$ & Sulprofos & & $\mathrm{X}$ & & & & & \\
\hline $3547-04-4$ & $\begin{array}{l}\text { DDE (p,p'- } \\
\text { Dichlorodiphenyldichloroeth } \\
\text { ylene) }\end{array}$ & $\mathrm{X}$ & & & & & & \\
\hline $3689-24-5$ & $\begin{array}{l}\text { Tetraethyldithiopyrophos- } \\
\text { phate (TEDP) }\end{array}$ & & $\mathrm{X}$ & & & & & \\
\hline $3697-24-3$ & 5-Methylchrysene & $\mathrm{X}$ & & & & & & \\
\hline $3761-53-3$ & Ponceau MX & $\mathrm{X}$ & & & & & & \\
\hline
\end{tabular}


Table B.4. Organic Analyte Regulatory Data Quality Objective Input List (623 Compounds). (Page 8 of 15 )

\begin{tabular}{|c|c|c|c|c|c|c|c|c|}
\hline CAst & Constituent & Class 1 & Class B & UHC & Dart 1 A & US & $\begin{array}{l}\text { DST } \\
\text { WSPS }\end{array}$ & $\begin{array}{l}\text { Tlammable } \\
\text { Gases }\end{array}$ \\
\hline $3825-26-1$ & $\begin{array}{l}\text { Ammonium } \\
\text { perfluorooctanoate }\end{array}$ & & $\mathrm{X}$ & & & & & \\
\hline $4016-14-2$ & $\begin{array}{l}\text { Isopropyl glycidyl ether } \\
\text { (IGE) }\end{array}$ & & $\mathrm{X}$ & & & & & \\
\hline $4098-71-9$ & Isophorone diisocyanate & & $\bar{X}$ & & & & & \\
\hline $4170-30-3$ & 2-Butenaldehyde & & $\mathrm{X}$ & & & & & \\
\hline $420-04-2$ & Cyanamide & & $\mathrm{X}$ & & & & & \\
\hline $463-51-4$ & Ketene & & $\mathrm{X}$ & & & & & \\
\hline $465-73-6$ & Isodrin & & & $\mathrm{X}$ & & $\mathrm{X}$ & & \\
\hline $4685-14-7$ & Paraquat & & $\mathrm{X}$ & & & & & \\
\hline $479-45-8$ & Tetryl & & $\mathrm{X}$ & & & & & \\
\hline $50-00-0$ & Formaldehyde & $\mathrm{X}$ & & & & & & \\
\hline $50-29-3$ & 4,4-DDT & $\mathrm{X}$ & & $\mathrm{X}$ & & $\mathrm{X}$ & & \\
\hline $50-32-8$ & Benzo(a)pyrene & $\mathrm{X}$ & & $\mathrm{X}$ & & $\mathrm{X}$ & & \\
\hline $504-29-0$ & 2-Aminopyridine & & $\mathrm{X}$ & $\mathrm{X}$ & & & & \\
\hline $509-14-8$ & Tetranitromethane & & $\mathrm{X}$ & & & & & \\
\hline $51-28-5$ & 2,4-Dinitrophenol & & $\mathrm{X}$ & $\mathrm{X}$ & & $\mathrm{X}$ & & \\
\hline $51-79-6$ & Ethyl carbamate (urethane) & & $\mathrm{X}$ & & & & & \\
\hline $510-15-6$ & Chlorobenzilate & $\mathrm{X}$ & & $\mathrm{X}$ & & $\mathrm{X}$ & & \\
\hline 5124-30-1 & $\begin{array}{l}\text { Methylene-bis-(4-cyclo- } \\
\text { hexylisocyanate) }\end{array}$ & & $\mathrm{X}$ & & & & & \\
\hline $52-85-7$ & Famphur & & & $\mathrm{X}$ & & $\mathrm{X}$ & & \\
\hline $528-29-0$ & Dinitrobenzene, all isomers & & $\mathrm{X}$ & $\mathrm{X}$ & & & & \\
\hline $52888-80-9$ & Prosulfocarb & & & & & $\mathrm{X}$ & & \\
\hline $53-19-0$ & o,p'-DDD (2,4'-DDD) & & & $\mathrm{X}$ & & $\mathrm{X}$ & & \\
\hline $53-70-3$ & Dibenz $[\mathrm{a}, \mathrm{h}]$ anthracene & $\mathrm{X}$ & & $\mathrm{X}$ & & $\mathrm{X}$ & & \\
\hline $53-96-3$ & 2-Acetylaminofluorene & $X$ & & $\mathrm{X}$ & & $\mathrm{X}$ & & \\
\hline $531-82-8$ & $\begin{array}{l}\text { N-(4-(5-Nitro-2-furyl)-2- } \\
\text { thiazolyl)acetamide }\end{array}$ & $\mathrm{X}$ & & & & & & \\
\hline $532-27-4$ & a-Chloroacetophenone & & $\mathrm{X}$ & & & & & \\
\hline $534-52-1$ & 4,6-Dinitro-o-cresol & & $\mathrm{X}$ & $\mathrm{X}$ & & $\mathrm{X}$ & & \\
\hline $54-11-5$ & Nicotine & & $\mathrm{X}$ & $\mathrm{X}$ & & & & \\
\hline $540-59-0$ & 1,2-Dichloroethylene & & $\mathrm{X}$ & & & & & \\
\hline $540-73-8$ & 1,2-Dimethylhydrazine & $\mathrm{X}$ & & & & & & \\
\hline $540-84-1$ & 2,2,4-Trimethylpentane & & $\mathrm{X}$ & & & & & \\
\hline $540-88-5$ & tert-Butyl acetate & & $\mathrm{X}$ & & & & & \\
\hline $541-73-1$ & 1,3-Dichlorobenzene & & & $\mathrm{X}$ & & $\mathrm{X}$ & & \\
\hline $541-85-5$ & Ethyl amyl ketone & & $\mathrm{X}$ & & & & & \\
\hline $542-75-6$ & 1,3-Dichloropropene & & $\mathrm{X}$ & & & & & \\
\hline $542-88-1$ & Dichloromethyl ether & $\mathrm{X}$ & & & & & & \\
\hline $542-92-7$ & Cyclopentadiene & & $\mathrm{X}$ & & & & & \\
\hline $55-18-5$ & N-Nitrosodiethylamine & $\mathrm{X}$ & & $\mathrm{X}$ & & $\mathrm{X}$ & & \\
\hline $55-38-9$ & Fenthion & & $\mathrm{X}$ & & & & & \\
\hline $55-63-0$ & Nitroglycerin & & $\bar{X}$ & & & & & \\
\hline $552-30-7$ & Trimellitic anhydride & & $\mathrm{X}$ & & & & & \\
\hline $55285-14-8$ & Carbosulfan & & & & & $\mathrm{X}$ & & \\
\hline $55406-53-6$ & $\begin{array}{l}\text { 3-Iodo-2-propynyl n- } \\
\text { butylcarbamate }\end{array}$ & & & $\mathrm{X}$ & & & & \\
\hline
\end{tabular}


Table B.4. Organic Analyte Regulatory Data Quality Objective Input List

(623 Compounds). (Page 9 of 15)

\begin{tabular}{|c|c|c|c|c|c|c|c|c|}
\hline CAst & Constituent & $\begin{array}{l}\text { Gass } A \\
\text { TAPs }\end{array}$ & Class B & UHC & Dartit A & UIS & WST: & Tlammable \\
\hline $555-84-9$ & $\begin{array}{l}\text { 1-(5- } \\
\text { Nitrofurfurylidene)amino)-2- } \\
\text { imidazolidinone }\end{array}$ & $\mathrm{X}$ & & & & & & \\
\hline $556-52-5$ & Glycidol & & $\mathrm{X}$ & & & & & \\
\hline $55720-99-5$ & Chlorinated diphenyl oxide & & $\mathrm{X}$ & & & & & \\
\hline $55738-54-0$ & $\begin{array}{l}\text { trans-2((Dimethylamino) } \\
\text { methylimino)-5-(2-(5-nitro- } \\
\text { 2-furyl) vinyl-1,3,4- } \\
\text { oxadiazole }\end{array}$ & $X$ & & & & & & \\
\hline $56-23-5$ & Carbon tetrachloride & $\mathrm{X}$ & & $\mathrm{X}$ & $\mathrm{X}$ & $\mathrm{X}$ & & \\
\hline $56-38-2$ & Parathion & & $\bar{X}$ & $\mathrm{X}$ & & $\overline{\mathrm{X}}$ & & \\
\hline $56-49-5$ & 3-Methylcholanthrene & & & $\mathrm{X}$ & & $\mathrm{X}$ & & \\
\hline $56-55-3$ & Benzo(a)anthracene & $\mathrm{X}$ & & $\mathrm{X}$ & & $\mathrm{X}$ & & \\
\hline $563-12-2$ & Ethion & & $\mathrm{X}$ & & & & & \\
\hline $563-80-4$ & 3-Methyl-2-butanone & & $\bar{X}$ & & & & & \\
\hline $57-14-7$ & 1,1-Dimethylhydrazine & & $\mathrm{X}$ & & & & & \\
\hline $57-24-9$ & Strychnine & & $\mathrm{X}$ & & & & & \\
\hline $57-47-6$ & Physostigmine & & & & & $\overline{\mathrm{X}}$ & & \\
\hline $57-57-8$ & B-Propiolactone & & $\mathrm{X}$ & & & & & \\
\hline $57-64-7$ & Physostigmine salicylate & & & & & $\mathrm{X}$ & & \\
\hline $57-74-9$ & Chlordane & $\bar{X}$ & & $\bar{X}$ & & $\bar{X}$ & & \\
\hline $58-89-9$ & gamma-BHC (Lindane) & $\mathrm{X}$ & & $\mathrm{X}$ & & $\mathrm{X}$ & & \\
\hline $58-90-2$ & $2,3,4,6$-Tetrachlorophenol & & & $\mathrm{X}$ & & $\bar{X}$ & & \\
\hline $583-60-8$ & o-Methylcyclohexanone & & $\mathrm{X}$ & & & & & \\
\hline $584-84-9$ & 2,4-Toluene diisocyanate & $\mathrm{X}$ & & & & & & \\
\hline $59-50-7$ & 4-Chloro-3-methylphenol & & & $\mathrm{X}$ & & $\mathrm{X}$ & & \\
\hline $59-87-0$ & Nitrofurazone & $\mathrm{X}$ & & & & & & \\
\hline $59-89-2$ & N-Nitrosomorpholine & $\bar{X}$ & & $\bar{X}$ & & $\mathrm{X}$ & & \\
\hline $591-78-6$ & 2-Hexanone & & $\mathrm{X}$ & & & & & \\
\hline $592-62-1$ & Methyl azoxymethyl acetate & $\mathrm{X}$ & & & & & & \\
\hline $593-60-2$ & Vinyl bromide & & $\mathrm{X}$ & & & & & \\
\hline $59355-75-8$ & $\begin{array}{l}\text { Methyl acetylene-propadiene } \\
\text { mixture (MAPP) }\end{array}$ & & $\mathrm{X}$ & & & & & \\
\hline $594-42-3$ & Perchloromethyl mercaptan & & $\mathrm{X}$ & & & & & \\
\hline $594-72-9$ & 1,1-Dichloro-1-nitroethane & & $\bar{X}$ & & & & & \\
\hline $5952-26-1$ & $\begin{array}{l}\text { Diethylene glycol, } \\
\text { dicarbamate }\end{array}$ & & & & & $\mathrm{X}$ & & \\
\hline $59669-26-0$ & Thiodicarb & & & & & $\mathrm{X}$ & & \\
\hline $60-11-7$ & $\begin{array}{l}\text { p-Dimethylaminoazo- } \\
\text { benzene }\end{array}$ & & $\mathrm{X}$ & $\mathrm{X}$ & & $\mathrm{X}$ & & \\
\hline $60-29-7$ & Ethyl ether & & $\mathrm{X}$ & $\mathrm{X}$ & $\mathrm{X}$ & $\mathrm{X}$ & & \\
\hline $60-34-4$ & Methylhydrazine & & $\bar{X}$ & & & & & \\
\hline $60-35-5$ & Acetamide & & $\mathrm{X}$ & & & & & \\
\hline $60-57-1$ & Dieldrin & $\mathrm{X}$ & & $\mathrm{X}$ & & $\mathrm{X}$ & & \\
\hline $600-25-9$ & 1-Chloro-1-nitropropane & & $\mathrm{X}$ & & & & & \\
\hline $602-87-9$ & 5-Nitroacenaphthene & $\mathrm{X}$ & & & & & & \\
\hline $603-34-9$ & Triphenyl amine & & $\mathrm{X}$ & & & & & \\
\hline $606-20-2$ & 2,6-Dinitrotoluene & & & $\mathrm{X}$ & & $\mathrm{X}$ & & \\
\hline
\end{tabular}


Table B.4. Organic Analyte Regulatory Data Quality Objective Input List (623 Compounds). (Page 10 of 15)

\begin{tabular}{|c|c|c|c|c|c|c|c|c|}
\hline CASH & Constituent & $\begin{array}{l}\text { Class A } \\
\text { TAPS. }\end{array}$ & Gass B & UHC: & $\begin{array}{l}\text { Part A } \\
\text { DSTISST }\end{array}$ & UTS & $\begin{array}{l}\text { DST } \\
\text { WSPS }\end{array}$ & Flammable \\
\hline $608-93-5$ & Pentachlorobenzene & & & $\bar{X}$ & & $\bar{X}$ & & \\
\hline $61-82-5$ & Amitrole & $\mathrm{X}$ & & & & & & \\
\hline $613-35-4$ & N,N-Diacetylbenzidine & $\mathrm{X}$ & & & . & & & \\
\hline $615-53-2$ & N-Nitroso-N-methylurethane & $\mathrm{X}$ & & & & & & \\
\hline $62-44-2$ & Phenacetin & & & $\mathrm{X}$ & & $\bar{X}$ & & \\
\hline $62-53-3$ & Aniline & $\bar{X}$ & $\bar{X}$ & $\mathrm{X}$ & & $\mathrm{X}$ & & \\
\hline $62-73-7$ & Dichlorvas & & $\mathrm{X}$ & & & & & \\
\hline $62-74-8$ & $\begin{array}{l}\text { Fluoroacetic acid, sodium } \\
\text { salt (Fratol) }\end{array}$ & & $\mathrm{X}$ & & & & & \\
\hline $62-75-9$ & $\begin{array}{l}\text { N-Nitroso-N,N- } \\
\text { dimethylamine }\end{array}$ & $\mathrm{X}$ & & $\mathrm{X}$ & & $\mathrm{X}$ & & \\
\hline $621-64-7$ & N-Nitroso-di-n-propylamine & $\bar{X}$ & & $\overline{\mathrm{X}}$ & & $\mathrm{X}$ & & \\
\hline $624-83-9$ & Methyl isocyanate & & $\mathrm{X}$ & & & & & \\
\hline $626-17-5$ & m-Phthalodinitrile & & $\mathrm{X}$ & & & & & \\
\hline $626-38-0$ & sec-Amyl acetate & & $\mathrm{X}$ & & & & & \\
\hline $627-13-4$ & Nitric acid, propyl ester & & $\overline{\mathrm{X}}$ & & & & & \\
\hline $628-63-7$ & n-Amyl acetate & & $\mathrm{X}$ & & & & & \\
\hline $628-96-6$ & Ethylene glycol dinitrate & & $\bar{X}$ & & & & & \\
\hline $63-25-2$ & Carbaryl & & $\bar{X}$ & $\mathrm{X}$ & & $\mathrm{X}$ & & \\
\hline $63-92-3$ & $\begin{array}{l}\text { Phenoxybenzamine } \\
\text { hydrochloride }\end{array}$ & $\mathrm{X}$ & & & & & & \\
\hline $630-20-6$ & $1,1,1,2$-Tetrachloroethane & & & $\mathrm{X}$ & $\mathrm{X}$ & $\mathrm{X}$ & & \\
\hline $636-21-5$ & o-Toluidine hydrochloride & $\mathrm{X}$ & & & & & & \\
\hline $638-21-1$ & Phenylphosphine & & $\mathrm{X}$ & & & & & \\
\hline $64-00-6$ & m-Cumenyl methylcarbamate & & & & & $\mathrm{X}$ & & \\
\hline $64-17-5$ & Ethyl alcohol & & $\bar{X}$ & & & & & \\
\hline $64-18-6$ & Formic acid & & $\bar{X}$ & & & & & \\
\hline $64-19-7$ & Acetic acid & & $\bar{X}$ & & & & & \\
\hline $64-67-5$ & Diethyl sulfate & & $\overline{\mathrm{X}}$ & & & & & \\
\hline $64091-91-4$ & $\begin{array}{l}\text { 4-(Methylnitrosamino)-1-(3- } \\
\text { pyridyl)-1-butanone }\end{array}$ & $\mathrm{X}$ & & & & & & \\
\hline $6423-43-4$ & Propylene glycol dinitrate & & $\mathrm{X}$ & & & & & \\
\hline $644-64-4$ & Dimetilan & & & & & $\mathrm{X}$ & & \\
\hline $66-27-3$ & Methyl methanesulfonate & & . & $\mathrm{X}$ & & $\mathrm{X}$ & & \\
\hline $67-45-8$ & Furazolidone & $\mathrm{X}$ & & & . & & & \\
\hline $67-56-1$ & Methyl alcohol & & $\mathrm{X}$ & $\bar{X}$ & $\bar{X}$ & $\overline{\mathrm{X}}$ & & \\
\hline $67-63-0$ & 2-Propyl alcohol & & $\bar{X}$ & & & & & \\
\hline 67-64-1 & 2-Propanone (Acetone) & & $\mathrm{X}$ & $\mathrm{X}$ & $\bar{X}$ & $\bar{X}$ & & \\
\hline $67-66-3$ & Chloroform & $\mathrm{X}$ & & $\bar{X}$ & $\mathrm{X}$ & $\bar{X}$ & & \\
\hline $67-72-1$ & Hexachloroethane & & $\bar{X}$ & $\mathrm{X}$ & $\bar{X}$ & $\mathrm{X}$ & & \\
\hline $68-11-1$ & Thioglycolic acid & & $\mathrm{X}$ & & & & & \\
\hline $68-12-2$ & Dimethylformamide & r & $\mathrm{X}$ & & & & & \\
\hline $680-31-9$ & Hexamethylphosphora-mide & $\bar{X}$ & & & & & & \\
\hline $681-84-5$ & Methyl silicate & & $\mathrm{X}$ & & & & & \\
\hline $684-16-2$ & Hexafluoroacetone & & $\mathrm{X}$ & & & & & \\
\hline $684-93-5$ & N-Nitroso-N-methylurea & & $\bar{X}$ & & & & & \\
\hline 68476-85-7 & Liquified petroleum gas & & $\overline{\mathrm{X}}$ & & & & & \\
\hline $6923-22-4$ & Monocrotophos & & $\bar{X}$ & & & & & \\
\hline
\end{tabular}


Table B.4. Organic Analyte Regulatory Data Quality Objective Input List (623 Compounds). (Page 11 of 15)

\begin{tabular}{|c|c|c|c|c|c|c|c|c|}
\hline CAst & Constituent & Class: & $\begin{array}{l}\text { Class B } \\
\text { TAPs }\end{array}$ & UHC & Part A & UTS & $\begin{array}{l}\text { BST } \\
\text { WSPS }\end{array}$ & Tlammable \\
\hline $696-28-6$ & Dichlorophenylarsine & $\mathrm{x}$ & & & & & & \\
\hline $71-23-8$ & n-Propyl alcohol & & $\mathrm{X}$ & & & & & \\
\hline $71-36-3$ & n-Butyl alcohol & & $\mathrm{X}$ & $\mathrm{X}$ & $\mathrm{X}$ & $\bar{X}$ & & \\
\hline $71-43-2$ & Benzene & $\bar{X}$ & & $\mathrm{X}$ & $\mathrm{X}$ & $\mathrm{X}$ & & \\
\hline $71-55-6$ & 1,1,1-Trichloroethane & & $\mathrm{X}$ & $\mathrm{X}$ & $\mathrm{X}$ & $\bar{X}$ & & \\
\hline $72-20-8$ & Endrin & & $\mathrm{X}$ & $\mathrm{X}$ & & $\overline{\mathrm{X}}$ & & \\
\hline $72-43-5$ & Methoxychlor & & $\mathrm{X}$ & $\mathrm{X}$ & & $\mathrm{X}$ & & \\
\hline $72-54-8$ & 4,4-DDD & & & $\mathrm{X}$ & & $\mathrm{X}$ & & \\
\hline $72-55-9$ & 4,4-DDE & & & $\mathrm{X}$ & & $\mathrm{X}$ & & \\
\hline $74-83-9$ & Bromomethane & & $\mathrm{X}$ & $\mathrm{X}$ & & $\mathrm{X}$ & & \\
\hline $74-87-3$ & Chloromethane & & $\mathrm{X}$ & $\mathrm{X}$ & & $\mathrm{X}$ & & \\
\hline $74-88-4$ & Iodomethane & & $\mathrm{X}$ & $\mathrm{X}$ & & $X$ & & \\
\hline $74-89-5$ & Methylamine & & $\mathrm{X}$ & & & & & \\
\hline $74-93-1$ & Thiomethanol & & $\mathrm{X}$ & & & & & \\
\hline $74-95-3$ & Dibromomethane & & - & $\bar{X}$ & & $\bar{X}$ & & \\
\hline $74-96-4$ & Ethyl bromide & & $\mathrm{X}$ & & & & & \\
\hline $74-97-5$ & Bromochloromethane & & $\mathrm{X}$ & & & & & \\
\hline $74-99-7$ & Methylacetylene & & $\mathrm{X}$ & & & & & \\
\hline $7421-93-4$ & Endrin aldehyde & & & $\bar{X}$ & & $\bar{X}$ & & \\
\hline $75-00-3$ & Chloroethane & & $\mathrm{X}$ & $\mathrm{X}$ & & $\mathrm{X}$ & & \\
\hline $75-01-4$ & 1-Chloroethene & $\mathrm{X}$ & & $\bar{X}$ & & $\mathrm{X}$ & & \\
\hline $75-04-7$ & Ethylamine & & $\mathrm{X}$ & & & & & \\
\hline $75-05-8$ & Acetonitrile & & $\mathrm{X}$ & $\mathrm{X}$ & & $\mathrm{X}$ & & \\
\hline $75-07-0$ & Acetaldehyde & $\mathrm{X}$ & & & & & & \\
\hline $75-08-1$ & Ethyl mercaptan & & $\mathrm{X}$ & & & & & \\
\hline $75-09-2$ & $\begin{array}{l}\text { Dichloromethane (Methylene } \\
\text { Chloride) }\end{array}$ & $\mathrm{X}$ & & $\mathrm{X}$ & $\mathrm{X}$ & $\mathrm{X}$ & & \\
\hline $75-12-7$ & Formamide & & $\mathrm{X}$ & & & & & \\
\hline $75-15-0$ & Carbon disulfide & & $\mathrm{X}$ & $\mathrm{X}$ & $\overline{\mathrm{X}}$ & $\mathrm{X}$ & & \\
\hline $75-21-8$ & Oxirane & $\mathrm{X}$ & & $\mathrm{X}$ & & $\mathrm{X}$ & & \\
\hline $75-25-2$ & Tribromomethane & $\mathrm{X}$ & & $\mathrm{X}$ & & $\bar{X}$ & & \\
\hline $75-27-4$ & Bromodichloromethane & & & $\mathrm{X}$ & & $\mathrm{X}$ & & \\
\hline $75-31-0$ & Isopropylamine & & $\bar{X}$ & & & & & \\
\hline $75-34-3$ & 1,1-Dichloroethane & & $\mathrm{X}$ & $\mathrm{X}$ & & $\mathrm{X}$ & & \\
\hline $75-35-4$ & 1,1-Dichloroethene & & $\mathrm{X}$ & $\mathrm{X}$ & & $\mathrm{X}$ & & \\
\hline $75-43-4$ & Dichlorofluoromethane & & $\mathrm{X}$ & & & & & \\
\hline $75-45-6$ & Chlorodifluoromethane & & $\mathrm{X}$ & & & & & \\
\hline $75-47-8$ & Iodoform & & $\mathrm{X}$ & & & & & \\
\hline $75-50-3$ & Trimethylamine & & $\mathrm{X}$ & & & & & \\
\hline $75-52-5$ & Nitromethane & & $\mathrm{X}$ & $\bar{X}$ & & & & \\
\hline $75-55-8$ & 2-Methylaziridine & & $\mathrm{X}$ & & & & & \\
\hline $75-56-9$ & Propylene oxide & $\mathrm{X}$ & & & & & & \\
\hline $75-61-6$ & Difluorodibromomethane & & $\overline{\mathrm{X}}$ & & & & & \\
\hline $75-63-8$ & Trifluorobromomethane & & $\mathrm{X}$ & & & & & \\
\hline $75-65-0$ & 2-Methyl-2-propanol & & $\overline{\mathrm{X}}$ & & & & & \\
\hline $75-69-4$ & Trichlorofluoromethane & & $\mathrm{X}$ & $\mathrm{X}$ & & $\mathrm{X}$ & & \\
\hline $75-71-8$ & Dichlorodifluoromethane & & $\mathrm{X}$ & $\mathrm{X}$ & & $\mathrm{X}$ & & \\
\hline $75-99-0$ & 2,2-Dichloropropionic acid & & $\mathrm{X}$ & & & & & \\
\hline
\end{tabular}


Table B.4. Organic Analyte Regulatory Data Quality Objective Input List (623 Compounds). (Page 12 of 15)

\begin{tabular}{|c|c|c|c|c|c|c|c|c|}
\hline CASH & Constituent & $\begin{array}{l}\text { Class A } \\
\text { TAPs }\end{array}$ & Class: B & UHC & Dart & UIS & $\begin{array}{l}\text { DST } \\
\text { WSPS }\end{array}$ & $\begin{array}{l}\text { Flammable } \\
\text { Gases }\end{array}$ \\
\hline $7572-29-4$ & Dichloroacetylene & & $\mathrm{X}$ & & & & & \\
\hline $759-73-9$ & N-Nitroso-N-ethylurea & $\mathrm{X}$ & & & & & & \\
\hline $759-94-4$ & EPTC & & & $\bar{X}$ & & $\mathrm{X}$ & & \\
\hline $76-01-7$ & Pentachloroethane & & & $\mathrm{X}$ & & $\mathrm{X}$ & & \\
\hline $76-03-9$ & Trichloroacetic acid & & $\mathrm{X}$ & & & & & \\
\hline $76-06-2$ & Chloropicrin & & $\mathrm{X}$ & & & & & \\
\hline $76-11-9$ & $\begin{array}{l}\text { 1,1,1,2-Tetrachloro-2,2- } \\
\text { difluoroethane }\end{array}$ & & $\mathrm{X}$ & & & & & \\
\hline $76-12-0$ & $\begin{array}{l}\text { 1,1,2,2-Tetrachloro-1,2- } \\
\text { difluoroethane }\end{array}$ & & $\mathrm{X}$ & & & & & \\
\hline $76-13-1$ & $\begin{array}{l}1,2,2- \\
\text { Trichlorotrifluoroethane }\end{array}$ & & $\mathrm{X}$ & $\mathrm{X}$ & $\mathrm{X}$ & $\mathrm{X}$ & & \\
\hline $76-14-2$ & $\begin{array}{l}\text { 1,2-Dichloro-1,1,2,2- } \\
\text { tetrafluoroethane }\end{array}$ & & $\mathrm{X}$ & & & & & \\
\hline $76-15-3$ & Chloropentafluoroethane & & $\mathrm{X}$ & & & & & \\
\hline $76-22-2$ & Camphor, synthetic & & $\mathrm{X}$ & & & & & \\
\hline $76-44-8$ & Heptachlor & $\mathrm{X}$ & & $\mathrm{X}$ & & $\mathrm{X}$ & & \\
\hline $764-41-0$ & 1,4-Dichloro-2-butene & $\mathrm{X}$ & & & & & & \\
\hline $765-34-4$ & Glycidylaldehyde & $\mathrm{X}$ & & & & & & \\
\hline $768-52-5$ & N-Isopropylaniline & & $\mathrm{X}$ & & & & & \\
\hline $77-47-4$ & Hexachlorocyclopen-tadiene & & $\bar{X}$ & $\mathrm{X}$ & & $\mathrm{X}$ & & \\
\hline $77-73-6$ & Dicyclopentadiene & & $\mathrm{X}$ & & & & & \\
\hline $77-78-1$ & Dimethyl sulfate & $\mathrm{X}$ & & & & & & \\
\hline $7782-41-4$ & Fluorine & & $\mathrm{X}$ & & & & & \\
\hline $7786-34-7$ & Mevinphos & & $\mathrm{X}$ & & & & & \\
\hline $78-10-4$ & Ethyl silicate & & $\bar{X}$ & & & & & \\
\hline $78-30-8$ & Triorthocresyl phosphate & & $\bar{X}$ & & & & & \\
\hline $78-34-2$ & Dioxathion & & $\mathrm{X}$ & & & & & \\
\hline $78-59-1$ & Isophorone & & $\mathrm{X}$ & & & & & \\
\hline $78-83-1$ & 2-Methylpropyl alcohol & & $\mathrm{X}$ & $\mathrm{X}$ & $\mathrm{X}$ & $\mathrm{X}$ & & \\
\hline $78-87-5$ & 1,2-Dichloropropane & $\mathrm{X}$ & & $\mathrm{X}$ & & $\mathrm{X}$ & & \\
\hline $78-92-2$ & 1-Methylpropyl alcohol & & $\mathrm{X}$ & & & & & \\
\hline $78-93-3$ & 2-Butanone & & $\mathrm{X}$ & $\mathrm{X}$ & $\mathrm{X}$ & $\mathrm{X}$ & & \\
\hline $7803-51-2$ & Phosphine & & $\mathrm{X}$ & & & & & \\
\hline $789-02-6$ & $0, \mathrm{p}^{\prime}-\mathrm{DDT}\left(2,4^{\prime}-\mathrm{DDT}\right)$ & & & $\mathrm{X}$ & & $\mathrm{X}$ & & \\
\hline $79-00-5$ & $1,1,2$-Trichloroethane & & $\mathrm{X}$ & $\mathrm{X}$ & $\mathrm{X}$ & $\bar{X}$ & & \\
\hline 79-01-6 & 1,1,2-Trichloroethylene & $\mathrm{X}$ & & $\mathrm{X}$ & $\mathrm{X}$ & $\mathrm{X}$ & & \\
\hline 79-04-9 & Chloroacetyl chloride & & $\mathrm{X}$ & & & & & \\
\hline $79-06-1$ & Acrylamide & $\mathrm{X}$ & & $\mathrm{X}$ & & $\mathrm{X}$ & & \\
\hline 79-09-4 & Propanoic acid & & $\mathrm{X}$ & & & & & \\
\hline $79-10-7$ & 2-Propenoic acid & & $\mathrm{X}$ & & & & & \\
\hline $79-11-8$ & Chloroacetic acid & & $\mathrm{X}$ & & & & & \\
\hline $79-20-9$ & Methyl acetate & & $\mathrm{X}$ & & & & & \\
\hline $79-24-3$ & Nitroethane & & $\mathrm{X}$ & & & & & \\
\hline $79-27-6$ & Acetylene tetrabromide & & $\mathrm{X}$ & & & & & \\
\hline $79-34-5$ & 1,1,2,2-Tetrachloroethane & & $\mathrm{X}$ & $\mathrm{X}$ & & $\mathrm{X}$ & & \\
\hline $79-41-4$ & Methacrylic acid & & $\mathrm{X}$ & & & & & \\
\hline $79-44-7$ & Dimethylcarbamoyl chloride & & $\mathrm{X}$ & & & & & \\
\hline
\end{tabular}


Table B.4. Organic Analyte Regulatory Data Quality Objective Input List (623 Compounds). (Page 13 of 15)

\begin{tabular}{|c|c|c|c|c|c|c|c|c|}
\hline CASH & Constituent & Class A & Class B & UHC & Dart A A & UTS & WST & $\begin{array}{l}\text { Flammable } \\
\text { Gases }\end{array}$ \\
\hline $79-46-9$ & 2-Nitropropane & $\mathrm{X}$ & & & & & & \\
\hline $794-93-4$ & $\begin{array}{l}\text { Panfuran S (dihydroxy- } \\
\text { methylfuratrizine) }\end{array}$ & $\mathrm{X}$ & & & & & & \\
\hline $80-62-6$ & Methyl methacrylate & & $\mathrm{X}$ & $\mathrm{X}$ & & $\mathrm{X}^{*}$ & & \\
\hline $8001-35-2$ & Toxaphene & $\mathrm{X}$ & & $\mathrm{X}$ & & $\mathrm{X}$ & & \\
\hline $8001-58-9$ & Creosote & $\bar{X}$ & & & & & & \\
\hline $8003-34-7$ & Pyrethrum & & $\mathrm{X}$ & & & & & \\
\hline $8006-64-2$ & Turpentine & & $\mathrm{X}$ & & & & & \\
\hline $8022-00-2$ & Methyl demeton & & $\mathrm{X}$ & & & & & \\
\hline $8052-42-4$ & Asphalt (petroleum) fumes & & $\mathrm{X}$ & & & & & \\
\hline $8065-48-3$ & Demeton & & $\mathrm{X}$ & & & & & \\
\hline $81-81-2$ & Warfarin $(>0.3 \%)$ & & $\mathrm{X}$ & & & & & \\
\hline $81-81-2 a$ & Warfarin $(<0.3 \%)$ & & $\mathrm{X}$ & & & & & \\
\hline $82-68-8$ & $\begin{array}{l}\text { Pentachloronitrobenzene } \\
\text { (PCNB) }\end{array}$ & & $\mathrm{X}$ & $\mathrm{X}$ & & $\mathrm{X}$ & & \\
\hline $822-06-0$ & Hexamethylene diisocyanate & & $\mathrm{X}$ & & & & & \\
\hline $83-26-1$ & Pindone & & $\mathrm{X}$ & & & & & \\
\hline $83-32-9$ & Acenaphthene & & & $\mathrm{X}$ & & $\mathrm{X}$ & & \\
\hline $83-79-4$ & Rotenone & & $\mathrm{X}$ & & & & & \\
\hline $838-88-0$ & $\begin{array}{l}\text { 4,4'-Methylenebis(2- } \\
\text { methylaniline) }\end{array}$ & $\mathrm{X}$ & & . & & & & \\
\hline $84-66-2$ & Diethyl phthalate & & $\mathrm{X}$ & $\mathrm{X}$ & & $\mathrm{X}$ & & \\
\hline $84-74-2$ & Di-n-butylphthalate & & $\mathrm{X}$ & $\mathrm{X}$ & & $\bar{X}$ & & \\
\hline $85-00-7$ & Diquat & & $\mathrm{X}$ & & & & & \\
\hline $85-01-8$ & Phenanthrene & & & $\mathrm{X}$ & & $\mathrm{X}$ & & \\
\hline $85-44-9$ & Phthalic anhydride & & $\mathrm{X}$ & $\mathrm{X}$ & & $\mathrm{X}$ & & \\
\hline $85-68-7$ & Butylbenzylphthalate & & & $\mathrm{X}$ & & $\mathrm{X}$ & & \\
\hline $86-30-6$ & N-Nitrosodiphenylamine & $\mathrm{X}$ & & $\mathrm{X}$ & & $\mathrm{X}$ & & \\
\hline $86-50-0$ & Azinphos-methyl & & $\mathrm{X}$ & & & & & \\
\hline $86-73-7$ & Fluorene & & & $\mathrm{X}$ & & $\bar{X}$ & & \\
\hline $86-88-4$ & alpha-Naphthylthiourea & & $\mathrm{X}$ & & & & & \\
\hline $87-65-0$ & 2,6-Dichlorophenol & & & $\mathrm{X}$ & & $\mathrm{X}$ & & \\
\hline $87-68-3$ & Hexachlorobutadiene & & $\mathrm{X}$ & $\mathrm{X}$ & $\mathrm{X}$ & $\mathrm{X}$ & & \\
\hline $87-86-5$ & Pentachlorophenol & $\mathrm{X}$ & & $\mathrm{X}$ & & $\mathrm{X}$ & & \\
\hline $88-06-2$ & 2,4,6-Trichlorophenol & $\mathrm{X}$ & & $\mathrm{X}$ & & $\mathrm{X}$ & & \\
\hline $88-72-2$ & Nitrotoluene & & $\mathrm{X}$ & & & & & \\
\hline $88-74-4$ & 2-Nitroaniline & & & $\mathrm{X}$ & & $\mathrm{X}$ & & \\
\hline $88-75-5$ & 2-Nitrophenol & & & $\mathrm{X}$ & & $\mathrm{X}$ & & \\
\hline $88-85-7$ & $\begin{array}{l}\text { 2-sec-Butyl-4,6- } \\
\text { dinitrophenol; syn Dinoseb }\end{array}$ & & & $\mathrm{X}$ & & $\mathrm{X}$ & & \\
\hline $88-89-1$ & Picric acid & $\cdot$ & $\mathrm{X}$ & & & & & \\
\hline $89-72-5$ & o-sec-Butylphenol & & $\mathrm{X}$ & & & & & \\
\hline 90-04-0 & o-Anisidine & $\mathrm{X}$ & & & & & & \\
\hline $91-20-3$ & Naphthalene & & $\mathrm{X}$ & $\mathrm{X}$ & & $\mathrm{X}$ & & \\
\hline $91-22-5$ & Quinoline & & $\mathrm{X}$ & & & & & \\
\hline $91-58-7$ & 2-Chloronaphthalene & & & $X$ & & $\mathrm{X}$ & & \\
\hline $91-59-8$ & 2-Napthylamine & & & $\mathrm{X}$ & & $\mathrm{X}$ & & \\
\hline $91-80-5$ & Methapyrilene & & & $\mathrm{X}$ & & $\underline{X}$ & & \\
\hline
\end{tabular}


Table B.4. Organic Analyte Regulatory Data Quality Objective Input List (623 Compounds). (Page 14 of 15)

\begin{tabular}{|c|c|c|c|c|c|c|c|c|}
\hline CASH & Constituent & $\begin{array}{l}\text { Class } \mathrm{A} \\
\text { TAPS. }\end{array}$ & $\begin{array}{l}\text { Class B } \\
\text { TAPS }\end{array}$ & UHC & Part A & UTS & WST: & Flammable \\
\hline $91-94-1$ & 3,3-Dichlorobenzidine & $\mathrm{X}$ & & & & & & \\
\hline $92-52-4$ & 1,1-Biphenyl & & $\mathrm{X}$ & & & & & \\
\hline $92-67-1$ & 4-Aminobiphenyl & $\mathrm{X}$ & & $\bar{X}$ & & $\bar{X}$ & & \\
\hline$\overline{92-84-2}$ & Phenothiazine & & $\mathrm{X}$ & & & & & \\
\hline $92-87-5$ & Benzidine & $\mathrm{X}$ & & & & & & \\
\hline $92-93-3$ & 4-Nitrobiphenyl & & $\mathrm{X}$ & & & & & \\
\hline $924-16-3$ & N-Nitrosodi-n-butylamine & $\mathrm{X}$ & & $\mathrm{X}$ & & $\mathrm{X}$ & & \\
\hline $93-72-1$ & Silvex $(2,4,5-\mathrm{TP})$ & & & $\bar{X}$ & & $\mathrm{X}$ & & \\
\hline $93-76-5$ & $2,4,5-\mathrm{T}$ & & $\mathrm{X}$ & $\mathrm{X}$ & & $\bar{X}$ & & \\
\hline $930-55-2$ & N-Nitrosopyrrolidine & & & $\mathrm{X}$ & & $\bar{X}$ & & \\
\hline $94-36-0$ & Benzoyl Peroxide & & $\mathrm{X}$ & & & & & \\
\hline 94-59-7 & Safrole & & & $\mathrm{X}$ & . & $\mathrm{X}$ & & \\
\hline $94-75-7$ & $2,4-\mathrm{D}$ & $\mathrm{X}$ & & $\mathrm{X}$ & & $\mathrm{X}$ & & \\
\hline $944-22-9$ & Fonofos & & $\mathrm{X}$ & & & & & \\
\hline $95-13-6$ & Indene & & $\bar{X}$ & & & & & \\
\hline $95-47-6$ & o-Xylene & & & $\mathrm{X}$ & $\mathrm{X}$ & $\mathrm{X}$ & & \\
\hline $95-48-7$ & o-Cresol & & $\mathrm{X}$ & $\bar{X}$ & $\mathrm{X}$ & $\bar{X}$ & & \\
\hline $95-49-8$ & o-Chlorotoluene & & $\mathrm{X}$ & & & & & \\
\hline $95-50-1$ & 1,2-Dichlorobenzene & & $\mathrm{X}$ & $\mathrm{X}$ & $\mathrm{X}$ & $\mathrm{X}$ & & \\
\hline $95-53-4$ & $\begin{array}{l}\text { o-Toluidine (2- } \\
\text { methylaniline) }\end{array}$ & $\mathrm{X}$ & & & & & & \\
\hline $95-54-5$ & 1,2-Phenylenediamine & & & & & $\mathrm{X}$ & & \\
\hline $95-57-8$ & 2-Chlorophenol & & & $\mathrm{X}$ & & $\mathrm{X}$ & & \\
\hline $95-80-7$ & Toluene-2,4-diamine & $X$ & & & & & & \\
\hline $95-94-3$ & $1,2,4,5$-Tetrachlorobenzene & & & $\mathrm{X}$ & & $\mathrm{X}$ & & \\
\hline $95-95-4$ & 2,4,5-Trichlorophenol & & $\mathrm{X}$ & $\mathrm{X}$ & $\mathrm{X}$ & $\mathrm{X}$ & & \\
\hline $959-98-8$ & Endosulfan I & & & $\mathrm{X}$ & & $\mathrm{X}$ & & \\
\hline $96-09-3$ & Styrene oxide & & $\mathrm{X}$ & & & & & \\
\hline $96-12-8$ & $\begin{array}{l}\text { 1,2-Dibromo-3- } \\
\text { chloropropane }\end{array}$ & & $\mathrm{X}$ & $\mathrm{X}$ & & $\mathrm{X}$ & & \\
\hline $96-18-4$ & 1,2,3-Trichloropropane & & $\mathrm{X}$ & $\mathrm{X}$ & & $\mathrm{X}$ & & \\
\hline $96-22-0$ & 3-Pentanone & & $\mathrm{X}$ & & & & & \\
\hline $96-33-3$ & Methyl acrylate & & $\mathrm{X}$ & & & & & \\
\hline $96-45-7$ & Ethylenethiourea & $\mathrm{X}$ & & & & & & \\
\hline $96-69-5$ & $\begin{array}{l}\text { Bis(3-tert-butyl-4-hydroxy-6- } \\
\text { methyl-phenyl) sulfide }\end{array}$ & & $\mathrm{X}$ & & & & & \\
\hline $97-56-3$ & o-Aminoazotoluene & $\mathrm{X}$ & & & & & & \\
\hline $97-63-2$ & Ethyl methacrylate & & & $X$ & & $\mathrm{X}$ & & \\
\hline $97-77-8$ & Disulfiram & & $X$ & & & & & \\
\hline $98-00-1$ & Furfuryl alcohol & & $\mathrm{X}$ & & & & & \\
\hline $98-01-1$ & Furfural & & $\mathrm{X}$ & & & & & \\
\hline $98-07-7$ & Benzotrichloride & & $\mathrm{X}$ & & 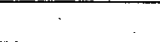 & & & \\
\hline $98-51-1$ & p-tert-Butyltoluene & & $\mathrm{X}$ & & & & & \\
\hline $98-82-2$ & Cumene & & $\mathrm{X}$ & & & & & \\
\hline $98-83-9$ & Methylstyrene & & $\mathrm{X}$ & & & & & \\
\hline $98-86-2$ & Acetophenone & & $\mathrm{X}$ & $\mathrm{X}$ & & $\mathrm{X}$ & & \\
\hline $98-87-3$ & Benzal chloride & & & $\mathrm{X}$ & & $\mathrm{X}$ & & \\
\hline $98-95-3$ & Nitrobenzene & & $\mathrm{X}$ & $\mathrm{X}$ & $\mathrm{X}$ & $\mathrm{X}$ & & \\
\hline
\end{tabular}


Table B.4. Organic Analyte Regulatory Data Quality Objective Input List

(623 Compounds). (Page 15 of 15)

\begin{tabular}{|c|c|c|c|c|c|c|c|c|}
\hline QAS\# & Constituent & Class & $\begin{array}{l}\text { Class } \mathrm{B} \\
\mathrm{TAPS}\end{array}$ & UHC & $\begin{array}{l}\text { Part A } \\
\text { DSTSST }\end{array}$ & UTS & $\begin{array}{l}\text { DST } \\
\text { WSPS }\end{array}$ & $\begin{array}{l}\text { Hammable } \\
\text { Gases }\end{array}$ \\
\hline $99-55-8$ & 5-Nitro-o-toluidine & & & $\mathrm{X}$ & & $\mathrm{X}$ & & \\
\hline $999-61-1$ & 2-Hydroxypropyl acrylate & & $\mathrm{X}$ & & & & & \\
\hline
\end{tabular}

CAS\# $=$ chemical abstract service number.

DST $=$ double-shell tank.

SST $=$ single-shell tank.

$\mathrm{TAP}=$ toxic air pollutant.

UHC = underlying hazardous constituents.

UTS $=$ universal treatment standards.

WSPS $=$ Waste Stream Profile Sheet. 
Table B.5. Regulated Organic Compounds with a Positive Analytical Detect in the

Single-Shell Tank/Double-Shell Tank Waste (146 Compounds). (Page 1 of 4)

\begin{tabular}{|c|c|c|c|}
\hline QSA & Constituent & $\begin{array}{l}\text { TWINS } \\
\text { Solidgliquid } \\
\text { Hits }\end{array}$ & TWMS Vapor \\
\hline $100-00-5$ & p-Nitrochlorobenzene & & 3 \\
\hline $100-41-4$ & Ethyl benzene & & 423 \\
\hline $100-42-5$ & Styrene & 3 & 195 \\
\hline $10061-01-5$ & cis-1,3-Dichloropropene & & 27 \\
\hline $10061-02-6$ & trans-1,3-Dichloropropene & 1 & 28 \\
\hline $101-84-8$ & Diphenyl ether & & 6 \\
\hline $106-35-4$ & 3-Heptanone & 7 & 158 \\
\hline $106-42-3$ & p-Xylene & & 35 \\
\hline $106-46-7$ & 1,4-Dichlorobenzene & & 120 \\
\hline $106-88-7$ & 1,2-Epoxybutane & & 1 \\
\hline $106-93-4$ & Ethylene dibromide & . & 45 \\
\hline $106-97-8$ & Butane & & 535 \\
\hline 106-99-0 & 1,3-Butadiene & & 46 \\
\hline $107-02-8$ & Acrolein & & 22 \\
\hline $107-05-1$ & 3-Chloropropene & & 4 \\
\hline $107-06-2$ & 1,2-Dichloroethane & 1 & 15 \\
\hline $107-12-0$ & Propionitrile & & 593 \\
\hline $107-13-1$ & Acrylonitrile & & 1 \\
\hline $107-18-6$ & 2-Propen-1-ol & & 5 \\
\hline $107-31-3$ & Formic acid, methyl ester & & 1 \\
\hline $107-87-9$ & 2-Pentanone & & 211 \\
\hline $108-03-2$ & 1-Nitropropane & & 3 \\
\hline $108-05-4$ & Acetic acid vinyl ester & & 1 \\
\hline $108-10-1$ & 4-Methyl-2-pentanone & 1 & 374 \\
\hline $108-20-3$ & Bis(isopropyl) ether & & 1 \\
\hline $108-38-3$ & m-Xylene & & 24 \\
\hline $108-39-4$ & $\mathrm{~m}$-Cresol & & 7 \\
\hline $108-87-2$ & Methylcyclohexane & & 132 \\
\hline $108-88-3$ & Toluene & 52 & 738 \\
\hline $108-90-7$ & Chlorobenzene & & 66 \\
\hline $108-93-0$ & Cyclohexanol & & 1 \\
\hline $108-94-1$ & Cyclohexanone & & 192 \\
\hline $108-95-2$ & Phenol & & 19 \\
\hline $109-66-0$ & n-Pentane & & 446 \\
\hline $109-99-9$ & Tetrahydrofuran & 1 & 562 \\
\hline $110-12-3$ & 5-Methyl-2-hexanone & & 12 \\
\hline $110-43-0$ & 2-Heptanone & & 209 \\
\hline $110-54-3$ & n-Hexane & & 623 \\
\hline $110-62-3$ & n-Valeraldehyde & & 54 \\
\hline $110-82-7$ & Cyclohexane & & 256 \\
\hline $110-83-8$ & Cyclohexene & 19 & 2 \\
\hline $110-86-1$ & Pyridine & & 279 \\
\hline $111-65-9$ & n-Octane & & 492 \\
\hline $111-76-2$ & 2-Butoxyethanol & 6 & 7 \\
\hline $111-84-2$ & n-Nonane & 22 & 528 \\
\hline $117-81-7$ & Bis(2-ethylhexyl) phthalate & 33 & 1 \\
\hline $117-84-0$ & Di-n-octylphthalate & 2 & \\
\hline
\end{tabular}


Table B.5. Regulated Organic Compounds with a Positive Analytical Detect in the Single-Shell Tank/Double-Shell Tank Waste (146 Compounds). (Page 2 of 4)

\begin{tabular}{|c|c|c|c|}
\hline CASH & Constituent & $\begin{array}{l}\text { TWINS } \\
\text { Solidriquid } \\
\text { rits }\end{array}$ & TWuss vapor \\
\hline $120-82-1$ & 1,2,4-Trichlorobenzene & 1 & 51 \\
\hline $122-39-4$ & N,N-Diphenylamine & & 22 \\
\hline $123-19-3$ & 4-Heptanone & & 44 \\
\hline $123-38-6$ & n-Propionaldehyde & & 56 \\
\hline $123-51-3$ & 3-Methyl-1-butanol & & 4 \\
\hline $123-86-4$ & Acetic acid n-butyl ester & & 25 \\
\hline $123-91-1$ & 1,4-Dioxan & & 19 \\
\hline $126-73-8$ & Tributyl phosphate & 40 & 73 \\
\hline $126-98-7$ & 2-Methyl-2-propenenitrile & & 1 \\
\hline $127-18-4$ & 1,1,2,2-Tetrachloroethene & 2 & 415 \\
\hline $127-19-5$ & N,N-Dimethylacetamide & & 2 \\
\hline $128-37-0$ & 2,6-Bis(tert-butyl)-4-methylphenol & 2 & 13 \\
\hline $129-00-0$ & Pyrene & 6 & \\
\hline $141-78-6$ & Acetic acid ethyl ester & & 10 \\
\hline $141-79-7$ & 4-Methyl-3-penten-2-one & & 9 \\
\hline $142-82-5$ & n-Heptane & & 626 \\
\hline $144-62-7$ & Oxalic acid & 1969 & 0 \\
\hline $206-44-0$ & Fluoranthene & 1 & \\
\hline $287-92-3$ & Cyclopentane & & 16 \\
\hline $4170-30-3$ & 2-Butenaldehyde & & 37 \\
\hline $50-00-0$ & Formaldehyde & & 3 \\
\hline $541-73-1$ & 1,3-Dichlorobenzene & & 57 \\
\hline $56-23-5$ & Carbon tetrachloride & & 181 \\
\hline $563-80-4$ & 3-Methyl-2-butanone & & 34 \\
\hline $57-14-7$ & 1,1-Dimethylhydrazine & & 6 \\
\hline $59-50-7$ & 4-Chloro-3-methylphenol & 1 & \\
\hline $59-89-2$ & N-Nitrosomorpholine & 3 & 1 \\
\hline $591-78-6$ & 2-Hexanone & 11 & 248 \\
\hline $60-34-4$ & Methylhydrazine & & 3 \\
\hline $60-35-5$ & Acetamide & & 3 \\
\hline $62-75-9$ & N-Nitroso-N,N-dimethylamine & & 62 \\
\hline $621-64-7$ & N-Nitroso-di-n-propylamine & 1 & \\
\hline $624-83-9$ & Methyl isocyanate & & 1 \\
\hline $627-13-4$ & Nitric acid, propyl ester & & 72 \\
\hline $64-17-5$ & Ethyl alcohol & . & 552 \\
\hline $64-18-6$ & Formic acid & 360 & 0 \\
\hline 64-19-7 & Acetic acid & & 56 \\
\hline $67-56-1$ & Methyl alcohol & & 594 \\
\hline $67-63-0$ & 2-Propyl alcohol & & 191 \\
\hline $67-64-1$ & 2-Propanone (Acetone) & 62 & 831 \\
\hline 67-66-3 & Chloroform & 1 & 118 \\
\hline $67-72-1$ & Hexachloroethane & & \\
\hline $71-23-8$ & n-Propyl alcohol & & 606 \\
\hline $71-36-3$ & n-Butyl alcohol & 23 & 775 \\
\hline $71-43-2$ & Benzene & 12 & 638 \\
\hline $71-55-6$ & 1,1,1-Trichloroethane & 22 & 221 \\
\hline $74-83-9$ & Bromomethane & & 22 \\
\hline
\end{tabular}


Table B.5. Regulated Organic Compounds with a Positive Analytical Detect in the Single-Shell Tank/Double-Shell Tank Waste (146 Compounds). (Page 3 of 4)

\begin{tabular}{|c|c|c|c|}
\hline CAS\# & Constituent & $\begin{array}{l}\text { TWVINS } \\
\text { Solid/iquid } \\
\text { Hits }\end{array}$ & TW" 1 Hits V \\
\hline $74-87-3$ & Chloromethane & 4 & 194 \\
\hline $74-99-7$ & Methylacetylene & & 9 \\
\hline$\overline{75-00-3}$ & Chloroethane & & 82 \\
\hline $75-01-4$ & 1-Chloroethene & & 26 \\
\hline $75-05-8$ & Acetonitrile & & 713 \\
\hline $75-07-0$ & Acetaldehyde & & 103 \\
\hline $75-09-2$ & Dichloromethane (Methylene Chloride) & 15 & 567 \\
\hline $75-12-7$ & Formamide & & 1 \\
\hline $75-15-0$ & Carbon disulfide & & 16 \\
\hline $75-21-8$ & Oxirane & & 1 \\
\hline $75-34-3$ & 1,1-Dichloroethane & & 29 \\
\hline $75-35-4$ & 1,1-Dichloroethene & & 113 \\
\hline $75-43-4$ & Dichlorofluoromethane & & 20 \\
\hline $75-45-6$ & Chlorodifluoromethane & & 12 \\
\hline $75-50-3$ & Trimethylamine & & 1 \\
\hline $75-52-5$ & Nitromethane & & 8 \\
\hline $75-55-8$ & 2-Methylaziridine & & 5 \\
\hline $75-65-0$ & 2-Methyl-2-propanol & & 144 \\
\hline $75-69-4$ & Trichlorofluoromethane & & 790 \\
\hline $75-71-8$ & Dichlorodifluoromethane & & 252 \\
\hline $76-13-1$ & 1,2,2-Trichlorotrifluoroethane & & 255 \\
\hline $76-14-2$ & 1,2-Dichloro-1,1,2,2-tetrafluoroethane & & 31 \\
\hline $78-83-1$ & 2-Methylpropyl alcohol & & 7 \\
\hline $78-87-5$ & 1,2-Dichloropropane & & 13 \\
\hline $78-92-2$ & 1-Methylpropyl alcohol & & 66 \\
\hline $78-93-3$ & 2-Butanone & 27 & 642 \\
\hline $79-00-5$ & 1,1,2-Trichloroethane & & 111 \\
\hline $79-01-6$ & 1,1,2-Trichloroethylene & 1 & 113 \\
\hline $79-09-4$ & Propanoic acid & & 5 \\
\hline $79-10-7$ & 2-Propenoic acid & & 1 \\
\hline $79-20-9$ & Methyl acetate & & $\overline{4}$ \\
\hline $79-34-5$ & 1,1,2,2-Tetrachloroethane & & 51 \\
\hline $83-32-9$ & Acenaphthene & 1 & \\
\hline $84-66-2$ & Diethyl phthalate & & 24 \\
\hline $84-74-2$ & Di-n-butylphthalate & 2 & 2 \\
\hline $85-68-7$ & Butylbenzylphthalate & 3 & \\
\hline $86-73-7$ & Fluorene & & 1 \\
\hline $87-68-3$ & Hexachlorobutadiene & & 42 \\
\hline $88-06-2$ & 2,4,6-Trichlorophenol & 1 & \\
\hline $88-75-5$ & 2-Nitrophenol & 1 & \\
\hline $91-20-3$ & Naphthalene & 2 & 4 \\
\hline $92-52-4$ & $1,1^{\circ}$-Biphenyl & & 7 \\
\hline $95-47-6$ & o-Xylene & & 411 \\
\hline $95-48-7$ & o-Cresol & & 2 \\
\hline $95-50-1$ & 1,2-Dichlorobenzene & & 27 \\
\hline $95-57-8$ & 2-Chlorophenol & 1 & \\
\hline $95-95-4$ & 2,4,5-Trichlorophenol & 1 & \\
\hline
\end{tabular}


Table B.5. Regulated Organic Compounds with a Positive Analytical Detect in the Single-Shell Tank/Double-Shell Tank Waste (146 Compounds). (Page 4 of 4)

\begin{tabular}{|c|c|c|c|}
\hline CAst & Constituent & $\begin{array}{l}\text { TWINS } \\
\text { Solid/Lig aid } \\
\text { rits }\end{array}$ & TWMS Yapor \\
\hline $96-22-0$ & 3-Pentanone & & 10 \\
\hline $96-69-5$ & Bis(3-tert-butyl-4-hydroxy-6-methyl-phenyl) sulfide & 1 & \\
\hline $98-83-9$ & Methylstyrene & & 3 \\
\hline $98-86-2$ & Acetophenone & & 43 \\
\hline $98-95-3$ & Nitrobenzene & & 5 \\
\hline
\end{tabular}

TWINS = Tank Waste Information Network System. Solid/liquid hits were recorded from theTank Characterization Database. Vapor hits were recorded from the vapor database. 
Table B.6. Regulated Detected Organic Compounds with Higher Toxicity (19 Compounds).

\begin{tabular}{|c|c|c|c|c|}
\hline $\mathrm{CAS}$ & Constituent & $\begin{array}{l}\text { Unic } \\
\text { Toxicity } \\
\text { Category }\end{array}$ & $\begin{array}{l}\text { TAP } \\
\text { Toxicity } \\
\text { Category }\end{array}$ & $\begin{array}{l}\text { Slope } \\
\text { Ractor. } \\
\text { Ranking }\end{array}$ \\
\hline $100-00-5$ & p-Nitrochlorobenzene & & II & \\
\hline $106-99-0$ & 1,3-Butadiene & & & $\mathrm{v}$ \\
\hline $107-02-8$ & Acrolein & B & I & \\
\hline $107-05-1$ & 3-Chloropropene & A & II & \\
\hline $107-12-0$ & Propionitrile & $\mathrm{B}$ & & \\
\hline $107-13-1$ & Acrylonitrile & $\mathrm{B}$ & & $\mathrm{BC}$ \\
\hline $126-73-8$ & Tributyl phosphate & & II & \\
\hline $126-98-7$ & 2-Methyl-2-propenenitrile & $\mathrm{B}$ & II & \\
\hline $144-62-7$ & Oxalic acid & & III & \\
\hline $57-14-7$ & 1,1-Dimethylhydrazine & & II & $\mathrm{v}$ \\
\hline $60-34-4$ & Methylhydrazine & & II & \\
\hline $62-75-9$ & $\mathrm{~N}-\mathrm{Nitroso}-\mathrm{N}, \mathrm{N}$-dimethylamine & B & & iv \\
\hline $624-83-9$ & Methyl isocyanate & & I & \\
\hline $74-83-9$ & Bromomethane & $\mathrm{C}$ & II & \\
\hline $75-21-8$ & Oxirane & B & & $\mathrm{BC}$ \\
\hline $79-10-7$ & 2-Propenoic acid & & I & \\
\hline $87-68-3$ & Héxachlorobutadiene & $\bar{B}$ & I & $\mathrm{BC}$ \\
\hline $92-52-4$ & 1,1'-Biphenyl & & II & \\
\hline $98-95-3$ & Nitrobenzene & $\mathrm{D}$ & II & \\
\hline $\begin{array}{l}\mathrm{CAS \#}= \\
\mathrm{TAP}= \\
\mathrm{UHC}=\end{array}$ & $\begin{array}{l}\text { chemical abstract service num } \\
\text { toxic air pollutant. } \\
\text { underlying hazardous constit }\end{array}$ & & & \\
\hline
\end{tabular}


Table B.7. Regulated Detected Organic Compounds with Lower Toxicity (127 Compounds). (Page 1 of 3 )

\begin{tabular}{|c|c|c|c|c|}
\hline CAS\# & Constituent & $\begin{array}{l}\text { UHC } \\
\text { Toxicity } \\
\text { Category }\end{array}$ & $\begin{array}{l}\text { TraP } \\
\text { Toxicity } \\
\text { Category }\end{array}$ & $\begin{array}{l}\text { Slope } \\
\text { Factor } \\
\text { Ranking }\end{array}$ \\
\hline $100-41-4$ & Ethyl benzene & $\mathrm{D}$ & IV & \\
\hline $100-42-5$ & Styrene & & IV & \\
\hline $10061-01-5$ & cis-1,3-Dichloropropene & & & \\
\hline $10061-02-6$ & trans-1,3-Dichloropropene & & & \\
\hline $101-84-8$ & Diphenyl ether & & III & \\
\hline $106-35-4$ & 3-Heptanone & & IV & \\
\hline $106-42-3$ & p-Xylene & $\mathrm{D}$ & $\mathrm{V}$ & \\
\hline $106-46-7$ & 1,4-Dichlorobenzene & $\mathrm{D}$ & & \\
\hline 106-88-7. & 1,2-Epoxybutane & & III & \\
\hline $106-93-4$ & Ethylene dibromide & $\mathrm{C}$ & & $\mathrm{BC}$ \\
\hline $106-97-8$ & Butane & & $\mathrm{V}$ & \\
\hline $107-06-2$ & 1,2-Dichloroethane & $\mathrm{D}$ & & $\mathrm{BC}$ \\
\hline $107-18-6$ & 2-Propen-1-ol & & III & \\
\hline $107-31-3$ & Formic acid, methyl ester & & IV & \\
\hline $107-87-9$ & 2-Pentanone & & $\mathrm{V}$ & \\
\hline $108-03-2$ & 1-Nitropropane & & III & \\
\hline $108-05-4$ & Acetic acid vinyl ester & & IV & \\
\hline $108-10-1$ & 4-Methyl-2-pentanone & $\mathrm{D}$ & IV & \\
\hline $108-20-3$ & Bis(isopropyl) ether & & $\mathrm{V}$ & \\
\hline $108-38-3$ & $\mathrm{~m}$-Xylene & $\mathrm{D}$ & $\mathrm{V}$ & \\
\hline $108-39-4$ & m-Cresol & $\mathrm{C}$ & III & \\
\hline $108-87-2$ & Methylcyclohexane & & $\mathrm{V}$ & \\
\hline $108-88-3$ & Toluene & $\mathrm{D}$ & IV & \\
\hline $108-90-7$ & Chlorobenzene & $\mathrm{D}$ & IV & \\
\hline $108-93-0$ & Cyclohexanol & & IV & \\
\hline $108-94-1$ & Cyclohexanone & C & IV & \\
\hline $108-95-2$ & Phenol & $\mathrm{C}$ & III & \\
\hline $109-66-0$ & n-Pentane & & V & \\
\hline $109-99-9$ & Tetrahydrofuran & & $\mathrm{V}$ & \\
\hline $110-12-3$ & 5-Methyl-2-hexanone & & IV & \\
\hline $110-43-0$ & 2-Heptanone & & IV & \\
\hline $110-54-3$ & n-Hexane & & IV & \\
\hline $110-62-3$ & n-Valeraldehyde & & IV & \\
\hline $110-82-7$ & Cyclohexane & & $\mathrm{V}$ & \\
\hline $110-83-8$ & Cyclohexene & & $\mathrm{V}$ & \\
\hline $110-86-1$ & Pyridine & $\mathrm{C}$ & III & \\
\hline $111-65-9$ & n-Octane & & $\mathrm{V}$ & \\
\hline $111-76-2$ & 2-Butoxyethanol & & IV & \\
\hline $111-84-2$ & $\mathrm{n}$-Nonane & & $\mathrm{V}$ & \\
\hline $117-81-7$ & Bis(2-ethylhexyl) phthalate & & & $\mathrm{BC}$ \\
\hline $117-84-0$ & Di-n-octylphthalate & & & \\
\hline $120-82-1$ & 1,2,4-Trichlorobenzene & $\mathrm{D}$ & IV & \\
\hline $122-39-4$ & N,N-Diphenylamine & D & III & \\
\hline $123-19-3$ & 4-Heptanone & & IV & \\
\hline $123-38-6$ & n-Propionaldehyde & & $\mathrm{V}$ & \\
\hline $123-51-3$ & 3-Methyl-1-butanol & & $\mathrm{V}$ & \\
\hline $123-86-4$ & Acetic acid n-butyl ester & & $\mathrm{V}$ & \\
\hline
\end{tabular}


Table B.7. Regulated Detected Organic Compounds with Lower Toxicity (127 Compounds). (Page 2 of 3)

\begin{tabular}{|c|c|c|c|c|}
\hline $\mathrm{CAS} \#$ & Constituent & $\begin{array}{l}\text { ruC } \\
\text { roxicis } \\
\text { Category }\end{array}$ & $\begin{array}{l}\text { TAP P } \\
\text { Toxicity } \\
\text { Category }\end{array}$ & $\begin{array}{l}\text { Slope } \\
\text { Factor } \\
\text { Ranking }\end{array}$ \\
\hline $123-91-1$ & 1,4-Dioxan & $\mathrm{D}$ & & \\
\hline $127-18-4$ & $1,1,2,2$-Tetrachloroethene & D & & $\mathrm{BC}$ \\
\hline $127-19-5$ & N,N-Dimethylacetamide & & IV & \\
\hline $128-37-0$ & $\begin{array}{l}\text { 2,6-Bis(tert-butyl)-4- } \\
\text { methylphenol }\end{array}$ & & III & \\
\hline $129-00-0$ & Pyrene & $\mathrm{D}$ & & \\
\hline $141-78-6$ & Acetic acid ethyl ester & $\mathrm{D}$ & $\mathrm{V}$ & \\
\hline $141-79-7$ & 4-Methyl-3-penten-2-one & & IV & \\
\hline $142-82-5$ & n-Heptane & & $\mathrm{V}$ & \\
\hline $206-44-0$ & Fluoranthene & $\mathrm{D}$ & & \\
\hline $287-92-3$ & Cyclopentane & & $\mathrm{V}$ & \\
\hline $4170-30-3$ & 2-Butenaldehyde & & III & \\
\hline $50-00-0$ & Formaldehyde & & & $\mathrm{BC}$ \\
\hline $541-73-1$ & 1,3-Dichlorobenzene & & & \\
\hline $56-23-5$ & Carbon tetrachloride & $\mathrm{D}$ & & $\mathrm{BC}$ \\
\hline $563-80-4$ & 3-Methyl-2-butanone & & $\mathrm{V}$ & \\
\hline $59-50-7$ & 4-Chloro-3-methylphenol & $\mathrm{D}$ & & \\
\hline $59-89-2$ & N-Nitrosomorpholine & & & \\
\hline $591-78-6$ & 2-Hexanone & & III & \\
\hline $60-35-5$ & Acetamide & & $\mathrm{V}$ & \\
\hline $621-64-7$ & N-Nitroso-di-n-propylamine & $\mathrm{C}$ & & \\
\hline $627-13-4$ & Nitric acid, propyl ester & & IV & \\
\hline $64-17-5$ & Ethyl alcohol & & $\mathrm{V}$ & \\
\hline 64-18-6 & Formic acid & & III & \\
\hline 64-19-7 & Acetic acid & & III & \\
\hline $67-56-1$ & Methyl alcohol & $\mathrm{D}$ & IV & \\
\hline $67-63-0$ & 2-Propyl alcohol & & $\mathrm{V}$ & \\
\hline $67-64-1$ & 2-Propanone (Acetone) & & $\mathrm{V}$ & \\
\hline $67-66-3$ & Chloroform & $\mathrm{D}$ & & $\mathrm{BC}$ \\
\hline $67-72-1$ & Hexachloroethane & D & III & $\mathrm{BC}$ \\
\hline $71-23-8$ & n-Propyl alcohol & & $\mathrm{V}$ & \\
\hline $71-36-3$ & n-Butyl alcohol & $\mathrm{D}$ & IV & \\
\hline $71-43-2$ & Benzene & $\mathrm{D}$ & & $\mathrm{BC}$ \\
\hline $71-55-6$ & 1,1,1-Trichloroethane & $\mathrm{D}$ & $\mathrm{V}$ & \\
\hline $74-87-3$ & Chloromethane & C & IV & $\mathrm{BC}$ \\
\hline $74-99-7$ & Methylacetylene & & $\mathrm{V}$ & \\
\hline $75-00-3$ & Chloroethane & $\mathrm{D}$ & V & \\
\hline $75-01-4$ & 1-Chloroethene & $\mathrm{D}$ & & $\mathrm{BC}$ \\
\hline $75-05-8$ & Acetonitrile & $\mathrm{C}$ & IV & \\
\hline $75-07-0$ & Acetaldehyde & & & $\mathrm{BC}$ \\
\hline $75-09-2$ & $\begin{array}{l}\text { Dichloromethane (Methylene } \\
\text { Chloride) }\end{array}$ & D & & $\mathrm{BC}$ \\
\hline $75-12-7$ & Formamide & & III & \\
\hline $75-15-0$ & Carbon disulfide & $\mathrm{D}$ & III & \\
\hline $75-34-3$ & 1,1-Dichloroethane & D & $\mathrm{V}$ & \\
\hline $75-35-4$ & 1,1-Dichloroethene & $\mathrm{C}$ & III & $\mathrm{BC}$ \\
\hline $75-43-4$ & Dichlorofluoromethane & & IV & \\
\hline
\end{tabular}


Table B.7. Regulated Detected Organic Compounds with Lower Toxicity (127. Compounds). (Page 3 of 3 )

\begin{tabular}{|c|c|c|c|c|}
\hline $\mathrm{CAS}$ & Constituent & $\begin{array}{l}\text { UHe } \\
\text { Toxicity } \\
\text { Category }\end{array}$ & $\begin{array}{l}\text { TAP } \\
\text { Toxicity: } \\
\text { Category }\end{array}$ & $\begin{array}{l}\text { Slope } \\
\text { Factor } \\
\text { Ranking }\end{array}$ \\
\hline $75-45-6$ & Chlorodifluoromethane & & $\mathrm{V}$ & \\
\hline $75-50-3$ & Trimethylamine & & III & \\
\hline $75-52-5$ & Nitromethane & D & IV & \\
\hline $75-55-8$ & 2-Methylaziridine & & III & \\
\hline $75-65-0$ & 2-Methyl-2-propanol & & IV & \\
\hline $75-69-4$ & Trichlorofluoromethane & & $\mathrm{V}$ & \\
\hline $75-71-8$ & Dichlorodifluoromethane & & $\mathrm{V}$ & \\
\hline $76-13-1$ & 1,2,2-Trichlorotrifluoroethane & & $\mathrm{V}$ & \\
\hline $76-14-2$ & $\begin{array}{l}\text { 1,2-Dichloro-1,1,2,2- } \\
\text { tetrafluoroethane }\end{array}$ & & $\mathrm{V}$ & \\
\hline $78-83-1$ & 2-Methylpropyl alcohol & $\mathrm{D}$ & IV & \\
\hline $78-87-5$ & 1,2-Dichloropropane & $\bar{D}$ & & \\
\hline $78-92-2$ & 1-Methylpropyl alcohol & & IV & \\
\hline $78-93-3$ & 2-Butanone & D & IV & \\
\hline $79-00-5$ & 1,1,2-Trichloroethane & $\overline{\mathrm{D}}$ & IV & $\mathrm{BC}$ \\
\hline $79-01-6$ & 1,1,2-Trichloroethylene & & & $\overline{\mathrm{BC}}$ \\
\hline $79-09-4$ & Propanoic acid & & III & \\
\hline $79-20-9$ & Methyl acetate & & $\mathrm{V}$ & \\
\hline $79-34-5$ & 1,1,2,2-Tetrachloroethane & $\mathrm{D}$ & III & $\mathrm{BC}$ \\
\hline $83-32-9$ & Acenaphthene & & & \\
\hline $84-66-2$ & Diethyl phthalate & & III & \\
\hline $84-74-2$ & Di-n-butylphthalate & C & III & \\
\hline $85-68-7$ & Butylbenzylphthalate & $\mathrm{D}$ & & \\
\hline $86-73-7$ & Fluorene & & & \\
\hline $88-06-2$ & 2,4,6-Trichlorophenol & $\mathrm{D}$ & & $\mathrm{BC}$ \\
\hline $88-75-5$ & 2-Nitrophenol & $\mathrm{C}$ & & \\
\hline $91-20-3$ & Naphthalene & $\mathrm{C}$ & IV & \\
\hline $95-47-6$ & o-Xylene & $\mathrm{D}$ & $\mathrm{V}$ & \\
\hline $95-48-7$ & o-Cresol & $\mathrm{C}$ & III & \\
\hline $95-50-1$ & 1,2-Dichlorobenzene & $\mathrm{D}$ & IV & \\
\hline $95-57-8$ & 2-Chlorophenol & $\mathrm{D}$ & & \\
\hline $95-95-4$ & 2,4,5-Trichlorophenol & $\mathrm{D}$ & V & \\
\hline $96-22-0$ & 3-Pentanone & & $\mathrm{V}$ & \\
\hline $96-69-5$ & $\begin{array}{l}\text { Bis(3-tert-butyl-4-hydroxy-6- } \\
\text { methyl-phenyl) sulfide }\end{array}$ & & IIII & \\
\hline 98-83-9 & Methylstyrene & & IV & \\
\hline $98-86-2$ & Acetophenone & D & $\mathrm{V}$ & \\
\hline $\begin{array}{l}\text { CAS\# }= \\
\text { TAP }= \\
\text { UHC }=\end{array}$ & $\begin{array}{l}\text { chemical abstract service numbe } \\
\text { toxic air pollutant. } \\
\text { underlying hazardous constituen }\end{array}$ & & & \\
\hline
\end{tabular}


Table B.8. Regulated Organic Compounds with Lower Toxicity and Less than 10 Detects in the Single-Shell Tank/Double-Shell Tank Waste, not Included for Further Analytical Considerations (42 Compounds). (Page 1 of 2)

\begin{tabular}{|c|c|c|c|c|c|c|}
\hline CASH & Constituent & $\begin{array}{l}\text { Swins } \\
\text { Solidil } \\
\text { Hits }\end{array}$ & 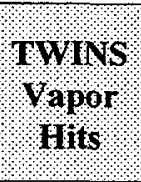 & $\begin{array}{l}\text { UMC } \\
\text { Toxicity } \\
\text { Category }\end{array}$ & $\begin{array}{l}\text { Tap } \\
\text { Categicity }\end{array}$ & $\begin{array}{l}\text { slope } \\
\text { Ractor } \\
\text { Ranking }\end{array}$ \\
\hline $101-84-8$ & Diphenyl ether & & 6 & & III & \\
\hline $106-88-7$ & 1,2-Epoxybutane & & 1 & & III & \\
\hline $107-18-6$ & 2-Propen-1-ol & & 5 & & III & \\
\hline $107-31-3$ & Formic acid, methyl ester & & 1 & & IV & \\
\hline $108-03-2$ & 1-Nitropropane & & 3 & & III & \\
\hline $108-05-4$ & Acetic acid vinyl ester & & 1 & & IV & \\
\hline $108-20-3$ & Bis(isopropyl) ether & & 1 & & $\mathrm{~V}$ & \\
\hline $108-39-4$ & $\mathrm{~m}$-Cresol & & 7 & $\mathrm{C}$ & III & \\
\hline $108-93-0$ & Cyclohexanol & & 1 & & IV & \\
\hline $111-76-2$ & 2-Butoxyethanol & 6 & 7 & & IV & \\
\hline $117-84-0$ & Di-n-octylphthalate & 2 & & & & \\
\hline $123-51-3$ & 3-Methyl-1-butanol & & 4 & & $\mathrm{~V}$ & \\
\hline $127-19-5$ & $\mathrm{~N}, \mathrm{~N}$-Dimethylacetamide & & 2 & & IV & \\
\hline $129-00-0$ & Pyrene & 6 & & D & & \\
\hline $141-79-7$ & 4-Methyl-3-penten-2-one & & 9 & & IV & \\
\hline $206-44-0$ & Fluoranthene & 1 & & $\mathrm{D}$ & & \\
\hline $50-00-0$ & Formaldehyde & & 3 & & & $\mathrm{BC}$ \\
\hline $59-50-7$ & 4-Chloro-3-methylphenol & 1 & & $\bar{D}$ & & \\
\hline $59-89-2$ & N-Nitrosomorpholine & 3 & 1 & & & \\
\hline $60-35-5$ & Acetamide & & 3 & & $\mathrm{~V}$ & \\
\hline $621-64-7$ & N-Nitroso-di-n-propylamine & 1 & & $\mathrm{C}$ & & \\
\hline $67-72-1$ & Hexachloroethane & & & $\mathrm{D}$ & III & $\mathrm{BC}$ \\
\hline $74-99-7$ & Methylacetylene & & 9 & & $\mathrm{~V}$ & \\
\hline $75-12-7$ & Formamide & & 1 & & III & \\
\hline $75-50-3$ & Trimethylamine & & 1 & & III & \\
\hline $75-52-5$ & Nitromethane & & 8 & $\mathrm{D}$ & IV & \\
\hline $75-55-8$ & 2-Methylaziridine & & 5 & & III & \\
\hline $78-83-1$ & 2-Methylpropyl alcohol & & 7 & $\mathrm{D}$ & IV & \\
\hline $79-09-4$ & Propanoic acid & & 5 & & III & \\
\hline $79-20-9$ & Methyl acetate & & 4 & & $\mathrm{~V}$ & \\
\hline $83-32-9$ & Acenaphthene & 1 & & & & \\
\hline 84-74-2 & Di-n-butylphthalate & 2 & 2 & $\mathrm{C}$ & III & \\
\hline $85-68-7$ & Butylbenzylphthalate & 3 & & $\bar{D}$ & & \\
\hline $86-73-7$ & Fluorene & & 1 & & & \\
\hline $88-06-2$ & 2,4,6-Trichlorophenol & 1 & & $\mathrm{D}$ & & $\mathrm{BC}$ \\
\hline $88-75-5$ & 2-Nitrophenol & 1 & & $\mathrm{C}$ & & \\
\hline $91-20-3$ & Naphthalene & 2 & 4 & $\mathrm{C}$ & IV & \\
\hline $95-48-7$ & 0 -Cresol & & 2 & $\mathrm{C}$ & III & \\
\hline $95-57-8$ & 2-Chlorophenol & 1 & & $\mathrm{D}$ & & \\
\hline 95-95-4 & 2,4,5-Trichlorophenol & 1 & & $\mathrm{D}$ & $\mathrm{V}$ & \\
\hline
\end{tabular}


Table B.8. Regulated Organic Compounds with Lower Toxicity and Less than 10 Detects in the Single-Shell Tank/Double-Shell Tank Waste, not Included for Further

Analytical Considerations (42 Compounds). (Page 2 of 2)

\begin{tabular}{|c|c|c|c|c|c|c|}
\hline CAst & Constituent & $\begin{array}{l}\text { TwiNs } \\
\text { solid } \\
\text { Liquid } \\
\text { Hits }\end{array}$ & $\begin{array}{l}\text { TWINS } \\
\text { Yapor } \\
\text { 11its }\end{array}$ & $\begin{array}{l}\text { GHO } \\
\text { Toxicity } \\
\text { Category }\end{array}$ & $\begin{array}{l}\text { TAPP } \\
\text { Toxicity } \\
\text { Category }\end{array}$ & $\begin{array}{l}\text { Slope } \\
\text { Factor. } \\
\text { Ranking }\end{array}$ \\
\hline $96-69-5$ & $\begin{array}{l}\text { Bis(3-tert-butyl-4-hydroxy-6-methyl- } \\
\text { phenyl) sulfide }\end{array}$ & 1 & & & III & \\
\hline $98-83-9$ & Methylstyrene & & 3 & & IV & \\
\hline
\end{tabular}

CAS\# $=$ chemical abstract service number.

TAP $=$ toxic air pollutant.

TWINS = Tank Waste Information Network System. Solid/liquid hits were recorded from the Tank

Characterization Database. Vapor hits were recorded from the vapor database.

$\mathrm{UHC}=$ underlying hazardous constituents. 
Table B.9. Regulated Organic Compounds with Lower Toxicity and $\geq 10$ Detects ( 85 Compounds). (Page 1 of 2)

\begin{tabular}{|c|c|c|c|c|c|c|}
\hline 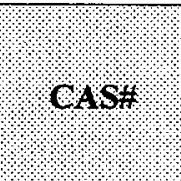 & Constituent & $\begin{array}{l}\text { TWins } \\
\text { Solidy } \\
\text { liquid } \\
\text { Hits }\end{array}$ & $\begin{array}{l}\text { TWINS } \\
\text { Yapor } \\
\text { fits }\end{array}$ & $\begin{array}{l}\text { UHY } \\
\text { roxicity } \\
\text { category }\end{array}$ & $\begin{array}{l}\text { TAP } \\
\text { roxicity } \\
\text { categorg }\end{array}$ & $\begin{array}{c}\text { Slope } \\
\text { ractor } \\
\text { Ranings }\end{array}$ \\
\hline $100-41-4$ & Ethyl benzene & & 423 & $\mathrm{D}$ & IV & \\
\hline $100-42-5$ & Styrene & 3 & 195 & & IV & \\
\hline $10061-01-5$ & cis-1,3-Dichloropropene & & 27 & & & \\
\hline $10061-02-6$ & trans-1,3-Dichloropropene & 1 & 28 & & & \\
\hline $106-35-4$ & 3-Heptanone & 7 & 158 & & IV & \\
\hline $106-42-3$ & p-Xylene & & 35 & $\mathrm{D}$ & $\mathrm{V}$ & \\
\hline $106-46-7$ & 1,4-Dichlorobenzene & & 120 & D & & \\
\hline $106-93-4$ & Ethylene dibromide & & 45 & $\mathrm{C}$ & & $\mathrm{BC}$ \\
\hline $106-97-8$ & Butane & & 535 & & $\mathrm{~V}$ & \\
\hline $107-06-2$ & 1,2-Dichloroethane & 1 & 15 & D & & $\mathrm{BC}$ \\
\hline $107-87-9$ & 2-Pentanone & & 211 & & $\mathrm{~V}$ & \\
\hline $108-10-1$ & 4-Methyl-2-pentanone & 1 & 374 & $\mathrm{D}$ & IV & \\
\hline $108-38-3$ & m-Xylene & & 24 & D & $\mathrm{V}$ & \\
\hline $108-87-2$ & Methylcyclohexane & & 132 & & $\bar{V}$ & \\
\hline $108-88-3$ & Toluene & 52 & 738 & $\mathrm{D}$ & IV & \\
\hline $108-90-7$ & Chlorobenzene & & 66 & $\mathrm{D}$ & IV & \\
\hline $108-94-1$ & Cyclohexanone & & 192 & $\bar{C}$ & IV & \\
\hline $108-95-2$ & Phenol & & 19 & $\mathrm{C}$ & III & \\
\hline $109-66-0$ & n-Pentane & & 446 & & $\mathrm{~V}$ & \\
\hline $109-99-9$ & Tetrahydrofuran & 1 & 562 & & $\mathrm{~V}$ & \\
\hline $110-12-3$ & 5-Methyl-2-hexanone & & 12 & & $\overline{I V}$ & \\
\hline $110-43-0$ & 2-Heptanone & & 209 & & IV & \\
\hline $110-54-3$ & n-Hexane & & 623 & & IV & \\
\hline $110-62-3$ & n-Valeraldehyde & & 54 & & IV & \\
\hline $110-82-7$ & Cyclohexane & & 256 & & $\mathrm{~V}$ & \\
\hline $110-83-8$ & Cyclohexene & 19 & 2 & & $\mathrm{~V}$ & \\
\hline $110-86-1$ & Pyridine & & 279 & $\mathrm{C}$ & III & \\
\hline $111-65-9$ & n-Octane & & 492 & & $\mathrm{~V}$ & \\
\hline $111-84-2$ & n-Nonane & 22 & 528 & & $\bar{V}$ & \\
\hline $117-81-7$ & Bis(2-ethylhexyl) phthalate & 33 & 1 & & & $\mathrm{BC}$ \\
\hline $120-82-1$ & 1,2,4-Trichlorobenzene & 1 & 51 & D & IV & \\
\hline $122-39-4$ & $\mathrm{~N}, \mathrm{~N}-$ Diphenylamine & & 22 & $\bar{D}$ & III & \\
\hline $123-19-3$ & 4-Heptanone & & 44 & & IV & \\
\hline $123-38-6$ & n-Propionaldehyde & & 56 & & $\mathrm{~V}$ & \\
\hline $123-86-4$ & Acetic acid n-butyl ester & & 25 & & $\mathrm{~V}$ & \\
\hline $123-91-1$ & 1,4-Dioxan & & 19 & $\mathrm{D}$ & & \\
\hline $127-18-4$ & $1,1,2,2$-Tetrachloroethene & 2 & 415 & $\mathrm{D}$ & & $\mathrm{BC}$ \\
\hline $128-37-0$ & 2,6-Bis(tert-butyl)-4-methylphenol & 2 & 13 & & III & \\
\hline $141-78-6$ & Acetic acid ethyl ester & & 10 & $\mathrm{D}$ & $\mathrm{V}$ & \\
\hline $142-82-5$ & n-Heptane & & 626 & & $\overline{\mathrm{V}}$ & \\
\hline $287-92-3$ & Cyclopentane & & 16 & & $\mathrm{~V}$ & \\
\hline $4170-30-3$ & 2-Butenaldehyde & & 37 & & III & \\
\hline $541-73-1$ & 1,3-Dichlorobenzene & & 57 & & & \\
\hline $56-23-5$ & Carbon tetrachloride & & 181 & D & & $\mathrm{BC}$ \\
\hline $563-80-4$ & 3-Methyl-2-butanone & & 34 & & $\mathrm{~V}$ & \\
\hline $591-78-6$ & 2-Hexanone & 11 & 248 & & III & \\
\hline
\end{tabular}


Table B.9. Regulated Organic Compounds with Lower Toxicity and $\geq 10$ Detects ( 85 Compounds). (Page 2 of 2 )

\begin{tabular}{|c|c|c|c|c|c|c|}
\hline CASH & Constituent & $\begin{array}{l}\text { TWINS } \\
\text { Solid } \\
\text { Giquid } \\
\text { Hits }\end{array}$ & 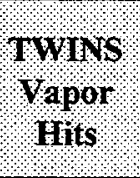 & $\begin{array}{l}\text { UHe } \\
\text { Caxicity }\end{array}$ & $\begin{array}{l}\text { Torip } \\
\text { Toxicity. } \\
\text { Category }\end{array}$ & $\begin{array}{l}\text { Slope } \\
\text { Factor } \\
\text { Ranking }\end{array}$ \\
\hline $627-13-4$ & Nitric acid, propyl ester & & 72 & & IV & \\
\hline $64-17-5$ & Ethyl alcohol & & 552 & & $\mathrm{~V}$ & \\
\hline $64-18-6$ & Formic acid & 360 & 0 & & III & \\
\hline 64-19-7 & Acetic acid & & 56 & & III & \\
\hline $67-56-1$ & Methyl alcohol. & & 594 & $\mathrm{D}$ & IV & \\
\hline $67-63-0$ & 2-Propyl alcohol & & 191 & & $\mathrm{~V}$ & \\
\hline $67-64-1$ & 2-Propanone (Acetone) & 62 & 831 & & V & \\
\hline $67-66-3$ & Chloroform & 1 & 118 & $\mathrm{D}$ & & $\overline{B C}$ \\
\hline $71-23-8$ & n-Propyl alcohol & & 606 & & $\overline{\mathrm{V}}$ & \\
\hline $71-36-3$ & n-Butyl alcohol & 23 & 775 & $\mathrm{D}$ & IV & \\
\hline $71-43-2$ & Benzene & 12 & 638 & $\mathrm{D}$ & & $\overline{B C}$ \\
\hline $71-55-6$ & 1,1,1-Trichloroethane & 22 & 221 & $\overline{\mathrm{D}}$ & $\overline{\mathrm{V}}$ & \\
\hline $74-87-3$ & Chloromethane & 4 & 194 & $\mathrm{C}$ & IV & $\mathrm{BC}$ \\
\hline $75-00-3$ & Chloroethane & & 82 & $\mathrm{D}$ & $\mathrm{V}$ & \\
\hline $75-01-4$ & 1-Chloroethene & & 26 & $\mathrm{D}$ & & $\mathrm{BC}$ \\
\hline $75-05-8$ & Acetonitrile & & 713 & $\mathrm{C}$ & IV & \\
\hline $75-07-0$ & Acetaldehyde & & 103 & & & $\mathrm{BC}$ \\
\hline $75-09-2$ & Dichloromethane (Methylene Chloride) & 15 & 567 & $\mathrm{D}$ & & $\mathrm{BC}$ \\
\hline $75-15-0$ & Carbon disulfide & & 16 & $\bar{D}$ & III & \\
\hline $75-34-3$ & 1,1-Dichloroethane & & 29 & $\mathrm{D}$ & V & \\
\hline $75-35-4$ & 1,1-Dichloroethene & & 113 & C & III & $\mathrm{BC}$ \\
\hline $75-43-4$ & Dichlorofluoromethane & & 20 & & IV & \\
\hline $75-45-6$ & Chlorodifluoromethane & & 12 & & $\mathrm{~V}$ & \\
\hline $75-65-0$ & 2-Methyl-2-propanol & & 144 & & IV & \\
\hline $75-69-4$ & Trichlorofluoromethane & & 790 & & $\mathrm{~V}$ & \\
\hline $75-71-8$ & Dichlorodifluoromethane & & 252 & & $\mathrm{~V}$ & \\
\hline $76-13-1$ & 1,2,2-Trichlorotrifluoroethane & & 255 & & $\mathrm{~V}$ & \\
\hline $76-14-2$ & 1,2-Dichloro-1,1,2,2-tetrafluoroethane & & 31 & & $\bar{V}$ & \\
\hline $78-87-5$ & 1,2-Dichloropropane & & 13 & $\mathrm{D}$ & & \\
\hline $78-92-2$ & 1-Methylpropyl alcohol & & 66 & & IV & \\
\hline $78-93-3$ & 2-Butanone & 27 & 642 & $\mathrm{D}$ & IV & \\
\hline $79-00-5$ & 1,1,2-Trichloroethane & & 111 & $\mathrm{D}$ & IV & $\overline{B C}$ \\
\hline $79-01-6$ & 1,1,2-Trichloroethylene & 1 & 113 & & & $\overline{\mathrm{BC}}$ \\
\hline $79-34-5$ & 1,1,2,2-Tetrachloroethane & & 51 & D & III & $\overline{B C}$ \\
\hline $84-66-2$ & Diethyl phthalate & & 24 & & III & \\
\hline $95-47-6$ & 0 -Xylene & & 411 & $\overline{\mathrm{D}}$ & $\mathrm{V}$ & \\
\hline $95-50-1$ & 1,2-Dichlorobenzene & & 27 & $\mathrm{D}$ & IV & \\
\hline $96-22-0$ & 3-Pentanone & & 10 & & $\mathrm{~V}$ & \\
\hline $98-86-2$ & Acetophenone & & $\overline{43}$ & $\bar{D}$ & $\mathrm{~V}$ & \\
\hline
\end{tabular}

CAS\# $=$ chemical abstract service number.

TAP $=$ toxic air pollutant.

TWINS = Tank Waste Information Network System. Solid/liquid hits were recorded from the Tank

Characterization Database. Vapor hits were recorded from the vapor database.

$\mathrm{UHC}=$ underlying hazardous constituents. 
Table B.10. Regulated Organic Compounds without a Positive Analytical Detect in Single-Shell Tank/Double-Shell Tank Waste (477 Compounds). (Page 1 of 11)

\begin{tabular}{|c|c|}
\hline $1 \mathrm{SSH}$ & Constituent \\
\hline $100-01-6$ & 4-Nitroaniline \\
\hline $100-02-7$ & 4-Nitrophenol \\
\hline $100-21-0$ & Phthalic acid \\
\hline $100-25-4$ & 1,4-Dinitrobenzene \\
\hline $100-37-8$ & Diethylaminoethanol \\
\hline $100-44-7$ & Benzyl chloride \\
\hline $100-61-8$ & N-Methylbenzenamine \\
\hline $100-63-0$ & Phenylhydrazine \\
\hline $100-74-3$ & N-Ethylmorpholine \\
\hline $100-75-4$ & N-Nitrosopiperidine \\
\hline $101-14-4$ & 4,4'-Methylenebis(2-chloroaniline) \\
\hline $101-27-9$ & Barban \\
\hline $101-55-3$ & 4-Bromophenylphenyl ether \\
\hline $101-68-8$ & Methylene bis(phenyl isocyanate) \\
\hline $101-77-9$ & 4,4-Methylene dianiline \\
\hline $101-80-4$ & 4,4'-Diaminodiphenyl ether \\
\hline $101-90-6$ & Diglycidyl resorcinol ether \\
\hline $102-81-8$ & 2-N-Dibutylaminoethanol \\
\hline $1024-57-3$ & Heptachlor Epoxide \\
\hline $1031-07-8$ & Endosulfan Sulfate \\
\hline $105-46-4$ & sec-Butyl acetate \\
\hline $105-60-2$ & Caprolactam, vapor \\
\hline $105-60-2 a$ & Caprolactam, dust \\
\hline $105-67-9$ & 2,4-Dimethylphenol \\
\hline $10595-95-6$ & N-Nitrosomethylethylamine \\
\hline $106-44-5$ & 4-Methylphenol \\
\hline $106-47-8$ & 4-Chloroaniline \\
\hline $106-49-0$ & p-Toluidine \\
\hline $106-50-3$ & p-Phenylenediamine \\
\hline $106-51-4$ & p-Benzoquinone \\
\hline $106-87-6$ & Vinyl cyclohexene dioxide \\
\hline $106-89-8$ & Epichlorohydrin \\
\hline $106-92-3$ & Allyl glycidyl ether \\
\hline $10605-21-7$ & Carbendazim \\
\hline $107-07-3$ & Ethylene chlorohydrin \\
\hline $107-15-3$ & Ethylene diamine \\
\hline $107-19-7$ & Propargyl alcohol \\
\hline $107-20-0$ & Chloroacetaldehyde \\
\hline $107-21-1$ & Ethylene glycol \\
\hline $107-30-2$ & Chloromethyl methyl ether \\
\hline $107-41-5$ & Hexylene glycol \\
\hline $107-49-3$ & Tetraethyl pyrophosphate \\
\hline $107-66-4$ & Dibutylphosphate \\
\hline
\end{tabular}


Table B.10. Regulated Organic Compounds without a Positive Analytical Detect in Single-Shell Tank/Double-Shell Tank Waste (477 Compounds). (Page 2 of 11)

\begin{tabular}{|c|c|}
\hline \& $\mathrm{SH}$ & Constituent \\
\hline $107-98-2$ & Propylene glycol monomethyl ether \\
\hline $108-11-2$ & Methyl isobutyl carbinol \\
\hline $108-18-9$ & Diisopropylamine \\
\hline $108-21-4$ & Isopropyl acetate \\
\hline 108-24-7 & Acetic anhydride \\
\hline $108-31-6$ & Maleic anhydride (2,5-Furandione) \\
\hline $108-43-0$ & Chlorophenols \\
\hline 108-44-1 & m-Toluidine \\
\hline $108-46-3$ & Resorcinol (1,3-Benzenediol) \\
\hline $108-60-1$ & Bis(2-Chloroisopropyl) ether \\
\hline $108-83-8$ & Diisobutyl ketone \\
\hline $108-84-9$ & sec-Hexyl acetate \\
\hline $108-91-8$ & Cyclohexylamine \\
\hline $108-98-5$ & Thiophenol \\
\hline $109-59-1$ & Isopropoxyethanol \\
\hline $109-60-4$ & n-Propyl acetate \\
\hline $109-73-9$ & n-Butylamine \\
\hline $109-79-5$ & n-Butyl mercaptan \\
\hline $109-86-4$ & 2-Methoxyethanol \\
\hline $109-87-5$ & Methylal \\
\hline $109-89-7$ & Diethylamine \\
\hline $109-94-4$ & Ethyl formate \\
\hline $110-19-0$ & Isobutyl acetate \\
\hline $110-49-6$ & 2-Methoxyethyl acetate \\
\hline $110-75-8$ & 2-Chloroethyl vinyl ether \\
\hline $110-80-5$ & 2-Ethoxyethanol \\
\hline $110-91-8$ & Morpholine \\
\hline $111-15-9$ & 2-Ethoxyethyl acetate \\
\hline $111-30-8$ & Glutaraldehyde \\
\hline $111-40-0$ & Diethylene triamine \\
\hline $111-42-2$ & Diethanolamine \\
\hline $111-44-4$ & Bis(2-chloroethyl) ether \\
\hline $111-91-1$ & Bis(2-Chloroethoxy)methane \\
\hline $1114-71-2$ & Pebulate \\
\hline $1120-71-4$ & 1,3-Propane sultone \\
\hline $1129-41-5$ & Metolcarb (3-methylcholanthrene) \\
\hline $1134-23-2$ & Cycloate \\
\hline 114-26-1 & Propoxur \\
\hline $115-29-7$ & Endosulfan \\
\hline $115-86-6$ & Triphenyl phosphate \\
\hline $115-90-2$ & Fensulfothion \\
\hline $117-79-3$ & 2-Aminoanthraquinone \\
\hline $118-52-5$ & 1,3-Dichloro-5,5-Dimethyl hydantoin \\
\hline
\end{tabular}


Table B.10. Regulated Organic Compounds without a Positive Analytical Detect in Single-Shell Tank/Double-Shell Tank Waste (477 Compounds). (Page 3 of 11)

\begin{tabular}{|c|c|}
\hline CASH & Constituent \\
\hline 118-74-1 & Hexachlorobenzene \\
\hline $118-96-7$ & 2,4,6-Trinitrotoluene \\
\hline $119-38-0$ & Isolan \\
\hline $119-90-4$ & 3,3'-Dimethoxybenzidine \\
\hline $119-93-7$ & 3,3'-Dimethylbenzidine. \\
\hline $120-12-7$ & Anthracene \\
\hline $120-58-1$ & Isosafrole \\
\hline $120-80-9$ & Catechol \\
\hline $120-83-2$ & 2,4-Dichlorophenol \\
\hline $121-14-2$ & 2,4-Dinitrotoluene \\
\hline $121-44-8$ & Triethylamine \\
\hline $121-45-9$ & Trimethyl phosphite \\
\hline $121-69-7$ & Dimethylaniline \\
\hline $121-75-5$ & Malathion \\
\hline $121-82-4$ & Cyclonite \\
\hline $122-42-9$ & Propham \\
\hline $122-60-1$ & Phenyl glycidyl ether \\
\hline $122-66-7$ & 1,2-Diphenylhydrazine \\
\hline $123-31-9$ & Hydroquinone \\
\hline $123-42-2$ & Diacetone alcohol \\
\hline $123-92-2$ & Isoamyl acetate \\
\hline $124-40-3$ & Dimethylamine \\
\hline $124-48-1$ & Dibromochloromethane \\
\hline $126-72-7$ & Tris(2,3-dibromopropyl) phosphate \\
\hline $126-85-2$ & Nitrogen mustard N-oxide \\
\hline $126-99-8$ & Chloroprene \\
\hline $129-15-7$ & 2-Methyl-1-nitroanthraquinone \\
\hline $1300-73-8$ & Xylidine \\
\hline $131-11-3$ & Dimethyl phthalate \\
\hline $13121-70-5$ & Cyhexatin \\
\hline $132-64-9$ & Dibenzofuran \\
\hline $1321-64-8$ & Pentachloronaphthalene \\
\hline $1321-65-9$ & Trichloronaphthalene \\
\hline $1321-74-0$ & Divinyl benzene \\
\hline $133-06-2$ & Captan \\
\hline $133-90-4$ & Chloramben \\
\hline $1335-87-1$ & Hexachloronaphthalene \\
\hline $1335-88-2$ & Tetrachloronaphthalene \\
\hline $1336-36-3$ & Polychlorinated biphenyls (PCBs) \\
\hline $1338-23-4$ & Methyl ethyl ketone peroxide \\
\hline $134-32-7$ & alpha-Naphthylamine \\
\hline $135-20-6$ & Cupferron \\
\hline $135-88-6$ & N-Phenyl-2-napthylamine \\
\hline
\end{tabular}


Table B.10. Regulated Organic Compounds without a Positive Analytical Detect in Single-Sheil Tank/Double-Shell

Tank Waste (477 Compounds). (Page 4 of 11)

\begin{tabular}{|c|c|}
\hline CAS\# & 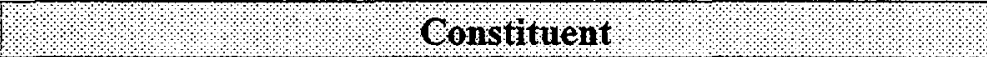 \\
\hline $13552-44-8$ & 4,4-Methylenedianiline dihydrochloride \\
\hline $136-78-7$ & Sesone \\
\hline $137-05-3$ & Methyl-2-cyanoacrylate \\
\hline $137-26-8$ & Thiram \\
\hline $137-30-4$ & Ziram \\
\hline $138-22-7$ & n-Butyl lactate \\
\hline $13838-16-9$ & Enflurane \\
\hline $139-65-1$ & 4,4'-Thiodianiline \\
\hline $139-91-3$ & 5-(Morpholinomethyl)-3-amino-2-oxazolidinone (furaltudone) \\
\hline $1395-21-7$ & Subtilisins \\
\hline $140-57-8$ & Aramite \\
\hline $140-88-5$ & Ethylacrylate \\
\hline $141-32-2$ & Butylacrylate \\
\hline $141-43-5$ & Ethanolamine \\
\hline $141-66-2$ & Dicrotophos \\
\hline $142-64-3$ & Piperazine dihydrochloride \\
\hline $143-50-0$ & Kepone \\
\hline 14484-64-1 & Ferbam \\
\hline $1477-55-0$ & $\mathrm{~m}$-Xylene-a, $\mathrm{a}^{\prime}$-diamine \\
\hline $148-01-6$ & Dinitolamide \\
\hline $150-76-5$ & 4-Methoxyphenol \\
\hline $151-56-4$ & Ethyleneimine \\
\hline $151-67-7$ & Halothane \\
\hline $156-60-5$ & 1,2-trans-Dichloroethene \\
\hline $1563-38-8$ & Carbofuran phenol \\
\hline $1563-66-2$ & Carbofuran \\
\hline $1582-09-8$ & Trifluralin \\
\hline $1615-80-1$ & $\mathrm{~N}, \mathrm{~N}^{\prime}$-Diethylhydrazine \\
\hline $16219-75-3$ & Ethylidene norbornene \\
\hline $1634-04-4$ & Methyl tert-butyl ether \\
\hline $1646-88-4$ & Aldicarb sulfone \\
\hline $16752-77-5$ & Methomyl \\
\hline $1694-09-3$ & Benzyl violet $4 b$ \\
\hline $1746-01-6$ & TCDD (Dioxin/Furan Indicator) \\
\hline $17702-57-7$ & Formparanate \\
\hline $17804-35-2$ & Benomyl \\
\hline $1836-75-5$ & Nitrofen \\
\hline $1888-71-7$ & Hexachloropropylene \\
\hline $189-55-9$ & Dibenzo[a,i]pyrene \\
\hline $189-64-0$ & Dibenzo[a,h]pyrene \\
\hline $191-24-2$ & Benzo(ghi)perylene \\
\hline $191-30-0$ & Dibenzo(a,1)pyrene \\
\hline $1912-24-9$ & Atrazine \\
\hline
\end{tabular}


Table B.10. Regulated Organic Compounds without a Positive Analytical Detect in Single-Shell Tank/Double-Shell Tank Waste (477 Compounds). (Page 5 of 11)

\begin{tabular}{|l|l|}
\hline \multicolumn{1}{|l|}{ CASH } & Pon $\quad$ Constituent \\
\hline $1918-02-1$ & Picloram \\
\hline $192-65-4$ & Dibenzo[a,e]pyrene \\
\hline $1929-77-7$ & Vernolate \\
\hline $1929-82-4$ & Nitrapyrin \\
\hline $193-39-5$ & Indeno(1,2,3-cd)pyrene \\
\hline $2008-41-5$ & Butylate \\
\hline $2032-65-7$ & Methiocarb \\
\hline $2039-87-4$ & o-Chlorostyrene \\
\hline $205-82-3$ & Benzo[j]fluoranthene \\
\hline $205-99-2$ & Benzo(b)fluoranthene \\
\hline $207-08-9$ & Benzo(k)fluoranthene \\
\hline $208-96-8$ & Acenaphthylene \\
\hline $2104-64-5$ & EPN \\
\hline $21087-64-9$ & Metribuzin \\
\hline $2179-59-1$ & Allyl propyl disulfide \\
\hline $218-01-9$ & Chrysene \\
\hline $2212-67-1$ & Molinate \\
\hline $22224-92-6$ & Fenamiphos \\
\hline $2234-13-1$ & Octachloronaphthalene \\
\hline $2238-07-5$ & Diglycidyl ether \\
\hline $224-42-0$ & Dibenz[a,j]acridine \\
\hline $226-36-8$ & Dibenz[a,h]acridine \\
\hline $22781-23-3$ & Bendiocarb \\
\hline $22961-82-6$ & Bendiocarb phenol \\
\hline $2303-17-5$ & Triallate \\
\hline $23135-22-0$ & Oxamy \\
\hline $23422-53-9$ & Formetanate hydrochloride \\
\hline $23564-05-8$ & Thiophanate-methyl \\
\hline $2385-85-5$ & Mirex \\
\hline $23950-58-5$ & Pronamide \\
\hline $2425-06-1$ & Captafol \\
\hline $2426-08-6$ & n-Butyl glycidyl ether \\
\hline $2465-27-2$ & Auramine (technical grade) \\
\hline $25013-15-4$ & Vinyl toluene \\
\hline $2551-13-7$ & Trimethyl benzene \\
\hline $25639-42-3$ & Methylcyclohexanol \\
\hline $26140-60-3$ & Terphenyls \\
\hline $2631-37-0$ & Promecarb \\
\hline $26419-73-8$ & Tirpate \\
\hline $2646-17-5$ & Oil orange SS \\
\hline $26952-21-6$ & Iso-ocytl alcohol \\
\hline $2698-41-1$ & o-Chlorobenylidene malonitrile \\
\hline $27154-33-2$ & Trichlorofluoroethane \\
\hline & \\
\hline
\end{tabular}


Table B.10. Regulated Organic Compounds without a Positive Analytical Detect in Single-Shell Tank/Double-Shell Tank Waste (477 Compounds). (Page 6 of 11)

\begin{tabular}{|c|c|}
\hline ( CAS\# & / \\
\hline 28434-86-8 & 3,3'-Dichloro-4,4'-diaminodiphenyl ether \\
\hline $29191-52-4$ & Anisidine (o-,p- isomers) \\
\hline $2921-88-2$ & Chlorpyrifos \\
\hline $2971-90-6$ & Clopidol \\
\hline $298-00-0$ & Methyl parathion \\
\hline $298-02-2$ & Phorate \\
\hline 298-04-4 & Disulfoton \\
\hline $299-84-3$ & Ronnel \\
\hline $299-86-5$ & Crufomate \\
\hline $300-76-5$ & Naled \\
\hline $302-01-2$ & Hydrazine \\
\hline $302-70-5$ & Nitrogen mustard N-oxide hydrochloride \\
\hline $30558-43-1$ & A2213 \\
\hline $3068-88-0$ & B-Butyrolactone \\
\hline $309-00-2$ & Aldrin \\
\hline 314-40-9 & Bromacil \\
\hline $315-18-4$ & Mexacarbate \\
\hline $319-84-6$ & alpha-BHC \\
\hline $319-85-7$ & beta-BHC \\
\hline $319-86-8$ & delta-BHC \\
\hline $330-54-1$ & Diuron \\
\hline $33213-65-9$ & Endosulfan II \\
\hline $333-41-5$ & Diazinon \\
\hline $3333-52-6$ & Tetramethyl succinonitrile \\
\hline 334-88-3 & Diazomethane \\
\hline $3383-96-8$ & Temephos \\
\hline $3424-82-6$ & $0, p^{\prime}-\mathrm{DDE}\left(2,4^{\prime}-\mathrm{DDE}\right)$ \\
\hline $34590-94-8$ & Dipropylene glycol methyl ether \\
\hline $35400-43-2$ & Sulprofos \\
\hline $3547-04-4$ & DDE (p,p'-Dichlorodiphenyldichloroethylene) \\
\hline $3689-24-5$ & Tetraethyldithiopyrophosphate (TEDP) \\
\hline $3697-24-3$ & 5-Methylchrysene \\
\hline $3761-53-3$ & Ponceau MX \\
\hline $3825-26-1$ & Ammonium perfluorooctanoate \\
\hline $4016-14-2$ & Isopropyl glycidyl ether (IGE) \\
\hline $4098-71-9$ & Isophorone diisocyanate \\
\hline $420-04-2$ & Cyanamide \\
\hline $463-51-4$ & Ketene \\
\hline $465-73-6$ & Isodrin \\
\hline $4685-14-7$ & Paraquat \\
\hline $479-45-8$ & Tetryl \\
\hline $50-29-3$ & 4,4-DDT \\
\hline $50-32-8$ & Benzo(a)pyrene \\
\hline
\end{tabular}


Table B.10. Regulated Organic Compounds without a Positive Analytical Detect in Single-Shell Tank/Double-Shell Tank Waste (477 Compounds). (Page 7 of 11)

\begin{tabular}{|l|l|}
\hline \multicolumn{1}{|c|}{ CASH } & \multicolumn{1}{|l|}{ Constituent } \\
\hline $504-29-0$ & 2-Aminopyridine \\
\hline $509-14-8$ & Tetranitromethane \\
\hline $51-28-5$ & $2,4-D i n i t r o p h e n o l$ \\
\hline $51-79-6$ & Ethyl carbamate (urethane) \\
\hline $510-15-6$ & Chlorobenzilate \\
\hline $5124-30-1$ & Methylene-bis-(4-cyclo-hexylisocyanate) \\
\hline $52-85-7$ & Famphur \\
\hline $528-29-0$ & Dinitrobenzene, all isomers \\
\hline $52888-80-9$ & Prosulfocarb \\
\hline $53-19-0$ & o,p'-DDD (2,4'-DDD) \\
\hline $53-70-3$ & Dibenz[a,h]anthracene \\
\hline $53-96-3$ & 2 -Acetylaminofluorene \\
\hline $531-82-8$ & N-(4-(5-Nitro-2-furyl)-2-thiazolyl)acetamide \\
\hline $532-27-4$ & a-Chloroacetophenone \\
\hline $534-52-1$ & 4,6 -Dinitro-o-cresol \\
\hline $54-11-5$ & Nicotine \\
\hline $540-59-0$ & $1,2-$ Dichloroethylene \\
\hline $540-73-8$ & $1,2-$ Dimethylhydrazine \\
\hline $540-84-1$ & $2,2,4-$ Trimethylpentane \\
\hline $540-88-5$ & tert-Butyl acetate \\
\hline $541-85-5$ & Ethyl amyl ketone \\
\hline $542-75-6$ & $1,3-D i c h l o r o p r o p e n e$ \\
\hline $542-88-1$ & Dichloromethyl ether \\
\hline $542-92-7$ & Cyclopentadiene \\
\hline $55-18-5$ & N-Nitrosodiethylamine \\
\hline $55-38-9$ & Fenthion \\
\hline $55-63-0$ & Nitroglycerin \\
\hline $552-30-7$ & Trimellitic anhydride \\
\hline $55285-14-8$ & Carbosulfan \\
\hline $55406-53-6$ & 3 -Iodo-2-propynyl n-butylcarbamate \\
\hline $555-84-9$ & $1-(5-$-Nitrofurfurylidene)amino)-2-imidazolidinone \\
\hline $556-52-5$ & Glycidol \\
\hline $55720-99-5$ & Chlorinated diphenyl oxide \\
\hline $55738-54-0$ & trans-2((Dimethylamino)methylimino)-5-(2-(5-nitro-2-furyl)vinyl- \\
\hline $56-38-2$ & Parathion \\
\hline $56-49-5$ & 3 -Methylcholanthrene \\
\hline $56-55-3$ & Benzo(a)anthracene \\
\hline $563-12-2$ & Ethion \\
\hline $57-24-9$ & Strychnine \\
\hline $57-47-6$ & Physostigmine \\
\hline $57-57-8$ & B-Propiolactone \\
\hline $57-64-7$ & Physostigmine salicylate \\
\hline & \\
\hline
\end{tabular}


Table B.10. Regulated Organic Compounds without a Positive Analytical Detect in Single-Shell Tank/Double-Shell Tank Waste (477 Compounds). (Page 8 of 11)

\begin{tabular}{|c|c|}
\hline \& CASH & Constituent \\
\hline $57-74-9$ & Chlordane \\
\hline $58-89-9$ & gamma-BHC (Lindane) \\
\hline $58-90-2$ & $2,3,4,6$-Tetrachlorophenol \\
\hline $583-60-8$ & o-Methylcyclohexanone \\
\hline $584-84-9$ & 2,4-Toluene diisocyanate \\
\hline $59-87-0$ & Nitrofurazone \\
\hline $592-62-1$ & Methyl azoxymethyl acetate \\
\hline $593-60-2$ & Vinyl bromide \\
\hline $59355-75-8$ & Methyl acetylene-propadiene mixture (MAPP) \\
\hline $594-42-3$ & Perchloromethyl mercaptan \\
\hline $594-72-9$ & 1,1-Dichloro-1-nitroethane \\
\hline $5952-26-1$ & Diethylene glycol, dicarbamate \\
\hline $59669-26-0$ & Thiodicarb \\
\hline $60-11-7$ & p-Dimethylaminoazobenzene \\
\hline $60-29-7$ & Ethyl ether \\
\hline $60-57-1$ & Dieldrin \\
\hline $600-25-9$ & 1-Chloro-1-nitropropane \\
\hline $602-87-9$ & 5-Nitroacenaphthene \\
\hline $603-34-9$ & Triphenyl amine \\
\hline $606-20-2$ & 2,6-Dinitrotoluene \\
\hline $608-93-5$ & Pentachlorobenzene \\
\hline $61-82-5$ & Amitrole \\
\hline $613-35-4$ & N,N-Diacetylbenzidine \\
\hline $615-53-2$ & N-Nitroso-N-methylurethane \\
\hline $62-44-2$ & Phenacetin \\
\hline $62-53-3$ & Aniline \\
\hline $62-73-7$ & Dichlorvas \\
\hline $62-74-8$ & Fluoroacetic acid, sodium salt (Fratól) \\
\hline $626-17-5$ & m-Phthalodinitrile \\
\hline $626-38-0$ & sec-Amyl acetate \\
\hline $628-63-7$ & n-Amyl acetate \\
\hline $628-96-6$ & Ethylene glycol dinitrate \\
\hline $63-25-2$ & Carbaryl \\
\hline $63-92-3$ & Phenoxybenzamine hydrochloride \\
\hline $630-20-6$ & 1,1,1,2-Tetrachloroethane \\
\hline $636-21-5$ & o-Toluidine hydrochloride \\
\hline 638-21-1 & Phenylphosphine \\
\hline $64-00-6$ & m-Cumenyl methylcarbamate \\
\hline $64-67-5$ & Diethyl sulfate \\
\hline 64091-91-4 & 4-(Methylnitrosamino)-1-(3-pyridyl)-1-butanone \\
\hline $6423-43-4$ & Propylene glycol dinitrate \\
\hline $644-64-4$ & Dimetilan \\
\hline $66-27-3$ & Methyl methanesulfonate \\
\hline
\end{tabular}


Table B.10. Regulated Organic Compounds without a Positive Analytical Detect in Single-Shell Tank/Double-Shell

Tank Waste (477 Compounds). (Page 9 of 11)

\begin{tabular}{|c|c|}
\hline CAs\# & Constituent \\
\hline $67-45-8$ & Furazolidone \\
\hline $68-11-1$ & Thioglycolic acid \\
\hline $68-12-2$ & Dimethylformamide \\
\hline $680-31-9$ & Hexamethylphosphoramide \\
\hline $681-84-5$ & Methyl silicate \\
\hline $684-16-2$ & Hexafluoroacetone \\
\hline $684-93-5$ & $\mathrm{~N}$-Nitroso-N-methylurea \\
\hline $68476-85-7$ & Liquified petroleum gas \\
\hline $6923-22-4$ & Monocrotophos \\
\hline $696-28-6$ & Dichlorophenylarsine \\
\hline $72-20-8$ & Endrin \\
\hline $72-43-5$ & Methoxychlor \\
\hline $72-54-8$ & 4,4-DDD \\
\hline $72-55-9$ & 4,4-DDE \\
\hline $74-88-4$ & Iodomethane \\
\hline $74-89-5$ & Methylamine \\
\hline $74-93-1$ & Thiomethanol \\
\hline $74-95-3$ & Dibromomethane \\
\hline $74-96-4$ & Ethyl bromide \\
\hline $74-97-5$ & Bromochloromethane \\
\hline $7421-93-4$ & Endrin aldehyde \\
\hline $75-04-7$ & Ethylamine \\
\hline $75-08-1$ & Ethyl mercaptan \\
\hline $75-25-2$ & Tribromomethane \\
\hline $75-27-4$ & Bromodichloromethane \\
\hline $75-31-0$ & Isopropylamine \\
\hline $75-47-8$ & Iodoform \\
\hline $75-56-9$ & Propylene oxide \\
\hline $75-61-6$ & Difluorodibromomethane \\
\hline $75-63-8$ & Trifluorobromomethane \\
\hline $75-99-0$ & 2,2-Dichloropropionic acid \\
\hline $7572-29-4$ & Dichloroacetylene \\
\hline $759-73-9$ & N-Nitroso-N-ethylurea \\
\hline $759-94-4$ & EPTC \\
\hline $76-01-7$ & Pentachloroethane \\
\hline 76-03-9 & Trichloroacetic acid \\
\hline $76-06-2$ & Chloropicrin \\
\hline $76-11-9$ & 1,1,1,2-Tetrachloro-2,2-difluoroethane \\
\hline $76-12-0$ & 1,1,2,2-Tetrachloro-1,2-difluoroethane \\
\hline $76-15-3$ & Chloropentafluoroethane \\
\hline $76-22-2$ & Camphor, synthetic \\
\hline $76-44-8$ & Heptachlor \\
\hline $764-41-0$ & 1,4-Dichloro-2-butene \\
\hline
\end{tabular}


Table B.10. Regulated Organic Compounds without a Positive Analytical Detect in Single-Shell Tank/Double-Shell Tank Waste (477 Compounds). (Page 10 of 11)

\begin{tabular}{|c|c|}
\hline CASH & Constituent \\
\hline $765-34-4$ & Glycidylaldehyde \\
\hline $768-52-5$ & $\mathrm{~N}$-Isopropylaniline \\
\hline $77-47-4$ & Hexachlorocyclopentadiene \\
\hline $77-73-6$ & Dicyclopentadiene \\
\hline $77-78-1$ & Dimethyl sulfate \\
\hline $7782-41-4$ & Fluorine \\
\hline $7786-34-7$ & Mevinphos \\
\hline $78-10-4$ & Ethyl silicate \\
\hline $78-30-8$ & Triorthocresyl phosphate \\
\hline $78-34-2$ & Dioxathion \\
\hline $78-59-1$ & Isophorone \\
\hline $7803-51-2$ & Phosphine \\
\hline $789-02-6$ & $0, p^{\prime}-$ DDT $\left(2,4^{\prime}-\right.$ DDT $)$ \\
\hline $79-04-9$ & Chloroacetyl chloride \\
\hline $79-06-1$ & Acrylamide \\
\hline $79-11-8$ & Chloroacetic acid \\
\hline $79-24-3$ & Nitroethane \\
\hline $79-27-6$ & Acetylene tetrabromide \\
\hline $79-41-4$ & Methacrylic acid \\
\hline $79-44-7$ & Dimethylcarbamoyl chloride \\
\hline $79-46-9$ & 2-Nitropropane \\
\hline $794-93-4$ & Panfuran S (dihydroxymethylfuratrizine) \\
\hline $80-62-6$ & Methyl methacrylate \\
\hline $8001-35-2$ & Toxaphene \\
\hline $8001-58-9$ & Creosote \\
\hline $8003-34-7$ & Pyrethrum \\
\hline $8006-64-2$ & Turpentine \\
\hline $8022-00-2$ & Methyl demeton \\
\hline $8052-42-4$ & Asphalt (petroleum) fumes \\
\hline $8065-48-3$ & Demeton \\
\hline $81-81-2$ & Warfarin $(>0.3 \%)$ \\
\hline $81-81-2 a$ & Warfarin $(<0.3 \%)$ \\
\hline $82-68-8$ & Pentachloronitrobenzene (PCNB) \\
\hline $822-06-0$ & Hexamethylene diisocyanate \\
\hline $83-26-1$ & Pindone \\
\hline $83-79-4$ & Rotenone \\
\hline $838-88-0$ & 4,4'-Methylenebis(2-methylaniline) \\
\hline $85-00-7$ & Diquat \\
\hline $85-01-8$ & Phenanthrene \\
\hline $85-44-9$ & Phthalic anhydride \\
\hline $86-30-6$ & N-Nitrosodiphenylamine \\
\hline $86-50-0$ & Azinphos-methyl \\
\hline $86-88-4$ & alpha-Naphthylthiourea \\
\hline
\end{tabular}


Table B.10. Regulated Organic Compounds without a Positive Analytical Detect in Single-Shell Tank/Double-Shell Tank Waste (477 Compounds). (Page 11 of 11)

\begin{tabular}{|c|c|}
\hline \&QSA & Constituent \\
\hline $87-65-0$ & 2,6-Dichlorophenol \\
\hline $87-86-5$ & Pentachlorophenol \\
\hline $88-72-2$ & Nitrotoluene \\
\hline $88-74-4$ & 2-Nitroaniline \\
\hline $88-85-7$ & 2-sec-Butyl-4,6-dinitrophenol; syn Dinoseb \\
\hline $88-89-1$ & Picric acid \\
\hline $89-72-5$ & o-sec-Butylphenol \\
\hline $90-04-0$ & o-Anisidine \\
\hline $91-22-5$ & Quinoline \\
\hline $91-58-7$ & 2-Chloronaphthalene \\
\hline $91-59-8$ & 2-Napthylamine \\
\hline $91-80-5$ & Methapyrilene \\
\hline $91-94-1$ & 3,3-Dichlorobenzidine \\
\hline $92-67-1$ & 4-Aminobiphenyl \\
\hline $92-84-2$ & Phenothiazine \\
\hline $92-87-5$ & Benzidine \\
\hline $92-93-3$ & 4-Nitrobiphenyl \\
\hline $924-16-3$ & N-Nitrosodi-n-butylamine \\
\hline $93-72-1$ & Silvex $(2,4,5-\mathrm{TP})$ \\
\hline $93-76-5$ & $2,4,5-\mathrm{T}$ \\
\hline $930-55-2$ & N-Nitrosopyrrolidine \\
\hline $94-36-0$ & Benzoyl Peroxide \\
\hline 94-59-7 & Safrole \\
\hline $94-75-7$ & $2,4-\mathrm{D}$ \\
\hline $944-22-9$ & Fonofos \\
\hline $95-13-6$ & Indene \\
\hline $95-49-8$ & o-Chlorotoluene \\
\hline $95-53-4$ & o-Toluidine (2-methylaniline) \\
\hline $95-54-5$ & 1,2-Phenylenediamine \\
\hline $95-80-7$ & Toluene-2,4-diamine \\
\hline $95-94-3$ & 1,2,4,5-Tetrachlorobenzene \\
\hline $959-98-8$ & Endosulfan I \\
\hline $96-09-3$ & Styrene oxide \\
\hline $96-12-8$ & 1,2-Dibromo-3-chloropropane \\
\hline $96-18-4$ & 1,2,3-Trichloropropane \\
\hline $96-33-3$ & Methyl acrylate \\
\hline $96-45-7$ & Ethylenethiourea \\
\hline $97-56-3$ & o-Aminoazotoluene \\
\hline $97-63-2$ & Ethyl methacrylate \\
\hline $97-77-8$ & Disulfiram \\
\hline 98-00-1 & Furfuryl alcohol \\
\hline $98-01-1$ & Furfural \\
\hline $98-07-7$ & Benzotrichloride \\
\hline
\end{tabular}


Table B.10. Regulated Organic Compounds without a Positive Analytical Detect in Single-Shell Tank/Double-Shell Tank Waste (477 Compounds). (Page 12 of 11)

\begin{tabular}{|l|l|}
\hline \multicolumn{1}{|c|}{ CAS\#: } & \multicolumn{1}{|c|}{ Constituent } \\
\hline $98-51-1$ & p-tert-Butyltoluene \\
\hline $98-82-2$ & Cumene \\
\hline $98-87-3$ & Benzal chloride \\
\hline $99-55-8$ & 5-Nitro-o-toluidine \\
\hline $999-61-1$ & 2-Hydroxypropyl acrylate \\
\hline CAS\# = chemical abstract service number.
\end{tabular}


Table B.11. Regulated Non-detected Organic Compounds that are Classified as Polycyclic Aromatic Hydrocarbons (14 Compounds).

\begin{tabular}{|l|l|}
\hline \multicolumn{1}{|c|}{ CASH } & \multicolumn{1}{|c|}{ Constituent } \\
\hline $120-12-7$ & Anthracene \\
\hline $191-24-2$ & Benzo(ghi)perylene \\
\hline $191-30-0$ & Dibenzo(a,l)pyrene \\
\hline $193-39-5$ & Indeno(1,2,3-cd)pyrene \\
\hline $205-99-2$ & Benzo(b)fluoranthene \\
\hline $207-08-9$ & Benzo(k)fluoranthene \\
\hline $208-96-8$ & Acenaphthylene \\
\hline $218-01-9$ & Chrysene \\
\hline $224-42-0$ & Dibenz[a,j]acridine \\
\hline $3697-24-3$ & 5-Methylchrysene \\
\hline $50-32-8$ & Benzo(a)pyrene \\
\hline $53-70-3$ & Dibenz[a,h]anthracene \\
\hline $56-55-3$ & Benzo(a)anthracene \\
\hline $85-01-8$ & Phenanthrene \\
\hline
\end{tabular}

CAS\# = chemical abstract service number. 
Table B.12. Regulated Non-detected Organic Compounds Classified as Chlorinated Pesticides and Herbicides That Were Likely to be Used During Early Hanford Site Operations (39 Compounds).

\begin{tabular}{|c|c|}
\hline .8 CASH & 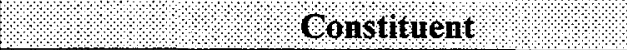 \\
\hline $1024-57-3$ & Heptachlor Epoxide \\
\hline $1031-07-8$ & Endosulfan Sulfate \\
\hline $118-74-1$ & Hexachlorobenzene \\
\hline $133-06-2$ & Captan \\
\hline $133-90-4$ & Chloramben \\
\hline $1582-09-8$ & Trifluralin \\
\hline $1836-75-5$ & Nitrofen \\
\hline 1918-02-1 & Picloram \\
\hline $2234-13-1$ & Octachloronaphthalene \\
\hline $2385-85-5$ & Mirex \\
\hline $2425-06-1$ & Captafol \\
\hline $309-00-2$ & Aldrin \\
\hline $319-84-6$ & alpha-BHC \\
\hline $319-85-7$ & beta-BHC \\
\hline $319-86-8$ & delta-BHC \\
\hline $33213-65-9$ & Endosulfan II \\
\hline $465-73-6$ & Isodrin \\
\hline $50-29-3$ & $4,4-\overline{D D T}$ \\
\hline $510-15-6$ & Chlorobenzilate \\
\hline $57-74-9$ & Chlordane \\
\hline $58-89-9$ & gamma-BHC (Lindane) \\
\hline $58-90-2$ & $2,3,4,6$-Tetrachlorophenol \\
\hline $60-57-1$ & Dieldrin \\
\hline $72-20-8$ & Endrin \\
\hline $72-43-5$ & Methoxychlor \\
\hline $72-54-8$ & 4,4-DDD \\
\hline $72-55-9$ & 4,4-DDE \\
\hline $7421-93-4$ & Endrin aldehyde \\
\hline $75-99-0$ & 2,2-Dichloropropionic acid \\
\hline $76-44-8$ & Heptachlor \\
\hline $77-47-4$ & Hexachlorocyclopentadiene \\
\hline $8001-35-2$ & Toxaphene \\
\hline $87-86-5$ & Pentachlorophenol \\
\hline $88-85-7$ & 2-sec-Butyl-4,6-dinitrophenol; syn Dinoseb \\
\hline $93-72-1$ & Silvex $(2,4,5-\mathrm{TP})$ \\
\hline $93-76-5$ & $2,4,5-\mathrm{T}$ \\
\hline $94-75-7$ & $2,4-\mathrm{D}$ \\
\hline $959-98-8$ & Endosulfan I \\
\hline $96-12-8$ & 1,2-Dibromo-3-chloropropane \\
\hline
\end{tabular}

CAS\# $=$ chemical abstract service number. 
Table B.13. Regulated Non-detected Organic

Compound, Plausibly a "Ghost"

Compound (1 Compound).

\begin{tabular}{|l|l|l|}
\hline 1. CASH & Constitiuent \\
\hline 1336-36-3 & Polychlorinated biphenyls (PCBs) \\
\hline
\end{tabular}

CAS\# = chemical abstract service number. 
Table B.14. Regulated Non-detected Organic Compounds Listed in Either Klem (1990) or Agnew (1997) (7 compounds).

\begin{tabular}{|l|l|c|c|}
\hline \multicolumn{1}{c|}{ CASt } & \multicolumn{1}{c|}{ Constituent } & Klem (1990) & Agner $(199)^{(2)}$ \\
\hline $107-21-1$ & Ethylene glycol & $X$ & \\
\hline $107-66-4$ & Dibutylphosphate & $X$ & $X$ \\
\hline $110-91-8$ & Morpholine & $X$ & \\
\hline $123-92-2$ & Isoamyl acetate & $X$ & \\
\hline $134-32-7$ & alpha-Naphthylamine & $X$ & \\
\hline $302-01-2$ & Hydrazine & $X$ & \\
\hline $60-29-7$ & Ethyl ether & $X$ & \\
\hline
\end{tabular}

(a)Previously known as the Historical Tank Content Estimate (HTCE).

CAS\# = chemical abstract service number. 
Table B.15. Regulated Non-detected Organic Compounds for Evaluation of Industry Uses Unrelated to Hanford Activities (416 Compounds). (Page 1 of 9)

\begin{tabular}{|c|c|}
\hline (1.: CASH & Constituent \\
\hline $100-01-6$ & 4-Nitroaniline \\
\hline $100-02-7$ & 4-Nitrophenol \\
\hline $100-21-0$ & Phthalic acid \\
\hline $100-25-4$ & 1,4-Dinitrobenzene \\
\hline $100-37-8$ & Diethylaminoethanol \\
\hline $100-44-7$ & Benzyl chloride \\
\hline $100-61-8$ & $\mathrm{~N}$-Methylbenzenamine \\
\hline $100-63-0$ & Phenylhydrazine \\
\hline $100-74-3$ & N-Ethylmorpholine \\
\hline $100-75-4$ & N-Nitrosopiperidine \\
\hline $101-14-4$ & 4,4'-Methylenebis(2-chloroaniline) \\
\hline $101-27-9$ & Barban \\
\hline $101-55-3$ & 4-Bromophenylphenyl ether \\
\hline $101-68-8$ & Methylene bis(phenyl isocyanate) \\
\hline $101-77-9$ & 4,4-Methylene dianiline \\
\hline $101-80-4$ & 4,4'-Diaminodiphenyl ether \\
\hline $101-90-6$ & Diglycidyl resorcinol ether \\
\hline $102-81-8$ & 2-N-Dibutylaminoethanol \\
\hline $105-46-4$ & sec-Butyl acetate \\
\hline $105-60-2$ & Caprolactam, vapor \\
\hline $105-60-2 a$ & Caprolactam, dust \\
\hline $105-67-9$ & 2,4-Dimethylphenol \\
\hline $10595-95-6$ & N-Nitrosomethylethylamine \\
\hline $106-44-5$ & 4-Methylphenol \\
\hline $106-47-8$ & 4-Chloroaniline \\
\hline $106-49-0$ & p-Toluidine \\
\hline $106-50-3$ & p-Phenylenediamine \\
\hline $106-51-4$ & p-Benzoquinone \\
\hline $106-87-6$ & Vinyl cyclohexene dioxide \\
\hline $106-89-8$ & Epichlorohydrin \\
\hline $106-92-3$ & Allyl glycidyl ether \\
\hline $10605-21-7$ & Carbendazim \\
\hline $107-07-3$ & Ethylene chlorohydrin \\
\hline $107-15-3$ & Ethylene diamine \\
\hline $107-19-7$ & Propargyl alcohol \\
\hline $107-20-0$ & Chloroacetaldehyde \\
\hline $107-30-2$ & Chloromethyl methyl ether \\
\hline $107-41-5$ & Hexylene glycol \\
\hline $107-49-3$ & Tetraethyl pyrophosphate \\
\hline $107-98-2$ & Propylene glycol monomethyl ether \\
\hline $108-11-2$ & Methyl isobutyl carbinol \\
\hline $108-18-9$ & Diisopropylamine \\
\hline $108-21-4$ & Isopropyl acetate \\
\hline $108-24-7$ & Acetic anhydride \\
\hline $108-31-6$ & Maleic anhydride (2,5-Furandione) \\
\hline $108-43-0$ & Chlorophenols \\
\hline $108-44-1$ & m-Toluidine \\
\hline $108-46-3$ & Resorcinol (1,3-Benzenediol) \\
\hline $108-60-1$ & Bis(2-Chloroisopropyl) ether \\
\hline
\end{tabular}


Table B.15. Regulated Non-detected Organic Compounds for Evaluation of Industry Uses Unrelated to Hanford Activities (416 Compounds). (Page 2 of 9)

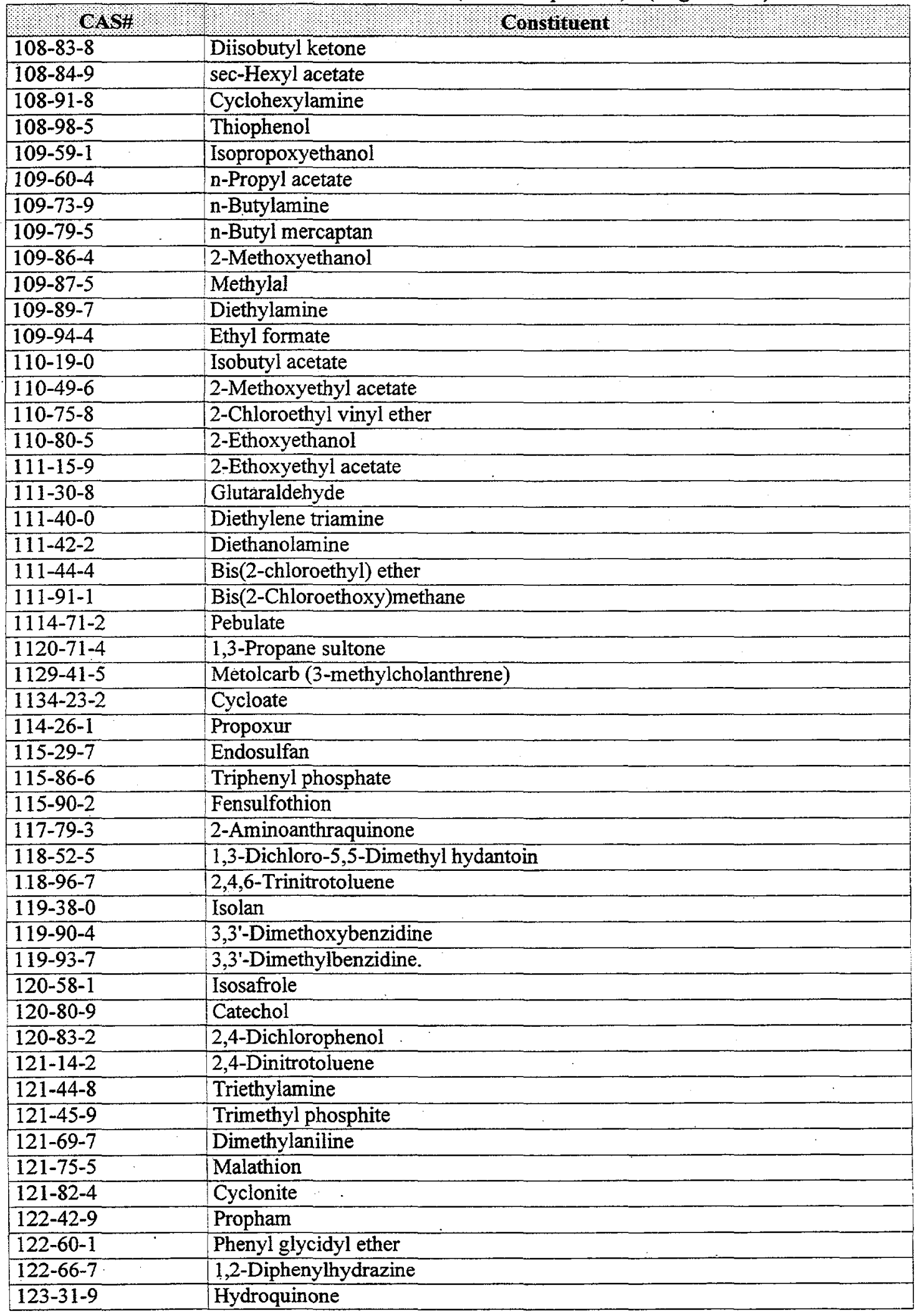


Table B.15. Regulated Non-detected Organic Compounds for Evaluation of Industry Uses Unrelated to Hanford Activities (416 Compounds). (Page 3 of 9)

\begin{tabular}{|c|c|}
\hline 1,1, CASH & Constituent \\
\hline $123-42-2$ & Diacetone alcohol \\
\hline $124-40-3$ & Dimethylamine \\
\hline $124-48-1$ & Dibromochloromethane \\
\hline $126-72-7$ & Tris(2,3-dibromopropyl) phosphate \\
\hline $126-85-2$ & Nitrogen mustard N-oxide \\
\hline $126-99-8$ & Chloroprene \\
\hline $129-15-7$ & 2-Methyl-1-nitroanthraquinone \\
\hline $1300-73-8$ & Xylidine \\
\hline 131-11-3 & Dimethyl phthalate \\
\hline $13121-70-5$ & Cyhexatin \\
\hline $132-64-9$ & Dibenzofuran \\
\hline $1321-64-8$ & Pentachloronaphthalene \\
\hline $1321-65-9$ & Trichloronaphthalene \\
\hline $1321-74-0$ & Divinyl benzene \\
\hline $1335-87-1$ & Hexachloronaphthalene \\
\hline $1335-88-2$ & Tetrachloronaphthalene \\
\hline $1338-23-4$ & Methyl ethyl ketone peroxide \\
\hline $135-20-6$ & Cupferron \\
\hline $135-88-6$ & N-Phenyl-2-napthylamine \\
\hline $13552-44-8$ & 4,4-Methylenedianiline dihydrochloride \\
\hline 136-78-7 & Sesone \\
\hline $137-05-3$ & Methyl-2-cyanoacrylate \\
\hline $137-26-8$ & Thiram \\
\hline $137-30-4$ & Ziram \\
\hline $138-22-7$ & n-Butyl lactate \\
\hline $13838-16-9$ & Enflurane \\
\hline $139-65-1$ & 4,4'-Thiodianiline \\
\hline $139-91-3$ & 5-(Morpholinomethyl)-3-amino-2-oxazolidinone (furaltudone) \\
\hline $1395-21-7$ & Subtilisins \\
\hline $140-57-8$ & Aramite \\
\hline $140-88-5$ & Ethylacrylate \\
\hline $141-32-2$ & Butylacrylate \\
\hline $141-43-5$ & Ethanolamine \\
\hline $141-66-2$ & Dicrotophos \\
\hline $142-64-3$ & Piperazine dihydrochloride \\
\hline $143-50-0$ & Kepone \\
\hline 14484-64-1 & Ferbam \\
\hline $1477-55-0$ & m-Xylene-a,a'-diamine \\
\hline $148-01-6$ & Dinitolamide \\
\hline $150-76-5$ & 4-Methoxyphenol \\
\hline $151-56-4$ & Ethyleneimine \\
\hline $151-67-7$ & Halothane \\
\hline $156-60-5$ & 1,2-trans-Dichloroethene \\
\hline $1563-38-8$ & Carbofuran phenol \\
\hline $1563-66-2$ & Carbofuran \\
\hline $1615-80-1$ & N,N'-Diethylhydrazine \\
\hline $16219-75-3$ & Ethylidene norbornene \\
\hline $1634-04-4$ & Methyl tert-butyl ether \\
\hline $1646-88-4$ & Aldicarb sulfone \\
\hline
\end{tabular}


Table B.15. Regulated Non-detected Organic Compounds for Evaluation of Industry Uses Unrelated to Hanford Activities (416 Compounds). (Page 4 of 9)

\begin{tabular}{|c|c|}
\hline CAS\# & Constituent \\
\hline $16752-77-5$ & Methomyl \\
\hline $1694-09-3$ & Benzyl violet $4 \mathrm{~b}$ \\
\hline $1746-01-6$ & TCDD (Dioxin/Furan Indicator) \\
\hline $17702-57-7$ & Formparanate \\
\hline $17804-35-2$ & Benomyl \\
\hline $1888-71-7$ & Hexachloropropylene \\
\hline $189-55-9$ & Dibenzo[a,i]pyrene \\
\hline $189-64-0$ & Dibenzo[a,h]pyrene \\
\hline $1912-24-9$ & Atrazine \\
\hline $192-65-4$ & Dibenzo[a,e]pyrene \\
\hline $1929-77-7$ & Vernolate \\
\hline $1929-82-4$ & Nitrapyrin \\
\hline $2008-41-5$ & Butylate \\
\hline $2032-65-7$ & Methiocarb \\
\hline $2039-87-4$ & o-Chlorostyrene \\
\hline $205-82-3$ & Benzo[j] fluoranthene \\
\hline $2104-64-5$ & EPN \\
\hline $21087-64-9$ & Metribuzin \\
\hline $2179-59-1$ & Allyl propyl disulfide \\
\hline $2212-67-1$ & Molinate \\
\hline $22224-92-6$ & Fenamiphos \\
\hline $2238-07-5$ & Diglycidyl ether \\
\hline $226-36-8$ & Dibenz $[\mathrm{a}, \mathrm{h}] \mathrm{acridine}$ \\
\hline $22781-23-3$ & Bendiocarb \\
\hline $22961-82-6$ & Bendiocarb phenol \\
\hline $2303-17-5$ & Triallate \\
\hline $23135-22-0$ & Oxamy \\
\hline $23422-53-9$ & Formetanate hydrochloride \\
\hline $23564-05-8$ & Thiophanate-methyl \\
\hline $23950-58-5$ & Pronamide \\
\hline $2426-08-6$ & n-Butyl glycidyl ether \\
\hline $2465-27-2$ & Auramine (technical grade) \\
\hline $25013-15-4$ & Vinyl toluene \\
\hline $2551-13-7$ & Trimethyl benzene \\
\hline $25639-42-3$ & Methylcyclohexanol \\
\hline $26140-60-3$ & Terphenyls \\
\hline $2631-37-0$ & Promecarb \\
\hline $26419-73-8$ & Tirpate \\
\hline $2646-17-5$ & Oil orange SS \\
\hline $26952-21-6$ & Iso-ocytl alcohol \\
\hline $2698-41-1$ & o-Chlorobenylidene malonitrile \\
\hline $27154-33-2$ & Trichlorofluoroethane \\
\hline $28434-86-8$ & 3,3'-Dichloro-4,4'-diaminodiphenyl ether \\
\hline $29191-52-4$ & Anisidine (o-,p-isomers) \\
\hline $2921-88-2$ & Chlorpyrifos \\
\hline $2971-90-6$ & Clopidol \\
\hline $298-00-0$ & Methyl parathion \\
\hline $298-02-2$ & Phorate \\
\hline $298-04-4$ & Disulfoton \\
\hline
\end{tabular}


Table B.15. Regulated Non-detected Organic Compounds for Evaluation of Industry Uses Unrelated to Hanford Activities (416 Compounds). (Page 5 of 9)

\begin{tabular}{|c|c|}
\hline $1 / 1$ CASH & Constituent \\
\hline $299-84-3$ & Ronnel \\
\hline $299-86-5$ & Crufomate \\
\hline $300-76-5$ & Naled \\
\hline $302-70-5$ & Nitrogen mustard N-oxide hydrochloride \\
\hline 30558-43-1 & $\mathrm{A} 2213$ \\
\hline $3068-88-0$ & B-Butyrolactone \\
\hline $314-40-9$ & Bromacil \\
\hline $315-18-4$ & Mexacarbate \\
\hline $330-54-1$ & Diuron \\
\hline $333-41-5$ & Diazinon \\
\hline $3333-52-6$ & Tetramethyl succinonitrile \\
\hline $334-88-3$ & Diazomethane \\
\hline $3383-96-8$ & Temephos \\
\hline $3424-82-6$ & $o, p^{\prime}-\mathrm{DDE}\left(2,4^{\prime}-\mathrm{DDE}\right)$ \\
\hline $34590-94-8$ & Dipropylene glycol methyl ether \\
\hline $35400-43-2$ & Sulprofos \\
\hline $3547-04-4$ & DDE (p,p'-Dichlorodiphenyldichloroethylene) \\
\hline $3689-24-5$ & Tetraethyldithiopyrophosphate (TEDP) \\
\hline $3761-53-3$ & Ponceau MX \\
\hline $3825-26-1$ & Ammonium perfluorooctanoate \\
\hline 4016-14-2 & Isopropyl glycidyl ether (IGE) \\
\hline 4098-71-9 & Isophorone diisocyanate \\
\hline $420-04-2$ & Cyanamide \\
\hline $463-51-4$ & Ketene \\
\hline 4685-14-7 & Paraquat \\
\hline $479-45-8$ & Tetryl \\
\hline $504-29-0$ & 2-Aminopyridine \\
\hline $509-14-8$ & Tetranitromethane \\
\hline $51-28-5$ & 2,4-Dinitrophenol \\
\hline $51-79-6$ & Ethyl carbamate (urethane) \\
\hline $5124-30-1$ & Methylene-bis-(4-cyclo-hexylisocyanate) \\
\hline $52-85-7$ & Famphur \\
\hline $528-29-0$ & Dinitrobenzene, all isomers \\
\hline $52888-80-9$ & Prosulfocarb \\
\hline $53-19-0$ & $0, p^{\prime}-\mathrm{DDD}\left(2,4^{\prime}-\mathrm{DDD}\right)$ \\
\hline $53-96-3$ & 2-Acetylaminofluorene \\
\hline $531-82-8$ & $\mathrm{~N}$-(4-(5-Nitro-2-furyl)-2-thiazolyl)acetamide \\
\hline $532-27-4$ & a-Chloroacetophenone \\
\hline $534-52-1$ & 4,6-Dinitro-o-cresol \\
\hline $54-11-5$ & Nicotine \\
\hline $540-59-0$ & 1,2-Dichloroethylene \\
\hline $540-73-8$ & 1,2-Dimethylhydrazine \\
\hline $540-84-1$ & 2,2,4-Trimethylpentane \\
\hline $540-88-5$ & tert-Butyl acetate \\
\hline $541-85-5$ & Ethyl amyl ketone \\
\hline $542-75-6$ & 1,3-Dichloropropene \\
\hline $542-88-1$ & Dichloromethyl ether \\
\hline $542-92-7$ & Cyclopentadiene \\
\hline $55-18-5$ & N-Nitrosodiethylamine \\
\hline
\end{tabular}


Table B.15. Regulated Non-detected Organic Compounds for Evaluation of Industry Uses Unrelated to Hanford Activities (416 Compounds). (Page 6 of 9)

\begin{tabular}{|c|c|}
\hline CASH: & Constituent \\
\hline $55-38-9$ & Fenthion \\
\hline $55-63-0$ & Nitroglycerin. \\
\hline $552-30-7$ & Trimellitic anhydride \\
\hline $55285-14-8$ & Carbosulfan \\
\hline $55406-53-6$ & 3-Iodo-2-propynyl n-butylcarbamate \\
\hline $555-84-9$ & 1-(5-Nitrofurfurylidene)amino)-2-imidazolidinone \\
\hline $556-52-5$ & Glycidol \\
\hline $55720-99-5$ & Chlorinated diphenyl oxide \\
\hline $55738-54-0$ & $\begin{array}{l}\text { trans-2((dimethylamino)methylimino })-5-(2-(5-\text { nitro-2-furyl }) \text { vinyl-1,3, } \\
\text { 4-oxadiazole }\end{array}$ \\
\hline $56-38-2$ & Parathion \\
\hline $56-49-5$ & 3-Methylcholanthrene \\
\hline $563-12-2$ & Ethion \\
\hline $57-24-9$ & Strychnine \\
\hline $57-47-6$ & Physostigmine \\
\hline $57-57-8$ & B-Propiolactone \\
\hline $57-64-7$ & Physostigmine salicylate \\
\hline $583-60-8$ & o-Methylcyclohexanone \\
\hline 584-84-9 & 2,4-Toluene diisocyanate \\
\hline $59-87-0$ & Nitrofurazone \\
\hline $592-62-1$ & Methyl azoxymethyl acetate \\
\hline $593-60-2$ & Vinyl bromide \\
\hline $59355-75-8$ & Methyl acetylene-propadiene mixture (MAPP) \\
\hline $594-42-3$ & Perchloromethyl mercaptan \\
\hline $594-72-9$ & 1,1-Dichloro-1-nitroethane \\
\hline $5952-26-1$ & Diethylene glycol, dicarbamate \\
\hline $59669-26-0$ & Thiodicarb \\
\hline $60-11-7$ & p-Dimethylaminoazobenzene \\
\hline $600-25-9$ & 1-Chloro-1-nitropropane \\
\hline $602-87-9$ & 5-Nitroacenaphthene \\
\hline $603-34-9$ & Triphenyl amine \\
\hline $606-20-2$ & 2,6-Dinitrotoluene \\
\hline $608-93-5$ & Pentachlorobenzene \\
\hline $61-82-5$ & Amitrole \\
\hline $613-35-4$ & N,N-Diacetylbenzidine \\
\hline $615-53-2$ & N-Nitroso-N-methylurethane \\
\hline $62-44-2$ & Phenacetin \\
\hline $62-53-3$ & Aniline \\
\hline $62-73-7$ & Dichlorvas \\
\hline $62-74-8$ & Fluoroacetic acid, sodium salt (Fratol) \\
\hline $626-17-5$ & m-Phthalodinitrile \\
\hline $626-38-0$ & sec-Amyl acetate \\
\hline $628-63-7$ & n-Amyl acetate \\
\hline $628-96-6$ & Ethylene glycol dinitrate \\
\hline $63-25-2$ & Carbaryl \\
\hline $63-92-3$ & Phenoxybenzamine hydrochloride \\
\hline $630-20-6$ & 1,1,1,2-Tetrachloroethane \\
\hline $636-21-5$ & o-Toluidine hydrochloride \\
\hline $638-21-1$ & Phenylphosphine \\
\hline
\end{tabular}


Table B.15. Regulated Non-detected Organic Compounds for Evaluation of Industry Uses Unrelated to Hanford Activities (416 Compounds). (Page 7 of 9)

\begin{tabular}{|c|c|}
\hline CASH & Constituent \\
\hline $64-00-6$ & m-Cumenyl methylcarbamate \\
\hline $64-67-5$ & Diethyl sulfate \\
\hline $64091-91-4$ & 4-(Methylnitrosamino)-1-(3-pyridyl)-1-butanone \\
\hline $6423-43-4$ & Propylene glycol dinitrate \\
\hline 644-64-4 & Dimetilan \\
\hline $66-27-3$ & Methyl methanesulfonate \\
\hline $67-45-8$ & Furazolidone \\
\hline $68-11-1$ & Thioglycolic acid \\
\hline $68-12-2$ & Dimethylformamide \\
\hline $680-31-9$ & Hexamethylphosphoramide \\
\hline $681-84-5$ & Methyl silicate \\
\hline $684-16-2$ & Hexafluoroacetone \\
\hline $684-93-5$ & N-Nitroso-N-methylurea \\
\hline 68476-85-7 & Liquified petroleum gas \\
\hline $6923-22-4$ & Monocrotophos \\
\hline $696-28-6$ & Dichlorophenylarsine \\
\hline $74-88-4$ & Iodomethane \\
\hline $74-89-5$ & Methylamine \\
\hline 74-93-1 & Thiomethanol \\
\hline $74-95-3$ & Dibromomethane \\
\hline 74-96-4 & Ethyl bromide \\
\hline$\overline{74-97-5}$ & Bromochloromethane \\
\hline 75-04-7 & Ethylamine \\
\hline$\overline{75-08-1}$ & Ethyl mercaptan \\
\hline $75-25-2$ & Tribromomethane \\
\hline $75-27-4$ & Bromodichloromethane \\
\hline $75-31-0$ & Isopropylamine \\
\hline $75-47-8$ & Iodoform \\
\hline $75-56-9$ & Propylene oxide \\
\hline $75-61-6$ & Difluorodibromomethane \\
\hline $75-63-8$ & Trifluorobromomethane \\
\hline $7572-29-4$ & Dichloroacetylene \\
\hline $759-73-9$ & N-Nitroso-N-ethylurea \\
\hline $759-94-4$ & EPTC \\
\hline $76-01-7$ & Pentachloroethane \\
\hline $76-03-9$ & Trichloroacetic acid \\
\hline $76-06-2$ & Chloropicrin \\
\hline $76-11-9$ & 1,1,1,2-Tetrachloro-2,2-difluoroethane \\
\hline $76-12-0$ & 1,1,2,2-Tetrachloro-1,2-difluoroethane \\
\hline $76-15-3$ & Chloropentafluoroethane \\
\hline $76-22-2$ & Camphor, synthetic \\
\hline $764-41-0$ & 1,4-Dichloro-2-butene \\
\hline $765-34-4$ & Glycidylaldehyde \\
\hline $768-52-5$ & $\mathrm{~N}$-Isopropylaniline \\
\hline $77-73-6$ & Dicyclopentadiene \\
\hline $77-78-1$ & Dimethyl sulfate \\
\hline $7782-41-4$ & Fluorine \\
\hline $7786-34-7$ & Mevinphos \\
\hline $78-10-4$ & Ethyl silicate \\
\hline
\end{tabular}


Table B.15. Regulated Non-detected Organic Compounds for Evaluation of Industry Uses Unrelated to Hanford Activities (416 Compounds). (Page 8 of 9)

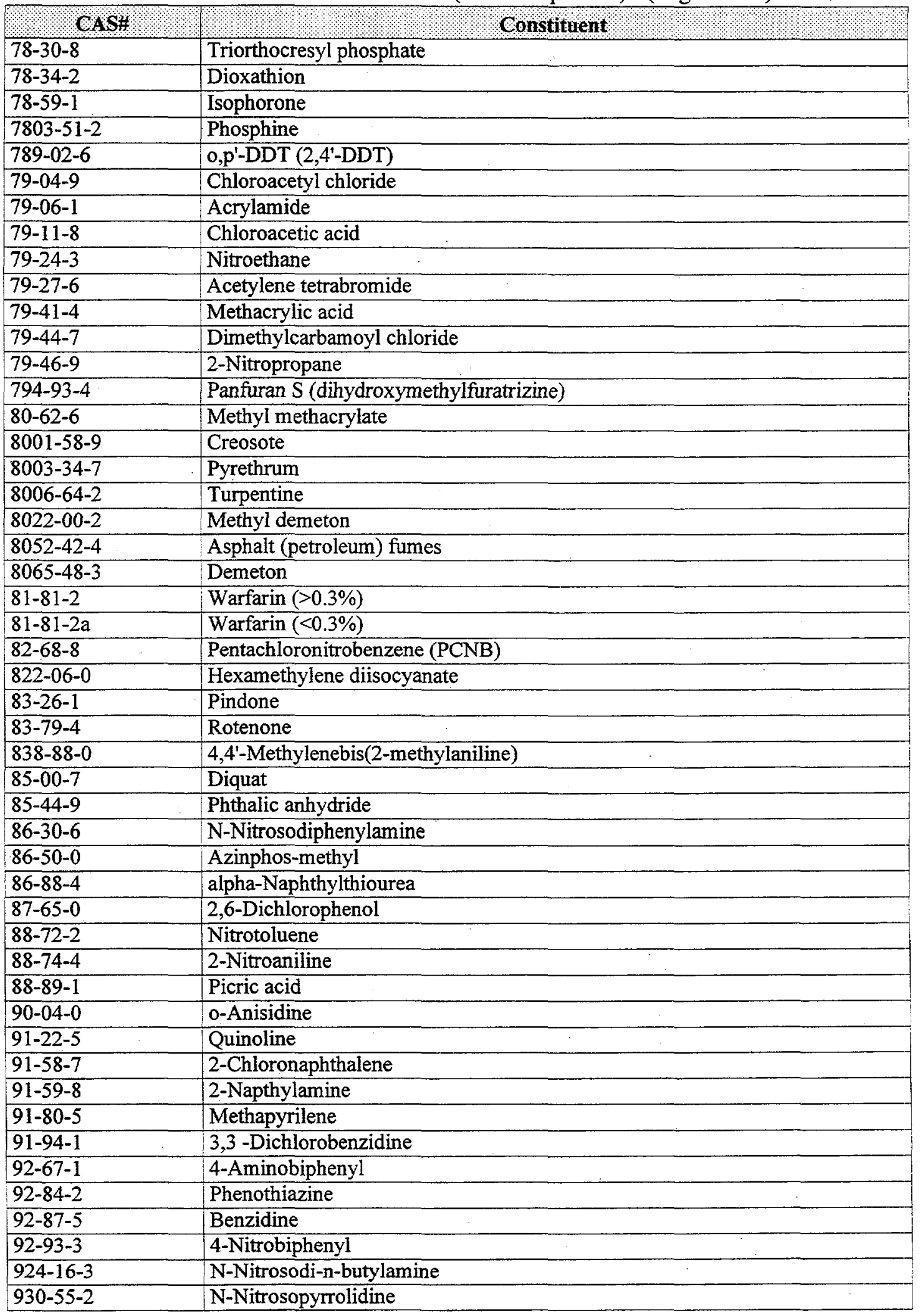


Table B.15. Regulated Non-detected Organic Compounds for Evaluation of Industry Uses Unrelated to Hanford Activities (416 Compounds). (Page 9 of 9)

\begin{tabular}{|l|l|}
\hline \multicolumn{1}{|c|}{ CASH } & \\
\hline $94-36-0$ & Benzoyl Peroxide \\
\hline $94-59-7$ & Safrole \\
\hline $944-22-9$ & Fonofos \\
\hline $95-13-6$ & Indene \\
\hline $95-49-8$ & o-Chlorotoluene \\
\hline $95-53-4$ & o-Toluidine (2-methylaniline) \\
\hline $95-54-5$ & 1,2-Phenylenediamine \\
\hline $95-80-7$ & Toluene-2,4-diamine \\
\hline $95-94-3$ & 1,2,4,5-Tetrachlorobenzene \\
\hline $96-09-3$ & Styrene oxide \\
\hline $96-18-4$ & $1,2,3-$ Trichloropropane \\
\hline $96-33-3$ & Methyl acrylate \\
\hline $96-45-7$ & Ethylenethiourea \\
\hline $97-56-3$ & o-Aminoazotoluene \\
\hline $97-63-2$ & Ethyl methacrylate \\
\hline $97-77-8$ & Disulfiram \\
\hline $98-00-1$ & Furfuryl alcohol \\
\hline $98-01-1$ & Furfural \\
\hline $98-07-7$ & Benzotrichloride \\
\hline $98-51-1$ & p-tert-Butyltoluene \\
\hline $98-82-2$ & Cumene \\
\hline $98-87-3$ & Benzal chloride \\
\hline $99-55-8$ & 5-Nitro-o-toluidine \\
\hline $999-61-1$ & 2-Hydroxypropyl acrylate \\
\hline
\end{tabular}

CAS\# = chemical abstract service number. 
Table B.16. Regulated Non-detected Compounds Removed Based on Industry Uses Unrelated to Hanford (207 Compounds). (Page 1 of 7)

\begin{tabular}{|c|c|c|c|c|c|c|c|c|c|c|}
\hline $\mathrm{CASH}$ & Constituent & Independent & Pesticide & Military & Dyestuff & Pharmaceutical & Solvent & Consumer & $\begin{array}{l}\text { Groupl } \\
\text { Mixture }\end{array}$ & Polymer \\
\hline $100-01-6$ & 4-Nitroaniline & $\mathrm{X}$ & & & & & & & & \\
\hline $100-44-7$ & Benzyl chloride & $\mathrm{X}$ & & & & & & & & \\
\hline $100-75-4$ & N-Nitrosopiperidine & $\mathrm{X}$ & & & & & & & & \\
\hline $101-14-4$ & 4,4'-Methylenebis(2-chloroaniline) & $\mathrm{X}$ & & & & & & & & \\
\hline $101-27-9$ & Barban & $\mathrm{X}$ & $\mathrm{X}$ & & & & & & & \\
\hline $101-77-9$ & 4,4-Methylene dianiline & $\mathrm{X}$ & & & & & & & & $\mathrm{X}$ \\
\hline $101-80-4$ & 4,4'-Diaminodiphenyl ether & $\mathrm{X}$ & & & $\mathrm{X}$ & & & & & \\
\hline $105-60-2$ & Caprolactam, vapor & $\mathrm{X}$ & & & & & & $\mathrm{X}$ & & \\
\hline $105-60-2 a$ & Caprolactam, dust & $\mathrm{X}$ & & & & & & $\mathrm{X}$ & & \\
\hline$\overline{10595-95-6}$ & N-Nitrosomethylethylamine & $\mathrm{X}$ & & & & & & & & \\
\hline $10605-21-7$ & Carbendazim & $X$ & $\mathrm{X}$ & & & & & & & \\
\hline $106-47-8$ & 4-Chloroaniline & $\mathrm{X}$ & & . & & & & & & \\
\hline $106-49-0$ & $\mathrm{p}$-Toluidine & $\mathrm{X}$ & & & & & & & & \\
\hline $106-51-4$ & p-Benzoquinone & $\mathrm{X}$ & & & & & & & & \\
\hline 106-89-8 & Epichlorohydrin & $\mathrm{X}$ & & & & & $\mathrm{X}$ & & & \\
\hline $107-19-7$ & Propargyl alcohol & $\mathrm{X}$ & & & & & & & & \\
\hline $107-20-0$ & Chloroacetaldehyde & $\mathrm{X}$ & & & & & & & & \\
\hline $107-30-2$ & Chloromethyl methyl ether & $\mathrm{X}$ & & & & & & & & \\
\hline $107-41-5$ & Hexylene glycol & $\mathrm{X}$ & & & & & & $\mathrm{X}$ & & \\
\hline $107-49-3$ & Tetraethyl pyrophosphate & $\mathrm{X}$ & & & & & & & & \\
\hline $108-31-6$ & Maleic anhydride (2,5-Furandione) & $\mathrm{X}$ & & & & & & & & \\
\hline $108-44-1$ & m-Toluidine & $\mathrm{X}$ & & & & & & & & $\mathrm{X}$ \\
\hline $108-46-3$ & Resorcinol (1,3-Benzenediol) & $\mathrm{X}$ & & & & & & $\dot{.}$ & & \\
\hline $108-98-5$ & Thiophenol & $\mathrm{X}$ & & & & & & & & \\
\hline $109-87-5$ & Methylal & $\mathrm{X}$ & & & & & & $X$ & & \\
\hline $110-80-5$ & 2-Ethoxyethanol & $\mathrm{X}$ & & & & & & & & \\
\hline $111-30-8$ & Glutaraldehyde & $\bar{X}$ & & & & $\mathrm{X}$ & & & & \\
\hline $1114-71-2$ & Pebulate & $\mathrm{X}$ & $\mathrm{X}$ & & & & & & & \\
\hline $1120-71-4$ & 1,3-Propane sultone & $\mathrm{X}$ & & & & & & & & \\
\hline $114-26-1$ & Propoxur & $\mathrm{X}$ & $\mathrm{X}$ & & & & & & & \\
\hline $115-29-7$ & Endosulfan & $\mathrm{X}$ & $\bar{X}$ & & & & & & & \\
\hline
\end{tabular}




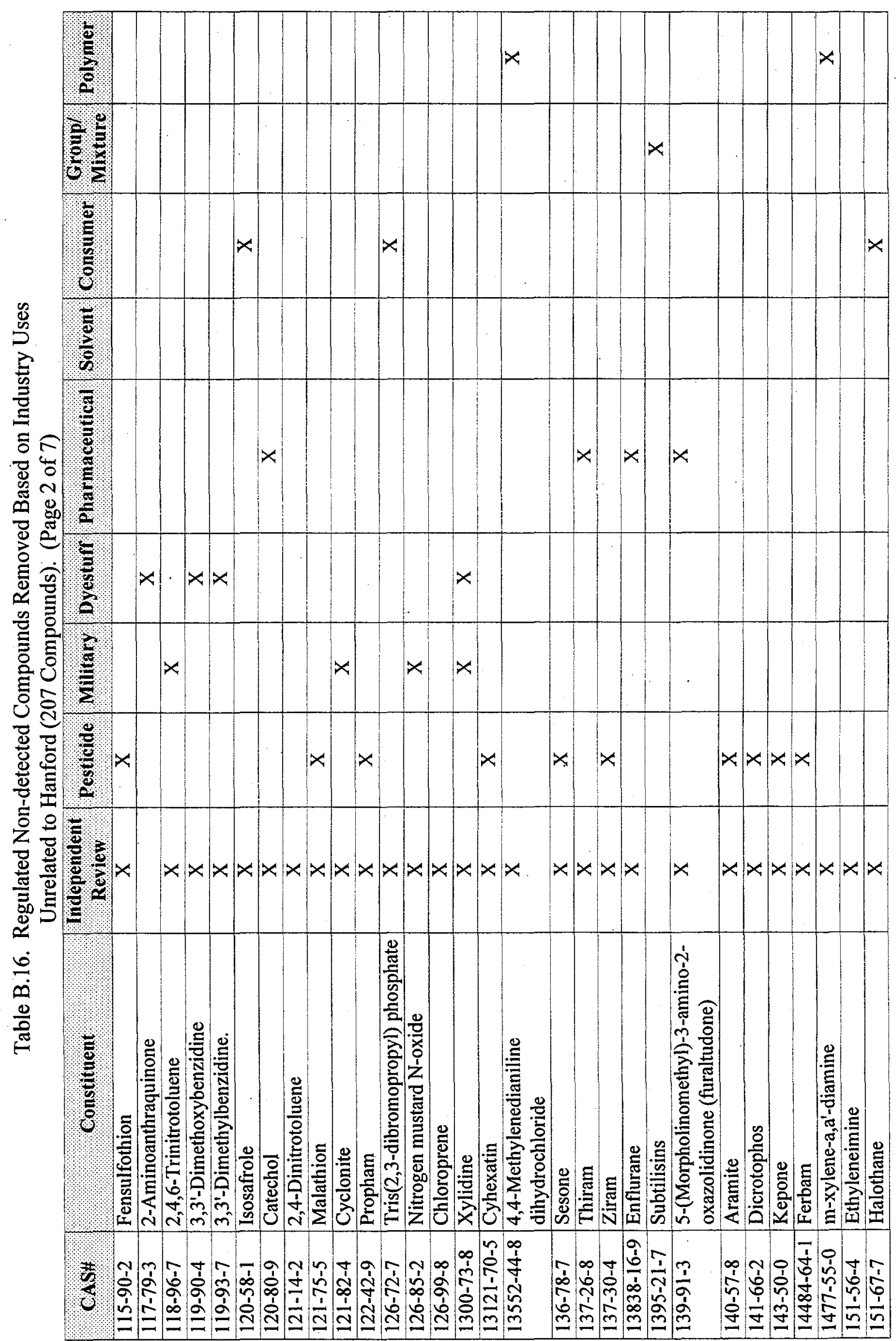

B. 109 
Table B.16. Regulated Non-detected Compounds Removed Based on Industry Uses Unrelated to Hanford (207 Compounds). (Page 3 of 7)

\begin{tabular}{|c|c|c|c|c|c|c|c|c|c|c|}
\hline CAS\# & Constituent & $\begin{array}{c}\text { Independent } \\
\text { Review }\end{array}$ & Pesticide & Military & Dyestuff & Pharmaceutical & Solvent & ensuner & Mroupl' & Polymer \\
\hline $1563-38-8$ & Carbofuran phenol & $\mathrm{X}$ & $\mathrm{X}$ & & & & & & & \\
\hline $1 \overline{563-66-2}$ & Carbofuran & $\mathrm{X}$ & $\bar{X}$ & & & & & 1. & & \\
\hline $16 \overline{15-80-1}$ & $\mathrm{~N}, \mathrm{~N}^{\prime}$-Diethylhydrazine & $\mathrm{X}$ & & & & & & & & $\therefore$ \\
\hline $1646-88-4$ & Aldicarb sulfone & $X$ & & & & & & & & \\
\hline $16752-77-5$ & Methomyl & $\mathrm{X}$ & $\mathrm{X}$ & & & & & & & \\
\hline $1694-09-3$ & Benzyl violet $4 \mathrm{~b}$ & $\mathrm{X}$ & & & $\mathrm{X}$ & & & & & \\
\hline $17804-35-2$ & Benomyl & $\mathrm{X}$ & $\mathrm{X}$ & & & & & & & \\
\hline $1888-71-7$ & Hexachloropropylene & $X$ & & & & & & & & \\
\hline $1912-24-9$ & Atrazine & $\mathrm{X}$ & $\mathrm{X}$ & & & & & & & \\
\hline $1929-77-7$ & Vernolate & $\mathrm{X}$ & $\bar{X}$ & & & & & & & \\
\hline $1929-82-4$ & Nitrapyrin & $\mathrm{X}$ & $\mathrm{X}$ & & & & & & & \\
\hline $2008-41-5$ & Butylate & $\bar{X}$ & $\mathrm{X}$ & & & & & & & \\
\hline $2032-65-7$ & Methiocarb & $\mathrm{X}$ & $\mathrm{X}$ & & & & & & & \\
\hline $2104-64-5$ & EPN & $\mathrm{X}$ & $\mathrm{X}$ & & & & & & & \\
\hline $21087-64-9$ & Metribuzin & $\mathrm{X}$ & $\mathrm{X}$ & & & & & & & \\
\hline $2179-59-1$ & Allyl propyl disulfide & $\mathrm{X}$ & & & & & & $\mathrm{X}$ & $\therefore$ & \\
\hline $2212-67-1$ & Molinate & $\mathrm{X}$ & $\mathrm{X}$ & & & & & & & \\
\hline $22224-92-6$ & Fenamiphos & $\mathrm{X}$ & $\mathrm{X}$ & & & & & & & \\
\hline $2303-17-5$ & Triallate & $\mathrm{X}$ & $\mathrm{X}$ & & & & & & & \\
\hline $23135-22-0$ & Oxamy & $\mathrm{X}$ & $\mathrm{X}$ & & & 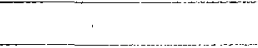 & & & & \\
\hline 23564-05-8 & Thiophanate-methyl & $\mathrm{X}$ & $\mathrm{X}$ & & & & & & & \\
\hline $23950-58-5$ & Pronamide & $X$ & $\mathrm{X}$ & . & & & & & & \\
\hline $2465-27-2$ & Auramine (technical grade) & $\mathrm{X}$ & & & $\mathrm{X}$ & & & & & \\
\hline $2631-37-0$ & Promecarb & $\mathrm{X}$ & $\vec{X}$ & & & & & & & \\
\hline $2646-17-5$ & Oil orange SS & $\mathrm{X}$ & & & $\mathrm{X}$ & & & & & \\
\hline $28434-86-8$ & $\begin{array}{l}\text { 3,3'-Dichloro-4,4'-diaminodiphenyl } \\
\text { ether }\end{array}$ & $\mathrm{X}$ & & & $\mathrm{X}$ & & . & & & \\
\hline $29191-52-4$ & Anisidine (o-,p- isomers) & $\mathrm{X}$ & & & $\mathrm{X}$ & & & & & \\
\hline $2971-90-6$ & Clopidol & $\mathrm{X}$ & $\mathrm{X}$ & & & & & & & \\
\hline $298-00-0$ & Methyl parathion & $\mathrm{X}$ & $\mathrm{X}$ & & & & & & & \\
\hline $298-02-2$ & Phorate & $x$ & $\mathrm{X}$ & & & & & & & \\
\hline 298-04-4 & Disulfoton & $X$ & $\mathrm{X}$ & & & & & & & \\
\hline
\end{tabular}




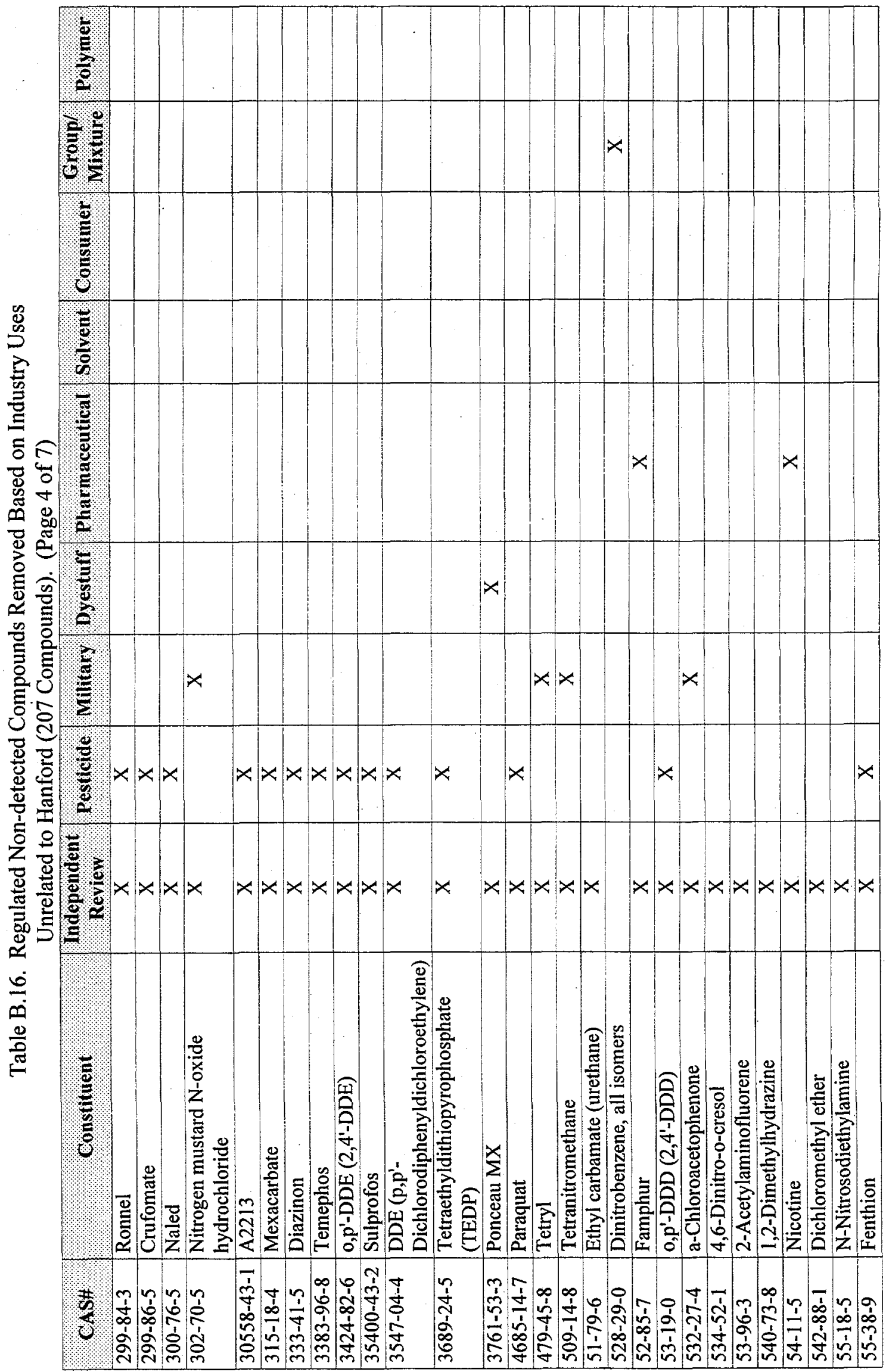




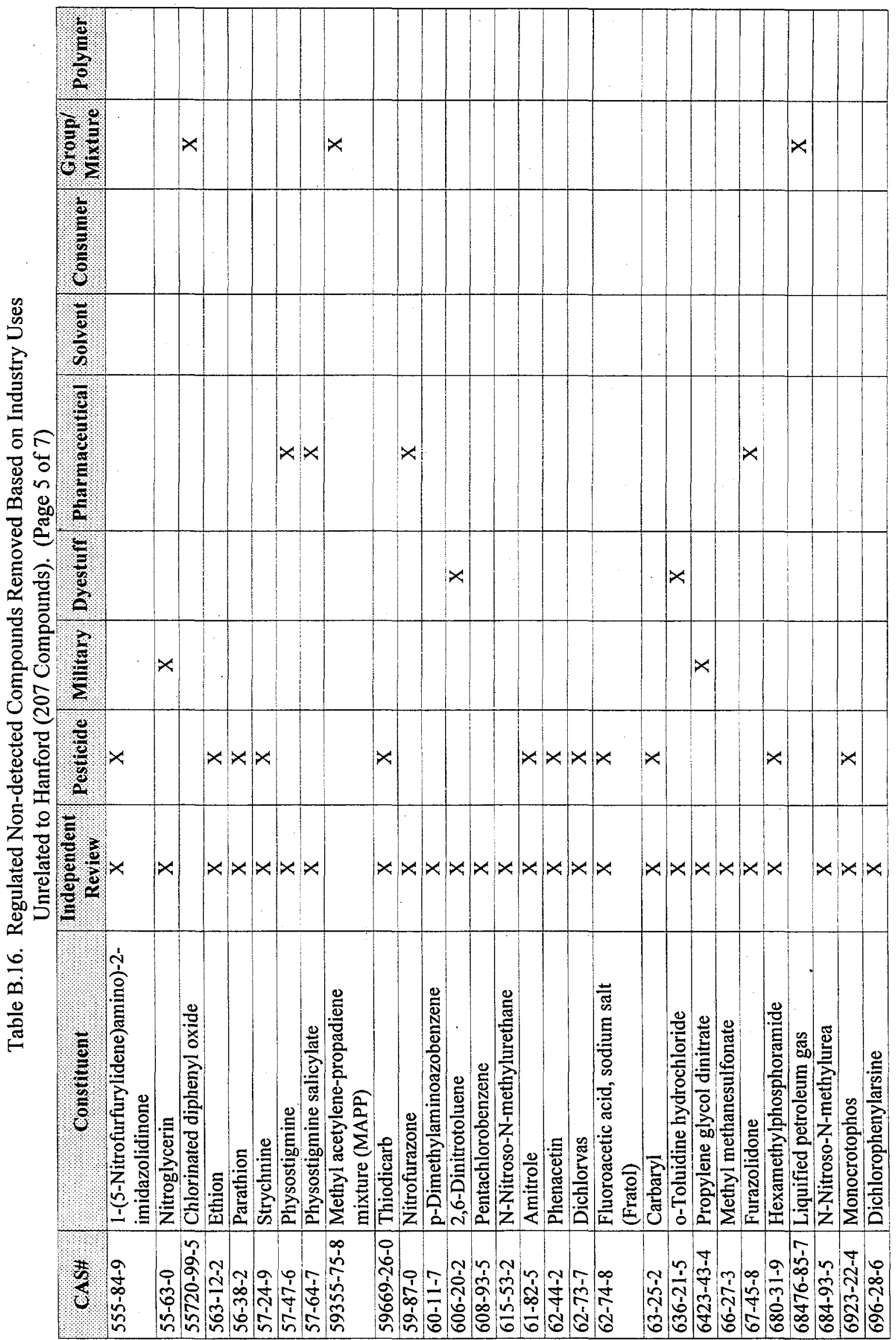

B. 112 
$\frac{19}{8}$

를

군

产

三

ธิธี

马 6 它.

$\infty$

ह

(

(

空

芌

Eㄴㄹㅇ

نㅇำ

总 $\frac{0}{2}$

垔?

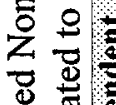

马

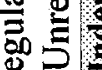

苟

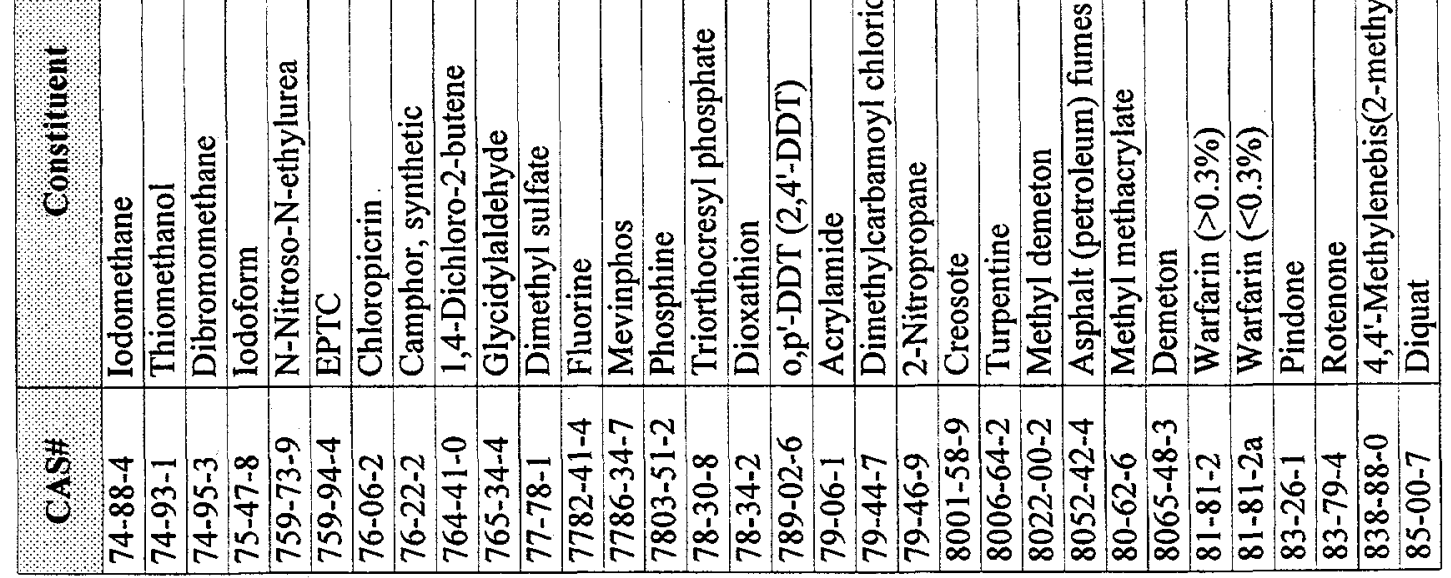


Table B.16. Regulated Non-detected Compounds Removed Based on Industry Uses Unrelated to Hanford (207 Compounds). (Page 7 of 7)

\begin{tabular}{|c|c|c|c|c|c|c|c|c|c|c|}
\hline $\mathrm{CASH}$ & Constifuent & $\begin{array}{l}\text { Independent } \\
\text { Review }\end{array}$ & Pesticide & Military & Byestuff & Pharmaceutical & Solvent & Consumer & Groupl & Polymer \\
\hline $85-44-9$ & Phthalic anhydride & $\mathrm{X}$ & & & & & & & & \\
\hline $86-50-0$ & Azinphos-methyl & $\mathrm{X}$ & $\mathrm{X}$ & & & & & & & \\
\hline $86-88-4$ & alpha-Naphthylthiourea & $\mathrm{X}$ & & & & & & & & \\
\hline $87-65-0$ & 2,6-Dichlorophenol & $\mathrm{X}$ & & & & & & & & \\
\hline $90-04-0$ & o-Anisidine & $\mathrm{X}$ & & & $\mathrm{X}$ & & & & & \\
\hline $91-80-5$ & Methapyrilene & $\mathrm{X}$ & & & & $\mathrm{X}$ & & & & \\
\hline $91-94-1$ & 3,3 -Dichlorobenzidine & $\mathrm{X}$ & & & $\mathrm{X}$ & & & & & \\
\hline 924-16-3 & N-Nitrosodi-n-butylamine & $\mathrm{X}$ & & & & & & & & \\
\hline $92-67-1$ & 4-Aminobiphenyl & $\mathrm{X}$ & & & & & & & & \\
\hline $92-84-2$ & Phenothiazine & $\mathrm{X}$ & $\mathrm{X}$ & & & & & & & \\
\hline $92-87-5$ & Benzidine & $\mathrm{X}$ & & & $\mathrm{X}$ & & & & & \\
\hline $930-55-2$ & N-Nitrosopyrrolidine & $\mathrm{X}$ & & & & & & & & \\
\hline $944-22-9$ & Fonofos & $\mathrm{X}$ & $\mathrm{X}$ & & & & & & & \\
\hline $94-59-7$ & Safrole & $\mathrm{X}$ & & & & $\mathrm{X}$ & & & & \\
\hline $95-53-4$ & o-Toluidine (2-methylaniline) & $\mathrm{X}$ & & & & & & & & \\
\hline $95-54-5$ & 1,2-Phenylenediamine & $\mathrm{X}$ & & & & & & $\mathrm{X}$ & & \\
\hline $95-80-7$ & Toluene-2,4-diamine & $\mathrm{X}$ & & & & 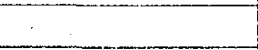 & & & & \\
\hline $95-94-3$ & 1,2,4,5-Tetrachlorobenzene & $\mathrm{X}$ & & & & & & & & \\
\hline $96-18-4$ & 1,2,3-Trichloropropane & $\mathrm{X}$ & & & & & & & & \\
\hline $96-45-7$ & Ethylenethiourea & $\mathrm{X}$ & & & & & & & & \\
\hline $97-63-2$ & Ethyl methacrylate & $\mathrm{X}$ & & & & & & & & \\
\hline $97-77-8$ & Disulfiram & & & & & $\mathrm{X}$ & & & & \\
\hline $98-00-1$ & Furfuryl alcohol & $\mathrm{X}$ & & & & & & $\mathrm{X}$ & & \\
\hline $98-07-7$ & Benzotrichloride & $\mathrm{X}$ & & & & & & & & \\
\hline $98-87-3$ & Benzal chloride & $\mathrm{X}$ & & & & & & & & \\
\hline $99-55-8$ & 5-Nitro-o-toluidine & $\mathrm{X}$ & & & & & & & & \\
\hline
\end{tabular}

CAS\# = chemical abstract service number. 
Table B.17. Regulated Non-detected Organic Compound Selected as Indicator Compound for Analytes, Classified as a Dioxin or Furan (1 Compound).

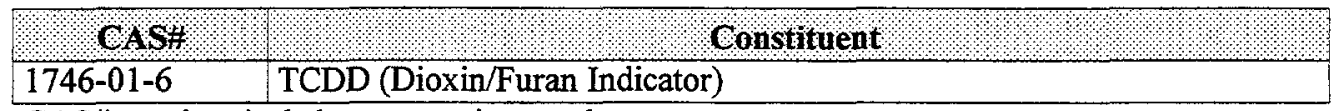

CAS\# = chemical abstract service number. 
Table B.18. Regulated Non-detected Organic Compounds, Used by Industries that are Potentially Unrelated to Hanford, and Dioxin/Furan Indicator Compound (208 Compounds). (Page 1 of 7)

\begin{tabular}{|c|c|c|c|c|c|c|c|c|c|c|}
\hline $\mathrm{cas} H$ & Constituent & Independent & Pesticude & Military & stuff & $\begin{array}{l}\text { Qharma- } \\
\text { ceutical }\end{array}$ & Solvent & Consumer & $\begin{array}{l}\text { moupl } \\
\text { Mixture }\end{array}$ & polymer \\
\hline $100-01-6$ & 4-Nitroaniline & $\mathrm{X}$ & & & & & & & & \\
\hline $100-44-7$ & Benzyl chloride & $\bar{X}$ & & & & & & & & \\
\hline $100-75-4$ & N-Nitrosopiperidine & $\mathrm{X}$ & & & & & & & & \\
\hline $101-14-4$ & 4,4'-Methylenebis(2-chloroaniline) & $\mathrm{X}$ & & & & & & & & \\
\hline $101-27-9$ & Barban & $\mathrm{X}$ & $\mathrm{X}$ & & & & & & & \\
\hline $101-77-9$ & 4,4-Methylene dianiline & $\mathrm{X}$ & & & & & & & & $\mathrm{X}$ \\
\hline $101-80-4$ & 4,4'-Diaminodiphenyl ether & $\mathrm{X}$ & & & $\mathrm{X}$ & & & & & \\
\hline $105-60-2$ & Caprolactam, vapor & $\mathrm{X}$ & & & & & & $\mathrm{X}$ & & \\
\hline $105-60-2 a$ & Caprolactam, dust & $\mathrm{X}$ & & & & & & $\bar{X}$ & . & \\
\hline $10595-95-6$ & $\mathrm{~N}$-Nitrosomethylethylamine & $\mathrm{X}$ & & & & & & 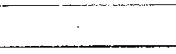 & . & \\
\hline $106-47-8$ & 4-Chloroaniline & $\mathrm{X}$ & & & & & & & & \\
\hline $106-49-0$ & p-Toluidine & $X$ & & & & & & & & \\
\hline $106-51-4$ & p-Benzoquinone & $\mathrm{X}$ & & & & & & & & \\
\hline $106-89-8$ & Epichlorohydrin & $\bar{X}$ & & & & & $\mathrm{X}$ & & & \\
\hline $10605-21-7$ & Carbendazim & $\mathrm{X}$ & $\mathrm{X}$ & & & & & & & \\
\hline $107-19-7$ & Propargyl alcohol & $\mathrm{X}$ & & & & & & & . & \\
\hline $107-20-0$ & Chloroacetaldehyde & $\mathrm{X}$ & & & & & & & & \\
\hline $107-30-2$ & Chloromethyl methyl ether & $\mathrm{X}$ & & & & & & & & \\
\hline $107-41-5$ & Hexylene glycol & $\mathrm{X}$ & & & & & & $\mathrm{X}$ & & \\
\hline $107-49-3$ & Tetraethyl pyrophosphate & $\mathrm{X}$ & & & & & . & & & \\
\hline $108-31-6$ & Maleic anhydride (2,5-Furandione) & $\mathrm{X}$ & & & & & & & & \\
\hline $108-44-1$ & m-Toluidine & $\mathrm{X}$ & & & & & & & . & $\mathrm{X}$ \\
\hline $108-46-3$ & Resorcinol (1,3-Benzenediol) & $\mathrm{X}$ & & & & & & & & \\
\hline $108-98-5$ & Thiophenol & $\mathrm{X}$ & & & & & & & & \\
\hline 109-87-5 & Methylal & $\mathrm{X}$ & & & & & & $\mathrm{X}$ & & \\
\hline $110-80-5$ & 2-Ethoxyethanol & $\mathrm{X}$ & & & & & & & & \\
\hline $111-30-8$ & Glutaraldehyde & $X$ & & & & $\mathrm{X}$ & & & & \\
\hline $1114-71-2$ & Pebulate & $\mathrm{X}$ & $X$ & & & & & & & \\
\hline $1120-71-4$ & 1,3-Propane sultone & $\mathrm{X}$ & & & & & & & & \\
\hline $114-26-1$ & Propoxur & $\mathrm{X}$ & $\mathrm{X}$ & & & & & & & \\
\hline $115-29-7$ & Endosulfan & $\bar{X}$ & $X$ & & & & & & & \\
\hline $115-90-2$ & Fensulfothion & $\mathrm{X}$ & $X$ & & & & & & & \\
\hline
\end{tabular}




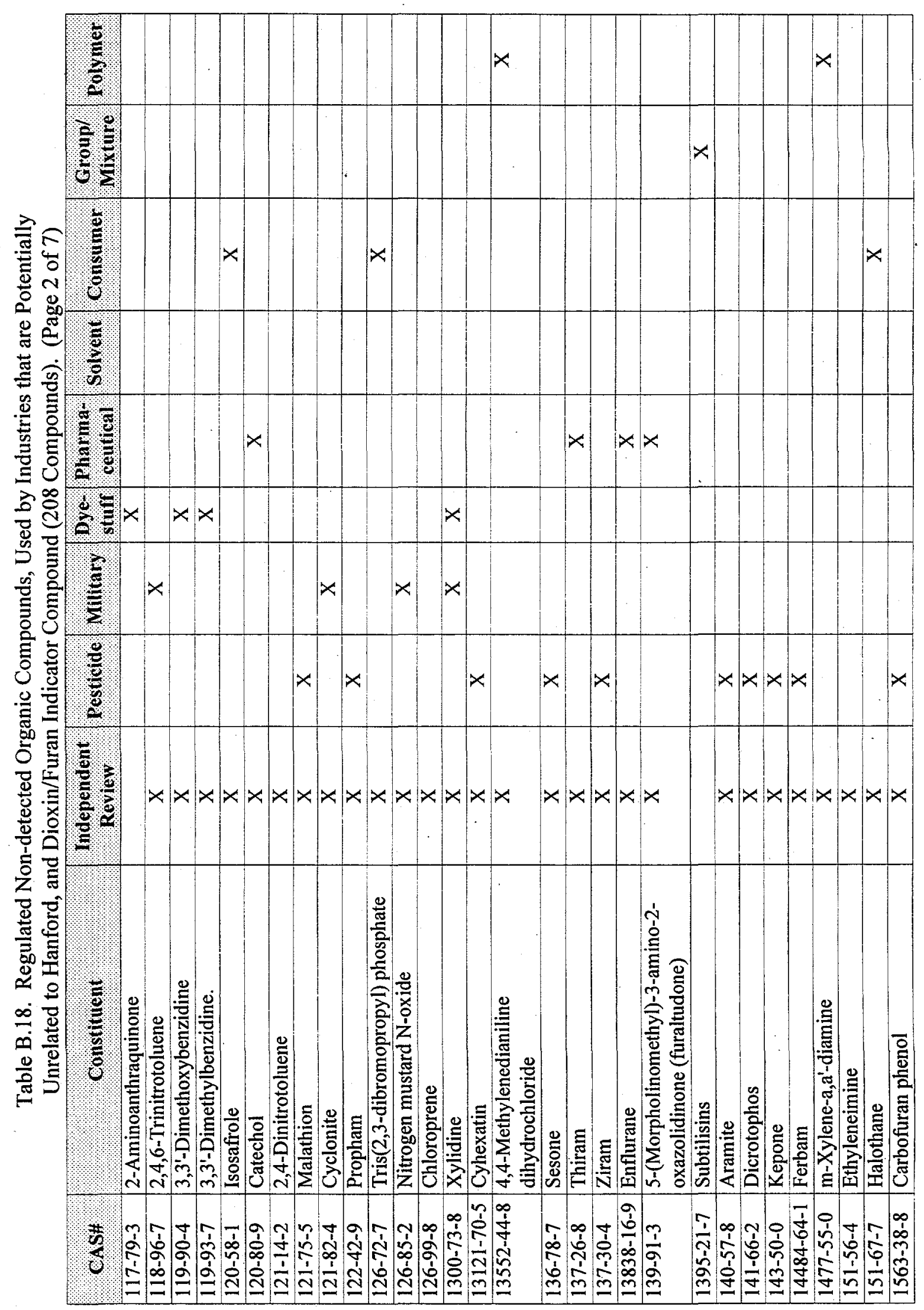


Table B.18. Regulated Non-detected Organic Compounds, Used by Industries that are Potentially Unrelated to Hanford, and Dioxin/Furan Indicator Compound (208 Compounds). (Page 3 of 7)

\begin{tabular}{|c|c|c|c|c|c|c|c|c|c|c|}
\hline QASH & Constituent & Independent & Pesticide & Military & stuff & Pharnat & Solvent & Consumer & Qroupt & Polymer \\
\hline $1563-66-2$ & Carbofuran & $\mathrm{X}$ & $\mathrm{X}$ & & & & & & & \\
\hline $1615-80-1$ & $\mathrm{~N}, N^{\prime}$-Diethylhydrazine & $\mathrm{X}$ & & & & & & & & \\
\hline $1646-88-4$ & Aldicarb sulfone & $\mathrm{X}$ & & & & & & & & \\
\hline $16752-77-5$ & Methomyl & $\mathrm{X}$ & $\mathrm{X}$ & & & & & & & \\
\hline $1694-09-3$ & Benzyl violet $4 \mathrm{~b}$ & $\mathrm{X}$ & & & . X & & & & & \\
\hline $1746-01-6$ & TCDD (Dioxin/Furan Indicator) & & & & & & & & & \\
\hline $17804-35-2$ & Benomyl & $\mathrm{X}$ & $\mathrm{X}$ & & & & & $\cdots$ & & \\
\hline $1888-71-7$ & Hexachloropropylene & $\mathrm{X}$ & & & & & & & & \\
\hline $1912-24-9$ & Atrazine & $\mathrm{X}$ & $\mathrm{X}$ & & & & & & & \\
\hline $1929-77-7$ & Vernolate & $\bar{X}$ & $\mathrm{X}$ & & & & & & & \\
\hline $1929-82-4$ & Nitrapyrin & $\mathrm{X}$ & $\mathrm{X}$ & & & & & & & \\
\hline $2008-41-5$ & Butylate & $X$ & $X$ & & & & & & & \\
\hline $2032-65-7$ & Methiocarb & $\mathrm{X}$ & $\mathrm{X}$ & & & & & & & \\
\hline $2104-64-5$ & EPN & $\mathrm{X}$ & $\mathrm{X}$ & & & & & & & \\
\hline $21087-64-9$ & Metribuzin & $\mathrm{X}$ & $\mathrm{X}$ & & & & & & & \\
\hline $2179-59-1$ & Allyl propyl disulfide & $\mathrm{X}$ & & & & & & $\mathrm{X}$ & & \\
\hline $2212-67-1$ & Molinate & $\mathrm{X}$ & $\mathrm{X}$ & & & & & & & \\
\hline $22224-92-6$ & Fenamiphos & $\mathrm{X}$ & $\mathrm{X}$ & & & & & & & \\
\hline $2303-17-5$ & Triallate & $\mathrm{X}$ & $\mathrm{X}$ & & & & & & & \\
\hline $23135-22-0$ & Oxamy & $\mathrm{X}$ & $\mathrm{X}$ & & & & & & & \\
\hline 23564-05-8 & Thiophanate-methyl & $\mathrm{X}$ & $\mathrm{X}$ & & & & & & & \\
\hline $23950-58-5$ & Pronamide & $\mathrm{X}$ & $\mathrm{X}$ & & & & & & & \\
\hline $2465-27-2$ & Auramine (technical grade) & $\mathrm{X}$ & & & $\mathrm{X}$ & & & & & \\
\hline $2631-37-0$ & Promecarb & $\bar{X}$ & $\mathrm{X}$ & & & & & & & \\
\hline $2646-17-5$ & Oil orange SS & $\mathrm{X}$ & & & $\mathrm{X}$ & & & & & \\
\hline $28434-86-8$ & $\begin{array}{l}3,3^{\prime} \text {-Dichloro-4,4'-diaminodiphenyl } \\
\text { ether }\end{array}$ & $\mathrm{X}$ & & & $\bar{X}$ & & & & & \\
\hline $29191-52-4$ & Anisidine (o-,p-isomers) & $\mathrm{X}$ & & & $\mathrm{X}$ & & & & & \\
\hline $2971-90-6$ & Clopidol & $\mathrm{X}$ & $\mathrm{X}$ & & & & & & & \\
\hline $298-00-0$ & Methyl parathion & $\mathrm{X}$ & $\mathrm{X}$ & & & & & & & \\
\hline $298-02-2$ & Phorate & $\mathrm{X}$ & $\mathrm{X}$ & & & & & & & \\
\hline 298-04-4 & Disulfoton & $X$ & $\mathrm{X}$ & & & & & & & \\
\hline
\end{tabular}




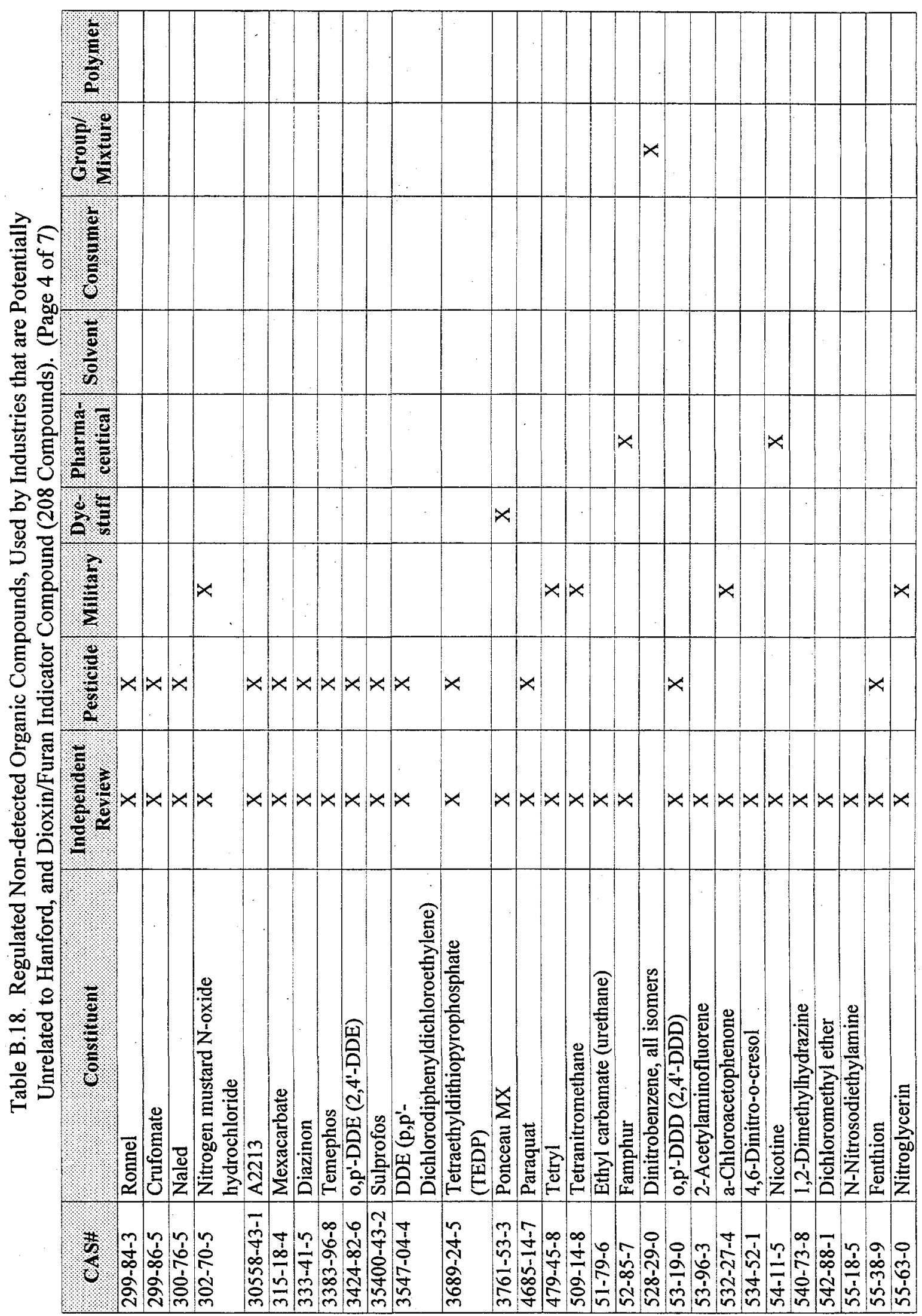




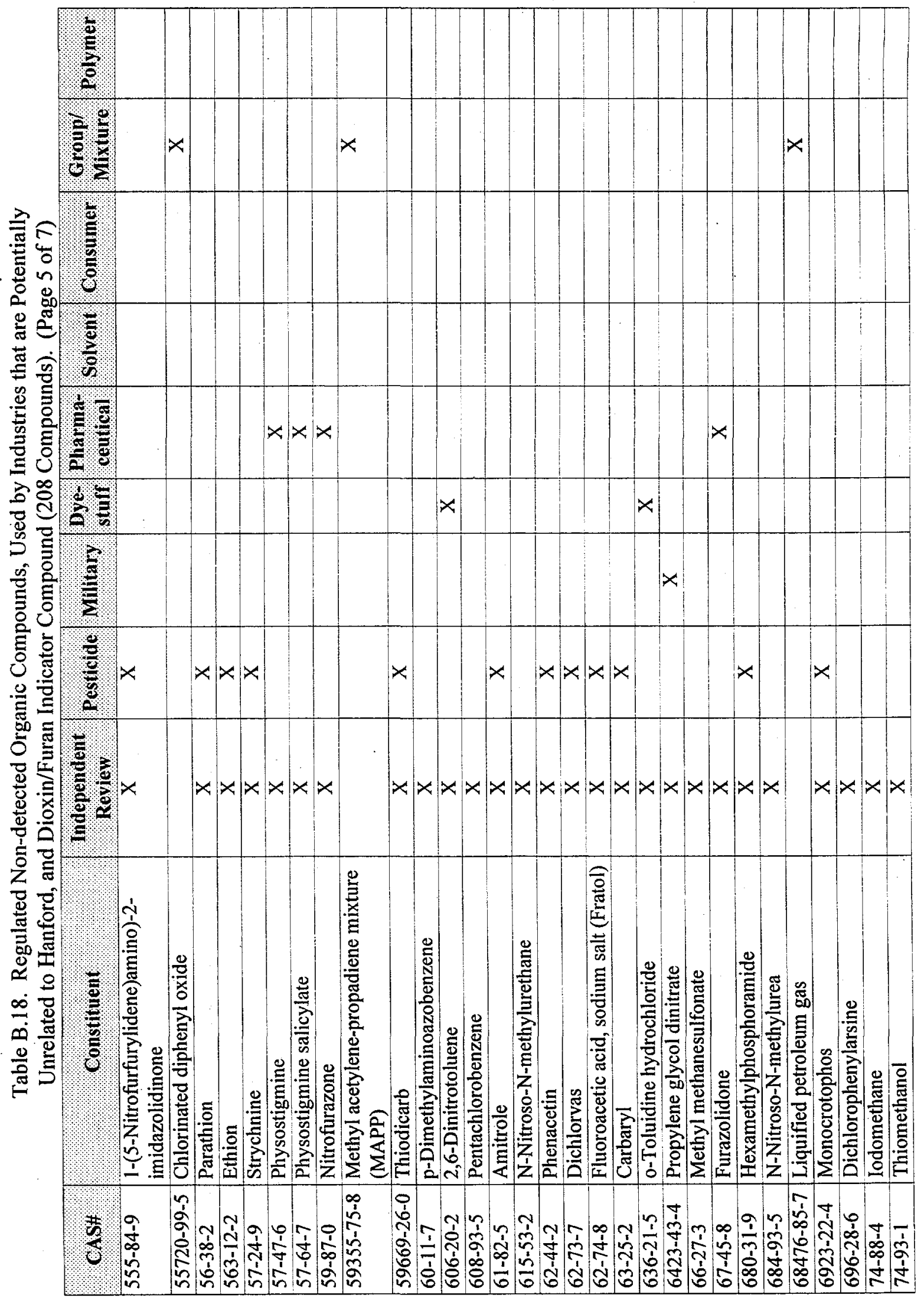



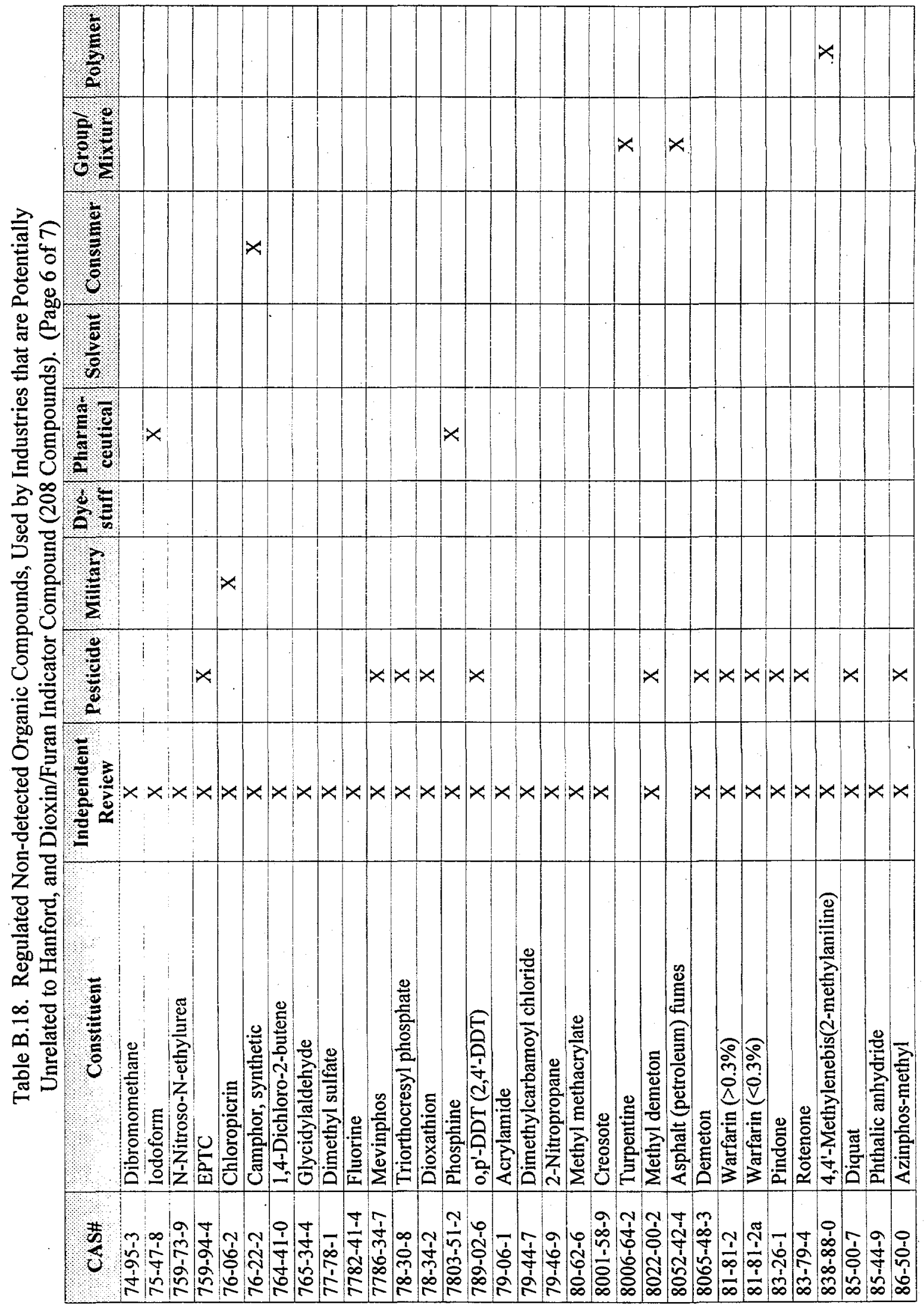
Table B.18. Regulated Non-detected Organic Compounds, Used by Industries that are Potentially Unrelated to Hanford, and Dioxin/Furan Indicator Compound (208 Compounds). (Page 7 of 7)

\begin{tabular}{|c|c|c|c|c|c|c|c|c|c|c|}
\hline OASH & Constituent & $\begin{array}{l}\text { lindependent } \\
\text { Review }\end{array}$ & Pesticide & Military & Dyc: & Plarnaa- & Solvent & Consuiner & $\begin{array}{l}\text { Groupl } \\
\text { Mixture }\end{array}$ & Polymer \\
\hline $86-88-4$ & alpha-Naphthylthiourea & $\mathrm{X}$ & & & & & & & & \\
\hline $87-65-0$ & 2,6-Dichlorophenol & $\mathrm{X}$ & & & & & & & & \\
\hline $90-04-0$ & o-Anisidine & $\mathrm{X}$ & & & $\mathrm{X}$ & & & & & \\
\hline $91-80-5$ & Methapyrilene & $\mathrm{X}$ & & & & $\mathrm{X}$ & & & & \\
\hline 91-94-1 & 3,3-Dichlorobenzidine & $\mathrm{x}$ & & & $\mathrm{X}$ & & & & & \\
\hline $92-67-1$ & 4-Aminobiphenyl & $\mathrm{X}$ & & & & & & & & \\
\hline $92-84-2$ & Phenothiazine & $\mathrm{X}$ & $\mathrm{X}$ & & & & & & & \\
\hline $92-87-5$ & Benzidine & $\mathrm{X}$ & & & $\mathrm{X}$ & & & & & \\
\hline $924-16-3$ & N-Nitrosodi-n-butylamine & $\mathrm{X}$ & & & & & & & & \\
\hline $930-55-2$ & N-Nitrosopyrrolidine & $\mathrm{X}$ & & & & & & & & \\
\hline $94-59-7$ & Safrole & $\mathrm{X}$ & & & & $\mathrm{X}$ & & & & \\
\hline $944-22-9$ & Fonofos & $\mathrm{X}$ & $\mathrm{X}$ & & & & & & & \\
\hline $95-53-4$ & o-Toluidine (2-methylaniline) & $\mathrm{X}$ & & & & & & & & \\
\hline 95-54-5 & 1,2-Phenylenediamine & $\mathrm{X}$ & & & & & & $\mathrm{X}$ & & \\
\hline $95-80-7$ & Toluene-2,4-diamine & $\mathrm{X}$ & & & & & & & & \\
\hline $95-94-3$ & 1,2,4,5-Tetrachlorobenzene & $\mathrm{X}$ & & & & & & & & \\
\hline 96-18-4 & 1,2,3-Trichloropropane & $\mathrm{X}$ & & & & & & & & \\
\hline $96-45-7$ & Ethylenethiourea & $\mathrm{X}$ & & & & & & & & \\
\hline $97-63-2$ & Ethyl methacrylate & $\mathrm{X}$ & & & & & & & & \\
\hline $97-77-8$ & Disulfiram & & & & & $\mathrm{X}$ & & & & \\
\hline 98-00-1 & Furfuryl alcohol & $\mathrm{X}$ & & & & & & $\mathrm{X}$ & & \\
\hline 98-07-7 & Benzotrichloride & $\mathrm{X}$ & & & & & & & & \\
\hline $98-87-3$ & Benzal chloride & $\mathrm{X}$ & & & & & & & & \\
\hline $99-55-8$ & 5-Nitro-o-toluidine & $\mathrm{X}$ & & & & & & & & \\
\hline
\end{tabular}

CAS\# = chemical abstract service number 
Table B.19. Regulated Non-detected Organic Compounds Likely Used at Hanford (208 Compounds). (Page 1 of 5)

\begin{tabular}{|c|c|}
\hline Q Ast & Constituent \\
\hline $100-02-7$ & 4-Nitrophenol \\
\hline $100-21-0$ & Phthalic acid \\
\hline $100-25-4$ & 1,4-Dinitrobenzene \\
\hline $100-37-8$ & Diethylaminoethanol \\
\hline $100-61-8$ & N-Methylbenzenamine \\
\hline $100-63-0$ & Phenylhydrazine \\
\hline $100-74-3$ & N-Ethylmorpholine \\
\hline $101-55-3$ & 4-Bromophenylphenyl ether \\
\hline 101-68-8 & Methylene bis(phenyl isocyanate) \\
\hline $101-90-6$ & Diglycidyl resorcinol ether \\
\hline 102-81-8 & 2-N-Dibutylaminoethanol \\
\hline $105-46-4$ & sec-Butyl acetate \\
\hline $105-67-9$ & 2,4-Dimethylphenol \\
\hline $106-44-5$ & 4-Methylphenol \\
\hline $106-50-3$ & p-Phenylenediamine \\
\hline $106-87-6$ & Vinyl cyclohexene dioxide \\
\hline $106-92-3$ & Allyl glycidyl ether \\
\hline $107-07-3$ & Ethylene chlorohydrin \\
\hline $107-15-3$ & Ethylene diamine \\
\hline 107-98-2 & Propylene glycol monomethyl ether \\
\hline $108-11-2$ & Methyl isobutyl carbinol \\
\hline $108-18-9$ & Diisopropylamine \\
\hline $108-21-4$ & Isopropyl acetate \\
\hline 108-24-7 & Acetic anhydride \\
\hline $108-43-0$ & Chlorophenols \\
\hline 108-60-1 & Bis(2-Chloroisopropyl) ether \\
\hline 108-83-8 & Diisobutyl ketone \\
\hline 108-84-9 & sec-Hexyl acetate \\
\hline $108-91-8$ & Cyclohexylamine \\
\hline $109-59-1$ & Isopropoxyethanol \\
\hline $109-60-4$ & n-Propyl acetate \\
\hline 109-73-9 & n-Butylamine \\
\hline $109-79-5$ & n-Butyl mercaptan \\
\hline $109-86-4$ & 2-Methoxyethanol \\
\hline 109-89-7 & Diethylamine \\
\hline $109-94-4$ & Ethyl formate \\
\hline $110-19-0$ & Isobutyl acetate \\
\hline $110-49-6$ & 2-Methoxyethyl acetate \\
\hline $110-75-8$ & 2-Chloroethyl vinyl ether \\
\hline $111-15-9$ & 2-Ethoxyethyl acetate \\
\hline $111-40-0$ & Diethylene triamine \\
\hline $111-42-2$ & Diethanolamine \\
\hline $111-44-4$ & Bis(2-chloroethyl) ether \\
\hline $111-91-1$ & Bis(2-Chloroethoxy)methane \\
\hline $1129-41-5$ & Metolcarb (3-methylcholanthrene) \\
\hline $1134-23-2$ & Cycloate \\
\hline $115-86-6$ & Triphenyl phosphate \\
\hline $118-52-5$ & 1,3-Dichloro-5,5-Dimethyl hydantoin \\
\hline $119-38-0$ & Isolan \\
\hline
\end{tabular}


Table B.19. Regulated Non-detected Organic Compounds Likely Used at Hanford (208 Compounds). (Page 2 of 5)

\begin{tabular}{|c|c|}
\hline $1 \mathrm{CAS} \#$ & Constituent \\
\hline $120-83-2$ & 2,4-Dichlorophenol \\
\hline $121-44-8$ & Triethylamine \\
\hline $121-45-9$ & Trimethyl phosphite \\
\hline $121-69-7$ & Dimethylaniline \\
\hline $122-60-1$ & Phenyl glycidyl ether \\
\hline $122-66-7$ & 1,2-Diphenylhydrazine \\
\hline $123-31-9$ & Hydroquinone \\
\hline $123-42-2$ & Diacetone alcohol \\
\hline $124-40-3$ & Dimethylamine \\
\hline $124-48-1$ & Dibromochloromethane \\
\hline $129-15-7$ & 2-Methyl-1-nitroanthraquinone \\
\hline $131-11-3$ & Dimethyl phthalate \\
\hline $132-64-9$ & Dibenzofuran \\
\hline $1321-64-8$ & Pentachloronaphthalene \\
\hline $1321-65-9$ & Trichloronaphthalene \\
\hline $1321-74-0$ & Divinyl benzene \\
\hline $1335-87-1$ & Hexachloronaphthalene \\
\hline $1335-88-2$ & Tetrachloronaphthalene \\
\hline $1338-23-4$ & Methyl ethyl ketone peroxide \\
\hline $135-20-6$ & Cupferron \\
\hline $135-88-6$ & N-Phenyl-2-napthylamine \\
\hline $137-05-3$ & Methyl-2-cyanoacrylate \\
\hline $138-22-7$ & n-Butyl lactate \\
\hline $139-65-1$ & 4,4'-Thiodianiline \\
\hline $140-88-5$ & Ethylacrylate \\
\hline $141-32-2$ & Butylacrylate \\
\hline $141-43-5$ & Ethanolamine \\
\hline $142-64-3$ & Piperazine dihydrochloride \\
\hline $148-01-6$ & Dinitolamide \\
\hline $150-76-5$ & 4-Methoxyphenol \\
\hline $156-60-5$ & 1,2-trans-Dichloroethene \\
\hline $16219-75-3$ & Ethylidene norbornene \\
\hline $1634-04-4$ & Methyl tert-butyl ether \\
\hline $17702-57-7$ & Formparanate \\
\hline $189-55-9$ & Dibenzo[a,i]pyrene \\
\hline $189-64-0$ & Dibenzo[a,h]pyrene \\
\hline $192-65-4$ & Dibenzo[a,e]pyrene \\
\hline $2039-87-4$ & o-Chlorostyrene \\
\hline $205-82-3$ & Benzo[j]fluoranthene \\
\hline $2238-07-5$ & Diglycidyl ether \\
\hline $226-36-8$ & Dibenz $[a, h]$ acridine \\
\hline $22781-23-3$ & Bendiocarb \\
\hline $22961-82-6$ & Bendiocarb phenol \\
\hline $23422-53-9$ & Formetanate hydrochloride \\
\hline $2426-08-6$ & n-Butyl glycidyl ether \\
\hline $25013-15-4$ & Vinyl toluene \\
\hline $2551-13-7$ & Trimethyl benzene \\
\hline $25639-42-3$ & Methylcyclohexanol \\
\hline $26140-60-3$ & Terphenyls \\
\hline
\end{tabular}


Table B.19. Regulated Non-detected Organic Compounds Likely Used at Hanford (208 Compounds). (Page 3 of 5)

\begin{tabular}{|c|c|}
\hline $1, \mathrm{CAsH}^{2}$ & Constituent \\
\hline $26419-73-8$ & Tirpate \\
\hline $26952-21-6$ & Iso-ocytl alcohol \\
\hline $2698-41-1$ & o-Chlorobenylidene malonitrile \\
\hline $27154-33-2$ & Trichlorofluoroethane \\
\hline 2921-88-2 & Chlorpyrifos \\
\hline $3068-88-0$ & B-Butyrolactone \\
\hline $314-40-9$ & Bromacil \\
\hline $330-54-1$ & Diuron \\
\hline $3333-52-6$ & Tetramethyl succinonitrile \\
\hline $334-88-3$ & Diazomethane \\
\hline $34590-94-8$ & Dipropylene glycol methyl ether \\
\hline $3825-26-1$ & Ammonium perfluorooctanoate \\
\hline $4016-14-2$ & Isopropyl glycidyl ether (IGE) \\
\hline $4098-71-9$ & Isophorone diisocyanate \\
\hline 420-04-2 & Cyanamide \\
\hline $463-51-4$ & Ketene \\
\hline 504-29-0 & 2-Aminopyridine \\
\hline $51-28-5$ & 2,4-Dinitrophenol \\
\hline $5124-30-1$ & Methylene-bis-(4-cyclo-hexylisocyanate) \\
\hline $52888-80-9$ & Prosulfocarb \\
\hline $531-82-8$ & N-(4-(5-Nitro-2-furyl)-2-thiazolyl)acetamide \\
\hline $540-59-0$ & 1,2-Dichloroethylene \\
\hline $540-84-1$ & 2,2,4-Trimethylpentane \\
\hline $540-88-5$ & tert-Butyl acetate \\
\hline $541-85-5$ & Ethyl amyl ketone \\
\hline $542-75-6$ & 1,3-Dichloropropene \\
\hline $542-92-7$ & Cyclopentadiene \\
\hline $552-30-7$ & Trimellitic anhydride \\
\hline $55285-14-8$ & Carbosulfan \\
\hline $55406-53-6$ & 3-Iodo-2-propynyl n-butylcarbamate \\
\hline $556-52-5$ & Glycidol \\
\hline 55738-54-0 & trans-2((Dimethylamino)methylimino)-5-(2-(5-nitro-2-furyl) vinyl-1,3,4-oxadiazole \\
\hline $56-49-5$ & 3-Methylcholanthrene \\
\hline $57-57-8$ & B-Propiolactone \\
\hline $583-60-8$ & o-Methylcyclohexanone \\
\hline $584-84-9$ & 2,4-Toluene diisocyanate \\
\hline $592-62-1$ & Methyl azoxymethyl acetate \\
\hline $593-60-2$ & Vinyl bromide \\
\hline $594-42-3$ & Perchloromethyl mercaptan \\
\hline $594-72-9$ & 1,1-Dichloro-1-nitroethane \\
\hline $5952-26-1$ & Diethylene glycol, dicarbamate \\
\hline $600-25-9$ & 1-Chloro-1-nitropropane \\
\hline $602-87-9$ & 5-Nitroacenaphthene \\
\hline $603-34-9$ & Triphenyl amine \\
\hline $613-35-4$ & $\mathrm{~N}, \mathrm{~N}$-Diacetylbenzidine \\
\hline $62-53-3$ & Aniline \\
\hline $626-17-5$ & m-Phthalodinitrile \\
\hline $626-38-0$ & sec-Amyl acetate \\
\hline $628-63-7$ & n-Amyl acetate \\
\hline
\end{tabular}


Table B.19. Regulated Non-detected Organic Compounds Likely Used at Hanford (208 Compounds). (Page 4 of 5)

\begin{tabular}{|c|c|}
\hline QASH & Constituent \\
\hline $628-96-6$ & Ethylene glycol dinitrate \\
\hline $63-92-3$ & Phenoxybenzamine hydrochloride \\
\hline $630-20-6$ & 1,1,1,2-Tetrachloroethane \\
\hline $638-21-1$ & Phenylphosphine \\
\hline $64-00-6$ & m-Cumenyl methylcarbamate \\
\hline $64-67-5$ & Diethyl sulfate \\
\hline $64091-91-4$ & 4-(Methylnitrosamino)-1-(3-pyridyl)-1-butanone \\
\hline $644-64-4$ & Dimetilan \\
\hline $68-11-1$ & Thioglycolic acid \\
\hline $68-12-2$ & Dimethylformamide \\
\hline $681-84-5$ & Methyl silicate \\
\hline $684-16-2$ & Hexafluoroacetone \\
\hline $74-89-5$ & Methylamine \\
\hline $74-96-4$ & Ethyl bromide \\
\hline $74-97-5$ & Bromochloromethane \\
\hline $75-04-7$ & Ethylamine \\
\hline $75-08-1$ & Ethyl mercaptan \\
\hline $75-25-2$ & Tribromomethane \\
\hline $75-27-4$ & Bromodichloromethane \\
\hline $75-31-0$ & Isopropylamine \\
\hline $75-56-9$ & Propylene oxide \\
\hline $75-61-6$ & Difluorodibromomethane \\
\hline $75-63-8$ & Trifluorobromomethane \\
\hline $7572-29-4$ & Dichloroacetylene \\
\hline $76-01-7$ & Pentachloroethane \\
\hline $76-03-9$ & Trichloroacetic acid \\
\hline $76-11-9$ & 1,1,1,2-Tetrachloro-2,2-difluoroethane \\
\hline $76-12-0$ & 1,1,2,2-Tetrachloro-1,2-difluoroethane \\
\hline $76-15-3$ & Chloropentafluoroethane \\
\hline $768-52-5$ & $\mathrm{~N}$-Isopropylaniline \\
\hline $77-73-6$ & Dicyclopentadiene \\
\hline $78-10-4$ & Ethyl silicate \\
\hline $78-59-1$ & Isophorone \\
\hline $79-04-9$ & Chloroacetyl chloride \\
\hline $79-11-8$ & Chloroacetic acid \\
\hline $79-24-3$ & Nitroethane \\
\hline $79-27-6$ & Acetylene tetrabromide \\
\hline $79-41-4$ & Methacrylic acid \\
\hline $794-93-4$ & Panfuran S (dihydroxymethylfuratrizine) \\
\hline $8003-34-7$ & Pyrethrum \\
\hline $82-68-8$ & Pentachloronitrobenzene (PCNB) \\
\hline $822-06-0$ & Hexamethylene diisocyanate \\
\hline $86-30-6$ & N-Nitrosodiphenylamine \\
\hline $88-72-2$ & Nitrotoluene \\
\hline $88-74-4$ & 2-Nitroaniline \\
\hline 88-89-1 & Picric acid \\
\hline $89-72-5$ & o-sec-Butylphenol \\
\hline $91-22-5$ & Quinoline \\
\hline $91-58-7$ & 2-Chloronaphthalene \\
\hline
\end{tabular}


Table B.19. Regulated Non-detected Organic Compounds Likely Used at Hanford (208 Compounds). (Page 5 of 5)

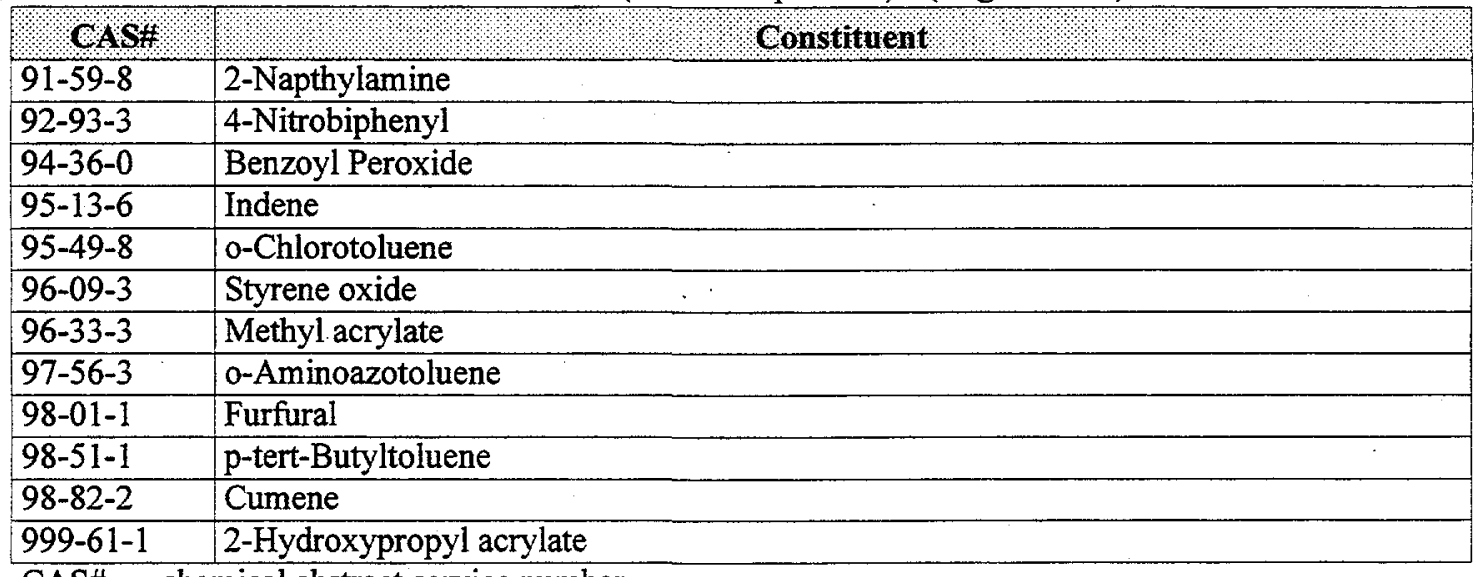

CAS\# $=$ chemical abstract service number. 
Table B.20. Regulated Non-detected Organic Compounds to be Considered for Stability Evaluation (269 Compounds). (Pages 1 of 6 )

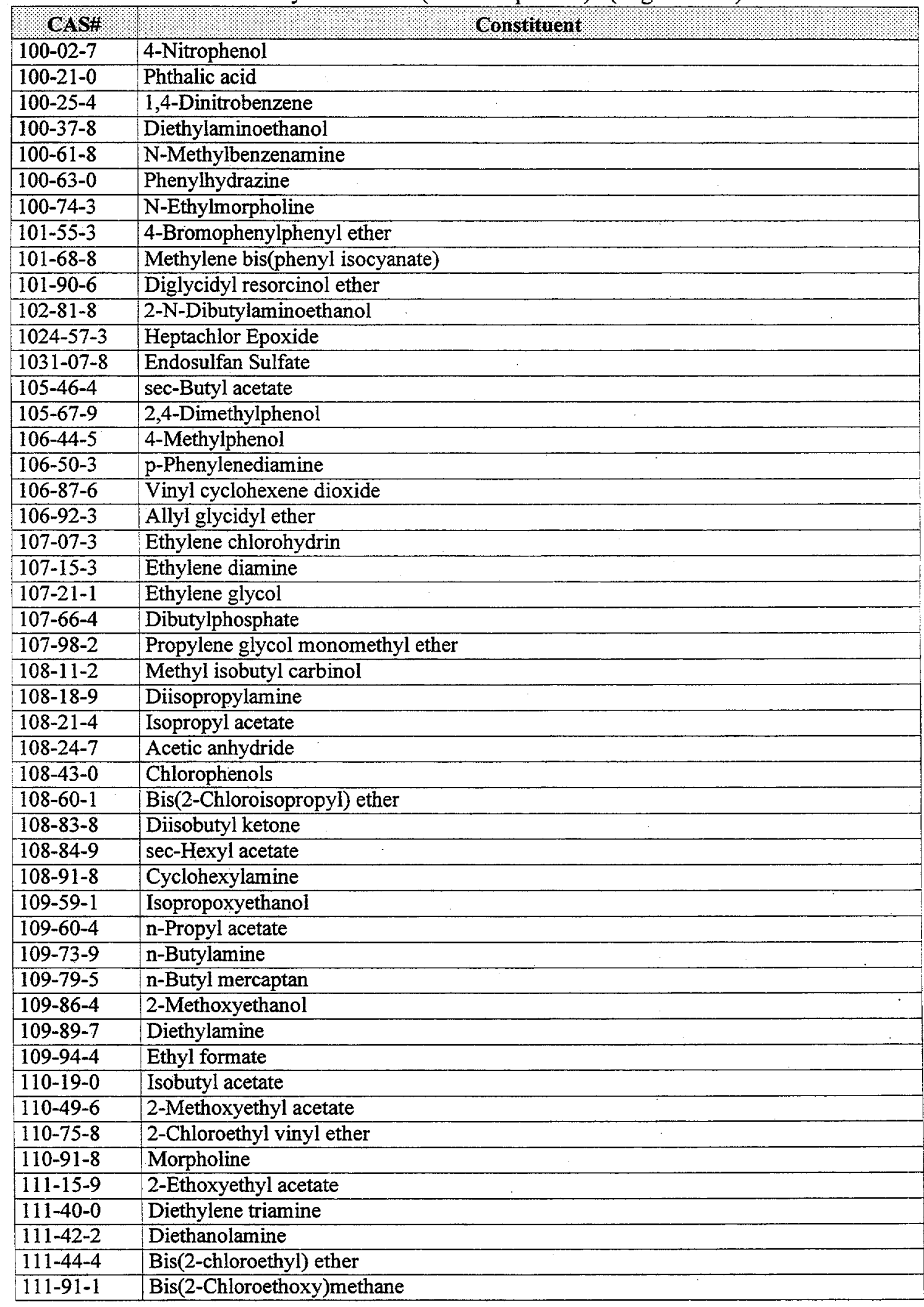


Table B.20. Regulated Non-detected Organic Compounds to be Considered for Stability Evaluation (269 Compounds). (Pages 2 of 6)

\begin{tabular}{|c|c|}
\hline $1 \mathrm{CASH}$ & Constituent \\
\hline $1129-41-5$ & Metolcarb (3-methylcholanthrene) \\
\hline $1134-23-2$ & Cycloate \\
\hline $115-86-6$ & Triphenyl phosphate \\
\hline $118-52-5$ & 1,3-Dichloro-5,5-Dimethyl hydantoin \\
\hline $118-74-1$ & Hexachlorobenzene \\
\hline $119-38-0$ & Isolan \\
\hline $120-12-7$ & Anthracene \\
\hline $120-83-2$ & 2,4-Dichlorophenol \\
\hline $121-44-8$ & Triethylamine \\
\hline $121-45-9$ & Trimethyl phosphite \\
\hline $121-69-7$ & Dimethylaniline \\
\hline $122-60-1$ & Phenyl glycidyl ether \\
\hline $122-66-7$ & 1,2-Diphenylhydrazine \\
\hline $123-31-9$ & Hydroquinone \\
\hline $123-42-2$ & Diacetone alcohol \\
\hline $123-92-2$ & Isoamyl acetate \\
\hline $124-40-3$ & Dimethylamine \\
\hline $124-48-1$ & Dibromochloromethane \\
\hline $129-15-7$ & 2-Methyl-1-nitroanthraquinone \\
\hline $131-11-3$ & Dimethyl phthalate \\
\hline $132-64-9$ & Dibenzofuran \\
\hline $1321-64-8$ & Pentachloronaphthalene \\
\hline $1321-65-9$ & Trichloronaphthalene \\
\hline $1321-74-0$ & Divinyl benzene \\
\hline $133-06-2$ & Captan \\
\hline $133-90-4$ & Chloramben \\
\hline $1335-87-1$ & Hexachloronaphthalene \\
\hline $1335-88-2$ & Tetrachloronaphthalene \\
\hline $1336-36-3$ & Polychlorinated biphenyls (PCBs) \\
\hline $1338-23-4$ & Methyl ethyl ketone peroxide \\
\hline $134-32-7$ & alpha-Naphthylamine \\
\hline $135-20-6$ & Cupferron \\
\hline $135-88-6$ & N-Phenyl-2-napthylamine \\
\hline $137-05-3$ & Methyl-2-cyanoacrylate \\
\hline $138-22-7$ & n-Butyl lactate \\
\hline $139-65-1$ & 4,4'-Thiodianiline \\
\hline $140-88-5$ & Ethylacrylate \\
\hline $141-32-2$ & Butylacrylate \\
\hline $141-43-5$ & Ethanolamine \\
\hline $142-64-3$ & Piperazine dihydrochloride \\
\hline 148-01-6 & Dinitolamide \\
\hline $150-76-5$ & 4-Methoxyphenol \\
\hline $156-60-5$ & 1,2-trans-Dichloroethene \\
\hline $1582-09-8$ & Trifluralin \\
\hline $16219-75-3$ & Ethylidene norbornene \\
\hline $1634-04-4$ & Methyl tert-butyl ether \\
\hline $17702-57-7$ & Formparanate \\
\hline $1836-75-5$ & Nitrofen \\
\hline $189-55-9$ & Dibenzo[a,i]pyrene \\
\hline
\end{tabular}


Table B.20. Regulated Non-detected Organic Compounds to be Considered for Stability Evaluation (269 Compounds). (Pages 3 of 6 )

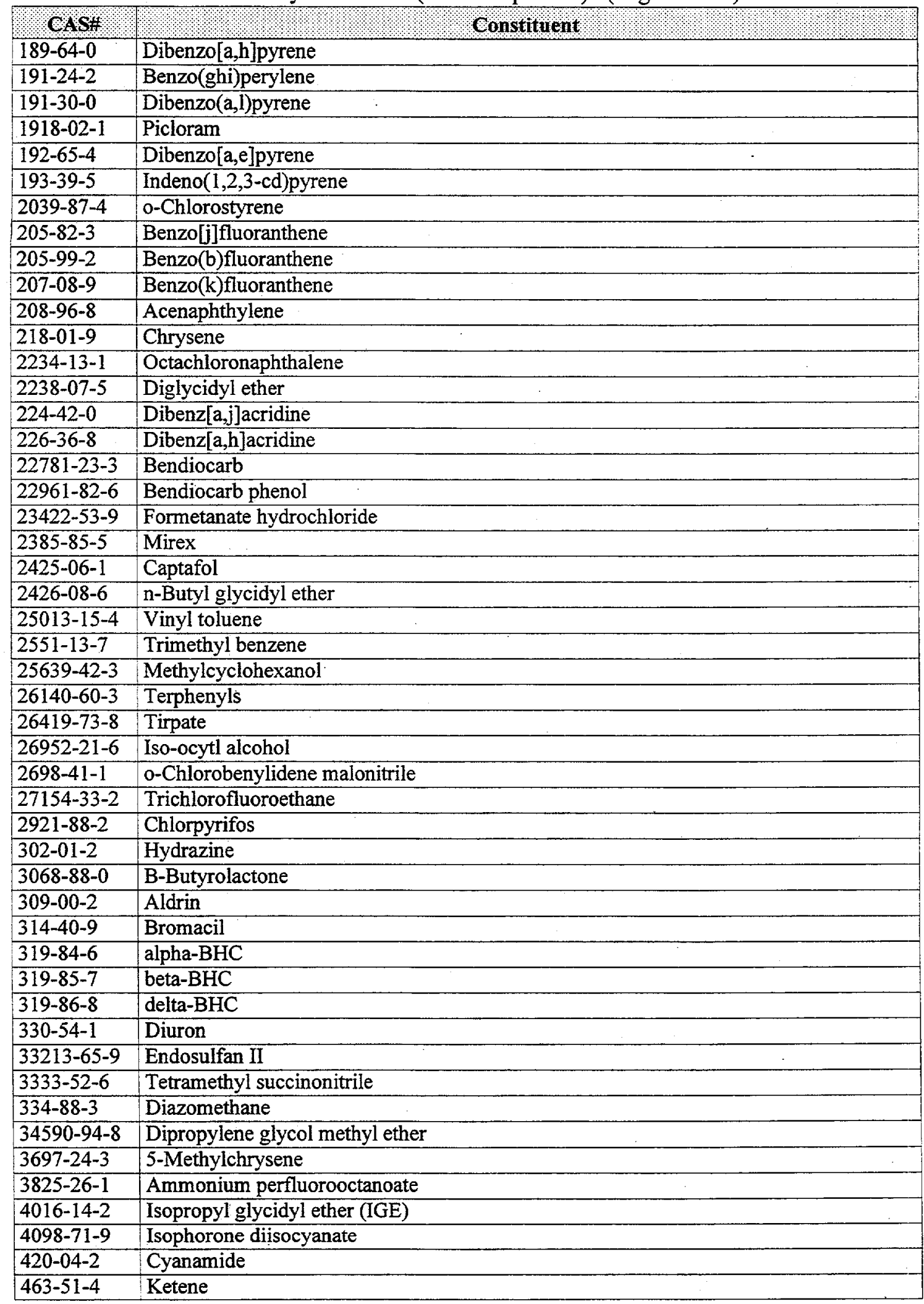


Table B.20. Regulated Non-detected Organic Compounds to be Considered for Stability Evaluation (269 Compounds). (Pages 4 of 6)

\begin{tabular}{|c|c|}
\hline $10 \mathrm{sA}$ & Constituent: \\
\hline $465-73-6$ & Isodrin \\
\hline $50-29-3$ & 4,4-DDT \\
\hline $50-32-8$ & Benzo(a)pyrene \\
\hline $504-29-0$ & 2-Aminopyridine \\
\hline $51-28-5$ & 2,4-Dinitrophenol \\
\hline $510-15-6$ & Chlorobenzilate \\
\hline $5124-30-1$ & Methylene-bis-(4-cyclo-hexylisocyanate) \\
\hline $52888-80-9$ & Prosulfocarb \\
\hline $53-70-3$ & Dibenz $[\mathrm{a}, \mathrm{h}]$ anthracene \\
\hline $531-82-8$ & $\mathrm{~N}$-(4-(5-Nitro-2-furyl)-2-thiazolyl)acetamide \\
\hline $540-59-0$ & 1,2-Dichloroethylene \\
\hline $540-84-1$ & 2,2,4-Trimethylpentane \\
\hline $540-88-5$ & tert-Butyl acetate \\
\hline $541-85-5$ & Ethyl amyl ketone \\
\hline $542-75-6$ & 1,3-Dichloropropene \\
\hline $542-92-7$ & Cyclopentadiene \\
\hline $552-30-7$ & Trimellitic anhydride \\
\hline 55285-14-8 & Carbosulfan \\
\hline $55406-53-6$ & 3-Iodo-2-propynyl n-butylcarbamate \\
\hline $556-52-5$ & Glycidol \\
\hline $55738-54-0$ & trans-2((Dimethylamino)methylimino)-5-(2-(5-nitro-2-furyl) vinyl-1,3,4-oxadiazole \\
\hline $56-49-5$ & 3-Methylcholanthrene \\
\hline $56-55-3$ & Benzo(a)anthracene \\
\hline $57-57-8$ & B-Propiolactone \\
\hline $57-74-9$ & Chlordane \\
\hline $58-89-9$ & gamma-BHC (Lindane) \\
\hline $58-90-2$ & 2,3,4,6-Tetrachlorophenol \\
\hline $583-60-8$ & o-Methylcyclohexanone \\
\hline 584-84-9 & 2,4-Toluene diisocyanate \\
\hline $592-62-1$ & Methyl azoxymethyl acetate \\
\hline $593-60-2$ & Vinyl bromide \\
\hline $594-42-3$ & Perchloromethyl mercaptan \\
\hline $594-72-9$ & 1,1-Dichloro-1-nitroethane \\
\hline $5952-26-1$ & Diethylene glycol, dicarbamate \\
\hline $60-29-7$ & Ethyl ether \\
\hline $60-57-1$ & Dieldrin \\
\hline $600-25-9$ & 1-Chloro-1-nitropropane \\
\hline $602-87-9$ & 5-Nitroacenaphthene \\
\hline 603-34-9 & Triphenyl amine \\
\hline $613-35-4$ & N,N-Diacetylbenzidine \\
\hline $62-53-3$ & Aniline \\
\hline $626-17-5$ & m-Phthalodinitrile \\
\hline $626-38-0$ & sec-Amyl acetate \\
\hline $628-63-7$ & n-Amyl acetate \\
\hline 628-96-6 & Ethylene glycol dinitrate \\
\hline $63-92-3$ & Phenoxybenzamine hydrochloride \\
\hline $630-20-6$ & 1,1,1,2-Tetrachloroethane \\
\hline $638-21-1$ & Phenylphosphine \\
\hline $64-00-6$ & m-Cumenyl methylcarbamate \\
\hline
\end{tabular}


Table B.20. Regulated Non-detected Organic Compounds to be Considered for Stability Evaluation (269 Compounds). (Pages 5 of 6)

\begin{tabular}{|c|c|}
\hline 84st & Qonstituent \\
\hline $64-67-5$ & Diethyl sulfate \\
\hline $64091-91-4$ & 4-(Methylnitrosamino)-1-(3-pyridyl)-1-butanone \\
\hline $644-64-4$ & Dimetilan \\
\hline $68-11-1$ & Thioglycolic acid \\
\hline $68-12-2$ & Dimethylformamide \\
\hline $681-84-5$ & Methyl silicate \\
\hline $684-16-2$ & Hexafluoroacetone \\
\hline $72-20-8$ & Endrin \\
\hline $72-43-5$ & Methoxychlor \\
\hline $72-54-8$ & 4,4-DDD \\
\hline $72-55-9$ & 4,4-DDE \\
\hline $74-89-5$ & Methylamine \\
\hline $74-96-4$ & Ethyl bromide \\
\hline $74-97-5$ & Bromochloromethane \\
\hline $7421-93-4$ & Endrin aldehyde \\
\hline $75-04-7$ & Ethylamine \\
\hline $75-08-1$ & Ethyl mercaptan \\
\hline $75-25-2$ & Tribromomethane \\
\hline $75-27-4$ & Bromodichloromethane. \\
\hline $75-31-0$ & Isopropylamine \\
\hline $75-56-9$ & Propylene oxide \\
\hline $75-61-6$ & Difluorodibromomethane \\
\hline $75-63-8$ & Trifluorobromomethane \\
\hline $75-99-0$ & 2,2-Dichloropropionic acid \\
\hline $7572-29-4$ & Dichloroacetylene \\
\hline $76-01-7$ & Pentachloroethane \\
\hline $76-03-9$ & Trichloroacetic acid \\
\hline $76-11-9$ & 1,1,1,2-Tetrachloro-2,2-difluoroethane \\
\hline $76-12-0$ & 1,1,2,2-Tetrachloro-1,2-difluoroethane \\
\hline $76-15-3$ & Chloropentafluoroethane \\
\hline $76-44-8$ & Heptachlor \\
\hline $768-52-5$ & N-Isopropylaniline \\
\hline $77-47-4$ & Hexachlorocyclopentadiene \\
\hline $77-73-6$ & Dicyclopentadiene \\
\hline $78-10-4$ & Ethyl silicate \\
\hline $78-59-1$ & Isophorone \\
\hline $79-04-9$ & Chloroacetyl chloride \\
\hline $79-11-8$ & Chloroacetic acid \\
\hline $79-24-3$ & Nitroethane \\
\hline $79-27-6$ & Acetylene tetrabromide \\
\hline $79-41-4$ & Methacrylic acid \\
\hline $794-93-4$ & Panfuran S (dihydroxymethylfuratrizine) \\
\hline $8001-35-2$ & Toxaphene \\
\hline $8003-34-7$ & Pyrethrum \\
\hline $82-68-8$ & Pentachloronitrobenzene (PCNB) \\
\hline $822-06-0$ & Hexamethylene diisocyanate \\
\hline $85-01-8$ & Phenanthrene \\
\hline $86-30-6$ & N-Nitrosodiphenylamine \\
\hline $87-86-5$ & Pentachlorophenol \\
\hline
\end{tabular}


Table B.20. Regulated Non-detected Organic Compounds to be Considered for Stability Evaluation (269 Compounds). (Pages 6 of 6 )

\begin{tabular}{|c|c|}
\hline \% $\mathrm{ss}$ & Constituent \\
\hline $88-72-2$ & Nitrotoluene \\
\hline $88-74-4$ & 2-Nitroaniline \\
\hline 88-85-7 & 2-sec-Butyl-4,6-dinitrophenol; syn Dinoseb \\
\hline $88-89-1$ & Picric acid \\
\hline $89-72-5$ & o-sec-Butylphenol \\
\hline $91-22-5$ & Quinoline \\
\hline 91-58-7 & 2-Chloronaphthalene \\
\hline $91-59-8$ & 2-Napthylamine \\
\hline $92-93-3$ & 4-Nitrobiphenyl \\
\hline $93-72-1$ & Silvex $(2,4 ; 5-\mathrm{TP})$ \\
\hline $93-76-5$ & $2,4,5-\mathrm{T}$ \\
\hline $94-36-0$ & Benzoyl Peroxide \\
\hline $94-75-7$ & $2,4-\mathrm{D}$ \\
\hline $95-13-6$ & Indene \\
\hline $95-49-8$ & o-Chlorotoluene \\
\hline $959-98-8$ & Endosulfan I \\
\hline $96-09-3$ & Styrene oxide \\
\hline $96-12-8$ & 1,2-Dibromo-3-chloropropane \\
\hline $96-33-3$ & Methyl acrylate \\
\hline $97-56-3$ & o-Aminoazotoluene \\
\hline $98-01-1$ & Furfural \\
\hline $98-51-1$ & p-tert-Butyltoluene \\
\hline $98-82-2$ & Cumene \\
\hline $999-61-1$ & 2-Hydroxypropyl acrylate \\
\hline
\end{tabular}

CAS\# = chemical abstract service number. 
Table B.21. Regulated Non-detected Organic Compounds Considered Unstable in Single-Shell Tank/Double-Shell Tank Waste Matrix

(179 Compounds). (Page 1 of 4)

\begin{tabular}{|c|c|}
\hline s s s & Constituent \\
\hline $100-02-7$ & 4-Nitrophenol \\
\hline $100-37-8$ & Diethylaminoethanol \\
\hline $100-61-8$ & N-Methylbenzenamine \\
\hline $100-63-0$ & Phenylhydrazine \\
\hline $100-74-3$ & N-Ethylmorpholine \\
\hline $101-68-8$ & Methylene bis(phenyl isocyanate) \\
\hline $101-90-6$ & Diglycidyl resorcinol ether \\
\hline $102-81-8$ & 2-N-Dibutylaminoethanol \\
\hline $1024-57-3$ & Heptachlor Epoxide \\
\hline $1031-07-8$ & Endosulfan Sulfate \\
\hline $105-46-4$ & sec-Butyl acetate \\
\hline $105-67-9$ & 2,4-Dimethylphenol \\
\hline $106-44-5$ & 4-Methylphenol \\
\hline $106-50-3$ & p-Phenylenediamine \\
\hline $106-87-6$ & Vinyl cyclohexene dioxide \\
\hline $106-92-3$ & Allyl glycidyl ether \\
\hline $107-07-3$ & Ethylene chlorohydrin \\
\hline $107-15-3$ & Ethylene diamine \\
\hline $107-21-1$ & Ethylene glycol \\
\hline $107-98-2$ & Propylene glycol monomethyl ether \\
\hline $108-11-2$ & Methyl isobutyl carbinol \\
\hline $108-18-9$ & Diisopropylamine \\
\hline $108-21-4$ & Isopropyl acetate \\
\hline $108-24-7$ & Acetic anhydride \\
\hline $108-43-0$ & Chlorophenols \\
\hline $108-60-1$ & Bis(2-Chloroisopropyl) ether \\
\hline $108-83-8$ & Diisobutyl ketone \\
\hline $108-84-9$ & sec-Hexyl acetate \\
\hline $108-91-8$ & Cyclohexylamine \\
\hline $109-59-1$ & Isopropoxyethanol \\
\hline $109-60-4$ & n-Propyl acetate \\
\hline $109-73-9$ & n-Butylamine \\
\hline $109-79-5$ & n-Butyl mercaptan \\
\hline $109-86-4$ & 2-Methoxyethanol \\
\hline $109-89-7$ & Diethylamine \\
\hline $109-94-4$ & Ethyl formate \\
\hline $110-19-0$ & Isobutyl acetate \\
\hline $110-49-6$ & 2-Methoxyethyl acetate \\
\hline $110-75-8$ & 2-Chloroethyl vinyl ether \\
\hline $110-91-8$ & Morpholine \\
\hline $111-15-9$ & 2-Ethoxyethyl acetate \\
\hline $111-40-0$ & Diethylene triamine \\
\hline $111-42-2$ & Diethanolamine \\
\hline $111-44-4$ & Bis(2-chloroethyl) ether \\
\hline $111-91-1$ & Bis(2-Chloroethoxy)methane \\
\hline $1129-41-5$ & Metolcarb (3-methylcholanthrene) \\
\hline $1134-23-2$ & Cycloate \\
\hline
\end{tabular}


Table B.21. Regulated Non-detected Organic Compounds Considered Unstable in Single-Shell Tank/Double-Shell Tank Waste Matrix

(179 Compounds). (Page 2 of 4 )

\begin{tabular}{|c|c|}
\hline $1 / \mathrm{CAs} \#$ & Constituent \\
\hline $115-86-6$ & Triphenyl phosphate \\
\hline $118-52-5$ & 1,3-Dichloro-5,5-Dimethyl hydantoin \\
\hline $119-38-0$ & Isolan \\
\hline $121-45-9$ & Trimethyl phosphite \\
\hline $122-60-1$ & Phenyl glycidyl ether \\
\hline $122-66-7$ & 1,2-Diphenylhydrazine \\
\hline $123-31-9$ & Hydroquinone \\
\hline $123-42-2$ & Diacetone alcohol \\
\hline $123-92-2$ & Isoamyl acetate \\
\hline $124-40-3$ & Dimethylamine \\
\hline $124-48-1$ & Dibromochloromethane \\
\hline $129-15-7$ & 2-Methyl-1-nitroanthraquinone \\
\hline $131-11-3$ & Dimethyl phthalate \\
\hline $1321-74-0$ & Divinyl benzene \\
\hline $133-06-2$ & Captan \\
\hline $133-90-4$ & Chloramben \\
\hline $1338-23-4$ & Methyl ethyl ketone peroxide \\
\hline $134-32-7$ & alpha-Naphthylamine \\
\hline $135-20-6$ & Cupferron \\
\hline $135-88-6$ & $\mathrm{~N}$-Phenyl-2-napthylamine \\
\hline $137-05-3$ & Methyl-2-cyanoacrylate \\
\hline $138-22-7$ & n-Butyl lactate \\
\hline $139-65-1$ & 4,4'-Thiodianiline \\
\hline $140-88-5$ & Ethylacrylate \\
\hline $141-32-2$ & Butylacrylate \\
\hline $141-43-5$ & Ethanolamine \\
\hline $142-64-3$ & Piperazine dihydrochloride \\
\hline $148-01-6$ & Dinitolamide \\
\hline $150-76-5$ & 4-Methoxyphenol \\
\hline $16219-75-3$ & Ethylidene norbornene \\
\hline $17702-57-7$ & Formparanate \\
\hline 1918-02-1 & Picloram \\
\hline $2039-87-4$ & o-Chlorostyrene \\
\hline $2238-07-5$ & Diglycidyl ether \\
\hline $22781-23-3$ & Bendiocarb \\
\hline $22961-82-6$ & Bendiocarb phenol \\
\hline $23422-53-9$ & Formetanate hydrochloride \\
\hline $2425-06-1$ & Captafol \\
\hline $2426-08-6$ & n-Butyl glycidyl ether \\
\hline 25013-15-4 & Vinyl toluene \\
\hline $25639-42-3$ & Methylcyclohexanol \\
\hline $26419-73-8$ & Tirpate \\
\hline $26952-21-6$ & Iso-ocytl alcohol \\
\hline $2698-41-1$ & o-Chlorobenylidene malonitrile \\
\hline $2921-88-2$ & Chlorpyrifos \\
\hline $302-01-2$ & Hydrazine \\
\hline $3068-88-0$ & B-Butyrolactone \\
\hline
\end{tabular}


Table B.21. Regulated Non-detected Organic Compounds Considered Unstable in Single-Shell Tank/Double-Shell Tank Waste Matrix (179 Compounds). (Page 3 of 4)

\begin{tabular}{|c|c|}
\hline $1 \mathrm{As}_{\mathrm{S}}$ & Constituent \\
\hline $314-40-9$ & Bromacil \\
\hline $330-54-1$ & Diuron \\
\hline $33213-65-9$ & Endosulfan II \\
\hline $3333-52-6$ & Tetramethyl succinonitrile \\
\hline $334-88-3$ & Diazomethane \\
\hline $34590-94-8$ & Dipropylene glycol methyl ether \\
\hline $4016-14-2$ & Isopropyl glycidyl ether (IGE) \\
\hline $4098-71-9$ & Isophorone diisocyanate \\
\hline $420-04-2$ & Cyanamide \\
\hline $463-51-4$ & Ketene \\
\hline $504-29-0$ & 2-Aminopyridine \\
\hline $51-28-5$ & 2,4-Dinitrophenol \\
\hline $510-15-6$ & Chlorobenzilate \\
\hline $5124-30-1$ & Methylene-bis-(4-cyclo-hexylisocyanate) \\
\hline $52888-80-9$ & Prosulfocarb \\
\hline $531-82-8$ & N-(4-(5-Nitro-2-furyl)-2-thiazolyl)acetamide \\
\hline $540-88-5$ & tert-Butyl acetate \\
\hline $541-85-5$ & Ethyl amyl ketone \\
\hline $542-75-6$ & 1,3-Dichloropropene \\
\hline $542-92-7$ & Cyclopentadiene \\
\hline $552-30-7$ & Trimellitic anhydride \\
\hline $55285-14-8$ & Carbosulfan \\
\hline $55406-53-6$ & 3-Iodo-2-propynyl n-butylcarbamate \\
\hline $556-52-5$ & Glycidol \\
\hline $55738-54-0$ & trans-2((Dimethylamino)methylimino)-5-(2-(5-nitro-2-furyl) vinyl-1,3,4-oxadiazole \\
\hline $57-57-8$ & B-Propiolactone \\
\hline $57-74-9$ & Chlordane \\
\hline $583-60-8$ & o-Methylcyclohexanone \\
\hline $584-84-9$ & 2,4-Toluene diisocyanate \\
\hline $592-62-1$ & Methyl azoxymethyl acetate \\
\hline $593-60-2$ & Vinyl bromide \\
\hline $594-42-3$ & Perchloromethyl mercaptan \\
\hline $594-72-9$ & 1,1-Dichloro-1-nitroethane \\
\hline $5952-26-1$ & Diethylene glycol, dicarbamate \\
\hline $600-25-9$ & 1-Chloro-1-nitropropane \\
\hline $613-35-4$ & N,N-Diacetylbenzidine \\
\hline $62-53-3$ & Aniline \\
\hline $626-17-5$ & m-Phthalodinitrile \\
\hline $626-38-0$ & sec-Amyl acetate \\
\hline $628-63-7$ & n-Amyl acetate \\
\hline $628-96-6$ & Ethylene glycol dinitrate \\
\hline $63-92-3$ & Phenoxybenzamine hydrochloride \\
\hline $638-21-1$ & Phenylphosphine \\
\hline $64-00-6$ & m-Cumenyl methylcarbamate \\
\hline $64-67-5$ & Diethyl sulfate \\
\hline $64091-91-4$ & 4-(Methylnitrosamino)-1-(3-pyridyl)-1-butanone \\
\hline $644-64-4$ & Dimetilan \\
\hline
\end{tabular}


Table B.21. Regulated Non-detected Organic Compounds Considered Unstable in Single-Shell Tank/Double-Shell Tank Waste Matrix

(179 Compounds). (Page 4 of 4 )

\begin{tabular}{|l|l|}
\hline \multicolumn{1}{|c|}{ CASH } & \multicolumn{1}{|c|}{ Constituent $: 100$} \\
\hline $68-11-1$ & Thioglycolic acid \\
\hline $68-12-2$ & Dimethylformamide \\
\hline $681-84-5$ & Methyl silicate \\
\hline $74-89-5$ & Methylamine \\
\hline $74-96-4$ & Ethyl bromide \\
\hline $7421-93-4$ & Endrin aldehyde \\
\hline $75-04-7$ & Ethylamine \\
\hline $75-08-1$ & Ethyl mercaptan \\
\hline $75-25-2$ & Tribromomethane \\
\hline $75-31-0$ & Isopropylamine \\
\hline $75-56-9$ & Propylene oxide \\
\hline $7572-29-4$ & Dichloroacetylene \\
\hline $76-01-7$ & Pentachloroethane \\
\hline $768-52-5$ & N-Isopropylaniline \\
\hline $77-47-4$ & Hexachlorocyclopentadiene \\
\hline $77-73-6$ & Dicyclopentadiene \\
\hline $78-10-4$ & Ethyl silicate \\
\hline $78-59-1$ & Isophorone \\
\hline $79-04-9$ & Chloroacetyl chloride \\
\hline $79-11-8$ & Chloroacetic acid \\
\hline $79-24-3$ & Nitroethane \\
\hline $79-27-6$ & Acetylene tetrabromide \\
\hline $79-41-4$ & Methacrylic acid \\
\hline $794-93-4$ & Panfuran S (dihydroxymethylfuratrizine) \\
\hline $8003-34-7$ & Pyrethrum \\
\hline $822-06-0$ & Hexamethylene diisocyanate \\
\hline $86-30-6$ & N-Nitrosodiphenylamine \\
\hline $88-74-4$ & 2-Nitroaniline \\
\hline $89-72-5$ & o-sec-Butylphenol \\
\hline $91-59-8$ & 2-Napthylamine \\
\hline $94-36-0$ & Benzoyl Peroxide \\
\hline $959-98-8$ & Endosulfan I \\
\hline $96-09-3$ & Styrene oxide \\
\hline $96-12-8$ & $1,2-$ Dibromo-3-chloropropane \\
\hline $96-33-3$ & Methyl acrylate \\
\hline $97-56-3$ & o-Aminoazotoluene \\
\hline $98-01-1$ & Furfural \\
\hline $999-61-1$ & $2-$ Hydroxypropyl acrylate \\
\hline CAS\# = chemical abstract service number. \\
\hline
\end{tabular}


Table B.22. Regulated Non-detected Organic Compounds Considered Stable in Single-Shell

Tank/Double-Shell Tank Waste Matrix

(90 Compounds). (Page 1 of 2)

\begin{tabular}{|l|l|}
\hline \multicolumn{1}{|c|}{ CASH } & \multicolumn{1}{|c|}{ Constituent } \\
\hline $100-21-0$ & Phthalic acid \\
\hline $100-25-4$ & 1,4 -Dinitrobenzene \\
\hline $101-55-3$ & 4 -Bromophenylphenyl ether \\
\hline $107-66-4$ & Dibutylphosphate \\
\hline $118-74-1$ & Hexachlorobenzene \\
\hline $120-12-7$ & Anthracene \\
\hline $120-83-2$ & $2,4-$ Dichlorophenol \\
\hline $121-44-8$ & Triethylamine \\
\hline $121-69-7$ & Dimethylaniline \\
\hline $132-64-9$ & Dibenzofuran \\
\hline $1321-64-8$ & Pentachloronaphthalene \\
\hline $1321-65-9$ & Trichloronaphthalene \\
\hline $1335-87-1$ & Hexachloronaphthalene \\
\hline $1335-88-2$ & Tetrachloronaphthalene \\
\hline $1336-36-3$ & Polychlorinated biphenyls (PCBs) \\
\hline $156-60-5$ & $1,2-$ trans-Dichloroethene \\
\hline $1582-09-8$ & Trifluralin \\
\hline $1634-04-4$ & Methyl tert-butyl ether \\
\hline $1836-75-5$ & Nitrofen \\
\hline $189-55-9$ & Dibenzo[a,i]pyrene \\
\hline $189-64-0$ & Dibenzo[a,h]pyrene \\
\hline $191-24-2$ & Benzo(ghi)perylene \\
\hline $191-30-0$ & Dibenzo(a,1)pyrene \\
\hline $192-65-4$ & Dibenzo[a,e]pyrene \\
\hline $193-39-5$ & Indeno(1,2,3-cd)pyrene \\
\hline $205-82-3$ & Benzo[j]fluoranthene \\
\hline $205-99-2$ & Benzo(b)fluoranthene \\
\hline $207-08-9$ & Benzo(k)fluoranthene \\
\hline $208-96-8$ & Acenaphthylene \\
\hline $218-01-9$ & Chrysene \\
\hline $2234-13-1$ & Octachloronaphthalene \\
\hline $224-42-0$ & Dibenz[a,j]acridine \\
\hline $226-36-8$ & Dibenz[a,h]acridine \\
\hline $2385-85-5$ & Mirex \\
\hline $2551-13-7$ & Trimethyl benzene \\
\hline $26140-60-3$ & Terphenyls \\
\hline $27154-33-2$ & Trichlorofluoroethane \\
\hline $309-00-2$ & Aldrin \\
\hline $319-84-6$ & alpha-BHC \\
\hline $319-85-7$ & beta-BHC \\
\hline $319-86-8$ & delta-BHC \\
\hline $3697-24-3$ & 5 -Methylchrysene \\
\hline $465-73-6$ & Isodrin \\
\hline $50-29-3$ & $4,4-D D T$ \\
\hline $50-32-8$ & Benzo(a)pyrene \\
\hline
\end{tabular}


Table B.22. Regulated Non-detected Organic Compounds Considered Stable in Single-Shell

Tank/Double-Shell Tank Waste Matrix

(90 Compounds). (Page 2 of 2)

\begin{tabular}{|c|c|}
\hline CASH & Qonstituent \\
\hline $53-70-3$ & Dibenz $[a, h]$ anthracene \\
\hline $540-59-0$ & 1,2-Dichloroethylene \\
\hline $540-84-1$ & 2,2,4-Trimethylpentane \\
\hline $56-49-5$ & 3-Methylcholanthrene \\
\hline $56-55-3$ & Benzo(a)anthracene \\
\hline $58-89-9$ & gamma-BHC (Lindane) \\
\hline $58-90-2$ & $2,3,4,6$-Tetrachlorophenol \\
\hline $60-29-7$ & Ethyl ether \\
\hline $60-57-1$ & Dieldrin \\
\hline $602-87-9$ & 5-Nitroacenaphthene \\
\hline $603-34-9$ & Triphenyl amine \\
\hline $630-20-6$ & 1,1,1,2-Tetrachloroethane \\
\hline $684-16-2$ & Hexafluoroacetone \\
\hline $72-20-8$ & Endrin \\
\hline $72-43-5$ & Methoxychlor \\
\hline $72-54-8$ & 4,4-DDD \\
\hline $72-55-9$ & 4,4-DDE \\
\hline $74-97-5$ & Bromochloromethane \\
\hline $75-27-4$ & Bromodichloromethane \\
\hline $75-61-6$ & Difluorodibromomethane \\
\hline $75-63-8$ & Trifluorobromomethane \\
\hline $75-99-0$ & 2,2-Dichloropropionic acid \\
\hline $76-03-9$ & Trichloroacetic acid \\
\hline $76-11-9$ & 1,1,1,2-Tetrachloro-2,2-difluoroethane \\
\hline $76-12-0$ & 1,1,2,2-Tetrachloro-1,2-difluoroethane \\
\hline $76-15-3$ & Chloropentafluoroethane \\
\hline $76-44-8$ & Heptachlor \\
\hline $8001-35-2$ & Toxaphene \\
\hline $82-68-8$ & Pentachloronitrobenzene (PCNB) \\
\hline $35-01-8$ & Phenanthrene \\
\hline $87-86-5$ & Pentachlorophenol \\
\hline $88-72-2$ & Nitrotoluene \\
\hline $88-85-7$ & 2-sec-Butyl-4,6-dinitrophenol; syn Dinoseb \\
\hline $88-89-1$ & Picric acid \\
\hline $91-22-5$ & Quinoline \\
\hline $91-58-7$ & 2-Chloronaphthalene \\
\hline $92-93-3$ & 4-Nitrobiphenyl \\
\hline $93-72-1$ & Silvex $(2,4,5-\mathrm{TP})$ \\
\hline $93-76-5$ & $2,4,5-\mathrm{T}$ \\
\hline $94-75-7$ & 2,4-D \\
\hline $95-13-6$ & Indene \\
\hline $95-49-8$ & o-Chlorotoluene \\
\hline $98-51-1$ & p-tert-Butyltoluene \\
\hline $98-82-2$ & Cumene \\
\hline
\end{tabular}

CAS\# = chemical abstract service number. 
Table B.23. Regulated Non-detected Stable Organic Compounds with Lower or Unknown Toxicity and Carcinogenicity (65 Compounds). (Page 1 of 2)

\begin{tabular}{|c|c|c|c|c|}
\hline OAS\# & Constituent & $\begin{array}{l}\text { UHC Toxicity } \\
\text { Category }\end{array}$ & TAP Toxicity & $\begin{array}{l}\text { Carcinogenieiry } \\
\text { (Slope Factor) } \\
\text { Ranking }\end{array}$ \\
\hline $100-21-0$ & Phthalic acid & & - & \\
\hline $101-55-3$ & 4-Bromophenylphenyl ether & & & . \\
\hline $107-66-4$ & Dibutylphosphate & & III & \\
\hline $120-12-7$ & Anthracene & & & \\
\hline $120-83-2$ & 2,4-Dichlorophenol & $\mathrm{D}$ & & \\
\hline $121-69-7$ & Dimethylaniline & & III & \\
\hline $132-64-9$ & Dibenzofuran & & & \\
\hline $1321-65-9$ & Trichloronaphthalene & & III & \\
\hline $156-60-5$ & 1,2-trans-Dichloroethene & $\mathrm{D}$ & & \\
\hline $1582-09-8$ & Trifluralin & & $\mathrm{V}$ & \\
\hline $1634-04-4$ & Methyl tert-butyl ether & & IV & \\
\hline $1836-75-5$ & Nitrofen & & & \\
\hline $189-55-9$ & Dibenzo[a,i]pyrene & & & \\
\hline $189-64-0$ & Dibenzo[a,h]pyrene & & & \\
\hline $191-24-2$ & Benzo(ghi)perylene & & & \\
\hline $191-30-0$ & Dibenzo $(a, 1)$ pyrene & & & \\
\hline $192-65-4$ & Dibenzo[a,e]pyrene & & & \\
\hline $193-39-5$ & Indeno(1,2,3-cd)pyrene & & & $\mathrm{BC}$ \\
\hline $205-82-3$ & Benzo[j] fluoranthene & & & \\
\hline $205-99-2$ & Benzo(b)fluoranthene & & & $\mathrm{BC}$ \\
\hline $207-08-9$ & Benzo(k)fluoranthene & & & $\mathrm{BC}$ \\
\hline $208-96-8$ & Acenaphthylene & & & \\
\hline 218-01-9 & Chrysene & & & $\mathrm{BC}$ \\
\hline $224-42-0$ & Dibenz $[a, j]$ acridine & & & \\
\hline $226-36-8$ & Diben $z[a, h]$ acridine & & & \\
\hline $2385-85-5$ & Mirex & & & \\
\hline $2551-13-7$ & Trimethyl benzene & & IV & \\
\hline $26140-60-3$ & Terphenyls & & III & \\
\hline $27154-33-2$ & Trichlorofluoroethane & & & \\
\hline $319-86-8$ & delta-BHC & D & - & \\
\hline $3697-24-3$ & 5-Methylchrysene & & & \\
\hline $50-29-3$ & 4,4-DDT & C & & $\mathrm{BC}$ \\
\hline $540-59-0$ & 1,2-Dichloroethylene & & $\mathrm{V}$ & \\
\hline 540-84-1 & 2,2,4-Trimethylpentane & & $\mathrm{V}$ & \\
\hline $56-49-5$ & 3-Methylcholanthrene & & & \\
\hline $56-55-3$ & Benzo(a)anthracene & & & $\mathrm{BC}$ \\
\hline $58-90-2$ & 2,3,4,6-Tetrachlorophenol & $\mathrm{C}$ & & \\
\hline $60-29-7$ & Ethyl ether & D & $\mathrm{V}$ & \\
\hline $602-87-9$ & 5-Nitroacenaphthene & & & \\
\hline $603-34-9$ & Triphenyl amine & & III & \\
\hline $630-20-6$ & 1,1,1,2-Tetrachloroethane & $\mathrm{C}$ & & $\mathrm{BC}$ \\
\hline $72-43-5$ & Methoxychlor & $\overline{\mathrm{D}}$ & III & \\
\hline $72-54-8$ & 4,4-DDD & $\mathrm{C}$ & & \\
\hline $72-55-9$ & 4,4-DDE & $\mathrm{D}$ & & \\
\hline $74-97-5$ & Bromochloromethane & & $\mathrm{V}$ & \\
\hline $75-27-4$ & Bromodichloromethane & $\mathrm{C}$ & & \\
\hline
\end{tabular}


Table B.23. Regulated Non-detected Stable Organic Compounds with Lower or Unknown Toxicity and Carcinogenicity (65 Compounds). (Page 2 of 2)

\begin{tabular}{|c|c|c|c|c|}
\hline Q & Constifuent & $\begin{array}{l}\text { UHC Toxicity } \\
\text { Category }\end{array}$ & TAP Toxicity & $\begin{array}{l}\text { Carcinogenicity } \\
\text { (Slope Factor) }\end{array}$ \\
\hline $75-61-6$ & Difluorodibromomethane & & $\mathrm{V}$ & \\
\hline $75-63-8$ & Trifluorobromomethane & & $\mathrm{V}$ & \\
\hline $75-99-0$ & 2,2-Dichloropropionic acid & & III & \\
\hline $76-03-9$ & Trichloroacetic acid & & III & \\
\hline $76-11-9$ & 1,1,1,2-Tetrachloro-2,2-difluoroethane & & $\mathrm{V}$ & \\
\hline $76-12-0$ & 1,1,2,2-Tetrachloro-1,2-difluoroethane & & $\mathrm{V}$ & \\
\hline $76-15-3$ & Chloropentafluoroethane & & V & \\
\hline $85-01-8$ & Phenanthrene & & & \\
\hline $88-72-2$ & Nitrotoluene & & III & \\
\hline $91-22-5$ & Quinoline & & $\mathrm{V}$ & \\
\hline $91-58-7$ & 2-Chloronaphthalene & $\mathrm{D}$ & & \\
\hline $92-93-3$ & 4-Nitrobiphenyl & & $\mathrm{V}$ & \\
\hline $93-72-1$ & Silvex $(2,4,5-\mathrm{TP})$ & $\overline{\mathrm{D}}$ & & \\
\hline $93-76-5$ & $2,4,5-\mathrm{T}$ & & III & \\
\hline $94-75-7$ & $2,4-\mathrm{D}$ & $\mathrm{C}$ & & \\
\hline $95-13-6$ & Indene & & IV & \\
\hline $95-49-8$ & o-Chlorotoluene & & IV & \\
\hline $98-51-1$ & p-tert-Butyltoluene & & $\overline{\mathrm{IV}}$ & \\
\hline $98-82-2$ & Cumene & & IV & \\
\hline $\begin{array}{l}\mathrm{CAS \#}= \\
\mathrm{TAP}= \\
\mathrm{UHC}=\end{array}$ & $\begin{array}{l}\text { chemical abstract service number. } \\
\text { toxic air pollutant. } \\
\text { underlying hazardous constituents. }\end{array}$ & & & \\
\hline
\end{tabular}


Table B.24. Regulated Non-detected Stable Organic Compounds with Higher Toxicity and/or Carcinogenicity (25 Compounds).

\begin{tabular}{|c|c|c|c|c|}
\hline CASH & Constituent & $\begin{array}{l}\text { UHC Toxicity } \\
\text { Category }\end{array}$ & $\begin{array}{l}\text { TAPP } \\
\text { Toxicity } \\
\text { Category }\end{array}$ & $\begin{array}{l}\text { Carcinogenicity } \\
\text { (Slope Factor) } \\
\text { Ranking }\end{array}$ \\
\hline $100-25-4$ & 1,4-Dinitrobenzene & $\mathrm{B}$ & II & \\
\hline $118-74-1$ & Hexachlorobenzene & $\mathrm{C}$ & & $\mathbf{v}$ \\
\hline $121-44-8$ & Triethylamine & $\mathrm{C}$ & $\Pi$ & \\
\hline $1321-64-8$ & Pentachloronaphthalene & & II & \\
\hline $1335-87-1$ & Hexachloronaphthalene & & I & \\
\hline $1335-88-2$ & Tetrachloronaphthalene & & III & \\
\hline $1336-36-3$ & Polychlorinated biphenyls (PCBs) & $\mathrm{B}$ & & $\mathrm{BC}$ \\
\hline 2234-13-1 & Octachloronaphthalene & & $\mathrm{I}$ & \\
\hline $309-00-2$ & Aldrin & A & & iv \\
\hline $319-84-6$ & alpha-BHC & $\mathrm{C}$ & & $\mathrm{v}$ \\
\hline $319-85-7$ & beta-BHC & & & $\mathrm{v}$ \\
\hline $3825-26-1$ & Ammonium perfluorooctanoate & & $\mathrm{I}$ & \\
\hline $465-73-6$ & Isodrin & B & & \\
\hline $50-32-8$ & Benzo(a)pyrene & & & $\mathrm{v}$ \\
\hline $53-70-3$ & Dibenz[a,h]anthracene & & & $\mathrm{v}$ \\
\hline $58-89-9$ & gamma-BHC (Lindane) & $\mathrm{B}$ & & \\
\hline $60-57-1$ & Dieldrin & $\mathrm{X}$ & & iv \\
\hline $684-16-2$ & Hexafluoroacetone & & II & \\
\hline $72-20-8$ & Endrin & A & I & \\
\hline $76-44-8$ & Heptachlor & B & & $\mathrm{v}$ \\
\hline $8001-35-2$ & Toxaphene & $\mathrm{C}$ & & $\mathrm{v}$ \\
\hline $82-68-8$ & Pentachloronitrobenzene (PCNB) & B & II & \\
\hline $87-86-5$ & Pentachlorophenol & B & & \\
\hline $88-85-7$ & 2-sec-Butyl-4,6-dinitrophenol; syn Dinoseb & B & & \\
\hline $88-89-1$ & Picric acid & & I & \\
\hline
\end{tabular}

CAS\# = chemical abstract service number.

$\mathrm{TAP}=$ toxic air pollutant.

$\mathrm{UHC}=$ underlying hazardous constituents. 
Table B.25. Regulated Detected Organic Compounds with Higher Toxicity and Non-detected Stable Organic Compounds with Higher Toxicity (44 Compounds).

\begin{tabular}{|c|c|c|c|c|}
\hline $\mathrm{CASH}$ & Constituent & $\begin{array}{l}\text { UHC } \\
\text { Toxicity } \\
\text { Category }\end{array}$ & $\begin{array}{l}\text { TAP } \\
\text { Toxicity } \\
\text { Category }\end{array}$ & Slope Ractor \\
\hline $100-00-5$ & p-Nitrochlorobenzene & & II & \\
\hline $100-25-4$ & 1,4-Dinitrobenzene & B & II & \\
\hline $106-99-0$ & 1,3-Butadiene & & & $\mathrm{v}$ \\
\hline $107-02-8$ & Acrolein & B & I & \\
\hline $107-05-1$ & 3-Chloropropene & $\mathrm{A}$ & II & \\
\hline $107-12-0$ & Propionitrile & $\mathrm{B}$ & & \\
\hline $107-13-1$ & Acrylonitrile & $\mathrm{B}$ & & $\mathrm{BC}$ \\
\hline $118-74-1$ & Hexachlorobenzene & $\bar{C}$ & & $\mathrm{v}$ \\
\hline $121-44-8$ & Triethylamine & $\mathrm{C}$ & II & \\
\hline $126-73-8$ & Tributyl phosphate & & $\overline{\mathrm{II}}$ & \\
\hline $126-98-7$ & 2-Methyl-2-propenenitrile & $\bar{B}$ & II & \\
\hline $1321-64-8$ & Pentachloronaphthalene & . & II & \\
\hline $13335-87-1$ & Hexachloronaphthalene & & I & \\
\hline $1335-88-2$ & Tetrachloronaphthalene & & II & \\
\hline $1336-36-3$ & Polychlorinated biphenyls (PCBs) & B & & $\mathrm{BC}$ \\
\hline $144-62-7$ & Oxalic acid & & II & \\
\hline 2234-13-1 & Octachloronaphthalene & & I & \\
\hline $309-00-2$ & Aldrin & A & & iv \\
\hline $319-84-6$ & alpha-BHC & $\mathrm{C}$ & & $\mathrm{v}$ \\
\hline $319-85-7$ & beta-BHC & & & $\mathrm{v}$ \\
\hline $3825-26-1$ & Ammonium perfluorooctanoate & & I & \\
\hline $465-73-6$ & Isodrin & B & & \\
\hline $50-32-8$ & Benzo(a)pyrene & & & $\mathrm{v}$ \\
\hline $53-70-3$ & Dibenz $[a, h]$ anthracene & & & $\mathrm{v}$ \\
\hline $57-14-7$ & 1,1-Dimethylhydrazine & & II & $\mathrm{v}$ \\
\hline $58-89-9$ & gamma-BHC (Lindane) & $\bar{B}$ & & \\
\hline $60-34-4$ & Methylhydrazine & & II & \\
\hline $60-57-1$ & Dieldrin & $\mathrm{X}$ & & iv \\
\hline $62-75-9$ & N-Nitroso-N,N-dimethylamine & $\mathrm{B}$ & & iv \\
\hline $624-83-9$ & Methyl isocyanate & & $\mathrm{I}$ & \\
\hline $684-16-2$ & Hexafluoroacetone & & II & \\
\hline $72-20-8$ & Endrin & A & $\mathrm{I}$ & \\
\hline 74-83-9 & Bromomethane & $\mathrm{C}$ & II & \\
\hline $75-21-8$ & Oxirane & $\mathrm{B}$ & & $\mathrm{BC}$ \\
\hline 76-44-8 & Heptachlor & $\mathrm{B}$ & & $v$ \\
\hline $79-10-7$ & 2-Propenoic acid & & I & \\
\hline $8001-35-2$ & Toxaphene & C & & $\mathrm{v}$ \\
\hline $82-68-8$ & Pentachloronitrobenzene (PCNB) & B & II & \\
\hline $87-68-3$ & Hexachlorobutadiene & B & I & $\mathrm{BC}$ \\
\hline $87-86-5$ & Pentachlorophenol & B & & \\
\hline 88-85-7 & 2-sec-Butyl-4,6-dinitrophenol; syn Dinoseb & B & & \\
\hline 88-89-1 & Picric acid & & I & \\
\hline $92-52-4$ & 1,1'-Biphenyl & & II & \\
\hline $98-95-3$ & Nitrobenzene & $\mathrm{D}$ & II & \\
\hline $\begin{array}{l}\text { CAS\# }= \\
\mathrm{TAP}=\end{array}$ & $\begin{array}{l}\text { chemical abstract service number. } \\
\text { toxic air pollutant. }\end{array}$ & $=$ & & ints. \\
\hline
\end{tabular}


Table B.26. Regulated Organic Compounds with Higher Toxicity Potentially Analyzed by Existing SW-846 Methods (EPA 1997) (28 Compounds).

\begin{tabular}{|l|l|c|}
\hline \multicolumn{1}{|c|}{ CASH, Constituent } & \multicolumn{1}{|c|}{ SW 846 Method } \\
\hline $100-25-4$ & 1,4-Dinitrobenzene & $8270 \mathrm{C}$ \\
\hline $107-02-8$ & Acrolein & $8260 \mathrm{~B}$ \\
\hline $107-05-1$ & 3-Chloropropene & $8260 \mathrm{~B}$ \\
\hline $107-12-0$ & Propionitrile & $8260 \mathrm{~B}$ \\
\hline $107-13-1$ & Acrylonitrile & $8260 \mathrm{~B}$ \\
\hline $118-74-1$ & Hexachlorobenzene & $8081 \mathrm{~A}$ \\
\hline $126-98-7$ & 2-Methyl-2-propenenitrile & $8260 \mathrm{~B}$ \\
\hline $1336-36-3$ & Polychlorinated biphenyls (PCBs) & 8082 \\
\hline $2234-13-1$ & Octachloronaphthalene & $8081 \mathrm{~A}$ \\
\hline $309-00-2$ & Aldrin & $8081 \mathrm{~A}$ \\
\hline $319-84-6$ & alpha-BHC & $8081 \mathrm{~A}$ \\
\hline $319-85-7$ & beta-BHC & $8081 \mathrm{~A}$ \\
\hline $465-73-6$ & Isodrin & $8081 \mathrm{~A}$ \\
\hline $50-32-8$ & Benzo(a)pyrene & $8270 \mathrm{C}$ \\
\hline $53-70-3$ & Dibenz[a,h]anthracene & $8270 \mathrm{C}$ \\
\hline $58-89-9$ & gamma-BHC (Lindane) & $8081 \mathrm{~A}$ \\
\hline $60-57-1$ & Dieldrin & $8081 \mathrm{~A}$ \\
\hline $62-75-9$ & N-Nitroso-N,N-dimethylamine & $8270 \mathrm{C}$ \\
\hline $72-20-8$ & Endrin & $8081 \mathrm{~A}$ \\
\hline $74-83-9$ & Bromomethane & $8260 \mathrm{~B}$ \\
\hline $75-21-8$ & Oxirane & $8260 \mathrm{~B}$ \\
\hline $76-44-8$ & Heptachlor & $8081 \mathrm{~A}$ \\
\hline $8001-35-2$ & Toxaphene & $8081 \mathrm{~A}$ \\
\hline $82-68-8$ & Pentachloronitrobenzene (PCNB) & $8270 \mathrm{C}$ \\
\hline $87-68-3$ & Hexachlorobutadiene & $8270 \mathrm{C}$ \\
\hline $87-86-5$ & Pentachlorophenol & $8151 \mathrm{~A}$ \\
\hline $88-85-7$ & 2-sec-Butyl-4,6-dinitrophenol; syn Dinoseb & $8151 \mathrm{~A}$ \\
\hline $98-95-3$ & Nitrobenzene & $8270 \mathrm{C}$ \\
\hline
\end{tabular}

CAS\# $=$ chemical abstract service number.

$\mathrm{EPA}=$ US Environmental Protection Agency. 
Table B.27. Regulated Organic Compounds with Higher Toxicity with No Existing SW-846 Methods (16 Compounds).

\begin{tabular}{|l|l|}
\hline \multicolumn{1}{|c|}{ CASH } & \multicolumn{1}{|c|}{ Constituent } \\
\hline $100-00-5$ & p-Nitrochlorobenzene \\
\hline $106-99-0$ & 1,3 -Butadiene \\
\hline $121-44-8$ & Triethylamine \\
\hline $126-73-8$ & Tributyl phosphate \\
\hline $1321-64-8$ & Pentachloronaphthalene \\
\hline $1335-87-1$ & Hexachloronaphthalene \\
\hline $1335-88-2$ & Tetrachloronaphthalene \\
\hline $144-62-7$ & Oxalic acid \\
\hline $3825-26-1$ & Ammonium perfluorooctanoate \\
\hline $57-14-7$ & 1,1 -Dimethylhydrazine \\
\hline $60-34-4$ & Methylhydrazine \\
\hline $624-83-9$ & Methyl isocyanate \\
\hline $684-16-2$ & Hexafluoroacetone \\
\hline $79-10-7$ & $2-$ Propenoic acid \\
\hline $88-89-1$ & Picric acid \\
\hline $92-52-4$ & 1, ''-Biphenyl \\
\hline
\end{tabular}

CAS\# = chemical abstract service number. 
Table B.28. Regulated Organic Compounds with Higher Toxicity Potentially Analyzed by Modified SW-846 Methods (EPA 1997) (16 Compounds).

\begin{tabular}{|l|l|c|}
\hline \multicolumn{1}{|c|}{ CASH } & \multicolumn{1}{|c|}{ Constituent } & Suggested Method \\
\hline $100-00-5$ & p-Nitrochlorobenzene & $8270 \mathrm{C}$ \\
\hline $106-99-0$ & 1,3 -Butadiene & $8260 \mathrm{~B}$ \\
\hline $121-44-8$ & Triethylamine & $8260 \mathrm{~B}$ \\
\hline $126-73-8$ & Tributyl phosphate & $8270 \mathrm{C}$ \\
\hline $1321-64-8$ & Pentachloronaphthalene & $8270 \mathrm{C}$ \\
\hline $1335-87-1$ & Hexachloronaphthalene & $8270 \mathrm{C}$ \\
\hline $1335-88-2$ & Tetrachloronaphthalene & $8270 \mathrm{C}$ \\
\hline $144-62-7$ & Oxalic acid & 9056 \\
\hline $3825-26-1$ & Ammonium perfluorooctanoate & 8330 \\
\hline $57-14-7$ & $1,1-$ Dimethylhydrazine & $8270 \mathrm{C}$ \\
\hline $60-34-4$ & Methylhydrazine & $8270 \mathrm{C}$ \\
\hline $624-83-9$ & Methyl isocyanate & 8330 \\
\hline $684-16-2$ & Hexafluoroacetone & $8260 \mathrm{~B}$ \\
\hline $79-10-7$ & 2-Propenoic acid & $8270 \mathrm{C}$ \\
\hline $88-89-1$ & Picric acid & 8330 \\
\hline $92-52-4$ & 1,1 -Biphenyl & $8270 \mathrm{C}$ \\
\hline
\end{tabular}

CAS\# = chemical abstract service number.

EPA = US Environmental Protection Agency.

Note: Pentachlorophenol (86-87-5) is identified as a compound in $8151 \mathrm{~A}$, however, may be measured by $8270 \mathrm{C}$. 
Table B.29. Regulated Detected and Non-detected Organic Compounds with Higher Toxicity that are Amenable to SW-846 or Modified SW-846 Methods (EPA 1997) (44 Compounds). (Page 1 of 2)

\begin{tabular}{|c|c|c|c|c|c|c|}
\hline CASt & Constituent & $\begin{array}{l}\text { UHC } \\
\text { Toxicity } \\
\text { Category }\end{array}$ & $\begin{array}{c}\text { TAPP } \\
\text { Toxicity } \\
\text { Category }\end{array}$ & $\begin{array}{l}\text { Slope } \\
\text { Factor: } \\
\text { Ranking }\end{array}$ & SWethod & $\begin{array}{l}\text { Suggested } \\
\text { Method }\end{array}$ \\
\hline $100-00-5$ & p-Nitrochlorobenzene & & II & & & $8270 \mathrm{C}$ \\
\hline $100-25-4$ & 1,4-Dinitrobenzene & $\bar{B}$ & II & & $8270 \mathrm{C}$ & \\
\hline $106-99-0$ & 1,3-Butadiene & & & $\mathrm{v}$ & & $8260 \mathrm{~B}$ \\
\hline $107-02-8$ & Acrolein & $\mathbf{B}$ & I & & $8260 \mathrm{~B}$ & \\
\hline $107-05-1$ & 3-Chloropropene & $\mathrm{A}$ & II & & $8260 \mathrm{~B}$ & \\
\hline $107-12-0$ & Propionitrile & $\mathrm{B}$ & & & $8260 \mathrm{~B}$ & \\
\hline $107-13-1$ & Acrylonitrile & B & & $\mathrm{BC}$ & $8260 \mathrm{~B}$ & \\
\hline $118-74-1$ & Hexachlorobenzene & $\mathrm{C}$ & & $\mathrm{v}$ & $8081 \mathrm{~A}$ & \\
\hline $121-44-8$ & Triethylamine & $\bar{C}$ & II & & & $8260 \mathrm{~B}$ \\
\hline $126-73-8$ & Tributyl phosphate & & II & & & $8270 \mathrm{C}$ \\
\hline $126-98-7$ & 2-Methyl-2-propenenitrile & B & II & & $8260 \mathrm{~B}$ & \\
\hline $1321-64-8$ & Pentachloronaphthalene & & II & & & $8270 \mathrm{C}$ \\
\hline $1335-87-1$ & Hexachloronaphthalene & & I & & & $8270 \mathrm{C}$ \\
\hline $1335-88-2$ & Tetrachloronaphthalene & & II & & & $8270 \mathrm{C}$ \\
\hline $1336-36-3$ & Polychlorinated biphenyls (PCBs) & B & & $\mathrm{BC}$ & 8082 & \\
\hline $144-62-7$ & Oxalic acid & & II & & & $8270 \mathrm{C}$ \\
\hline 2234-13-1 & Octachloronaphthalene & & $\mathrm{I}$ & & $8081 \mathrm{~A}$ & \\
\hline $309-00-2$ & Aldrin & A & & iv & $8081 \mathrm{~A}$ & \\
\hline $319-84-6$ & alpha-BHC & $\mathrm{C}$ & & $\mathrm{v}$ & $8081 \mathrm{~A}$ & \\
\hline $319-85-7$ & beta-BHC & & & $\mathrm{v}$ & $8081 \mathrm{~A}$ & \\
\hline $3825-26-1$ & Ammonium perfluorooctanoate & & $\mathrm{I}$ & & & 8330 \\
\hline $465-73-6$ & Isodrin & B & & & $8081 \mathrm{~A}$ & \\
\hline $50-32-8$ & Benzo(a)pyrene & & & $\mathrm{v}$ & $8270 \mathrm{C}$ & \\
\hline $53-70-3$ & Dibenz[a,h]anthracene & & & $\mathrm{v}$ & $8270 \mathrm{C}$ & \\
\hline $57-14-7$ & 1,1-Dimethylhydrazine & & II & $\mathrm{v}$ & & $8270 \mathrm{C}$ \\
\hline $58-89-9$ & gamma-BHC (Lindane) & B & & & $8081 \mathrm{~A}$ & \\
\hline $60-34-4$ & Methylhydrazine & & II & & & $8270 \mathrm{C}$ \\
\hline $60-57-1$ & Dieldrin & $\mathrm{X}$ & & iv & $8081 \mathrm{~A}$ & \\
\hline $62-75-9$ & N-Nitroso-N,N-dimethylamine & $\mathrm{B}$ & & iv & $8270 \mathrm{C}$ & \\
\hline $624-83-9$ & Methyl isocyanate & & $\mathrm{I}$ & & & 8330 \\
\hline $684-16-2$ & Hexafluoroacetone & & II & & & $8260 \mathrm{~B}$ \\
\hline $72-20-8$ & Endrin & A & $\mathrm{I}$ & & $8081 \mathrm{~A}$ & \\
\hline $74-83-9$ & Bromomethane & $\mathrm{C}$ & II & & $8260 \mathrm{~B}$ & \\
\hline $75-21-8$ & Oxirane & $\mathrm{B}$ & & $\mathrm{BC}$ & $8260 \mathrm{~B}$ & \\
\hline $76-44-8$ & Heptachlor & B & & $\mathbf{v}$ & $8081 \mathrm{~A}$ & \\
\hline $79-10-7$ & 2-Propenoic acid & & $\mathrm{I}$ & & & $8270 \mathrm{C}$ \\
\hline $8001-35-2$ & Toxaphene & $\mathrm{C}$ & & $v$ & $8081 \mathrm{~A}$ & \\
\hline $82-68-8$ & Pentachloronitrobenzene (PCNB) & $\overline{\mathrm{B}}$ & II & & $8270 \mathrm{C}$ & \\
\hline $87-68-3$ & Hexachlorobutadiene & $\overline{\mathrm{B}}$ & I & $\mathrm{BC}$ & $8270 \mathrm{C}$ & \\
\hline $87-86-5$ & Pentachlorophenol & $\bar{B}$ & & & $8151 \mathrm{~A}$ & $8270 \mathrm{C}$ \\
\hline $88-85-7$ & $\begin{array}{l}\text { 2-sec-Butyl-4,6-dinitrophenol; } \\
\text { Dinoseb }\end{array}$ & $\bar{B}$ & & & $8151 \mathrm{~A}$ & \\
\hline
\end{tabular}


Table B.29. Regulated Detected and Non-detected Organic Compounds with Higher Toxicity that are Amenable to SW-846 or Modified SW-846 Methods (EPA 1997) (44 Compounds). (Page 2 of 2)

\begin{tabular}{|c|c|c|c|c|c|c|}
\hline CAS\# & Constifuent & $\begin{array}{l}\text { UHC } \\
\text { Toxicity } \\
\text { Category }\end{array}$ & $\begin{array}{l}\text { TAP } \\
\text { Toxicity } \\
\text { Category }\end{array}$ & $\begin{array}{l}\text { Slope } \\
\text { Factor } \\
\text { Ranking }\end{array}$ & $\begin{array}{l}\text { SW } 846 \\
\text { Method }\end{array}$ & Suggested \\
\hline $88-89-1$ & Picric acid & & $\mathrm{I}$ & . & & 8330 \\
\hline $92-52-4$ & 1,1`-Biphenyl & & II & & & $8270 \mathrm{C}$ \\
\hline $98-95-3$ & Nitrobenzene & $\mathrm{D}$ & II & & $8270 \mathrm{C}$ & \\
\hline $\mathrm{CAS \#}=$ & emical abstract servi & TAP & $=$ & & & \\
\hline
\end{tabular}


Table B.30. Regulated Detected Organic Compounds with Lower Toxicity that are Common Laboratory Contaminants (2 Compounds).

\begin{tabular}{|c|c|c|c|c|c|c|}
\hline YSA & Constituent & $\begin{array}{l}\text { TwiNs } \\
\text { solid/: } \\
\text { riquid } \\
\text { Hits }\end{array}$ & $\begin{array}{l}\text { TWMS' } \\
\text { Vapor nits }\end{array}$ & $\begin{array}{l}\text { UHC } \\
\text { Toxicity } \\
\text { Category }\end{array}$ & $\begin{array}{l}\text { TAP } \\
\text { Toxicity } \\
\text { Category }\end{array}$ & $\begin{array}{l}\text { Slope } \\
\text { factor. } \\
\text { Ranking }\end{array}$ \\
\hline $117-81-7$ & Bis(2-ethylhexyl) phthalate & 33 & 1 & & & $\mathrm{BC}$ \\
\hline $84-66-2$ & Diethyl phthalate & & 24 & & III & \\
\hline
\end{tabular}

CAS\# = chemical abstract service number.

TAP $=$ toxic air pollutant.

TWINS = Tank Waste Information Network System. Solid/liquid hits were recorded from the Tank Characterization Database. Vapor hits were recorded from the vapor database.

$\mathrm{UHC}=$ underlying hazardous constituents. 
Table B.31. Regulated Detected Organic Compounds with $\geq 10$ Detects and Lower Toxicity and Associated Methods to be Compared to the Analytical Methods Chosen for the Regulated Organic Compounds with Higher Toxicity (83 Compounds). (Page 1 of 2)

\begin{tabular}{|c|c|c|c|}
\hline dAst & Constituent & $\begin{array}{l}\text { SW-846 Method } \\
\text { (EPA 1997) }\end{array}$ & Suggested Method \\
\hline $100-41-4$ & Ethyl benzene & $8260 \mathrm{~B}$ & \\
\hline $100-42-5$ & Styrene & $8260 \mathrm{~B}$ & \\
\hline $10061-01-5$ & cis-1,3-Dichloropropene & $8260 \mathrm{~B}$ & \\
\hline $10061-02-6$ & trans-1,3-Dichloropropene & $8260 \mathrm{~B}$ & \\
\hline $106-35-4$ & 3-Heptanone & & $8260 \mathrm{~B}$ \\
\hline $106-42-3$ & p-Xylene & $8260 \mathrm{~B}$ & \\
\hline $106-46-7$ & 1,4-Dichlorobenzene & $8270 \mathrm{C}$ & \\
\hline $106-93-4$ & Ethylene dibromide & $8260 \mathrm{~B}$ & \\
\hline $106-97-8$ & Butane & & $8260 \mathrm{~B}$ \\
\hline $107-06-2$ & 1,2-Dichloroethane & $8260 \mathrm{~B}$ & \\
\hline $107-87-9$ & 2-Pentanone & $8260 \mathrm{~B}$ & $8260 \mathrm{~B}$ \\
\hline $108-10-1$ & 4-Methyl-2-pentanone & $8260 \mathrm{~B}$ & \\
\hline $108-38-3$ & m-Xylene & $8260 \mathrm{~B}$ & \\
\hline $108-87-2$ & Methylcyclohexane & & $8260 \mathrm{~B}$ \\
\hline $108-88-3$ & Toluene & $8260 \mathrm{~B}$ & \\
\hline $108-90-7$ & Chlorobenzene & $8260 \mathrm{~B}$ & \\
\hline $108-94-1$ & Cyclohexanone & $8260 \bar{B}$ & \\
\hline $108-95-2$ & Phenol & $8270 \mathrm{C}$ & \\
\hline $109-66-0$ & n-Pentane & & $8260 \mathrm{~B}$ \\
\hline $109-99-9$ & Tetrahydrofuran & & $8270 \mathrm{C}$ \\
\hline $110-12-3$ & 5-Methyl-2-hexanone & & $8260 B$ \\
\hline $110-43-0$ & 2-Heptanone & & $8260 \mathrm{~B}$ \\
\hline $110-54-3$ & n-Hexane & $8260 \mathrm{~B}$ & \\
\hline $110-62-3$ & n-Valeraldehyde & $8315 \mathrm{~A}$ & \\
\hline $110-82-7$ & Cyclohexane & & $8260 \mathrm{~B}$ \\
\hline $110-83-8$ & Cyclohexene & & $8260 \mathrm{~B}$ \\
\hline $110-86-1$ & Pyridine & $8270 \mathrm{C}$ & \\
\hline $111-65-9$ & n-Octane & & $8260 \mathrm{~B}$ \\
\hline $111-84-2$ & n-Nonane & & $8260 \mathrm{~B}$ \\
\hline $120-82-1$ & 1,2,4-Trichlorobenzene & $8270 \mathrm{C}$ & \\
\hline $122-39-4$ & $\mathrm{~N}, \mathrm{~N}$-Diphenylamine & $8270 \mathrm{C}$ & \\
\hline $123-19-3$ & 4-Heptanone & & $8260 \mathrm{~B}$ \\
\hline $123-38-6$ & n-Propionaldehyde & $8260 \mathrm{~B}$ & \\
\hline $123-86-4$ & Acetic acid n-butyl ester & & $8260 \mathrm{~B}$ \\
\hline $123-91-1$ & 1,4-Dioxan & $8260 \mathrm{~B}$ & \\
\hline $127-18-4$ & $1,1,2,2$-Tetrachloroethene & $8260 \mathrm{~B}$ & \\
\hline $128-37-0$ & 2,6-Bis(tert-butyl)-4-methylphenol & & $8270 \mathrm{C}$ \\
\hline $141-78-6$ & Acetic acid ethyl ester & $8260 \mathrm{~B}$ & \\
\hline $142-82-5$ & n-Heptane & & $8260 \mathrm{~B}$ \\
\hline $287-92-3$ & Cyclopentane & & $8270 \mathrm{C}$ \\
\hline $4170-30-3$ & 2-Butenaldehyde & $8260 \mathrm{~B}$ & \\
\hline $541-73-1$ & 1,3-Dichlorobenzene & $8270 \mathrm{C}$ & \\
\hline $56-23-5$ & Carbon tetrachloride & $8260 \mathrm{~B}$ & \\
\hline $563-80-4$ & 3-Methyl-2-butanone & & $8260 \mathrm{~B}$ \\
\hline $591-78-6$ & 2-Hexanone & $8260 \mathrm{~B}$ & \\
\hline $627-13-4$ & Nitric acid, propyl ester & & $8270 \mathrm{C}$ \\
\hline
\end{tabular}


Table B.31. Regulated Detected Organic Compounds with $\geq 10$ Detects and Lower Toxicity and Associated Methods to be Compared to the Analytical Methods Chosen for the Regulated Organic Compounds with Higher Toxicity ( 83 Compounds). (Page 2 of 2)

\begin{tabular}{|c|c|c|c|}
\hline CASH & Constituent & $\begin{array}{l}\text { SW 846 Method } \\
\text { (EPA A } 1997 \text { ) }\end{array}$ & Suggested Method \\
\hline $64-17-5$ & Ethyl alcohol & $8260 \mathrm{~B}$ & \\
\hline $64-18-6$ & Formic acid & & 9056 \\
\hline $64-19-7$ & Acetic acid & & 9056 \\
\hline $67-56-1$ & Methyl alcohol & $8260 \mathrm{~B}$ & \\
\hline $67-63-0$ & 2-Propyl alcohol & $8260 \mathrm{~B}$ & \\
\hline $67-64-1$ & 2-Propanone (Acetone) & $8260 \mathrm{~B}$ & \\
\hline $67-66-3$ & Chloroform & $8260 \mathrm{~B}$ & \\
\hline $71-23-8$ & n-Propyl alcohol & $8260 \mathrm{~B}$ & \\
\hline $71-36-3$ & n-Butyl alcohol & $8260 \mathrm{~B}$ & \\
\hline $71-43-2$ & Benzene & $8260 \mathrm{~B}$ & \\
\hline $71-55-6$ & 1,1,1-Trichloroethane & $8260 \mathrm{~B}$ & \\
\hline $74-87-3$ & Chloromethane & $8260 \mathrm{~B}$ & \\
\hline$\overline{75-00-3}$ & Chloroethane & $8260 \mathrm{~B}$ & \\
\hline $75-01-4$ & 1-Chloroethene & $8260 \mathrm{~B}$ & \\
\hline $75-05-8$ & Acetonitrile & $8260 \mathrm{~B}$ & \\
\hline $75-07-0$ & Acetaldehyde & $8315 \mathrm{~A}$ & \\
\hline $75-09-2$ & Dichloromethane (Methylene Chloride) & $8260 \mathrm{~B}$ & \\
\hline $75-15-0$ & Carbon disulfide & $8260 \mathrm{~B}$ & \\
\hline $75-34-3$ & 1,1-Dichloroethane & $8260 \mathrm{~B}$ & \\
\hline $75-35-4$ & 1,1-Dichloroethene & $8260 \mathrm{~B}$ & \\
\hline $75-43-4$ & Dichlorofluoromethane & & $8260 \mathrm{~B}$ \\
\hline $75-45-6$ & Chlorodifluoromethane & & $8260 \mathrm{~B}$ \\
\hline $75-65-0$ & 2-Methyl-2-propanol & $8260 \mathrm{~B}$ & $8260 \mathrm{~B}$ \\
\hline $75-69-4$ & Trichlorofluoromethane & $8260 \mathrm{~B}$ & \\
\hline $75-71-8$ & Dichlorodifluoromethane & $8260 \mathrm{~B}$ & \\
\hline $76-13-1$ & 1,2,2-Trichlorotrifluoroethane & $8260 \mathrm{~B}$ & $8260 \mathrm{~B}$ \\
\hline 76-14-2 & 1,2-Dichloro-1,1,2,2-tetrafluoroethane & $8260 \mathrm{~B}$ & \\
\hline $78-87-5$ & 1,2-Dichloropropane & $8260 \mathrm{~B}$ & \\
\hline $78-92-2$ & 1-Methylpropyl alcohol & & $8260 \mathrm{~B}$ \\
\hline $78-93-3$ & 2-Butanone & $8260 \mathrm{~B}$ & \\
\hline $79-00-5$ & 1,1,2-Trichloroethane & $8260 \mathrm{~B}$ & \\
\hline $79-01-6$ & 1,1,2-Trichloroethylene & $8260 \mathrm{~B}$ & \\
\hline $79-34-5$ & 1,1,2,2-Tetrachloroethane & $8260 \mathrm{~B}$ & \\
\hline $95-47-6$ & o-Xylene & $8260 \mathrm{~B}$ & \\
\hline $95-50-1$ & 1,2-Dichlorobenzene & $8270 \mathrm{C}$ & \\
\hline $96-22-0$ & 3-Pentanone & & $8260 \mathrm{~B}$ \\
\hline $98-86-2$ & Acetophenone & $8270 \mathrm{C}$ & \\
\hline
\end{tabular}

CAS\# = chemical abstract service number.

$\mathrm{EPA}=$ US Environmental Protection Agency. 
Table B.32. Regulated Detected Organic Compounds $\geq 10$ Detects and Lower Toxicity Not Analyzed by Methods Applicable to Higher Toxicity Organic Compounds (2 Compounds).

\begin{tabular}{|c|c|c|c|c|c|c|c|}
\hline 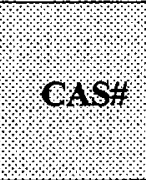 & Constituent & 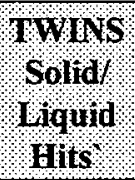 & $\begin{array}{l}\text { WW } \\
\text { Hapors } \\
\text { Hits }\end{array}$ & $\begin{array}{l}\text { ure } \\
\text { Goxicity } \\
\text { Category }\end{array}$ & $\begin{array}{l}\text { ThP } \\
\text { caxicits } \\
\text { category }\end{array}$ & $\begin{array}{c}\text { slope } \\
\text { ractort } \\
\text { Ranking }\end{array}$ & 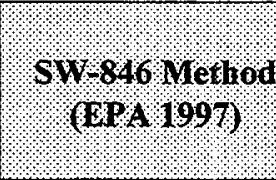 \\
\hline $110-62-3$ & n-Valeraldehyde & & 54 & & IV & & $8315 \mathrm{~A}$ \\
\hline $75-07-0$ & Acetaldehyde & & 103 & & & $\mathrm{BC}$ & $8315 \mathrm{~A}$ \\
\hline
\end{tabular}

CAS\# = chemical abstract service number.

EPA = US Environmental Protection Agency.

TAP = toxic air pollutant.

TWINS = Tank Waste Information Network System. Solid/liquid hits were recorded from the Tank Characterization Database. Vapor hits were recorded from the vapor database.

UHC = underlying hazardous constituents. 
Table B.33. Analytical Methods Used for Analysis of Higher Toxicity Organic Compounds.

\begin{tabular}{|c|}
\hline SW 846 Method (EPA 1997) \\
\hline $8081 \mathrm{~A}$ \\
\hline 8082 \\
\hline $8151 \mathrm{~A}$ \\
\hline $8260 \mathrm{~B}$ \\
\hline $8270 \mathrm{C}$ \\
\hline Suggested SW8846 Method . \\
\hline 350 \\
\hline $8260 \mathrm{~B}$ \\
\hline $8270 \mathrm{C}$ \\
\hline 8330 \\
\hline $9010 \mathrm{~A}$ \\
\hline 9056 \\
\hline
\end{tabular}

EPA $=$ U.S. Environmental Protection Agency. 
Table B.34. Regulated Detected Organic Compounds with $\geq 10$ Detects and Lower Toxicity that are Amenable to the Same Analytical Methods as the Non-detected, Stable Organic Compounds of Higher Toxicity (82 Compounds). (Page 1 of 2)

\begin{tabular}{|c|c|c|c|c|c|c|}
\hline CASA & Constituent & $\begin{array}{l}\text { GHe } \\
\text { Toxicity } \\
\text { Category }\end{array}$ & $\begin{array}{l}\text { TAP } \\
\text { Toxicity } \\
\text { Category }\end{array}$ & $\begin{array}{l}\text { Slope } \\
\text { Factor } \\
\text { Ranking }\end{array}$ & $\begin{array}{l}\text { SW } 846 \\
\text { Method } \\
\text { (EPA } \\
1997)\end{array}$ & $\begin{array}{l}\text { Suggested } \\
\text { Method }\end{array}$ \\
\hline $100-41-4$ & Ethyl benzene & $\mathrm{D}$ & IV & & $8260 \mathrm{~B}$ & \\
\hline $100-42-5$ & Styrene & & IV & & $8260 \mathrm{~B}$ & \\
\hline $10061-01-5$ & cis-1,3-Dichloropropene & & & & $8260 \mathrm{~B}$ & \\
\hline $10061-02-6$ & trans-1,3-Dichloropropene & & & & $8260 \mathrm{~B}$ & \\
\hline $106-35-4$ & 3-Heptanone & & IV & & & $8260 \mathrm{~B}$ \\
\hline $106-42-3$ & p-Xylene & $\mathrm{D}$ & $\mathrm{V}$ & & $8260 \mathrm{~B}$ & \\
\hline $106-46-7$ & 1,4-Dichlorobenzene & $\mathrm{D}$ & & & $8270 \mathrm{C}$ & \\
\hline $106-93-4$ & Ethylene dibromide & $\mathrm{C}$ & & $\mathrm{BC}$ & $8260 \mathrm{~B}$ & \\
\hline $106-97-8$ & Butane & & $\mathrm{V}$ & & & $8260 \mathrm{~B}$ \\
\hline $107-06-2$ & 1,2-Dichloroethane & $\mathrm{D}$ & & $\mathrm{BC}$ & $8260 \mathrm{~B}$ & \\
\hline $107-87-9$ & 2-Pentanone & & $\mathrm{V}$ & & $8260 \mathrm{~B}$ & $8260 \mathrm{~B}$ \\
\hline $108-10-1$ & 4-Methyl-2-pentanone & $\mathrm{D}$ & IV & & $8260 \mathrm{~B}$ & \\
\hline $108-38-3$ & m-Xylene & D & $\mathrm{V}$ & & $8260 \mathrm{~B}$ & \\
\hline $108-87-2$ & Methylcyclohexane & & $\mathrm{V}$ & & & $8260 \mathrm{~B}$ \\
\hline $108-88-3$ & Toluene & $\mathrm{D}$ & IV & & $8260 \mathrm{~B}$ & \\
\hline $108-90-7$ & Chlorobenzene & $\mathrm{D}$ & IV & & $8260 \mathrm{~B}$ & \\
\hline $108-94-1$ & Cyclohexanone & $\overline{\mathrm{C}}$ & IV & & $8260 \mathrm{~B}$ & \\
\hline $108-95-2$ & Phenol & $\bar{C}$ & III & & $8270 \mathrm{C}$ & \\
\hline 109-66-0 & n-Pentane & & $\mathrm{V}$ & & & $8260 \mathrm{~B}$ \\
\hline $109-99-9$ & Tetrahydrofuran & & $\mathrm{V}$ & & & $8270 \mathrm{C}$ \\
\hline $110-12-3$ & 5-Methyl-2-hexanone & & IV & & & $8260 \mathrm{~B}$ \\
\hline $110-43-0$ & 2-Heptanone & & IV & & & $8260 \mathrm{~B}$ \\
\hline $110-54-3$ & n-Hexane & & IV & & $8260 \mathrm{~B}$ & \\
\hline $110-82-7$ & Cyclohexane & & $\mathrm{V}$ & & & $8260 \mathrm{~B}$ \\
\hline $110-83-8$ & Cyclohexene & & $\mathrm{V}$ & & & $8260 \mathrm{~B}$ \\
\hline $110-86-1$ & Pyridine & $\mathrm{C}$ & III & & $8270 \mathrm{C}$ & \\
\hline $111-65-9$ & n-Octane & & $\mathrm{V}$ & & & $8260 \mathrm{~B}$ \\
\hline $111-84-2$ & n-Nonane & & V & & & $8260 \mathrm{~B}$ \\
\hline $120-82-1$ & 1,2,4-Trichlorobenzene & $\mathrm{D}$ & IV & & $8270 \mathrm{C}$ & \\
\hline $122-39-4$ & N,N-Diphenylamine & $\mathrm{D}$ & III & & $8270 \mathrm{C}$ & \\
\hline $123-19-3$ & 4-Heptanone & & IV & & & $8260 \mathrm{~B}$ \\
\hline $123-38-6$ & n-Propionaldehyde & & $\mathrm{V}$ & & $8260 \mathrm{~B}$ & \\
\hline $123-86-4$ & Acetic acid n-butyl ester & & V & & & $8260 \mathrm{~B}$ \\
\hline $123-91-1$ & 1,4-Dioxan & $\bar{D}$ & & & $8260 \mathrm{~B}$ & \\
\hline $127-18-4$ & 1,1,2,2-Tetrachloroethene & $\mathrm{D}$ & & $\mathrm{BC}$ & $8260 \mathrm{~B}$ & \\
\hline $128-37-0$ & 2,6-Bis(tert-butyl)-4-methylphenol & & III & & & $8270 \mathrm{C}$ \\
\hline $141-78-6$ & Acetic acid ethyl ester & $\mathrm{D}$ & $\mathrm{V}$ & & $8260 \mathrm{~B}$ & \\
\hline $142-82-5$ & n-Heptane & & $\mathrm{V}$ & & & $8260 \mathrm{~B}$ \\
\hline $287-92-3$ & Cyclopentane & & $\mathrm{V}$ & & & $8270 \mathrm{C}$ \\
\hline $4170-30-3$ & 2-Butenaldehyde & & III & & $8260 \mathrm{~B}$ & \\
\hline $541-73-1$ & 1,3-Dichlorobenzene & & & & $8270 \mathrm{C}$ & \\
\hline $56-23-5$ & Carbon tetrachloride & $\mathrm{D}$ & & $\mathrm{BC}$ & $8260 \mathrm{~B}$ & \\
\hline $563-80-4$ & 3-Methyl-2-butanone & & $\mathrm{V}$ & & & $8260 \mathrm{~B}$ \\
\hline $591-78-6$ & 2-Hexanone & & III & & $8260 \mathrm{~B}$ & \\
\hline
\end{tabular}


Table B.34. Regulated Detected Organic Compounds with $\geq 10$ Detects and Lower Toxicity that are Amenable to the Same Analytical Methods as the Non-detected, Stable Organic Compounds of Higher Toxicity ( 82 Compounds). (Page 2 of 2)

\begin{tabular}{|c|c|c|c|c|c|c|}
\hline CASH & Constituent & $\begin{array}{l}\text { UHC } \\
\text { roxicity } \\
\text { Category }\end{array}$ & $\begin{array}{l}\text { TAP } \\
\text { Toxicity } \\
\text { Category }\end{array}$ & $\begin{array}{l}\text { Slope } \\
\text { ractor } \\
\text { Ranking }\end{array}$ & $\begin{array}{l}\text { SW } 846 \\
\text { Method } \\
(\mathrm{EPA} \\
1997)\end{array}$ & $\begin{array}{l}\text { Suggested } \\
\text { Method }\end{array}$ \\
\hline $627-13-4$ & Nitric acid, propyl ester & & IV & & & $8270 \mathrm{C}$ \\
\hline $64-17-5$ & Ethyl alcohol & & $\mathrm{V}$ & & $8260 \mathrm{~B}$ & \\
\hline $64-18-6$ & Formic acid & & III & & & 9056 \\
\hline $64-19-7$ & Acetic acid & & III & & & 9056 \\
\hline $67-56-1$ & Methyl alcohol & D & IV & & $8260 \mathrm{~B}$ & \\
\hline $67-63-0$ & 2-Propyl alcohol & & $\mathrm{V}$ & & $8260 \mathrm{~B}$ & \\
\hline $67-64-1$ & 2-Propanone (Acetone) & & $\mathrm{V}$ & & $8260 \mathrm{~B}$ & \\
\hline $67-66-3$ & Chloroform & $\mathrm{D}$ & & $\mathrm{BC}$ & $8260 \mathrm{~B}$ & \\
\hline $71-23-8$ & n-Propyl alcohol & & $\bar{V}$ & & $8260 \mathrm{~B}$ & \\
\hline $71-36-3$ & n-Butyl alcohol & D & IV & & $8260 \mathrm{~B}$ & \\
\hline $71-43-2$ & Benzene & $\mathrm{D}$ & & $\mathrm{BC}$ & $8260 \mathrm{~B}$ & \\
\hline $71-55-6$ & 1,1,1-Trichloroethane & $\mathrm{D}$ & $\mathrm{V}$ & & $8260 \mathrm{~B}$ & \\
\hline 74-87-3 & Chloromethane & $\mathrm{C}$ & IV & $\mathrm{BC}$ & $8260 \mathrm{~B}$ & \\
\hline $75-00-3$ & Chloroethane & $\mathrm{D}$ & $\mathrm{V}$ & & $8260 \mathrm{~B}$ & \\
\hline $75-01-4$ & 1-Chloroethene & $\mathrm{D}$ & & $\mathrm{BC}$ & $8260 \mathrm{~B}$ & \\
\hline $75-05-8$ & Acetonitrile & $\mathrm{C}$ & IV & & $8260 \mathrm{~B}$ & \\
\hline $75-09-2$ & Dichloromethane (Methylene Chloride) & $\mathrm{D}$ & & $\mathrm{BC}$ & $8260 \mathrm{~B}$ & \\
\hline $75-15-0$ & Carbon disulfide & $\mathrm{D}$ & III & & $8260 \mathrm{~B}$ & \\
\hline $75-34-3$ & 1,1-Dichloroethane & $\mathrm{D}$ & $\mathrm{V}$ & & $8260 \mathrm{~B}$ & \\
\hline $75-35-4$ & 1,1-Dichloroethene & $\mathrm{C}$ & III & $\mathrm{BC}$ & $8260 \mathrm{~B}$ & \\
\hline $75-43-4$ & Dichlorofluoromethane & & IV & & & $8260 \mathrm{~B}$ \\
\hline $75-45-6$ & Chlorodifluoromethane & & $\mathrm{V}$ & & & $8260 \mathrm{~B}$ \\
\hline $75-65-0$ & 2-Methyl-2-propanol & & IV & & $8260 \mathrm{~B}$ & $8260 \mathrm{~B}$ \\
\hline $75-69-4$ & Trichlorofluoromethane & & $\mathrm{V}$ & & $8260 \mathrm{~B}$ & \\
\hline $75-71-8$ & Dichlorodifluoromethane & & $\bar{V}$ & & $8260 \mathrm{~B}$ & \\
\hline $76-13-1$ & 1,2,2-Trichlorotrifluoroethane & & $\mathrm{V}$ & & $8260 \mathrm{~B}$ & $8260 \mathrm{~B}$ \\
\hline $76-14-2$ & 1,2-Dichloro-1,1,2,2-tetrafluoroethane & & $\mathrm{V}$ & & $8260 \mathrm{~B}$ & \\
\hline $78-87-5$ & 1,2-Dichloropropane & $\mathrm{D}$ & & & $8260 \mathrm{~B}$ & \\
\hline $78-92-2$ & 1-Methylpropyl alcohol & & IV & & & $8260 \mathrm{~B}$ \\
\hline $78-93-3$ & 2-Butanone & $\mathrm{D}$ & IV & & $8260 \mathrm{~B}$ & \\
\hline $79-00-5$ & 1,1,2-Trichloroethane & $\mathrm{D}$ & IV & $\mathrm{BC}$ & $8260 \mathrm{~B}$ & \\
\hline $79-01-6$ & 1,1,2-Trichloroethylene & & & $\mathrm{BC}$ & $8260 \mathrm{~B}$ & \\
\hline $79-34-5$ & 1,1,2,2-Tetrachloroethane & D & III & $\overline{B C}$ & $8260 \mathrm{~B}$ & \\
\hline $95-47-6$ & o-Xylene & $\mathrm{D}$ & $\mathrm{V}$ & & $8260 \mathrm{~B}$ & \\
\hline $95-50-1$ & 1,2-Dichlorobenzene & $\mathrm{D}$ & IV & & $8270 \mathrm{C}$ & \\
\hline $96-22-0$ & 3-Pentanone & & $\mathrm{V}$ & & & $8260 \mathrm{~B}$ \\
\hline $98-86-2$ & Acetophenone & D & $\mathrm{V}$ & & $8270 \mathrm{C}$ & \\
\hline \multicolumn{7}{|c|}{ CAS\# = chemical abstract service number } \\
\hline $\begin{array}{l}\text { EPA } \\
\text { TAP }\end{array}$ & $\begin{array}{l}\text { S Environmental Protection Agency. } \\
\text { xic air pollutant. }\end{array}$ & & & & & \\
\hline
\end{tabular}




\section{References}

Agnew SM. 1997. Hanford Tank Chemical and Radionuclide Inventories: HDW Model.

LA-UR-96-3860, Rev. 4. Los Alamos National Laboratory, Los Alamos, New Mexico.

EPA. 1997. Test Methods for Evaluation Solid Waste Physical/Chemical Methods. SW-846, 3rd Edition, as amended by Updates I (July, 1992), IIA (August, 1993), IIB (January, 1995), and III. US Environmental Protection Agency, Washington, D.C.

Klem MJ. 1990. Inventory of Chemicals Used at Hanford Site Production Plants and Support Operations (1944-1980). WHC-EP-0172, Rev. 1. Westinghouse Hanford Company, Richland, Washington. 


\section{Appendix C}

Rationale for Selection of Organic Toxic and Carcinogenic Compounds from the Hanford Single-Shell Tank/Double-Shell Tank Waste Considered for Analysis in Support of the Regulatory Data Quality Objective 


\section{Contents}

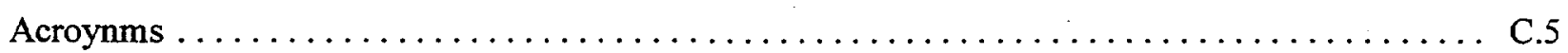

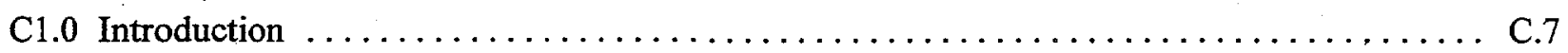

C2.0 Regulatory Data Quality Objective Input List $\ldots \ldots \ldots \ldots \ldots \ldots \ldots \ldots \ldots \ldots \ldots \ldots$

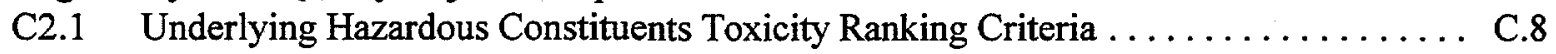

C2.2 WAC 173-460, Class B Toxic Air Pollutant Toxicity Ranking Criteria . . . . . . . . C.9

C2.3 WAC 173-460, Class A Toxic Air Pollutant Carcinogenicities .............. C.9

C2.4 Universal Treatment Standard $\ldots \ldots \ldots \ldots \ldots \ldots \ldots \ldots \ldots \ldots \ldots \ldots \ldots \ldots \ldots$

C2.5 Integrated Risk Information System and Health Effects Assessment Summary Tables

Carcinogenicity Ranking Criteria $\ldots \ldots \ldots \ldots \ldots \ldots \ldots \ldots \ldots \ldots \ldots \ldots \ldots \ldots \ldots \ldots \ldots \ldots$

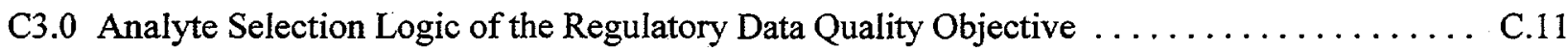

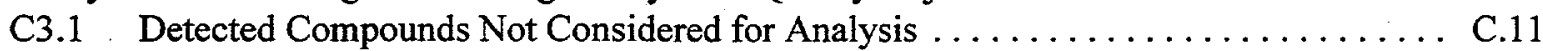

C3.2 Undetected Compounds Removed During "Used in Industries

Potentially Unrelated to Hanford" Evaluation $\ldots \ldots \ldots \ldots \ldots \ldots \ldots \ldots$. . . 12

C3.3 Undetected Compounds, Considered Unstable .................... C.12

C3.4 Undetected, Stable Compounds with Lower Toxicity . . . . . . . . . . . . . . C.13

C3.5 Lower Toxicity Compounds, Detected Due to Common Lab Contamination ....... C.13

C3.6 Detected Compounds, Lower Toxicity, Not Analyzed by Methods Applicable to

Higher Toxicity Compounds . . . . . . . . . . . . . . . . . . . . . C.13

C3.7 Priority Regulated Compounds for Characterization in Support of the

Regulatory Data Quality Objective $\ldots \ldots \ldots \ldots \ldots \ldots \ldots \ldots \ldots \ldots \ldots \ldots \ldots \ldots \ldots \ldots$

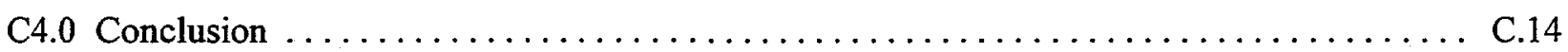

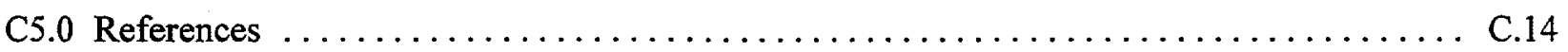

\section{Tables}

C.1 Regulatory Data Quality Objective Input List Distribution for Organic Compounds $\ldots \ldots \ldots$ C.8

C.2 Toxic Categories Used for Ranking Compounds $\ldots \ldots \ldots \ldots \ldots \ldots \ldots \ldots \ldots \ldots \ldots$

C.3 Prioritization Grouping of Associated Acceptable Source Impact Levels Values . . . . . . . C.9

C.4 Prioritization Grouping of $\log _{(10)}$ Slope Factors $\ldots \ldots \ldots \ldots \ldots \ldots \ldots \ldots \ldots \ldots \ldots \ldots \ldots \ldots \ldots$

C.5 Summary Accounting of Regulated Toxins in the Regulatory Data Quality Objective ...... C.11

C.6 Detected and Undetected, Stable Compounds with Higher Toxicity for Characterization .... C.15

C.7 Detected Compounds with Lower Toxicity Considered for Characterization ......... C.17 


\section{Attachments}

1. Regulated Organic Compounds Without Toxicity or Carcinogenicity Ranking ........ C.19

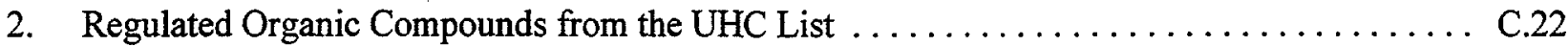

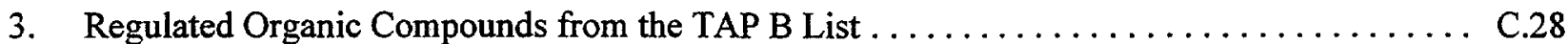

4. Regulated Organic Compounds from the TAP A List $\ldots \ldots \ldots \ldots \ldots \ldots \ldots \ldots \ldots \ldots$

5. Regulated Organic Compounds from the UTS List $\ldots \ldots \ldots \ldots \ldots \ldots \ldots \ldots \ldots \ldots$

6. Regulated Organic Compounds with a Carcinogenicity Ranking $\ldots \ldots \ldots \ldots \ldots \ldots \ldots$ C.46

7. Q5-4, Detected Compounds, Lower Toxicity and Less Than 10 Detects, Not Considered

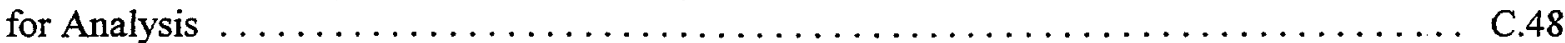

8. Q16-2, Undetected Compounds Removed During "Used In Industries Potentially Unrelated to Hanford" Evaluation . . . . . . . . . . . . . . . . . . . . . . . . . . . . C

9. Q18R, Undetected Compounds, Considered Unstable $\ldots \ldots \ldots \ldots \ldots \ldots \ldots \ldots \ldots \ldots \ldots \ldots$

10. Q24, Undetected, Stable Compounds with Lower Toxicity $\ldots \ldots \ldots \ldots \ldots \ldots \ldots \ldots \ldots$ C.60

11. Q37, Lower Toxicity Compounds, Detected Due to Common Lab Contamination ........ C.61

12. Q40b, Detected Compounds, Lower Toxicity, Not Analyzed by Methods Applicable to Higher

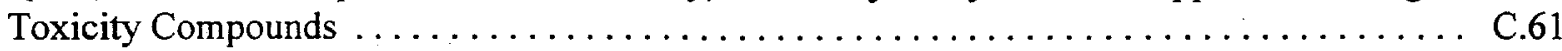




\section{Acronyms}

ASIL associated acceptable source impact levels

$\mathrm{BC}$

CFR

DQO

DST

EPA

HEAST

IRIS

RCRA

SST

TAP

TIC

below cut-point

Code of Federal Regulations

Data Quality Objectives

double-shell tank

U.S. Environmental Protection Agency

Health Effects Assessment Summary Tables

Integrated Risk Information System

Resource Conservation and Recovery Act of 1976

TWINS

single-shell tank

Toxic Air Pollutant

tentative identification of compounds

UHC

Tank Waste Information Network System

UTS

Underlying Hazardous Constituents

WAC

Universal Treatment Standards

WSPS

Washington Administrative Code

Waste Stream Profile Sheet 



\section{C1.0 Introduction}

The objective of this technical rationale is to provide descriptions of the completed activities that answer the question: "What toxic and carcinogenicity organic compounds should be considered for analysis of compounds from the Hanford single-shell and double-shell tank (SST/DST) waste in support of the Regulatory Data Quality Objectives (DQO) for privatization?"

The toxicity information was collected from the following sources:

- Universal Treatment Standards, Resource Conservation and Recovery Act of 1976 (RCRA), 40 Code of Federal Regulations (CFR) 268.48,

- Washington Administrative Code (WAC) 173-460,

- Health Effects Assessment Summary Tables (HEAST), and

- Integrated Risk Information System (IRIS) database.

The contents of these documents and resources are discussed in detail in Section C2.0, and the relationship of the toxic compounds to the Regulatory DQO analyte selection logic is discussed in Section C3.0. Compounds were divided into those detected in the SST/DST waste and those that were undetected. Undetected compounds were reviewed for stability in the tanks, as described Section C4.0 of the Regulatory DQO, level of toxicity, and carcinogenicity. Compounds rated with higher toxicity and carcinogenicity are included for potential analyses. Compounds detected 10 or more times with lower toxicity are included for potential analyses. The summary of the number of compounds resulting at each point in the evaluation is presented in Table $\mathrm{C} 5$, and the final list of compounds remaining for potential analysis is presented in Tables $\mathrm{C} 6$ and $\mathrm{C7}$. The referenced figure numbers are based on the figures presented in the Regulatory DQO. ${ }^{1}$

The treatment contractor will assess the risk drivers based on information from the source tanks and the process design. Since the designs are not finalized and the treatment facility design information is not available for use in the Regulatory DQO, the toxicity/carcinogenicity evaluation does not presuppose risk pathways and receptors. The risk assessment work plan to be completed by the treatment contractor should evaluate the risk pathways and receptors.

'Some of the tables provided in Appendix $\mathrm{C}$ are redundant with Appendix B tables referenced in the main body of the DQO. Redundancy was maintained to provide complete compound traceability to the reader solely interested in toxicity rankings. 


\section{C2.0 Regulatory Data Quality Objective Input List}

The starting list in the Regulatory DQO contains 850 compounds; 623 are organic compounds. These 623 organic compounds originate from the Underlying Hazardous Constituents (UHC), Universal Treatment Standards (UTS) (40 CFR 268), Toxic Air Pollutant (TAP) Classes A and B lists (WAC 173460), as well as from the DST Part A permit application and the DST Waste Stream Profile Sheet (WSPS). Table $\mathrm{Cl}$ provides the contribution of compounds between the list from the Regulatory DQO input list. From the 623 organic compounds, 518 compounds have a ranking for toxicity or carcinogenicity; 105 compounds do not have an associated ranking. The 105 compounds are listed in Attachment 1. The remainder of Section C2.0 discusses the criteria applied to the compounds to determine toxicity or carcinogenicity ranking.

Table C1. Regulatory Data Quality Objective Input List Distribution for Organic Compounds.

\begin{tabular}{|l|c|}
\hline \multicolumn{1}{|c|}{ Regulatory Input List } & Number of Compounds \\
\hline Underlying Hazardous Constituents (UHC) & 223 \\
\hline Universal Treatment Standards (UTS) & 232 \\
\hline Toxic Air Pollutant A (TAP A) & 128 \\
\hline Toxic Air Pollutant B (TAP B) & 381 \\
\hline DST Part A permit application & 39 \\
\hline DST Waste Stream Profile Sheet (DST WSPS) & 1 \\
\hline Total Unique Organic Compounds & $623^{*}$ \\
\hline
\end{tabular}

*Many compounds are common to multiple regulatory lists; therefore, the total of the individual lists is not the same total as the number of unique organic analytes in the Regulatory DQO starting list.

\section{C2.1 Underlying Hazardous Constituents Toxicity Ranking Criteria}

The UHC list was included in the Regulatory DQO starting list. For the UHCs, each compound's toxicity ranking was determined by Rust Federal Services of Hanford, Inc., in accordance with the method provided under the "Dangerous Waste Regulations" [WAC 173-303-100(5)(b)], book designation procedure. This method ranks compounds into toxic categories of $\mathrm{X}, \mathrm{A}, \mathrm{B}, \mathrm{C}$, and D as shown in Table C2. The Regulatory DQO input list contains 223 organic compounds from the UHCs, which are listed in Attachment 2. In the Regulatory DQO logic, regulated compounds with a higher toxicity ranking $(\mathrm{X}, \mathrm{A}$, or $\mathrm{B})$ were retained for further consideration.

Table C2. Toxic Categories Used for Ranking Compounds.

\begin{tabular}{|c|c|c|c|c|}
\hline Tovic Rankingt & $\mathrm{LC}_{50}$ (mish $\left./ \mathrm{m}\right)$ & $\begin{array}{c}\text { Oral (Rat) } \\
\text { LD }_{s 0}(\mathbf{m g} / \mathbf{k g})\end{array}$ & Inhalation (Rat) & Bermal (Rabbit) \\
\hline $\mathrm{X}$ & $<0.01$ & $<0.5$ & $<0.02$ & $<2$ \\
\hline $\bar{A}$ & $0.01 \leq 0.1$ & $0.5 \leq 5$ & $0.02 \leq 0.2$ & $2 \leq 20$ \\
\hline B & $0.1 \leq 1$ & $5 \leq 50$ & $0.2 \leq 2$ & $20 \leq 200$ \\
\hline C & $1 \leq 10$ & $50 \leq 500$ & $2 \leq 20$ & $200 \leq 2,000$ \\
\hline D & $10-100$ & $500-5,000$ & $20-200$ & $2,000-20,000$ \\
\hline
\end{tabular}

*Toxicity decreases from $\mathrm{X}$ to $\mathrm{D}$. 


\section{C2.2 WAC 173-460, Class B Toxic Air Pollutant Toxicity Ranking Criteria}

The Washington State Department of Ecology (Ecology) published the TAPs in WAC 173-460. WAC 173-460-160 lists 527 compounds from the Class B TAPs and classifies them based on toxicity. The measure of toxicity used for Class B TAPs is based on the TAP's associated acceptable source impact levels (ASIL), which are given in micrograms per cubic meter for a continuous 24-hr period. The smaller the ASIL value the more toxic the compound.

The process used for this assessment sorted all TAPs Class B compounds by their ASIL; from highly toxic to less toxic. The organic compounds were then broken into groups as shown in Table $\mathrm{C} 3$. Each compound's ASIL was compared to the comparable toxicity range for the UHC levels X, A, B, C and D. The comparison between the higher toxicity UHCs and the ASILs of the TAP B list resulted in categories I and II being selected to represent higher toxicity. The Regulatory. DQO input list contains 381 organic compounds from the Class B TAPs, which are listed in Attachment 3. For the Regulatory DQO logic, the regulated compounds with a higher toxicity ranking (I and II) were retained for further consideration.

Table C3. Prioritization Grouping of Associated Acceptable Source Impact Levels Values.

\begin{tabular}{|l|c|}
\hline \multicolumn{1}{|c|}{ ASII Toxicity Range } & Ranking \\
\hline$<1 \mu \mathrm{g} / \mathrm{m}^{3}-24$ hour & $\mathrm{I}$ \\
\hline $1 \mu \mathrm{g} / \mathrm{m}^{3}$ to $10 \mu \mathrm{g} / \mathrm{m}^{3}-24$ hour & II \\
\hline$>10 \mu \mathrm{g} / \mathrm{m}^{3}$ to $100 \mu \mathrm{g} / \mathrm{m}^{3}-24$ hour & III \\
\hline$>100 \mu \mathrm{g} / \mathrm{m}^{3}$ to $1,000 \mu \mathrm{g} / \mathrm{m}^{3}-24$ hour & IV \\
\hline$>1,000 \mu \mathrm{g} / \mathrm{m}^{3}-24$ hour & V \\
\hline
\end{tabular}

*Toxicity decreases from I to $\mathrm{V}$.

\section{C2.3 WAC 173-460, Class A Toxic Air Pollutant Carcinogenicities}

Ecology published the TAPs in WAC 173-460. WAC 173-460-150 lists the Class A TAPs that are known or probable carcinogenicities. There are 128 organic compounds that are common to both the Class A TAPs and the Regulatory DQO input list. These compounds are listed in Attachment 4. These compounds are part of the Regulatory DQO initial starting list and ranking for carcinogenicity was done via the approach discussed in Section C2.5.

\section{C2.4 Universal Treatment Standard}

The UTS is part of the Regulatory DQO starting list. Comparison of the UTS and the UHC indicates that 22 organic compounds are included on the UTS list that are not part of the UHC list. All the organic UTS compounds were included in the toxicity and carcinogenicity evaluation. No specific ranking was done for the UTS because most of the compounds are covered by the UHC toxicity evaluation. All compounds were evaluated per the approach discussed in Section C2.5 for carcinogenicity. The UTS compounds from the Regulatory DQO input list are shown in Attachment 5. 


\section{C2.5 Integrated Risk Information System and Health Effects Assessment Summary Tables Carcinogenicity Ranking Criteria}

The IRIS database and the HEAST are U.S. Environmental Protection Agency (EPA) sources that contain reference doses and carcinogenic potency slope factors for nearly 600 chemicals. The carcinogen rankings were assigned by using the greatest of the two slope factors from IRIS and HEAST, taking the logarithm and sorting the results into the groups listed in Table C4. The cut-off point was set at slope factor $=1$. Compounds below slope factor $=1$ are designated below cut-point $(B C)$.

Table C4. Prioritization Grouping of $\log _{(10)}$ Slope Factors.

\begin{tabular}{|c|c|c|}
\hline Ranking* & Log or Slope Factor & Range of Slope Factors \\
\hline $\mathrm{i}$ & $>3.5$ & $>3,162$ \\
\hline ii & 3.5 to $>3.0$ & 3,162 to $>1,000$ \\
\hline iii & 3.0 to $>2.0$ & 1,000 to $>100$ \\
\hline iv & 2.0 to $>1.0$ & 100 to $>10$ \\
\hline $\mathrm{v}$ & 1.0 to 0 & 10 to 1 \\
\hline $\mathrm{BC}$ & $<0$ & $<1$ \\
\hline
\end{tabular}

*Carcinogenicity decreases from I to $\mathrm{v}$.

The weight of evidence of the compounds was reviewed. Because the cut-point for inclusion of compounds was set conservatively low, the weight of evidence was not necessary for the evaluation of including or excluding compounds of interest.

There are 48 compounds from the Regulatory DQO starting list that have carcinogenicity rankings above the cut-off point. These compounds are listed in Attachment 6. For the Regulatory DQO logic, regulated compounds with a carcinogenicity ranking of $i$ to $v$ were retained for further consideration. 


\section{C3.0 Analyte Selection Logic of the Regulatory Data Quality Objective}

The present Regulatory DQO analyte selection logic was applied to the regulated toxins and carcinogens. The following text explains the results of the comparison. References made to items such as "Q2, Q3, Q5-4," etc., refer to the individual queries in the database, and are marked as such on the logic flowchart (Figures 4.1 through 4.6 of the DQO main body). The attachments represent the compounds not considered for analysis in the SST/DST waste. Table C5 summarizes the result of the comparison to the database.

Table C5. Summary Accounting of Regulated Toxins in the Regulatory Data Quality Objective.

\begin{tabular}{|c|c|c|}
\hline Table/Attachment & Contents & Count \\
\hline Attachment 1 & Total number of organics in the DQO starting list & 623 \\
\hline Attachment 7 & Detected compounds, lower toxicity and less than 10 detects & 42 \\
\hline Attachment 8 & $\begin{array}{l}\text { Undetected compounds removed during "Used in Industries } \\
\text { Potentially Unrelated to Hanford" Evaluation }\end{array}$ & 208 \\
\hline Attachment 9 & Undetected compounds, considered unstable & 179 \\
\hline Attachment 10 & Undetected, stable compounds with lower toxicity & 65 \\
\hline Attachment 11 & $\begin{array}{l}\text { Lower toxicity compounds, detected due to common lab } \\
\text { contamination }\end{array}$ & 2 \\
\hline Attachment 12 & $\begin{array}{l}\text { Detected compounds, lower toxicity, not analyzed by methods } \\
\text { applicable to higher toxicity compounds }\end{array}$ & 2 \\
\hline Table C6 & $\begin{array}{l}\text { Detected and undetected, stable compounds with higher } \\
\text { toxicity for characterization }\end{array}$ & 44 \\
\hline Table C7 & $\begin{array}{l}\text { Detected compounds with lower toxicity considered for } \\
\text { characterization }\end{array}$ & 81 \\
\hline
\end{tabular}

\section{C3.1 Detected Compounds Not Considered for Analysis}

From the list of regulated compounds in Attachments 1 through 5, 42 compounds are not considered for further analysis since they have been detected in the SST/DST waste less than 10 times and have lower toxicity and carcinogenicity (Figure 4.2, Q5-4). These 42 compounds are shown in Attachment 7. Those compounds detected 9 or fewer times were primarily detected in the headspace of the tanks. The primary method of detection is by tentative identification of compounds (TICs) in the tank headspace using gas chromatography/mass spectrometry. Compounds reported as TICs are identified by comparison of mass spectra from the sample to libraries of spectra. The identification and quantitation are not confirmed by the running of standards on the instrument used to analyze the sample. Therefore, significant uncertainty is associated in the identity and quantification of TICs. TICs are identified by either a compound name from best match from the library, as a compound class (e.g., aromatic), or are reported as an unknown. Since these compounds were not detected frequently, are mostly TICs, and are of lower toxicity, additional analyses are not recommended. The detected compounds of higher toxicity (e.g., rankings X, A, B, I, II, or i-v) are considered for analyses. 


\section{C3.2 Undetected Compounds Removed During "Used in Industries Potentially Unrelated to Hanford" Evaluation}

The Regulatory DQO input list contains 208 regulated compounds that were assigned to "Used in Industries Potentially Unrelated to Hanford" (Wiemers et al. 1998a) (Figure 4.3, Q.16-2). These analytes are listed in Attachment 8. Excluded from this list are all chlorinated pesticides and herbicides that remain for tank stability assessment, possible "ghost" compounds, and analytes reported by either Agnew (1997) or Klem (1990).

One example of the logic used to assess a specific toxin as a consumer chemical is presented:

Caprolactam (CAS \# 105-60-2) was found at the website NTP CHEMICAL REPOSITORY (RADIAN CORPORATION, AUGUST 29, 1991), http://ntp-db.niehs.nih.gov/NTP_Reports/ NTP_Chem_H\&S/NTP_Chem1/Radian105-60-2.txt. The information provided in the MSDS states: "*USES: This compound is used in the manufacture of synthetic fibers, plastics, bristles, film, coatings, synthetic leather, plasticizers and paint vehicles. It is a cross-linking agent for polyurethanes and it is used in the synthesis of lysine."

The Tank Waste Information Network System (TWINS) Tank Characterization Database and vapor database does not report any detections in the SST/DST waste for this compound; conversely, documentation is not available to verify if analyses were performed for this compound. The compound Caprolactam was listed as "consumer product" and being "Used in Industries Potentially Unrelated to Hanford."

\section{C3.3 Undetected Compounds, Considered Unstable}

The next step in the Regulatory DQO logic is to evaluate the regulated compounds for stability in the tank waste environment (Figure 4.4, Q21R). A total of 179 regulated compounds are considered unstable in the tank waste environment, and did not continue through in the analyte selection logic (Figure 4.4, Q18R). These 179 compounds are listed in Attachment 9. The technical rationale for the stability evaluation can be found in Wiemers et al. (1998b).

\section{C3.4 Undetected, Stable Compounds with Lower Toxicity}

The remaining undetected, stable, and potentially used at Hanford analytes were then evaluated for their specific toxicity and carcinogenicity rankings (Figure 4.4, Q24). The selection criteria for toxicity was set so that regulated compounds with a toxicity ranking of X, A, B, I, II, i, ii, iii, iv, or v (see Tables C2, C3, and C4) were retained for further consideration. Of these analytes, 65 compounds are of lower toxicity and carcinogenicity and are listed in Attachment 10 (Figure 4.4, Q24). The compounds in Attachment 10 are not considered for analysis in the SST/DST waste. 


\section{C3.5 Lower Toxicity Compounds, Detected Due to Common Lab Contamination}

The regulated detected compounds were reviewed to ensure the reported detections are not due to common lab contaminations during the analysis process (Figure 4.6, Q37). From these detections, 2 compounds were reported that are common laboratory contaminants, and were removed from the logic selection process. These 2 compounds are listed in Attachment 11 and are not considered for analysis in the SST/DST waste.

\section{C3.6 Detected Compounds, Lower Toxicity, Not Analyzed by Methods Applicable to Higher Toxicity Compounds}

The regulated detected and non-detected compounds with higher toxicity were associated with the respective SW-846 methods for analysis (Figure 4.5, Q36). The selection of methods for the detected compounds of lower toxicity was limited to the methods selected for the compounds of higher toxicity. A comparison (Figure 4.6, Q40b) between the higher and lower toxic compounds showed only 2 compounds that were detected more than 10 times and are not amenable to the same analytical methods that are applicable to the higher toxicity compounds. These compounds are listed in Attachment 12.

\section{C3.7 Priority Regulated Compounds for Characterization in Support of the Regulatory Data Quality Objective}

Applying the logic shown in Figure 4.6, Q42 of the logic flowchart, results in a list of compounds that will be used for characterization support of the Regulatory DQO. The priority-regulated compounds are a combination of the compounds that are stable and of higher toxicity, and the detected compounds of lower toxicity. Table $\mathrm{C} 6$ lists the 44 detected and undetected, stable compounds with higher toxicity for characterization. Table $\mathrm{C} 7$ lists the 81 detected compounds with lower toxicity considered for characterization.

\section{C4.0 Conclusion}

The toxic and carcinogenic compounds have been evaluated for their potential past use at Hanford and their current use. The starting list of these compounds is based on regulatory lists discussed in Section 4.0 of the Regulatory DQO. The toxic and carcinogenic compounds considered for analysis of Hanford SST/DST waste in support of the Regulatory DQO for privatization are summarized in Tables $\mathrm{C} 6$ and $\mathrm{C} 7$.

The compounds considered for additional analysis are:

- Undetected, considered stable in the tank matrix, and of higher toxicity/carcinogenicity,

- Detected and of higher toxicity/carcinogenicity, and

- Detected $\geq 10$ times and of lower in toxicity. 


\section{C5.0 References}

40 CFR 268.48. "Land Disposal Restrictions." Code of Federal Regulations, as amended.

Agnew, SM. 1997. Hanford Tank Chemical and Radionuclide Inventories: HDW Model.

LA-UR-96-3860, Rev. 4. Los Alamos National Laboratory, Los Alamos, New Mexico.

Klem, MJ. 1990. Inventory of Chemicals Used at Hanford Site Production Plants and Support Operations (1944-1980). WHC-EP-0172, Rev. 1. Westinghouse Hanford Company, Richland, Washington.

Resource Conservation and Recovery Act of 1976. 42 USC 6901 et seq.

WAC 173-303-100(5)(b). "Dangerous Waste Regulations." Washington Administrative Code, as amended.

WAC 173-460. "Controls for New Sources of Toxic Air Pollutants." Washington Administrative Code, as amended.

Weimers, KD, RT Hallen, H Babad, LK Jagoda, and K Meier. 1998a A Compilation of Regulated Organic Constituents Not Associated with the Hanford Site, Richland, Washington. PNNL-11927. Pacific Northwest National Laboratory, Richland, Washington.

Weimers, KD, H Babad, RT Hallen, ME Lerchen, and LP Jackson. 1998b. An Assessment of the Stability and the Potential for In-Situ Synthesis of Regulated Organic Compounds in High Level Radioactive Waste Stored at Hanford, Richland, Washington. PNNL-11943. Pacific Northwest National Laboratory, Richland, Washington. 
Table C6. Detected and Undetected, Stable Compounds with Higher Toxicity for Characterization. (44 Compounds) (Page 1 of 2)

\begin{tabular}{|c|c|c|c|c|c|c|}
\hline CAS & Constituent & $\begin{array}{l}\text { roxicity } \\
\text { ranking }\end{array}$ & $\begin{array}{l}\text { rap } \\
\text { rowicity } \\
\text { Ranking }\end{array}$ & $\begin{array}{l}\text { slope } \\
\text { factor } \\
\text { Ranking }\end{array}$ & SW 846 & Suggested \\
\hline $100-00-5$ & p-Nitrochlorobenzene & & II & & & $8270 \mathrm{C}$ \\
\hline $100-25-4$ & 1,4-Dinitrobenzene & $\mathrm{B}$ & II & & $8270 \mathrm{C}$ & \\
\hline 106-99-0 & 1,3-Butadiene & & & $\mathrm{v}$ & & $8260 \mathrm{~B}$ \\
\hline $107-02-8$ & Acrolein & $\mathrm{B}$ & $\mathrm{I}$ & & $8260 \mathrm{~B}$ & \\
\hline 107-05-1 & 3-Chloropropene & A & II & & $8260 \mathrm{~B}$ & \\
\hline $107-12-0$ & Propionitrile & $\mathrm{B}$ & & & $8260 \mathrm{~B}$ & \\
\hline $107-13-1$ & Acrylonitrile & $\mathrm{B}$ & & $\mathrm{BC}$ & $8260 \mathrm{~B}$ & \\
\hline $118-74-1$ & Hexachlorobenzene & $\mathrm{C}$ & & $\mathrm{v}$ & $8081 \mathrm{~A}$ & \\
\hline $121-44-8$ & Triethylamine & $\mathrm{C}$ & II & & & $8260 \mathrm{~B}$ \\
\hline $126-73-8$ & Tributyl phosphate & & II & & & $8270 \mathrm{C}$ \\
\hline $126-98-7$ & 2-Methyl-2-propenenitrile & $\mathrm{B}$ & II & & $8260 \mathrm{~B}$ & \\
\hline $1321-64-8$ & Pentachloronaphthalene & & II & & & $8270 \mathrm{C}$ \\
\hline $1335-87-1$ & Hexachloronaphthalene & & $\mathrm{I}$ & & & $8270 \mathrm{C}$ \\
\hline $1335-88-2$ & Tetrachloronaphthalene & & II & & & $8270 \mathrm{C}$ \\
\hline $1336-36-3$ & Polychlorinated biphenyls (PCBs) & $\mathrm{B}$ & & $\mathrm{BC}$ & 8082 & \\
\hline $144-62-7$ & Oxalic acid & & II & & & 9056 \\
\hline 2234-13-1 & Octachloronaphthalene & & $\mathrm{I}$ & & $8081 \mathrm{~A}$ & \\
\hline $309-00-2$ & Aldrin & A & & iv & $8081 \mathrm{~A}$ & \\
\hline 319-84-6 & alpha-BHC & $\mathrm{C}$ & & $\mathrm{v}$ & $8081 \mathrm{~A}$ & \\
\hline $319-85-7$ & beta-BHC & & & $\mathrm{v}$ & $8081 \mathrm{~A}$ & \\
\hline $3825-26-1$ & Ammonium perfluorooctanoate & & $\mathrm{I}$ & & & 8330 \\
\hline $465-73-6$ & Isodrin & $\mathrm{B}$ & & & $8081 \mathrm{~A}$ & \\
\hline $50-32-8$ & Benzo(a)pyrene & & & $\mathrm{v}$ & $8270 \mathrm{C}$ & \\
\hline $53-70-3$ & Dibenz[a,h]anthracene & & & $\mathrm{v}$ & $8270 \mathrm{C}$ & \\
\hline $57-14-7$ & 1,1-Dimethylhydrazine & & II & $\mathrm{v}$ & & $8270 \mathrm{C}$ \\
\hline $58-89-9$ & gamma-BHC (Lindane) & B & & & $8081 \mathrm{~A}$ & \\
\hline $60-34-4$ & Methylhydrazine & & II & & & $8270 \mathrm{C}$ \\
\hline $60-57-1$ & Dieldrin & $\mathrm{X}$ & & iv & $8081 \mathrm{~A}$ & \\
\hline $62-75-9$ & N-Nitroso-N,N-dimethylamine & $\mathrm{B}$ & & iv & $8270 \mathrm{C}$ & \\
\hline $624-83-9$ & Methyl isocyanate & & $\mathrm{I}$ & & & 8330 \\
\hline $684-16-2$ & Hexafluoroacetone & & II & & & $8260 \mathrm{~B}$ \\
\hline $72-20-8$ & Endrin & A & $\mathrm{I}$ & & $8081 \mathrm{~A}$ & \\
\hline $74-83-9$ & Bromomethane & $\mathrm{C}$ & II & & $8260 \mathrm{~B}$ & \\
\hline $75-21-8$ & Oxirane & $\mathrm{B}$ & & $\mathrm{BC}$ & $8260 \mathrm{~B}$ & \\
\hline $76-44-8$ & Heptachlor & $\mathrm{B}$ & & $\mathrm{v}$ & $8081 \mathrm{~A}$ & \\
\hline $79-10-7$ & 2-Propenoic acid & & I & & & $8270 \mathrm{C}$ \\
\hline $8001-35-2$ & Toxaphene & $\mathrm{C}$ & $\therefore$ & $\mathrm{v}$ & $8081 \mathrm{~A}$ & \\
\hline $82-68-8$ & Pentachloronitrobenzene (PCNB) & $\mathrm{B}$ & II & & $8270 \mathrm{C}$ & \\
\hline $87-68-3$ & Hexachlorobutadiene & B & $\mathrm{I}$ & $\mathrm{BC}$ & $8270 \mathrm{C}$ & \\
\hline $87-86-5$ & Pentachlorophenol & $\mathrm{B}$ & & & & $8270 \mathrm{C}$ \\
\hline $88-85-7$ & $\begin{array}{l}\text { 2-sec-Butyl-4,6-dinitrophenol; syn } \\
\text { Dinoseb }\end{array}$ & B & & & $8151 \mathrm{~A}$ & \\
\hline
\end{tabular}


Table C6. Detected and Undetected, Stable Compounds with Higher Toxicity for Characterization. (44 Compounds) (Page 2 of 2)

\begin{tabular}{|c|c|c|c|c|c|c|}
\hline CASH & Constituent & $\begin{array}{l}\text { UrT } \\
\text { roxuly } \\
\text { Ranking }\end{array}$ & $\begin{array}{l}\text { hap } \\
\text { roxicis } \\
\text { Ranking }\end{array}$ & $\begin{array}{l}\text { Slope } \\
\text { Ractor } \\
\text { Ranling }\end{array}$ & $\begin{array}{l}\text { SW-846 } \\
\text { Method }\end{array}$ & Suggested \\
\hline $88-89-1$ & Picric acid & & I & & & 8330 \\
\hline $92-52-4$ & 1,1'-Biphenyl & & II & & & $8270 \mathrm{C}$ \\
\hline $98-95-3$ & Nitrobenzene & $\mathrm{D}$ & II & & $8270 \mathrm{C}$ & \\
\hline
\end{tabular}


Table C7. Detected Compounds with Lower Toxicity Considered for Characterization. (81 Compounds) (Page 1 of 2)

\begin{tabular}{|c|c|c|c|c|c|c|}
\hline $\mathrm{Cas} \#$ & Constituent. & $\begin{array}{l}\text { unO } \\
\text { roxicity } \\
\text { Ranking }\end{array}$ & $\begin{array}{l}\text { mop } \\
\text { Rankity } \\
\text { Rang }\end{array}$ & $\begin{array}{l}\text { slope } \\
\text { ractor } \\
\text { Ranling }\end{array}$ & SWethod & $\begin{array}{l}\text { Suggested } \\
\text { Method }\end{array}$ \\
\hline $100-41-4$ & Ethyl benzene & $\mathrm{D}$ & IV & & $8260 \mathrm{~B}$ & \\
\hline $100-42-5$ & Styrene & & IV & & $8260 \mathrm{~B}$ & \\
\hline $10061-01-5$ & cis-1,3-Dichloropropene & & & & $8260 \mathrm{~B}$ & \\
\hline $10061-02-6$ & trans-1,3-Dichloropropene & & & & $8260 \mathrm{~B}$ & \\
\hline $106-35-4$ & 3-Heptanone & & IV & & & $8260 \mathrm{~B}$ \\
\hline $106-42-3$ & p-Xylene & D & $\mathrm{V}$ & & $8260 \mathrm{~B}$ & \\
\hline $106-46-7$ & 1,4-Dichlorobenzene & $\mathrm{D}$ & & & $8270 \mathrm{C}$ & \\
\hline $106-93-4$ & Ethylene dibromide & $\mathrm{C}$ & & $\mathrm{BC}$ & $8260 \mathrm{~B}$ & \\
\hline 106-97-8 & Butane & & $\mathrm{V}$ & & & $8260 \mathrm{~B}$ \\
\hline $107-06-2$ & 1,2-Dichloroethane & $\mathrm{D}$ & & $\mathrm{BC}$ & $8260 \mathrm{~B}$ & \\
\hline $107-87-9$ & 2-Pentanone & & $\mathrm{V}$ & & $8260 \mathrm{~B}$ & \\
\hline $108-10-1$ & 4-Methyl-2-pentanone & $\mathrm{D}$ & IV & & $8260 \mathrm{~B}$ & \\
\hline $108-38-3$ & m-Xylene & $\mathrm{D}$ & $\mathrm{V}$ & & $8260 \mathrm{~B}$ & \\
\hline $108-87-2$ & Methylcyclohexane & & $\mathrm{V}$ & & & $8260 \mathrm{~B}$ \\
\hline $108-88-3$ & Toluene & $\mathrm{D}$ & IV & & $8260 \mathrm{~B}$ & \\
\hline $108-90-7$ & Chlorobenzene & $\mathrm{D}$ & IV & & $8260 \mathrm{~B}$ & \\
\hline 108-94-1 & Cyclohexanone & $\mathrm{C}$ & IV & & $8260 \mathrm{~B}$ & \\
\hline $108-95-2$ & Phenol & $\mathrm{C}$ & III & & $8270 \mathrm{C}$ & \\
\hline $109-66-0$ & n-Pentane & & $\mathrm{V}$ & & & $8260 \mathrm{~B}$ \\
\hline $109-99-9$ & Tetrahydrofuran & & $\mathrm{V}$ & & & $8270 \mathrm{C}$ \\
\hline $110-12-3$ & 5-Methyl-2-hexanone & & IV & & & $8260 \mathrm{~B}$ \\
\hline $110-43-0$ & 2-Heptanone & & IV & & & $8260 \mathrm{~B}$ \\
\hline $110-54-3$ & n-Hexane & & IV & & $8260 \mathrm{~B}$ & \\
\hline $110-82-7$ & Cyclohexane & & $\mathrm{V}$ & & & $8260 \mathrm{~B}$ \\
\hline $110-83-8$ & Cyclohexene & & $\bar{V}$ & & & $8260 \mathrm{~B}$ \\
\hline $110-86-1$ & Pyridine & $\mathrm{C}$ & III & & $8270 \mathrm{C}$ & \\
\hline $111-65-9$ & n-Octane & & $\mathrm{V}$ & & & $8260 \mathrm{~B}$ \\
\hline $111-84-2$ & n-Nonane & & $\mathrm{V}$ & & & $8260 \mathrm{~B}$ \\
\hline $120-82-1$ & 1,2,4-Trichlorobenzene & $\mathrm{D}$ & IV & & $8270 \mathrm{C}$ & \\
\hline $122-39-4$ & $\mathrm{~N}, \mathrm{~N}$-Diphenylamine & $\mathrm{D}$ & III & & $8270 \mathrm{C}$ & \\
\hline 123-19-3 & 4-Heptanone & & IV & & & $8260 \mathrm{~B}$ \\
\hline $123-38-6$ & n-Propionaldehyde & & $\mathrm{V}$ & & $8260 \mathrm{~B}$ & \\
\hline $123-86-4$ & Acetic acid n-butyl ester & & $\mathrm{V}$ & & & $8260 \mathrm{~B}$ \\
\hline $123-91-1$ & 1,4-Dioxan & $\mathrm{D}$ & & & $8260 \mathrm{~B}$ & \\
\hline $127-18-4$ & 1,1,2,2-Tetrachloroethene & $\mathrm{D}$ & & $\mathrm{BC}$ & $8260 \mathrm{~B}$ & \\
\hline $128-37-0$ & 2,6-Bis(tert-butyl)-4-methylphenol & & III & & & $8270 \mathrm{C}$ \\
\hline $141-78-6$ & Acetic acid ethyl ester & $\mathrm{D}$ & $\mathrm{V}$ & & $8260 \mathrm{~B}$ & \\
\hline $142-82-5$ & n-Heptane & & $\mathrm{V}$ & & & $8260 \mathrm{~B}$ \\
\hline $287-92-3$ & Cyclopentane & & $\mathrm{V}$ & & & $8270 \mathrm{C}$ \\
\hline $4170-30-3$ & 2-Butenaldehyde & & III & & $8260 \mathrm{~B}$ & \\
\hline $541-73-1$ & 1,3-Dichlorobenzene & & & & $8270 \mathrm{C}$ & \\
\hline $56-23-5$ & Carbon tetrachloride & $\mathrm{D}$ & & $\mathrm{BC}$ & $8260 \mathrm{~B}$ & \\
\hline
\end{tabular}


Table C7. Detected Compounds with Lower Toxicity Considered for Characterization. (81 Compounds) (Page 2 of 2)

\begin{tabular}{|c|c|c|c|c|c|c|}
\hline CAS\# & Constitnent & $\begin{array}{l}\text { Uuc } \\
\text { Toxicity. } \\
\text { Ranking. }\end{array}$ & $\begin{array}{l}\text { TAPP } \\
\text { Toxicity. } \\
\text { Ranking }\end{array}$ & $\begin{array}{l}\text { Slope } \\
\text { factor } \\
\text { Ranking }\end{array}$ & SWethod & $\begin{array}{l}\text { Suggested } \\
\text { Method }\end{array}$ \\
\hline $563-80-4$ & 3-Methyl-2-butanone & & $\mathrm{V}$ & & & $8260 \mathrm{~B}$ \\
\hline $591-78-6$ & 2-Hexanone & & III & & $8260 \mathrm{~B}$ & \\
\hline $627-13-4$ & Nitric acid, propyl ester & & IV & & & $8270 \mathrm{C}$ \\
\hline $64-17-5$ & Ethyl alcohol & & $\mathrm{V}$ & & $8260 \mathrm{~B}$ & \\
\hline $64-18-6$ & Formic acid & & III & & & 9056 \\
\hline 64-19-7 & Acetic acid & & III & & & 9056 \\
\hline $67-56-1$ & Methyl alcohol & $\mathrm{D}$ & IV & & $8260 \mathrm{~B}$ & \\
\hline $67-63-0$ & 2-Propyl alcohol & & $\mathrm{V}$ & & $8260 B$ & \\
\hline 67-64-1 & 2-Propanone (Acetone) & & $\mathrm{V}$ & & $8260 B$ & \\
\hline $67-66-3$ & Chloroform & $\mathrm{D}$ & & $\mathrm{BC}$ & $8260 B$ & \\
\hline $71-23-8$ & n-Propyl alcohol & & $\mathrm{V}$ & & $8260 \mathrm{~B}$ & \\
\hline $71-36-3$ & n-Butyl alcohol & D & IV & & $8260 \mathrm{~B}$ & \\
\hline $71-43-2$ & Benzene & D & & $\mathrm{BC}$ & $8260 \mathrm{~B}$ & \\
\hline $71-55-6$ & 1,1,1-Trichloroethane & $\mathrm{D}$ & $\mathrm{V}$ & & $8260 \mathrm{~B}$ & \\
\hline $74-87-3$ & Chloromethane & $\mathrm{C}$ & IV & $\mathrm{BC}$ & $8260 \mathrm{~B}$ & \\
\hline $75-00-3$ & Chloroethane & $\mathrm{D}$ & $\mathrm{V}$ & & $8260 \mathrm{~B}$ & \\
\hline $75-01-4$ & 1-Chloroethene & $\mathrm{D}$ & & $\mathrm{BC}$ & $8260 \mathrm{~B}$ & \\
\hline $75-05-8$ & Acetonitrile & $\mathrm{C}$ & IV & & $8260 \mathrm{~B}$ & \\
\hline $75-09-2$ & $\begin{array}{l}\text { Dichloromethane (Methylene } \\
\text { Chloride) }\end{array}$ & $\bar{D}$ & & $\mathrm{BC}$ & $8260 \mathrm{~B}$ & \\
\hline $75-15-0$ & Carbon disulfide & $\mathrm{D}$ & III & & $8260 \mathrm{~B}$ & \\
\hline $75-34-3$ & 1,1-Dichloroethane & $\mathrm{D}$ & $\mathrm{V}$ & & $8260 \mathrm{~B}$ & \\
\hline $75-35-4$ & 1,1-Dichloroethene & $\mathrm{C}$ & III & $\mathrm{BC}$ & $8260 \mathrm{~B}$ & \\
\hline $75-43-4$ & Dichlorofluoromethane & & IV & & & $8260 \mathrm{~B}$ \\
\hline $75-45-6$ & Chlorodifluoromethane & & $\mathrm{V}$ & & & $8260 \mathrm{~B}$ \\
\hline $75-65-0$ & 2-Methyl-2-propanol & & IV & & $8260 \mathrm{~B}$ & \\
\hline $75-69-4$ & Trichlorofluoromethane & & $\mathrm{V}$ & & $8260 \mathrm{~B}$ & \\
\hline $75-71-8$ & Dichlorodifluoromethane & & $\overline{\mathrm{V}}$ & & $8260 \mathrm{~B}$ & \\
\hline $76-13-1$ & 1,2,2-Trichlorotrifluoroethane & & $\bar{V}$ & & $8260 \mathrm{~B}$ & \\
\hline $76-14-2$ & $\begin{array}{l}\text { 1,2-Dichloro-1,1,2,2- } \\
\text { tetrafluoroethane }\end{array}$ & & $\mathrm{V}$ & & $8260 \mathrm{~B}$ & \\
\hline $78-87-5$ & 1,2-Dichloropropane & $\mathrm{D}$ & & & $8260 \mathrm{~B}$ & \\
\hline $78-92-2$ & 1-Methylpropyl alcohol & & IV & & & $8260 \mathrm{~B}$ \\
\hline $78-93-3$ & 2-Butanone & $\mathrm{D}$ & IV & & $8260 \mathrm{~B}$ & \\
\hline $79-00-5$ & 1,1,2-Trichloroethane & $\mathrm{D}$ & IV & $\mathrm{BC}$ & $8260 \mathrm{~B}$ & \\
\hline $79-01-6$ & 1,1,2-Trichloroethylene & & & $\mathrm{BC}$ & $8260 \mathrm{~B}$ & \\
\hline $79-34-5$ & 1,1,2,2-Tetrachloroethane & $\mathrm{D}$ & III & $\mathrm{BC}$ & $8260 \mathrm{~B}$ & \\
\hline $95-47-6$ & o-Xylene & $\mathrm{D}$ & $\mathrm{V}$ & & $8260 \mathrm{~B}$ & \\
\hline $95-50-1$ & 1,2-Dichlorobenzene & $\mathrm{D}$ & IV & & $8270 \mathrm{C}$ & \\
\hline $96-22-0$ & 3-Pentanone & & $\mathrm{V}$ & & & $8260 \mathrm{~B}$ \\
\hline $98-86-2$ & Acetophenone & $\mathrm{D}$ & $\mathrm{V}$ & & $8270 \mathrm{C}$ & \\
\hline
\end{tabular}




\section{Attachment 1. Regulated Organic Compounds Without Toxicity or Carcinogenicity Ranking. (105 Compounds) (Page 1 of 3)}

\begin{tabular}{|c|c|}
\hline CASH & Constituent \\
\hline $100-21-0$ & Phthalic acid \\
\hline $10061-01-5$ & cis-1,3-Dichloropropene \\
\hline $10061-02-6$ & trans-1,3-Dichloropropene \\
\hline $101-27-9$ & Barban \\
\hline $101-55-3$ & 4-Bromophenylphenyl ether \\
\hline $101-77-9$ & 4,4-Methylene dianiline \\
\hline $101-80-4$ & 4,4'-Diaminodiphenyl ether \\
\hline $10605-21-7$ & Carbendazim \\
\hline $107-30-2$ & Chloromethyl methyl ether \\
\hline $108-43-0$ & Chlorophenols \\
\hline $1120-71-4$ & 1,3-Propane sultone \\
\hline $1129-41-5$ & Metolcarb (3-methylcholanthrene) \\
\hline $117-79-3$ & 2-Aminoanthraquinone \\
\hline $117-84-0$ & Di-n-octylphthalate \\
\hline $119-38-0$ & Isolan \\
\hline $119-90-4$ & 3,3'-Dimethoxybenzidine \\
\hline $119-93-7$ & 3,3'-Dimethylbenzidine. \\
\hline $120-12-7$ & Anthracene \\
\hline $120-58-1$ & Isosafrole \\
\hline $122-42-9$ & Propham \\
\hline $126-85-2$ & Nitrogen mustard N-oxide \\
\hline $129-15-7$ & 2-Methyl-1-nitroanthraquinone \\
\hline $132-64-9$ & Dibenzofuran \\
\hline $135-20-6$ & Cupferron \\
\hline $13552-44-8$ & 4,4-Methylenedianiline dihydrochloride \\
\hline $139-91-3$ & $\begin{array}{l}\text { 5-(Morpholinomethyl)-3-amino-2-oxazolidinone } \\
\text { (furaltudone) }\end{array}$ \\
\hline $1563-38-8$ & Carbofuran phenol \\
\hline $1615-80-1$ & $\mathrm{~N}, \mathrm{~N}^{\prime}$-Diethylhydrazine \\
\hline 1694-09-3 & Benzyl violet $4 \mathrm{~b}$ \\
\hline $17702-57-7$ & Formparanate \\
\hline $1836-75-5$ & Nitrofen \\
\hline $189-55-9$ & Dibenzo[a,i]pyrene \\
\hline $189-64-0$ & Dibenzo[a,h]pyrene \\
\hline $191-24-2$ & Benzo(ghi)perylene \\
\hline $191-30-0$ & Dibenzo(a,l)pyrene \\
\hline $192-65-4$ & Dibenzo[a,e]pyrene \\
\hline $205-82-3$ & Benzo[j]fluoranthene \\
\hline $208-96-8$ & Acenaphthylene \\
\hline $224-42-0$ & Dibenz $[\mathrm{a}, \mathrm{j}]$ acridine \\
\hline $226-36-8$ & Dibenz $[\mathrm{a}, \mathrm{h}]$ acridine \\
\hline $22961-82-6$ & Bendiocarb phenol \\
\hline $2303-17-5$ & Triallate \\
\hline
\end{tabular}




\section{Attachment 1. Regulated Organic Compounds Without Toxicity or Carcinogenicity Ranking. (105 Compounds) (Page 2 of 3)}

\begin{tabular}{|c|c|}
\hline CAS* & Constituent \\
\hline $23422-53-9$ & Formetanate hydrochloride \\
\hline $23564-05-8$ & Thiophanate-methyl \\
\hline $2385-85-5$ & Mirex \\
\hline $2465-27-2$ & Auramine (technical grade) \\
\hline $2631-37-0$ & Promecarb \\
\hline $26419-73-8$ & Tirpate \\
\hline $2646-17-5$ & Oil orange SS \\
\hline $27154-33-2$ & Trichlorofluoroethane \\
\hline $28434-86-8$ & 3,3'-Dichloro-4,4'-diaminodiphenyl ether \\
\hline $302-70-5$ & Nitrogen mustard N-oxide hydrochloride \\
\hline $30558-43-1$ & A2213 \\
\hline $3068-88-0$ & B-Butyrolactone \\
\hline $3547-04-4$ & DDE (p,p'-Dichlorodiphenyldichloroethylene) \\
\hline $3697-24-3$ & 5-Methylchrysene \\
\hline $3761-53-3$ & Ponceau $\mathrm{MX}$ \\
\hline $52888-80-9$ & Prosulfocarb \\
\hline $531-82-8$ & $\mathrm{~N}$-(4-(5-Nitro-2-furyl)-2-thiazolyl)acetamide \\
\hline $53-19-0$ & o,p'-DDD (2,4'-DDD) \\
\hline $53-96-3$ & 2-Acetylaminofluorene \\
\hline $541-73-1$ & 1,3-Dichlorobenzene \\
\hline $55285-14-8$ & Carbosulfan \\
\hline $55406-53-6$ & 3-Iodo-2-propynyl n-butylcarbamate \\
\hline $555-84-9$ & 1-(5-Nitrofurfurylidene)amino)-2-imidazolidinone \\
\hline $55738-54-0$ & $\begin{array}{l}\text { trans-2((Dimethylamino)methylimino)-5-(2-(5-nitro- } \\
\text { 2-furyl) vinyl-1,3,4-oxadiazole }\end{array}$ \\
\hline $56-49-5$ & 3-Methylcholanthrene \\
\hline $57-47-6$ & Physostigmine \\
\hline $57-64-7$ & Physostigmine salicylate \\
\hline $584-84-9$ & 2,4-Toluene diisocyanate \\
\hline $592-62-1$ & Methyl azoxymethyl acetate \\
\hline $5952-26-1$ & Diethylene glycol, dicarbamate \\
\hline 59669-26-0 & Thiodicarb \\
\hline $59-89-2$ & N-Nitrosomorpholine \\
\hline $602-87-9$ & 5-Nitroacenaphthene \\
\hline $613-35-4$ & N,N-Diacetylbenzidine \\
\hline $615-53-2$ & $\mathrm{~N}$-Nitroso-N-methylurethane \\
\hline $61-82-5$ & Amitrole \\
\hline $636-21-5$ & o-Toluidine hydrochloride \\
\hline $63-92-3$ & Phenoxybenzamine hydrochloride \\
\hline $64-00-6$ & m-Cumenyl methylcarbamate \\
\hline $64091-91-4$ & 4-(Methylnitrosamino)-1-(3-pyridyl)-1-butanone \\
\hline 644-64-4 & Dimetilan \\
\hline $67-45-8$ & Furazolidone \\
\hline
\end{tabular}




\section{Attachment 1. Regulated Organic Compounds Without Toxicity or Carcinogenicity Ranking. (105 Compounds) (Page 3 of 3)}

\begin{tabular}{|l|l|}
\hline \multicolumn{1}{|c|}{ CAS $\#$. Constituent } & \multicolumn{1}{|c|}{ Hexamethylphosphoramide } \\
\hline $680-31-9$ & Dichlorophenylarsine \\
\hline $696-28-6$ & Endrin aldehyde \\
\hline $7421-93-4$ & N-Nitroso-N-ethylurea \\
\hline $759-73-9$ & Glycidylaldehyde \\
\hline $765-34-4$ & Dimethyl sulfate \\
\hline $77-78-1$ & o,p'-DDT (2,4'-DDT) \\
\hline $789-02-6$ & Panfuran S (dihydroxymethylfuratrizine) \\
\hline $794-93-4$ & Acenaphthene \\
\hline $83-32-9$ & $4,4^{\prime}$-Methylenebis(2-methylaniline) \\
\hline $838-88-0$ & Phenanthrene \\
\hline $85-01-8$ & Fluorene \\
\hline $86-73-7$ & 2,6-Dichlorophenol \\
\hline $87-65-0$ & Methapyrilene \\
\hline $91-80-5$ & 3,3 -Dichlorobenzidine \\
\hline $91-94-1$ & o-Toluidine (2-methylaniline) \\
\hline $95-53-4$ & $1,2-$ Phenylenediamine \\
\hline $95-54-5$ & Toluene-2,4-diamine \\
\hline $95-80-7$ & Ethylenethiourea \\
\hline $96-45-7$ & o-Aminoazotoluene \\
\hline $97-56-3$ & 5-Nitro-o-toluidine \\
\hline $99-55-8$ & \\
\hline
\end{tabular}




\section{Attachment 2. Regulated Organic Compounds from the} UHC List. (233 Compounds) (Page 1 of 6)

\begin{tabular}{|l|l|}
\hline \multicolumn{1}{|c|}{ CAS $\#$} & \multicolumn{1}{|c|}{ Constituent } \\
\hline $100-01-6$ & 4-Nitroaniline \\
\hline $100-02-7$ & 4-Nitrophenol \\
\hline $100-21-0$ & Phthalic acid \\
\hline $100-25-4$ & $1,4-$ Dinitrobenzene \\
\hline $100-41-4$ & Ethyl benzene \\
\hline $10061-01-5$ & cis-1,3-Dichloropropene \\
\hline $10061-02-6$ & trans-1,3-Dichloropropene \\
\hline $100-75-4$ & N-Nitrosopiperidine \\
\hline $101-14-4$ & 4,4-Methylenebis(2-chloroaniline) \\
\hline $101-55-3$ & 4-Bromophenylphenyl ether \\
\hline $101-90-6$ & Diglycidyl resorcinol ether \\
\hline $1024-57-3$ & Heptachlor Epoxide \\
\hline $1031-07-8$ & Endosulfan Sulfate \\
\hline $105-67-9$ & 2,4-Dimethylphenol \\
\hline $10595-95-6$ & N-Nitrosomethylethylamine \\
\hline $106-42-3$ & p-Xylene \\
\hline $106-44-5$ & 4-Methylphenol \\
\hline $106-46-7$ & 1,4-Dichlorobenzene \\
\hline $106-47-8$ & 4-Chloroaniline \\
\hline $106-50-3$ & p-Phenylenediamine \\
\hline $106-93-4$ & Ethylene dibromide \\
\hline $107-02-8$ & Acrolein \\
\hline $107-05-1$ & 3-Chloropropene \\
\hline $107-06-2$ & 1,2-Dichloroethane \\
\hline $107-12-0$ & Propionitrile \\
\hline $107-13-1$ & Acrylonitrile \\
\hline $108-10-1$ & 4-Methyl-2-pentanone \\
\hline $108-38-3$ & m-Xylene \\
\hline $108-39-4$ & m-Cresol \\
\hline $108-60-1$ & Bis(2-Chloroisopropyl) ether \\
\hline $108-88-3$ & Toluene \\
\hline $108-90-7$ & Chlorobenzene \\
\hline $108-94-1$ & Cyclohexanone \\
\hline $108-95-2$ & Phenol \\
\hline $110-75-8$ & 2-Chloroethyl vinyl ether \\
\hline $110-86-1$ & Pyridine \\
\hline $111-44-4$ & Bis(2-chloroethyl) ether \\
\hline $1114-71-2$ & Pebulate \\
\hline $111-91-1$ & Bis(2-Chloroethoxy)methane \\
\hline $1134-23-2$ & Cycloate \\
\hline $114-26-1$ & Propoxur \\
\hline $117-81-7$ & Bis(2-ethylhexyl) phthalate \\
\hline $117-84-0$ & Di-n-octylphthalate \\
\hline $118-74-1$ & \\
\hline
\end{tabular}


Attachment 2. Regulated Organic Compounds from the

UHC List. (233 Compounds) (Page 2 of 6)

\begin{tabular}{|l|l|}
\hline \multicolumn{1}{|c|}{ CASH } & \multicolumn{1}{|c|}{ Constituent . . } \\
\hline $120-12-7$ & Anthracene \\
\hline $120-58-1$ & Isosafrole \\
\hline $120-82-1$ & $1,2,4-$ Trichlorobenzene \\
\hline $120-83-2$ & $2,4-$ Dichlorophenol \\
\hline $121-14-2$ & $2,4-$ Dinitrotoluene \\
\hline $121-44-8$ & Triethylamine \\
\hline $122-39-4$ & N,N-Diphenylamine \\
\hline $122-66-7$ & 1,2 -Diphenylhydrazine \\
\hline $123-31-9$ & Hydroquinone \\
\hline $123-91-1$ & $1,4-$ Dioxan \\
\hline $124-48-1$ & Dibromochloromethane \\
\hline $126-72-7$ & Tris(2,3-dibromopropyl) phosphate \\
\hline $126-98-7$ & 2 -Methyl-2-propenenitrile \\
\hline $126-99-8$ & Chloroprene \\
\hline $127-18-4$ & $1,1,2,2-$ Tetrachloroethene \\
\hline $129-00-0$ & Pyrene \\
\hline $131-11-3$ & Dimethyl phthalate \\
\hline $1336-36-3$ & Polychlorinated biphenyls (PCBs) \\
\hline $134-32-7$ & alpha-Naphthylamine \\
\hline $135-88-6$ & N-Phenyl-2-napthylamine \\
\hline $137-30-4$ & Ziram \\
\hline $139-65-1$ & 4,4'-Thiodianiline \\
\hline $140-57-8$ & Aramite \\
\hline $141-78-6$ & Acetic acid ethyl ester \\
\hline $143-50-0$ & Kepone \\
\hline $1563-66-2$ & Carbofuran \\
\hline $156-60-5$ & 1,2 -trans-Dichloroethene \\
\hline $1646-88-4$ & Aldicarb sulfone \\
\hline $16752-77-5$ & Methomyl \\
\hline $1746-01-6$ & TCDD (Dioxin/Furan Indicator) \\
\hline $17804-35-2$ & Benomyl \\
\hline $1888-71-7$ & Hexachloropropylene \\
\hline $191-24-2$ & Benzo(ghi)perylene \\
\hline $192-65-4$ & Dibenzo[a,e]pyrene \\
\hline $1929-77-7$ & Vernolate \\
\hline $193-39-5$ & Indeno(1,2,3-cd)pyrene \\
\hline $2008-41-5$ & Butylate \\
\hline $2032-65-7$ & Methiocarb \\
\hline $205-99-2$ & Benzo(b)fluoranthene \\
\hline $206-44-0$ & Fluoranthene \\
\hline $207-08-9$ & Benzo(k)fluoranthene \\
\hline $208-96-8$ & Acenaphthylene \\
\hline $218-01-9$ & Chrysene \\
\hline $2212-67-1$ & Molinate \\
\hline
\end{tabular}


Attachment 2. Regulated Organic Compounds from the UHC List. (233 Compounds) (Page 3 of 6)

\begin{tabular}{|c|c|}
\hline CAS\# & Constituent \\
\hline $22781-23-3$ & Bendiocarb \\
\hline $23135-22-0$ & Oxamy \\
\hline $23950-58-5$ & Pronamide \\
\hline $298-00-0$ & Methyl parathion \\
\hline 298-02-2 & Phorate \\
\hline 298-04-4 & Disulfoton \\
\hline $309-00-2$ & Aldrin \\
\hline $315-18-4$ & Mexacarbate \\
\hline $319-84-6$ & alpha-BHC \\
\hline $319-85-7$ & beta-BHC \\
\hline $319-86-8$ & delta-BHC \\
\hline $33213-65-9$ & Endosulfan II \\
\hline $3424-82-6$ & $0, p^{\prime}-\mathrm{DDE}\left(2,4^{\prime}-\mathrm{DDE}\right)$ \\
\hline $465-73-6$ & Isodrin \\
\hline $50-29-3$ & 4,4-DDT \\
\hline $50-32-8$ & Benzo(a)pyrene \\
\hline $504-29-0$ & 2-Aminopyridine \\
\hline $510-15-6$ & Chlorobenzilate \\
\hline $51-28-5$ & 2,4-Dinitrophenol \\
\hline $528-29-0$ & Dinitrobenzene, all isomers \\
\hline $52-85-7$ & Famphur \\
\hline $53-19-0$ & $0, p^{\prime}-$ DDD $\left(2,4^{\prime}-D D D\right)$ \\
\hline $534-52-1$ & 4,6-Dinitro-o-cresol \\
\hline $53-70-3$ & Dibenz[a,h]anthracene \\
\hline $53-96-3$ & 2-Acetylaminofluorene \\
\hline $54-11-5$ & Nicotine \\
\hline $541-73-1$ & 1,3-Dichlorobenzene \\
\hline $55-18-5$ & N-Nitrosodiethylamine \\
\hline $55406-53-6$ & 3-Iodo-2-propynyl n-butylcarbamate \\
\hline $56-23-5$ & Carbon tetrachloride \\
\hline $56-38-2$ & Parathion \\
\hline $56-49-5$ & 3-Methylcholanthrene \\
\hline $56-55-3$ & Benzo(a)anthracene \\
\hline $57-74-9$ & Chlordane \\
\hline $58-89-9$ & gamma-BHC (Lindane) \\
\hline $58-90-2$ & 2,3,4,6-Tetrachlorophenol \\
\hline $59-50-7$ & 4-Chloro-3-methylphenol \\
\hline $59-89-2$ & N-Nitrosomorpholine \\
\hline $60-11-7$ & p-Dimethylaminoazobenzene \\
\hline $60-29-7$ & Ethyl ether \\
\hline $60-57-1$ & Dieldrin \\
\hline $606-20-2$ & 2,6-Dinitrotoluene \\
\hline $608-93-5$ & Pentachlorobenzene \\
\hline $621-64-7$ & N-Nitroso-di-n-propylamine \\
\hline
\end{tabular}


Attachment 2. Regulated Organic Compounds from the UHC List. (233 Compounds) (Page 4 of 6)

\begin{tabular}{|l|l|}
\hline \multicolumn{1}{|c|}{ CAS } & I \\
\hline $62-44-2$ & Phenacetin \\
\hline $62-53-3$ & Aniline \\
\hline $62-75-9$ & N-Nitroso-N,N-dimethylamine \\
\hline $630-20-6$ & $1,1,1,2-$ Tetrachloroethane \\
\hline $63-25-2$ & Carbaryl \\
\hline $66-27-3$ & Methyl methanesulfonate \\
\hline $67-56-1$ & Methyl alcohol \\
\hline $67-64-1$ & 2-Propanone (Acetone) \\
\hline $67-66-3$ & Chloroform \\
\hline $67-72-1$ & Hexachloroethane \\
\hline $71-36-3$ & n-Butyl alcohol \\
\hline $71-43-2$ & Benzene \\
\hline $71-55-6$ & 1,1,1-Trichloroethane \\
\hline $72-20-8$ & Endrin \\
\hline $72-43-5$ & Methoxychlor \\
\hline $72-54-8$ & 4,4-DDD \\
\hline $72-55-9$ & 4,4-DDE \\
\hline $7421-93-4$ & Endrin aldehyde \\
\hline $74-83-9$ & Bromomethane \\
\hline $74-87-3$ & Chloromethane \\
\hline $74-88-4$ & Iodomethane \\
\hline $74-95-3$ & Dibromomethane \\
\hline $75-00-3$ & Chloroethane \\
\hline $75-01-4$ & 1-Chloroethene \\
\hline $75-05-8$ & Acetonitrile \\
\hline $75-09-2$ & Dichloromethane (Methylene Chloride) \\
\hline $75-15-0$ & Carbon disulfide \\
\hline $75-21-8$ & Oxirane \\
\hline $75-25-2$ & Tribromomethane \\
\hline $75-27-4$ & Bromodichloromethane \\
\hline $75-34-3$ & $1,1-$ Dichloroethane \\
\hline $75-35-4$ & $1,1-$ Dichloroethene \\
\hline $75-52-5$ & Nitromethane \\
\hline $75-69-4$ & Trichlorofluoromethane \\
\hline $75-71-8$ & Dichlorodifluoromethane \\
\hline $759-94-4$ & EPTC \\
\hline $76-01-7$ & Pentachloroethane \\
\hline $76-13-1$ & $1,2,2-$ Trichlorotrifluoroethane \\
\hline $76-44-8$ & Heptachlor \\
\hline $77-47-4$ & Hexachlorocyclopentadiene \\
\hline $78-83-1$ & 2-Methylpropyl alcohol \\
\hline $78-87-5$ & $1,2-$ Dichloropropane \\
\hline $789-02-6$ & o,p'-DDT (2,4'-DDT) \\
\hline $78-93-3$ & 2-Butanone \\
\hline
\end{tabular}


Attachment 2. Regulated Organic Compounds from the UHC List. (233 Compounds) (Page 5 of 6)

\begin{tabular}{|c|c|}
\hline $\mathrm{CAS}+$ & Constituent \\
\hline $79-00-5$ & 1,1,2-Trichloroethane \\
\hline $79-01-6$ & 1,1,2-Trichloroethylene \\
\hline $79-06-1$ & Acrylamide \\
\hline $79-34-5$ & 1,1,2,2-Tetrachloroethane \\
\hline $8001-35-2$ & Toxaphene \\
\hline $80-62-6$ & Methyl methacrylate \\
\hline $82-68-8$ & Pentachloronitrobenzene (PCNB) \\
\hline $83-32-9$ & Acenaphthene \\
\hline $84-66-2$ & Diethyl phthalate \\
\hline $84-74-2$ & Di-n-butylphthalate \\
\hline $85-01-8$ & Phenanthrene \\
\hline $85-44-9$ & Phthalic anhydride \\
\hline $85-68-7$ & Butylbenzylphthalate \\
\hline $86-30-6$ & $\mathrm{~N}$-Nitrosodiphenylamine \\
\hline $86-73-7$ & Fluorene \\
\hline $87-65-0$ & 2,6-Dichlorophenol \\
\hline $87-68-3$ & Hexachlorobutadiene \\
\hline $87-86-5$ & Pentachlorophenol \\
\hline $88-06-2$ & 2,4,6-Trichlorophenol \\
\hline $88-74-4$ & 2-Nitroaniline \\
\hline $88-75-5$ & 2-Nitrophenol \\
\hline $88-85-7$ & 2-sec-Butyl-4,6-dinitrophenol; syn Dinoseb \\
\hline $91-20-3$ & Naphthalene \\
\hline $91-58-7$ & 2-Chloronaphthalene \\
\hline $91-59-8$ & 2-Napthylamine \\
\hline $91-80-5$ & Methapyrilene \\
\hline $924-16-3$ & N-Nitrosodi-n-butylamine \\
\hline $92-67-1$ & 4-Aminobiphenyl \\
\hline $930-55-2$ & N-Nitrosopyrrolidine \\
\hline $93-72-1$ & Silvex $(2,4,5-\mathrm{TP})$ \\
\hline $93-76-5$ & $2,4,5-\mathrm{T}$ \\
\hline $94-59-7$ & Safrole \\
\hline 94-75-7 & $2,4-\mathrm{D}$ \\
\hline $95-47-6$ & 0 -Xylene \\
\hline $95-48-7$ & o-Cresol \\
\hline $95-50-1$ & 1,2-Dichlorobenzene \\
\hline $95-57-8$ & 2-Chlorophenol \\
\hline $95-94-3$ & $1,2,4,5$-Tetrachlorobenzene \\
\hline $95-95-4$ & 2,4,5-Trichlorophenol \\
\hline 959-98-8 & Endosulfan I \\
\hline $96-12-8$ & 1,2-Dibromo-3-chloropropane \\
\hline $96-18-4$ & 1,2,3-Trichloropropane \\
\hline $97-63-2$ & Ethyl methacrylate \\
\hline $98-86-2$ & Acetophenone \\
\hline
\end{tabular}


Attachment 2. Regulated Organic Compounds from the UHC List. (233 Compounds) (Page 6 of 6)

\begin{tabular}{|c|c|}
\hline CAS & Constituent \\
\hline $98-87-3$ & Benzal chloride \\
\hline $98-95-3$ & Nitrobenzene \\
\hline $99-55-8$ & 5-Nitro-o-toluidine \\
\hline
\end{tabular}




\section{Attachment 3. Regulated Organic Compounds from the} TAP B List. (381 Compounds) (Page 1 of 9)

\begin{tabular}{|l|l|}
\hline \multicolumn{1}{|c|}{ CAS $\#$} & \multicolumn{1}{|c|}{ ( Constituent } \\
\hline $100-00-5$ & p-Nitrochlorobenzene \\
\hline $100-01-6$ & 4-Nitroaniline \\
\hline $100-02-7$ & 4-Nitrophenol \\
\hline $100-37-8$ & Diethylaminoethanol \\
\hline $100-42-5$ & Styrene \\
\hline $100-44-7$ & Benzyl chloride \\
\hline $100-61-8$ & N-Methylbenzenamine \\
\hline $100-63-0$ & Phenylhydrazine \\
\hline $100-74-3$ & N-Ethylmorpholine \\
\hline $101-68-8$ & Methylene bis(phenyl isocyanate) \\
\hline $101-84-8$ & Diphenyl ether \\
\hline $102-81-8$ & 2-N-Dibutylaminoethanol \\
\hline $105-46-4$ & sec-Butyl acetate \\
\hline $105-60-2$ & Caprolactam, vapor \\
\hline $105-60-2 a$ & Caprolactam, dust \\
\hline $106-35-4$ & 3-Heptanone \\
\hline $106-49-0$ & p-Toluidine \\
\hline $106-50-3$ & p-Phenylenediamine \\
\hline $106-51-4$ & p-Benzoquinone \\
\hline $106-87-6$ & Vinyl cyclohexene dioxide \\
\hline $106-88-7$ & 1,2-Epoxybutane \\
\hline $106-92-3$ & Allyl glycidyl ether \\
\hline $106-97-8$ & Butane \\
\hline $107-02-8$ & Acrolein \\
\hline $107-05-1$ & 3-Chloropropene \\
\hline $107-07-3$ & Ethylene chlorohydrin \\
\hline $107-15-3$ & Ethylene diamine \\
\hline $107-18-6$ & 2-Propen-1-ol \\
\hline $107-19-7$ & Propargyl alcohol \\
\hline $107-20-0$ & Chloroacetaldehyde \\
\hline $107-21-1$ & Ethylene glycol \\
\hline $107-31-3$ & Formic acid, methyl ester \\
\hline $107-41-5$ & Hexylene glycol \\
\hline $107-49-3$ & Tetraethyl pyrophosphate \\
\hline $107-66-4$ & Dibutylphosphate \\
\hline $107-87-9$ & 2-Pentanone \\
\hline $107-98-2$ & Propylene glycol monomethyl ether \\
\hline $108-03-2$ & 1-Nitropropane \\
\hline $108-05-4$ & Acetic acid vinyl ester \\
\hline $108-10-1$ & 4-Methyl-2-pentanone \\
\hline $108-11-2$ & Methyl isobutyl carbinol \\
\hline $108-18-9$ & Diisopropylamine \\
\hline $108-20-3$ & Betic anhydride \\
\hline $108-24-7$ & \\
\hline
\end{tabular}


Attachment 3. Regulated Organic Compounds from the

TAP B List. (381 Compounds) (Page 2 of 9)

\begin{tabular}{|c|c|}
\hline $\mathrm{CAS} \#$ & Constituent: \\
\hline $108-31-6$ & Maleic anhydride (2,5-Furandione) \\
\hline $108-39-4$ & $\mathrm{~m}$-Cresol \\
\hline $108-44-1$ & m-Toluidine \\
\hline $108-46-3$ & Resorcinol (1,3-Benzenediol) \\
\hline $108-83-8$ & Diisobutyl ketone \\
\hline $108-84-9$ & sec-Hexyl acetate \\
\hline $108-87-2$ & Methylcyclohexane \\
\hline $108-88-3$ & Toluene \\
\hline $108-90-7$ & Chlorobenzene \\
\hline $108-91-8$ & Cyclohexylamine \\
\hline $108-93-0$ & Cyclohexanol \\
\hline 108-94-1 & Cyclohexanone \\
\hline $108-95-2$ & Phenol \\
\hline $108-98-5$ & Thiophenol \\
\hline $109-59-1$ & Isopropoxyethanol \\
\hline $109-60-4$ & n-Propyl acetate \\
\hline $109-66-0$ & n-Pentane \\
\hline $109-73-9$ & n-Butylamine \\
\hline $109-79-5$ & n-Butyl mercaptan \\
\hline $109-86-4$ & 2-Methoxyethanol \\
\hline $109-87-5$ & Methylal \\
\hline $109-89-7$ & Diethylamine \\
\hline $109-94-4$ & Ethyl formate \\
\hline $109-99-9$ & Tetrahydrofuran \\
\hline $110-12-3$ & 5-Methyl-2-hexanone \\
\hline $110-19-0$ & Isobutyl acetate \\
\hline $110-43-0$ & 2-Heptanone \\
\hline $110-49-6$ & 2-Methoxyethyl acetate \\
\hline $110-54-3$ & n-Hexane \\
\hline $110-62-3$ & n-Valeraldehyde \\
\hline $110-80-5$ & 2-Ethoxyethanol \\
\hline $110-82-7$ & Cyclohexane \\
\hline $110-83-8$ & Cyclohexene \\
\hline $110-86-1$ & Pyridine \\
\hline $110-91-8$ & Morpholine \\
\hline $111-15-9$ & 2-Ethoxyethyl acetate \\
\hline $111-30-8$ & Glutaraldehyde \\
\hline $111-40-0$ & Diethylene triamine \\
\hline $111-42-2$ & Diethanolamine \\
\hline $111-65-9$ & n-Octane \\
\hline $111-76-2$ & 2-Butoxyethanol \\
\hline $111-84-2$ & n-Nonane \\
\hline $114-26-1$ & Propoxur \\
\hline $115-29-7$ & Endosulfan \\
\hline $115-86-6$ & Triphenyl phosphate \\
\hline
\end{tabular}




\section{Attachment 3. Regulated Organic Compounds from the TAP B List. (381 Compounds) (Page 3 of 9)}

\begin{tabular}{|c|c|}
\hline SAS\# & Constituent \\
\hline $115-90-2$ & Fensulfothion \\
\hline $118-52-5$ & 1,3-Dichloro-5,5-Dimethyl hydantoin \\
\hline $118-96-7$ & 2,4,6-Trinitrotoluene \\
\hline $120-80-9$ & Catechol \\
\hline $120-82-1$ & 1,2,4-Trichlorobenzene \\
\hline $121-14-2$ & 2,4-Dinitrotoluene \\
\hline $121-44-8$ & Triethylamine \\
\hline $121-45-9$ & Trimethyl phosphite \\
\hline $121-69-7$ & Dimethylaniline \\
\hline $121-75-5$ & Malathion \\
\hline $121-82-4$ & Cyclonite \\
\hline $122-39-4$ & N,N-Diphenylamine \\
\hline $122-60-1$ & Phenyl glycidyl ether \\
\hline $123-19-3$ & 4-Heptanone \\
\hline $123-31-9$ & Hydroquinone \\
\hline $123-38-6$ & n-Propionaldehyde \\
\hline $123-42-2$ & Diacetone alcohol \\
\hline $123-51-3$ & 3-Methyl-1-butanol \\
\hline $123-86-4$ & Acetic acid n-butyl ester \\
\hline $123-92-2$ & Isoamyl acetate \\
\hline $124-40-3$ & Dimethylamine \\
\hline $126-73-8$ & Tributyl phosphate \\
\hline $126-98-7$ & 2-Methyl-2-propenenitrile \\
\hline $127-19-5$ & N,N-Dimethylacetamide \\
\hline $128-37-0$ & 2,6-Bis(tert-butyl)-4-methylphenol \\
\hline $1300-73-8$ & Xylidine \\
\hline $131-11-3$ & Dimethyl phthalate \\
\hline $13121-70-5$ & Cyhexatin \\
\hline $1321-64-8$ & Pentachloronaphthalene \\
\hline $1321-65-9$ & Trichloronaphthalene \\
\hline $1321-74-0$ & Divinyl benzene \\
\hline $133-06-2$ & Captan \\
\hline $1335-87-1$ & Hexachloronaphthalene \\
\hline $1335-88-2$ & Tetrachloronaphthalene \\
\hline $1338-23-4$ & Methyl ethyl ketone peroxide \\
\hline $133-90-4$ & Chloramben \\
\hline $136-78-7$ & Sesone \\
\hline $137-05-3$ & Methyl-2-cyanoacrylate \\
\hline $137-26-8$ & Thiram \\
\hline $138-22-7$ & n-Butyl lactate \\
\hline $13838-16-9$ & Enflurane \\
\hline $1395-21-7$ & Subtilisins \\
\hline $140-88-5$ & Ethylacrylate \\
\hline $141-32-2$ & Butylacrylate \\
\hline $141-43-5$ & Ethanolamine \\
\hline
\end{tabular}


Attachment 3. Regulated Organic Compounds from the

TAP B List. (381 Compounds) (Page 4 of 9)

\begin{tabular}{|l|l|}
\hline \multicolumn{1}{|c|}{ CAS\# } & . \\
\hline $141-66-2$ & Dicrotophos \\
\hline $141-78-6$ & Acetic acid ethyl ester \\
\hline $141-79-7$ & 4-Methyl-3-penten-2-one \\
\hline $142-64-3$ & Piperazine dihydrochloride \\
\hline $142-82-5$ & n-Heptane \\
\hline $144-62-7$ & Oxalic acid \\
\hline $14484-64-1$ & Ferbam \\
\hline $1477-55-0$ & m-Xylene-a,a'-diamine \\
\hline $148-01-6$ & Dinitolamide \\
\hline $150-76-5$ & 4-Methoxyphenol \\
\hline $151-56-4$ & Ethyleneimine \\
\hline $151-67-7$ & Halothane \\
\hline $1563-66-2$ & Carbofuran \\
\hline $1582-09-8$ & Trifluralin \\
\hline $16219-75-3$ & Ethylidene norbornene \\
\hline $1634-04-4$ & Methyl tert-butyl ether \\
\hline $16752-77-5$ & Methomyl \\
\hline $17804-35-2$ & Benomyl \\
\hline $1912-24-9$ & Atrazine \\
\hline $1918-02-1$ & Picloram \\
\hline $1929-82-4$ & Nitrapyrin \\
\hline $2039-87-4$ & o-Chlorostyrene \\
\hline $2104-64-5$ & EPN \\
\hline $21087-64-9$ & Metribuzin \\
\hline $2179-59-1$ & Allyl propyl disulfide \\
\hline $22224-92-6$ & Fenamiphos \\
\hline $2234-13-1$ & Octachloronaphthalene \\
\hline $2238-07-5$ & Diglycidyl ether \\
\hline $2425-06-1$ & Captafol \\
\hline $2426-08-6$ & n-Butyl glycidyl ether \\
\hline $25013-15-4$ & Vinyl toluene \\
\hline $2551-13-7$ & Trimethyl benzene \\
\hline $25639-42-3$ & Methylcyclohexanol \\
\hline $26140-60-3$ & Terphenyls \\
\hline $26952-21-6$ & Iso-ocytl alcohol \\
\hline $2698-41-1$ & o-Chlorobenylidene malonitrile \\
\hline $287-92-3$ & Cyclopentane \\
\hline $29191-52-4$ & Anisidine (o-,p- isomers) \\
\hline $2921-88-2$ & Chlorpyrifos \\
\hline $2971-90-6$ & Clopidol \\
\hline $298-00-0$ & Methyl parathion \\
\hline $298-02-2$ & Phorate \\
\hline $299-84-4-3$ & Disulfoton \\
\hline & Connel \\
\hline
\end{tabular}


Attachment 3. Regulated Organic Compounds from the TAP B List. (381 Compounds) (Page 5 of 9)

\begin{tabular}{|l|l|}
\hline \multicolumn{1}{|c|}{ CAS\# } & \\
\hline $300-76-5$ & Naled \\
\hline $314-40-9$ & Bromacil \\
\hline $330-54-1$ & Diuron \\
\hline $3333-52-6$ & Tetramethyl succinonitrile \\
\hline $333-41-5$ & Diazinon \\
\hline $334-88-3$ & Diazomethane \\
\hline $3383-96-8$ & Temephos \\
\hline $34590-94-8$ & Dipropylene glycol methyl ether \\
\hline $35400-43-2$ & Sulprofos \\
\hline $3689-24-5$ & Tetraethyldithiopyrophosphate (TEDP) \\
\hline $3825-26-1$ & Ammonium perfluorooctanoate \\
\hline $4016-14-2$ & Isopropyl glycidyl ether (IGE) \\
\hline $4098-71-9$ & Isophorone diisocyanate \\
\hline $4170-30-3$ & 2-Butenaldehyde \\
\hline $420-04-2$ & Cyanamide \\
\hline $463-51-4$ & Ketene \\
\hline $4685-14-7$ & Paraquat \\
\hline $479-45-8$ & Tetryl \\
\hline $504-29-0$ & 2-Aminopyridine \\
\hline $509-14-8$ & Tetranitromethane \\
\hline $5124-30-1$ & Methylene-bis-(4-cyclo-hexylisocyanate) \\
\hline $51-28-5$ & 2,4-Dinitrophenol \\
\hline $51-79-6$ & Ethyl carbamate (urethane) \\
\hline $528-29-0$ & Dinitrobenzene, all isomers \\
\hline $532-27-4$ & a-Chloroacetophenone \\
\hline $534-52-1$ & 4,6-Dinitro-o-cresol \\
\hline $540-59-0$ & 1,2-Dichloroethylene \\
\hline $540-84-1$ & 2,2,4-Trimethylpentane \\
\hline $540-88-5$ & tert-Butyl acetate \\
\hline $54-11-5$ & Nicotine \\
\hline $541-85-5$ & Ethyl amyl ketone \\
\hline $542-75-6$ & 1,3-Dichloropropene \\
\hline $542-92-7$ & Cyclopentadiene \\
\hline $552-30-7$ & Trimellitic anhydride \\
\hline $55-38-9$ & Fenthion \\
\hline $55-63-0$ & Nitroglycerin \\
\hline $556-52-5$ & Glycidol \\
\hline $55720-99-5$ & Chlorinated diphenyl oxide \\
\hline $563-12-2$ & Ethion \\
\hline $563-80-4$ & 3-Methyl-2-butanone \\
\hline $57-38-2$ & Parathion \\
\hline $57-24-9-9$ & $1,1-$ Dimethylhydrazine \\
\hline
\end{tabular}




\section{Attachment 3. Regulated Organic Compounds from the}

TAP B List. (381 Compounds) (Page 6 of 9)

\begin{tabular}{|l|l|}
\hline \multicolumn{1}{|c|}{ CAS $\#$} & L \\
\hline $591-78-6$ & 2-Hexanone \\
\hline $59355-75-8$ & Methyl acetylene-propadiene mixture (MAPP) \\
\hline $593-60-2$ & Vinyl bromide \\
\hline $594-42-3$ & Perchloromethyl mercaptan \\
\hline $594-72-9$ & $1,1-$ Dichloro-1-nitroethane \\
\hline $600-25-9$ & 1-Chloro-1-nitropropane \\
\hline $60-11-7$ & p-Dimethylaminoazobenzene \\
\hline $60-29-7$ & Ethyl ether \\
\hline $603-34-9$ & Triphenyl amine \\
\hline $60-34-4$ & Methylhydrazine \\
\hline $60-35-5$ & Acetamide \\
\hline $624-83-9$ & Methyl isocyanate \\
\hline $62-53-3$ & Aniline \\
\hline $626-17-5$ & m-Phthalodinitrile \\
\hline $626-38-0$ & sec-Amyl acetate \\
\hline $627-13-4$ & Nitric acid, propyl ester \\
\hline $62-73-7$ & Dichlorvas \\
\hline $62-74-8$ & Fluoroacetic acid, sodium salt (Fratol) \\
\hline $628-63-7$ & n-Amyl acetate \\
\hline $628-96-6$ & Ethylene glycol dinitrate \\
\hline $63-25-2$ & Carbaryl \\
\hline $638-21-1$ & Phenylphosphine \\
\hline $64-17-5$ & Ethyl alcohol \\
\hline $64-18-6$ & Formic acid \\
\hline $64-19-7$ & Acetic acid \\
\hline $6423-43-4$ & Propylene glycol dinitrate \\
\hline $64-67-5$ & Diethyl sulfate \\
\hline $67-56-1$ & Methyl alcohol \\
\hline $67-63-0$ & 2-Propyl alcohol \\
\hline $67-64-1$ & 2-Propanone (Acetone) \\
\hline $67-72-1$ & Hexachloroethane \\
\hline $68-11-1$ & Thioglycolic acid \\
\hline $68-12-2$ & Dimethylformamide \\
\hline $681-84-5$ & Methyl silicate \\
\hline $684-16-2$ & Hexafluoroacetone \\
\hline $68476-85-7$ & Liquified petroleum gas \\
\hline $684-93-5$ & N-Nitroso-N-methylurea \\
\hline $6923-22-4$ & Monocrotophos \\
\hline $71-23-8$ & n-Propyl alcohol \\
\hline $71-36-3$ & n-Butyl alcohol \\
\hline $71-55-6$ & 1,1 -Trichloroethane \\
\hline $72-43-8-5$ & Endrin \\
\hline $74-87-3$ & Methoxychlor \\
\hline
\end{tabular}




\section{Attachment 3. Regulated Organic Compounds from the} TAP B List. (381 Compounds) (Page 7 of 9)

\begin{tabular}{|l|l|}
\hline \multicolumn{1}{|c|}{ CAS\# } & Iod Constituent \\
\hline $74-88-4$ & Iodomethane \\
\hline $74-89-5$ & Methylamine \\
\hline $74-93-1$ & Thiomethanol \\
\hline $74-96-4$ & Ethyl bromide \\
\hline $74-97-5$ & Bromochloromethane \\
\hline $74-99-7$ & Methylacetylene \\
\hline $75-00-3$ & Chloroethane \\
\hline $75-04-7$ & Ethylamine \\
\hline $75-05-8$ & Acetonitrile \\
\hline $75-08-1$ & Ethyl mercaptan \\
\hline $75-12-7$ & Formamide \\
\hline $75-15-0$ & Carbon disulfide \\
\hline $75-31-0$ & Isopropylamine \\
\hline $75-34-3$ & 1,1 -Dichloroethane \\
\hline $75-35-4$ & 1,1 -Dichloroethene \\
\hline $75-43-4$ & Dichlorofluoromethane \\
\hline $75-45-6$ & Chlorodifluoromethane \\
\hline $75-47-8$ & Iodoform \\
\hline $75-50-3$ & Trimethylamine \\
\hline $75-52-5$ & Nitromethane \\
\hline $75-55-8$ & 2-Methylaziridine \\
\hline $75-61-6$ & Difluorodibromomethane \\
\hline $75-63-8$ & Trifluorobromomethane \\
\hline $75-65-0$ & 2-Methyl-2-propanol \\
\hline $75-69-4$ & Trichlorofluoromethane \\
\hline $75-71-8$ & Dichlorodifluoromethane \\
\hline $7572-29-4$ & Dichloroacetylene \\
\hline $75-99-0$ & 2,2 -Dichloropropionic acid \\
\hline $76-03-9$ & Trichloroacetic acid \\
\hline $76-06-2$ & Chloropicrin \\
\hline $76-11-9$ & $1,1,1,2-T e t r a c h l o r o-2,2-$ difluoroethane \\
\hline $76-12-0$ & $1,1,2,2-$ Tetrachloro-1,2-difluoroethane \\
\hline $76-13-1$ & $1,2,2-$ Trichlorotrifluoroethane \\
\hline $76-14-2$ & 1,2 -Dichloro-1,1,2,2-tetrafluoroethane \\
\hline $76-15-3$ & Chloropentafluoroethane \\
\hline $76-22-2$ & Camphor, synthetic \\
\hline $768-52-5$ & N-Isopropylaniline \\
\hline $77-47-4$ & Hexachlorocyclopentadiene \\
\hline $77-73-6$ & Dicyclopentadiene \\
\hline $7782-41-4$ & Fluorine \\
\hline $7786-34-7$ & Mevinphos \\
\hline $7803-51-2$ & Phosphine \\
\hline $78-10-4$ & Ethyl silicate \\
\hline $78-30-8$ & Dioxathion \\
\hline
\end{tabular}


Attachment 3. Regulated Organic Compounds from the TAP B List. (381 Compounds) (Page 8 of 9)

\begin{tabular}{|c|c|}
\hline CAS & Constituent \\
\hline $78-59-1$ & Isophorone \\
\hline $78-83-1$ & 2-Methylpropyl alcohol \\
\hline $78-92-2$ & 1-Methylpropyl alcohol \\
\hline $78-93-3$ & 2-Butanone \\
\hline $79-00-5$ & 1,1,2-Trichloroethane \\
\hline $79-04-9$ & Chloroacetyl chloride \\
\hline $79-09-4$ & Propanoic acid \\
\hline $79-10-7$ & 2-Propenoic acid \\
\hline $79-11-8$ & Chloroacetic acid \\
\hline $79-20-9$ & Methyl acetate \\
\hline $79-24-3$ & Nitroethane \\
\hline $79-27-6$ & Acetylene tetrabromide \\
\hline $79-34-5$ & 1,1,2,2-Tetrachloroethane \\
\hline $79-41-4$ & Methacrylic acid \\
\hline $79-44-7$ & Dimethylcarbamoyl chloride \\
\hline $8003-34-7$ & Pyrethrum \\
\hline $8006-64-2$ & Turpentine \\
\hline $8022-00-2$ & Methyl demeton \\
\hline $8052-42-4$ & Asphalt (petroleum) fumes \\
\hline $80-62-6$ & Methyl methacrylate \\
\hline $8065-48-3$ & Demeton \\
\hline $81-81-2$ & Warfarin $(>0.3 \%)$ \\
\hline $81-81-2 a$ & Warfarin $(<0.3 \%)$ \\
\hline $822-06-0$ & Hexamethylene diisocyanate \\
\hline $82-68-8$ & Pentachloronitrobenzene (PCNB) \\
\hline $83-26-1$ & Pindone \\
\hline $83-79-4$ & Rotenone \\
\hline $84-66-2$ & Diethyl phthalate \\
\hline $84-74-2$ & Di-n-butylphthalate \\
\hline $85-00-7$ & Diquat \\
\hline $85-44-9$ & Phthalic anhydride \\
\hline $86-50-0$ & Azinphos-methyl \\
\hline $86-88-4$ & alpha-Naphthylthiourea \\
\hline $87-68-3$ & Hexachlorobutadiene \\
\hline $88-72-2$ & Nitrotoluene \\
\hline $88-89-1$ & Picric acid \\
\hline $89-72-5$ & o-sec-Butylphenol \\
\hline $91-20-3$ & Naphthalene \\
\hline $91-22-5$ & Quinoline \\
\hline $92-52-4$ & 1,1'-Biphenyl \\
\hline $92-84-2$ & Phenothiazine \\
\hline $92-93-3$ & 4-Nitrobiphenyl \\
\hline $93-76-5$ & $2,4,5-\mathrm{T}$ \\
\hline $94-36-0$ & Benzoyl Peroxide \\
\hline $944-22-9$ & Fonofos \\
\hline
\end{tabular}


Attachment 3. Regulated Organic Compounds from the

TAP B List. (381 Compounds) (Page 9 of 9)

\begin{tabular}{|c|c|}
\hline CAS\# & Constituent \\
\hline $95-13-6$ & Indene \\
\hline $95-48-7$ & o-Cresol \\
\hline $95-49-8$ & o-Chlorotoluene \\
\hline $95-50-1$ & 1,2-Dichlorobenzene \\
\hline $95-95-4$ & 2,4,5-Trichlorophenol \\
\hline $96-09-3$ & Styrene oxide \\
\hline $96-12-8$ & 1,2-Dibromo-3-chloropropane \\
\hline 96-18-4 & 1,2,3-Trichloropropane \\
\hline $96-22-0$ & 3-Pentanone \\
\hline $96-33-3$ & Methyl acrylate \\
\hline $96-69-5$ & Bis(3-tert-butyl-4-hydroxy-6-methyl-phenyl) sulfide \\
\hline $97-77-8$ & Disulfiram \\
\hline $98-00-1$ & Furfuryl alcohol \\
\hline 98-01-1 & Furfural \\
\hline 98-07-7 & Benzotrichloride \\
\hline $98-51-1$ & p-tert-Butyltoluene \\
\hline $98-82-2$ & Cumene \\
\hline $98-83-9$ & Methylstyrene \\
\hline $98-86-2$ & Acetophenone \\
\hline $98-95-3$ & Nitrobenzene \\
\hline $999-61-1$ & 2-Hydroxypropyl acrylate \\
\hline
\end{tabular}


Attachment 4. Regulated Organic Compounds from the TAP A List. (128 Compounds) (Page 1 of 3)

\begin{tabular}{|c|c|}
\hline Cast & Constituent \\
\hline $101-14-4$ & 4,4'-Methylenebis(2-chloroaniline) \\
\hline $101-77-9$ & 4,4-Methylene dianiline \\
\hline $101-80-4$ & 4,4'-Diaminodiphenyl ether \\
\hline $101-90-6$ & Diglycidyl resorcinol ether \\
\hline $10595-95-6$ & N-Nitrosomethylethylamine \\
\hline $106-46-7$ & 1,4-Dichlorobenzene \\
\hline $106-89-8$ & Epichlorohydrin \\
\hline $106-93-4$ & Ethylene dibromide \\
\hline $106-99-0$ & 1,3-Butadiene \\
\hline $107-06-2$ & 1,2-Dichloroethane \\
\hline 107-13-1 & Acrylonitrile \\
\hline $107-30-2$ & Chloromethyl methyl ether \\
\hline $108-43-0$ & Chlorophenols \\
\hline $111-44-4$ & Bis(2-chloroethyl) ether \\
\hline $1120-71-4$ & 1,3-Propane sultone \\
\hline $117-79-3$ & 2-Aminoanthraquinone \\
\hline $117-81-7$ & Bis(2-ethylhexyl) phthalate \\
\hline 118-74-1 & Hexachlorobenzene \\
\hline $119-90-4$ & 3,3'-Dimethoxybenzidine \\
\hline 119-93-7 & 3,3'-Dimethylbenzidine. \\
\hline $122-66-7$ & 1,2-Diphenylhydrazine \\
\hline $123-91-1$ & 1,4-Dioxan \\
\hline $126-85-2$ & Nitrogen mustard N-oxide \\
\hline $126-99-8$ & Chloroprene \\
\hline $127-18-4$ & 1,1,2,2-Tetrachloroethene \\
\hline $129-15-7$ & 2-Methyl-1-nitroanthraquinone \\
\hline $132-64-9$ & Dibenzofuran \\
\hline $1336-36-3$ & Polychlorinated biphenyls (PCBs) \\
\hline $134-32-7$ & alpha-Naphthylamine \\
\hline $135-20-6$ & Cupferron \\
\hline $13552-44-8$ & 4,4-Methylenedianiline dihydrochloride \\
\hline $139-65-1$ & 4,4'-Thiodianiline \\
\hline $139-91-3$ & $\begin{array}{l}\text { 5-(Morpholinomethyl)-3-amino-2-oxazolidinone } \\
\text { (furaltudone) }\end{array}$ \\
\hline $1615-80-1$ & N,N'-Diethylhydrazine \\
\hline 1694-09-3 & Benzyl violet $4 \mathrm{~b}$ \\
\hline $1746-01-6$ & TCDD (Dioxin/Furan Indicator) \\
\hline $1836-75-5$ & Nitrofen \\
\hline $189-55-9$ & Dibenzo[a,i]pyrene \\
\hline 189-64-0 & Dibenzo[a,h]pyrene \\
\hline $191-30-0$ & Dibenzo(a,l)pyrene \\
\hline $192-65-4$ & Dibenzo[a,e]pyrene \\
\hline $193-39-5$ & Indeno(1,2,3-cd)pyrene \\
\hline $205-82-3$ & Benzo[j]fluoranthene \\
\hline $205-99-2$ & Benzo(b)fluoranthene \\
\hline
\end{tabular}


Attachment 4. Regulated Organic Compounds from the TAP A List. (128 Compounds) (Page 2 of 3)

\begin{tabular}{|c|c|}
\hline $\mathrm{QAS} \#$ & Constituent \\
\hline $207-08-9$ & Benzo(k)fluoranthene \\
\hline $224-42-0$ & Dibenz $[a, j]$ acridine \\
\hline $226-36-8$ & Dibenz $[a, h]$ acridine \\
\hline $2385-85-5$ & Mirex \\
\hline $2465-27-2$ & Auramine (technical grade) \\
\hline $2646-17-5$ & Oil orange SS \\
\hline $28434-86-8$ & 3,3'-Dichloro-4,4'-diaminodiphenyl ether \\
\hline $302-01-2$ & Hydrazine \\
\hline $302-70-5$ & Nitrogen mustard N-oxide hydrochloride \\
\hline $3068-88-0$ & B-Butyrolactone \\
\hline $309-00-2$ & Aldrin \\
\hline 319-84-6 & alpha-BHC \\
\hline $319-85-7$ & beta-BHC \\
\hline $3547-04-4$ & DDE (p,p'-Dichlorodiphenyldichloroethylene) \\
\hline $3697-24-3$ & 5-Methylchrysene \\
\hline $3761-53-3$ & Ponceau MX \\
\hline $50-00-0$ & Formaldehyde \\
\hline $50-29-3$ & 4,4-DDT \\
\hline $50-32-8$ & Benzo(a)pyrene \\
\hline $510-15-6$ & Chlorobenzilate \\
\hline $531-82-8$ & N-(4-(5-Nitro-2-furyl)-2-thiazolyl)acetamide \\
\hline $53-70-3$ & Dibenz $[\mathrm{a}, \mathrm{h}]$ anthracene \\
\hline $53-96-3$ & 2-Acetylaminofluorene \\
\hline $540-73-8$ & 1,2-Dimethylhydrazine \\
\hline $542-88-1$ & Dichloromethyl ether \\
\hline $55-18-5$ & N-Nitrosodiethylamine \\
\hline $555-84-9$ & 1-(5-Nitrofurfurylidene)amino)-2-imidazolidinone \\
\hline $55738-54-0$ & $\begin{array}{l}\text { trans-2((Dimethylamino)methylimino })-5-(2-(5-\text { nitro- } \\
\text { 2-furyl) vinyl-1,3,4-oxadiazole }\end{array}$ \\
\hline $56-23-5$ & Carbon tetrachloride \\
\hline $56-55-3$ & Benzo(a)anthracene \\
\hline $57-74-9$ & Chlordane \\
\hline $584-84-9$ & 2,4-Toluene diisocyanate \\
\hline $58-89-9$ & gamma-BHC (Lindane) \\
\hline $592-62-1$ & Methyl azoxymethyl acetate \\
\hline $59-87-0$ & Nitrofurazone \\
\hline $59-89-2$ & N-Nitrosomorpholine \\
\hline $602-87-9$ & 5-Nitroacenaphthene \\
\hline $60-57-1$ & Dieldrin \\
\hline $613-35-4$ & N,N-Diacetylbenzidine \\
\hline $615-53-2$ & $\mathrm{~N}$-Nitroso-N-methylurethane \\
\hline $61-82-5$ & Amitrole \\
\hline $621-64-7$ & N-Nitroso-di-n-propylamine \\
\hline $62-53-3$ & Aniline \\
\hline $62-75-9$ & N-Nitroso-N,N-dimethylamine \\
\hline
\end{tabular}


Attachment 4. Regulated Organic Compounds from the TAP A List. (128 Compounds) (Page 3 of 3)

\begin{tabular}{|l|l|}
\hline \multicolumn{1}{|c|}{ CAS\# } & \multicolumn{1}{|c|}{ Constituent .1} \\
\hline $636-21-5$ & o-Toluidine hydrochloride \\
\hline $63-92-3$ & Phenoxybenzamine hydrochloride \\
\hline $64091-91-4$ & 4-(Methylnitrosamino)-1-(3-pyridyl)-1-butanone \\
\hline $67-45-8$ & Furazolidone \\
\hline $67-66-3$ & Chloroform \\
\hline $680-31-9$ & Hexamethylphosphoramide \\
\hline $696-28-6$ & Dichlorophenylarsine \\
\hline $71-43-2$ & Benzene \\
\hline $75-01-4$ & 1 -Chloroethene \\
\hline $75-07-0$ & Acetaldehyde \\
\hline $75-09-2$ & Dichloromethane (Methylene Chloride) \\
\hline $75-21-8$ & Oxirane \\
\hline $75-25-2$ & Tribromomethane \\
\hline $75-56-9$ & Propylene oxide \\
\hline $759-73-9$ & N-Nitroso-N-ethylurea \\
\hline $764-41-0$ & $1,4-$ Dichloro-2-butene \\
\hline $76-44-8$ & Heptachlor \\
\hline $765-34-4$ & Glycidylaldehyde \\
\hline $77-78-1$ & Dimethyl sulfate \\
\hline $78-87-5$ & $1,2-$ Dichloropropane \\
\hline $79-01-6$ & $1,1,2-$ Trichloroethylene \\
\hline $79-06-1$ & Acrylamide \\
\hline $79-46-9$ & 2-Nitropropane \\
\hline $794-93-4$ & Panfuran S (dihydroxymethylfuratrizine) \\
\hline $8001-35-2$ & Toxaphene \\
\hline $8001-58-9$ & Creosote \\
\hline $838-88-0$ & 4,4'-Methylenebis(2-methylaniline) \\
\hline $86-30-6$ & N-Nitrosodiphenylamine \\
\hline $87-86-5$ & Pentachlorophenol \\
\hline $88-06-2$ & $2,4,6-$ Trichlorophenol \\
\hline $90-04-0$ & o-Anisidine \\
\hline $91-94-1$ & $3,3-$ Dichlorobenzidine \\
\hline $924-16-3$ & N-Nitrosodi-n-butylamine \\
\hline $92-67-1$ & 4-Aminobiphenyl \\
\hline $92-87-5$ & Benzidine \\
\hline $94-75-7$ & $2,4-D$ \\
\hline $95-53-4$ & o-Toluidine (2-methylaniline) \\
\hline $96-45-7$ & Toluene-2,4-diamine \\
\hline & Othylenethiourea \\
\hline
\end{tabular}


Attachment 5. Regulated Organic Compounds from the UTS List. (232 Compounds) (Page 1 of 6)

\begin{tabular}{|l|l|}
\hline \multicolumn{1}{|c|}{ CAS } & \\
\hline $100-01-6$ & 4-Nitroaniline \\
\hline $100-02-7$ & 4-Nitrophenol \\
\hline $100-25-4$ & 1,4-Dinitrobenzene \\
\hline $100-41-4$ & Ethyl benzene \\
\hline $10061-01-5$ & cis-1,3-Dichloropropene \\
\hline $10061-02-6$ & trans-1,3-Dichloropropene \\
\hline $100-75-4$ & N-Nitrosopiperidine \\
\hline $101-14-4$ & 4,4-Methylenebis(2-chloroaniline) \\
\hline $101-27-9$ & Barban \\
\hline $101-55-3$ & 4-Bromophenylphenyl ether \\
\hline $1024-57-3$ & Heptachlor Epoxide \\
\hline $1031-07-8$ & Endosulfan Sulfate \\
\hline $105-67-9$ & 2,4-Dimethylphenol \\
\hline $10595-95-6$ & N-Nitrosomethylethylamine \\
\hline $10605-21-7$ & Carbendazim \\
\hline $106-42-3$ & p-Xylene \\
\hline $106-44-5$ & 4-Methylphenol \\
\hline $106-46-7$ & 1,4-Dichlorobenzene \\
\hline $106-47-8$ & 4-Chloroaniline \\
\hline $106-93-4$ & Ethylene dibromide \\
\hline $107-02-8$ & Acrolein \\
\hline $107-05-1$ & 3-Chloropropene \\
\hline $107-06-2$ & 1,2-Dichloroethane \\
\hline $107-12-0$ & Propionitrile \\
\hline $107-13-1$ & Acrylonitrile \\
\hline $108-10-1$ & 4-Methyl-2-pentanone \\
\hline $108-38-3$ & m-Xylene \\
\hline $108-39-4$ & m-Cresol \\
\hline $108-60-1$ & Bis(2-Chloroisopropyl) ether \\
\hline $108-88-3$ & Toluene \\
\hline $108-90-7$ & Chlorobenzene \\
\hline $108-94-1$ & Cyclohexanone \\
\hline $108-95-2$ & Phenol \\
\hline $110-75-8$ & 2-Chloroethyl vinyl ether \\
\hline $110-86-1$ & Pyridine \\
\hline $111-44-4$ & Bis(2-chloroethyl) ether \\
\hline $1114-71-2$ & Pebulate \\
\hline $111-91-1$ & Bis(2-Chloroethoxy)methane \\
\hline $1129-41-5$ & Metolcarb (3-methylcholanthrene) \\
\hline $114-26-1$ & Propoxur \\
\hline $117-81-7$ & Bis(2-ethylhexyl) phthalate \\
\hline $117-84-0$ & Di-n-octylphthalate \\
\hline $118-74-1$ & Hexachlorobenzene \\
\hline $119-38-0$ & \\
\hline
\end{tabular}


Attachment 5. Regulated Organic Compounds from the UTS List. (232 Compounds) (Page 2 of 6)

\begin{tabular}{|l|l|}
\hline \multicolumn{1}{|c|}{ CAS } & . \\
\hline $120-12-7$ & Anthracene \\
\hline $120-58-1$ & Isosafrole \\
\hline $120-82-1$ & $1,2,4-$ Trichlorobenzene \\
\hline $120-83-2$ & $2,4-$ Dichlorophenol \\
\hline $121-14-2$ & $2,4-$ Dinitrotoluene \\
\hline $121-44-8$ & Triethylamine \\
\hline $122-39-4$ & N,N-Diphenylamine \\
\hline $122-42-9$ & Propham \\
\hline $122-66-7$ & 1,2 -Diphenylhydrazine \\
\hline $123-91-1$ & $1,4-$ Dioxan \\
\hline $124-48-1$ & Dibromochloromethane \\
\hline $126-72-7$ & Tris(2,3-dibromopropyl) phosphate \\
\hline $126-98-7$ & 2-Methyl-2-propenenitrile \\
\hline $126-99-8$ & Chloroprene \\
\hline $127-18-4$ & $1,1,2,2-$ Tetrachloroethene \\
\hline $129-00-0$ & Pyrene \\
\hline $131-11-3$ & Dimethyl phthalate \\
\hline $1336-36-3$ & Polychlorinated biphenyls (PCBs) \\
\hline $137-30-4$ & Ziram \\
\hline $140-57-8$ & Aramite \\
\hline $141-78-6$ & Acetic acid ethyl ester \\
\hline $143-50-0$ & Kepone \\
\hline $1563-38-8$ & Carbofuran phenol \\
\hline $1563-66-2$ & Carbofuran \\
\hline $156-60-5$ & 1,2 -trans-Dichloroethene \\
\hline $1646-88-4$ & Aldicarb sulfone \\
\hline $16752-77-5$ & Methomyl \\
\hline $17702-57-7$ & Formparanate \\
\hline $17804-35-2$ & Benomyl \\
\hline $1888-71-7$ & Hexachloropropylene \\
\hline $191-24-2$ & Benzo(ghi)perylene \\
\hline $192-65-4$ & Dibenzo[a,e]pyrene \\
\hline $1929-77-7$ & Vernolate \\
\hline $193-39-5$ & Indeno(1,2,3-cd)pyrene \\
\hline $2008-41-5$ & Butylate \\
\hline $2032-65-7$ & Methiocarb \\
\hline $205-99-2$ & Benzo(b)fluoranthene \\
\hline $206-44-0$ & Fluoranthene \\
\hline $207-08-9$ & Benzo(k)fluoranthene \\
\hline $208-96-8$ & Acenaphthylene \\
\hline $218-01-9$ & Chrysene \\
\hline $2212-67-1$ & Molinate \\
\hline $22781-23-3$ & Bendiocarb \\
\hline & Bendiocarb phenol \\
\hline
\end{tabular}




\section{Attachment 5. Regulated Organic Compounds from the}

UTS List. (232 Compounds) (Page 3 of 6)

\begin{tabular}{|c|c|}
\hline CAS\# & Constituent \\
\hline $2303-17-5$ & Triallate \\
\hline $23135-22-0$ & Oxamy \\
\hline $23422-53-9$ & Formetanate hydrochloride \\
\hline $23564-05-8$ & Thiophanate-methyl \\
\hline $23950-58-5$ & Pronamide \\
\hline $2631-37-0$ & Promecarb \\
\hline 26419-73-8 & Tirpate \\
\hline $298-00-0$ & Methyl parathion \\
\hline $298-02-2$ & Phorate \\
\hline $298-04-4$ & Disulfoton \\
\hline $30558-43-1$ & A2213 \\
\hline $309-00-2$ & Aldrin \\
\hline $315-18-4$ & Mexacarbate \\
\hline $319-84-6$ & alpha-BHC \\
\hline $319-85-7$ & beta-BHC \\
\hline $319-86-8$ & delta-BHC \\
\hline $33213-65-9$ & Endosulfan II \\
\hline $3424-82-6$ & $0, \mathrm{p}^{\prime}-\mathrm{DDE}\left(2,4^{\prime}-\mathrm{DDE}\right)$ \\
\hline $465-73-6$ & Isodrin \\
\hline $50-29-3$ & 4,4-DDT \\
\hline $50-32-8$ & Benzo(a)pyrene \\
\hline $510-15-6$ & Chlorobenzilate \\
\hline $51-28-5$ & 2,4-Dinitrophenol \\
\hline $52-85-7$ & Famphur \\
\hline $52888-80-9$ & Prosulfocarb \\
\hline $53-19-0$ & $0, \mathrm{p}^{\prime}-\mathrm{DDD}\left(2,4^{\prime}-\mathrm{DDD}\right)$ \\
\hline $534-52-1$ & 4,6-Dinitro-o-cresol \\
\hline $53-70-3$ & Dibenz[a,h]anthracene \\
\hline $53-96-3$ & 2-Acetylaminofluorene \\
\hline $541-73-1$ & 1,3-Dichlorobenzene \\
\hline $55-18-5$ & $\mathrm{~N}$-Nitrosodiethylamine \\
\hline 55285-14-8 & Carbosulfan \\
\hline $56-23-5$ & Carbon tetrachloride \\
\hline $56-38-2$ & Parathion \\
\hline $56-49-5$ & 3-Methylcholanthrene \\
\hline $56-55-3$ & Benzo(a)anthracene \\
\hline $57-47-6$ & Physostigmine \\
\hline $57-64-7$ & Physostigmine salicylate \\
\hline $57-74-9$ & Chlordane \\
\hline $58-89-9$ & gamma-BHC (Lindane) \\
\hline $58-90-2$ & 2,3,4,6-Tetrachlorophenol \\
\hline $59-50-7$ & 4-Chloro-3-methylphenol \\
\hline $5952-26-1$ & Diethylene glycol, dicarbamate \\
\hline $59669-26-0$ & Thiodicarb \\
\hline
\end{tabular}


Attachment 5. Regulated Organic Compounds from the UTS List. (232 Compounds) (Page 4 of 6)

\begin{tabular}{|l|l|}
\hline \multicolumn{1}{|c|}{ CAS\# } & Nit Constituent \\
\hline $59-89-2$ & N-Nitrosomorpholine \\
\hline $60-11-7$ & p-Dimethylaminoazobenzene \\
\hline $60-29-7$ & Ethyl ether \\
\hline $60-57-1$ & Dieldrin \\
\hline $606-20-2$ & 2,6 -Dinitrotoluene \\
\hline $608-93-5$ & Pentachlorobenzene \\
\hline $621-64-7$ & N-Nitroso-di-n-propylamine \\
\hline $62-44-2$ & Phenacetin \\
\hline $62-53-3$ & Aniline \\
\hline $62-75-9$ & N-Nitroso-N,N-dimethylamine \\
\hline $630-20-6$ & $1,1,1,2-$ Tetrachloroethane \\
\hline $63-25-2$ & Carbaryl \\
\hline $64-00-6$ & m-Cumenyl methylcarbamate \\
\hline $644-64-4$ & Dimetilan \\
\hline $66-27-3$ & Methyl methanesulfonate \\
\hline $67-56-1$ & Methyl alcohol \\
\hline $67-64-1$ & $2-$ Propanone (Acetone) \\
\hline $67-66-3$ & Chloroform \\
\hline $67-72-1$ & Hexachloroethane \\
\hline $71-36-3$ & n-Butyl alcohol \\
\hline $71-43-2$ & Benzene \\
\hline $71-55-6$ & $1,1,1-T$ richloroethane \\
\hline $72-20-8$ & Endrin \\
\hline $72-43-5$ & Methoxychlor \\
\hline $72-54-8$ & 4,4-DDD \\
\hline $72-55-9$ & 4,4-DDE \\
\hline $7421-93-4$ & Endrin aldehyde \\
\hline $74-83-9$ & Bromomethane \\
\hline $74-87-3$ & Chloromethane \\
\hline $74-88-4$ & Iodomethane \\
\hline $74-95-3$ & Dibromomethane \\
\hline $75-00-3$ & Chloroethane \\
\hline $75-01-4$ & 1 -Chloroethene \\
\hline $75-05-8$ & Acetonitrile \\
\hline $75-09-2$ & Dichloromethane (Methylene Chloride) \\
\hline $75-15-0$ & Carbon disulfide \\
\hline $75-21-8$ & Oxirane \\
\hline $75-25-2$ & Tribromomethane \\
\hline $75-27-4$ & Bromodichloromethane \\
\hline $75-34-3$ & $1,1-$ Dichloroethane \\
\hline $75-35-4$ & 1, Dichloroethene \\
\hline $75-69-4$ & \\
\hline $759-94-4$ & EPTC \\
\hline
\end{tabular}


Attachment 5. Regulated Organic Compounds from the UTS List $\quad 32$ Compounds) (Page 5 of 6)

\begin{tabular}{|c|c|}
\hline CAS\# & Constituent \\
\hline $76-01-7$ & Pentachloroethane \\
\hline $76-13-1$ & 1,2,2-Trichlorotrifluoroethane \\
\hline $76-44-8$ & Heptachlor \\
\hline $77-47-4$ & Hexachlorocyclopentadiene \\
\hline 78-83-1 & 2-Methylpropyl alcohol \\
\hline $78-87-5$ & 1,2-Dichloropropane \\
\hline $789-02-6$ & $o, p^{\prime}-$ DDT $\left(2,4^{\prime}-\mathrm{DDT}\right)$ \\
\hline $78-93-3$ & 2-Butanone \\
\hline $79-00-5$ & 1,1,2-Trichloroethane \\
\hline $79-01-6$ & 1,1,2-Trichloroethylene \\
\hline $79-06-1$ & Acrylamide \\
\hline $79-34-5$ & 1,1,2,2-Tetrachloroethane \\
\hline $8001-35-2$ & Toxaphene \\
\hline $80-62-6$ & Methyl methacrylate \\
\hline $82-68-8$ & Pentachloronitrobenzene (PCNB) \\
\hline $83-32-9$ & Acenaphthene \\
\hline $84-66-2$ & Diethyl phthalate \\
\hline $84-74-2$ & Di-n-butylphthalate \\
\hline $85-01-8$ & Phenanthrene \\
\hline $85-44-9$ & Phthalic anhydride \\
\hline $85-68-7$ & Butylbenzylphthalate \\
\hline $86-30-6$ & N-Nitrosodiphenylamine \\
\hline $86-73-7$ & Fluorene \\
\hline $87-65-0$ & 2,6-Dichlorophenol \\
\hline $87-68-3$ & Hexachlorobutadiene \\
\hline $87-86-5$ & Pentachlorophenol \\
\hline $88-06-2$ & 2,4,6-Trichlorophenol \\
\hline 88-74-4 & 2-Nitroaniline \\
\hline $88-75-5$ & 2-Nitrophenol \\
\hline $88-85-7$ & 2-sec-Butyl-4,6-dinitrophenol; syn Dinoseb \\
\hline 91-20-3 & Naphthalene \\
\hline $91-58-7$ & 2-Chloronaphthalene \\
\hline $91-59-8$ & 2-Napthylamine \\
\hline $91-80-5$ & Methapyrilene \\
\hline $924-16-3$ & N-Nitrosodi-n-butylamine \\
\hline $92-67-1$ & 4-Aminobiphenyl \\
\hline $930-55-2$ & N-Nitrosopyrrolidine \\
\hline $93-72-1$ & Silvex $(2,4,5-\mathrm{TP})$ \\
\hline $93-76-5$ & $2,4,5-\mathrm{T}$ \\
\hline 94-59-7 & Safrole \\
\hline $94-75-7$ & $2,4-\mathrm{D}$ \\
\hline $95-47-6$ & o-Xylene \\
\hline $95-48-7$ & o-Cresol \\
\hline $95-50-1$ & 1,2-Dichlorobenzene \\
\hline
\end{tabular}


Attachment 5. Regulated Organic Compounds from the

UTS List. (232 Compounds) (Page 6 of 6)

\begin{tabular}{|c|c|}
\hline $\mathrm{CASH}$ & Constituent \\
\hline $95-54-5$ & 1,2-Phenylenediamine \\
\hline $95-57-8$ & 2-Chlorophenol \\
\hline $95-94-3$ & 1,2,4,5-Tetrachlorobenzene \\
\hline $95-95-4$ & 2,4,5-Trichlorophenol \\
\hline $959-98-8$ & Endosulfan I \\
\hline $96-12-8$ & 1,2-Dibromo-3-chloropropane \\
\hline $96-18-4$ & 1,2,3-Trichloropropane \\
\hline $97-63-2$ & Ethyl methacrylate \\
\hline $98-86-2$ & Acetophenone \\
\hline 98-87-3 & Benzal chloride \\
\hline $98-95-3$ & Nitrobenzene \\
\hline $99-55-8$ & 5-Nitro-0-toluidine \\
\hline
\end{tabular}


Attachment 6. Regulated Organic Compounds with a Carcinogenicity Ranking. (48 Compounds) (Page 1 of 2)

\begin{tabular}{|c|c|c|c|c|}
\hline CAS & Constituent & $\begin{array}{l}\text { Greatest Slope } \\
\text { Factor }\end{array}$ & Unit & $\begin{array}{l}\text { Slope Factor } \\
\text { Ranking }\end{array}$ \\
\hline $1024-57-3$ & Heptachlor Epoxide & 9.1 & $(\mathrm{mg} / \mathrm{kg} / \text { day })^{\wedge}-1$ & $\mathrm{v}$ \\
\hline $106-99-0$ & 1,3-Butadiene & 2 & $(\mathrm{mg} / \mathrm{kg} / \text { day })^{\wedge}-1$ & $\mathrm{v}$ \\
\hline $111-44-4$ & Bis(2-chloroethyl) ether & 1.16 & $(\mathrm{mg} / \mathrm{kg} / \text { day })^{\wedge}-1$ & $\mathrm{v}$ \\
\hline 118-74-1 & Hexachlorobenzene & 1.61 & $(\mathrm{mg} / \mathrm{kg} / \mathrm{day})^{\wedge}-1$ & $\mathrm{v}$ \\
\hline $12035-72-2$ & Nickel refinery dust & 1.7 & $(\mathrm{mg} / \mathrm{kg} / \text { day })^{\wedge}-1$ & $\mathrm{v}$ \\
\hline $123-73-9$ & trans-2-Buten-1-al & 1.9 & $(\mathrm{mg} / \mathrm{kg} / \text { day })^{\wedge}-1$ & $\mathrm{v}$ \\
\hline $1746-01-6$ & TCDD (Dioxin/Furan Indicator) & 160000 & $(\mathrm{mg} / \mathrm{kg} / \text { day })^{\wedge}-1$ & $\mathrm{i}$ \\
\hline $18540-29-9$ & Chromium(VI) & 42 & $(\mathrm{mg} / \mathrm{kg} / \mathrm{day})^{\wedge}-1$ & iv \\
\hline $19408-74-3$ & $\begin{array}{l}\text { Hexachlorinated dibenzo-p-dioxin, } \\
1,2,3,7,8,9 \text { - }\end{array}$ & 16000 & $(\mathrm{mg} / \mathrm{kg} / \mathrm{day})^{\wedge}-1$ & $\mathrm{i}$ \\
\hline $302-01-2$ & Hydrazine & 17.1 & $(\mathrm{mg} / \mathrm{kg} / \mathrm{day})^{\wedge}-1$ & iv \\
\hline $30402-15-4$ & Pentachlorinated dibenzofuran & 8000 & $(\mathrm{mg} / \mathrm{kg} / \mathrm{day})^{\wedge}-1$ & $\mathrm{i}$ \\
\hline $309-00-2$ & Aldrin & 17.1 & $(\mathrm{mg} / \mathrm{kg} / \text { day })^{\wedge}-1$ & iv \\
\hline 319-84-6 & alpha-BHC & 6.3 & $(\mathrm{mg} / \mathrm{kg} / \text { day })^{\wedge}-1$ & $v$ \\
\hline $319-85-7$ & beta-BHC & 1.8 & $(\mathrm{mg} / \mathrm{kg} / \text { day })^{\wedge}-1$ & $\mathrm{v}$ \\
\hline $35822-46-9$ & $\begin{array}{l}\text { Heptachlorinated dibenzo-p-dioxin, } \\
1,2,3,4,6,7,8 \text { - }\end{array}$ & 1600 & $(\mathrm{mg} / \mathrm{kg} / \mathrm{day})^{\wedge}-1$ & ii \\
\hline $39227-28-6$ & $\begin{array}{l}\text { Hexachlorinated dibenzo-p-dioxin, } \\
1,2,3,4,7,8 \text { - }\end{array}$ & 16000 & $(\mathrm{mg} / \mathrm{kg} / \text { day })^{\wedge}-1$ & i \\
\hline $40321-76-4$ & $\begin{array}{l}\text { Pentachlorinated dibenzo-p-dioxin, } \\
1,2,3,7,8 \text { - }\end{array}$ & 80000 & $(\mathrm{mg} / \mathrm{kg} / \text { day })^{\wedge}-1$ & $\mathrm{i}$ \\
\hline $50-32-8$ & Benzo(a)pyrene & 3.1 & $(\mathrm{mg} / \mathrm{kg} / \mathrm{day})^{\wedge}-1$ & $\mathrm{v}$ \\
\hline $51207-31-9$ & Tetrachlorodibenzofuran, $2,3,7,8-$ & 16000 & $(\mathrm{mg} / \mathrm{kg} / \text { day })^{\wedge}-1$ & $\mathrm{i}$ \\
\hline $53-70-3$ & Dibenz $[\mathrm{a}, \mathrm{h}]$ anthracene & 3.1 & $(\mathrm{mg} / \mathrm{kg} / \text { day })^{\wedge}-1$ & $\mathrm{v}$ \\
\hline $540-73-8$ & 1,2-Dimethylhydrazine & 37 & $(\mathrm{mg} / \mathrm{kg} / \text { day })^{\wedge}-1$ & iv \\
\hline $542-88-1$ & Dichloromethyl ether & 217 & $(\mathrm{mg} / \mathrm{kg} / \text { day })^{\wedge}-1$ & iii \\
\hline $55-18-5$ & N-Nitrosodiethylamine & 151 & $(\mathrm{mg} / \mathrm{kg} / \text { day })^{\wedge}-1$ & iii \\
\hline $57117-41-6$ & $\begin{array}{l}\text { Pentachlorinated dibenzofuran, } \\
1,2,3,7,8 \text { - }\end{array}$ & 80000 & $(\mathrm{mg} / \mathrm{kg} / \text { day })^{\wedge}-1$ & i \\
\hline $57117-44-9$ & $\begin{array}{l}\text { Hexachlorinated dibenzofuran, } \\
1,2,3,6,7,8 \text { - }\end{array}$ & 16000 & $(\mathrm{mg} / \mathrm{kg} / \mathrm{day})^{\wedge}-1$ & i \\
\hline $57-14-7$ & 1,1-Dimethylhydrazine & 3.5 & $(\mathrm{mg} / \mathrm{kg} / \text { day })^{\wedge}-1$ & $\mathbf{v}$ \\
\hline $57653-85-7$ & $\begin{array}{l}\text { Hexachlorinated dibenzo-p-dioxin, } \\
1,2,3,6,7,8 \text {. }\end{array}$ & 16000 & $(\mathrm{mg} / \mathrm{kg} / \text { day })^{\wedge}-1$ & $\overline{\mathrm{i}}$ \\
\hline $57-74-9$ & Chlordane & 1 & $(\mathrm{mg} / \mathrm{kg} / \mathrm{day})^{\wedge}-1$ & $\mathrm{v}$ \\
\hline $59-87-0$ & Nitrofurazone & 9.4 & $(\mathrm{mg} / \mathrm{kg} / \mathrm{day})^{\wedge}-1$ & $\mathrm{v}$ \\
\hline $60-57-1$ & Dieldrin & 16.1 & $(\mathrm{mg} / \mathrm{kg} / \text { day })^{\wedge}-1$ & iv \\
\hline $60851-34-5$ & $\begin{array}{l}\text { Hexachlorinated dibenzofuran, } \\
2,3,4,6,7,8 \text { - }\end{array}$ & 16000 & $(\mathrm{mg} / \mathrm{kg} / \text { day })^{\wedge}-1$ & $\overline{\mathrm{i}}$ \\
\hline $62-75-9$ & N-Nitroso-N,N-dimethylamine & 51 & $(\mathrm{mg} / \mathrm{kg} / \text { day })^{\wedge}-1$ & iv \\
\hline $67562-39-4$ & $\begin{array}{l}\text { Heptachlorinated dibenzofuran, } \\
1,2,3,4,6,7,8-\end{array}$ & 1600 & $(\mathrm{mg} / \mathrm{kg} / \mathrm{day})^{\wedge}-1$ & ii \\
\hline $70648-26-9$ & $\begin{array}{l}\text { Hexachlorinated dibenzofuran, } \\
1,2,3,4,7,8-\end{array}$ & 16000 & $(\mathrm{mg} / \mathrm{kg} / \mathrm{day})^{\wedge}-1$ & $\mathrm{i}$ \\
\hline
\end{tabular}




\section{Attachment 6. Regulated Organic Compounds with a Carcinogenicity} Ranking. (48 Compounds) (Page 2 of 2)

\begin{tabular}{|c|c|c|c|c|}
\hline CAs\# & Constituent & Greatest Slope & Unit & $\begin{array}{l}\text { Slope factor } \\
\text { Ranking }\end{array}$ \\
\hline $72918-21-9$ & $\begin{array}{l}\text { Hexachlorinated dibenzofuran, } \\
1,2,3,7,8,9 \text { - }\end{array}$ & 16000 & $(\mathrm{mg} / \mathrm{kg} / \text { day })^{\wedge}-1$ & $i$ \\
\hline $7440-38-2$ & Arsenic & 50 & $(\mathrm{mg} / \mathrm{kg} / \text { day })^{\wedge}-1$ & iv \\
\hline $7440-41-7$ & Beryllium & 8.4 & $(\mathrm{mg} / \mathrm{kg} / \text { day })^{\wedge}-1$ & $\mathrm{v}$ \\
\hline $7440-43-9$ & Cadmium & 6.3 & $(\mathrm{mg} / \mathrm{kg} / \mathrm{day})^{\wedge}-1$ & $\mathrm{v}$ \\
\hline $764-41-0$ & 1,4-Dichloro-2-butene & .9 .3 & $(\mathrm{mg} / \mathrm{kg} / \mathrm{day})^{\wedge}-1$ & $v$ \\
\hline $76-44-8$ & Heptachlor & 4.55 & $(\mathrm{mg} / \mathrm{kg} / \text { day })^{\wedge}-1$ & $\mathrm{v}$ \\
\hline $79-06-1$ & Acrylamide & 4.55 & $(\mathrm{mg} / \mathrm{kg} / \text { day })^{\wedge}-1$ & $\mathrm{v}$ \\
\hline $79-46-9$ & 2-Nitropropane & 9.4 & $(\mathrm{mg} / \mathrm{kg} / \text { day })^{\wedge}-1$ & $\mathrm{v}$ \\
\hline $8001-35-2$ & Toxaphene & 1.12 & $(\mathrm{mg} / \mathrm{kg} / \mathrm{day})^{\wedge}-1$ & $\mathrm{v}$ \\
\hline $8001-58-9$ & Creosote & 2.2 & $(\mathrm{mg} / \mathrm{kg} / \mathrm{day})^{\wedge}-1$ & $\mathrm{v}$ \\
\hline $8007-45-2$ & Coal tar creosote & 2.17 & $(\mathrm{mg} / \mathrm{kg} / \mathrm{day})^{\wedge}-1$ & $\mathrm{v}$ \\
\hline $924-16-3$ & N-Nitrosodi-n-butylamine & 5.6 & $(\mathrm{mg} / \mathrm{kg} / \text { day })^{\wedge}-1$ & $\mathrm{v}$ \\
\hline $92-87-5$ & Benzidine & 235 & $(\mathrm{mg} / \mathrm{kg} / \text { day })^{\wedge}-1$ & iii \\
\hline $930-55-2$ & N-Nitrosopyrrolidine & 2.13 & $(\mathrm{mg} / \mathrm{kg} / \text { day })^{\wedge}-1$ & $\mathrm{v}$ \\
\hline
\end{tabular}


Attachment 7. Q5-4, Detected Compounds, Lower Toxicity and Less Than 10 Detects, Not Considered for Analysis. (42 Compounds) (Page 1 of 2)

\begin{tabular}{|c|c|c|c|c|c|c|}
\hline QAS\# & Constituent & $\begin{array}{l}\text { SWINS } \\
\text { solid } \\
\text { Brquid } \\
\text { Betects }\end{array}$ & $\begin{array}{l}\text { PNBN } \\
\text { paport } \\
\text { Bects }\end{array}$ & $\begin{array}{l}\text { gro } \\
\text { roxucry } \\
\text { ranking }\end{array}$ & $\begin{array}{c}\text { PAp } \\
\text { roxpisy } \\
\text { Ranking }\end{array}$ & 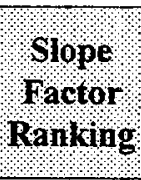 \\
\hline $101-84-8$ & Diphenyl ether & & 6 & & III & \\
\hline $106-88-7$ & 1,2-Epoxybutane & & 1 & & III & \\
\hline $107-18-6$ & 2-Propen-1-ol & & 5 & & III & \\
\hline $107-31-3$ & Formic acid, methyl ester & & 1 & & IV & \\
\hline 108-03-2 & 1-Nitropropane & & 3 & & III & \\
\hline $108-05-4$ & Acetic acid vinyl ester & & 1 & & IV & \\
\hline $108-20-3$ & Bis(isopropyl) ether & & 1 & & $\mathrm{~V}$ & \\
\hline $108-39-4$ & m-Cresol & & 7 & $\mathrm{C}$ & III & \\
\hline 108-93-0 & Cyclohexanol & & 1 & & IV & . \\
\hline $111-76-2$ & 2-Butoxyethanol & 6 & 7 & & IV & \\
\hline $117-84-0$ & Di-n-octylphthalate & 2 & & & & \\
\hline $123-51-3$ & 3-Methyl-1-butanol & & 4 & & $\mathrm{~V}$ & \\
\hline $127-19-5$ & N,N-Dimethylacetamide & & 2 & & IV & \\
\hline $129-00-0$ & Pyrene & 6 & & $\mathrm{D}$ & & \\
\hline $141-79-7$ & 4-Methyl-3-penten-2-one & & 9 & & IV & \\
\hline $206-44-0$ & Fluoranthene & 1 & & $\mathrm{D}$ & & \\
\hline $50-00-0$ & Formaldehyde & & 3 & & & $\mathrm{BC}$ \\
\hline $59-50-7$ & 4-Chloro-3-methylphenol & 1 & & $\mathrm{D}$ & & \\
\hline $59-89-2$ & N-Nitrosomorpholine & 3 & 1 & & & \\
\hline $60-35-5$ & Acetamide & & 3 & & $\mathrm{~V}$ & \\
\hline $621-64-7$ & N-Nitroso-di-n-propylamine & 1 & & $\mathrm{C}$ & & \\
\hline $67-72-1$ & Hexachloroethane & & & $\mathrm{D}$ & III & $\mathrm{BC}$ \\
\hline $74-99-7$ & Methylacetylene & & 9 & & $\mathrm{~V}$ & \\
\hline $75-12-7$ & Formamide & & 1 & & III & \\
\hline $75-50-3$ & Trimethylamine & & 1 & & III & \\
\hline $75-52-5$ & Nitromethane & & 8 & $\mathrm{D}$ & IV & \\
\hline $75-55-8$ & 2-Methylaziridine & & 5 & & III & \\
\hline $78-83-1$ & 2-Methylpropyl alcohol & & 7 & $\mathrm{D}$ & IV & \\
\hline $79-09-4$ & Propanoic acid & & 5 & & III & \\
\hline $79-20-9$ & Methyl acetate & & 4 & & $\mathrm{~V}$ & \\
\hline $83-32-9$ & Acenaphthene & 1 & & & & \\
\hline $84-74-2$ & Di-n-butylphthalate & 2 & 2 & $\mathrm{C}$ & III & \\
\hline $85-68-7$ & Butylbenzylphthalate & 3 & & $\mathrm{D}$ & & \\
\hline $86-73-7$ & Fluorene & & 1 & & & \\
\hline $88-06-2$ & 2,4,6-Trichlorophenol & 1 & & $\mathrm{D}$ & & $\mathrm{BC}$ \\
\hline $88-75-5$ & 2-Nitrophenol & 1 & & C & & \\
\hline $91-20-3$ & Naphthalene & 2 & 4 & $\mathrm{C}$ & IV & \\
\hline
\end{tabular}


Attachment 7. Q5-4, Detected Compounds, Lower Toxicity and Less Than 10 Detects, Not Considered for Analysis. (42 Compounds) (Page 2 of 2)

\begin{tabular}{|c|c|c|c|c|c|c|}
\hline CASH & Constituent & $\begin{array}{l}\text { Woins } \\
\text { soind } \\
\text { Detects }\end{array}$ & 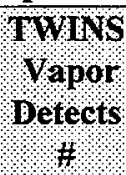 & $\begin{array}{l}\text { UHC } \\
\text { Toxicity } \\
\text { Ranking }\end{array}$ & $\begin{array}{l}\text { TAP } \\
\text { Toxicity } \\
\text { Ranking }\end{array}$ & $\begin{array}{l}\text { Slope } \\
\text { Factor } \\
\text { Ranking }\end{array}$ \\
\hline $95-48-7$ & o-Cresol & & 2 & C & III & \\
\hline $95-57-8$ & 2-Chlorophenol & 1 & & $\mathrm{D}$ & & \\
\hline $95-95-4$ & 2,4,5-Trichlorophenol & 1 & & D & $\mathrm{V}$ & \\
\hline $96-69-5$ & $\begin{array}{l}\text { Bis(3-tert-butyl-4-hydroxy-6- } \\
\text { methyl-phenyl) sulfide }\end{array}$ & 1 & & & III & \\
\hline $98-83-9$ & Methylstyrene & & 3 & & IV & \\
\hline
\end{tabular}

TWINS = Tank Waste Information Network System. Solid/liquid hits were recorded from the Tank Characterization Database. Vapor hits were recorded from the vapor database

$\mathrm{UHC}=$ underlying hazardous constituents 
Attachment 8. Q16-2, Undetected Compounds Removed During "Used In Industries Potentially Unrelated to Hanford" Evaluation. (208 Compounds) (Page 1 of 5)

\begin{tabular}{|c|c|}
\hline CAS & Constituent \\
\hline $100-01-6$ & 4-Nitroaniline \\
\hline $100-44-7$ & Benzyl chloride \\
\hline $100-75-4$ & N-Nitrosopiperidine \\
\hline $101-14-4$ & 4,4'-Methylenebis(2-chloroaniline) \\
\hline $101-27-9$ & Barban \\
\hline $101-77-9$ & 4,4-Methylene dianiline \\
\hline $101-80-4$ & 4,4'-Diaminodiphenyl ether \\
\hline $105-60-2$ & Caprolactam, vapor \\
\hline $105-60-2 \mathrm{a}$ & Caprolactam, dust \\
\hline $10595-95-6$ & N-Nitrosomethylethylamine \\
\hline $106-47-8$ & 4-Chloroaniline \\
\hline $106-49-0$ & p-Toluidine \\
\hline $106-51-4$ & p-Benzoquinone \\
\hline $106-89-8$ & Epichlorohydrin \\
\hline $10605-21-7$ & Carbendazim \\
\hline $107-19-7$ & Propargyl alcohol \\
\hline $107-20-0$ & Chloroacetaldehyde \\
\hline $107-30-2$ & Chloromethyl methyl ether \\
\hline $107-41-5$ & Hexylene glycol \\
\hline $107-49-3$ & Tetraethyl pyrophosphate \\
\hline $108-31-6$ & Maleic anhydride (2,5-Furandione) \\
\hline $108-44-1$ & m-Toluidine \\
\hline $108-46-3$ & Resorcinol (1,3-Benzenediol) \\
\hline $108-98-5$ & Thiophenol \\
\hline $109-87-5$ & Methylal \\
\hline $110-80-5$ & 2-Ethoxyethanol \\
\hline $111-30-8$ & Glutaraldehyde \\
\hline $1114-71-2$ & Pebulate \\
\hline $1120-71-4$ & 1,3-Propane sultone \\
\hline $114-26-1$ & Propoxur \\
\hline $115-29-7$ & Endosulfan \\
\hline $115-90-2$ & Fensulfothion \\
\hline $117-79-3$ & 2-Aminoanthraquinone \\
\hline $118-96-7$ & 2,4,6-Trinitrotoluene \\
\hline $119-90-4$ & 3,3'-Dimethoxybenzidine \\
\hline $119-93-7$ & 3,3'-Dimethylbenzidine. \\
\hline $120-58-1$ & Isosafrole \\
\hline $120-80-9$ & Catechol \\
\hline $121-14-2$ & 2,4-Dinitrotoluene \\
\hline $121-75-5$ & Malathion \\
\hline $121-82-4$ & Cyclonite \\
\hline $122-42-9$ & Propham \\
\hline $126-72-7$ & Tris(2,3-dibromopropyl) phosphate \\
\hline
\end{tabular}




\section{Attachment 8. Q16-2, Undetected Compounds Removed During "Used In Industries Potentially Unrelated to Hanford" Evaluation. (208 Compounds) (Page 2 of 5)}

\begin{tabular}{|c|c|}
\hline CASt & Constituent \\
\hline $126-85-2$ & Nitrogen mustard N-oxide \\
\hline $126-99-8$ & Chloroprene \\
\hline 1300-73-8 & Xylidine \\
\hline $13121-70-5$ & Cyhexatin \\
\hline $13552-44-8$ & 4,4-Methylenedianiline dihydrochloride \\
\hline $136-78-7$ & Sesone \\
\hline $137-26-8$ & Thiram \\
\hline $137-30-4$ & Ziram \\
\hline $13838-16-9$ & Enflurane \\
\hline $139-91-3$ & $\begin{array}{l}\text { 5-(Morpholinomethyl)-3-amino-2-oxazolidinone } \\
\text { (furaltudone) }\end{array}$ \\
\hline $1395-21-7$ & Subtilisins \\
\hline $140-57-8$ & Aramite \\
\hline $141-66-2$ & Dicrotophos \\
\hline $143-50-0$ & Kepone \\
\hline 14484-64-1 & Ferbam \\
\hline $1477-55-0$ & m-Xylene-a,a'-diamine \\
\hline $151-56-4$ & Ethyleneimine \\
\hline $151-67-7$ & Halothane \\
\hline $1563-38-8$ & Carbofuran phenol \\
\hline $1563-66-2$ & Carbofuran \\
\hline $1615-80-1$ & N,N'-Diethylhydrazine \\
\hline $1646-88-4$ & Aldicarb sulfone \\
\hline $16752-77-5$ & Methomyl \\
\hline 1694-09-3 & Benzyl violet $4 \mathrm{~b}$ \\
\hline $1746-01-6$ & TCDD (Dioxin/Furan Indicator) \\
\hline $17804-35-2$ & Benomyl \\
\hline $1888-71-7$ & Hexachloropropylene \\
\hline $1912-24-9$ & Atrazine \\
\hline $1929-77-7$ & Vernolate \\
\hline $1929-82-4$ & Nitrapyrin \\
\hline $2008-41-5$ & Butylate \\
\hline $2032-65-7$ & Methiocarb \\
\hline $2104-64-5$ & EPN \\
\hline $21087-64-9$ & Metribuzin \\
\hline $2179-59-1$ & Allyl propyl disulfide \\
\hline $2212-67-1$ & Molinate \\
\hline $22224-92-6$ & Fenamiphos \\
\hline $2303-17-5$ & Triallate \\
\hline $23135-22-0$ & Oxamy \\
\hline $23564-05-8$ & Thiophanate-methyl \\
\hline $23950-58-5$ & Pronamide \\
\hline $2465-27-2$ & Auramine (technical grade) \\
\hline
\end{tabular}




\section{Attachment 8. Q16-2, Undetected Compounds Removed During "Used In Industries Potentially Unrelated to Hanford" Evaluation. (208 Compounds) (Page 3 of 5)}

\begin{tabular}{|c|c|}
\hline $\mathrm{CAs}+$ & Constituent \\
\hline $2631-37-0$ & Promecarb \\
\hline $2646-17-5$ & Oil orange SS \\
\hline $28434-86-8$ & $3,3^{\dagger}$-Dichloro-4,4'-diaminodiphenyl ether \\
\hline $29191-52-4$ & Anisidine (o-,p- isomers) \\
\hline $2971-90-6$ & Clopidol \\
\hline $298-00-0$ & Methyl parathion \\
\hline $298-02-2$ & Phorate \\
\hline $298-04-4$ & Disulfoton \\
\hline $299-84-3$ & Ronnel \\
\hline $299-86-5$ & Crufomate \\
\hline $300-76-5$ & Naled \\
\hline $302-70-5$ & Nitrogen mustard N-oxide hydrochloride \\
\hline $30558-43-1$ & A2213 \\
\hline $315-18-4$ & Mexacarbate \\
\hline $333-41-5$ & Diazinon \\
\hline $3383-96-8$ & Temephos \\
\hline $3424-82-6$ & $o, p^{\prime}-D D E\left(2,4^{\prime}-D D E\right)$ \\
\hline $35400-43-2$ & Sulprofos \\
\hline $3547-04-4$ & DDE (p,p'-Dichlorodiphenyldichloroethylene) \\
\hline $3689-24-5$ & Tetraethyldithiopyrophosphate (TEDP) \\
\hline $3761-53-3$ & Ponceau MX \\
\hline $4685-14-7$ & Paraquat \\
\hline $479-45-8$ & Tetryl \\
\hline $509-14-8$ & Tetranitromethane \\
\hline $51-79-6$ & Ethyl carbamate (urethane) \\
\hline $52-85-7$ & Famphur \\
\hline $528-29-0$ & Dinitrobenzene, all isomers \\
\hline $53-19-0$ & $0, p^{\prime}-\mathrm{DDD}\left(2,4^{\prime}-\mathrm{DDD}\right)$ \\
\hline $53-96-3$ & 2-Acetylaminofluorene \\
\hline $532-27-4$ & a-Chloroacetophenone \\
\hline $534-52-1$ & 4,6-Dinitro-o-cresol \\
\hline $54-11-5$ & Nicotine \\
\hline $540-73-8$ & 1,2-Dimethylhydrazine \\
\hline $542-88-1$ & Dichloromethyl ether \\
\hline $55-18-5$ & N-Nitrosodiethylamine \\
\hline $55-38-9$ & Fenthion \\
\hline $55-63-0$ & Nitroglycerin \\
\hline $555-84-9$ & 1-(5-Nitrofurfurylidene)amino)-2-imidazolidinone \\
\hline $55720-99-5$ & Chlorinated diphenyl oxide \\
\hline $56-38-2$ & Parathion \\
\hline $563-12-2$ & Ethion \\
\hline $57-24-9$ & Strychnine \\
\hline $57-47-6$ & Physostigmine \\
\hline
\end{tabular}




\section{Attachment 8. Q16-2, Undetected Compounds Removed} During "Used In Industries Potentially Unrelated to Hanford" Evaluation. (208 Compounds) (Page 4 of 5)

\begin{tabular}{|c|c|}
\hline CASt & Constituent \\
\hline $57-64-7$ & Physostigmine salicylate \\
\hline $59-87-0$ & Nitrofurazone \\
\hline $59355-75-8$ & Methyl acetylene-propadiene mixture (MAPP) \\
\hline $59669-26-0$ & Thiodicarb \\
\hline $60-11-7$ & p-Dimethylaminoazobenzene \\
\hline $606-20-2$ & 2,6-Dinitrotoluene \\
\hline $608-93-5$ & Pentachlorobenzene \\
\hline $61-82-5$ & Amitrole \\
\hline $615-53-2$ & $\mathrm{~N}$-Nitroso-N-methylurethane \\
\hline $62-44-2$ & Phenacetin \\
\hline 62-73-7 & Dichlorvas \\
\hline $62-74-8$ & Fluoroacetic acid, sodium salt (Fratol) \\
\hline $63-25-2$ & Carbaryl \\
\hline $636-21-5$ & o-Toluidine hydrochloride \\
\hline $6423-43-4$ & Propylene glycol dinitrate \\
\hline $66-27-3$ & Methyl methanesulfonate \\
\hline $67-45-8$ & Furazolidone \\
\hline $680-31-9$ & Hexamethylphosphoramide \\
\hline $684-93-5$ & $\mathrm{~N}$-Nitroso-N-methylurea \\
\hline $68476-85-7$ & Liquified petroleum gas \\
\hline $6923-22-4$ & Monocrotophos \\
\hline $696-28-6$ & Dichlorophenylarsine \\
\hline $74-88-4$ & Iodomethane \\
\hline 74-93-1 & Thiomethanol \\
\hline $74-95-3$ & Dibromomethane \\
\hline $75-47-8$ & Iodoform \\
\hline $759-73-9$ & N-Nitroso-N-ethylurea \\
\hline $759-94-4$ & EPTC \\
\hline $76-06-2$ & Chloropicrin \\
\hline $76-22-2$ & Camphor, synthetic \\
\hline $764-41-0$ & 1,4-Dichloro-2-butene \\
\hline $765-34-4$ & Glycidylaldehyde \\
\hline $77-78-1$ & Dimethyl sulfate \\
\hline $7782-41-4$ & Fluorine \\
\hline $7786-34-7$ & Mevinphos \\
\hline $78-30-8$ & Triorthocresyl phosphate \\
\hline $78-34-2$ & Dioxathion \\
\hline $7803-51-2$ & Phosphine \\
\hline $789-02-6$ & o,p'-DDT $\left(2,4^{\prime}-\mathrm{DDT}\right)$ \\
\hline $79-06-1$ & Acrylamide \\
\hline 79-44-7 & Dimethylcarbamoyl chloride \\
\hline $79-46-9$ & 2-Nitropropane \\
\hline $80-62-6$ & Methyl methacrylate \\
\hline
\end{tabular}




\section{Attachment 8. Q16-2, Undetected Compounds Removed During "Used In Industries Potentially Unrelated to Hanford" Evaluation. (208 Compounds) (Page 5 of 5)}

\begin{tabular}{|l|l|}
\hline \multicolumn{1}{|c|}{ CAS } & C \\
\hline $8001-58-9$ & Creosote \\
\hline $8006-64-2$ & Turpentine \\
\hline $8022-00-2$ & Methyl demeton \\
\hline $8052-42-4$ & Asphalt (petroleum) fumes \\
\hline $8065-48-3$ & Demeton \\
\hline $81-81-2$ & Warfarin (>0.3\%) \\
\hline $81-81-2$ a & Warfarin (<0.3\%) \\
\hline $83-26-1$ & Pindone \\
\hline $83-79-4$ & Rotenone \\
\hline $838-88-0$ & 4,4'-Methylenebis(2-methylaniline) \\
\hline $85-00-7$ & Diquat \\
\hline $85-44-9$ & Phthalic anhydride \\
\hline $86-50-0$ & Azinphos-methyl \\
\hline $86-88-4$ & alpha-Naphthylthiourea \\
\hline $87-65-0$ & 2,6-Dichlorophenol \\
\hline $90-04-0$ & o-Anisidine \\
\hline $91-80-5$ & Methapyrilene \\
\hline $91-94-1$ & 3,3 -Dichlorobenzidine \\
\hline $92-67-1$ & 4-Aminobiphenyl \\
\hline $92-84-2$ & Phenothiazine \\
\hline $92-87-5$ & Benzidine \\
\hline $924-16-3$ & N-Nitrosodi-n-butylamine \\
\hline $930-55-2$ & N-Nitrosopyrrolidine \\
\hline $94-59-7$ & Safrole \\
\hline $944-22-9$ & Fonofos \\
\hline $95-53-4$ & o-Toluidine (2-methylaniline) \\
\hline $95-54-5$ & $1,2-$ Phenylenediamine \\
\hline $95-80-7$ & Toluene-2,4-diamine \\
\hline $95-94-3$ & $1,2,4,5-$ Tetrachlorobenzene \\
\hline $96-18-4$ & $1,2,3-$ Trichloropropane \\
\hline $96-45-7$ & Ethylenethiourea \\
\hline $97-63-2$ & Ethyl methacrylate \\
\hline $97-77-8$ & Disulfiram \\
\hline $98-00-1$ & Furfuryl alcohol \\
\hline $98-07-7$ & Benzotrichloride \\
\hline $98-87-3$ & Benzal chloride \\
\hline $99-55-8$ & 5 -Nitro-o-toluidine \\
\hline
\end{tabular}


Attachment 9. Q18R, Undetected Compounds, Considered Unstable. (179 Compounds) (Page 1 of 5)

\begin{tabular}{|c|c|c|c|c|}
\hline CAS\# & Constifuent & $\begin{array}{l}\text { UHC Toxicity } \\
\text { Ranking }\end{array}$ & $\begin{array}{l}\text { TAP Toxicity } \\
\text { Raniking }\end{array}$ & $\begin{array}{l}\text { Slope Factor } \\
\text { Ranking }\end{array}$ \\
\hline $100-02-7$ & 4-Nitrophenol & $\mathrm{C}$ & V & \\
\hline $100-37-8$ & Diethylaminoethanol & & IV & \\
\hline $100-61-8$ & N-Methylbenzenamine & & II & \\
\hline $100-63-0$ & Phenylhydrazine & & II & \\
\hline $100-74-3$ & N-Ethylmorpholine & & III & \\
\hline $101-68-8$ & Methylene bis(phenyl isocyanate) & & $\mathrm{I}$ & \\
\hline $101-90-6$ & Diglycidyl resorcinol ether & $\mathrm{D}$ & & \\
\hline $102-81-8$ & 2-N-Dibutylaminoethanol & & III & \\
\hline $1024-57-3$ & Heptachlor Epoxide & & & $\mathrm{v}$ \\
\hline 1031-07-8 & Endosulfan Sulfate & $\mathrm{B}$ & & \\
\hline $105-46-4$ & sec-Butyl acetate & & $\mathrm{V}$ & \\
\hline $105-67-9$ & 2,4-Dimethylphenol & $\mathrm{D}$ & & \\
\hline $106-44-5$ & 4-Methylphenol & $\mathrm{C}$ & & \\
\hline $106-50-3$ & p-Phenylenediamine & $\mathrm{C}$ & $\mathrm{I}$ & \\
\hline $106-87-6$ & Vinyl cyclohexene dioxide & & IV & \\
\hline $106-92-3$ & Allyl glycidyl ether & & III & \\
\hline $107-07-3$ & Ethylene chlorohydrin & & III & \\
\hline $107-15-3$ & Ethylene diamine & & III & \\
\hline $107-21-1$ & Ethylene glycol & & IV & \\
\hline $107-98-2$ & Propylene glycol monomethyl ether & & $\mathrm{V}$ & \\
\hline $108-11-2$ & Methyl isobutyl carbinol & & IV & \\
\hline $108-18-9$ & Diisopropylamine & & III & \\
\hline $108-21-4$ & Isopropyl acetate & & $\mathrm{V}$ & \\
\hline $108-24-7$ & Acetic anhydride & & III & \\
\hline $108-43-0$ & Chlorophenols & & & \\
\hline $108-60-1$ & Bis(2-Chloroisopropyl) ether & $\mathrm{C}$ & & $\overline{B C}$ \\
\hline 108-83-8 & Diisobutyl ketone & & IV & \\
\hline $108-84-9$ & sec-Hexyl acetate & & IV & \\
\hline $108-91-8$ & Cyclohexylamine & & IV & \\
\hline $109-59-1$ & Isopropoxyethanol & & IV & \\
\hline $109-60-4$ & n-Propyl acetate & & $\mathrm{V}$ & \\
\hline $109-73-9$ & n-Butylamine & & III & \\
\hline $109-79-5$ & n-Butyl mercaptan & & II & \\
\hline $109-86-4$ & 2-Methoxyethanol & & III & \\
\hline $109-89-7$ & Diethylamine & & III & \\
\hline $109-94-4$ & Ethyl formate & & IV & \\
\hline $110-19-0$ & Isobutyl acetate & & $\mathrm{V}$ & \\
\hline $110-49-6$ & 2-Methoxyethyl acetate & & III & \\
\hline $110-75-8$ & 2-Chloroethyl vinyl ether & $\mathrm{C}$ & & \\
\hline $110-91-8$ & Morpholine & & IV & \\
\hline $111-15-9$ & 2-Ethoxyethyl acetate & & III & \\
\hline $111-40-0$ & Diethylene triamine & & III & \\
\hline $111-42-2$ & Diethanolamine & & III & \\
\hline
\end{tabular}




\section{Attachment 9. Q18R, Undetected Compounds, Considered Unstable. (179 Compounds) (Page 2 of 5)}

\begin{tabular}{|c|c|c|c|c|}
\hline CAs & Constituent & $\begin{array}{l}\text { UHC Toxicity } \\
\text { Ranking }\end{array}$ & TAP Toxicity & Slope Factor \\
\hline $111-44-4$ & Bis(2-chloroethyl) ether & B & & $\mathbf{v}$ \\
\hline $111-91-1$ & Bis(2-Chloroethoxy)methane & $\mathrm{C}$ & & \\
\hline $1129-41-5$ & Metolcarb (3-methylcholanthrene) & & & \\
\hline $1134-23-2$ & Cycloate & $\mathrm{D}$ & & \\
\hline $115-86-6$ & Triphenyl phosphate & & II & \\
\hline $118-52-5$ & 1,3-Dichloro-5,5-Dimethyl hydantoin & & $\mathrm{I}$ & \\
\hline $119-38-0$ & Isolan & & & \\
\hline $121-45-9$ & Trimethyl phosphite & & III & \\
\hline $122-60-1$ & Phenyl glycidyl ether & & $\mathrm{V}$ & \\
\hline $122-66-7$ & 1,2-Diphenylhydrazine & & & $\mathrm{BC}$ \\
\hline $123-31-9$ & Hydroquinone & $\mathrm{C}$ & II & \\
\hline $123-42-2$ & Diacetone alcohol & & IV & \\
\hline $123-92-2$ & Isoamyl acetate & & $\mathrm{V}$ & \\
\hline $124-40-3$ & Dimethylamine & & III & \\
\hline $124-48-1$ & Dibromochloromethane & $\mathrm{C}$ & & \\
\hline $129-15-7$ & 2-Methyl-1-nitroanthraquinone & & & \\
\hline $131-11-3$ & Dimethyl phthalate & & III & \\
\hline $1321-74-0$ & Divinyl benzene & & IV & \\
\hline $133-06-2$ & Captan & & III & \\
\hline $133-90-4$ & Chloramben . & & $\mathrm{V}$ & \\
\hline $1338-23-4$ & Methyl ethyl ketone peroxide & & II & \\
\hline $134-32-7$ & alpha-Naphthylamine & $\mathrm{D}$ & & \\
\hline $135-20-6$ & Cupferron & & & \\
\hline $135-88-6$ & N-Phenyl-2-napthylamine & $E$ & & \\
\hline $137-05-3$ & Methyl-2-cyanoacrylate & & III & \\
\hline $138-22-7$ & n-Butyl lactate & & III & \\
\hline $139-65-1$ & 4,4'-Thiodianiline & D & & \\
\hline $140-88-5$ & Ethylacrylate & & III & \\
\hline $141-32-2$ & Butylacrylate & & IV & \\
\hline $141-43-5$ & Ethanolamine & & III & \\
\hline $142-64-3$ & Piperazine dihydrochloride & & III & \\
\hline 148-01-6 & Dinitolamide & & III & \\
\hline $150-76-5$ & 4-Methoxyphenol & & III & \\
\hline $16219-75-3$ & Ethylidene norbornene & & III & \\
\hline $17702-57-7$ & Formparanate & & & \\
\hline 1918-02-1 & Picloram & & III & \\
\hline $2039-87-4$ & o-Chlorostyrene & & IV & \\
\hline $2238-07-5$ & Diglycidyl ether & & II & \\
\hline $22781-23-3$ & Bendiocarb & $\mathrm{C}$ & & \\
\hline $22961-82-6$ & Bendiocarb phenol & & & \\
\hline $23422-53-9$ & Formetanate hydrochloride & & & \\
\hline $2425-06-1$ & Captafol & & $I$ & \\
\hline $2426-08-6$ & n-Butyl glycidyl ether & & IV & \\
\hline
\end{tabular}


Attachment 9. Q18R, Undetected Compounds, Considered Unstable. (179 Compounds) (Page 3 of 5)

\begin{tabular}{|c|c|c|c|c|}
\hline CAS\# & Constituent & UHC Roxicity & TAP Toxicity & $\begin{array}{l}\text { Slope Factor } \\
\text { Ranking }\end{array}$ \\
\hline $25013-15-4$ & Vinyl toluene & & IV & \\
\hline $25639-42-3$ & Methylcyclohexanol & & IV & \\
\hline $26419-73-8$ & Tirpate & & & \\
\hline $26952-21-6$ & Iso-ocytl alcohol & & IV & \\
\hline $2698-41-1$ & o-Chlorobenylidene malonitrile & & II & \\
\hline $2921-88-2$ & Chlorpyrifos & & $\mathrm{I}$ & \\
\hline $302-01-2$ & Hydrazine & & & iv \\
\hline $3068-88-0$ & B-Butyrolactone & & & \\
\hline $314-40-9$ & Bromacil & & III & \\
\hline $330-54-1$ & Diuron & & III & \\
\hline $33213-65-9$ & Endosulfan II & $\mathrm{C}$ & & \\
\hline $3333-52-6$ & Tetramethyl succinonitrile & & II & \\
\hline $334-88-3$ & Diazomethane & & II & \\
\hline $34590-94-8$ & Dipropylene glycol methyl ether & & $\mathrm{V}$ & \\
\hline $4016-14-2$ & Isopropyl glycidyl ether (IGE) & & IV & \\
\hline $4098-71-9$ & Isophorone diisocyanate & & I & \\
\hline $420-04-2$ & Cyanamide & & II & \\
\hline $463-51-4$ & Ketene & & II & \\
\hline 504-29-0 & 2-Aminopyridine & C & II & \\
\hline $51-28-5$ & 2,4-Dinitrophenol & B & $\mathrm{V}$ & \\
\hline $510-15-6$ & Chlorobenzilate & $\mathrm{D}$ & & $\mathrm{BC}$ \\
\hline $5124-30-1$ & $\begin{array}{l}\text { Methylene-bis-(4-cyclo- } \\
\text { hexylisocyanate) }\end{array}$ & & $I$ & \\
\hline $52888-80-9$ & Prosulfocarb & & & \\
\hline $531-82-8$ & $\begin{array}{l}\mathrm{N}-(4-(5-\mathrm{Nitro}-2-\text { furyl)-2- } \\
\text { thiazolyl)acetamide }\end{array}$ & & & \\
\hline $540-88-5$ & tert-Butyl acetate & & $\mathrm{V}$ & \\
\hline $541-85-5$ & Ethyl amyl ketone & & IV & \\
\hline $542-75-6$ & 1,3-Dichloropropene & & III & $\mathrm{BC}$ \\
\hline $542-92-7$ & Cyclopentadiene & & IV & \\
\hline $552-30-7$ & Trimellitic anhydride & & I & \\
\hline $55285-14-8$ & Carbosulfan & & & \\
\hline $55406-53-6$ & 3-Iodo-2-propynyl n-butylcarbamate & & & \\
\hline $556-52-5$ & Glycidol & & IV & \\
\hline $55738-54-0$ & $\begin{array}{l}\text { trans-2((Dimethylamino)methylimino)- } \\
\text { 5-(2-(5-nitro-2-furyl) vinyl-1,3,4- } \\
\text { oxadiazole }\end{array}$ & & & \\
\hline $57-57-8$ & B-Propiolactone & & II & \\
\hline $57-74-9$ & Chlordane & $\mathrm{C}$ & & $\mathbf{v}$ \\
\hline $583-60-8$ & o-Methylcyclohexanone & & IV & \\
\hline $584-84-9$ & 2,4-Toluene diisocyanate & & & \\
\hline $592-62-1$ & Methyl azoxymethyl acetate & & & \\
\hline $593-60-2$ & Vinyl bromide & & III & BC \\
\hline $594-42-3$ & Perchloromethyl mercaptan & & II & \\
\hline
\end{tabular}




\section{Attachment 9. Q18R, Undetected Compounds, Considered} Unstable. (179 Compounds) (Page 4 of 5)

\begin{tabular}{|c|c|c|c|c|}
\hline +\$ & Sonstituent & UHCroxitit & 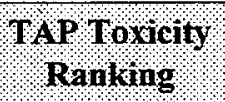 & Slope Factor \\
\hline $594-72-9$ & 1,1-Dichloro-1-nitroethane & & III & \\
\hline $5952-26-1$ & Diethylene glycol, dicarbamate & & & $\cdot$ \\
\hline $600-25-9$ & 1-Chloro-1-nitropropane & & III & \\
\hline $613-35-4$ & N,N-Diacetylbenzidine & & & \\
\hline $62-53-3$ & Aniline & $\mathrm{C}$ & II & . \\
\hline $626-17-5$ & m-Phthalodinitrile & & III & . \\
\hline $626-38-0$ & sec-Amyl acetate & & $\mathrm{V}$ & \\
\hline $628-63-7$ & n-Amyl acetate & & $\mathrm{V}$ & \\
\hline $628-96-6$ & Ethylene glycol dinitrate & & II & \\
\hline $63-92-3$ & Phenoxybenzamine hydrochloride & & & \\
\hline $638-21-1$ & Phenylphosphine & & I & \\
\hline $64-00-6$ & m-Cumenyl methylcarbamate & & & \\
\hline $64-67-5$ & Diethyl sulfate & & $\mathrm{V}$ & \\
\hline $64091-91-4$ & $\begin{array}{l}\text { 4-(Methylnitrosamino)-1-(3-pyridyl)-1- } \\
\text { butanone }\end{array}$ & & & \\
\hline 644-64-4 & Dimetilan & & & \\
\hline $68-11-1$ & Thioglycolic acid & & III & \\
\hline $68-12-2$ & Dimethylformamide & . & III & \\
\hline $681-84-5$ & Methyl silicate & & III & \\
\hline $74-89-5$ & Methylamine & & III & . \\
\hline 74-96-4 & Ethyl bromide & & $\mathrm{V}$ & \\
\hline $7421-93-4$ & Endrin aldehyde & & & \\
\hline $75-04-7$ & Ethylamine & & III & \\
\hline $75-08-1$ & Ethyl mercaptan & & II & \\
\hline $75-25-2$ & Tribromomethane & $\mathrm{D}$ & & $\mathrm{BC}$ \\
\hline $75-31-0$ & Isopropylamine & & III & \\
\hline $75-56-9$ & Propylene oxide & & & $\mathrm{BC}$ \\
\hline $7572-29-4$ & Dichloroacetylene & & II & \\
\hline $76-01-7$ & Pentachloroethane & $\mathrm{D}$ & & \\
\hline $768-52-5$ & N-Isopropylaniline & & III & \\
\hline $77-47-4$ & Hexachlorocyclopentadiene & $\mathrm{X}$ & $\mathrm{I}$ & \\
\hline $77-73-6$ & Dicyclopentadiene & & III & \\
\hline $78-10-4$ & Ethyl silicate & & IV & \\
\hline $78-59-1$ & Isophorone & & III & \\
\hline $79-04-9$ & Chloroacetyl chloride & & 1 & \\
\hline $79-11-8$ & Chloroacetic acid & & $\mathrm{V}$ & \\
\hline $79-24-3$ & Nitroethane & & IV & \\
\hline $79-27-6$ & Acetylene tetrabromide & & III & \\
\hline $79-41-4$ & Methacrylic acid & & IV & \\
\hline $794-93-4$ & $\begin{array}{l}\text { Panfuran } \mathrm{S} \\
\text { (dihydroxymethylfuratrizine) }\end{array}$ & & & \\
\hline $8003-34-7$ & Pyrethrum & & II & \\
\hline $822-06-0$ & Hexamethylene diisocyanate & & I & \\
\hline $86-30-6$ & N-Nitrosodiphenylamine & $\mathrm{D}$ & & \\
\hline
\end{tabular}




\section{Attachment 9. Q18R, Undetected Compounds, Considered}

Unstable. (179 Compounds) (Page 5 of 5)

\begin{tabular}{|c|c|c|c|c|}
\hline CAS\# & Constituent & $\begin{array}{l}\text { UMC Toxicity } \\
\text { Ranking }\end{array}$ & TAP Troxicity & Slope fractor \\
\hline $88-74-4$ & 2-Nitroaniline & D & & \\
\hline $89-72-5$ & o-sec-Butylphenol & & III & \\
\hline $91-59-8$ & 2-Napthylamine & $\mathrm{D}$ & & \\
\hline $94-36-0$ & Benzoyl Peroxide & & III & \\
\hline $959-98-8$ & Endosulfan I & $\mathrm{C}$ & & \\
\hline $96-09-3$ & Styrene oxide & & $\mathrm{V}$ & \\
\hline $96-12-8$ & 1,2-Dibromo-3-chloropropane & C & I & $\mathrm{BC}$ \\
\hline $96-33-3$ & Methyl acrylate & & IV & \\
\hline $97-56-3$ & o-Aminoazotoluene & & & \\
\hline $98-01-1$ & Furfural & & III & \\
\hline $999-61-1$ & 2-Hydroxypropyl acrylate & & II & \\
\hline
\end{tabular}


Attachment 10. Q24, Undetected, Stable Compounds with Lower Toxicity. (65 Compounds) (Page 1 of 2)

\begin{tabular}{|c|c|c|c|c|}
\hline $\mathrm{CHS}$ & Constituent & UHC Toxicity & TAP Toxicity & Slope Factor \\
\hline $100-21-0$ & Phthalic acid & & & \\
\hline $101-55-3$ & 4-Bromophenylphenyl ether & & & \\
\hline $107-66-4$ & Dibutylphosphate & & III & \\
\hline $120-12-7$ & Anthracene & & & \\
\hline $120-83-2$ & 2,4-Dichlorophenol & $\mathrm{D}$ & & \\
\hline $121-69-7$ & Dimethylaniline & & III & \\
\hline $132-64-9$ & Dibenzofuran & & & \\
\hline $1321-65-9$ & Trichloronaphthalene & & III & \\
\hline $156-60-5$ & 1,2-trans-Dichloroethene & $\mathrm{D}$ & & \\
\hline $1582-09-8$ & Trifluralin & & $\mathrm{V}$ & \\
\hline $1634-04-4$ & Methyl tert-butyl ether & & IV & \\
\hline $1836-75-5$ & Nitrofen & & & \\
\hline $189-55-9$ & Dibenzo[a,i]pyrene & & & \\
\hline 189-64-0 & Dibenzo[a,h]pyrene & & & \\
\hline $191-24-2$ & Benzo(ghi)perylene & & & \\
\hline 191-30-0 & Dibenzo(a,l)pyrene & & & \\
\hline $192-65-4$ & Dibenzo[a,e]pyrene & & & \\
\hline $193-39-5$ & Indeno( $1,2,3-c d)$ pyrene & & & $\mathrm{BC}$ \\
\hline $205-82-3$ & Benzo[j]fluoranthene & & & \\
\hline $205-99-2$ & Benzo(b)fluoranthene & & & $\mathrm{BC}$ \\
\hline 207-08-9 & Benzo(k)fluoranthene & & & $\mathrm{BC}$ \\
\hline 208-96-8 & Acenaphthylene & & & \\
\hline 218-01-9 & Chrysene & & & $\mathrm{BC}$ \\
\hline $224-42-0$ & Dibenz $[\mathrm{a}, \mathrm{j}]$ acridine & & & \\
\hline $226-36-8$ & Dibenz $[\mathrm{a}, \mathrm{h}]$ acridine & & & \\
\hline $2385-85-5$ & Mirex & & & \\
\hline $2551-13-7$ & Trimethyl benzene & & IV & \\
\hline $26140-60-3$ & Terphenyls & & III & \\
\hline $27154-33-2$ & Trichlorofluoroethane & & & \\
\hline $319-86-8$ & delta-BHC & $\mathrm{D}$ & & \\
\hline $3697-24-3$ & 5-Methylchrysene & & & \\
\hline $50-29-3$ & 4,4-DDT & $\mathrm{C}$ & & $\mathrm{BC}$ \\
\hline $540-59-0$ & 1,2-Dichloroethylene & & $\mathrm{V}$ & \\
\hline $540-84-1$ & 2,2;4-Trimethylpentane & & $\mathrm{V}$ & \\
\hline $56-49-5$ & 3-Methylcholanthrene & & & \\
\hline $56-55-3$ & Benzo(a)anthracene & & & $\mathrm{BC}$ \\
\hline $58-90-2$ & 2,3,4,6-Tetrachlorophenol & $\mathrm{C}$ & & \\
\hline $60-29-7$ & Ethyl ether & $\mathrm{D}$ & $\mathrm{V}$ & \\
\hline $602-87-9$ & 5-Nitroacenaphthene & & & \\
\hline $603-34-9$ & Triphenyl amine & & III & \\
\hline $630-20-6$ & 1,1,1,2-Tetrachloroethane & $\mathrm{C}$ & & $\mathrm{BC}$ \\
\hline $72-43-5$ & Methoxychlor & $\mathrm{D}$ & III & \\
\hline $72-54-8$ & 4,4-DDD & $\mathrm{C}$ & & \\
\hline
\end{tabular}




\section{Attachment 10. Q24, Undetected, Stable Compounds with Lower} Toxicity. (65 Compounds) (Page 2 of 2)

\begin{tabular}{|c|c|c|c|c|}
\hline $\mathrm{CASH}$ & Constituent & GHC Toxicity & TAP Toxacity & $\begin{array}{l}\text { Slope Factor } \\
\text { Ranking }\end{array}$ \\
\hline $72-55-9$ & 4,4-DDE & D & & \\
\hline $74-97-5$ & Bromochloromethane & & $\mathrm{V}$ & \\
\hline $75-27-4$ & Bromodichloromethane & $\mathrm{C}$ & & \\
\hline $75-61-6$ & Difluorodibromomethane & & $\mathrm{V}$ & \\
\hline $75-63-8$ & Trifluorobromomethane & & $\mathrm{V}$ & \\
\hline $75-99-0$ & 2,2-Dichloropropionic acid & & III & \\
\hline $76-03-9$ & Trichloroacetic acid & & III & \\
\hline $76-11-9$ & 1,1,1,2-Tetrachloro-2,2-difluoroethane & & $\mathrm{V}$ & \\
\hline $76-12-0$ & 1,1,2,2-Tetrachloro-1,2-difluoroethane & & $\mathrm{V}$ & \\
\hline $76-15-3$ & Chloropentafluoroethane & & $\mathrm{V}$ & \\
\hline $85-01-8$ & Phenanthrene & & & \\
\hline $88-72-2$ & Nitrotoluene & & III & \\
\hline $91-22-5$ & Quinoline & & $\mathrm{V}$ & \\
\hline 91-58-7 & 2-Chloronaphthalene & D & & \\
\hline $92-93-3$ & 4-Nitrobiphenyl & & $\mathrm{V}$ & \\
\hline $93-72-1$ & Silvex $(2,4,5-\mathrm{TP})$ & $\mathrm{D}$ & & \\
\hline $93-76-5$ & $2,4,5-\mathrm{T}$ & & III & \\
\hline 94-75-7 & $2,4-\mathrm{D}$ & $\mathrm{C}$ & & \\
\hline $95-13-6$ & Indene & & IV & \\
\hline $95-49-8$ & o-Chlorotoluene & & IV & \\
\hline $98-51-1$ & p-tert-Butyltoluene & & IV & \\
\hline $98-82-2$ & Cumene & & IV & \\
\hline
\end{tabular}

Attachment 11. Q37, Lower Toxicity Compounds, Detected Due to Common Lab Contamination. (2 Compounds)

\begin{tabular}{|c|c|c|c|c|c|c|}
\hline CAst & Constifuent & $\begin{array}{l}\text { IWINS Solid } \\
\text { Lquuid } \\
\text { Detects } \# \text { ? }\end{array}$ & $\begin{array}{l}\text { TWuss } \\
\text { Vetects:A }\end{array}$ & $\begin{array}{l}\text { UHC. } \\
\text { Toxicity } \\
\text { Ranking. }\end{array}$ & $\begin{array}{l}\text { TAP } \\
\text { Toxicity } \\
\text { Ranking }\end{array}$ & $\begin{array}{l}\text { Slope } \\
\text { Ractor } \\
\text { Ranking }\end{array}$ \\
\hline $117-81-7$ & Bis(2-ethylhexyl) phthalate & 33 & 1 & & & $\mathrm{BC}$ \\
\hline $84-66-2$ & Diethyl phthalate & & 24 & & III & \\
\hline
\end{tabular}

TWINS = Tank Waste Information Network System. Solid/liquid hits were recorded from the Tank Characterization Database. Vapor hits were recorded from the vapor database 
Attachment 12. Q40b, Detected Compounds, Lower Toxicity, Not Analyzed by Methods Applicable to Higher Toxicity Compounds. (2 Compounds)

\begin{tabular}{|c|c|c|c|c|c|c|}
\hline $\mathrm{Gas}+$ & Constituent & $\begin{array}{l}\text { TWINS Solid/ } \\
\text { Liquid } \\
\text { Detects } \# \text { ? }\end{array}$ & $\begin{array}{l}\text { TWINS } \\
\text { Vapor } \\
\text { Detects } \#\end{array}$ & $\begin{array}{l}\text { Urie } \\
\text { Toxicity } \\
\text { Ranting }\end{array}$ & $\begin{array}{l}\text { TAPr } \\
\text { Toxicity } \\
\text { Ranking }\end{array}$ & $\begin{array}{l}\text { Slope } \\
\text { Factor: } \\
\text { Ranking }\end{array}$ \\
\hline $110-62-3$ & $\mathrm{n}$-Valeraldehyde & & 54 & & IV & \\
\hline $75-07-0$ & Acetaldehyde & & 103 & & & $\mathrm{BC}$ \\
\hline
\end{tabular}

TWINS = Tank Waste Information Network System. Solid/liquid hits were recorded from the Tank Characterization Database. Vapor hits were recorded from the vapor database 


\section{Distribution}

No. of

Copies

\section{OFFSITE}

Harry Babad, Ph. D.

2540 Cordoba Court

Richland, WA 99352-1609

Mitzi Miller (3)

Environmental Quality Management 2000 Logston Blvd.

Richland, WA 99352

ONSITE

21 DOE Richland Operations Office

D.W. Bowser

N.R. Brown (2)

R. Carreon (2)

C.E. Clark

P.K. Clark

R.A. Gilbert

L.A. Huffman (5)

A.C. McKarns

J.A. Poppiti

J.F. Thompson

N.C. Welliver (5)

2 Fluor Daniel Hanford

G.R. Franz

S.M. Price
$57-40$

A2-22

A $0-21$

$\mathrm{A} 0-21$

A5-15

S7-55

A0-21

$\mathrm{A} 0-21$

A5-15

S7-54

S7-54

A0-21

H6-23
No. of

Copies

7 Lockheed Martin Hanford

D.L. Banning

R1-12

K.A. Gasper (2)

A3-03

K.M. Hall

$\mathrm{R} 2-12$

C.H. Mulkey

R1-51

L.D. Pennington

S7-01

R.D. Potter

R3-73

25 Pacific Northwest National Laboratory

J.A. Campbell

P8-08

P.M. Daling

$\mathrm{K} 8-03$

S.C. Goheen

P8-08

R.T. Hallen

$\mathrm{K} 2-12$

L.K. Holton

$\mathrm{A} 0-21$

K.J. Kjarmo

A2-22

J.L. Kovach (Consultant)

$\mathrm{A} 0-21$

M.E. Lerchen (2)

$\mathrm{A} 0-21$

B.A. Reynolds

$\mathrm{A} 0-21$

L.A. Smyser (2)

A $0-21$

W.C. Weimer

P7-27

K.D. Wiemers (5)

A0-21

Information Release Office (7) K1-06

2 Waste Management Federal Services of Hanford, Inc.

R.C. Bowman

H6-24

C.M. Seidel

S3-30

Distr.1 